\title{
ANÁLISE DINÂMICA BIDIMENSIONAL NÃO-LINEAR FÍSICA E GEOMÉTRICA DE TRELIÇAS DE AÇO E PÓRTICOS DE CONCRETO ARMADO
}

ROGÉRIO DE OLIVEIRA RODRIGUES

Tese apresentada à Escola de Engenharia
de São Carlos, da Universidade de São
Paulo, como parte dos requisitos para
obtenção do Título de Doutor em
Engenharia de Estruturas.

ORIENTADOR: Prof. Dr. Wilson Sergio Venturini 
Ficha catalográfica preparada pela Seção de Tratamento da Informação do Serviço de Biblioteca - EESC-USP

Rodrigues, Rogério de Oliveira
Análise dinâmica bidimensional não-linear
fisica e geométrica de treliças de aço e pórticos
de concreto armado / Rogério de oliveira
Rodrigues. -- São Carlos, 1997.
Tese (Doutorado) -- Escola de Engenharia
de São Carlos-Universidade de São Paulo, 1997.
Área: Engenharia de Estruturas
Orientador: Prof. Dr. Wilson Sergio Venturini
I. Dinâmica estrutural. 2. Comportamento não-
Iinear. I. Titulo.


À minha esposa Luzia Marta

e à minha filha Maria Gabriela, dedico este trabalho. 


\section{AGRADECIMENTOS}

Ao Professor Wilson Sergio Venturini, pelos ensinamentos e orientação recebidos durante a elaboração deste trabalho, pela contribuição que deu à minha formação profissional e, sobretudo, pela amizade.

Aos Professores do Departamento de Engenharia de Estruturas - SET da Escola de Engenharia de São Carlos EESC/USP, pelo incentivo no transcorrer do trabalho.

Aos Professores do Departamento de Engenharia Civil - DEC da Faculdade de Engenharia de Ilha Solteira FEIS/UNESP, pela confiança e amizade demonstrada.

Ao Eng. José Benaque Rubert, pelo auxilio prestado no início deste trabalho.

Ao Serviço de Secretaria do DEC, pelo trabalho de digitação do texto e ao Serviço de Biblioteca e Documentação, pelo trabalho de organização da bibliografia, ambos da FEIS/UNESP.

À CAPES/PICD, pelo auxílio financeiro.

Finalmente, à todas as pessoas que direta ou indiretamente tornaram possível a elaboração deste trabalho. 


\section{SUMÁRIO}

LISTA DE FIGURAS....................

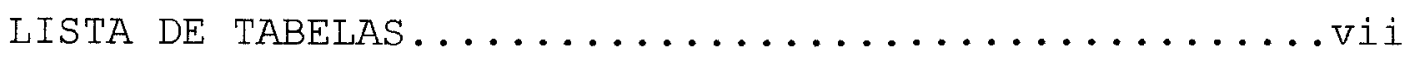

ABREVIATURAS, SIGLAS E SÍMBOLOS....................

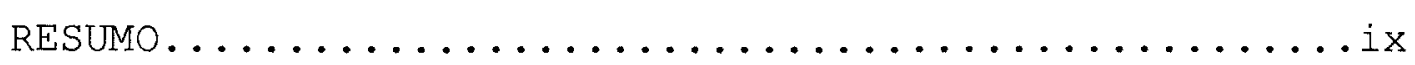

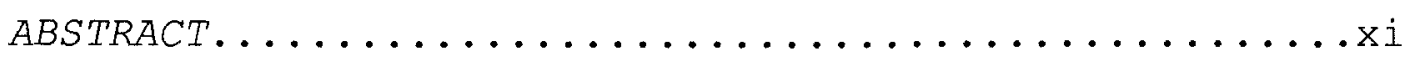

1 - INTRODUÇÃo. . . . . . . . . . . . . . . . . 1

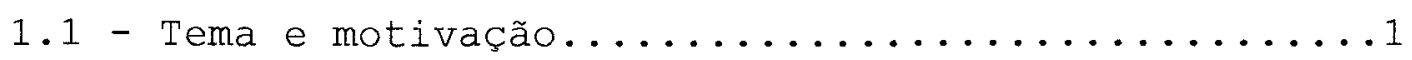

1.2 - objetivos do trabalho..................4

1.3 - Apresentação do trabalho..................

2 - ANÁLISE ESTRUTURAL DINÂMICA NÃO-LINEAR.......... 7

2.1 - Aspectos principais...................

2.2 - Discretização de um sistema estrutural

contínuo..........................

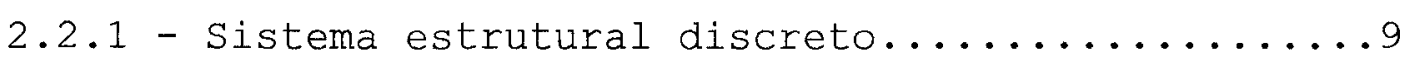

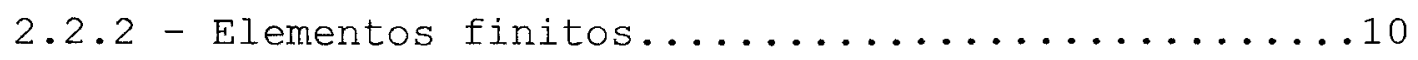

2.2.2.1 - Elemento para treliça plana..............12

2.2.2.2 - Elemento finito para pórtico plano.........13

2.3 - Esforços atuantes em um sistema estrutural

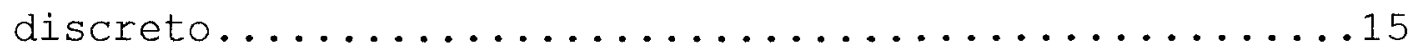

2.3.1 - Esforços devidos ao meio externo...........15

2.3.1.1 - Esforços volumétricos.................15

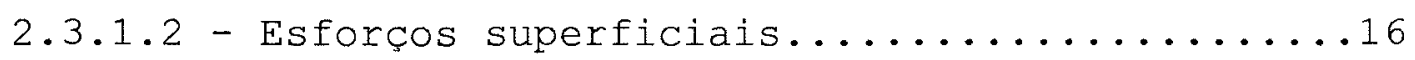

2.3 .1 .3 - Esforços concentrados................16 
2.3.1.4 - Dependência dos esforços externos.........17

2.3.2 - Forças devidas ao movimento.............18

2.3 .2 .1 - Forças inerciais...................18

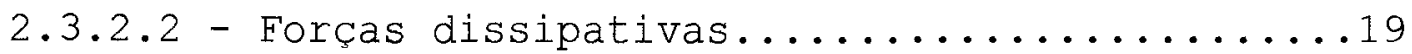

2.4 - Princípios básicos...................... 0

2.4 .1 - Estruturas em repouso.................21

2.4.1.1 - Princípio da Energia Potencial

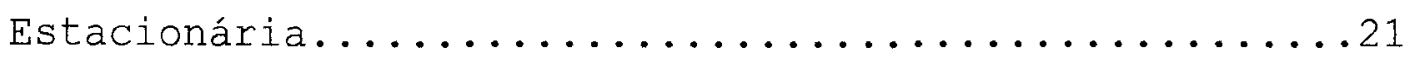

2.4.1.2 - Princípio dos Trabalhos Virtuais.........22

2.4 .2 - Estruturas em movimento...............23

2.4.2.1 - Princípio de D'Alembert................23

2.4.2.2 - Princípio dos Trabalhos Virtuais..........24

2.5 - Equação do movimento para um sistema estrutural

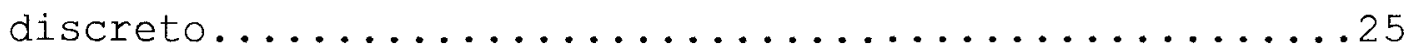

2.5.1 - Equação de equilíbrio via P.T.V. .........25

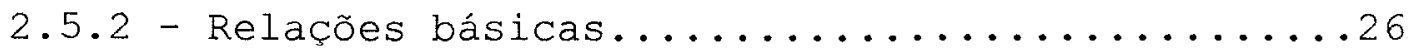

2.5 .3 - Equação geral do movimento..............28

\section{3 - INTEGRAÇÃO NUMÉRICA DA EQUAÇÃO GERAL DO}

MOVIMENTO . . . . . . . . . . . . . . . . . . . . . 31

3.1 - Métodos de integração numérica...............31

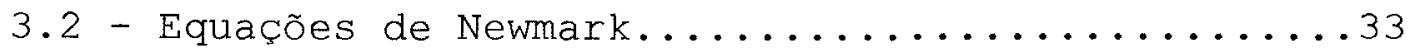

3.2.1 - Aceleração constante durante o intervalo de tempo................................... 34

3.2.2 - Aceleração variando linearmente durante o

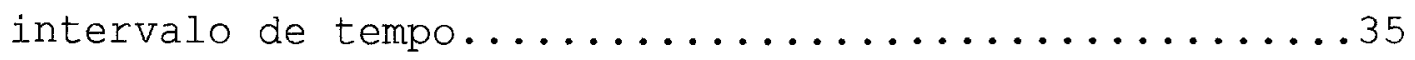

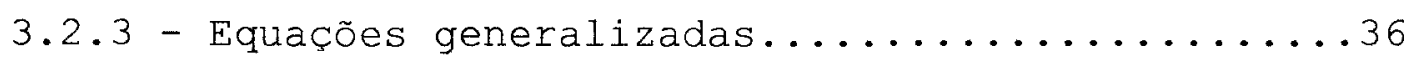

3.3 - Algoritmos numéricos para resolução de sistemas

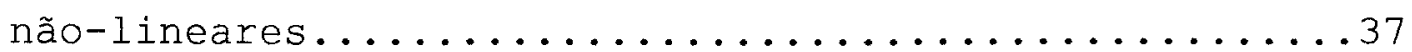

3.3 .1 - Processos iterativos..........................

3.3.1.1 - Iteração de Newton-Raphson Modificado......39

3.3.1.2 - Iteração de Newton-Raphson..............40

3.3 .2 - Processo incremental................41 
3.4 - Método de Newmark para integração numérica no tempo.............................. 42

3.4 .1 - Equacionamento básico...............42

3.4 .2 - Algoritmo numérico para resolução do

processo............................46

3.5 - Aspectos computacionais.................50

3.5.1 - Esquema geral de cálculo................50

3.5 .2 - Descrição das subrotinas..............52

\section{4 - NÃO-LINEARIDADE GEOMÉ TRICA NA DINÂMICA DAS}

ESTRUTURAS RETICULADAS PLANAS............. 56

4.1 - Generalidades........................56

4.2 - Sistemas de coordenadas...................57

4.2 .1 - Treliça plana.....................58

4.2 .2 - Pórtico plano.....................58

4.3 - Modelo elemental.......................59

4.3 .1 - Hipóteses básicas...................60

4.3 .2 - Campo de deslocamentos e de deformações......60

4.3 .3 - Funções de forma....................64

4.3 .3 .1 - Treliça plana....................64

4.3.3.2 - Pórtico plano...................65

4.4 - Matriz de rigidez...................67

4.4 .1 - Conceituação via formulação energética.......67

4.4 .2 - Atualização de coordenadas..............75

4.4 .3 - Elemento de barra em uma dimensão..........78

4.4 .3 .1 - Energia de deformação...............78

4.4.3.2 - Matriz de rigidez secante.............80

4.4.3.3 - Matriz de rigidez tangente.............84

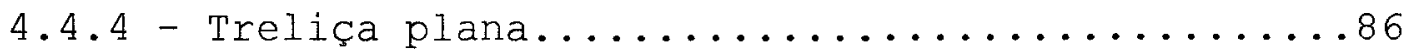

4.4 .4 .1 - Energia de deformação.............86

4.4 .4 .2 - Matriz de rigidez secante.............88

4.4.4.3 - Matriz de rigidez tangente............91

4.4 .5 - Pórtico plano.....................992 
4.4.5.1 - Energia de deformação...............992

4.4.5.2 - Matriz de rigidez secante.............96

4.4.5.3 - Matriz de rigidez tangente.............999

4.4.6 - Atualização das matrizes de rigidez.........101

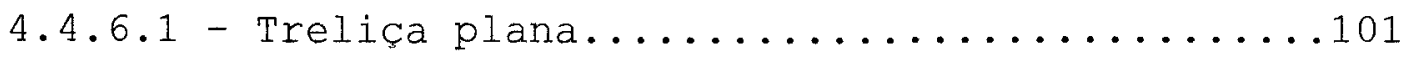

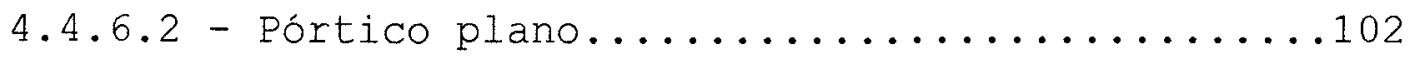

4.4 .7 - Aspectos computacionais.................103

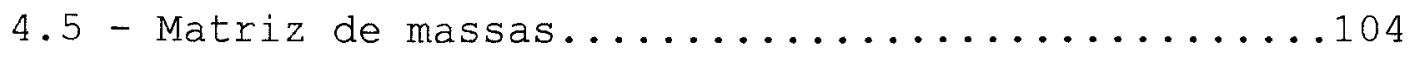

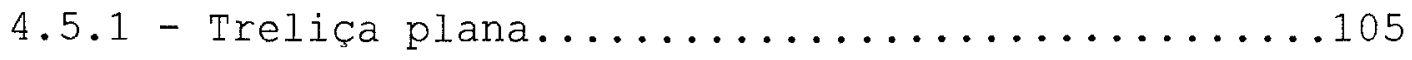

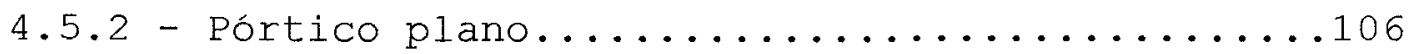

4.5 .3 - Massas concentradas....................107

4.5 .4 - Aspectos computacionais................108

4.6 - Matriz de amortecimento..................109

4.6 .1 - Frequiências naturais de vibração...........109

4.6 .2 - Amortecimento Rayleigh.................113

4.6 .3 - Aspectos computacionais.................114

\section{5 - MODELOS FÍSICOS NÃO-LINEARES PARA O AÇO}

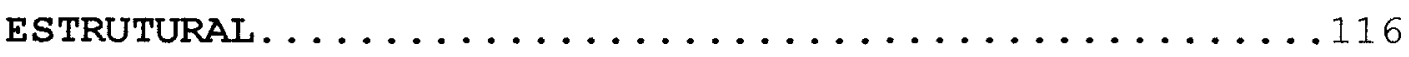

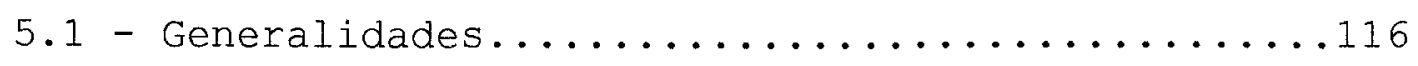

5.2 - Comportamento uniaxial do aço estrutural......116

5.2 .1 - Carregamento unidirecional...............117

5.2 .2 - Descarregamento e recarregamento...........118

5.2 .3 - Inversão de carregamento...............119

5.3 - Modelos elastoplásticos unidimensionais para

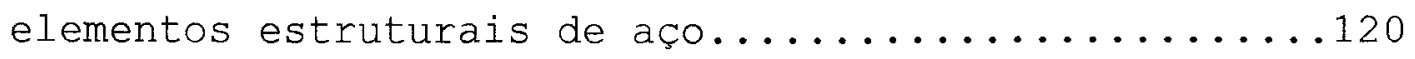

5.3 .1 - Modelo elastoplástico perfeito............120

5.3 .2 - Modelo elastoplástico com endurecimento

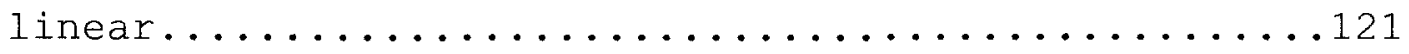

5.4 - Modelos com endurecimento linear para

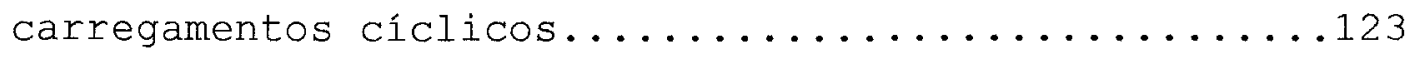

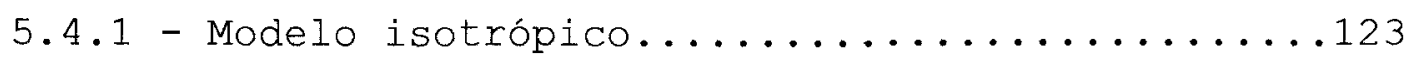

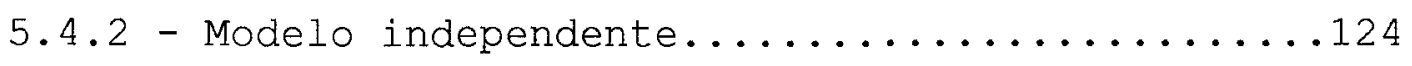




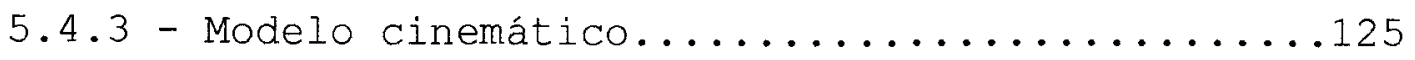

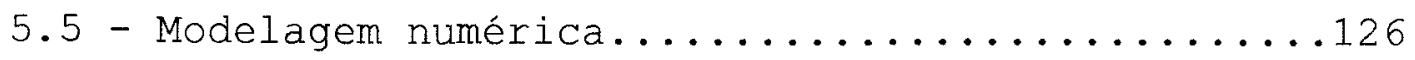

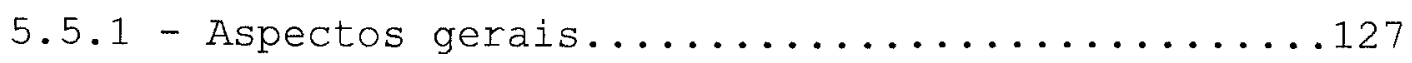

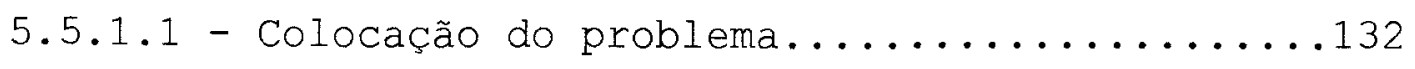

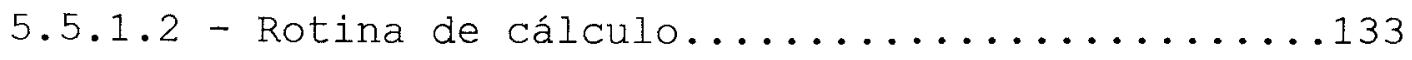

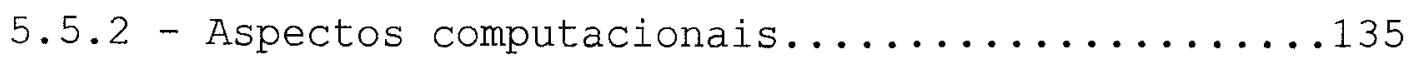

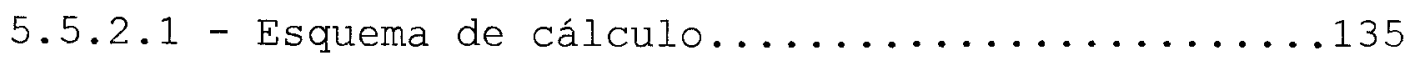

5.5 .2 .2 - Descrição das funções internas..........136

\section{6 - MODELOS FÍSICOS NÃO-LINEARES PARA O CONCRETO}

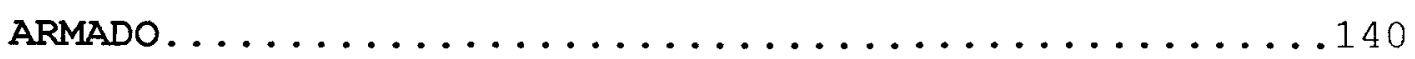

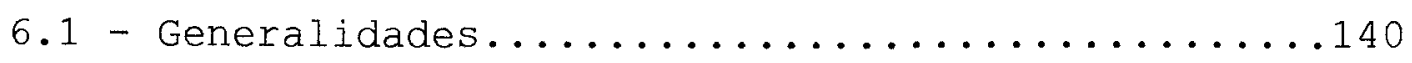

6.2 - Conceitos gerais sobre o concreto armado.......141

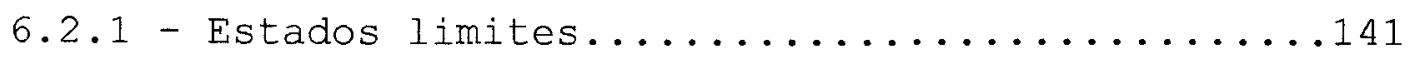

6.2 .2 - Estádios de solicitação.................. 142

6.3 - Comportamento em serviço do concreto armado....146

6.3 .1 - Disposições geométricas................146

6.3 .2 - Parâmetros auxiliares.................147

6.3 .3 - Equacionamento no Estádio $I_{a} \ldots \ldots \ldots \ldots . \ldots 149$

6.3.4 - Equacionamento no Estádio II.............. 152

6.4 - Modelos físicos não-lineares................154

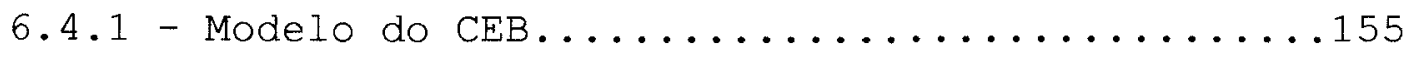

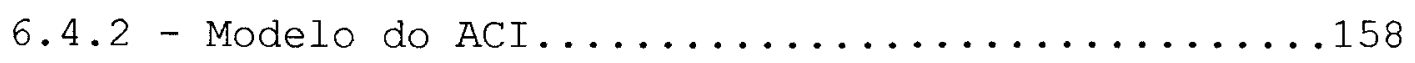

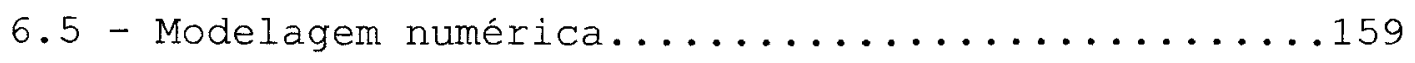

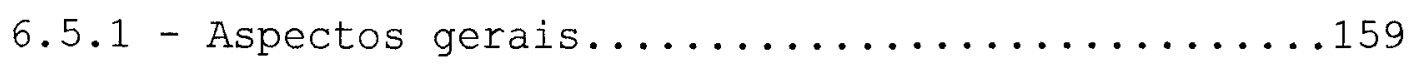

6.5 .1 .1 - Colocação do problema................160

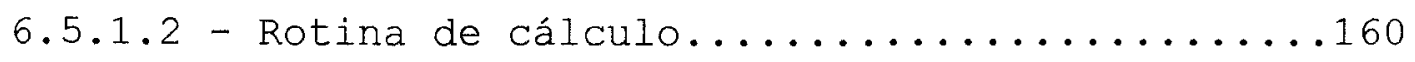

6.5 .1 .3 - Descarregamento e inversão de carregamento.162

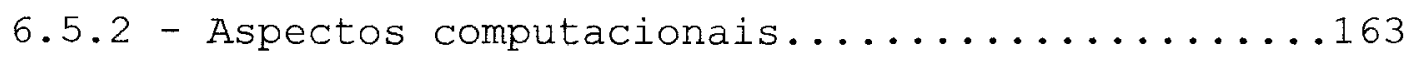

6.5 .2 .1 - Esquema de cálculo..................163

6.5 .2 .2 - Descrição das funções internas...........164 
7 - ANÁLISE NUMÉRICA.......................... 167

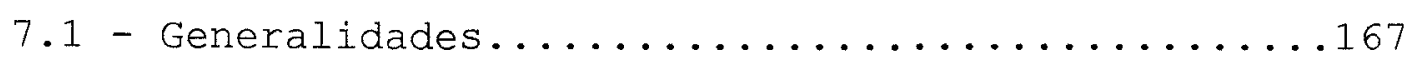

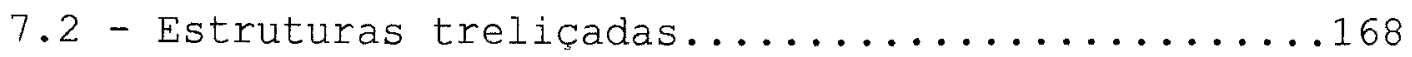

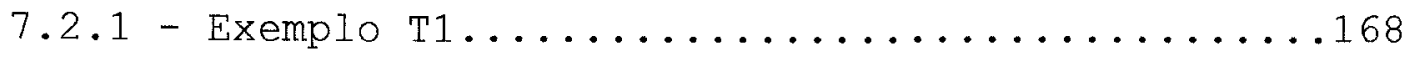

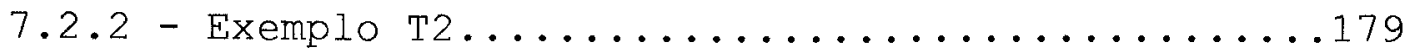

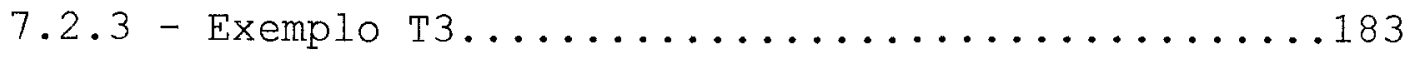

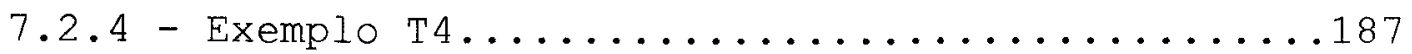

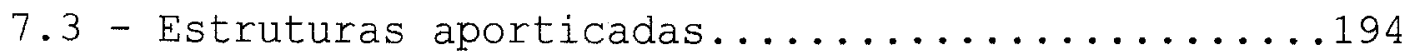

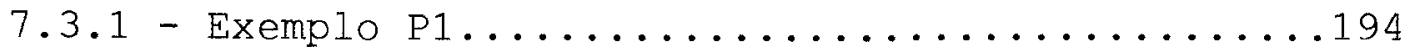

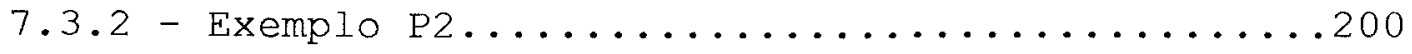

7.3 .3 - Exemplo P3........................202

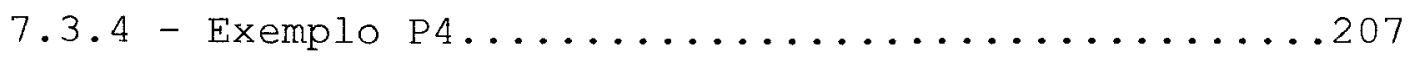

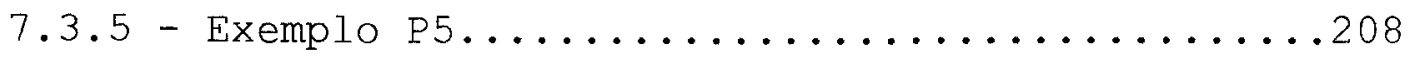

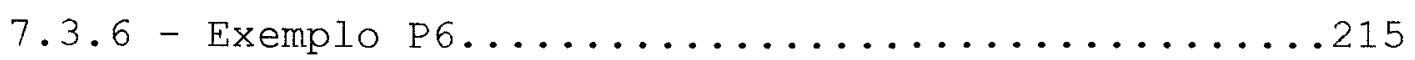

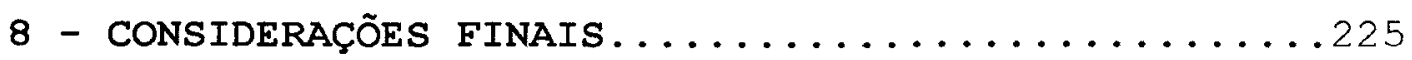

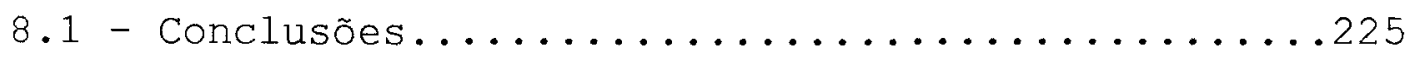

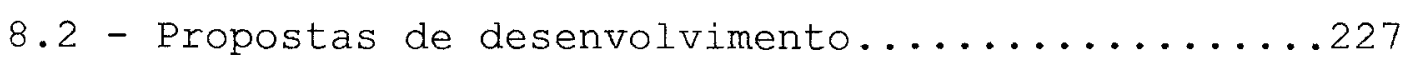

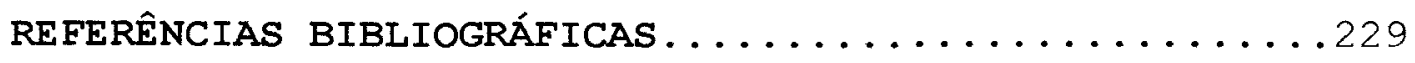

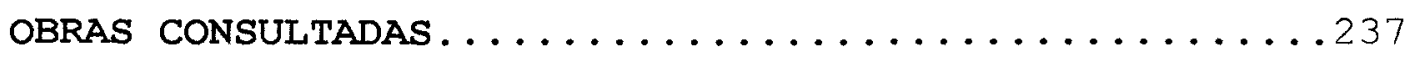

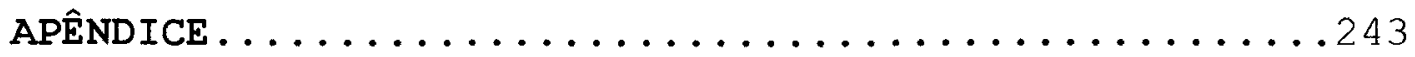

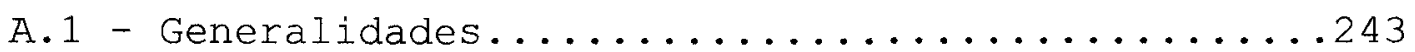

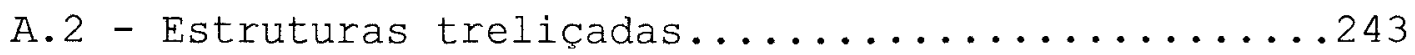

A.3 - Estruturas aporticadas..................262 


\section{IISTA DE EIGURAS}

FIGURA 2.1 - Elemento de barra para treliça plana.....12 FIGURA 2.2 - Configuração de equilíbrio do elemento para

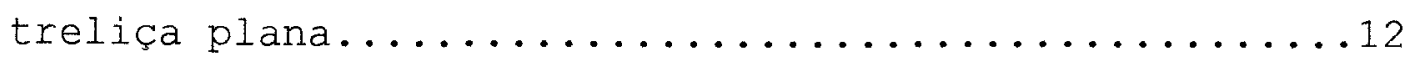
FIGURA 2.3 - Elemento de barra para pórtico plano.....13 FIGURA 2.4 - Configuração de equilíbrio do elemento para

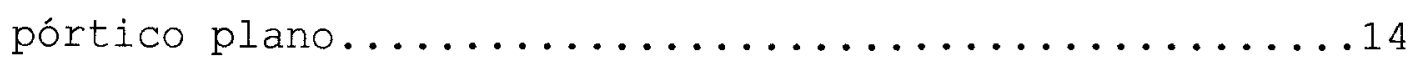
FIGURA 2.5 - Viga biengastada discretizada por elementos finitos............................. 15 FIGURA 2.6 - Viga em balanço discretizada por elementos finitos............................ . . . .

FIGURA 3.1 - Iteração de Newton-Raphson Modificado....39

FIGURA 3.2 - Iteração de Newton-Raphson............40

FIGURA 3.3 - Processo incremental / iterativo........41

FIGURA 3.4 - Diagrama de blocos do método de Newmark..49 FIGURA 3.5 - Diagrama de blocos do esquema geral de cálculo............................... 51 FIGURA 4.1 - Sistema de coordenadas para treliça

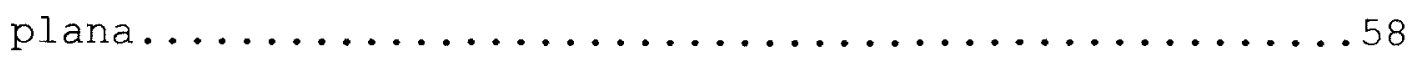
FIGURA 4.2 - Sistema de coordenadas para pórtico

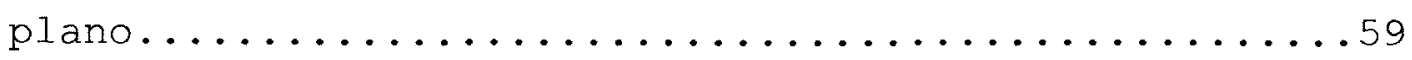
FIGURA 4.3 - Campo de deslocamentos..............61 FIGURA 4.4 - Comportamento não-linear. Matriz de rigidez secante, CORREA(1991) ......................... 72 FIGURA 4.5 - Comportamento não-linear. Matriz de rigidez tangente, CORREA(1991)...................... 74 FIGURA 4.6 - Atualização de coordenadas para um elemento de barra trabalhando em uma dimensão.............77 FIGURA 4.7 - Atualização de coordenadas para um elemento de treliça plana.........................77 FIGURA 4.8 - Atualização de coordenadas para um elemento de pórtico plano........................77 
FIGURA 4.9 - Atualização da matriz de rigidez tangente

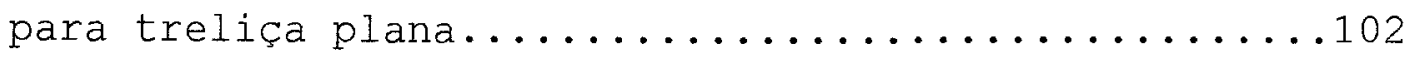
FIGURA 4.10 - Atualização da matriz de rigidez tangente

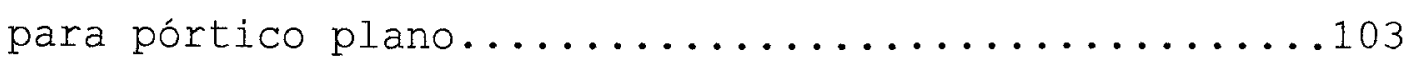
FIGURA 5.1 - Relação tensão x deformação elastoplástica. Carregamento............................ 117 FIGURA 5.2 - Relação tensão x deformação elastoplástica.

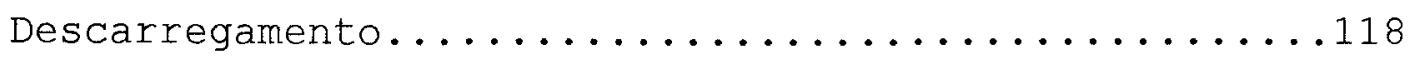
FIGURA 5.3 - Relação tensão x deformação elostoplástica. Recarregamento..........................119 FIGURA 5.4 - Relação tensão x deformação elastoplástica. Efeito Bauschinger........................119 FIGURA 5.5 - Modelo elastoplástico perfeito.........121 FIGURA 5.6 - Modelo elastoplástico com endurecimento

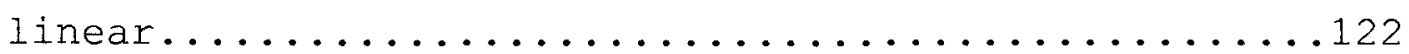

FIGURA 5.7 - Modelo com endurecimento linear isotrópico.......... . . . . . . . . . . . . 123 FIGURA 5.8 - Modelo com endurecimento linear

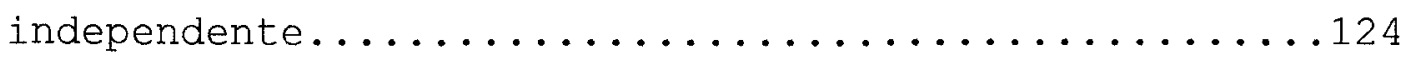
FIGURA 5.9 - Modelo com endurecimento linear

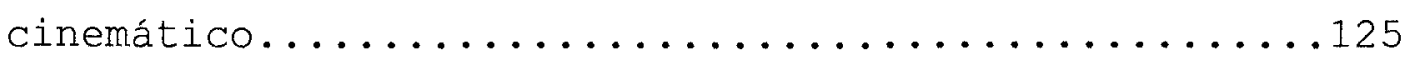
FIGURA 5.10 - Variação incremental da tensão e deformação para o caso unidimensional............127 FIGURA 5.11 - Variação incremental da tensão no regime

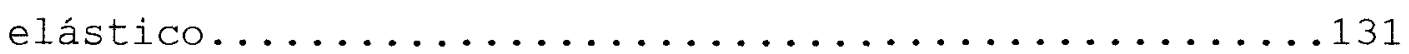
FIGURA 5.12 - Variação incremental da tensão no regime

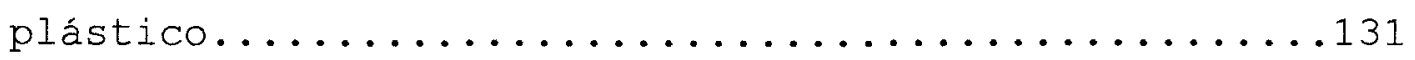
FIGURA 5.13 - Rotina de cálculo para não-linearidade

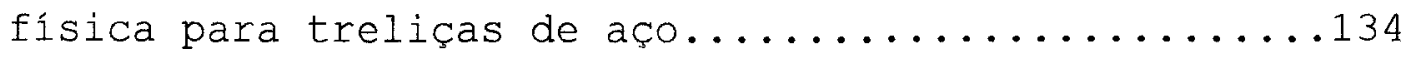
FIGURA 5.14 - Diagrama de blocos interno da subrotina

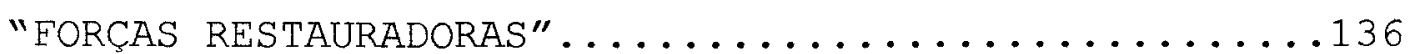
EIGURA 5.15 - Variação do comprimento para não-

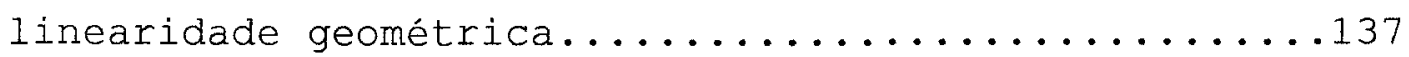
FIGURA 5.16 - Variação do comprimento para linearidade

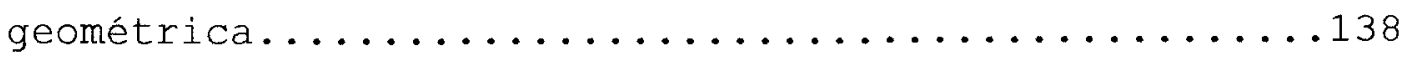


FIGURA 6.1 - Diagramas de tensão e de deformação para

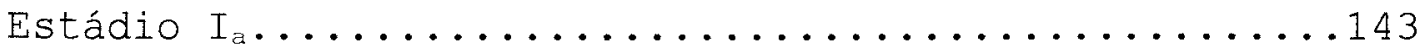

FIGURA 6.2 - Diagrama de tensão e de deformação para

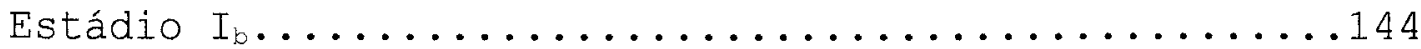
FIGURA 6.3 - Diagramas de tensão e de deformação para Estádio II............................ 144

FIGURA 6.4 - Diagramas de tensão e de deformação para

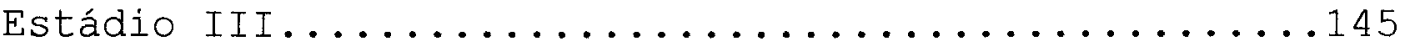
FIGURA 6.5 - Disposições geométricas de uma seção retangular de concreto armado...............146 FIGURA 6.6 - Seção transversal submetida à flexão normal

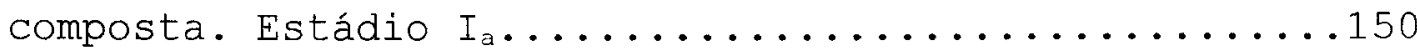
FIGURA 6.7 - Seção transversal submetida à flexão normal

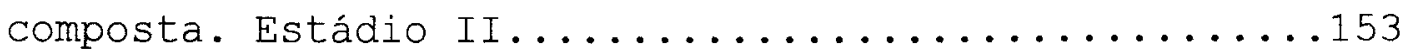
FIGURA 6.8 - Diagrama de blocos para o modelo físico do

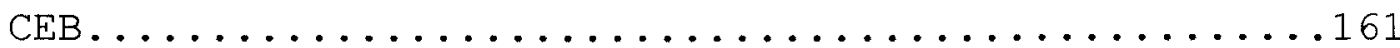
FIGURA 6.9 - Diagrama de blocos para o modelo físico do

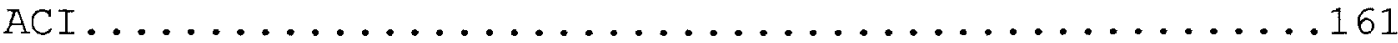

FIGURA 6.10 - Diagrama momento-curvatura...........162 FIGURA 6.11 - Diagrama de blocos interno da subrotina

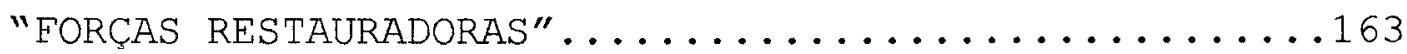
FIGURA 7.1 - Treliça constituída por apenas um elemento

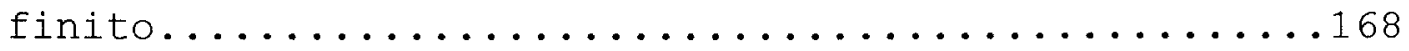
FIGURA 7.2 - Gráfico tempo x deslocamento considerando-

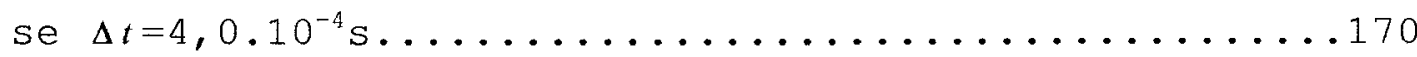
FIGURA 7.3 - Gráfico tempo x deslocamento considerando-

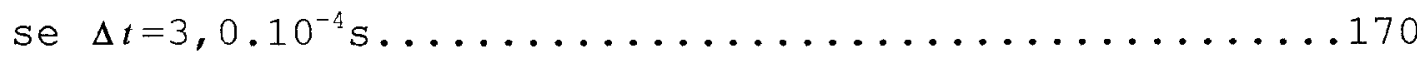
EIGURA 7.4 - Gráfico tempo x deslocamento considerandose $\Delta t=2,0.10^{-4}$ s.......................... 171 FIGURA 7.5 - Gráfico tempo x deslocamento considerandose $\Delta t=1,0.10^{-4}$ s........................... FIGURA 7.6 - Gráfico tempo x deslocamento considerando-

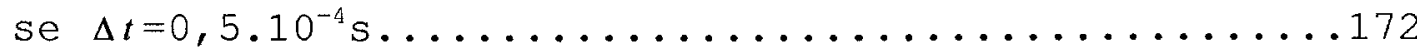
FIGURA 7.7 - Gráfico tempo x força considerando-se nãolinearidade física, com $\Delta t=0,5.10^{-4}$ s.............173 
FIGURA 7.8 - Gráfico tempo x deslocamento considerandose não-linearidade física, com $\Delta t=0,5.10^{-4} \mathrm{~s} \ldots \ldots \ldots . .173$ FIGURA 7.9 - Treliça constituída por vários elementos

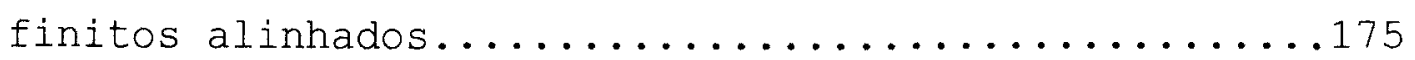
FIGURA 7.10 - Gráfico tempo x deslocamento do nó "4".175 FIGURA 7.11 - Gráfico tempo x deslocamento do nó "7".176 FIGURA 7.12 - Gráfico tempo x deslocamento do nó

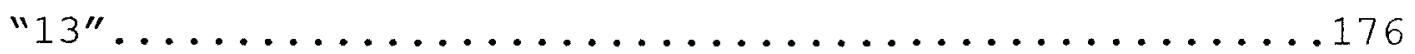
FIGURA 7.13 - Gráfico tempo x força do elemento "1"..177 FIGURA 7.14 - Gráfico tempo x força do elemento "6"..177 FIGURA 7.15 - Gráfico tempo x força do elemento "12".178 FIGURA 7.16 - Treliça constituída por dois elementos

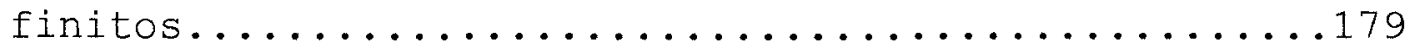
FIGURA 7.17 - Gráfico força x deslocamento do nó "1".180 FIGURA 7.18 - Gráfico tempo x força do elemento "1"..181 FIGURA 7.19 - Gráfico tempo x desiocamento do nó "1".182 FIGURA 7.20 - Treliça em balanço. Arranjo "1".......184 FIGURA 7.21 - Treliça em balanço. Arranjo "2".......184 FIGURA 7.22 - Gráfico tempo x deslocamento do nó "8"

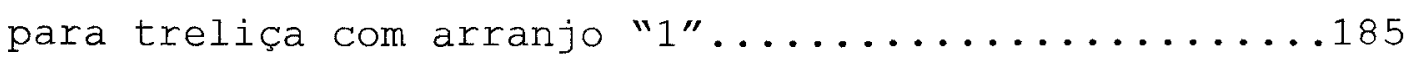
FIGURA 7.23 - Gráfico tempo x deslocamento do nó "21" para treliça com arranjo "2".................186 FIGURA 7.24 - Viga principal de uma ponte metálica

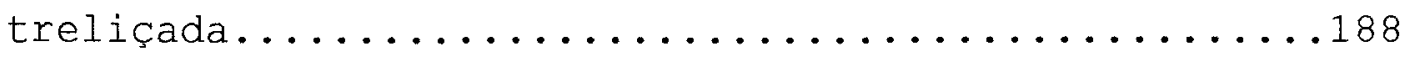
FIGURA 7.25 - Carregamento da viga principal da ponte

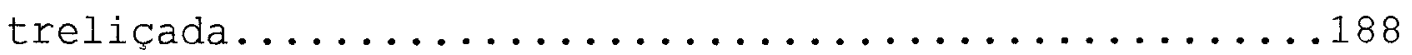
FIGURA 7.26 - Primeiro modo de vibração da estrutura.189 FIGURA 7.27 - Segundo modo de vibração da estrutura..189 FIGURA 7.28 - Terceiro modo de vibração da estrutura.190 FIGURA 7.29 - Gráfico tempo x deslocamento do nó "3".193 FIGURA 7.30 - Pórtico formado por um elemento finito.194 FIGURA 7.31 - Gráfico tempo x deslocamento considerando-

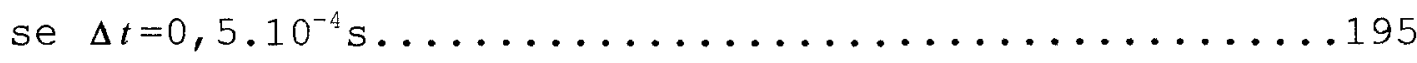
FIGURA 7.32 - Pórtico constituído por vários elementos

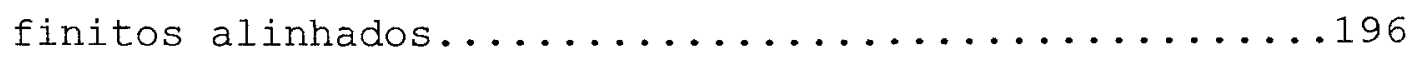


FIGURA 7.33 - Gráfico tempo x deslocamento do nó "4".196 FIGURA 7.34 - Gráfico tempo x deslocamento do nó "7".197 FIGURA 7.35 - Gráfico tempo x deslocamento do nó

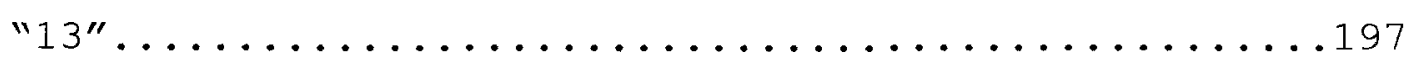
FIGURA 7.36 - Gráfico tempo x força do elemento "1"..198 FIGURA 7.37 - Gráfico tempo x força do elemento "6"..198 FIGURA 7.38 - Gráfico tempo x força do elemento "12".199 FIGURA 7.39 - Viga em balanço discretizada por elementos

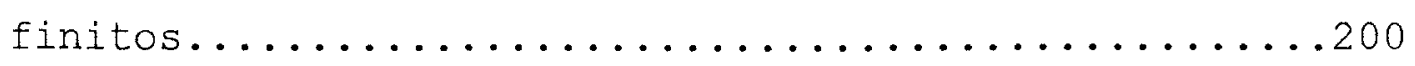
FIGURA 7.40 - Gráfico força x deslocamento do nó

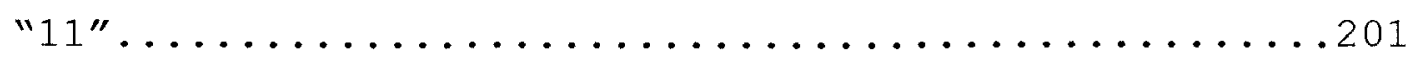
FIGURA 7.41 - Posição deslocada da viga após a aplicação

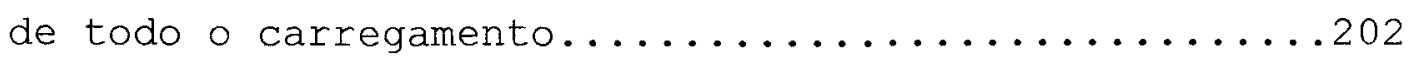
FIGURA 7.42 - Pórtico simples biengastado discretizado

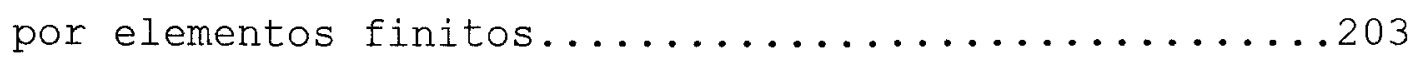
FIGURA 7.43 - Gráfico força $x$ deslocamento do nó "7"

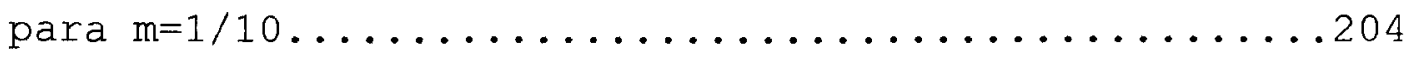
FIGURA 7.44 - Gráfico força x deslocamento do nó "7"

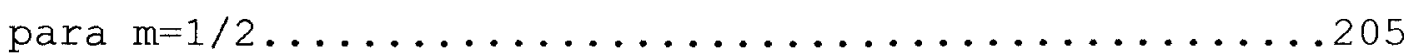
FIGURA 7.45 - Posição deslocada do pórtico considerando-

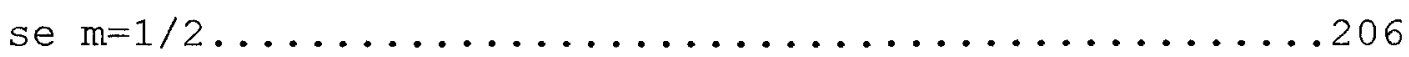
FIGURA 7.46 - Viga biengastada discretizada por elementos finitos........................207 FIGURA 7.47 - Gráfico tempo x deslocamento do nó "4".208 FIGURA 7.48 - Viga biapoiada discretizada por elementos

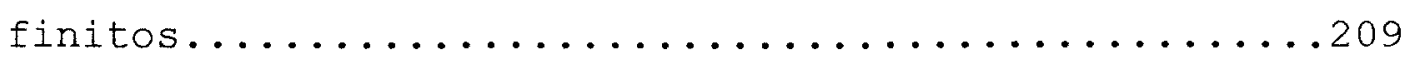
FIGURA 7.49 - Seção transversal da viga. Arranjo "1".210 FIGURA 7.50 - Seção transversal da viga. Arranjo "2".210 FIGURA 7.51 - Seção transversal da viga. Arranjo "3".210 FIGURA 7.52 - Gráfico força $x$ deslocamento do nó "7"

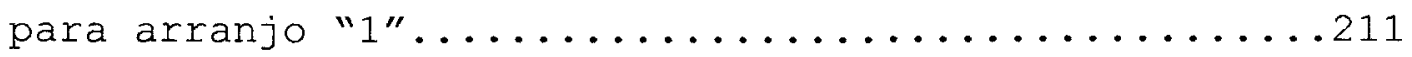
FIGURA 7.53 - Gráfico força x deslocamento do nó "7"

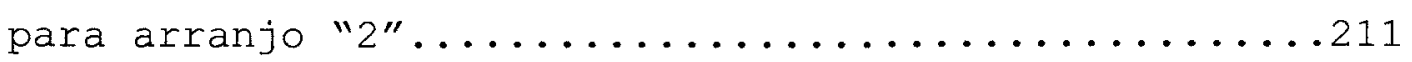
FIGURA 7.54 - Gráfico força $x$ deslocamento do nó "7" para arranjo " $3 " \ldots . \ldots \ldots \ldots . \ldots \ldots \ldots . \ldots \ldots 212$ 
FIGURA 7.55 - Gráfico força x deslocamento do nó "7" para " $F$ " variando de $0,0 \mathrm{kN}$ até $20,0 \mathrm{kN}$. Carregamento

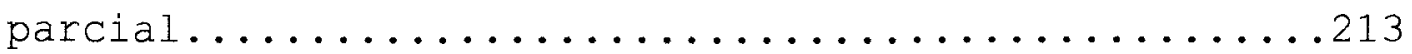
FIGURA 7.56 - Gráfico força x deslocamento do nó "7" para " $\mathrm{F}$ " variando de $20,0 \mathrm{kN}$ até $0,0 \mathrm{kN}$. Descarregamento

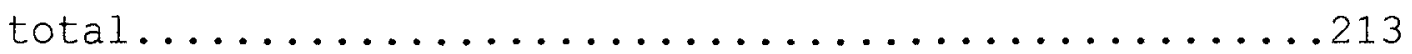
FIGURA 7.57 - Gráfico força x deslocamento do nó "7" para " $E$ " variando de $0,0 \mathrm{kN}$ até $20,0 \mathrm{kN}$. Recarregamento

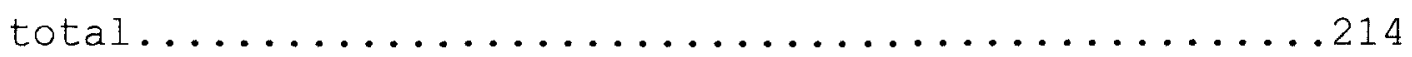
FIGURA 7.58 - Gráfico força $x$ deslocamento do nó "7" para " $F$ " variando de $20,0 \mathrm{kN}$ até $40,0 \mathrm{kN}$. Carregamento

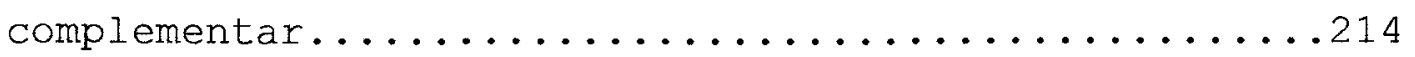
FIGURA 7.59 - Pórtico simples biengastado discretizado

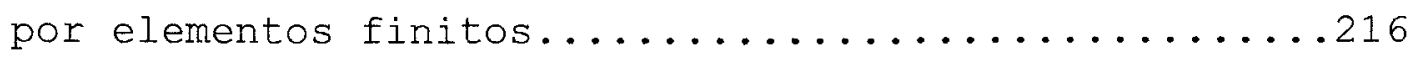
FIGURA 7.60 - Seção transversal de todos os elementos do

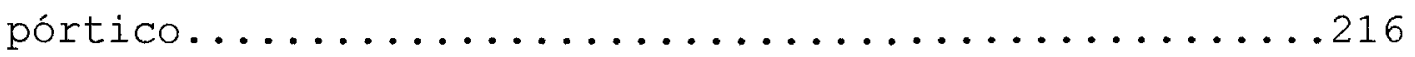
FIGURA 7.61 - Variação do módulo da força "F" com o

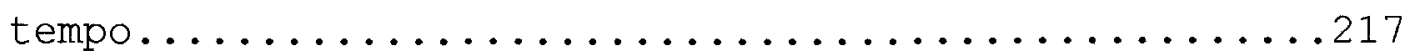

FIGURA 7.62 - Primeiro modo de vibração da estrutura.217 FIGURA 7.63 - Segundo modo de vibração da estrutura..218 FIGURA 7.64 - Terceiro modo de vibração da estrutura.218 FIGURA 7.65 - Gráfico tempo x deslocamento do nó "5",

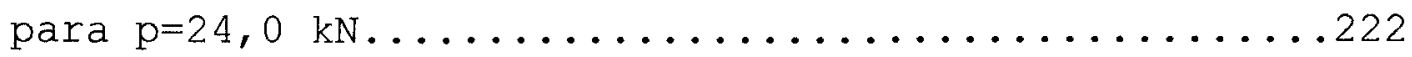
FIGURA 7.66A - Gráfico tempo x deslocamento do nó "5", considerando-se amortecimento, para $p=24,0$ kN......223 FIGURA 7.66B - Gráfico tempo x deslocamento do nó "5", considerando-se amortecimento, para $\mathrm{p}=24,0 \mathrm{kN} \ldots \ldots .224$ 


\section{IISTA DE TABELAS}

TABELA 7.1 - Deslocamentos máximos obtidos no nó "3", na direção global "Y", em "cm"....................191 TABELA 7.2 - Deslocamentos máximos obtidos no nó "5", na

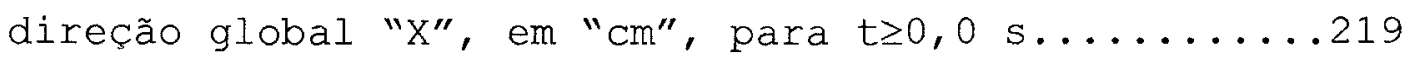
TABELA 7.3 - Deslocamentos máximos obtidos no nó "5", na direção global " $\mathrm{X}$ ", em "cm", para $t \geq 0,032$ s.......220 TABELA 7.4 - Deslocamentos finais obtidos no nó "5", na direção global " $\mathrm{X}$ ", em "cm", para $t=\infty$ s..........220 


\title{
ABREVIATURAS, SIGLAS E SÍMBOLOS
}

\author{
As principais abreviaturas e siglas utilizadas \\ neste trabalho são listadas a seguir: \\ CEB - Comité Euro-International du Béton \\ ACI - American Concrete Institute \\ MEF - Método dos Elementos Finitos \\ Já os símbolos utilizados são identificados no \\ transcorrer do trabalho, quando da sua primeira \\ utilização ou quando se fizer necessário.
}




\section{RESUMO}

RODRIGUES, R. O.(1997). Análise dinâmica bidimensional não-linear física e geométrica de treliças de aço e pórticos de concreto armado. São Carlos, 275p. Tese (Doutorado) - Escola de Engenharia de São Carlos, Universidade de São Paulo.

Este trabalho trata da análise dinâmica bidimensional de treliças de aço e pórticos de concreto armado, onde estudam-se os efeitos da não-linearidade física desses materiais e os efeitos da não-linearidade geométrica de tais estruturas.

Neste contexto, define-se a equação geral que descreve o comportamento de estruturas discretizadas por elementos finitos, utilizando-se o Princípio dos Trabalhos Virtuais para estruturas em movimento. Para a integração temporal dessa equação, utiliza-se um método implícito de integração numérica, onde adota-se um processo previsor-corretor com auxilio das equações generalizadas de Newmark.

$\mathrm{Na}$ análise da não-linearidade geométrica, define-se - campo de deformações através de uma função quadrática dos deslocamentos, que ocorrem ao longo de cada elemento finito, sendo que para treliças planas consideram-se todas as parcelas provenientes de tal relação e para pórticos planos desprezam-se os termos que contém produtos de parcelas de ordem superior. Para descrever a posição de equilíbrio do sistema estrutural ao longo do processo de integração numérica, utiliza-se a formulação Lagrangeana atualizada que resulta na dedução das matrizes de rigidez incrementais secante e tangente.

Com relação à não-linearidade física do aço, elabora-se uma modelagem numérica através da utilização 
de um diagrama tensão x deformação bilinear, destacandose os modelos cinemático, isotrópico e independente. Já para a não-linearidade física do concreto armado, elabora-se uma modelagem numérica através da utilização dos modelos propostos pelo CEB e pelo ACI, onde corrigese o valor do momento de inércia em função do grau de fissuração do elemento. Estas modelagens contemplam, também, o comportamento para carregamento cíclico e sua inversão.

Para finalizar, apresentam-se exemplos numéricos com posterior análises qualitativa e quantitativa dos resultados.

Palavras-chave: Dinâmica estrutural; Comportamento não-Iinear. 


\section{ABSTRACT}

RODRIGUES, R. O.(1997). Physical and geometrical non-linear twodimensional dynamic analysis of steel trusses and reinforced concrete frames. São Carlos, 275p. Tese (Doutorado) - Escola de Engenharia de São Carlos, Universidade de São Paulo.

This work deals with the two-dimensional dynamic analysis of steel trusses and reinforced concrete frames. The physical non-linear effects of these materials as well as the geometrical non-linearity of such structures are studied.

In this context, a general equation that describes the behaviour of structures approximated by finite elements is defined, using the Virtual Works Principle for structures in movement. In order to integrate this differential equation along the time an implicit procedure is adopted based on the predictor-corrector process taking into account the Newmark's generalised equations.

For the geometrical non-linear analysis, the deformation field is defined by assuming displacements approximated along each finite element by quadratic shape functions. All terms resulting from that assumption are taken into account for the plane trusses, while for plane frame, terms representing higher order products are neglected. In order to describe the equilibrium position of the structural system, during the numeric integration process, the updated Lagrangean formulation is used to give the secant and tangent incremental stiffness matrices.

Regarding the steel non-linear physical behaviour, a numerical procedure is achieved based on a bilinear 
stress-strain curve that is able to describe kinematic, isotropic and independent responses. For the reinforced concrete physical non-linear behaviour the well known $\mathrm{CEB}$ and ACI models were taken to derive and implement the numeric process. In this case, the moment of inertia is corrected according to the element level of cracking. These models also consider the material behaviour when cyclic loads are applied causing stress sign inversion. Finally, numeric examples are presented to illustrate the quality and accuracy of obtained results.

Keywords: Structural dynamics; Non-linear behaviour. 


\section{CAPÍTULO 1 - INTRODUÇÃO}

\section{1 - Tema e motivação}

A análise realista do comportamento estático e dinâmico de sistemas estruturais é, sem dúvida, um dos principais objetivos almejados pelo Engenheiro de Estruturas nas últimas quatro décadas.

Com a idealização do Método dos Elementos Finitos, que ocorreu na década de cinquienta com os trabalhos de Argyris e Kelsey, publicados em 1954, e de Turner et al. publicado em 1956, os pesquisadores passaram a ter uma ferramenta poderosa que permite a modelação matemática de fenômenos envolvidos na análise estrutural, tais como os provenientes da alteração da geometria do sistema estrutural (não-linearidade geométrica) e da alteração das propriedades físicas dos materiais que compõem o mesmo (não-linearidade física).

Na década de sessenta, com o trabalho de Clough, publicado em 1960, inicia-se uma nova fase na Engenharia de Estruturas, onde procura-se empregar o MEF na análise estrutural com auxílio de computadores de grande porte, através da sua implementação via linguagem FORTRAN. Ao final da mesma década surgem alguns programas comerciais que fazem este tipo de análise, tais como o "STARDYNE", "NEST", "NASTRAN", "SAP", "ANSYS" e outros, como mostra BRASIL(1990), deflagrando, assim, uma corrida em busca de melhores programas computacionais, sempre baseados em modelos estruturais mais precisos e abrangentes. 
Nas décadas de setenta e oitenta é publicado um número muito grande de trabalhos que tratam do assunto, vide CORREAA(1991) e CILONI(1993), em especial aqueles que consideram a não-linearidade geométrica na análise estática de edifícios altos e a não-linearidade física para materiais usuais, como o aço e o concreto armado.

Com a disseminação da informática ocorrida no final da década de oitenta, e principalmente em função do aumento vertiginoso da capacidade de armazenamento, gerenciamento e processamento de dados aduzido pelos computadores de pequeno porte, o Engenheiro de Estruturas passa a ter acesso a equipamentos e programas computacionais que possibilitam uma análise estrutural baseada em modelos mais refinados, proporcionando um aumento da segurança e diminuição de custos dos projetos e das construções.

Já no início desta década, alguns trabalhos que abordam este tipo de análise merecem destaque, a saber: BRASIL(1990) trata da não-linearidade geométrica na análise dinâmica de estruturas aporticadas planas utilizando a formulação Lagrangeana total, com termos não-lineares nas matrizes de massas e de amortecimento; CORREA(1991) trata da não-linearidade geométrica na análise estática de estruturas reticuladas planas e espaciais utilizando a formulação Lagrangeana atualizada; MAZZILLI et al.(1992) elaboram o programa computacional "ANDROS" para análise dinâmica não-linear geométrica de estruturas reticuladas planas; BRASIL et al.(1992) apresentam algumas simplificações relativas à análise dinâmica não-linear geométrica de estruturas reticuladas; CILONI(1993) trata da não-linearidade geométrica na análise estática de estruturas aporticadas planas utilizando a formulação Lagrangeana atualizada e da não-linearidade física do concreto armado; 
SOLER(1995) trata da análise não-linear de pórticos espaciais de concreto armado utilizando uma formulação consistente baseada na teoria de grandes deslocamentos e deformações; e SILVA(1996) trata da análise não-linear de pórticos planos de concreto armado utilizando um sistema corrotacional solidário ao elemento para a obtenção da matriz de rigidez.

Atualmente, em função desse avanço científico e tecnológico, a realização de análises dinâmicas nãolineares se torna cada vez mais premente, tendo em vista a necessidade de se simular, da forma mais realista possível, o comportamento estrutural de edificações e equipamentos existentes, tais como fundações aporticadas de máquinas, pontes rodoviárias e ferroviárias sujeitas à grandes deslocamentos, edifícios altos submetidos à ação do vento e estruturas em geral sujeitas à vibrações induzidas por abalos sísmicos.

Neste contexto, o autor deste trabalho sentiu-se motivado a analisar o comportamento dinâmico de estruturas reticuladas planas considerando-se dupla nãolinearidade, através da implementação, de forma aprimorada, da formulação Lagrangeana atualizada para descrever a posição de equilíbrio da estrutura e da utilização de modelos físicos não-lineares para os materiais aço e concreto armado. Para esta finalidade, o autor desenvolveu programas computacionais, em linguagem PASCAL, O'BRIEN(1992), que contemplam as diversas possibilidades de análise estrutural, permitindo, sempre que possível, realizar a comparação entre o comportamento estático e dinâmico de tais sistemas estruturais. Cabe ressaltar que este tema faz parte de uma das linhas de pesquisa desenvolvidas no âmbito do Departamento de Engenharia de Estruturas da Escola de Engenharia de São Carlos, da Universidade de São Paulo USP. 


\section{2 - Objetivos do trabalho}

Este trabalho tem por objetivos:

- implementar a não-linearidade geométrica na análise dinâmica estrutural utilizando-se a formulação Lagrangeana atualizada;

- aprimorar a formulação Lagrangeana atualizada existente para as estruturas reticuladas planas;

- introduzir a não-linearidade física para materiais usuais, como o aço e o concreto armado, na análise dinâmica estrutural;

- elaborar um conjunto de programas computacionais que contemplem as diversas possibilidades de análise estrutural;

- analisar o comportamento estático e dinâmico das treliças de aço e pórticos de concreto armado, considerando-se as não-linearidades física e geométrica.

\section{3 - Apresentação do trabalho}

Após a introdução deste capítulo, que tem por finalidade ilustrar $O$ assunto a ser discutido, apresentam-se, na sequiência deste trabalho, mais sete capítulos que foram organizados de acordo com a ordem natural de uma análise estrutural.

Dessa forma, no capítulo 2, descrevem-se os motivos da transformação de um sistema estrutural contínuo em um sistema estrutural discreto, através da utilização de elementos finitos previamente escolhidos em função do 
sistema estudado, e descrevem-se as forças que atuam em um sistema estrutural já discretizado. Apresentam-se, também, os princípios básicos que regem o comportamento de estruturas em repouso e em movimento, possibilitandose, na continuidade do capitulo, a montagem da equação geral que descreve o movimento de tais sistemas.

No capitulo 3, apresentam-se os métodos utilizados na integração numérica da equação geral do movimento, as equações generalizadas de Newmark e os algoritmos utilizados na resolução de sistemas não-lineares. Adotando-se o método de Newmark para integração numérica no tempo, elabora-se o equacionamento pertinente e descreve-se o funcionamento do algoritmo numérico para resolução de tal método. Abordam-se, também, os aspectos computacionais necessários para a análise estrutural dinâmica.

Já no capitulo 4, aborda-se a não-linearidade geométrica que ocorre em estruturas discretizadas por elementos de barra, utilizando-se a formulação Lagrangeana atualizada de forma aprimorada, através da consideração de novas parcelas da equação que define o campo de deformações de cada elemento estrutural. Para isso, adotam-se um sistema de coordenadas adequado e um modelo elemental compativel, propiciando-se a dedução das matrizes incrementais de rigidez secante e tangente para os elementos que compõem treliças planas e pórticos planos, bem como a dedução das matrizes de massas e de amortecimento para tais sistemas. Consideram-se, também, os aspectos computacionais pertinentes para a implementação dessas matrizes nos programas computacionais que foram desenvolvidos.

No capítulo 5, trata-se a não-linearidade física do material estrutural aço, aplicado na construção de treliças planas. Preliminarmente, estudam-se 0 comportamento uniaxial do aço, os modelos 
elastoplásticos unidimensionais e os modelos com endurecimento linear para carregamento cíclico, destacando-se os modelos isotrópico, cinemático e independente. Com isso, elabora-se uma modelagem numérica compatível com o problema proposto, destacandose os aspectos computacionais principais.

Finalizando-se a parte teórica deste trabalho, no capitulo 6, trata-se a não-linearidade física do material estrutural concreto armado, aplicado na construção de pórticos planos. Preliminarmente, descrevem-se os conceitos gerais relativos ao material estudado e, posteriormente, estudam-se 0 seu comportamento em serviço e os modelos físicos nãolineares, tais como os modelos propostos pelo CEB e pelo ACI. Analogamente ao capítulo 5, elabora-se uma modelagem numérica compatível com o problema proposto, destacando-se os aspectos computacionais principais.

No capítulo 7, encontram-se vários exemplos relativos à análise estática e dinâmica não-linear física e geométrica de estruturas treliçadas e aporticadas, onde procura-se fazer uma análise quantitativa e qualitativa dos resultados encontrados, através da comparação de resultados obtidos por outros pesquisadores.

Ao final deste trabalho, no capítulo 8, faz-se a conclusão do mesmo e descrevem-se as propostas de desenvolvimento que ainda podem ser realizadas nesta linha de pesquisa. 


\section{CAPÍTULO 2 - ANÁLISE ESTRUTURAL DINÂMICA NÃO-IINEAR}

\section{1 - Aspectos principais}

Uma análise estrutural dinâmica tem por objetivo principal quantificar a magnitude dos esforços internos, das velocidades, das acelerações e dos deslocamentos que se manifestam em qualquer sistema estrutural, quando 0 mesmo é submetido a um carregamento arbitrário, cuja intensidade, direção ou sentido variem com o tempo. Tal procedimento deverá fornecer uma ampla gama de resultados numéricos, compatíveis com a história temporal do carregamento aplicado, cuja avaliação de forma qualitativa viabilizará a sua utilização na elaboração do projeto estrutural do sistema analisado.

Com relação ao tipo de análise que pode ser feita destacam-se a análise linear e a não-linear, sendo a linear proveniente da manutenção da geometria inicial como referência para a verificação do equilíbrio e da manutenção das propriedades físicas específicas do material da estrutura. Já a não-linear pode ser proveniente da alteração da geometria e/ou das propriedades físicas do material estrutural.

A caracteristica principal da análise dinâmica nãolinear, tendo em vista as possiveis alterações já mencionadas, é dada pela grande variabilidade de opções que podem ser adotadas na sua elaboração. A seguir, 
destacam-se os vários níveis de decisão que estão envolvidos em tal análise:

a- discretização do sistema estrutural contínuo;

b- definição das forças atuantes no sistema estrutural;

c- escolha de um princípio para elaborar a equação de equilíbrio do sistema estrutural;

d- escolha do método de integração da equação que descreve o movimento do sistema estrutural;

e- escolha do algoritmo para resolução do sistema de equações;

f- escolha do sistema de coordenadas;

g- definição do modelo elemental;

h- formalismo adotado na decomposição das matrizes de rigidez;

i- definição da relação entre tensão / carregamento e deformação / deslocamento.

$\mathrm{Na}$ sequência, cada um dos níveis de decisão descritos anteriormente serão abordados de forma pormenorizada, enfatizando-se os subníveis que serão utilizados na elaboração deste trabalho.

\section{2 - Discretização de um sistema estrutural} contínuo

Define-se sistema estrutural como sendo uma associação de elementos estruturais formando um conjunto resistente, adequado a resistir a solicitações. Entendese como esses elementos os corpos sólidos elásticodeformáveis, com capacidade de receber e transmitir esforços de uma forma geral. 
Um meio contínuo resulta da distribuição homogênea da matéria no volume. Fisicamente, a hipótese do contínuo consiste em abstrair-se da composição molecular da matéria que compõe o meio, e da sua consequiente descontinuidade.

Neste contexto, pode-se dizer que um sistema estrutural é continuo desde que o menor elemento estrutural retirado do sistema possua as mesmas propriedades físicas específicas e não haja descontinuidade no conjunto.

A dificuldade decorrente da admissão de tal hipótese reside na formulação das equações consistentes que governam o sistema estrutural, uma vez que essas são equações diferenciais ou integrais e devem satisfazer as condições de contorno do mesmo. Cabe ressaltar que os sistemas estruturais contínuos possuem um número infinito de graus de liberdade, em função dessa continuidade.

\subsection{1 - Sistema estrutural discreto}

Para contornar o problema descrito ao final do item anterior, empregam-se métodos numéricos que transformam um sistema estrutural contínuo em um sistema estrutural discreto, através da divisão do modelo geométrico dos elementos estruturais em pequenas regiões chamadas de elementos finitos, sendo essas interconectadas entre si para formar o conjunto estrutural. Esse processo de discretização é a base do conceito dos métodos finitos.

os métodos finitos permitem expressar a solução exata dos sistemas contínuos de uma forma aproximada, através da utilização de sistemas discretos que contém um número finito de graus de liberdade. Em problemas estáticos, este procedimento resulta um sistema de 
equações algébricas que pode ser facilmente resolvido com a ajuda de técnicas computacionais. Já em problemas dinâmicos, a discretização resulta um sistema de equações diferenciais ordinárias do movimento, que requerem o uso de técnica computacional apropriada e métodos numéricos adequados de integração no tempo. Esses métodos numéricos requerem, também, a discretização do tempo contínuo.

Com a obtenção desses sistemas de equações resolvese o problema já citado, uma vez que tais sistemas facilitam a imposição das condições de contorno da estrutura. Por outro lado, a solução obtida passa a ser aproximada e para se obter uma resposta satisfatória, usualmente, deve-se escolher o tipo adequado de elemento finito, a quantidade e a disposição geométrica do mesmo.

\subsection{2 - Elementos finitos}

A definição do tipo apropriado de elemento finito é dada em função do sistema estrutural que se deseja analisar. Para isso, os elementos finitos são classificados em:

- elementos lineares;

- elementos laminares;

- elementos sólidos.

o elementos lineares, também conhecidos como elementos de barras, são elementos em que uma dimensão é muito maior do que as outras duas. Estes são subdivididos em elementos de pórticos planos e espaciais, de treliças planas e espaciais, de vigas e de grelhas. 
Já os elementos laminares são elementos em que uma dimensão é muito menor do que as outras duas e são subdivididos em elementos de placa, de chapa, de membrana e de casca.

Os elementos sólidos são elementos em que as três dimensões tem a mesma ordem de grandeza e permitem obter uma distribuição qualquer de tensões na estrutura.

Para que estes elementos finitos possam se relacionar uns com os outros, os mesmos devem ser interconectados por meio de um numero discreto de pontos comuns distribuídos no contorno. Esses pontos comuns são denominados pontos nodais ou, simplesmente, nós. Com isso, o comportamento estrutural de cada elemento pode ser definido somente em função de variáveis nodais, tais como: coordenadas, deslocamentos e carregamentos, permitindo-se a montagem dos sistemas de equações já mencionados no item anterior.

Uma vez definido o tipo e a disposição dos elementos finitos, deve-se estabelecer a quantidade a ser utilizada na discretização da estrutura. Essa quantidade vai afetar a precisão da solução e o tempo de processamento numérico, visto que o tamanho dos sistemas de equações a serem resolvidos dependem do número de nós existentes. Cabe ressaltar que a quantidade de nós define o número de graus de liberdade da estrutura e, consequientemente, os seus modos de vibração em problemas dinâmicos.

Após a resolução desses sistemas de equações, utilizam-se funções de interpolação, também chamadas funções de forma, para descrever o comportamento estrutural genérico de cada elemento.

$\mathrm{Na}$ seqüência, destacam-se os tipos de elementos que serão utilizados neste trabalho, mostrando-se as suas respectivas peculiaridades. 


\subsubsection{1 - Elemento para treliça plana}

O elemento utilizado na análise estrutural de treliças planas, com suas respectivas coordenadas locais, é mostrado na figura 2.1 .

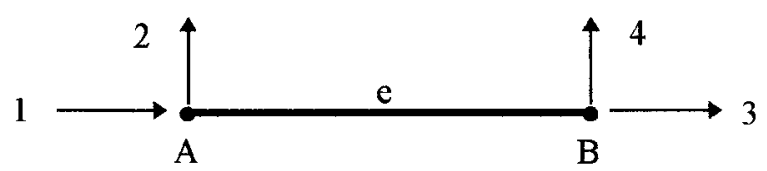

FIGURA 2.1 - Elemento de barra para treliça plana.

Já a figura 2.2 ilustra uma configuração qualquer de equilíbrio do elemento para treliça plana após a sua deformação.

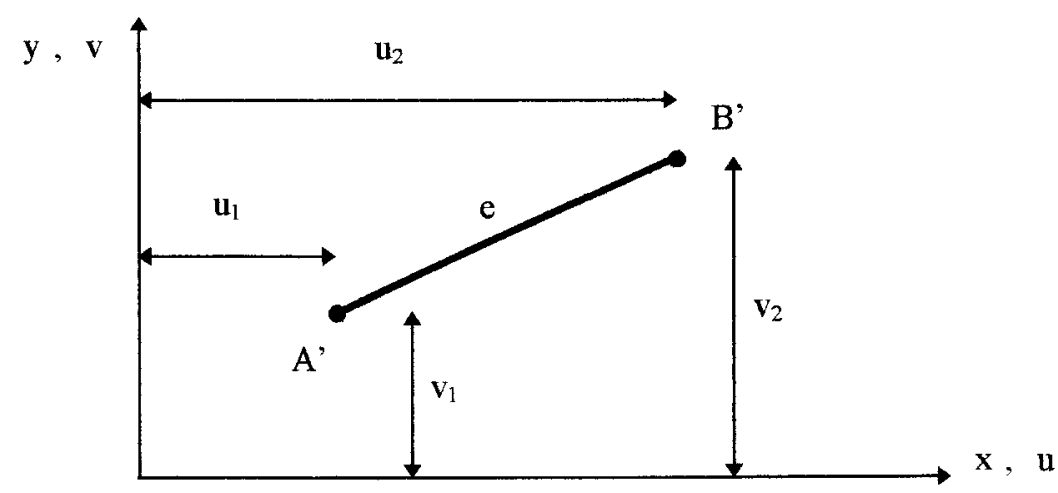

FIGURA 2.2 - Configuração de equilíbrio do elemento para treliça plana.

Os deslocamentos genéricos dos pontos situados sobre o eixo do elemento " $e$ " mostrado na figura 2.2, segundo os eixos " $\mathrm{x}$ " e " $\mathrm{y}$ " respectivamente, são dados na forma matricial por:

$$
u^{T}=\left\{\begin{array}{ll}
u & v
\end{array}\right\}
$$


Já as componentes dos deslocamentos genéricos para cada nó do elemento, ver figura 2.2, são dadas na forma matricial por:

$$
d^{T}=\left\{\begin{array}{llll}
u_{1} & v_{1} & u_{2} & v_{2}
\end{array}\right\}
$$

Com isso, os deslocamentos " $u$ " podem ser escritos em função dos deslocamentos " $d$ " através da utilização das funções de forma. Essa relação matricial é dada por:

$$
\underset{\sim}{u}=\phi \underset{\sim}{\mathrm{d}}
$$

onde " $\phi$ " é a matriz que contém as funções de forma.

\subsubsection{2 - Elemento finito para pórtico plano}

o elemento finito utilizado na análise estrutural de pórticos planos, com suas respectivas coordenadas locais, é mostrado na figura 2.3 .

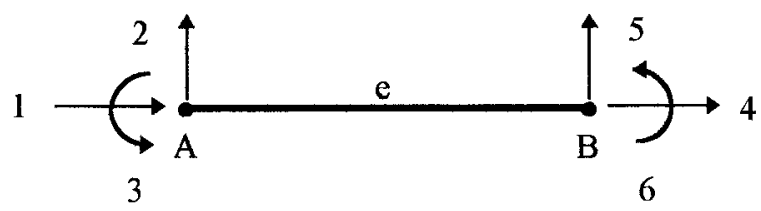

FIGURA 2.3 - Elemento de barra para pórtico plano.

Já a figura 2.4 ilustra uma configuração qualquer de equilibrio do elemento para pórtico plano após a sua deformação. 


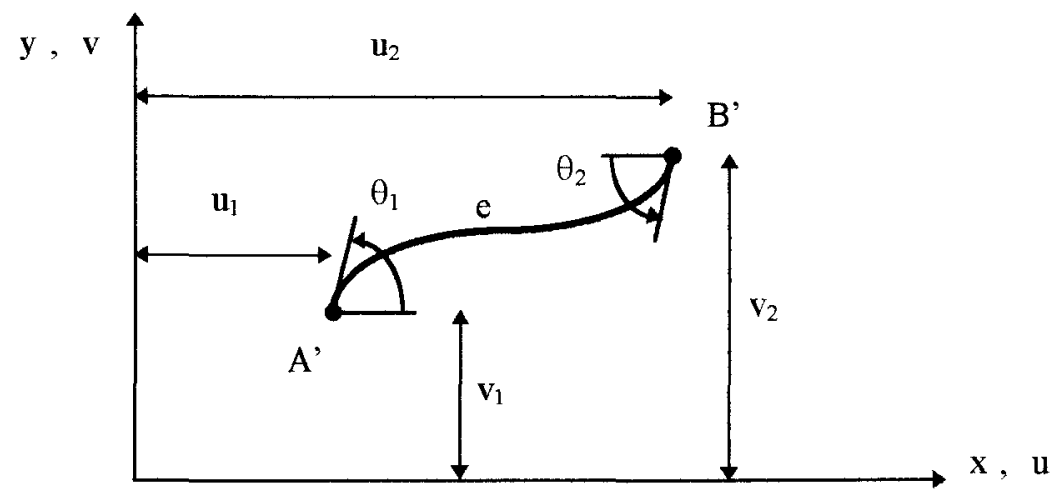

FIGURA 2.4 - Configuração de equilíbrio do elemento para pórtico plano.

Com relação aos deslocamentos genéricos dos pontos situados sobre o eixo do elemento " $e$ ", os mesmos são dados na forma matricial por:

$$
u^{T}=\left\{\begin{array}{ll}
u & v
\end{array}\right\}
$$

Já as componentes dos deslocamentos genéricos para cada nó do elemento, ver figura 2.4, são dadas na forma matricial por:

$$
d^{T}=\left\{\begin{array}{llllll}
u_{1} & v_{1} & \theta_{1} & u_{2} & v_{2} & \theta_{2}
\end{array}\right\}
$$

De forma análoga ao item anterior, feito para representar o elemento de treliça, para o elemento de pórtico plano fica valendo a equação (2.3), respeitandose a ordem da matriz " $\phi$ " $e$ as suas respectivas funções intrínsecas. 


\section{3 - Esforços atuantes em um sistema estrutural discreto}

Dado um sistema estrutural arbitrário discretizado por uma série de elementos finitos, conforme ilustra a figura 2.5, pode-se isolar um cubo infinitesimal com volume "dV" de qualquer elemento, com a finalidade de se analisar os esforços atuantes no mesmo, de acordo com os itens subseqüentes.
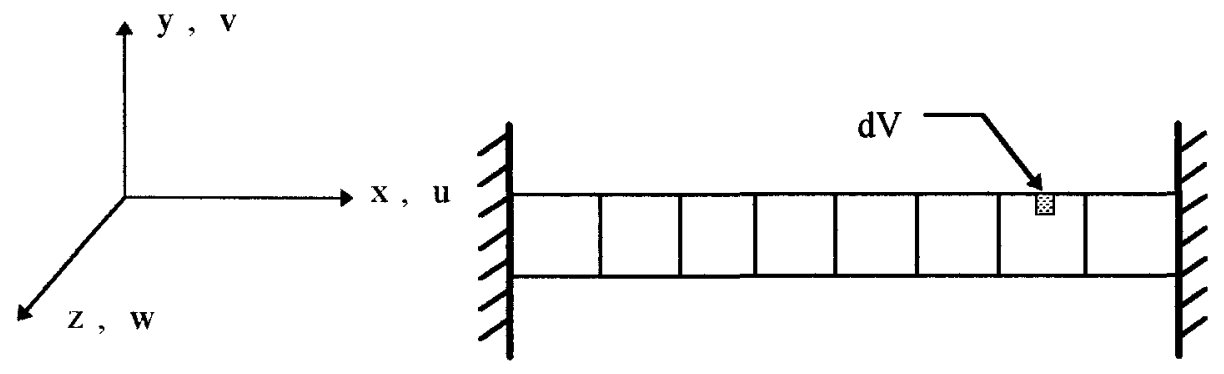

FIGURA 2.5 - Viga biengastada discretizada por elementos finitos.

\subsection{1 - Esforços devidos ao meio externo}

\subsubsection{1 - Esforços volumétricos}

Os esforços volumétricos são aplicados em todos os pontos do material e tem dimensão de força por unidade de volume, uma vez que os momentos volumétricos não serão considerados. Esses podem ser provenientes de campos magnéticos, da gravidade, etc. Logo, sobre cada elemento diferencial de volume " $d V$ " atuam as componentes dos esforços volumétricos, que organizadas na forma matricial resultam: 


$$
p_{\sim V e}^{T}=\left\{\begin{array}{lll}
V_{x} & V_{y} & V_{z}
\end{array}\right\}
$$

$$
\sim V e
$$

\subsubsection{2- Esforços superficiais}

Os esforços superficiais são aplicados de forma distribuída nas superfícies externas dos elementos e tem dimensão de força por unidade de área, uma vez que os momentos superficiais não serão considerados. Esses podem ser provenientes da ação do vento, do peso próprio da alvenaria, das reações das lajes, etc. Logo, sobre cada elemento diferencial com área externa "dS" atuam as componentes dos esforços superficiais, que organizadas na forma matricial resultam:

$$
p^{T}=\left\{\begin{array}{lll}
\mathrm{S}_{x} & \mathrm{~S}_{y} & \mathrm{~S}_{z}
\end{array}\right\}
$$

\subsubsection{3 - Esforços concentrados}

Os esforços concentrados são, geralmente, aplicados nos nós dos elementos e têm dimensão de força e de força vezes unidade métrica, visto que os momentos são incluídos nesta categoria de esforço. Esses podem ser provenientes das reações das vigas ou pilares, carregamentos pontuais, etc. Logo, sobre cada nó de um elemento finito atuam as componentes dos esforcos concentrados, que organizadas na forma matricial resultam: 


$$
\underset{\sim C}{p}=\left\{\begin{array}{lll}
\mathrm{C}_{x} & \mathrm{C}_{y} & \mathrm{C}_{z}
\end{array}\right\}
$$

\subsubsection{4 - Dependência dos esforços externos}

Em virtude dos esforcos externos apresentados nos itens anteriores possuirem módulo, direção e sentido, os mesmos podem depender, no caso de problemas dinâmicos, da variação dos deslocamentos, das velocidades, das acelerações e do tempo.

Como neste trabalho só serão considerados os esforços concentrados, essa dependência ficará restrita somente à variação do tempo, de tal forma que a direção se mantenha constante e o módulo e o sentido possam variar com o mesmo.

A figura 2.6 ilustra tal dependência, mostrando uma viga em balanço, discretizada por uma série de elementos finitos lineares, na sua posição inicial e na sua posição deslocada.

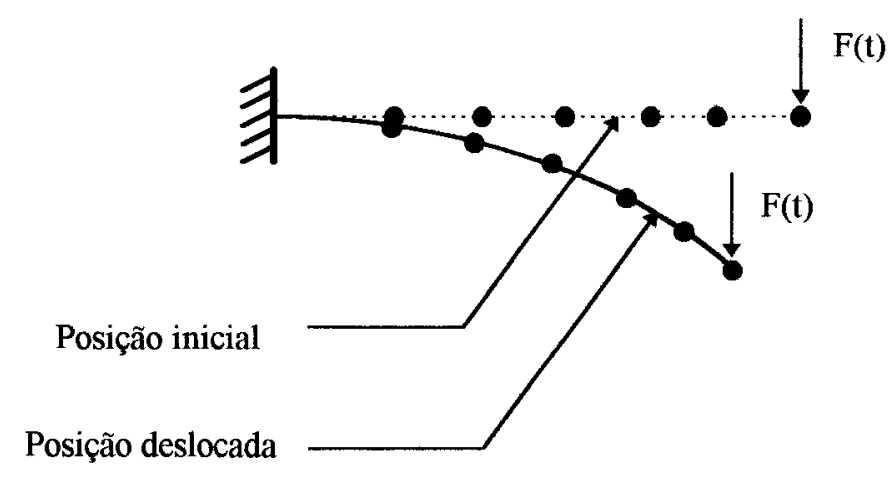

FIGURA 2.6 - Viga em balanço discretizada por elementos finitos. 
Dessa forma, para que o módulo e o sentido sejam afetados pelo tempo, o módulo das forças será multiplicado por uma função "P", dada pela seguinte expressão:

$$
P=A+B t+C t^{2}+D \operatorname{sen}(E t)+F \cos (G \mathrm{t})+R \exp (S \mathrm{t})
$$

onde "A", "B", "C", "D", "E", "F", "G", "R" e "S" são constantes da função multiplicadora e "t" é o tempo em questão.

\subsection{2 - Forças devidas ao movimento}

\subsubsection{1 - Forças inerciais}

Considerando-se, agora, que o cubo infinitesimal de volume "dV", cuja densidade específica é " $\rho$ ", seja acelerado nas direções " $x$ ", " $y$ " e " $z$ ", então as forças inerciais podem ser obtidas pela segunda lei de Newton.

A segunda lei de Newton afirma que a força resultante " $R$ " exercida sobre um corpo é diretamente proporcional à aceleração "a" produzida pela mesma, de tal forma que:

$$
R=m \mathrm{a}
$$

onde "m" é a massa do corpo.

Dividindo-se ambos os membros da equação (2.10) pelo volume do cubo, obtém-se: 


$$
\frac{R}{d V}=\frac{m}{d V} a
$$

Desse modo, as forças inerciais por unidade de volume nas direçôes das coordenadas " $x$ ", " $y$ " e " $z$ ", como expresso por ARGYRIS et al.(1991), são dadas na forma matricial por:

$$
p_{I}=\rho(x, y, z)\left\{\begin{array}{c}
\bullet \bullet \\
u \\
\bullet \\
v \\
\cdots \\
w
\end{array}\right\}=\rho u
$$

Cabe ressaltar que as forças inerciais atuantes no elemento infinitesimal são aplicadas na estrutura que fica em torno do elemento. Logo, a estrutura sofre uma distribuição de forças na direção oposta ao vetor da aceleração " $\ddot{u}$ " do elemento, fazendo com que as forças inerciais tenham sentido contrário à direção do movimento.

\subsubsection{2 - Forças dissipativas}

A formulação consistente de um mecanismo que considere as forças dissipativas é de difícil elaboração, visto que tais forças podem ser oriundas do arrasto aerodinâmico, da fricção interna e das microfissuras que ocorrem no interior do material estrutural.

Em face à esta dificuldade, formalmente pode-se admitir, de uma forma bastante simplista, que todos os 
elementos do sistema estrutural estejam submetidos aos efeitos de um amortecimento viscoso uniformemente distribuído, de tal forma que as forças dissipativas por unidade de volume nas direções das coordenadas " $\mathrm{x}$ ", " $\mathrm{Y}$ " e "z", BIGGS(1964), possam ser definidas de forma análoga à equação (2.12), por:

$$
p_{D}=\mu(x, y, z)\left\{\begin{array}{c}
\bullet \\
u \\
\bullet \\
v \\
\bullet \\
w
\end{array}\right\}=\mu \stackrel{u}{u}
$$

onde " $\mu$ " é o parâmetro de amortecimento viscoso do material estrutural.

Como o elemento infinitesimal se move com uma velocidade ": $\boldsymbol{u}$ " em uma dada direção, então as forças dissipativas serão aplicadas na direção oposta ao sentido do movimento do mesmo.

\section{4 - Princípios básicos}

Para descrever o comportamento de um sistema estrutural através de uma equação de equilíbrio, é necessário formular o problema utilizando-se os princípios básicos da Mecânica dos Sólidos.

Esses princípios são divididos em diferenciais e integrais, podendo ser aplicados em problemas estáticos ou dinâmicos. Na sequiência, destacam-se os princípios que serão utilizados neste trabalho. 


\subsection{1 - Estruturas em repouso}

\subsubsection{1 - Princípio da Energia Potencial Estacionária}

Um sistema estrutural é chamado de conservativo desde que o trabalho dos esforços internos e o trabalho dos esforços externos independam do caminho percorrido pela estrutura, quando da passagem da sua configuração de equilíbrio inicial para uma outra qualquer.

Essa configuração é definida como sendo o estabelecimento da posição de todas as partículas de uma estrutura, e essa é chamada de admissivel desde que satisfaça a compatibilidade interna $e$ as condições essenciais de contorno do sistema estrutural.

Com relação à energia potencial, também chamada de energia potencial total, essa é definida como sendo uma função " $\pi_{\mathrm{p}}$ " dada pela soma entre a energia de deformação "U", também chamada de energia potencial interna, e o potencial dos esforços externos " $\Omega$ " que atuam sobre um sistema estrutural qualquer. Essa soma possibilita expressar a energia potencial contida no sistema em função de uma configuração deformada qualquer.

Após a descrição de tais definições, pode-se, finalmente, enunciar o Princípio da Energia Potencial Estacionária:

Entre todas as configurações admissíveis de um sistema estrutural conservativo, aquela que satisfaz as condições de equilíbrio conduz a energia potencial a assumir un valor estacionário com relação à admissão de uma pequena variação de deslocamentos. COOK et al. (1989) . 
Em outras palavras, para o equilíbrio de um sistema a função da energia potencial total " $\pi_{\mathrm{p}}$ " deve ser estacionária, ou seja, a sua variação deve-se igualar a zero, isto é:

$$
\delta \pi_{p}=0
$$

Em termos de funções ordinárias, existe uma condição em que a derivada de uma função em relação à uma variável independente é nula e a função em si têm um máximo, um mínimo ou um valor constante. Se a condição de estacionaridade fornece uma relação mínima, então, o estado de equilíbrio é estável (Teorema de Lagrange).

\subsubsection{2 - Princípio dos Trabalhos Virtuais}

Considerando-se um sistema estrutural qualquer submetido à esforços externos " $F$ " ativos e reativos, com "n" componentes " $F_{j}$ ", o mesmo estará em equilíbrio se satisfizer a condição dada por:

$$
\sum_{j}^{n} F_{j}=0
$$

Introduzido-se um deslocamento virtual " $\delta u ", ~ s e n d o$ este infinitesimal e cinematicamente compatível com o sistema estrutural, com componentes em todas as " $\mathrm{n}$ " direções, pode-se calcular o trabalho virtual realizado pelo sistema através da equação (2.16). 


$$
\delta W=\sum_{j}^{n} F_{j} \delta u_{j}
$$

Para que o sistema continue em equilíbrio após a introdução do deslocamento virtual, é necessário que o trabalho realizado seja nulo, ou seja:

$$
\delta W=0
$$

Superpondo-se as equações (2.16) e (2.17), pode-se, finalmente, formular o Princípio dos Trabalhos Virtuais (P.T.V.), HURTY et al.(1967), para um sistema em repouso, dado pela equação (2.18) .

$$
\delta W=\sum_{j}^{n} F_{j} \delta u_{j}=0
$$

\section{4 .2 - Estruturas em movimento}

\subsubsection{1 - Princípio de D'Alembert}

Dado o mesmo sistema estrutural descrito no item 2.4.1.2, considera-se, agora, que o mesmo esteja em movimento. Logo, se ele não está em repouso, então as diversas massas " $M_{j}$ " do sistema aceleram de acordo com a segunda lei de Newton, neste caso expressa por:

$$
M_{j} \ddot{u}_{j}=F_{j}
$$

ou 


$$
M_{j} \ddot{u}_{j}-F_{j}=0
$$

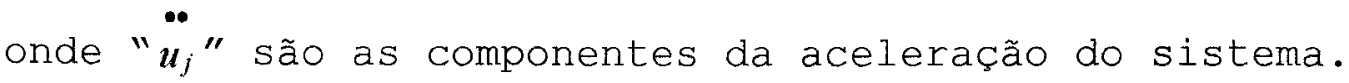

Introduzindo-se um deslocamento virtual " $\delta u^{\prime \prime}$ em um instante "t" genérico e utilizando-se a equação (2.19), obtém-se:

$$
\left(M_{j} \ddot{u}_{j}-F_{j}\right) \delta u_{j}=0
$$

Promovendo-se a somatória sobre todas as "n" componentes que compõem o sistema, pode-se, finalmente, formular o Princípio de D'Alembert, HURTY et al.(1967), dado pela equação (2.21).

$$
\sum_{j}^{n}\left(M_{j} \ddot{u}_{j}-F_{j}\right) \delta u_{j}=0
$$

\subsubsection{2 - Princípio dos Trabalhos Virtuais}

Trabalhando-se algebricamente a equação (2.21), obtém-se o Princípio dos Trabalhos Virtuais para um sistema em movimento, HURTY et al.(1967), dado por:

$$
\delta W=\sum_{j}^{n} F_{j} \delta u_{j}=\sum_{j}^{n} M_{j} \ddot{u}_{j} \delta u_{j}
$$

Com base neste princípio, pode-se enunciar a lei de conservação do trabalho: 
O trabalho total de um sistema físico isolado, para trajetórias reais de movimento, tem um valor constante em cada intervalo de tempo; ele é conservado. HENRYCH (1990).

Em outras palavras, tem-se a igualdade entre o trabalho dos esforços internos e externos durante todo o movimento da estrutura, isto é:

$$
W_{I}=W_{E}
$$

2.5 - Equação do movimento para um sistema estrutural discreto

\subsection{1 - Equação de equilíbrio via P.T.V.}

A equação do equilíbrio que governa a resposta dinâmica de um sistema estrutural discreto pode ser obtida utilizando-se o Principio dos Trabalhos Virtuais para estruturas em movimento, conforme visto no item 2.4.2.2 deste trabalho.

Aplicando-se, então, um deslocamento virtual arbitrário qualquer e lembrando-se que tal sistema está submetido às forças descritas no item 2.3, além das tensões restauradoras provocadas pela deformação do sistema, obtém-se a equação de equilíbrio para um elemento genérico do sistema, Cook et al.(1989), dada por: 


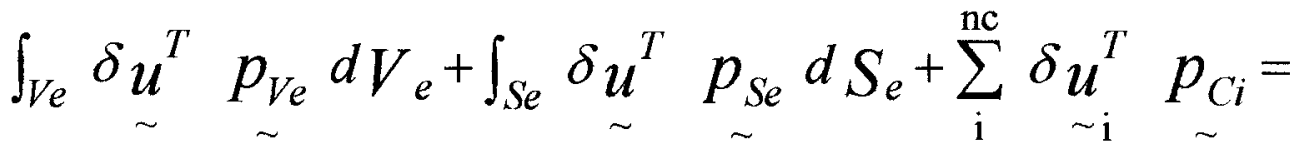

$$
\begin{aligned}
& \int_{V e} \delta{\underset{\sim}{\varepsilon}}^{T} \underset{\sim}{\sigma} d V_{e}+\int_{V e} \delta \underset{\sim}{u^{T} \rho \ddot{\sim}} \ddot{\sim} d V_{e}+\int_{V e} \delta \underset{\sim}{u^{T}} \mu \underset{\sim}{\dot{u}} d V_{e}
\end{aligned}
$$

onde

" $\delta \boldsymbol{u}$ " é o vetor dos deslocamentos virtuais;

" $\delta \varepsilon$ " é o vetor das deformações virtuais correspondentes à " $\delta u$ ";

" $\sigma$ " é o vetor das tensões restauradoras;

" $\delta u_{i} "$ é o vetor de deslocamentos virtuais correspondentes aos pontos onde os esforços do vetor " $p_{C i}$ " são aplicados; "nc" é o número de pontos nodais do elemento.

A equação (2.24) fornece na primeira parte da igualdade o trabalho dos esforços externos, dado pelo produto dos esforços atuantes no elemento com os respectivos deslocamentos virtuais. Já a segunda parte fornece o trabalho total interno, dado pelo produto entre as deformações virtuais e as tensões restauradoras, e pelo produto das forças inerciais e dissipativas com os respectivos deslocamentos virtuais.

\subsection{2 - Relações básicas}

Conforme visto no item 2.2.2 deste trabalho, os deslocamentos genéricos dos pontos situados sobre o eixo de um elemento finito podem ser relacionados com os seus 
respectivos deslocamentos nodais, através da utilização da equação (2.3). Essa relação se dá através da utilização de funções de forma, que são dependentes apenas do espaço. Em função disto, pode-se derivar tal equação em relação ao tempo, obtendo-se as seguintes relações básicas:

$$
\stackrel{\bullet}{u}=\phi \stackrel{\bullet}{d}
$$

e

$$
\stackrel{\bullet}{u}=\phi \stackrel{\bullet}{d}
$$

válidas para elementos reticulados, admitindo-se a hipótese de pequenas rotações.

Outra relação básica importante é dada pela associação entre a deformação longitudinal " $\varepsilon$ " e os deslocamentos axiais e transversais que ocorrem no elemento finito. Admitindo-se que essa relação seja dada por uma função quadrática, conforme será visto no item 4.3.2, obtém-se:

$$
\underset{\sim}{\varepsilon}=\underset{\sim}{\boldsymbol{u}}
$$

onde " $L$ " é a matriz que contém os operadores diferenciais.

Substituindo-se a equação (2.3) na equação (2.27), obtém-se, também:

$$
\underset{\sim}{\varepsilon}=\underset{\sim}{L} \underset{\sim}{\phi}
$$

ou

$$
\underset{\sim}{\varepsilon}=\underset{\sim}{B}
$$


onde

$$
B=L \phi
$$

2.5.3 - Equação geral do movimento

Para a obtenção da equação geral do movimento de um sistema estrutural discreto, substituem-se as equações $(2.3),(2.25),(2.26)$ e (2.28) na equação (2.24), resultando:

$$
\begin{aligned}
& \int_{V e} \delta d^{T} \phi^{T} p_{V e} d V_{e}+\int_{S e} \delta d^{T} \phi^{T} p_{S e} d S_{e}+ \\
& \sum_{\mathrm{i}}^{\mathrm{nc}} \delta \underset{\sim \mathrm{i}}{d^{T}} p_{C i}=\int_{V e} \delta \underset{\sim}{d^{T}} \underset{\sim}{B^{T}} \underset{\sim}{\sigma} d V_{e^{+}} \\
& \int_{V e} \delta d^{T} \phi^{T} \rho \phi \ddot{d} d V_{e}+\int_{V e} \delta d^{T} \phi^{T} \mu \phi \dot{d} d V_{e}
\end{aligned}
$$

Colocando-se os deslocamentos nodais virtuais em evidência e rearrumando-se a equação (2.30), obtém-se:

$$
\begin{aligned}
& \underset{\sim}{d} d^{T}\left\{\int_{V e} \phi_{\sim}^{T} p_{V e} d V_{e}+\int_{S e} \phi_{\sim}^{T} p_{S e} d S_{e}+\sum_{\mathrm{i}}^{\mathrm{nc}} p_{C i}-\right. \\
& \int_{V e} B_{\sim}^{T} \sigma d V_{e}-\int_{V e} \rho \phi^{T} \phi d V_{e} \stackrel{\bullet}{\dot{d}-} \\
& \left.\int_{V e} \mu \phi^{T} \phi d V_{e} \dot{d}\right\}=0
\end{aligned}
$$


Para que o produto dado na equação anterior seja nulo, tendo em vista que os deslocamentos nodais virtuais são arbitrários, ou seja, não todos nulos, é necessário que seja mantida a seguinte igualdade:

$$
\begin{aligned}
& \int_{V e} \phi^{T} p_{V e} d V_{e}+\int_{S e} \phi_{\sim}^{T} p_{S e} d S_{e}+\sum_{i}^{\mathrm{nc}} p_{C i}= \\
& \int_{V e} \boldsymbol{B}_{\sim}^{T} \underset{\sim}{\sigma} d V_{e}+\int_{V e} \rho \dot{\phi}^{T} \underset{\sim}{\phi} d V_{e} \stackrel{\bullet}{d}+\int_{V e} \mu \phi^{T} \underset{\sim}{\phi} d V_{e} \stackrel{\bullet}{\dot{d}}
\end{aligned}
$$

A expressão (2.32) fornece a equação do movimento para um elemento finito genérico, que escrita de forma simplificada resulta:

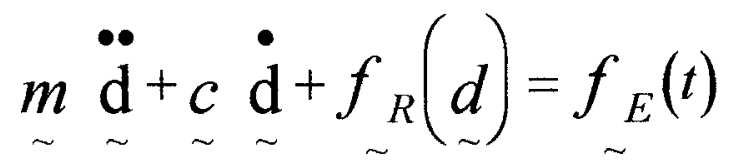

onde

$$
\begin{gathered}
m=\int_{V e} \rho \phi^{T} \underset{\sim}{\phi} d V_{e} \\
\underset{\sim}{c}=\int_{V e} \mu \phi^{T} \underset{\sim}{\phi} d V_{e} \\
f_{R}(d)=\int_{V e} B_{\sim} \underset{\sim}{\sigma} d V_{e}
\end{gathered}
$$$$
f_{E}(t)=\int_{V e} \phi^{T} p_{V e} d V_{e}+\int_{S e} \phi^{T} p_{S e} d S_{e}+\sum_{\sim}^{\mathrm{nc}} p_{C i}
$$ 
Para todo o sistema estrutural discreto utiliza-se - processo de expansão e acumulação, obtendo-se, finalmente, a equação geral do movimento dada pelo sistema de equações (2.38), ARGYRIS et al. (1991).

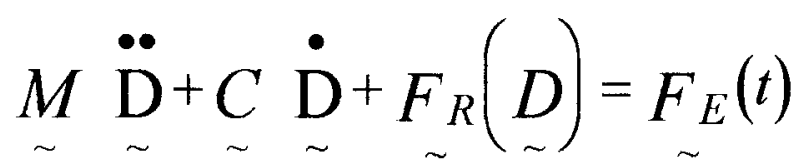

Cabe ressaltar que na equação anterior os esforços externos " $F_{E}$ " são dependentes apenas do tempo, conforme foi visto no item 2.3.1.4 deste trabalho. Já as forças restauradoras " $F_{R}$ " são dependentes dos deslocamentos globais " $D$ " e da relação tensão x deformação, enquanto que a matriz de massas " $M$ " e a matriz de amortecimento "C ${ }_{\sim}$ " vão permanecer constantes durante o procedimento de integração, conforme será visto no capítulo 4 deste trabalho.

$\mathrm{Na}$ sequiencia, destacam-se os métodos numéricos para integração da equação geral do movimento e as técnicas computacionais para resolução de tal sistema de equações. 


\section{CAPÍTULO 3 - INTEGRAÇÃO NUMÉRICA DA EQUAÇÃO GERAL DO MOVIMENTO}

\section{1 - Métodos de integração numérica}

A integração da equação geral que descreve o movimento de sistemas lineares pode ser feita utilizando-se métodos numéricos, onde destacam-se os métodos de integração direta e as técnicas de superposição modal, OWEN(1980), ou através da resolução analítica da mesma. As hipóteses básicas para sistemas lineares são dadas pelas relações lineares entre carregamento $\mathrm{x}$ deslocamento e tensão $\mathrm{x}$ deformação, permitindo-se, por exemplo, a utilização do princípio da superposição como ferramenta para a obtenção das soluções numéricas.

No caso de sistemas estruturais com comportamento não-linear, as propriedades físicas dos materiais podem não ser assumidas como constantes, podendo, também, ocorrer uma mudança significativa da geometria da estrutura durante o processo de integração. Essas alterações podem causar uma modificação apreciável no valor dos coeficientes de rigidez, tendo como efeito uma resposta estrutural não-linear. Em função disso, as técnicas de superposição modal e a resolução analitica não são normalmente utilizadas na análise de tais sistemas. Conseqüentemente, o procedimento de aplicação 
geral para a resolução de sistemas não-lineares é dado pelos métodos de integração direta, sendo que tais métodos são geralmente classificados em métodos explícitos e implícitos, OWEN et al.(1980).

Os métodos explícitos permitem expressar os deslocamentos finais " $D_{n}$ ", do intervalo de tempo " $n \Delta t$ ", em função da história temporal anterior, sendo essa composta pelos deslocamentos e suas respectivas derivadas temporais finais em relação aos intervalos de tempo anteriores " $(n-1) \Delta t$ " e " $(n-2) \Delta t "$, conforme equação (3.1). Entre os métodos explícitos destacam-se o processo da diferença central e o processo generalizado de Adams, HENRYCH (1990).

$$
\underset{\sim}{D_{n}}=f\left(\underset{\sim}{D_{n-1}}, \underset{\sim}{D_{n-1}}, \underset{\sim}{D_{n-1}^{\bullet}},{\underset{\sim}{n-2}}_{\sim}, \ldots \ldots\right)
$$

Já os métodos implícitos permitem expressar os deslocamentos finais " $D_{n}$ ", do intervalo de tempo " $n \Delta t$ ", em função das derivadas temporais dos deslocamentos " $D_{n}$ ", que a priori não são conhecidas, e dos deslocamentos e suas respectivas derivadas temporais finais em relação ao intervalo de tempo " $(n-1) \Delta t$ ", conforme equação (3.2) . Entre os métodos implícitos destacam-se o processo de Newmark e o processo previsor-corretor, HENRYCH(1990).

$$
\underset{\sim}{D_{n}}=f\left(\underset{\sim}{D_{n}}, \stackrel{\bullet}{\dot{D}_{n}},{\underset{\sim}{D_{n-1}},}_{\sim}^{D_{n-1}}, \ldots \ldots\right)
$$


Existe, ainda, a possibilidade de se utilizar os métodos explícitos para resolver uma sub-região específica do sistema estrutural e os métodos implícitos para resolver o restante. Tal esquema é chamado de método implícito-explícito, onde destacam-se o processo de Park et al., Belytschko \& Mullen e Hughes et al., OWEN et al. (1980) e HUGHES et al. (1978a, 1978b, 1979).

Em geral, os métodos implícitos possuem essencialmente duas vantagens quando comparados com os métodos explícitos, WILSON et al.(1973) e GERADIN et al.(1986), a saber: elevada exatidão e estabilidade numérica melhorada. Em contra partida, a desvantagem dos métodos implícitos reside na necessidade de ter que se resolver o sistema de equações a cada iteração, que ocorre durante o processo de integração para cada intervalo de tempo " $n \Delta t$ ".

$\mathrm{Na}$ sequiência deste trabalho, abordar-se-á o método implícito de Newmark, tendo em vista que esse método é indicado para análise determinística de sistemas estruturais com comportamento não-linear submetidos à carregamentos prescritos, ARGYRIS et al.(1991).

\section{2 - Equações de Newmark}

Conforme visto no item anterior, os métodos implícitos estão fundamentados no conhecimento das derivadas temporais dos deslocamentos finais " $D_{n}$ " do intervalo de tempo " $n \Delta t$ ", conforme equação (3.2).

Para isso, utilizam-se as equações de Newmark que serão mostradas na sequiência. 
3.2.1 - Aceleração constante durante o intervalo de tempo

Assumindo-se que a aceleração durante o intervalo de tempo " $n \Delta t$ " seja igual à uma constante, dada pela média entre a aceleração do início do intervalo e do final do intervalo, tem-se:

$$
\underset{\sim}{\stackrel{\bullet}{D}}(\tau)=\frac{1}{2}\left(\underset{\sim}{\ddot{D}_{n}+\dot{\sim}_{n-1}^{\bullet}}\right)
$$

onde " $\tau$ " é uma variável de tempo auxiliar, variando de zero até " $\Delta t$ ".

Integrando-se duas vezes a equação (3.3) em relação à variável " $\tau$ ", obtém-se:

$$
\begin{aligned}
& \underset{\sim}{\bullet}(\tau)=\dot{\sim}_{n-1}^{\bullet}+\frac{1}{2}\left(\underset{\sim}{\dot{D}_{n}}+\underset{\sim}{D_{n-1}}\right) \tau \\
& \underset{\sim}{D}(\tau)=\underset{\sim}{D_{n-1}}+\underset{\sim}{D_{n-1}} \tau+\frac{1}{4}\left(\underset{\sim}{D_{n}}+\underset{\sim}{D_{n-1}}\right) \tau^{2}
\end{aligned}
$$

Calculando-se as variáveis ao final do intervalo de tempo, com " $\tau=\Delta t$ ", e rearrumando-se o resultado, obtémse:

$$
\stackrel{\bullet}{\dot{D}_{n}}=\dot{D}_{n-1}+\left(1-\frac{1}{2}\right) \Delta t \quad \stackrel{\bullet}{D_{n-1}}+\frac{1}{2} \Delta t \quad \dot{\sim}_{n}
$$




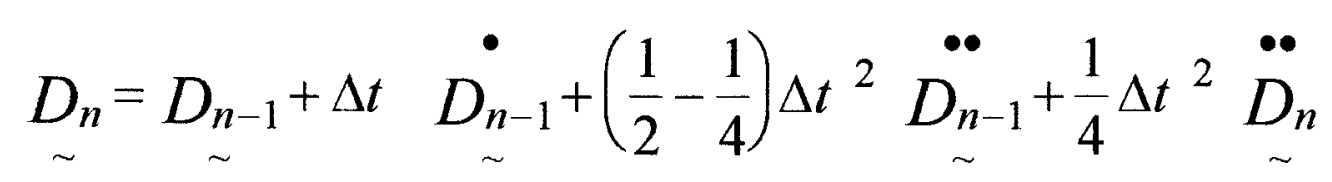

3.2.2 - Aceleração variando linearmente durante o intervalo de tempo

Assumindo-se que a aceleração durante o intervalo de tempo " $n \Delta t$ " varie linearmente entre a aceleração do inicio do intervalo e do final do intervalo, tem-se:

$$
\underset{\sim}{\ddot{D}}(\tau)=\underset{\sim}{\stackrel{\bullet}{D_{n-1}}}+\left(\underset{\sim}{\ddot{D_{n}}-} \stackrel{\bullet}{D_{n-1}}\right) \frac{\tau}{\Delta t}
$$

Analogamente ao item anterior, obtém-se:

$$
\begin{aligned}
& \underset{\sim}{\dot{D}}(\tau)=\underset{\sim}{\dot{D}_{n-1}}+\stackrel{\bullet}{\operatorname{D}_{n-1}} \tau+\left(\underset{\sim}{\dot{\sim}_{n}-\underset{\sim}{D_{n-1}}}\right) \frac{\tau^{2}}{2 \Delta t}
\end{aligned}
$$

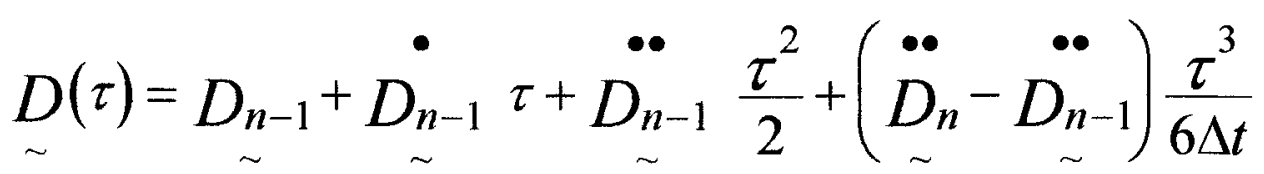

Calculando-se as variáveis ao final do intervalo de tempo, com " $\tau=\Delta t$ ", e rearrumando-se o resultado, obtémse:

$$
\underset{\sim}{\dot{D}_{n}}=\underset{\sim}{\stackrel{\bullet}{D_{n-1}}}+\left(1-\frac{1}{2}\right) \Delta t \quad \underset{\sim}{\stackrel{\bullet}{D_{n-1}}}+\frac{1}{2} \Delta t \quad \stackrel{\bullet}{\dot{D}_{n}}
$$




$$
\underset{\sim}{D_{n}}=\underset{\sim}{D_{n-1}}+\Delta t \quad \underset{\sim}{D_{n-1}}+\left(\frac{1}{2}-\frac{1}{6}\right) \Delta t^{2} \underset{\sim}{D_{n-1}}+\frac{1}{6} \Delta t^{2} \stackrel{\bullet}{\operatorname{D}_{n}}
$$

\section{2 .3 - Equações generalizadas}

Conforme visto nos itens 3.2 .1 e 3.2.2, o resultado final obtido é praticamente o mesmo, com exceção dos coeficientes numéricos que aparecem multiplicando determinadas parcelas.

Com isso, pode-se unificar as respostas encontradas, resultando as equações generalizadas de Newmark, WARBURTON(1976), dadas por:

$$
\begin{aligned}
& \dot{D}_{n}=\dot{D}_{n-1}+(1-\gamma) \Delta t \quad \stackrel{\bullet}{D_{n-1}}+\gamma \Delta t \quad \stackrel{\bullet}{D_{n}} \\
& \underset{\sim}{D_{n}=D_{n-1}+\Delta t} \underset{\sim}{D_{n-1}}+\left(\frac{1}{2}-\beta\right) \Delta t^{2} \underset{\sim}{\dot{D}_{n-1}}+\beta \Delta t^{2} \stackrel{\bullet}{\ddot{D}_{n}}
\end{aligned}
$$

onde " $\gamma$ " e " $\beta$ " são conhecidos como parâmetros de Newmark.

Desse modo, para aceleração constante durante o intervalo de tempo tem-se: $\gamma=1 / 2$ e $\beta=1 / 4$, e para aceleração variando linearmente durante $O$ intervalo de tempo tem-se: $\gamma=1 / 2$ e $\beta=1 / 6$.

Cabe ressaltar que as equações generalizadas de Newmark permitem alterações dos parâmetros " $\gamma$ " e " $\beta$ ", 
conforme variante de Fox-Goodwin que define $\gamma=1 / 2$ e $\beta=1 / 12$, ARGYRIS et al. (1991).

Com a obtenção das equações (3.13) e (3.14), podese calcular o valor dos deslocamentos e das velocidades ao final do intervalo de tempo, tendo ainda como incógnita o valor das acelerações do final do intervalo. Tal problema será contornado no item 3.4 deste trabalho.

\section{3 - Algoritmos numéricos para resolução de} sistemas não-lineares

A utilização de algoritmos numéricos está relacionada com a necessidade de ter que se resolver sistemas de equações não-lineares, originados pela discretização de estruturas que manifestam este tipo de comportamento, tendo em vista que a solução de tais sistemas só é possível com aplicação de procedimentos incrementais e/ou iterativos.

Assim sendo, destacam-se, na seqüência, os principais processos numéricos relacionados com 0 assunto em questão.

\subsection{1 - Processos iterativos}

Para a resolução da equação geral do movimento de um sistema estrutural deve-se adotar um procedimento iterativo, visto que tal equação resulta um sistema de equações não-lineares.

A primeira relação importante para descrever tal procedimento é dada pelo equilíbrio dinâmico ao longo de cada intervalo de tempo " $\Delta t$ ", que pode ser expressa 
através da adaptação da equação (2.38), conforme mostra a seguinte equação:

$$
\underset{\sim}{R}\left(\underset{\sim}{D_{k}}\right)=\underset{\sim}{F_{E}}(t)-\underset{\sim}{M} \stackrel{\bullet}{\dot{D}_{k}-\underset{\sim}{C}} \underset{\sim}{D_{k}-F_{R}}\left(\underset{\sim}{D_{k}}\right)
$$

onde " $\underset{\sim}{R}\left(\underset{\sim}{D_{k}}\right)$ " é o resíduo das forças dinâmicas não equilibradas, em função de deslocamentos previstos " $D_{k}$ ".

A condição de equilíbrio ao final do intervalo de tempo " $n \Delta t$ " para sistemas não-lineares é dada por:

$$
\underset{\sim}{R} \underset{\sim}{\left.D_{k}+\Delta \underset{\sim}{D_{k}}\right)=0}
$$

onde " $\Delta D_{k}$ " é o acréscimo de deslocamentos que ocorre durante o intervalo de tempo.

Com isso, pode-se iniciar um processo iterativo para o intervalo de tempo " $n \Delta t$ ", que consiste em uma sucessão de atualizações das forças internas, a partir de acréscimos de deslocamentos e suas derivadas temporais, até que a condição dada pela equação (3.16) seja satisfeita. A descrição detalhada deste procedimento será fornecida no item 3.4 deste trabalho.

Entre os vários processos iterativos pode-se destacar o processo de Newton-Raphson Modificado e o de Newton-Raphson, RUBERT(1993), MATTHIES et al.(1979) e OWEN et al.(1984). Na sequiência, os aspectos essenciais de cada processo serão mostrados de forma sucinta. 


\subsubsection{1 - Iteração de Newton-Raphson Modificado}

O processo iterativo de Newton-Raphson Modificado consiste na manutenção da rigidez da estrutura, obtida no início de cada intervalo de tempo, vide item 4.4, para o cálculo das forças internas durante todas as iterações. Dessa forma, a representação gráfica desse procedimento é dada pela figura 3.1 .

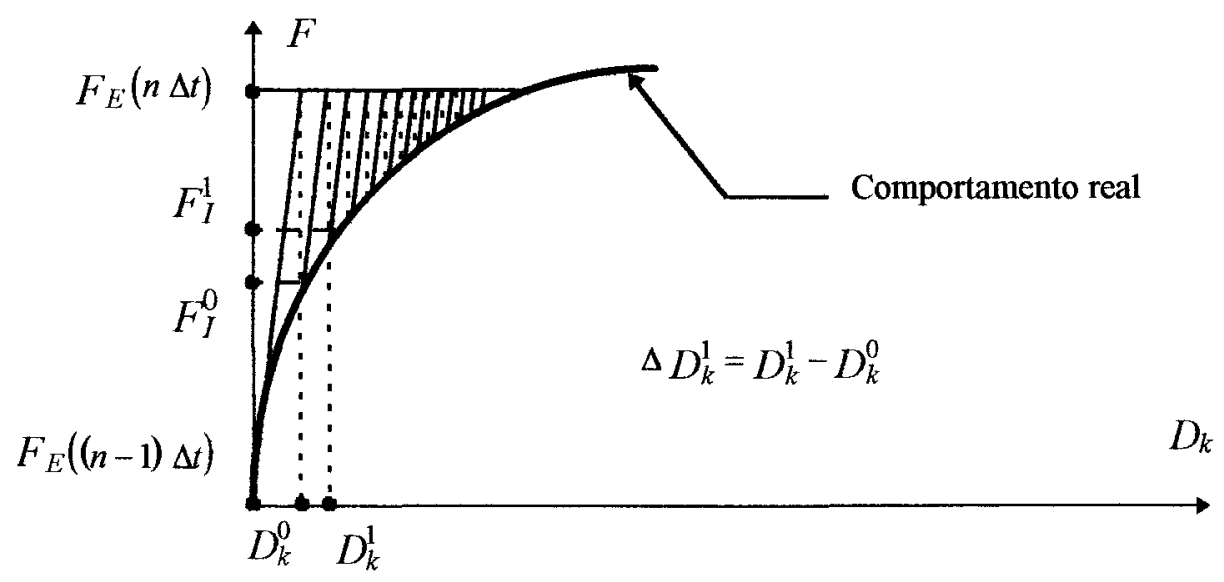

FIGURA 3.1 - Iteração de Newton-Raphson Modificado.

Desse modo, aplicando-se as forças " $F_{E}(n \Delta t)$ " para uma dada rigidez estrutural inicial e resolvendo-se o sistema de equações, obtém-se os deslocamentos " $D_{k}^{0}$ " e as respectivas forças internas " $F_{I}^{0 "}$ em função desses deslocamentos. Caso " $F_{I}^{0}$ " seja diferente de " $F_{E}(n \Delta t)$ ", ou seja, resíduo não nulo, aplica-se a diferença de força " $F_{E}(n \Delta t)-F_{I}^{0} "$ na estrutura já deformada e calcula-se o acréscimo de deslocamentos " $\Delta D_{k}^{1} "$. Na seqüência, faz-se uma correção nos deslocamentos, onde obtém-se " $D_{k}^{1}$ ", e 
calculam-se as novas forças internas " $F_{I}^{1}$ ". Assim, repete-se a sistemática já descrita até se atingir a igualdade entre as forças internas e externas. Portanto, quando o resíduo for nulo, obtém-se o equilíbrio estrutural procurado.

\subsubsection{2 - Iteração de Newton-Raphson}

Já o processo iterativo de Newton-Raphson consiste na alteração da rigidez da estrutura, obtida a cada iteração, para o cálculo das forças internas. Assim, a representação gráfica desse procedimento é dada pela figura 3.2, sendo que o mecanismo de funcionamento é análogo ao processo descrito no item anterior.

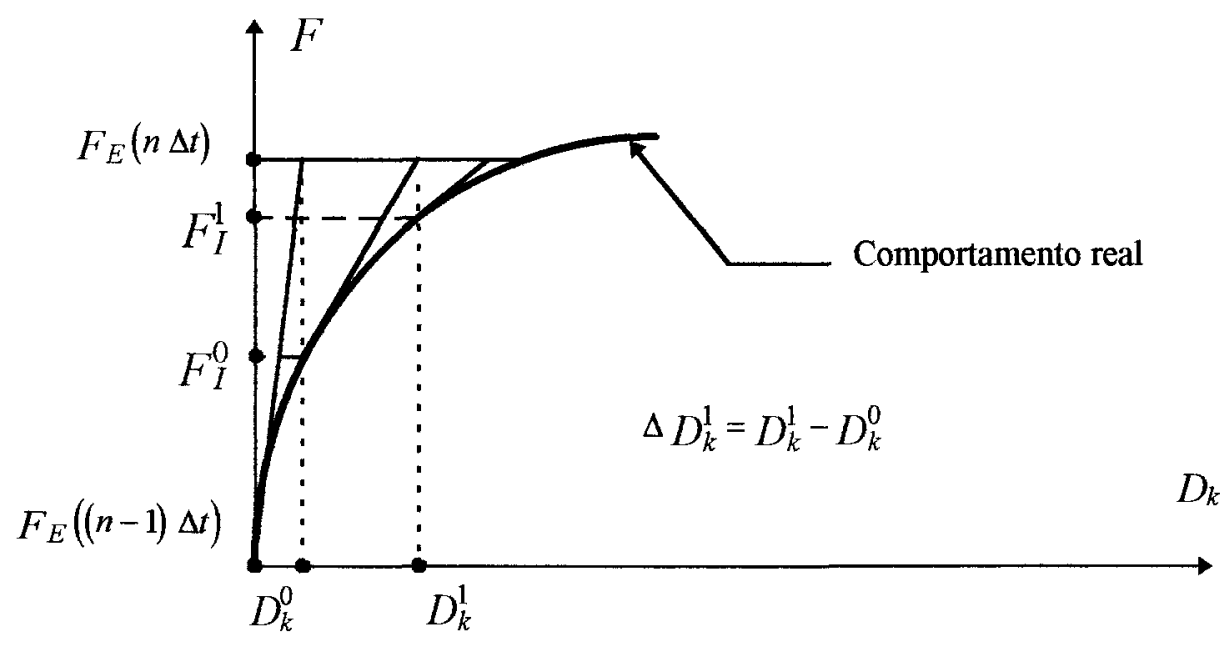

FIGURA 3.2 - Iteração de Newton-Raphson.

Comparando-se os processos já mencionados, deve-se ressaltar os seguintes aspectos: velocidade de convergência e esforço computacional envolvido.

Com relação à velocidade de convergência, o processo iterativo de Newton-Raphson é superior ao processo de Newton-Raphson Modificado, visto que sua 
convergência é quadrática, CHEN et al. (1988). Já em relação ao esforço computacional envolvido, o processo de Newton-Raphson Modificado é menos trabalhoso, uma vez que a rigidez da estrutura não precisa ser atualizada a cada iteração. No cômputo geral, o processo iterativo de Newton-Raphson é mais eficiente, RUBERT(1993) .

\subsection{2 - Processo incremental}

O procedimento incremental consiste na aplicação gradual do carregamento externo no sistema estrutural, através de pequenas parcelas do carregamento total. Este procedimento deve ser utilizado quando o nível de nãolinearidade for grande, de tal forma que se possa garantir o equilíbrio real e, também, respeitar as hipóteses básicas do modelo elemental, vide item 4.3.1, durante o acréscimo de cada parcela.

Tal procedimento deve ser associado à um processo iterativo, cuja representação gráfica é mostrada pela Eigura 3.3 .

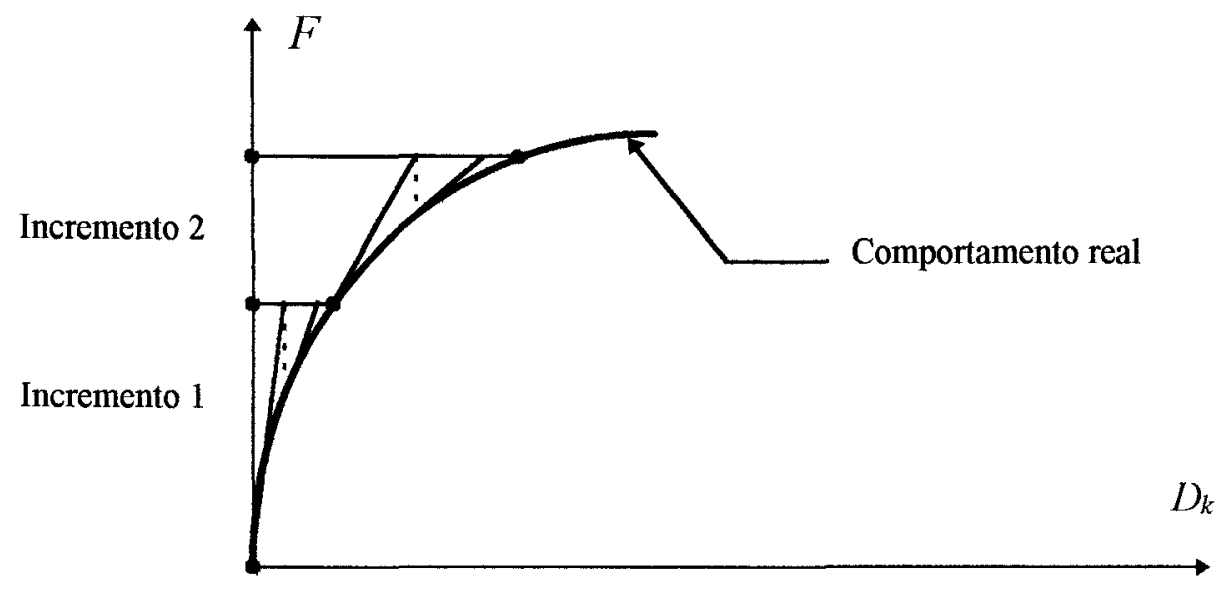

FIGURA 3.3 - Processo incremental / iterativo. 


\section{4 - Método de Newmark para integração numérica no} tempo

A idéia básica do método é dada pela previsão do valor das acelerações ao final do intervalo de tempo que se deseja conhecer. Com isso, aplicando-se as equações generalizadas de Newmark, pode-se prever, também, o valor dos deslocamentos e das acelerações ao final do mesmo intervalo de tempo. Na seqüência, utiliza-se um processo iterativo onde, ao final de cada iteração, fazse uma correção nos valores dos deslocamentos e suas derivadas temporais, em função última resposta encontrada. Quando for atingida uma determinada tolerância para o residuo das forças dinâmicas, assumese que os últimos valores obtidos estão corretos e inicia-se novamente 0 processo de integração para $\circ$ próximo intervalo de tempo.

$\mathrm{Na}$ sequiência, tal processo será descrito em detalhes.

\subsection{1 - Equacionamento básico}

Expandindo-se a função dada pela equação (3.16) pela relação linearizada de Taylor, obtém-se:

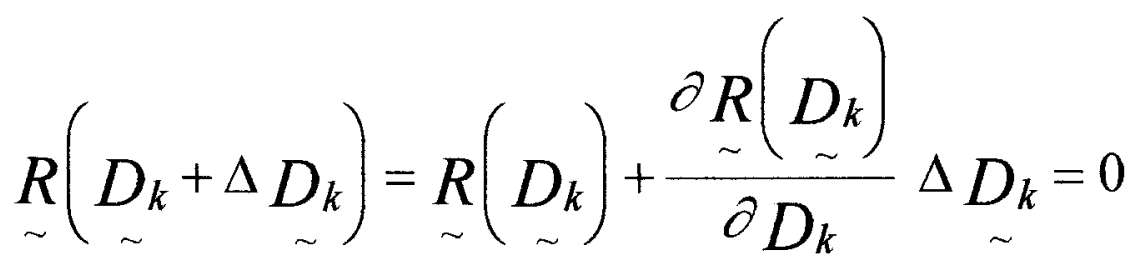

ou, simplesmente, 


$$
-\frac{\partial \underset{\sim}{R}\left(\underset{\sim}{D_{k}}\right)}{\partial D_{k}} \Delta{\underset{\sim}{D_{k}}}=\underset{\sim}{R}\left(\underset{\sim}{D_{k}}\right)
$$

Derivando-se o resíduo, dado pela equação (3.15), em relação aos deslocamentos " $D_{k}$ ", chega-se a:

$$
\frac{\partial \sim \sim \sim \sim}{\partial D_{k}}=+\frac{\partial F_{E}(t)}{\partial D_{k}}-\underset{\sim}{M} \frac{\partial \stackrel{\bullet}{D_{k}}}{\partial D_{k}}-\underset{\sim}{\sim} \frac{\partial \underset{\sim}{D_{k}}}{\partial D_{k}}-\frac{\partial F_{R}\left(\underset{\sim}{D_{k}}\right)}{\partial D_{k}}
$$




$$
\begin{aligned}
& \dot{D}_{k}=\dot{D}_{k-1}+(1-\gamma) \Delta t \stackrel{\bullet}{D_{k-1}}+\gamma \Delta t \stackrel{\bullet}{D_{k}} \\
& \underset{\sim}{D_{k}}=\underset{\sim}{D_{k-1}}+\Delta t \underset{\sim}{D_{k-1}}+\left(\frac{1}{2}-\beta\right) \Delta t^{2} \underset{\sim}{D_{k-1}^{\bullet \bullet}}+\beta \Delta t^{2}{\stackrel{\sim}{D_{k}}}_{\sim}
\end{aligned}
$$

$$
\text { Derivando-se a equação (3.22) em relação à " } \ddot{D}_{k} \text { ", }
$$
obtém-se:

$$
\frac{\partial \tilde{D}_{k}}{\partial \ddot{D}_{k}} \cong \beta \Delta t^{2}
$$

ou seja,

$$
\frac{\stackrel{\bullet}{\partial D_{k}}}{\partial D_{k}}=\frac{1}{\beta \Delta t^{2}}
$$

Derivando-se, agora, a equação (3.21) em relação à " $\ddot{D_{k}} "$ ", chega-se a:

$$
\begin{aligned}
& \partial D_{k} \\
& \stackrel{\sim}{\bullet \bullet} \cong \gamma \Delta t \\
& \partial D_{k}
\end{aligned}
$$


Já a derivada de " $\dot{D}_{k}$ " em relação à " $D_{k}$ " pode ser expressa pelo produto de duas derivadas, conforme mostra a equação (3.26).

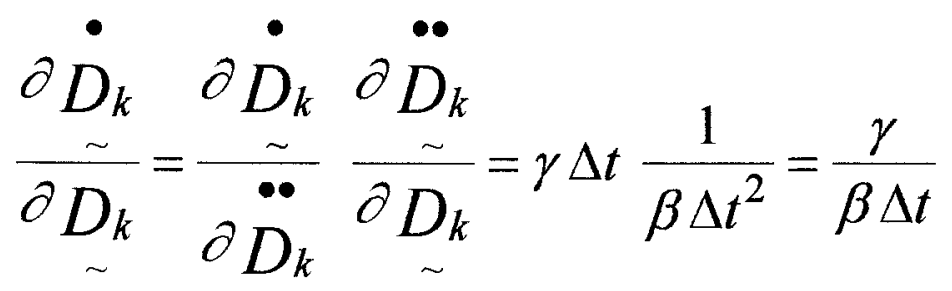

Substituindo-se as equações (3.20), (3.24) e (3.26) na equação (3.19), obtém-se:

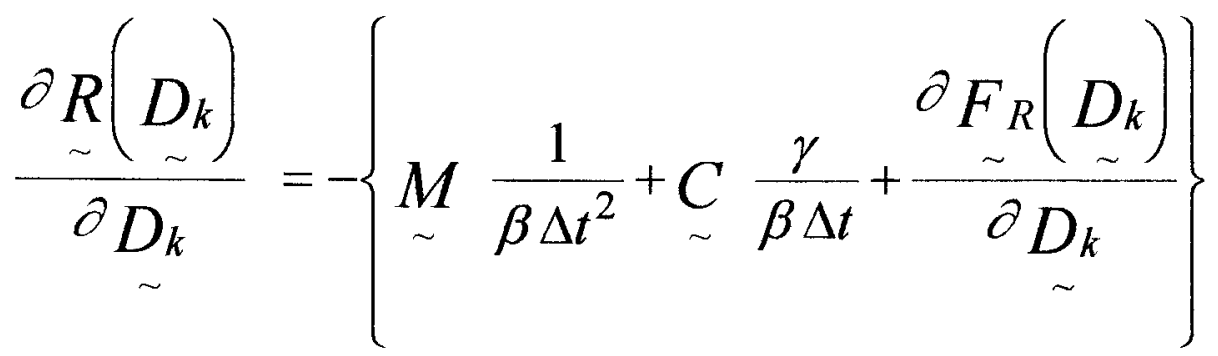

Logo, substituindo-se a equação anterior na equação (3.18), obtém-se a equação que fornecerá o acréscimo de deslocamentos " $\Delta D_{k}$ ", dada por (3.28), sendo esta utilizada na correção dos deslocamentos que ocorrem ao longo de cada iteração.

$$
\left\{\underset{\sim}{M} \frac{1}{\beta \Delta t^{2}}+C \frac{\gamma}{\beta \Delta t}+\frac{\partial F_{R}\left(\underset{\sim}{D_{k}}\right)}{\partial \underset{\sim}{D_{k}}}\right\} \Delta \underset{\sim}{D_{k}}=\underset{\sim}{R}\left(\underset{\sim}{D_{k}}\right)
$$


3.4.2 - Algoritmo numérico para resolução do processo

O ponto de partida para deflagrar o processo de integração está no conhecimento prévio das condições iniciais do problema no instante $t=0$, dadas pelos deslocamentos " $D_{0}$ " e velocidades " $\dot{D}_{0}$ ". Com isso, podese obter as acelerações " $\ddot{D_{0}}$ ", utilizando-se a equação de equilíbrio (2.38) da seguinte forma:

$$
\underset{\sim}{D_{0}}=M_{\sim}^{-1}\left\{F_{\sim}(0)-\underset{\sim}{C} \underset{\sim}{D_{0}-F_{R}}\left(\underset{\sim}{D_{0}}\right)\right\}
$$

Dando-se, então, início ao processo de integração numérica ao longo do tempo, deve-se fazer uma previsão das acelerações, dos deslocamentos e das velocidades para o primeiro intervalo de tempo " $n \Delta t$ ", com $k=\mathrm{n}=1$, utilizando-se as equações generalizadas de Newmark da seguinte forma:

$$
\begin{aligned}
& \stackrel{\bullet \bullet}{D_{k}}=\stackrel{\bullet}{D_{n-1}} \\
& D_{\sim}=D_{\sim}^{D_{n-1}}+\Delta t \underset{\sim}{D_{n-1}^{\bullet}}+\left(\frac{1}{2}-\beta\right) \Delta t^{2} \underset{\sim}{D_{n-1}}+\beta \Delta t^{2}{\stackrel{\bullet}{D_{k}}}_{\sim}^{\bullet}
\end{aligned}
$$




$$
\stackrel{\bullet}{D_{k}}=\stackrel{\bullet}{D_{n-1}}+(1-\gamma) \Delta t \stackrel{\bullet}{D_{n-1}}+\gamma \Delta t \stackrel{\bullet}{D_{k}}
$$

Com essa primeira aproximação calculam-se as forças inerciais, dissipativas, restauradoras e, consequientemente, o resíduo das forças dinâmicas não equilibradas através da equação (3.15).

Para verificar o equilíbrio utiliza-se uma tolerância para o erro de cálculo " $\varepsilon$ ", dada pela seguinte relação:

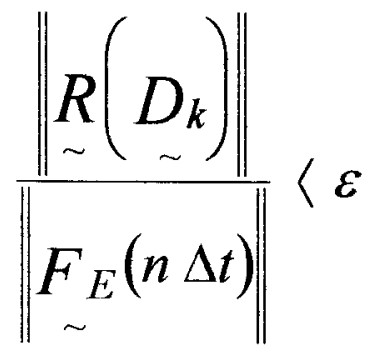

onde " $\left\|\underset{\sim}{R}\left(D_{\sim}\right)\right\| "$ e $\left\|F_{E}(n \Delta t)\right\| "$ são as normas Eulerianas do residuo e das forças externas, respectivamente.

Se a equação (3.33) for satisfeita, deve-se voltar para o início do processo e incrementar o valor de " $k$ " e "n". Caso contrário, deve-se calcular o acréscimo de deslocamentos dado pela equação (3.28).

Com o valor do acréscimo de deslocamentos " $\Delta D_{k}$ ", faz-se uma correção nos valores dos deslocamentos da seguinte forma:

$$
D_{k} \quad=D_{k}+\Delta D_{k}
$$

$\sim$ (corrigido) 
Para correção das velocidades, com auxílio da equação (3.26) que permite o cálculo do acréscimo das velocidades, utiliza-se a equação (3.35).

$$
\underset{\sim \text { (corrigido) }}{\dot{D}_{k}}=\stackrel{\bullet}{\dot{D}_{k}}+\frac{\gamma}{\beta \Delta t} \Delta \underset{\sim}{D_{k}}
$$

Já para correção das acelerações, com auxílio da equação (3.24) que permite o cálculo do acréscimo das acelerações, utiliza-se a equação (3.36).

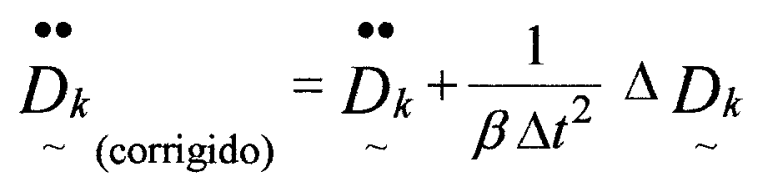

Após a correção destas variáveis, volta-se novamente ao ponto onde o equilíbrio é verificado, concluindo-se, assim, o processo de integração numérica.

Cabe ressaltar que o valor de cada intervalo de tempo " $\Delta t$ " permanecerá constante ao longo de todo o processo de integração. O valor desse intervalo de tempo depende de umá série de fatores e será objeto de discussão no capítulo 7 deste trabalho.

Com a finalidade de ilustrar o método de Newmark, apresenta-se na figura 3.4 um diagrama de blocos contendo apenas as equações básicas, onde pode-se visualizar de forma global todos os passos descritos anteriormente. 


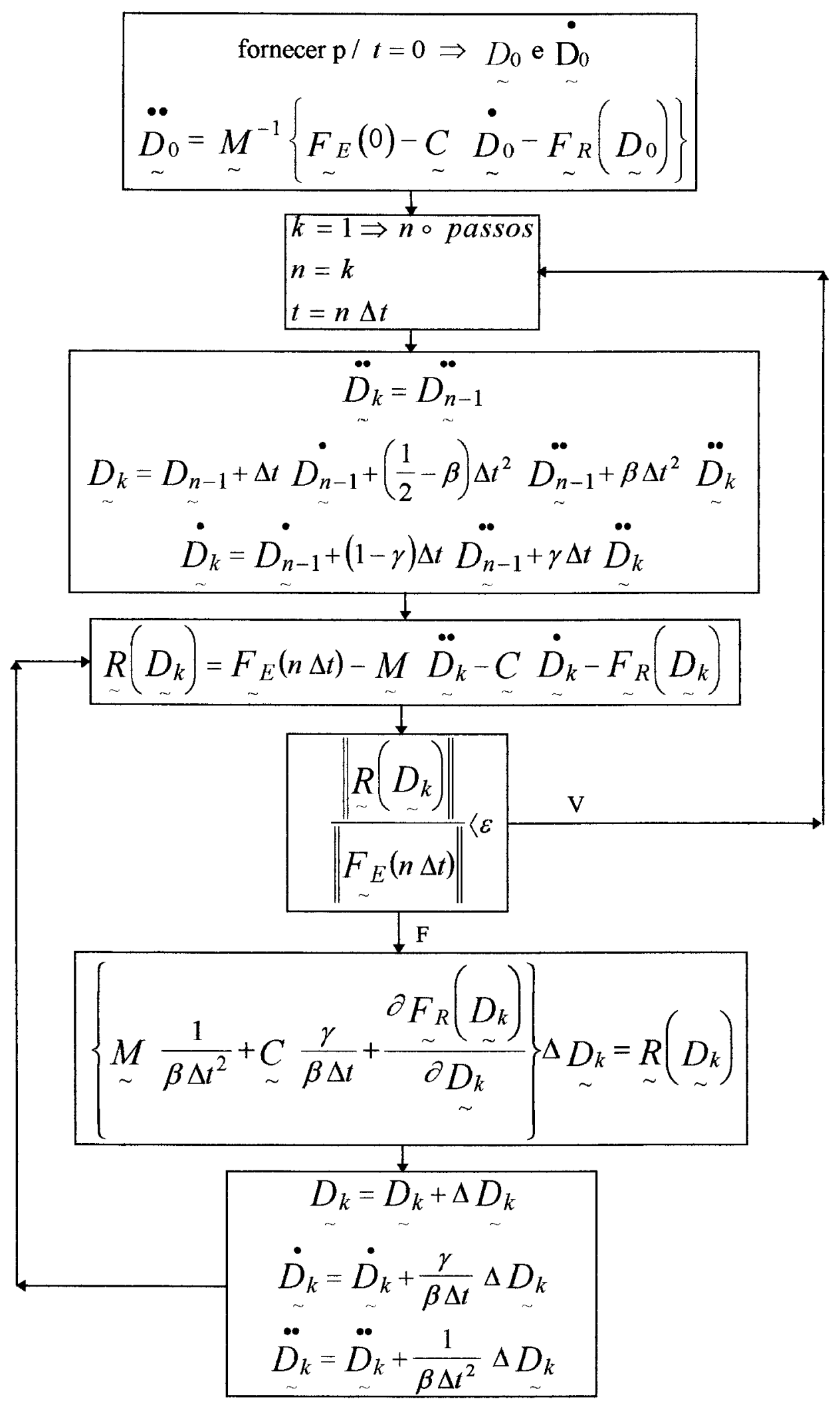

FIGURA 3.4 - Diagrama de blocos do método de Newmark. 


\section{5 - Aspectos computacionais}

Para implementação do método de Newmark apresentase, na sequiência, a documentação básica relativa ao código computacional para análise dinâmica não-linear de estruturas. Merece destaque o código relativo ao cálculo propriamente dito, vide diagrama de blocos na figura 3.4, visto que os códigos relativos à leitura e saída de dados, traçador gráfico, subrotinas auxiliares e gerenciador principal, que fazem parte dos programas computacionais que foram elaborados, não tem papel relevante no contexto deste trabalho.

\subsection{1 - Esquema geral de cálculo}

O diagrama de blocos referente ao esquema geral de cálculo é mostrado na figura 3.5, sendo que cada bloco contém o nome de uma subrotina específica, cuja função será descrita no item 3.5.2. Tal diagrama é autoexplicativo, onde o seu funcionamento já foi descrito no item 3.4.2 deste trabalho.

Cabe ressaltar que este esquema de cálculo é genérico, permitindo-se realizar uma análise estática ou dinâmica, com ou sem não-linearidade física e/ou geométrica. Tal esquema foi utilizado na elaboração dos programas computacionais "DINATREL" e "DINAPORT", relativos à análise estrutural de treliças planas e pórticos planos, respectivamente. Os aspectos principais pertinentes à cada um dos programas mencionados serão abordados no transcorrer deste trabalho. 


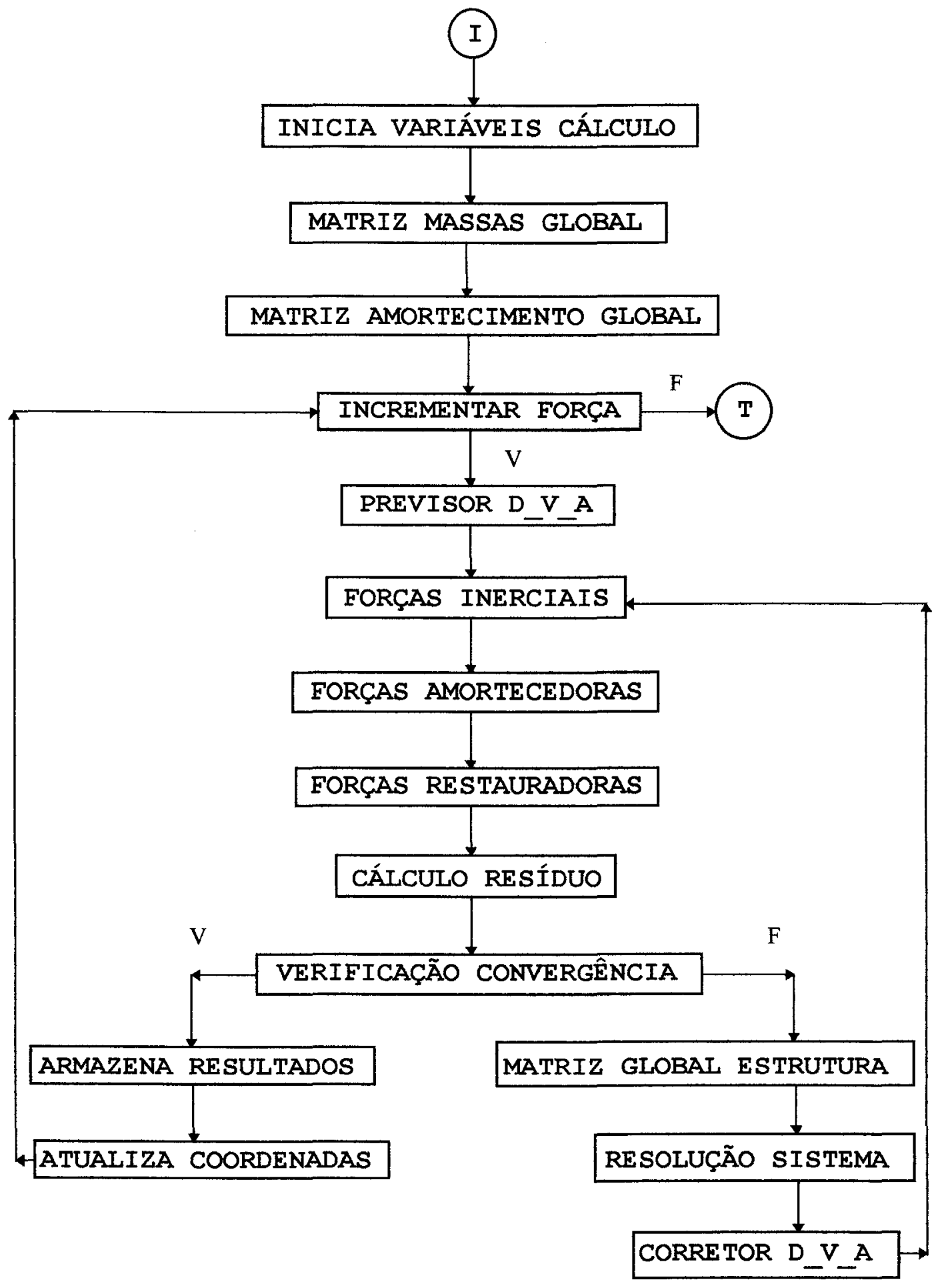

FIGURA 3.5 - Diagrama de blocos do esquema geral de cálculo. 


\subsection{2 - Descrição das subrotinas}

A descrição das funções de cada subrotina contida na figura 3.5 é fornecida na seqüência.

\section{A - Subrotina "INICIA VARIÁVEIS CÁLCULO"}

Esta subrotina têm a função de zerar as variáveis utilizadas no cálculo, bem como de calcular os valores iniciais de algumas variáveis específicas.

\section{B - Subrotina "MATRIZ MASSAS GLOBAL"}

Calcula a matriz de massas de cada elemento, cuja matriz será fornecida no item 4.5 deste trabalho, e monta a matriz de massas global " $M$ " da estrutura.

\section{C - Subrotina "MATRIz AMORTECIMENTO GLOBAL"}

Calcula a matriz de amortecimento global " $C$ " da estrutura, conforme será visto no item 4.6 deste trabalho.

\section{D - Subrotina "INCREMENTAR FORÇA"}

Esta subrotina tem a função de atualizar o valor das forças externas " $F_{E}$ ", sendo que esse valor é fornecido para o final do intervalo de tempo " $n \Delta t$ ". 


\section{E - Subrotina "PREVISOR D_V_A"}

Realiza a previsão das acelerações " $\ddot{D_{k}} "$, dos deslocamentos " $D_{k}$ " e das velocidades " $\dot{D}_{k}$ ", com auxílio das equações $(3.30),(3.31)$ e (3.32), respectivamente.

\section{F - Subrotina "FORÇAS INERCIAIS"}

Calcula o valor das forças inerciais através do produto matricial " $M \ddot{D_{k}}$ ".

\section{G - Subrotina "FORÇAS AMORTECEDORAS"}

Calcula o valor das forças amortecedoras através do produto matricial " $\mathrm{C} \dot{D_{k}}$ ".

\section{H - Subrotina "FORÇAS RESTAURADORAS"}

Esta subrotina tem a função de calcular as forças restauradoras " $F_{R}\left(D_{\sim}\right)$ ". Tais forças são dependentes dos deslocamentos (não-linearidade geométrica) e da relação tensão $x$ deformação (não-linearidade física). Dessa forma, no capítulo 4 será tratada a não-linearidade geométrica e nos capítulos 5 e 6 serão tratadas as nãolinearidades físicas para $\circ$ aço e para o concreto armado, respectivamente. 


\section{I - Subrotina "CÁLCULO RESÍDUO"}

Calcula o valor do resíduo das forças dinâmicas não equilibradas " $\underset{\sim}{R}\left(D_{*}\right)$ ", com auxílio da equação (3.15).

\section{J - Subrotina "VERIFICAÇÃO CONVERGÊNCIA"}

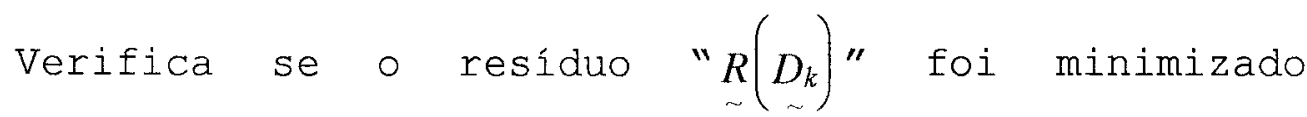
através da relação fornecida pela equação(3.33).

\section{K - Subrotina "MATRIZ GLOBAL ESTRUTURA"}

Monta a matriz global da estrutura dada pela seguinte equação:

$$
\underset{\sim}{G}=\left\{\underset{\sim}{M} \frac{1}{\beta \Delta t^{2}}+\underset{\sim}{\operatorname{C} \frac{\gamma}{\beta \Delta t}}+\frac{\partial F_{R}\left(\underset{\sim}{D_{k}}\right)}{\partial \underset{\sim}{D_{k}}}\right\}
$$

Para o cálculo da matriz global " $G$ " se faz necessário calcular a derivada de " $F_{R}\left(\underset{\sim}{D_{k}}\right)$ " em relação à " $D_{k}$ ", conforme será visto no capítulo 4 deste trabalho. 


\section{L - Subrotina "RESOLUÇÃo SISTEMA"}

Resolve o sistema de equações fornecido pela equação (3.28), utilizando-se o método de Gauss, SORIANO(1981). Com isso, obtém-se o acréscimo de deslocamentos " $\Delta D_{k}$ ".

\section{M - Subrotina "CORRETOR D_V_A"}

Realiza a correção dos deslocamentos " $D_{k}$ ", das velocidades " $\dot{D}_{k}$ " e das acelerações " $\ddot{D_{k}}$ ", com auxilio das equações $(3.34),(3.35)$ e (3.36), respectivamente.

\section{N - Subrotina "ARMAZENA RESULTADOS"}

Esta subrotina tem a função de armazenar os resultados obtidos no intervalo de tempo " $n \Delta t$ ", tais como: deslocamentos, velocidades, acelerações, forças normais, forças cortantes, momentos fletores e demais valores numéricos necessários para a integração do próximo intervalo de tempo.

\section{o - Subrotina "ATUALIZA COORDENADAS"}

Atualiza as coordenadas dos nós estruturais quando - cálculo é feito considerando-se a não-linearidade geométrica. 


\section{CAPÍTULO 4 - NÃO-LINEARIDADE GEOMÉTRICA NA DINÂMICA DAS ESTRUTURAS RETICULADAS PLANAS}

\section{1 - Generalidades}

A análise não-linear geométrica de um sistema estrutural se faz necessária quando a configuração do sistema deformado difere de modo significativo da sua configuração inicial, de tal modo que a magnitude do acréscimo das forças internas, em relação à análise linear, não possa ser desprezada.

Neste caso, o estabelecimento do equilíbrio final do sistema estrutural é dado em relação à sua configuração deformada, de tal forma que os deslocamentos ocorridos sejam computados no cálculo das forças internas. Para isto, deve-se definir um sistema de coordenadas adequado, uma relação não-linear entre deformação $x$ deslocamento e funções de forma apropriadas para os elementos finitos.

Uma vez definidas tais componentes, pode-se obter as matrizes elementais não-lineares de rigidez e as matrizes de massas e amortecimento, conforme será visto no transcorrer deste capítulo. 


\section{2 - Sistemas de coordenadas}

Como já foi visto anteriormente, uma análise nãolinear geométrica tem como fundamento principal a verificação do equilíbrio da estrutura na sua configuração deformada. Logo, para o cálculo das coordenadas dos elementos finitos ao final de cada intervalo de tempo " $n \Delta t$ ", se faz necessária a utilização de um sistema de coordenadas adequado, tendo em vista que ao longo do processo de integração temporal ter-se-á uma sequiência de configurações de equilíbrio.

Basicamente, existem dois sistemas de coordenadas que podem ser utilizados em uma análise dinâmica nãolinear, a saber: coordenadas Eulerianas e coordenadas Lagrangeanas.

o sistema de coordenadas Euleriano tem como característica principal a definição dos deslocamento em relação à última configuração deformada do elemento. Já - sistema de coordenadas Lagrangeano define os deslocamentos em função de uma configuração indeformada do mesmo.

Com relação à este último sistema, a configuração indeformada de referência pode ser qualquer, permitindose que se faça uma subdivisão em função do referencial adotado, CILONI (1993), WEN et al. (1983) e WONG et al. (1990b), a saber: Lagrangeano total, Lagrangeano geral, Lagrangeano atualizado e Lagrangeano parcialmente atualizado.

Neste trabalho, conforme visto no capítulo 1, optou-se pela utilização, de forma aprimorada, da formulação Lagrangeana atualizada, conforme será visto a seguir. 


\subsection{1 - Treliça plana}

A figura 4.1 mostra a configuração de equilíbrio "A-B" do elemento para treliça plana, situada sobre o eixo " $\mathrm{x}$ " do sistema local de coordenadas $(\mathrm{x}, \mathrm{y})$, que servirá como referencial inicial ao longo do processo iterativo que ocorrerá durante a integração numérica para cada intervalo de tempo " $n \Delta t$ ".

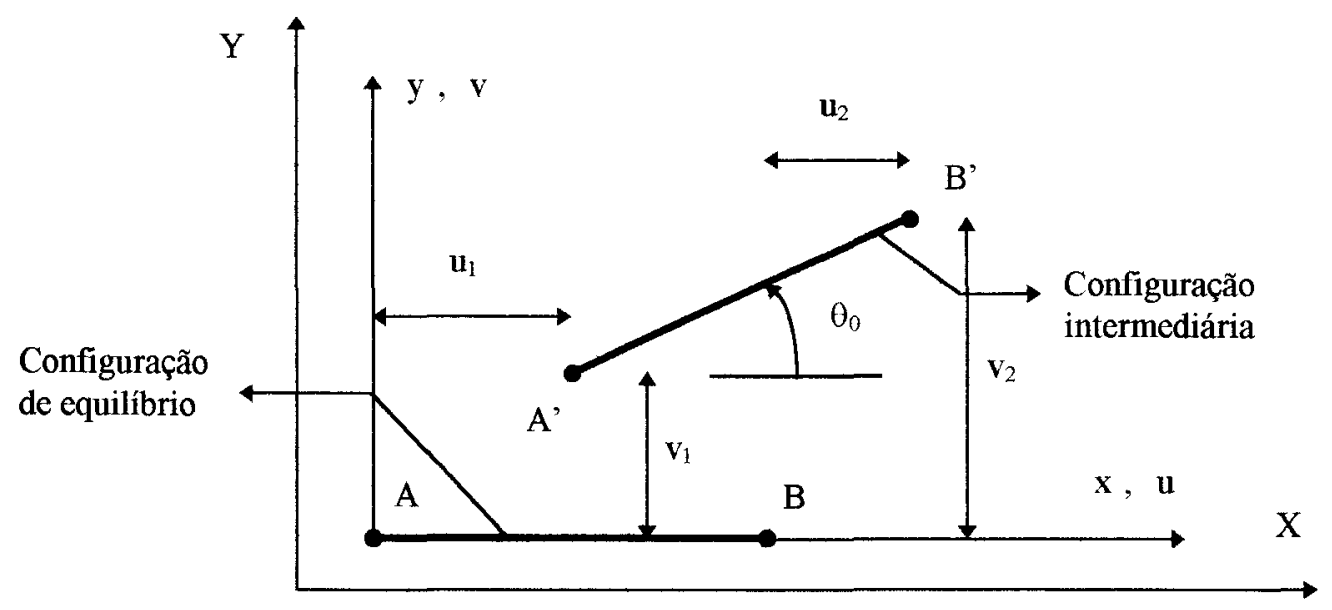

FIGURA 4.1 - Sistema de coordenadas para treliça plana.

A configuração intermediária "A'-B'", vide figura 4.1, têm coordenadas " $u_{1}$ ", " $v_{1}$ ", " $u_{2}$ " e " $v_{2} "$, que são as componentes dos deslocamentos nodais " $u$ " $e$ " $v$ " do elemento. Dessa forma, ficam mantidas as relações (2.1), (2.2) e (2.3) estabelecidas no item 2.2.2.1.

\subsection{2 - Pórtico plano}

De forma análoga ao item anterior, a figura 4.2 mostra a configuração de equilíbrio " $A-B$ " do elemento para pórtico plano. 


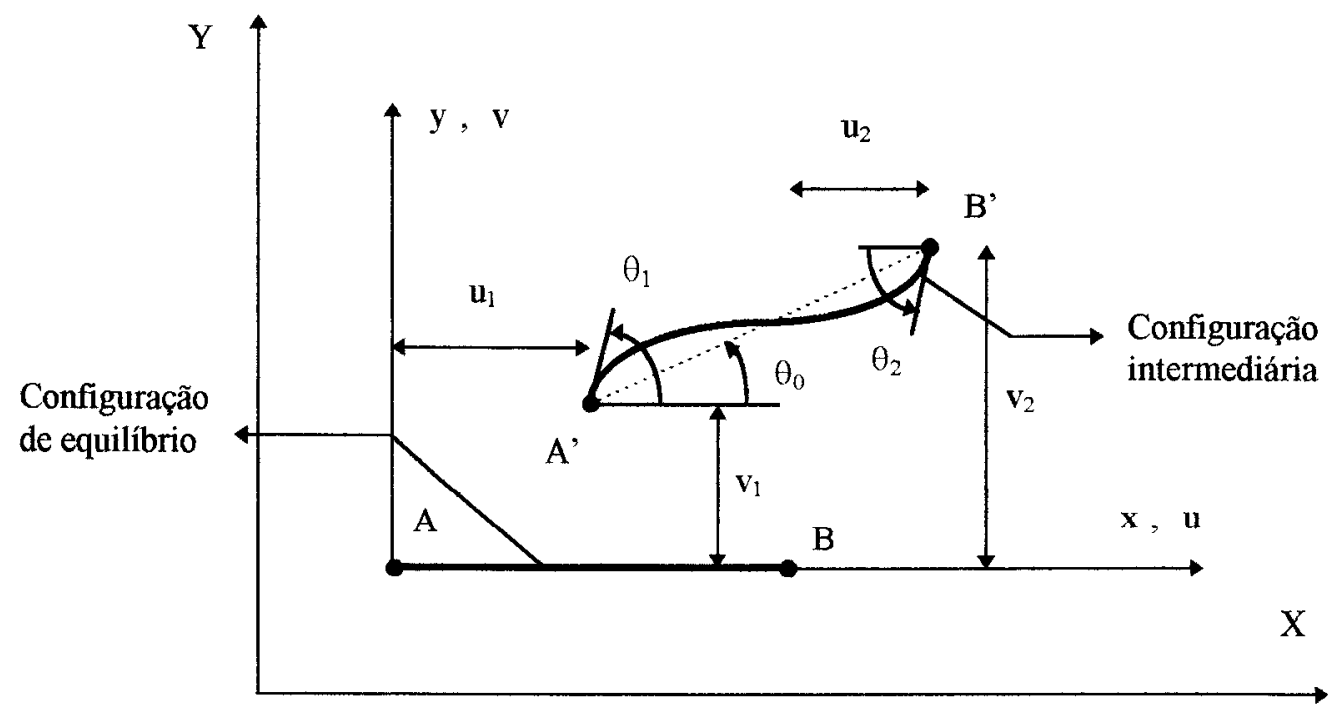

FIGURA 4.2 - Sistema de coordenadas para pórtico plano.

A configuração intermediária " $A$ '-B" ", vide figura 4.2, têm coordenadas " $u_{1}$ ", " $v_{1}$ ", " $\theta_{1}$ ", " $u_{2}$ ", " $v_{2}$ " e " $\theta_{2}$ ", que são as coordenadas dos deslocamentos nodais "u" e " $v$ " do elemento. Dessa forma, ficam mantidas as relações $(2.4),(2.5)$ e (2.3).

Com relação à atualização das coordenadas, tal assunto será tratado no transcorrer deste capitulo.

\section{3 - Modelo elemental}

O modelo elemental está fundamentado na definição das hipóteses básicas, da relação deformação $x$ deslocamentos e das funções de forma.

$\mathrm{Na}$ seqüência, abordar-se-á cada um dos tópicos mencionados. 


\subsection{1 - Hipóteses básicas}

As hipóteses básicas que serão assumidas neste trabalho, estão relacionadas com a definição do sistema estrutural, com o comportamento dos elementos estruturais e suas características geométricas e com o comportamento do material estrutural.

Dessa forma, conforme visto no capítulo 2, o sistema estrutural adotado é definido pela discretização via elementos finitos e pela aplicação do carregamento, devido ao meio externo, nos nós que unem tais elementos.

Com relação ao comportamento do elemento, admite-se uma pequena rotação " $\theta_{0}$ " do mesmo, conforme ilustram as figuras 4.1 e 4.2, durante cada intervalo de tempo " $n \Delta t$ ", cujo limite pode ser fixado em torno de 0,045 rad ou 2,56\%, CORREAA(1991). As características geométricas são definidas pela área da seção transversal " $A$ ", sendo esta constante, pelo comprimento inicial "L" e, para pórtico plano, pelo momento de inércia "I" que será calculado em função da não-linearidade física, conforme será visto no capítulo 6 .

Já o material estrutural é definido como isótropo, com módulo de elasticidade longitudinal "E", sendo que para treliças planas tal valor poderá ser alterado em função da não-linearidade física, conforme será visto no capítulo 5, considerando-se desprezível o efeito de Poisson.

\subsection{2 - Campo de deslocamentos e de deformações}

Para a definição do campo de deformações que ocorrem em um elemento, se faz necessário estabelecer previamente o campo de deslocamentos e a relação 
deformação x deslocamento do mesmo. Para isto, a figura 4.3 ilustra o deslocamento axial "u", o deslocamento transversal " $v$ " e a rotação " $\theta$ " da seção transversal de um elemento de pórtico plano submetido à flexão normal composta, BRASIL et al. (1993).

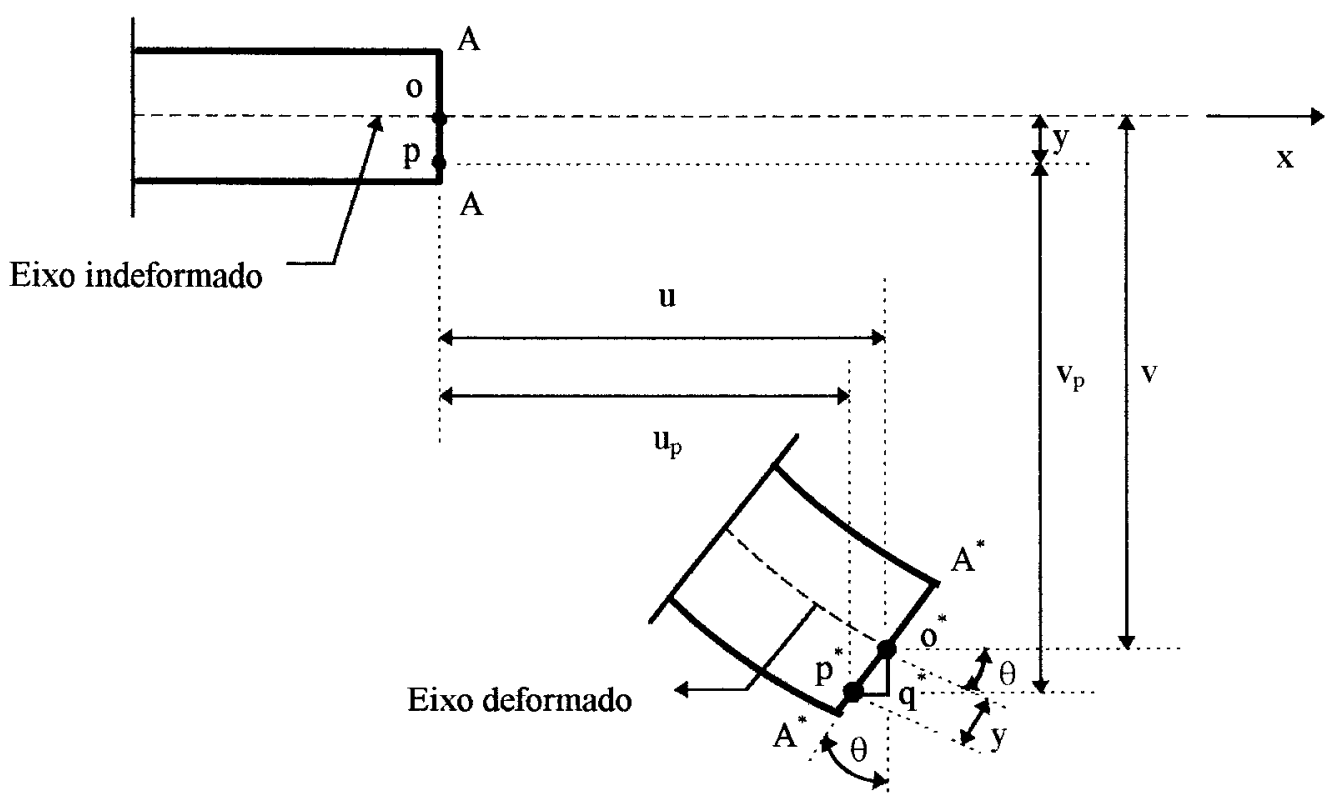

FIGURA 4.3 - Campo de deslocamentos.

Dessa forma, os deslocamentos de um ponto genérico "p", vide figura 4.3, são dados por:

$$
\begin{gathered}
u_{p}=u-y \operatorname{sen} \theta \\
v_{p}=v-y+y \cos \theta
\end{gathered}
$$

Como admitem-se pequenas rotações para o elemento, pode-se adotar as seguintes simplificações, CILONI (1993) :

$$
\operatorname{sen} \theta \cong \theta=v^{\prime}
$$




$$
\cos \theta \cong 1-\frac{\theta^{2}}{2}=1-\frac{v^{\prime 2}}{2}
$$

Substituindo-se as equações (4.3) e (4.4) nas equações (4.1) e (4.2), obtém-se o campo de deslocamentos dado por:

$$
\begin{aligned}
& u_{p}=u-y v^{\prime} \\
& v_{p}=v-y \frac{v^{\prime 2}}{2}
\end{aligned}
$$

Para uma análise não-linear geométrica, estabelecese uma relação não-linear entre deformação e deslocamento, de tal forma que a deformação longitudinal " $\varepsilon$ " seja definida por uma função quadrática dos deslocamentos, MAZZILLI(1986), onde:

$$
\varepsilon=\frac{\partial u_{p}}{\partial x}+\frac{1}{2}\left(\frac{\partial v_{p}}{\partial x}\right)^{2}+\frac{1}{2}\left(\frac{\partial u_{p}}{\partial x}\right)^{2}
$$

Derivando-se as equações (4.5) e (4.6) em relação à "x", obtém-se:

$$
\begin{aligned}
& \frac{\partial u_{p}}{\partial x}=u^{\prime}-y v^{\prime \prime} \\
& \frac{\partial v_{p}}{\partial x}=v^{\prime}-y v^{\prime} v^{\prime \prime}
\end{aligned}
$$


Substituindo-se as equações (4.8) e (4.9) na equação (4.7) e efetuando-se os cálculos, obtém-se:

$$
\begin{aligned}
\varepsilon= & \left(u^{\prime}+\frac{v^{\prime 2}}{2}-y v^{\prime \prime}\right)+\left(\frac{u^{\prime 2}}{2}-y u^{\prime} v^{\prime \prime}\right)+\left(-y v^{\prime 2} v^{\prime \prime}+\right. \\
& \left.\frac{y^{2} v^{\prime 2} v^{\prime \prime 2}}{2}+\frac{y^{2} v^{\prime \prime 2}}{2}\right)
\end{aligned}
$$

Desprezando-se os termos que contém produtos de parcelas de ordem superior, obtém-se o campo de deformações para um elemento de pórtico plano, dado por:

$$
\varepsilon=\left(u^{\prime}+\frac{v^{\prime 2}}{2}-y v^{\prime \prime}\right)+\left(\frac{u^{\prime 2}}{2}-y u^{\prime} v^{\prime \prime}\right)
$$

Para o caso de treliças planas, cuja característica é dada pela nulidade da curvatura, ou seja, v'r=0, o campo de deformações dado por (4.10) fica reduzido a:

$$
\varepsilon=\left(u^{\prime}+\frac{v^{\prime 2}}{2}\right)+\left(\frac{u^{\prime 2}}{2}\right)
$$

Cabe ressaltar que vários pesquisadores desprezam as parcelas contidas dentro dos dois últimos colchetes que se encontram nas equações (4.11) e (4.12), tais como CORREA.(1991), CILONI(1993), WEN et al. (1983) e WONG et al. (1990a, 1990b) . 


\section{3 .3 - Funções de forma}

Conforme foi visto no item 2.2.2, os deslocamentos genéricos " $u$ " dos pontos situados sobre o eixo de um elemento finito, podem ser escritos em função dos deslocamentos nodais " $d$ ", através da utilização da equação (2.3) .

$\mathrm{Na}$ sequiência, serão apresentadas as funções de forma que relacionam tais deslocamentos para os elementos de treliça plana e pórtico plano.

\subsubsection{1 - Treliça plana}

Admitindo-se uma variação linear para os deslocamentos axiais " $u$ " que ocorrem ao longo do eixo longitudinal do elemento, tem-se:

$$
u(x)=\alpha_{0}+\alpha_{1} x
$$

As condições de contorno do problema são dadas por:

$$
\left\{\begin{array}{l}
\mathrm{p} / x=0 \Rightarrow u(x)=u_{1} \\
\mathrm{p} / x=L \Rightarrow u(x)=u_{2}
\end{array}\right.
$$

Impondo-se as condições de contorno (4.14) na equação (4.13), chega-se a:

$$
u(x)=u_{1}+\varphi x
$$




$$
\varphi=\frac{\left(u_{2}-u_{1}\right)}{L}
$$

Analogamente para os deslocamentos transversais "v", obtém-se:

$$
v(x)=v_{1}+\theta_{0} x
$$

com

$$
\theta_{0}=\frac{\left(v_{2}-v_{1}\right)}{L}
$$

Na forma matricial, tem-se:

$$
\phi=\left[\begin{array}{cccc}
1-\frac{x}{L} & 0 & \frac{x}{L} & 0 \\
0 & 1-\frac{x}{L} & 0 & \frac{x}{L}
\end{array}\right]
$$

onde " $\phi$ " é a matriz que contém as funções de forma e relaciona os deslocamentos que ocorrem ao longo do eixo longitudinal com os deslocamentos nodais do elemento, de acordo com a equação (2.3) .

\subsubsection{2 - Pórtico plano}

Analogamente ao item anterior, os deslocamentos axiais "u" para o elemento de pórtico plano são dados pelas equações $(4.15)$ e $(4.16)$.

Já para os deslocamentos transversais " $v$ ", admitese uma variação cúbica dada por: 


$$
v(x)=\alpha_{0}+\alpha_{1} x+\alpha_{2} x^{2}+\alpha_{3} x^{3}
$$

As condições de contorno do problema são dadas por:

$$
\left\{\begin{array}{l}
\mathrm{p} / x=0 \Rightarrow v(x)=v_{1} \\
\mathrm{p} / x=0 \Rightarrow v^{\prime}(x)=\theta_{1} \\
\mathrm{p} / x=L \Rightarrow v(x)=v_{2} \\
\mathrm{p} / x=L \Rightarrow v^{\prime}(x)=\theta_{2}
\end{array}\right.
$$

Impondo-se as condições de contorno (4.21) na equação (4.20), obtém-se:

$$
v(x)=c+d x+e x^{2}+f x^{3}
$$

onde

$$
\begin{aligned}
& c=v_{1} ; d=\theta_{1} ; e=\frac{-2 \theta_{1}-\theta_{2}+3 \theta_{0}}{L} ; \\
& \mathrm{f}=\frac{\theta_{1}+\theta_{2}-2 \theta_{0}}{L^{2}} ; \quad \theta_{0}=\frac{\left(v_{2}-v_{1}\right)}{L}
\end{aligned}
$$

$\mathrm{Na}$ forma matricial, tem-se:

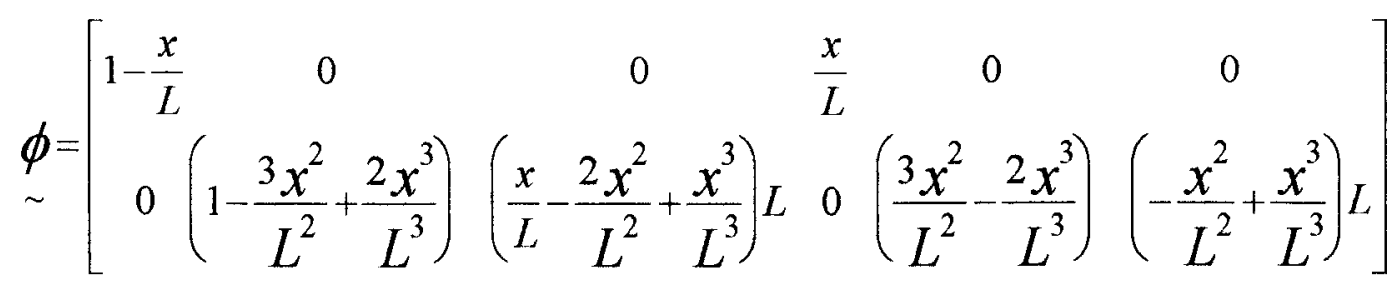

onde " $\phi$ " é definida ao final ao item anterior. 


\section{4 - Matriz de rigidez}

A matriz de rigidez de uma estrutura é definida pela relação entre as forças externas e os deslocamentos estruturais correspondentes, SOUZA et al.(1995), válido para estruturas trabalhando no regime elástico. Tal definição será apresentada na seqüência, bem como a dedução dos coeficientes de rigidez dessa matriz.

\section{4 .1 - Conceituação via formulação energética}

Dado um sistema estrutural discreto em equilibrio estático, formado por um conjunto de elementos finitos contidos no plano $(X, Y)$, o funcional da energia potencial total " $\pi_{\mathrm{p}}$ " do sistema pode ser escrito em função dos funcionais dos elementos finitos " $\pi_{\mathrm{pe}}$ ", da seguinte forma:

$$
\Pi_{p}=\sum_{l=1}^{n e} \Pi_{p e}{ }^{l}
$$

onde "ne" é o número de elementos finitos que compõem o sistema estrutural.

Para cada elemento, o funcional é dado por:

$$
\Pi_{p e}=U_{e}+\Omega_{e}
$$

onde

"Ue" é a energia de deformação acumulada pelo elemento; " $\Omega_{e}$ " é o potencial dos esforços externos na configuração deformada do elemento. 
Admitindo-se que o carregamento do sistema seja aplicado nos nós estruturais, conforme visto no item 4.3.1, o potencial dos esforços externos é dado por:

$$
\Omega_{e}=-f_{\sim}^{f_{E}^{T}} \underset{\sim}{d}
$$

onde " $f_{E}$ " é o vetor de forças nodais equivalentes do elemento.

Já a energia de deformação é definida por:

$$
U_{e}=\int_{V e} \mu_{0} d V_{e}
$$

onde

"V"é o volume do elemento;

" $\mu_{0}$ " é a energia de deformação específica, dada por:

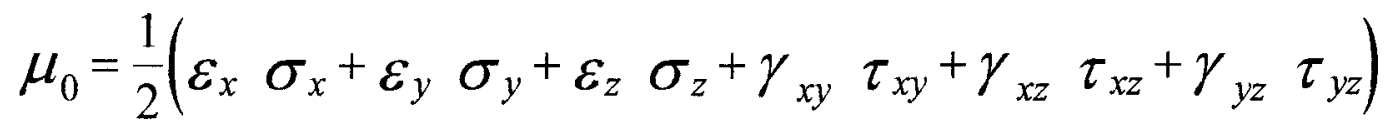

ou, simplesmente,

$$
\mu_{0}=\frac{1}{2} \varepsilon_{\sim}^{T} \sigma
$$

sendo

$$
\begin{aligned}
& \underset{\sim}{\mathcal{E}^{T}}=\left[\begin{array}{llllll}
\mathcal{E}_{x} & \mathcal{E}_{y} & \mathcal{E}_{z} & \gamma_{x y} & \gamma_{x z} & \gamma_{y z}
\end{array}\right] \\
& \underset{\sim}{\sigma^{T}}=\left[\begin{array}{llllll}
\sigma_{x} & \sigma_{y} & \sigma_{z} & \tau_{x y} & \tau_{x z} & \tau_{y z}
\end{array}\right]
\end{aligned}
$$


Como trata-se de um sistema estrutural discreto contido no plano $(X, Y)$ e como o eixo do elemento está orientado segundo o eixo local " $\mathrm{x}$ ", admitem-se as seguintes simplificações:

a $-\sigma_{z}=0 ; \tau_{x z}=0$ e $\tau_{y z}=0$, pois na direção "z" só atua a pressão atmosférica;

b - $\sigma_{y} \cong 0$, pois sua magnitude é desprezível quando comparada com a magnitude de " $\sigma_{x}$ ";

c - $\gamma_{x y}=0$, pois vale a Lei de Navier, onde a seção transversal plana permanece plana após a sua deformação.

Chamando-se de " $E$ " a matriz dos coeficientes elásticos, pode-se relacionar as tensões " $\sigma$ " com as deformações " $\varepsilon$ " da seguinte forma:

$$
\underset{\sim}{\sigma}=\underset{\sim}{E} \underset{\sim}{\sim}
$$

ou, após as simplificações anteriormente citadas,

$$
\sigma_{x}=E \varepsilon_{x}
$$

Substituindo-se as equações (4.32), (4.29) e (4.27) em (4.26), obtém-se:

$$
\Pi_{p e}=\frac{1}{2} \int_{V e} \varepsilon_{\sim}^{T} \underset{\sim}{E} \underset{\sim}{ } d V_{e}-f_{E}^{T} \underset{\sim}{d}
$$


Substituindo-se a equação (2.28) na equação (4.44), obtém-se:

$$
\Pi_{p e}=\frac{1}{2} \int_{V e} d_{\sim}^{T} B_{\sim}^{T} \underset{\sim}{\operatorname{Ex}} \underset{\sim}{\operatorname{di}} d V_{e}-f_{E}^{T} d
$$

ou, simplesmente,

$$
\Pi_{p e}=U_{e}(d)-f_{f^{\prime}}^{T} d
$$

Uma vez que " $\pi_{\text {pe }}$ " é, agora, uma função dos deslocamentos nodais " $d$ ", a variação de " $\pi_{\text {pe }}$ é igual ao seu diferencial, ou seja, $\delta \pi_{\mathrm{pe}}=\mathrm{d} \pi_{\mathrm{pe}}$. Desse modo, tem-se:

$$
\delta \Pi_{p e}=\frac{\partial \Pi_{p e}}{\partial d_{1}} \delta d_{1}+\frac{\partial \Pi_{p e}}{\partial d_{2}} \delta d_{2}+\ldots \ldots \ldots \ldots .+\frac{\partial \Pi_{p e}}{\partial d_{n}} \delta d_{n}
$$

sendo $\delta d_{1}=d d_{1} ; \delta d_{2}=d d_{2} ; \ldots \ldots \ldots \ldots ; \quad \delta d_{n}=d d_{n}$

Analisando-se a expressão anterior, tem-se que cada parcela é o resultado do produto de uma força pelo respectivo deslocamento. Como esses deslocamentos são quaisquer e simultaneamente não nulos, pode-se aplicar o princípio da energia potencial estacionária, SAVASSI (1996), resultando: 


$$
\frac{\partial \prod_{p e}}{\partial d_{1}}=0 ; \frac{\partial \Pi_{p e}}{\partial d_{2}}=0 ; \ldots \ldots . . ; \frac{\partial \Pi_{p e}}{\partial d_{n}}=0
$$

ou, simplesmente,

$$
\frac{\partial U_{e}(\underset{\sim}{d})}{\partial d_{j}}-f_{E}=0
$$

Cada uma das expressões do tipo (4.48) fornecerá uma equação algébrica, que organizadas na forma matricial resultará:

$$
k_{s} d=f_{E}
$$

onde " $\boldsymbol{k}_{S}$ " é a matriz de rigidez secante do elemento.

Para todo o sistema estrutural, a partir das contribuições de todos os elementos, pode-se utilizar o processo de expansão e acumulação, encontrando-se, finalmente:

$$
K_{S} D=F_{E}
$$

Particularizando-se a equação geral do movimento (2.38) para o caso estático, tem-se:

$$
F_{R}(\underset{\sim}{D})=K_{S} \underset{\sim}{D}
$$


onde " $K_{S}$ " é a matriz de rigidez secante do sistema estrutural e " $F_{R}(\underset{\sim}{D})$ " são as forças restauradoras procuradas ao final do capítulo anterior.

$\dot{E}$ importante salientar que em virtude de ter-se assumido uma relação deformação $x$ deslocamento nãolinear, a matriz de rigidez " $K_{S}$ " altera-se à medida que os deslocamentos ocorrem, conforme ilustra a figura 4.4 .

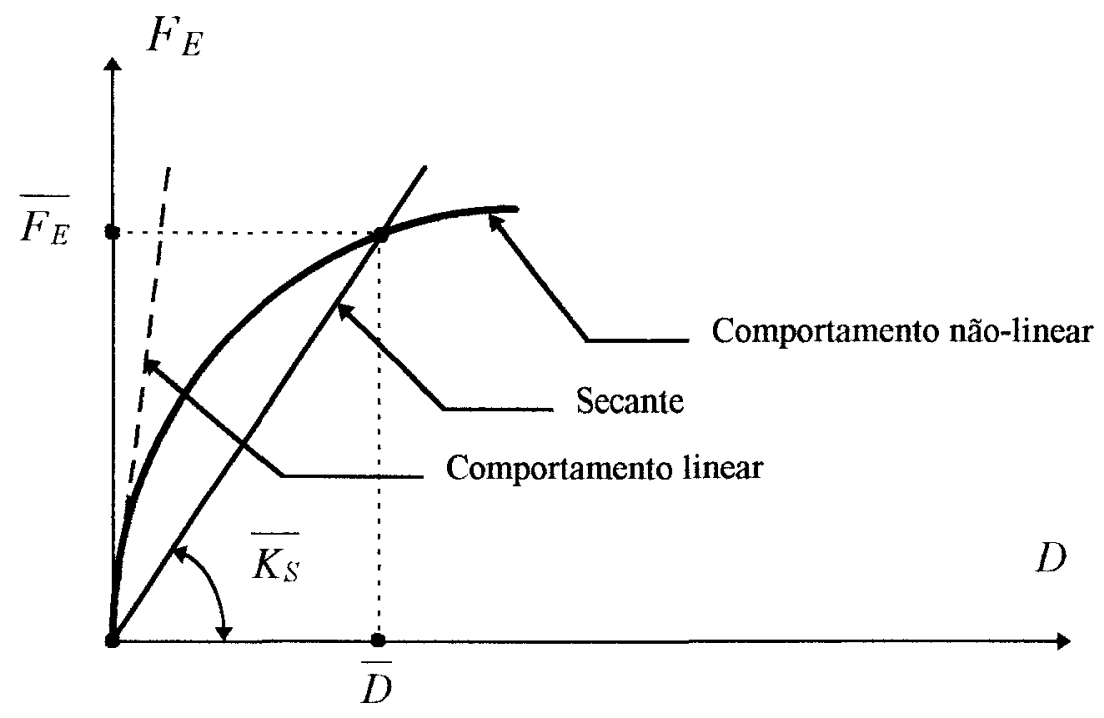

FIGURA 4.4 - Comportamento não-linear. Matriz de rigidez secante, CORRÊA(1991).

Analisando-se, agora, a equação (4.48), esta pode ser reescrita da seguinte forma:

$$
\frac{\partial U_{e}(d)}{\partial d_{j}}=f_{E}
$$

ou, simplesmente, 


$$
\varphi\left(d_{i}\right)=f_{E}
$$

Aplicando-se uma variação finita " $\Delta \mathrm{d}_{\mathrm{i}}$ " nos deslocamentos nodais na configuração deformada e expandindo-se a função " $\varphi\left(d_{i}+\Delta d_{i}\right)$ " pela relação linearizada de Taylor, obtém-se:

$$
\varphi\left(d_{i}+\Delta d_{i}\right)=\varphi\left(d_{i}\right)+\frac{\partial \varphi\left(d_{i}\right)}{\partial d_{i}} \Delta d_{i}
$$

ou, simplesmente,

$$
\Delta f_{E}=\frac{\partial^{2} U_{e}(\underset{\sim}{d})}{\partial d_{i} \partial d_{j}} \Delta d_{i}
$$

De forma análoga à equação (4.48), cada uma das expressões do tipo (4.55) fornecerá uma equação algébrica, que organizadas na forma matricial resultará:

$$
k_{T} \Delta d=\Delta f_{E}
$$

onde " $k_{T}$ " é a matriz de rigidez tangente do elemento. Após a contribuição de todos os elementos, chega-se a:

$$
\underset{\sim}{K_{T}} \Delta \underset{\sim}{D}=\Delta \underset{\sim}{F_{E}}
$$


sendo " $K_{T}$ " a matriz de rigidez tangente do sistema estrutural.

A figura 4.5 ilustra 0 conceito da matriz de rigidez tangente, lembrando-se que tal conceito é utilizado nos processos iterativos descritos no item 3.3 .1 .

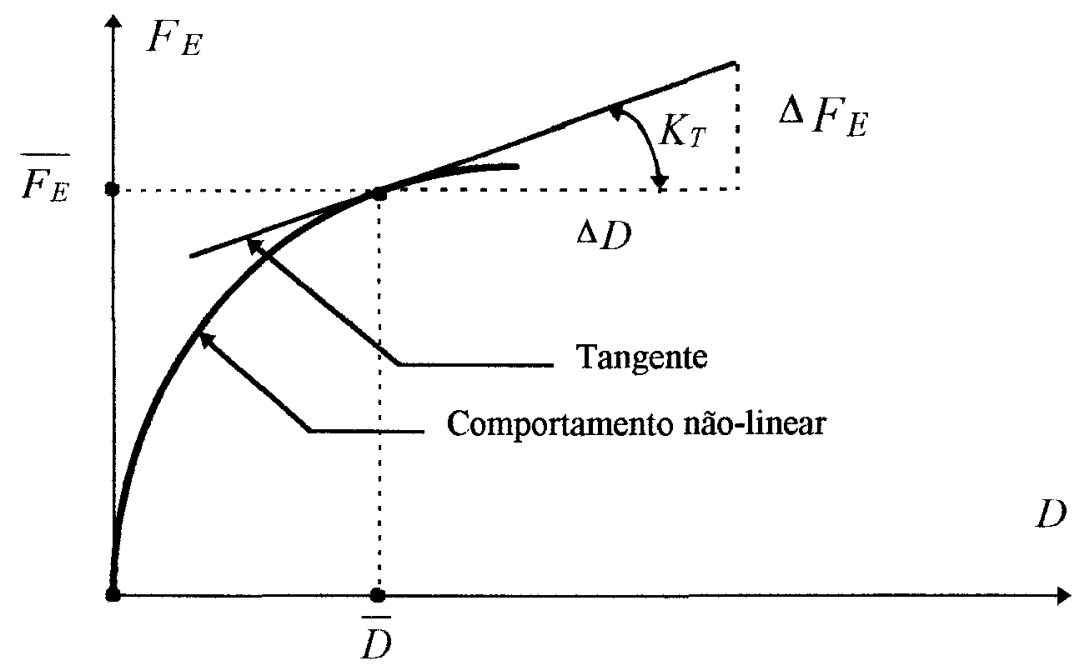

FIGURA 4.5 - Comportamento não-linear. Matriz de rigidez tangente, CORREAA(1991).

Dessa forma, conclui-se que as forças restauradoras e suas respectivas derivadas são obtidas, respectivamente, através da primeira e segunda derivações da energia de deformação em relação aos deslocamentos nodais, conforme mostram as seguintes equações.

$$
\underset{\sim}{F_{R}}(\underset{\sim}{D})=\frac{\partial U}{\partial D_{j}}
$$




$$
\frac{\partial F_{R}(\underset{\sim}{D})}{\partial D_{i}}=\frac{\partial^{2} U}{\partial D_{i} \partial D_{j}}
$$

\subsection{2 - Atualização de coordenadas}

Conforme visto no item 4.2, optou-se pela escolha da formulação Lagrangeana atualizada para descrever a posição de equilíbrio do sistema estrutural ao longo do processo de integração numérica.

Tal formulação preconiza que ao final de cada intervalo de tempo, ou incremento de carregamento para o caso estático, deva ser feita uma atualização das coordenadas do sistema, permitindo-se que o mesmo venha a ter grandes deslocamentos, através de uma sucessão de posições de equilíbrio onde valem as simplificações impostas pela adoção de pequenas rotações para cada elemento.

Sabendo-se que a energia de deformação de cada elemento é dada pela equação (4.28) e promovendo-se as devidas simplificações já mencionadas no item anterior, obtém-se:

$$
U_{e}=\frac{1}{2} \int_{V_{e}} E \varepsilon_{x}{ }^{2} d V_{e}
$$

Como o problema é incremental, tem-se:

$$
U_{e}=\frac{1}{2} \int_{V_{e}} E\left({ }^{m+1} \varepsilon_{x}\right)^{2} d V_{e}
$$

onde ${ }^{~}{ }^{m+1} \boldsymbol{\varepsilon}_{\mathrm{x}}$ " é a deformação total do elemento ocorrida até a configuração de equilíbrio " $m+1$ ". 
Expressando-se a variação da deformação que ocorre durante o incremento " $n$ ", tem-se que:

$$
\Delta{ }^{n} \mathcal{E}_{x}={ }^{m+1} \mathcal{E}_{x}-{ }^{m} \mathcal{E}_{x}
$$

onde " $\boldsymbol{\varepsilon}_{\mathrm{x}}$ " é a deformação total do elemento ocorrida até a configuração de equilíbrio "m".

Substituindo-se a equação (4.62) na equação (4.61) e efetuando-se as operações matemáticas, obtém-se:

$$
U_{e}=\frac{1}{2} \int_{V_{e}} E\left(\Delta^{n} \varepsilon_{x}{ }^{2}+2 \Delta^{n} \varepsilon_{x}{ }^{m} \varepsilon_{x}{ }^{m}{ }^{m} \varepsilon_{x}{ }^{2}\right) d V_{e}
$$

Como " ${ }^{n} \boldsymbol{\varepsilon}_{\mathrm{x}}$ " não depende dos deslocamentos ocorridos durante o incremento "n", qualquer derivação em relação a esses deslocamentos se anula. Logo, pode-se reescrever a expressão da energia de deformação em função das parcelas que contribuem na rigidez, CORREA(1991), como:

$$
U_{e}=\frac{1}{2} \int_{V_{e}} E \Delta^{n} \varepsilon_{x}{ }^{2} d V_{e}{ }^{m}{ }^{m} \varepsilon_{x} \int_{V_{e}} E \Delta^{n} \varepsilon_{x} d V_{e}
$$

Dessa forma, a primeira parcela da equação anterior fornecerá o acréscimo de energia ocorrido durante cada intervalo ou incremento " $n$ " e a segunda parcela fornecerá a energia acumulada até a configuração de equilíbrio "m", valendo a relação $\mathrm{n}=\mathrm{m}+1$.

$\mathrm{Na}$ sequiência, as figuras $4.6,4.7$ e 4.8 ilustram, respectivamente, a sistemática utilizada na atualização das coordenadas para um elemento de barra trabalhando em uma dimensão, para um elemento de treliça plana e para um elemento de pórtico plano. 


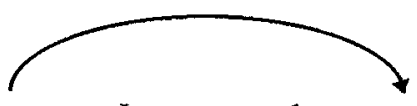

Incremento 1

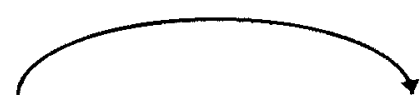

Incremento 2

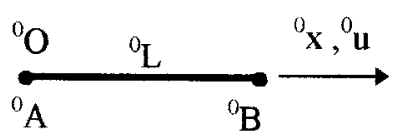

Conf. equilibrio 0

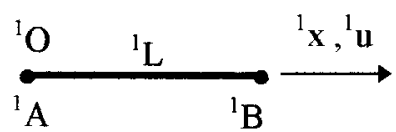

Conf. equilíbrio 1

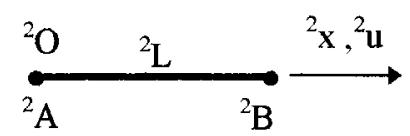

Conf. equilibrio 2

FIGURA 4.6 - Atualização de coordenadas para um elemento de barra trabalhando em uma dimensão.

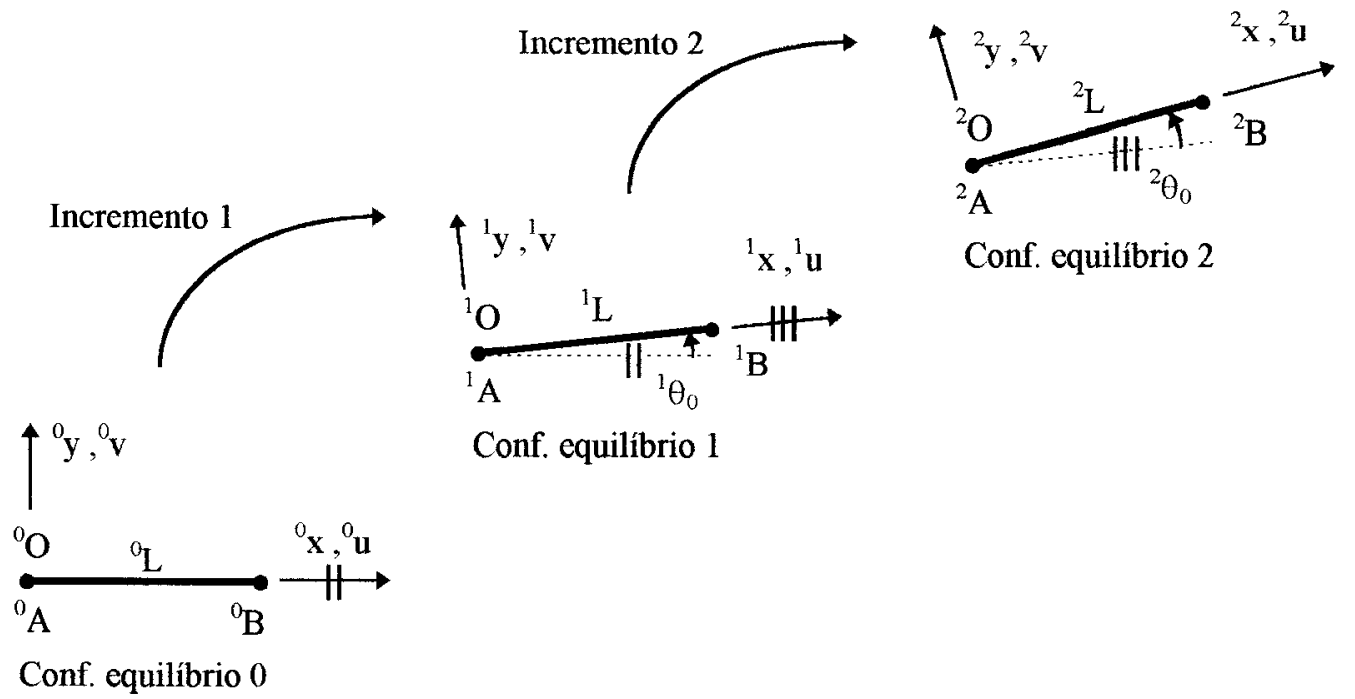

FIGURA 4.7 - Atualização de coordenadas para um elemento de treliça plana.
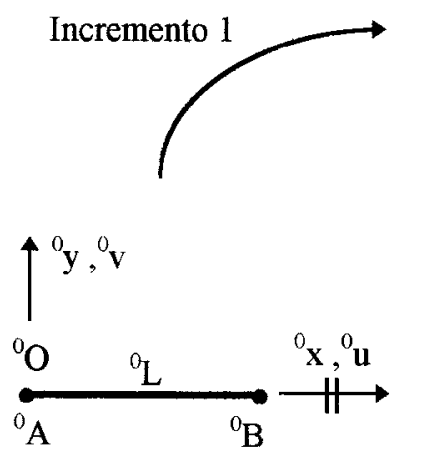

Conf. equilíbrio 0

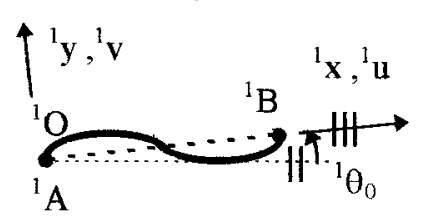

Conf. equilíbrio 1

$$
{ }^{1} \mathrm{~L}={ }^{1} \mathrm{~A}^{1} \mathrm{~B}
$$

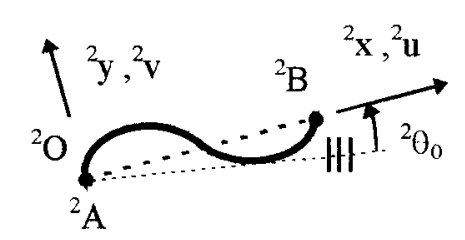

Conf. equilibrio 2 ${ }^{2} \mathrm{~L}={ }^{2} \mathrm{~A}^{2} \mathrm{~B}$

FIGURA 4.8 - Atualização de coordenadas para um elemento de pórtico plano. 


\subsection{3 - Elemento de barra em uma dimensão}

Este item tem por objetivo principal ilustrar, de forma completa, toda a dedução das matrizes de rigidez secante e tangente para um elemento de barra trabalhando em uma dimensão, em função da sua simplicidade. Tal dedução irá facilitar de modo significativo a dedução das mesmas matrizes para o elemento de treliça plana e pórtico plano, conforme itens 4.4 .4 e 4.4 .5 .

\subsubsection{1 - Energia de deformação}

o campo de deformações para este elemento é dado pela equação (4.12), tomando-se $\mathrm{V}^{\prime}=0$ por se tratar de um elemento trabalhando segundo o eixo " $x$ ". Logo, tem-se:

$$
\varepsilon_{x}=u^{\prime}+\frac{u^{\prime 2}}{2}
$$

De forma análoga ao elemento de treliça plana, as funções de forma são dadas somente pelas equações (4.15) e (4.16). Derivando-se a equação (4.15) em relação à "x", obtém-se:

$$
u^{\prime}=\varphi=\frac{u_{2}-u_{1}}{L}
$$

Substituindo-se tal equação em (4.65), chega-se a:

$$
\varepsilon_{x}=\left(\frac{u_{2}-u_{1}}{L}\right)+\frac{1}{2}\left(\frac{u_{2}-u_{1}}{L}\right)^{2}
$$


79

Com isso, a variação do campo de deformações, que ocorre durante o incremento " $n$ ", é dada por:

$$
\Delta^{n} \varepsilon_{x}=\left(\frac{\Delta^{n} u_{2}-\Delta^{n} u_{1}}{m L}\right)+\frac{1}{2}\left(\frac{\Delta^{n} u_{2}-\Delta^{n} u_{1}}{m}\right)^{2}
$$

Substituindo-se a equação (4.68) na equação (4.64), tem-se:

$$
\begin{aligned}
U_{e} & =\frac{1}{2} \int_{V_{e}} E\left[\left(\frac{\Delta^{n} u_{2}-\Delta^{n} u_{1}}{m}\right)+\frac{1}{2}\left(\frac{\Delta^{n} u_{2}-\Delta^{n} u_{1}}{m}\right)^{2}\right]^{2} d V_{e}+ \\
& { }_{\varepsilon_{x} \int_{V_{e}} E}\left[\left(\frac{\Delta^{n} u_{2}-\Delta^{n} u_{1}}{m}\right)+\frac{1}{2}\left(\frac{\Delta^{n} u_{2}-\Delta^{n} u_{1}}{m}\right)^{2}\right] d V_{e}
\end{aligned}
$$

Efetuando-se a integração, obtém-se:

$$
\begin{array}{r}
U_{e}=\frac{1}{2} E^{m}{ }^{m} L\left[\left(\frac{\Delta^{n} u_{2}-\Delta^{n} u_{1}}{m}\right)+\frac{1}{2}\left(\frac{\Delta^{n} u_{2}-\Delta^{n} u_{1}}{m}\right)^{2}\right]^{2}+ \\
E^{m}{ }_{E_{x}}^{m}{ }^{m} L\left[\left(\frac{\Delta^{n} u_{2}-\Delta^{n} u_{1}}{m}\right)+\frac{1}{2}\left(\frac{\Delta^{n} u_{2}-\Delta^{n} u_{1}}{m}\right)^{2}\right]
\end{array}
$$

$(4.70)$ 
Como o efeito de Poisson foi desprezado, vide item 4.3.1, tem-se que $A={ }^{m} A=$ constante. Interpretando-se o termo " $\mathrm{E}^{\mathrm{m}} \mathrm{A}^{\mathrm{m}} \boldsymbol{\varepsilon}_{\mathrm{x}}$ " como a força normal acumulada " $\mathrm{N}$ " e desenvolvendo-se a equação (4.70), obtém-se a equação que expressa a energia de deformação do elemento, dada por:

$$
\begin{aligned}
U_{e}= & \frac{E A}{2}{ }^{m} L\left[\left(\frac{\Delta^{n} u_{2}-\Delta^{n} u_{1}}{m}\right)^{2}+\left(\frac{\Delta^{n} u_{2}-\Delta^{n} u_{1}}{m}\right)^{3}+\right. \\
& \left.\frac{1}{4}\left(\frac{\Delta^{n} u_{2}-\Delta^{n} u_{1}}{m}\right)^{4}\right]+{ }^{m} N^{m} L\left[\left(\frac{\Delta^{n} u_{2}-\Delta^{n} u_{1}}{m}\right)_{L}+\right. \\
& \left.\frac{1}{2}\left(\frac{\Delta^{n} u_{2}-\Delta^{n} u_{1}}{m}\right)^{2}\right]
\end{aligned}
$$

ou, simplesmente,

$$
U_{e}=\sum_{i=0}^{4} U_{i}
$$

onde cada uma das parcelas " $U_{i}$ " representam, respectivamente, os termos da equação (4.71).

\subsubsection{2 - Matriz de rigidez secante}

A matriz de rigidez secante do elemento é obtida através da primeira derivação da energia de deformação em relação aos deslocamentos nodais, conforme equações (4.48) e (4.49). 
Dessa forma, derivando-se cada uma das parcelas " $U_{i}$ " descritas no item anterior, obtém-se:

a - em relação a "Uo":

$$
\begin{aligned}
& \frac{\partial U_{0}}{\partial \Delta^{n} u_{1}}=\frac{E A}{{ }^{m} L}\left(\Delta^{n} u_{1}-\Delta^{n} u_{2}\right) \\
& \frac{\partial U_{0}}{\partial \Delta^{n} u_{2}}=\frac{E A}{{ }^{m} L}\left(\Delta^{n} u_{2}-\Delta^{n} u_{1}\right)
\end{aligned}
$$

b - em relação a "Ul":

$$
\begin{aligned}
& \frac{\partial U_{1}}{\partial \Delta^{n} u_{1}}=\frac{E A}{{ }^{m} L} \frac{3}{2} \Delta \varphi\left(\Delta^{n} u_{1}-\Delta^{n} u_{2}\right) \\
& \frac{\partial U_{1}}{\partial \Delta^{n} u_{2}}=\frac{E A}{{ }^{m} L} \frac{3}{2} \Delta \varphi\left(\Delta^{n} u_{2}-\Delta^{n} u_{1}\right)
\end{aligned}
$$

onde

$$
\Delta \varphi=\frac{\Delta^{n} u_{2}-\Delta^{n} u_{1}}{m_{L}}
$$

c - em relação a "U2":

$$
\begin{aligned}
& \frac{\partial U_{2}}{\partial \Delta^{n} u_{1}}=\frac{E A}{{ }^{m} L} \frac{1}{2} \Delta \varphi^{2}\left(\Delta^{n} u_{1}-\Delta^{n} u_{2}\right) \\
& \frac{\partial U_{2}}{\partial \Delta^{n} u_{2}}=\frac{E A}{{ }^{m} L} \frac{1}{2} \Delta \varphi^{2}\left(\Delta^{n} u_{2}-\Delta^{n} u_{1}\right)
\end{aligned}
$$


d - em relação a "U3":

$$
\begin{aligned}
& \frac{\partial U_{3}}{\partial \Delta^{n} u_{1}}=-{ }^{m} N \\
& \frac{\partial U_{3}}{\partial \Delta^{n} u_{2}}={ }^{m} N
\end{aligned}
$$

e - em relação a "Ut":

$$
\begin{aligned}
& \frac{\partial U_{4}}{\partial \Delta^{n} u_{1}}=\frac{{ }^{m} N}{{ }^{m} L}\left(\Delta^{n} u_{1}-\Delta^{n} u_{2}\right) \\
& \frac{\partial U_{4}}{\partial \Delta^{n} u_{2}}=\frac{{ }^{m} N}{{ }^{m} L}\left(\Delta^{n} u_{2}-\Delta^{n} u_{1}\right)
\end{aligned}
$$

Substituindo-se tais derivadas na equação (4.52), tem-se:

a - primeira equação contendo as derivadas em relação a " $\Delta \mathrm{u}_{1} "$ :

$$
\begin{aligned}
& \frac{E A}{{ }^{m} L}\left(\Delta^{n} u_{1}-\Delta^{n} u_{2}\right)+\frac{E A}{{ }^{m} L} \frac{3}{2} \Delta \varphi\left(\Delta^{n} u_{1}-\Delta^{n} u_{2}\right)+ \\
& \frac{E A}{{ }^{m} L} \frac{1}{2} \Delta \varphi^{2}\left(\Delta^{n} u_{1}-\Delta^{n} u_{2}\right)-{ }^{m} N+\frac{{ }^{m} N}{{ }^{m} L}\left(\Delta^{n} u_{1}-\Delta^{n} u_{2}\right)={ }^{m+1} f_{E 1}
\end{aligned}
$$


b - segunda equação contendo as derivadas em relação a " $\Delta \mathrm{n} \mathrm{u}_{2} "$ :

$$
\begin{aligned}
& \frac{E A}{{ }^{m} L}\left(\Delta^{n} u_{2}-\Delta^{n} u_{1}\right)+\frac{E A}{{ }^{m} L} \frac{3}{2} \Delta \varphi\left(\Delta^{n} u_{2}-\Delta^{n} u_{1}\right)+ \\
& \frac{E A}{{ }^{m} L} \frac{1}{2} \Delta \varphi^{2}\left(\Delta^{n} u_{2}-\Delta^{n} u_{1}\right)+{ }^{m} N+\frac{{ }^{m} N}{{ }^{m} L}\left(\Delta^{n} u_{2}-\Delta^{n} u_{1}\right)={ }^{m+1} f_{E 2}
\end{aligned}
$$

Organizando-se as equações (4.79) e (4.80) na forma matricial, obtém-se:

$$
\begin{aligned}
& \left\{\frac{E A}{m_{L}}\left[\begin{array}{cc}
1 & -1 \\
-1 & 1
\end{array}\right]+\frac{1}{2} \frac{E A}{m L}\left[\begin{array}{cc}
3 \Delta \varphi & -3 \Delta \varphi \\
-3 \Delta \varphi & 3 \Delta \varphi
\end{array}\right]+\right. \\
& \left.\frac{1}{3} \frac{E A}{m L}\left[\begin{array}{cc}
\frac{3 \Delta \varphi^{2}}{2} & -\frac{3 \Delta \varphi^{2}}{2} \\
-\frac{3 \Delta \varphi^{2}}{2} & \frac{3 \Delta \varphi^{2}}{2}
\end{array}\right]+\frac{m}{{ }^{m} L}\left[\begin{array}{cc}
1 & -1 \\
-1 & 1
\end{array}\right]\right\}\left\{\begin{array}{l}
\Delta^{n} u_{1} \\
\Delta^{n} u_{2}
\end{array}\right\}+ \\
& \left\{\begin{array}{c}
-{ }^{m} N \\
{ }^{m} N
\end{array}\right\}={ }^{m+1} f_{E}
\end{aligned}
$$

ou, simplesmente,

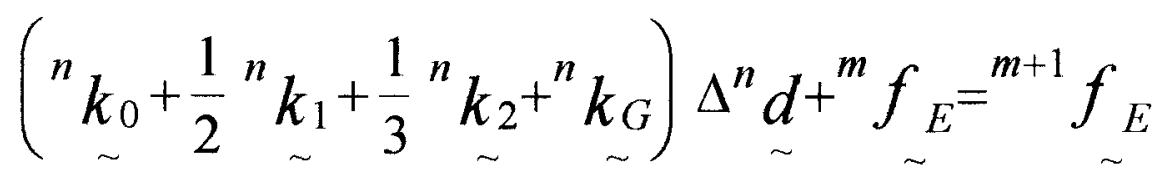

Finalmente, simplificando-se a equação anterior, obtém-se: 


$$
{ }^{n} k_{S} \Delta^{n} d=\Delta^{n} f_{E}
$$

onde " $\boldsymbol{k}_{S}$ " é a matriz de rigidez secante procurada, dada pela soma entre a matriz elástica " ${ }^{n} \boldsymbol{k}_{0}$, as matrizes incrementais " $k_{1}$ " e " $\boldsymbol{k}_{2}$ " e a matriz geométrica " $k_{G}$ ". A parcela " $\Delta^{n} f_{E}$ " é o incremento ou acréscimo do carregamento externo e a parcela " $\Delta^{n} d "$ é o acréscimo de deslocamentos que ocorre no elemento.

\subsubsection{3 - Matriz de rigidez tangente}

A matriz de rigidez tangente do elemento é obtida através da segunda derivação da energia de deformação em relação aos deslocamentos nodais, conforme equações $(4.55)$ e $(4.56)$.

Dessa forma, derivando-se novamente cada uma das derivadas obtidas no item anterior, obtém-se:

a - em relação a "Un":

$$
\begin{aligned}
& \frac{\partial^{2} U_{0}}{\partial \Delta^{n} u_{1} \partial \Delta^{n} u_{1}}=-\frac{\partial^{2} U_{0}}{\partial \Delta^{n} u_{1} \partial \Delta^{n} u_{2}}=-\frac{\partial^{2} U_{0}}{\partial \Delta^{n} u_{2} \partial \Delta^{n} u_{1}}= \\
& \frac{\partial^{2} U_{0}}{\partial \Delta^{n} u_{2} \partial \Delta^{n} u_{2}}=\frac{E A}{{ }^{m} L}
\end{aligned}
$$


b - em relação a " $U_{1}$ ":

$$
\begin{aligned}
& \frac{\partial^{2} U_{1}}{\partial \Delta^{n} u_{1} \partial \Delta^{n} u_{1}}=-\frac{\partial^{2} U_{1}}{\partial \Delta^{n} u_{1} \partial \Delta^{n} u_{2}}=-\frac{\partial^{2} U_{1}}{\partial \Delta^{n} u_{2} \partial \Delta^{n} u_{1}}= \\
& \frac{\partial^{2} U_{1}}{\partial \Delta^{n} u_{2} \partial \Delta^{n} u_{2}}=3 \Delta \varphi \frac{E A}{{ }^{m} L}
\end{aligned}
$$

c - em relação a "U $\mathrm{U}_{2}$ ":

$$
\begin{aligned}
& \frac{\partial^{2} U_{2}}{\partial \Delta^{n} u_{1} \partial \Delta^{n} u_{1}}=-\frac{\partial^{2} U_{2}}{\partial \Delta^{n} u_{1} \partial \Delta^{n} u_{2}}=-\frac{\partial^{2} U_{2}}{\partial \Delta^{n} u_{2} \partial \Delta^{n} u_{1}}= \\
& \frac{\partial^{2} U_{2}}{\partial \Delta^{n} u_{2} \partial \Delta^{n} u_{2}}=\frac{3}{2} \Delta \varphi^{2} \frac{E A}{{ }^{m} L}
\end{aligned}
$$

d - em relação a "U,":

$$
\frac{\partial^{2} U_{3}}{\partial \Delta^{n} u_{i} \partial \Delta^{n} u_{j}}=0
$$

e - em relação a " $U_{4}$ ":

$$
\begin{aligned}
& \frac{\partial^{2} U_{4}}{\partial \Delta^{n} u_{1} \partial \Delta^{n} u_{1}}=-\frac{\partial^{2} U_{4}}{\partial \Delta^{n} u_{1} \partial \Delta^{n} u_{2}}=-\frac{\partial^{2} U_{4}}{\partial \Delta^{n} u_{2} \partial \Delta^{n} u_{1}}= \\
& \frac{\partial^{2} U_{4}}{\partial \Delta^{n} u_{2} \partial \Delta^{n} u_{2}}=\frac{{ }^{m} N}{{ }^{m} L}
\end{aligned}
$$


Organizando-se as equações (4.84) a (4.88) na forma matricial, obtém-se:

$$
\begin{gathered}
{ }_{\sim}^{{ }_{k_{T}}}=\frac{E A}{{ }^{m} L}\left[\begin{array}{cc}
1 & -1 \\
-1 & 1
\end{array}\right]+\frac{E A}{{ }^{m} L}\left[\begin{array}{cc}
3 \Delta \varphi & -3 \Delta \varphi \\
-3 \Delta \varphi & 3 \Delta \varphi
\end{array}\right]+ \\
\frac{E A}{{ }^{m} L}\left[\begin{array}{cc}
\frac{3 \Delta \varphi^{2}}{2} & -\frac{3 \Delta \varphi^{2}}{2} \\
-\frac{3 \Delta \varphi^{2}}{2} & \frac{3 \Delta \varphi^{2}}{2}
\end{array}\right]+\frac{m}{m}\left[\begin{array}{cc}
1 & -1 \\
-1 & 1
\end{array}\right]
\end{gathered}
$$

ou, simplesmente,

$$
{ }^{n} k_{T}={ }^{n} k_{0}+{ }^{n} k_{1}+{ }^{n} k_{2}+{ }^{n} k_{G}
$$

Convém observar o formalismo entre " ${ }^{n} \boldsymbol{k}_{S}$ e $"{ }^{n} \boldsymbol{k}_{T} "$, cuja diferença reside nas frações numéricas que multiplicam " ${ }^{n} \boldsymbol{k}_{1}$ e " ${ }^{n} \boldsymbol{k}_{2}$ ".

\subsection{4 - Treliça plana}

\subsubsection{1 - Energia de deformação}

O campo de deformações para um elemento de treliça plana é dado pela equação (4.12). Já as funções de forma são dadas por (4.15), (4.16), (4.17) e (4.18). Derivando-se as equações $(4.15)$ e (4.17) em relação a " $x "$ ", tem-se: 


$$
\begin{aligned}
& u^{\prime}=\varphi=\frac{u_{2}-u_{1}}{L} \\
& v^{\prime}=\theta_{0}=\frac{v_{2}-v_{1}}{L}
\end{aligned}
$$

Substituindo-se tais derivadas na equação (4.12), obtém-se:

$$
\varepsilon_{x}=\left(\frac{u_{2}-u_{1}}{L}\right)+\frac{1}{2}\left(\frac{u_{2}-u_{1}}{L}\right)^{2}+\frac{1}{2}\left(\frac{v_{2}-v_{1}}{L}\right)^{2}
$$

Com isso, a variação do campo de deformações que ocorre durante o incremento " $n$ " é dada por:

$$
\Delta^{n} \varepsilon_{x}=\left(\frac{\Delta^{n} u_{2}-\Delta^{n} u_{1}}{{ }^{m} L}\right)+\frac{1}{2}\left(\frac{\Delta^{n} u_{2}-\Delta^{n} u_{1}}{{ }^{m} L}\right)^{2}+\frac{1}{2}\left(\frac{\Delta^{n} v_{2}-\Delta^{n} v_{1}}{{ }^{m} L}\right)^{2}
$$

Substituindo-se a equação (4.93) na equação (4.64), tem-se:

$$
\begin{aligned}
U_{e}= & \frac{1}{2} \int_{V_{e}} E\left(\Delta \varphi^{2}+\Delta \varphi^{3}+\frac{1}{4} \Delta \varphi^{4}+\Delta \varphi \Delta \theta_{0}^{2}+\frac{1}{2} \Delta \varphi^{2} \Delta \theta_{0}{ }^{2}+\right. \\
& \left.\frac{1}{4} \Delta \theta_{0}^{4}\right) d V_{e^{+}}{ }^{m} \varepsilon_{x} \int_{V_{e}} E\left(\Delta \varphi+\frac{1}{2} \Delta \varphi^{2}+\frac{1}{2} \Delta \theta_{0}{ }^{2}\right) d V_{e}
\end{aligned}
$$

onde " $\Delta \varphi$ " é dado pela equação (4.75) e " $\Delta \theta_{\circ}$ " por: 


$$
\Delta \theta_{0}=\frac{\Delta^{n} v_{2}-\Delta^{n} v_{1}}{{ }^{m} L}
$$

Analogamente ao item 4.4.3.1, obtém-se a equação que expressa a energia de deformação do elemento dada por:

$$
\begin{aligned}
U_{e}= & \frac{E A}{2}{ }^{m} L\left(\Delta \varphi^{2}+\Delta \varphi^{3}+\frac{1}{4} \Delta \varphi^{4}+\Delta \varphi \Delta \theta_{0}{ }^{2}+\frac{1}{2} \Delta \varphi^{2} \Delta \theta_{0}{ }^{2}+\right. \\
& \left.\frac{1}{4} \Delta \theta_{0}{ }^{4}\right)+{ }^{m} \mathrm{~N}^{m} L\left(\Delta \varphi+\frac{1}{2} \Delta \varphi^{2}+\frac{1}{2} \Delta \theta_{0}{ }^{2}\right)
\end{aligned}
$$

ou, simplesmente,

$$
U_{e}=\sum_{i=0}^{8} U_{i}
$$

onde cada uma das parcelas " $U_{i}$ " representam, respectivamente, os termos da equação (4.96).

\subsubsection{2 - Matriz de Rigidez Secante}

Analogamente ao item 4.4.3.2, derivando-se cada uma das parcelas " $U_{i}$ " descritas no item anterior em relação aos deslocamentos nodais, substituindo-se o resultado na equação (4.52) e organizando-se na forma matricial, obtém-se: 


$$
\begin{aligned}
& \left\{\frac{E A}{{ }^{m} L}\left[\begin{array}{cccc}
1 & 0 & -1 & 0 \\
0 & 0 & 0 & 0 \\
-1 & 0 & 1 & 0 \\
0 & 0 & 0 & 0
\end{array}\right]+\frac{1}{2} \frac{E A}{{ }^{m} L}\left[\begin{array}{cccc}
3 \Delta \varphi & 0 & -3 \Delta \varphi & 0 \\
0 & 0 & 0 & 0 \\
-3 \Delta \varphi & 0 & 3 \Delta \varphi & 0 \\
0 & 0 & 0 & 0
\end{array}\right]+\right. \\
& \frac{1}{3} \frac{E A}{{ }^{m} L}\left[\begin{array}{cccc}
\frac{3 \Delta \varphi^{2}}{2} & 0 & -\frac{3 \Delta \varphi^{2}}{2} & 0 \\
0 & 0 & 0 & 0 \\
-\frac{3 \Delta \varphi^{2}}{2} & 0 & \frac{3 \Delta \varphi^{2}}{2} & 0 \\
0 & 0 & 0 & 0
\end{array}\right]+\frac{1}{2} \frac{E A}{{ }^{m} L}\left[\begin{array}{cccc}
0 & \Delta \theta_{0} & 0 & -\Delta \theta_{0} \\
\Delta \theta_{0} & \Delta \varphi & -\Delta \theta_{0} & -\Delta \varphi \\
0 & -\Delta \theta_{0} & 0 & \Delta \theta_{0} \\
-\Delta \theta_{0} & -\Delta \varphi & \Delta \theta_{0} & \Delta \varphi
\end{array}\right]+ \\
& \frac{E A}{{ }^{m} L}\left[\begin{array}{cccc}
\frac{\Delta \theta_{0}^{2}}{4} & \frac{\Delta \varphi \Delta \theta_{0}}{4} & -\frac{\Delta \theta_{0}^{2}}{4} & -\frac{\Delta \varphi \Delta \theta_{0}}{4} \\
\frac{\Delta \varphi \Delta \theta_{0}}{4} & \frac{\Delta \varphi^{2}}{4} & -\frac{\Delta \varphi \Delta \theta_{0}}{4} & -\frac{\Delta \varphi^{2}}{4} \\
-\frac{\Delta \theta_{0}^{2}}{4} & -\frac{\Delta \varphi \Delta \theta_{0}}{4} & \frac{\Delta \theta_{0}^{2}}{4} & \frac{\Delta \varphi \Delta \theta_{0}}{4} \\
-\frac{\Delta \varphi \Delta \theta_{0}}{4} & -\frac{\Delta \varphi^{2}}{4} & \frac{\Delta \varphi \Delta \theta_{0}}{4} & \frac{\Delta \varphi^{2}}{4}
\end{array}\right]+ \\
& \frac{1}{3} \frac{E A}{{ }^{m} L}\left[\begin{array}{cccc}
0 & 0 & 0 & 0 \\
0 & \frac{3 \Delta \theta_{0}^{2}}{2} & 0 & -\frac{3 \Delta \theta_{0}^{2}}{2} \\
0 & 0 & 0 & 0 \\
0 & -\frac{3 \Delta \theta_{0}^{2}}{2} & 0 & \frac{3 \Delta \theta_{0}^{2}}{2}
\end{array}\right]+\frac{{ }^{m} N}{{ }^{m} L}\left[\begin{array}{cccc}
1 & 0 & -1 & 0 \\
0 & 0 & 0 & 0 \\
-1 & 0 & 1 & 0 \\
0 & 0 & 0 & 0
\end{array}\right]+
\end{aligned}
$$$$
\left.{ }^{m} N\left[\begin{array}{cccc}
{ }^{m} L & 0 & 0 & 0 \\
0 & 1 & 0 & -1 \\
0 & 0 & 0 & 0 \\
0 & -1 & 0 & 1
\end{array}\right]\right\}\left\{\begin{array}{c}
\Delta^{n} u_{1} \\
\Delta^{n} v_{1} \\
\Delta^{n} u_{2} \\
\Delta^{n} v_{2}
\end{array}\right\}+\left\{\begin{array}{c}
-{ }^{m} N \\
0 \\
{ }^{m} N \\
0
\end{array}\right\}={ }^{m+1} f_{E}
$$

Dessa forma, fica valendo a equação (4.83), onde:

$$
{ }^{n}{\underset{\sim}{S}}_{S}={ }^{n} k_{0}+\frac{1}{2}{ }^{n}{\underset{\sim}{k}}_{1}+\frac{1}{3}{ }^{n}{ }_{\sim}{ }_{\sim}+{ }^{n} k_{S N}+{ }^{n} k_{\sim}
$$




$$
\begin{aligned}
& { }^{n} k_{0}=\frac{E A}{m_{L}}\left[\begin{array}{cccc}
1 & 0 & -1 & 0 \\
0 & 0 & 0 & 0 \\
-1 & 0 & 1 & 0 \\
0 & 0 & 0 & 0
\end{array}\right] \\
& { }_{\sim}^{k_{1}}=\frac{E A}{{ }^{m} L}\left[\begin{array}{cccc}
3 \Delta \varphi & \Delta \theta_{0} & -3 \Delta \varphi & -\Delta \theta_{0} \\
\Delta \theta_{0} & \Delta \varphi & -\Delta \theta_{0} & -\Delta \varphi \\
-3 \Delta \varphi & -\Delta \theta_{0} & 3 \Delta \varphi & \Delta \theta_{0} \\
-\Delta \theta_{0} & -\Delta \varphi & \Delta \theta_{0} & \Delta \varphi
\end{array}\right] \\
& { }_{\sim}^{k}=\frac{E A}{m}\left[\begin{array}{cccc}
\frac{3 \Delta \varphi^{2}}{2} & 0 & -\frac{3 \Delta \varphi^{2}}{2} & 0 \\
0 & \frac{3 \Delta \theta_{0}^{2}}{2} & 0 & -\frac{3 \Delta \theta_{0}^{2}}{2} \\
-\frac{3 \Delta \varphi^{2}}{2} & 0 & \frac{3 \Delta \varphi^{2}}{2} & 0 \\
0 & -\frac{3 \Delta \theta_{0}^{2}}{2} & 0 & \frac{3 \Delta \theta_{0}^{2}}{2}
\end{array}\right] \\
& { }_{k S N}=\frac{E A}{m} L\left[\begin{array}{cccc}
\frac{\Delta \theta_{0}^{2}}{4} & \frac{\Delta \varphi \Delta \theta_{0}}{4} & -\frac{\Delta \theta_{0}^{2}}{4} & -\frac{\Delta \varphi \Delta \theta_{0}}{4} \\
\frac{\Delta \varphi \Delta \theta_{0}}{4} & \frac{\Delta \varphi^{2}}{4} & -\frac{\Delta \varphi \Delta \theta_{0}}{4} & -\frac{\Delta \varphi^{2}}{4} \\
-\frac{\Delta \theta_{0}^{2}}{4} & -\frac{\Delta \varphi \Delta \theta_{0}}{4} & \frac{\Delta \theta_{0}^{2}}{4} & \frac{\Delta \varphi \Delta \theta_{0}}{4} \\
-\frac{\Delta \varphi \Delta \theta_{0}}{4} & -\frac{\Delta \varphi^{2}}{4} & \frac{\Delta \varphi \Delta \theta_{0}}{4} & \frac{\Delta \varphi^{2}}{4}
\end{array}\right] \\
& { }_{\sim}^{n} \underset{k_{G}}{\sim}=\frac{{ }^{m} N}{m_{L}}\left[\begin{array}{cccc}
1 & 0 & -1 & 0 \\
0 & 1 & 0 & -1 \\
-1 & 0 & 1 & 0 \\
0 & -1 & 0 & 1
\end{array}\right]
\end{aligned}
$$




\subsubsection{3 - Matriz de rigidez tangente}

Analogamente ao item 4.4.3.3, derivando-se novamente cada uma das parcelas " $U_{i}$ " em relação aos deslocamentos nodais e organizando-se o resultado na forma matricial, obtém-se:

$$
{ }^{n} k_{T}={ }^{n} k_{0}{ }^{n} k_{1}{ }^{n} k_{2}+{ }^{n} k_{T N}{ }^{n} k_{G}
$$

sendo que $"{ }^{n} \boldsymbol{k}_{0} ", "{ }^{n} \boldsymbol{k}_{1} ",{ }^{n} \boldsymbol{k}_{2} "$ e ${ }^{n} \boldsymbol{k}_{G} "$ são as mesmas matrizes dadas em (4.100). Já a matriz " $\boldsymbol{k}_{T N} "$ é dada por:

$$
{ }^{n}{ }_{\sim}=\frac{E A}{{ }^{m} L}\left[\begin{array}{cccc}
\frac{\Delta \theta_{0}{ }^{2}}{2} & \Delta \varphi \Delta \theta_{0} & -\frac{\Delta \theta_{0}{ }^{2}}{2} & -\Delta \varphi \Delta \theta_{0} \\
\Delta \varphi \Delta \theta_{0} & \frac{\Delta \varphi^{2}}{2} & -\Delta \varphi \Delta \theta_{0} & -\frac{\Delta \varphi^{2}}{2} \\
-\frac{\Delta \theta_{0}^{2}}{2} & -\Delta \varphi \Delta \theta_{0} & \frac{\Delta \theta_{0}{ }^{2}}{2} & \Delta \varphi \Delta \theta_{0} \\
-\Delta \varphi \Delta \theta_{0} & -\frac{\Delta \varphi^{2}}{2} & \Delta \varphi \Delta \theta_{0} & \frac{\Delta \varphi^{2}}{2}
\end{array}\right]
$$

Cabe ressaltar que o formalismo entre " ${ }^{n} k_{S} "$ e $"{ }^{n} k_{T} "$ foi mantido, sendo que a diferença reside, agora, nas frações numéricas que multiplicam " ${ }^{n}{ }^{\prime}$ e " ${ }^{n}{ }_{2}$ " e nos coeficientes numéricos internos das matrizes " ${ }^{n} \boldsymbol{k}_{S N} " \mathrm{e}$ $"{ }^{n} \boldsymbol{k}_{T N} "$. 


\subsection{5 - Pórtico plano}

\subsubsection{1 - Energia de deformação}

O campo de deformações para um elemento de pórtico plano é dado pela equação (4.11). Tomando-se o valor médio para a parcela "[(V') $\left.{ }^{2}\right] / 2$ ", CORREA(1991), o campo de deformações fica dado por:

$$
\varepsilon_{x}=u^{\prime}+\frac{1}{L} \int_{0}^{L} \frac{v^{\prime 2}}{2} \mathrm{dx}-y v^{\prime \prime}+\frac{u^{\prime 2}}{2}-y u^{\prime} v^{\prime \prime}
$$

Já as funções de forma são dadas por (4.15), (4.16), (4.22) e (4.23). Derivando-se as equações (4.15) e (4.22) em relação a " $x$ ", tem-se:

$$
\begin{aligned}
& u^{\prime}=\varphi=\frac{u_{2}-u_{1}}{L} \\
& v^{\prime}=d+2 e x+3 f x^{2}
\end{aligned}
$$

$$
\ldots(4.104 a)
$$

e derivando-se novamente " $v$ ", tem-se:

$$
v^{\prime \prime}=2 e+6 f x
$$

onde "d", "e" e "f" são definidos em (4.23).

$$
\text { Substituindo-se tais derivadas na equação (4.103), }
$$
obtém-se: 


$$
\begin{aligned}
\varepsilon_{x}= & \varphi+\frac{1}{L} \int_{0}^{L} \frac{\left(d+2 e x+3 f x^{2}\right)^{2}}{2} \mathrm{dx}-y(2 e+6 f x)+ \\
& \frac{\varphi^{2}}{2}-y \varphi(2 e+6 f x)
\end{aligned}
$$

Com isso, a variação do campo de deformações que ocorre durante o incremento "n" é dada por:

$$
\begin{aligned}
\Delta^{n} \varepsilon_{x}= & \Delta \varphi+\frac{1}{m_{L}} \int_{0}^{m} \frac{\left(\Delta d+2 \Delta e x+3 \Delta f x^{2}\right)^{2}}{2} \mathrm{dx}+ \\
& (-y)(2 \Delta e+6 \Delta f x)+\frac{\Delta \varphi^{2}}{2}-y \Delta \varphi(2 \Delta e+6 \Delta f x)
\end{aligned}
$$

onde " $\Delta \varphi$ " e " $\Delta \theta_{0}$ " são dados, respectivamente, pelas equações $(4.75)$ e (4.95). Já os demais parâmetros são dados por:

$$
\begin{aligned}
& \Delta d=\Delta^{n} \theta_{1} \\
& \Delta e=\frac{-2 \Delta^{n} \theta_{1}-\Delta^{n} \theta_{2}+3 \Delta \theta_{0}}{{ }^{m} L} \\
& \Delta f=\frac{\Delta^{n} \theta_{1}+\Delta^{n} \theta_{2}-2 \Delta \theta_{0}}{m} L^{2}
\end{aligned}
$$

Substituindo-se a equação (4.106) na equação (4.64) e de forma análoga ao item 4.4.4.1, obtém-se: 


$$
U_{e}=\sum_{i=1}^{20} U_{i}
$$

onde cada uma das parcelas " $U_{i}$ " são dadas por:

$$
\begin{aligned}
& U_{1}=\frac{1}{2} \int_{V_{e}} E(\Delta \varphi)^{2} d V_{e} \\
& U_{2}=\frac{1}{2} \int_{V_{e}} E[y(2 \Delta e+6 \Delta f x)]^{2} d V_{e} \\
& U_{3}=\frac{1}{2} \int_{V_{e}} E 2 \Delta \varphi\left[\frac{1}{m_{L}} \int_{0}^{m} L \frac{\left(\Delta d+2 \Delta e x+3 \Delta f x^{2}\right)^{2}}{2} d x\right] d V_{e}
\end{aligned}
$$$$
U_{4}=\frac{1}{2} \int_{V_{e}} E\left[\frac{1}{m_{L}} \int_{0}^{m} L \frac{\left(\Delta d+2 \Delta e x+3 \Delta f x^{2}\right)^{2}}{2} d x\right]^{2} d V_{e}
$$

$U_{5}=\frac{1}{2} \int_{V_{e}} E\left[-2 y \Delta \varphi(2 \Delta e+6 \Delta x x) d V_{e}\right.$

$U_{6}=\frac{1}{2} \int_{V_{e}} E[-2 y(2 \Delta e+6 \Delta x)]\left[\frac{1}{m_{L}} \int_{0}^{m_{L}} \frac{\left(\Delta d+2 \Delta e x+3 \Delta x^{2}\right)^{2}}{2} d x\right] d V_{e}$

$U_{7}=\frac{1}{2} \int_{V_{e}} E(\Delta \varphi)^{3} d V_{e}$

$U_{8}=\frac{1}{2} \int_{V_{e}} E \frac{(\Delta \varphi)^{4}}{4} d V_{e}$

$U_{9}=\frac{1}{2} \int_{V_{e}} E(\Delta \varphi)^{2}\left[\frac{1}{m_{L}} \int_{0}^{m_{L}} \frac{\left(\Delta d+2 \Delta e x+3 \Delta y x^{2}\right)^{2}}{2} d x\right] d V_{e}$ 


$$
\begin{aligned}
& U_{10}=\frac{1}{2} \int_{V_{e}} E\left[-(\Delta \varphi)^{2} y(2 \Delta e+6 \Delta x x)\right] d V_{e} \\
& U_{11}=\frac{1}{2} \int_{V_{e}} E \Delta \varphi[-(\Delta \varphi) y(2 \Delta e+6 \Delta x x)] d V_{e} \\
& U_{12}=\frac{1}{2} \int_{V_{e}} E[-y \Delta \varphi(2 \Delta e+6 \Delta x x)]\left[\frac{1}{m_{L}} \int_{0}^{m_{L}} \frac{\left(\Delta d+2 \Delta e x+3 \Delta x^{2}\right)^{2}}{2} d x\right] d V_{e} \\
& U_{13}=\frac{1}{2} \int_{V_{e}} E \frac{(\Delta \phi)^{2}}{2}[-y \Delta \varphi(2 \Delta e+6 \Delta x x)] d V_{e} \\
& U_{14}=\frac{1}{2} \int_{V_{e}} E[-y(2 \Delta e+6 \Delta x)][-y \Delta \varphi(2 \Delta e+6 \Delta x x)] d V_{e} \\
& U_{15}=\frac{1}{2} \int_{V_{e}} E[-y \Delta \varphi(2 \Delta e+6 \Delta x x)]^{2} d V_{e} \\
& U_{16}={ }^{m} \varepsilon_{x} \int_{V_{e}} E \Delta \varphi d V_{e} \\
& U_{17}={ }^{m} \varepsilon_{x} \int_{V_{e}} E\left[\frac{1}{{ }^{m} L} \int_{0}^{m_{L}} L \frac{\left(\Delta d+2 \Delta e x+3 \Delta f x^{2}\right)^{2}}{2} d x\right] d V_{e} \\
& U_{18}={ }^{m} \varepsilon_{x} \int_{V_{e}} E[-y(2 \Delta e+6 \Delta f x)] d V_{e} \\
& U_{19}={ }^{m} \varepsilon_{x} \int_{V_{e}} E \frac{(\Delta \varphi)^{2}}{2} d V_{e} \\
& U_{20}={ }^{m} \varepsilon_{x} \int_{V_{e}} E[-y \Delta \varphi(2 \Delta e+6 \Delta f x)] d V_{e}
\end{aligned}
$$




\subsubsection{2 - Matriz de rigidez secante}

Analogamente ao item 4.4.4.2, derivando-se cada uma das parcelas " $U_{i}$ " descritas no item anterior em relação aos deslocamentos nodais, após a integração das mesmas, substituindo-se o resultado na equação (4.52) e organizando-se na forma matricial, a matriz de rigidez secante fica determinada por:

$$
{ }^{n} k_{S}={ }^{n} k_{0}+\frac{1}{2}{ }^{n} k_{\sim}+\frac{1}{3}{ }^{n}{\underset{\sim}{2}}+{ }^{n} k_{S N}+{ }^{n} k_{S F}+{ }_{\sim}^{n} k_{\sim}
$$

onde

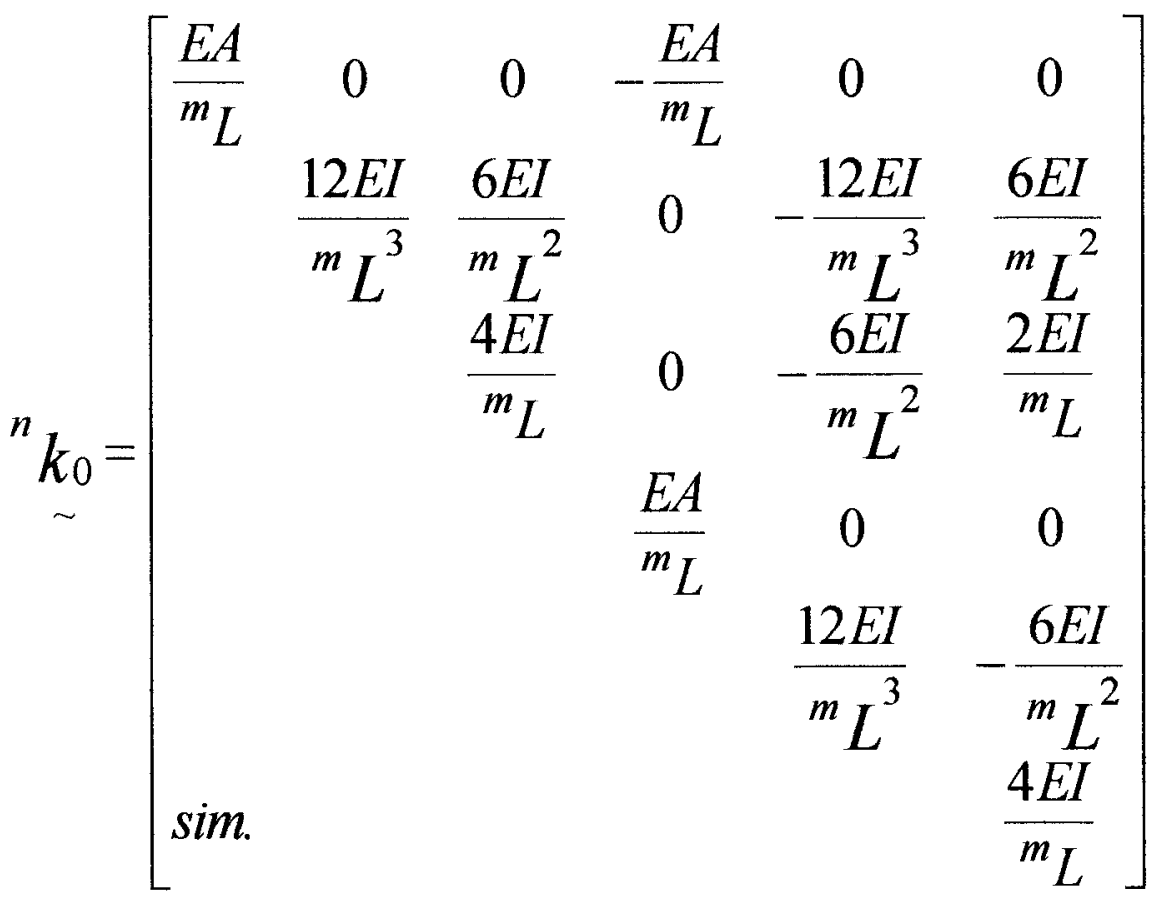




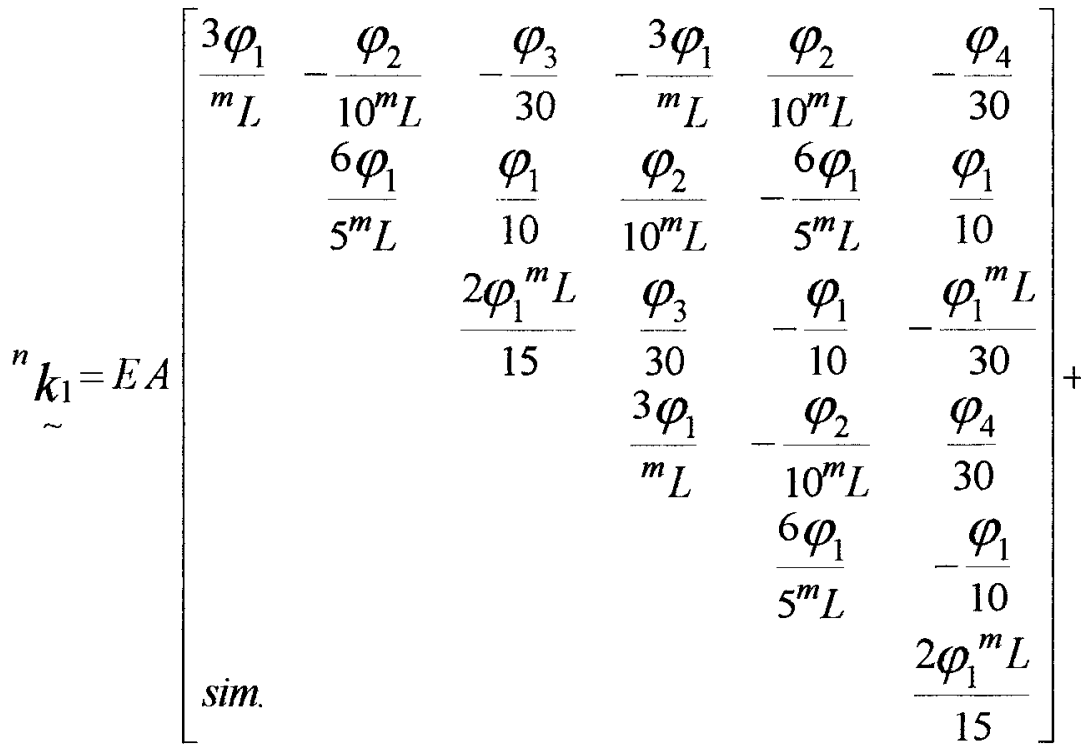

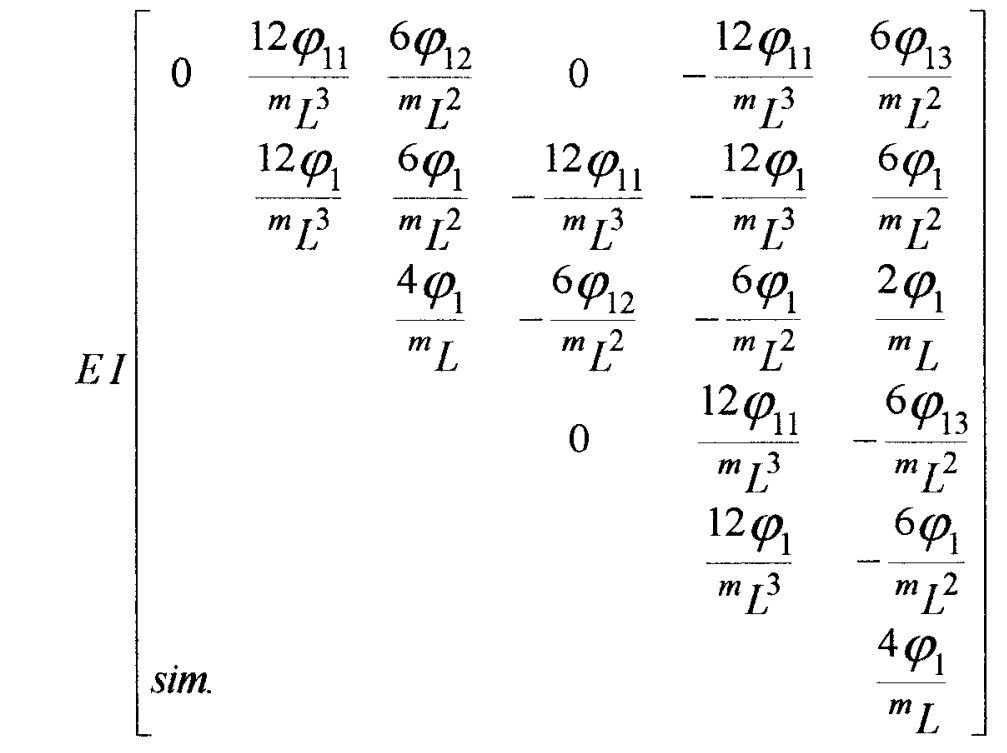

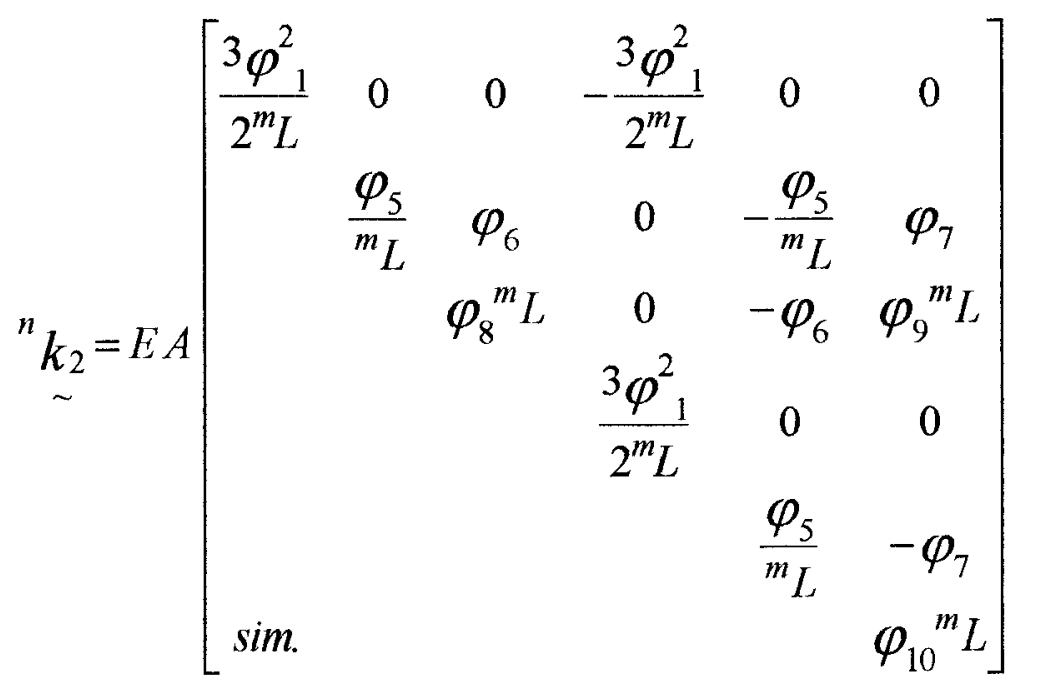




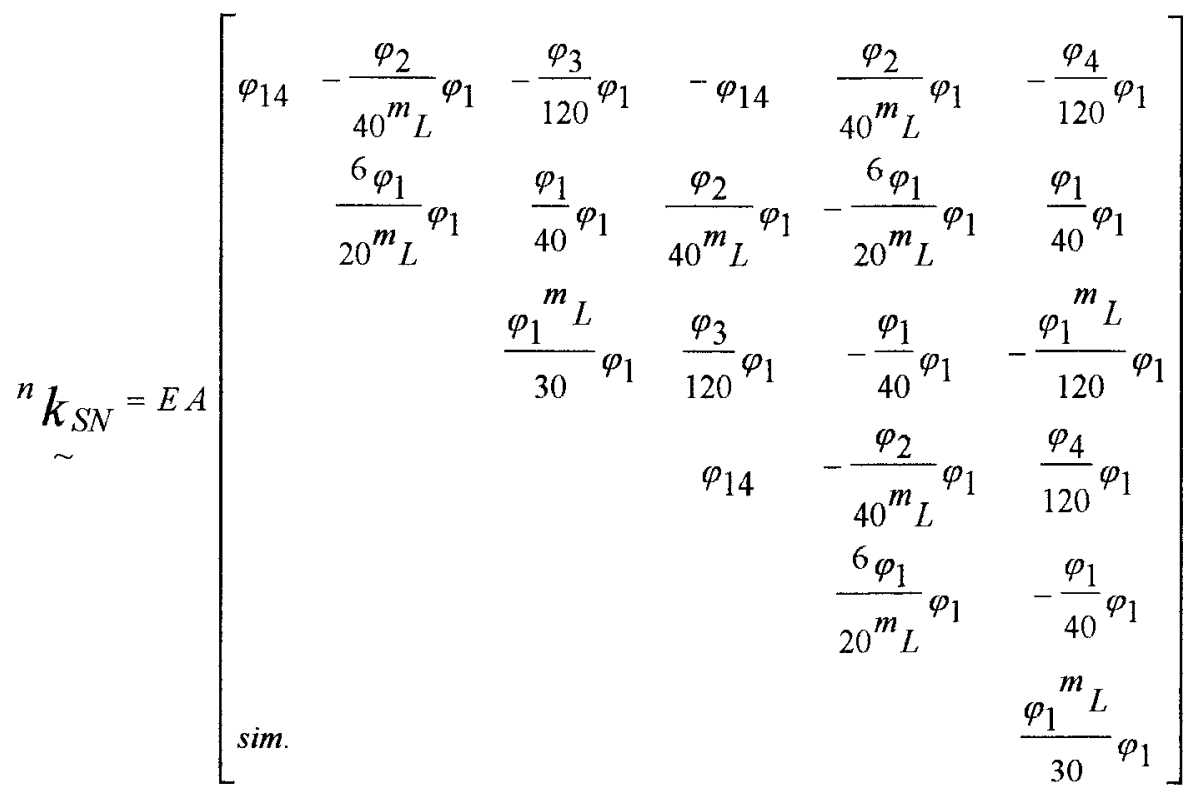

${ }_{k \underset{S F}{ }=\frac{E I}{2}}^{n}\left[\begin{array}{cccccc}\frac{12 \varphi_{15}}{{ }^{m} L^{3}} & \frac{12 \varphi_{1} \varphi_{11}}{{ }^{3} L^{3}} & \frac{6 \varphi_{1} \varphi_{12}}{{ }^{m} L^{2}} & -\frac{12 \varphi_{15}}{m^{3}} & -\frac{12 \varphi_{1} \varphi_{11}}{{ }^{m} L^{3}} & \frac{6 \varphi_{1} \varphi_{13}}{{ }^{m} L^{2}} \\ & \frac{12 \varphi_{1}^{2}}{{ }^{m} L^{3}} & \frac{6 \varphi_{1}^{2}}{{ }^{m} L^{2}} & -\frac{12 \varphi_{1} \varphi_{11}}{{ }^{3} L^{3}} & -\frac{12 \varphi_{1}^{2}}{{ }^{m} L^{3}} & \frac{6 \varphi_{1}^{2}}{{ }^{m} L^{2}} \\ & & \frac{4 \varphi_{1}^{2}}{{ }^{m} L} & -\frac{6 \varphi_{1} \varphi_{12}}{{ }^{m} L^{2}} & -\frac{6 \varphi_{1}^{2}}{{ }^{m} L^{2}} & \frac{2 \varphi_{1}^{2}}{{ }^{m} L} \\ & & & \frac{12 \varphi_{15}}{{ }^{m} L^{3}} & -\frac{12 \varphi_{1} \varphi_{11}}{m} L^{3} & -\frac{6 \varphi_{1} \varphi_{13}}{{ }^{m} L^{2}} \\ & & & & \frac{12 \varphi_{1}^{2}}{{ }^{m} L^{3}} & -\frac{6 \varphi_{1}^{2}}{{ }^{m} L^{2}} \\ & & & & & \frac{4 \varphi_{1}^{2}}{{ }^{2} L}\end{array}\right]$

$$
{ }_{k_{G}}^{n}={ }^{m} N\left[\begin{array}{cccccc}
\frac{1}{{ }^{m} L} & 0 & 0 & -\frac{1}{{ }^{m} L} & 0 & 0 \\
& \frac{6}{5^{m} L} & \frac{1}{10} & 0 & -\frac{6}{5^{m} L} & \frac{1}{10} \\
& & \frac{2^{m} L}{15} & 0 & -\frac{1}{10} & -\frac{{ }^{m} L}{30} \\
& & & \frac{1}{{ }^{m} L} & 0 & 0 \\
& & & & \frac{6}{5^{m} L} & -\frac{1}{10} \\
\text { sim. } & & & & & \frac{2^{m} L}{15}
\end{array}\right]
$$




$$
\begin{aligned}
& \varphi_{1}=\Delta \varphi \\
& \varphi_{2}=\Delta^{n} \theta_{1}+\Delta^{n} \theta_{2}-12 \Delta \theta_{0} \\
& \varphi_{3}=4 \Delta^{n} \theta_{1}-\Delta^{n} \theta_{2}-3 \Delta \theta_{0} \\
& \varphi_{4}=-\Delta^{n} \theta_{1}+4 \Delta^{n} \theta_{2}-3 \Delta \theta_{0} \\
& \varphi_{5}=\frac{1}{100}\left(9 \Delta^{n} \theta_{1}{ }^{2}+9 \Delta^{n} \theta_{2}{ }^{2}-2 \Delta^{n} \theta_{1} \Delta^{n} \theta_{2}-36 \Delta^{n} \theta_{1} \Delta \theta_{0}-36 \Delta^{n} \theta_{2} \Delta \theta_{0}+216 \Delta \theta_{0}{ }^{2}\right) \\
& \varphi_{6}=\frac{1}{300}\left(6 \Delta^{n} \theta_{1}{ }^{2}+\Delta^{n} \theta_{2}{ }^{2}+2 \Delta^{n} \theta_{1} \Delta^{n} \theta_{2}-54 \Delta^{n} \theta_{1} \Delta \theta_{0}+6 \Delta^{n} \theta_{2} \Delta \theta_{0}+54 \Delta \theta_{0}{ }^{2}\right) \\
& \varphi_{7}=\frac{1}{300}\left(\Delta^{n} \theta_{1}^{2}+6 \Delta^{n} \theta_{2}{ }^{2}+2 \Delta^{n} \theta_{1} \Delta^{n} \theta_{2}+6 \Delta^{n} \theta_{1} \Delta \theta_{0}-54 \Delta^{n} \theta_{2} \Delta \theta_{0}+54 \Delta \theta_{0}{ }^{2}\right) \\
& \varphi_{8}=\frac{1}{300}\left(8 \Delta^{n} \theta_{1}^{2}+3 \Delta^{n} \theta_{2}{ }^{2}-4 \Delta^{n} \theta_{1} \Delta^{n} \theta_{2}-12 \Delta^{n} \theta_{1} \Delta \theta_{0}-2 \Delta^{n} \theta_{2} \Delta \theta_{0}+27 \Delta \theta_{0}{ }^{2}\right) \\
& \varphi_{9}=\frac{1}{300}\left(-2 \Delta^{n} \theta_{1}^{2}-2 \Delta^{n} \theta_{2}^{2}+6 \Delta^{n} \theta_{1} \Delta^{n} \theta_{2}-2 \Delta^{n} \theta_{1} \Delta \theta_{0}-2 \Delta^{n} \theta_{2} \Delta \theta_{0}-3 \Delta \theta_{0}{ }^{2}\right) \\
& \varphi_{10}=\frac{1}{300}\left(3 \Delta^{n} \theta_{1}{ }^{2}+8 \Delta^{n} \theta_{2}{ }^{2}-4 \Delta^{n} \theta_{1} \Delta^{n} \theta_{2}-2 \Delta^{n} \theta_{1} \Delta \theta_{0}-12 \Delta^{n} \theta_{2} \Delta \theta_{0}+27 \Delta \theta_{0}{ }^{2}\right) \\
& \varphi_{11}=-\frac{\Delta^{n} \theta_{1}}{2}-\frac{\Delta^{n} \theta_{2}}{2}+\Delta \theta_{0} \\
& \varphi_{12}=-\frac{2 \Delta^{n} \theta_{1}}{3}-\frac{\Delta^{n} \theta_{2}}{3}+\Delta \theta_{0} \\
& \varphi_{13}=-\frac{\Delta^{n} \theta_{1}}{3}-\frac{2 \Delta^{n} \theta_{2}}{3}+\Delta \theta_{0} \\
& \varphi_{14}=\frac{\varphi_{3}}{120^{m} L} \Delta^{n} \theta_{1}+\frac{\varphi_{4}}{120^{m} L} \Delta^{n} \theta_{2}-\frac{\varphi_{2}}{40^{m} L} \Delta \theta_{0} \\
& \varphi_{15}=-\frac{\varphi_{12}}{2} \Delta^{n} \theta_{1}-\frac{\varphi_{13}}{2} \Delta^{n} \theta_{2}+\varphi_{11} \Delta \theta_{0}
\end{aligned}
$$

Cabe ressaltar que as deduções relativas aos termos

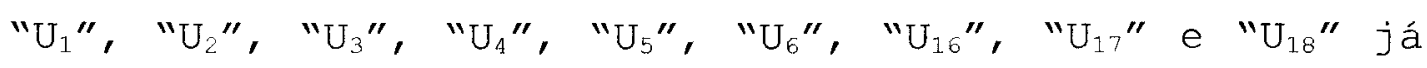
foram mostradas por CORREA(1991) de forma minuciosa.

\subsubsection{3 - Matriz de rigidez tangente}

Analogamente ao item 4.4.4.3, a matriz de rigidez tangente é dada por: 


$$
{ }^{n} k_{T}={ }^{n} k_{0}+{ }_{\sim}^{n} k_{1}+{ }^{n} k_{2}+{ }^{n} k_{T N}+{ }^{n} k_{T F}+{ }^{n} k_{G}
$$

sendo que " ${ }^{n} k_{0} ", \quad "{ }^{n} k_{1} ", \quad "{ }^{n} k_{2} "$ e $"{ }^{n} k_{G} "$ são as mesmas matrizes dadas em (4.111). Já as matrizes " $k_{T N} "$ e "n $k_{T F} "$ são dadas por:

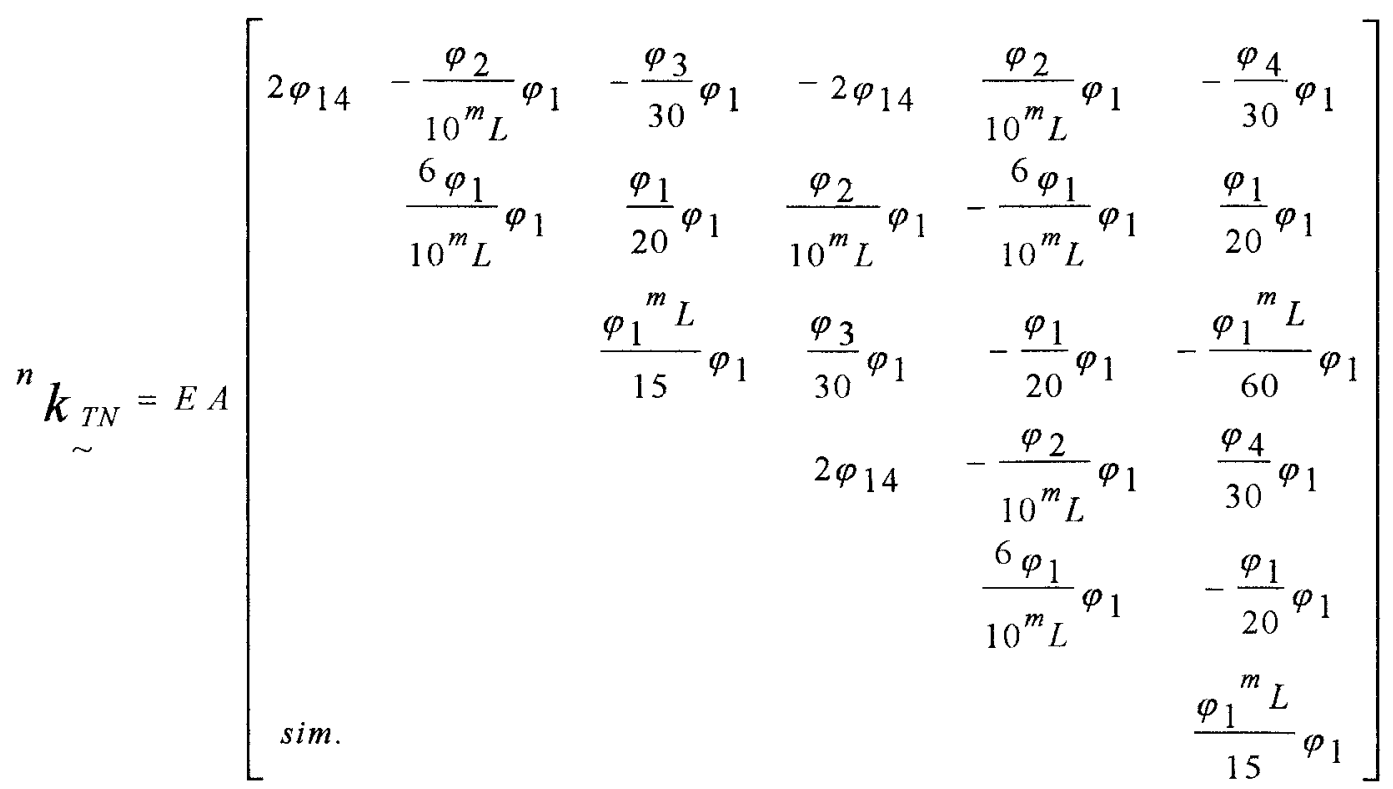

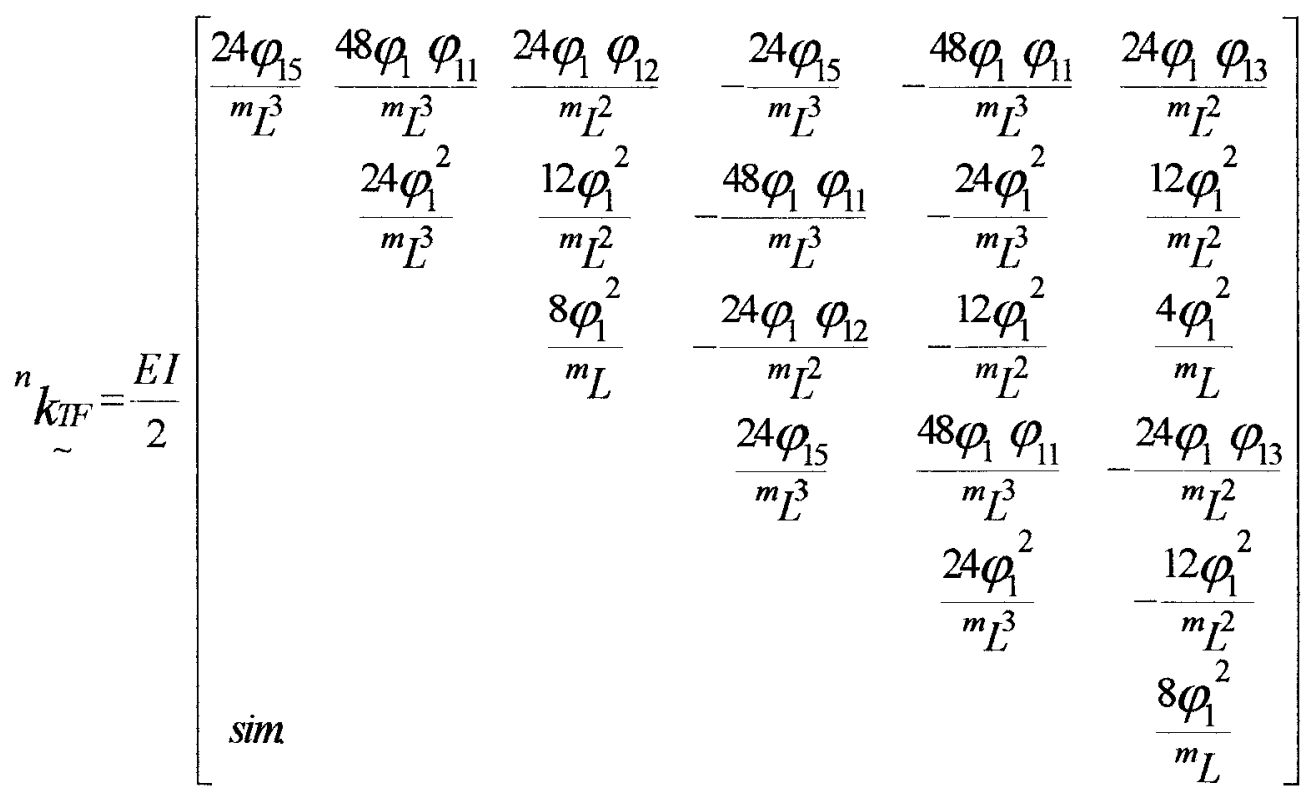


Da mesma forma, o formalismo entre " ${ }^{n} k_{S} "$ e $"{ }^{n} k_{T} "$ foi mantido, sendo que a diferença reside, agora, nas frações numéricas que multiplicam " ${ }^{n} k_{1} "$ e ${ }^{n} k_{2}$ " e nos coeficientes numéricos internos das matrizes " $k_{S N}$ ", $"{ }^{n} k_{S F} ", "{ }^{n} k_{T N} "$ e ${ }^{n n} k_{T F} "$.

\subsection{6 - Atualização das matrizes de rigidez}

Conforme visto nos itens anteriores, as matrizes de rigidez secante e tangente são definidas pela somatória entre várias matrizes, sendo que algumas dessas são dependentes dos deslocamentos nodais que ocorrem durante as iterações. Assim sendo, se faz necessário a atualização de tais matrizes durante a aplicação de cada incremento, conforme mostram os itens subsequientes.

\subsubsection{1 - Treliça plana}

A figura 4.9 ilustra o procedimento de atualização da matriz de rigidez tangente para uma estrutura formada por um elemento de treliça plana.

Neste procedimento a soma entre as matrizes de rigidez elástica " $k_{0} "$ e geométrica " ${ }^{n} k_{G} "$ permanece constante durante todas as iterações necessárias para a obtenção do equilíbrio, visto que as mesmas só dependem de parâmetros relativos à configuração de equilíbrio anterior. Já as matrizes de rigidez incrementais " $\boldsymbol{k}_{\mathbf{1}}$ ", 
$"{ }^{n} \boldsymbol{k}_{2} "$ e " ${ }^{n} \boldsymbol{k}_{T N} "$ são atualizadas a cada iteração pelos acréscimos de deslocamentos que ocorrem durante a aplicação do incremento de tempo ou carregamento. Cabe ressaltar que este procedimento também é válido para o cálculo da matriz de rigidez secante.

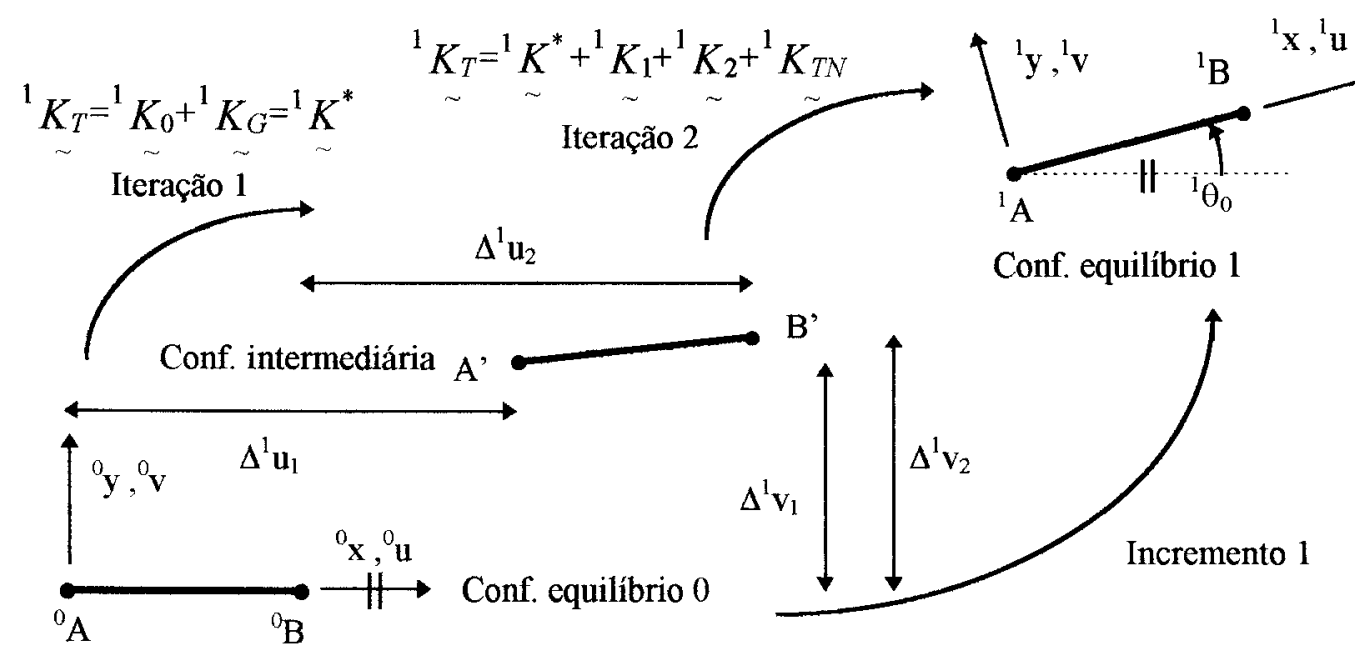

FIGURA 4.9 - Atualização da matriz de rigidez tangente para treliça plana.

\subsubsection{2 - Pórtico plano}

A figura 4.10 ilustra o procedimento de atualização da matriz de rigidez tangente para uma estrutura formada por um elemento de pórtico plano.

De forma análoga ao item anterior, a soma entre $"{ }^{n} k_{0} "$ e $"{ }^{n} k_{G} "$ permanece constante, enquanto que as matrizes incrementais $"{ }^{n} \boldsymbol{k}_{1} ", "{ }^{n} \boldsymbol{k}_{2} ", "{ }^{n} \boldsymbol{k}_{T N} "$ e $"{ }^{n} \boldsymbol{k}_{T F} "$ são atualizadas pelos acréscimos de deslocamentos nodais de cada elemento. 


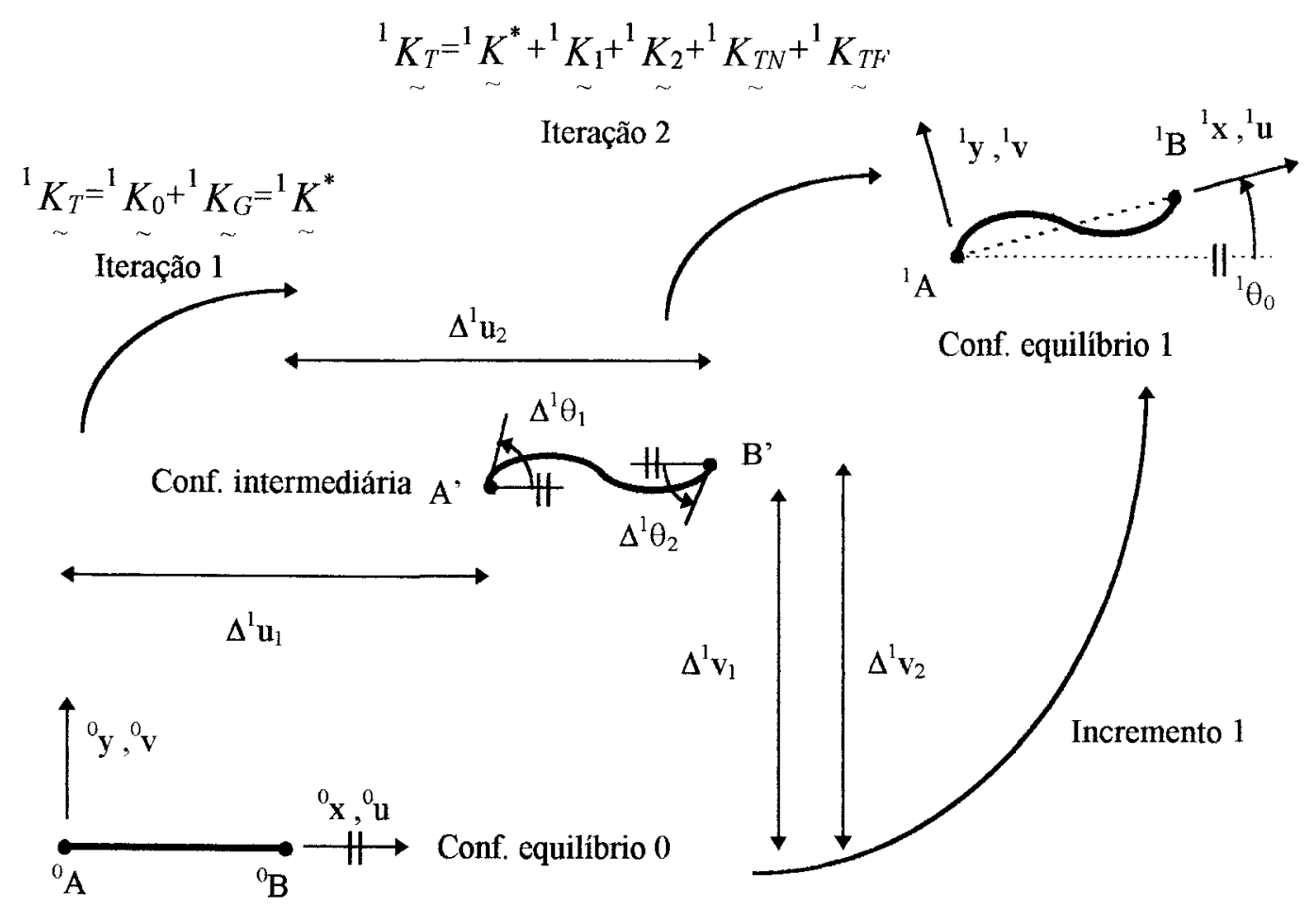

FIGURA 4.10 - Atualização da matriz de rigidez tangente para pórtico plano.

\subsection{7 - Aspectos computacionais}

Antes de se aplicar o processo de expansão e acumulação em cada matriz de rigidez do elemento, secante ou tangente, para a obtenção da matriz de rigidez da estrutura, se faz necessário rotacionar as matrizes elementais em função da posição original do elemento na estrutura, através da utilização da seguinte equação:

$$
{ }^{n} k_{S, T}{ }^{*}=r^{T}{ }^{n} k_{S, T} r
$$


onde " $r$ " é a matriz que contém os co-senos diretores de cada elemento.

Para treliças planas, tal matriz é dada por:

$$
r=\left[\begin{array}{cccc}
\cos \alpha & \cos \beta & 0 & 0 \\
-\cos \beta & \cos \alpha & 0 & 0 \\
0 & 0 & \cos \alpha & \cos \beta \\
0 & 0 & -\cos \beta & \cos \alpha
\end{array}\right]
$$

onde " $\alpha$ " é o ângulo formado entre o eixo local " $x$ " e o eixo global " $\mathrm{X}$ " e " $\beta$ " é o complemento de " $\alpha$ ".

Já para pórticos planos, tem-se:

$$
\sim \sim\left[\begin{array}{cccccc}
\cos \alpha & \cos \beta & 0 & 0 & 0 & 0 \\
-\cos \beta & \cos \alpha & 0 & 0 & 0 & 0 \\
0 & 0 & 1 & 0 & 0 & 0 \\
0 & 0 & 0 & \cos \alpha & \cos \beta & 0 \\
0 & 0 & 0 & -\cos \beta & \cos \alpha & 0 \\
0 & 0 & 0 & 0 & 0 & 1
\end{array}\right]
$$

\section{5 - Matriz de massas}

A matriz de massas global de um sistema estrutural discreto é obtida através da contribuição de todas as matrizes de massas dos elementos finitos que compõem tal sistema, sendo a matriz elemental dada pela equação (2.34). 
A principio, para uma análise dinâmica não-linear deve-se considerar as parcelas lineares e não-lineares para a obtenção da matriz elemental, conforme mostra BRASIL(1990). Entretanto, BRASIL et al. (1992) concluem que é desnecessário a consideração de coeficientes nãolineares para a obtenção das matrizes elementais de massas e amortecimento, ficando tais termos restritos à obtenção das matrizes de rigidez secante e tangente.

Assim sendo, a obtenção da matriz de massas fica bastante simplificada, conforme mostra os itens subseqüentes.

\subsection{1 - Treliça plana}

A matriz " $\phi$ " que contém as funções de forma para um elemento de treliça plana é dada pela equação (4.19). Admitindo-se que o elemento seja composto por um material homogêneo, com densidade específica " $\rho$ " constante, basta substituir a matriz " $\phi$ " na equação (2.34) e promover a integração para obter-se a matriz elemental de massas para o elemento em questão. Dessa forma, obtém-se:

$$
\underset{\sim}{m}=\frac{\rho A L}{6}\left[\begin{array}{cc}
2 I_{2} & I_{2} \\
\sim & \sim \\
I_{2} & 2 I_{2}
\end{array}\right]
$$

onde " $I_{2}$ " é a matriz identidade de ordem dois. 


\subsection{2 - Pórtico plano}

A matriz elemental de massas para um elemento de pórtico plano também é obtida através da integração da equação (2.34), sendo a matriz " $\phi$ " dada pela equação (4.24), lembrando-se que as funções de forma do elemento são relativas ao seu eixo longitudinal.

Considerando-se, então, a deformação longitudinal devida à flexão do elemento, utiliza-se a equação completa do campo de deslocamentos, dada pela equação (4.5). Assim sendo, a matriz " $\phi$ " fica definida por:

$$
\begin{aligned}
& \underset{\sim}{\sim}=\left[\begin{array}{cccccc}
1-\frac{x}{L} & 0 & 0 & \frac{x}{L} & 0 & 0 \\
0 & \left(1-\frac{3 x^{2}}{L^{2}}+\frac{2 x^{3}}{L^{3}}\right) & \left(\frac{x}{L}-\frac{2 x^{2}}{L^{2}}+\frac{x^{3}}{L^{3}}\right) & 0 & \left(\frac{3 x^{2}}{L^{2}}-\frac{2 x^{3}}{L^{3}}\right) & \left(-\frac{x^{2}}{L^{2}}+\frac{x^{3}}{L^{3}}\right)
\end{array}\right]+
\end{aligned}
$$

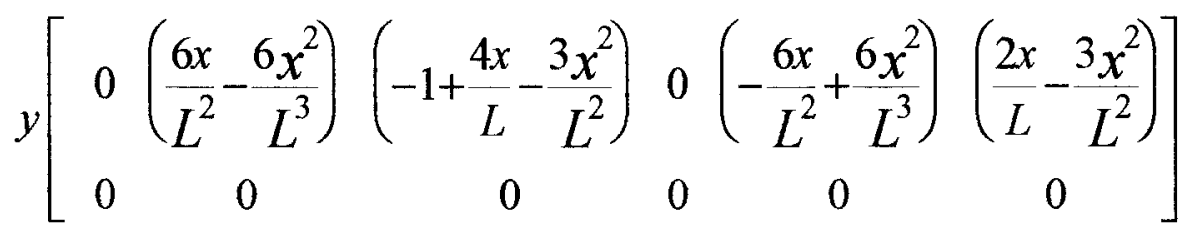

Substituindo-se a equação (4.119) na equação (2.34) e promovendo-se a integração analitica, obtém-se a matriz elemental de massas para o elemento de pórtico plano dada pela equação (4.120).

com relação à matriz elemental " $m$ ", a mesma é chamada de matriz de massas consistente, VENANCIO FILHO(1975), sendo que a segunda parcela da matriz dada pela equação (4.120) representa os efeitos da inércia rotacional, ARGYRIS et al. (1991). 


$$
\begin{gathered}
\underset{\sim}{m}=\frac{\rho A L}{420}\left[\begin{array}{cccccc}
140 & 0 & 0 & 70 & 0 & 0 \\
& 156 & 22 L & 0 & 54 & -13 L \\
& & 4 L^{2} & 0 & 13 L & -3 L^{2} \\
& & & 140 & 0 & 0 \\
& & & & 156 & -22 L \\
\operatorname{sim} . & & & & & 4 L^{2}
\end{array}\right]+ \\
\frac{\rho I}{30 L}\left[\begin{array}{cccccc}
0 & 0 & 0 & 0 & 0 & 0 \\
& 36 & 3 L & 0 & -36 & 3 L \\
& & 4 L^{2} & 0 & -3 L & -L^{2} \\
& & & 0 & 0 & 0 \\
\operatorname{sim} . & & & & 36 & -3 L \\
& & & & & 4 L^{2}
\end{array}\right]
\end{gathered}
$$

$(4.120)$

\subsection{3 - Massas concentradas}

$\mathrm{Na}$ existência de massas concentradas que possam gerar qualquer tipo de perturbação na estrutura, tais como as provenientes de maquinário industrial, as mesmas devem ser introduzidas na matriz de massas global da estrutura.

Neste trabalho, consideram-se apenas as massas concentradas que possuam deslocabilidade nas direções globais "X" e "Y", desconsiderando-se, portanto, o efeito rotacional das mesmas. Dessa forma, cada massa concentrada deve estar associada à um nó estrutural qualquer, possibilitando a sua soma aos termos da diagonal principal da matriz de massas global, sendo esta proveniente da superposição de todos os elementos, respeitando-se o grau de liberdade correspondente. 
Cabe ressaltar que tal procedimento é válido para a análise de treliças planas e pórticos planos.

\subsection{4 - Aspectos computacionais}

Analogamente ao item 4.4 .7 deste trabalho, se faz necessário rotacionar as matrizes de massas elementais " $\boldsymbol{m}$ " em função da posição original do elemento na estrutura, conforme mostra a seguinte equação:

$$
m_{\sim}^{*}=r_{\sim}^{T} m \underset{\sim}{r}
$$

onde a matriz " $r$ " é dada pelas expressões (4.116) e (4.117), respectivamente para treliças planas e pórticos planos.

Fato curioso ocorre na análise de treliças planas pois o produto matricial dado por (4.121) não altera a matriz original " $m$ ", com isso, tem-se que $\boldsymbol{m}^{*}=\boldsymbol{m}$ para qualquer matriz " $r$ ". Já o mesmo não ocorre no caso da análise de pórticos planos.

Com a obtenção das matrizes de massas elementais já rotacionadas, monta-se a matriz de massas global no inicio da análise através do processo de expansão e acumulação, sendo que a mesma deverá permanecer constante ao longo de todo o processo de integração numérica. Isto é possível em virtude da matriz " $m$ " não depender dos deslocamentos que ocorrerem na estrutura e pelo fato de que a matriz " $m$ " não se altera de modo 
significativo ao longo do processo de integração, no caso da análise de pórticos planos.

Cabe ressaltar que este procedimento pode ser mantido na presença de grandes deslocamentos e grandes deformações, conforme afirma ARGYRIS et al. (1991) .

\section{6 - Matriz de amortecimento}

Em principio, a matriz de amortecimento elemental " $c$ " pode ser obtida de forma análoga à matriz de massas elemental " $m$ ", visto que a única diferença existente entre as equações (2.34) e (2.35) reside nos parâmetros que multiplicam o produto entre as funções de forma de cada elemento. O grande obstáculo está relacionado com a determinação da magnitude do parâmetro de amortecimento viscoso " $\mu$ " do material, HALLAN et al. (1978), sem o qual a matriz " $c$ " fica indeterminada.

Para contornar tal problemática, utiliza-se o método de amortecimento modal, também conhecido como amortecimento Rayleigh, onde o amortecimento viscoso é introduzido por meio de frações específicas do amortecimento crítico, conforme será visto a seguir.

\subsection{1 - Freqüências naturais de vibração}

Dado um sistema estrutural com comportamento linear, livre de carregamentos externos dependentes do tempo e desprovido de qualquer tipo de mecanismo de amortecimento, pode-se particularizar a equação (2.38) que rege o comportamento dinâmico estrutural da seguinte forma: 


$$
\underset{\sim}{M} \underset{\sim}{\stackrel{\bullet}{\mathrm{D}}}+K_{\sim} \underset{\sim}{\mathrm{D}}=\underset{\sim}{0}
$$

onde " 0 " é o vetor nulo.

A solução analítica da equação (4.122) é dada por:

$$
\underset{\sim}{\mathrm{D}}=\underset{\sim}{X \operatorname{sen} \omega t}
$$

onde " $X$ " é um vetor, também chamado de autovetor, e " $\omega$ " é um escalar que quantifica a freqüência natural de vibração da estrutura.

Derivando-se duas vezes a equação (4.123) em relação ao tempo, obtém-se:

$$
\ddot{\sim}=-X \omega^{2} \operatorname{sen} \omega t
$$

Substituindo-se as equações (4.123) e (4.124) na equação de vibração livre sem amortecimento (4.122), obtém-se:

$$
\left(-\underset{\sim}{M} \underset{\sim}{X} \omega^{2}+\underset{\sim}{K_{0}} \underset{\sim}{X}\right) \operatorname{sen} \omega t=\underset{\sim}{0}
$$

Para que tal produto seja nulo, uma vez que a parcela "sen( $\omega t)$ " pode assumir qualquer valor, é necessário que seja mantida a seguinte igualdade:

$$
M X \omega^{2}=K_{0} X
$$


Multiplicando-se ambos os membros da equação (4.126) por " $K_{0}^{-1 ", ~ o b t e ́ m-s e: ~}$

$$
\left(\begin{array}{cc}
K_{0}^{-1} & M
\end{array}\right)_{\sim}^{X}=\underset{\sim}{X} \Lambda
$$

onde " $\Lambda$ " é o autovalor dado por:

$$
\Lambda=\frac{1}{\omega^{2}}
$$

Para a obtenção dos autovetores " $X$ " e do autovalor " $\Lambda$ " empregando-se a equação (4.127), pode-se utilizar o método de Householder, GRAD et al.(1980), visto que o produto " $K_{0}{ }^{-1} M$ " não resulta necessariamente uma matriz simétrica.

Aplicando-se a decomposição de Cholesky na matriz " $K_{0}$ ", GOLUB et al. (1985), tem-se:

$$
K_{0}=L_{\sim}^{T} L
$$

onde " $L$ " é uma matriz triangular superior não singular. Utilizando-se a matriz " $L$ " para transformar os autovetores, tem-se:

$$
\underset{\sim}{\bar{X}}=\underset{\sim}{\operatorname{Lx}}
$$


ou

$$
\underset{\sim}{X}=\underset{\sim}{L^{-1} \bar{X}}
$$

Multiplicando-se a equação (4.126) por " $\left[L^{T}\right]^{-1}$ " e utilizando-se as equações (4.128) e (4.131), obtém-se:

$$
\left[L_{\sim}^{T}\right]_{\sim}^{-1} \underset{\sim}{M} L^{-1} \bar{\sim}=\left[\underset{\sim}{L^{T}}\right]_{\sim}^{-1} \underset{\sim}{K} L_{\sim}^{-1} \bar{\sim} \Lambda
$$

Substituindo-se a equação (4.129) na equação anterior, obtém-se:

$$
\left[L_{\sim}^{T}\right]_{\sim}^{-1} \underset{\sim}{L^{-1} \bar{X}}=\underset{\sim}{X} \Lambda
$$

Neste caso o produto " $\left[\underset{\sim}{L^{T}}\right]^{-1} \underset{\sim}{M} \underset{\sim}{L^{-1}}$ "resulta uma matriz simétrica, permitindo-se a utilização do método de Jacobi que é indicado para a obtenção dos autovalores e autovetores de tal matriz, BATHE(1996).

Uma vez obtido cada um dos autovalores " $\Lambda$ ", pode-se calcular as freqüências naturais de vibração da estrutura através da equação:

$$
\omega_{i}=\sqrt{\frac{1}{\Lambda_{i}}}
$$




\subsection{2 - Amortecimento Rayleigh}

- amortecimento Rayleigh é definido pela combinação linear entre as matrizes de rigidez e de massas, CLOUGH et al. (1975), sendo que tal amortecimento é dado por:

$$
C=\lambda_{m} M+\lambda_{k} K_{0}
$$

onde " $\lambda_{\mathrm{m}}$ " e " $\boldsymbol{\lambda}_{\mathrm{k}}$ " são constantes da matriz de amortecimento " $C$ " e quantificam uma proporção das matrizes de massas e de rigidez, respectivamente.

A relação existente entre as constantes de amortecimento " $\lambda_{\mathrm{m}}$ " e " $\boldsymbol{\lambda}_{k}$ " e a fração do amortecimento crítico " $\xi$ " para uma dada frequiência natural de vibração " $\omega$ " é dada pela equação (4.136), COOK et al. (1989).

$$
\xi_{i}=\frac{1}{2}\left(\lambda_{k} \omega_{i}+\frac{\lambda_{m}}{\omega_{i}}\right)
$$

Dessa forma, as constantes de amortecimento podem ser determinadas utilizando-se frações do amortecimento critico para duas diferentes frequiencias naturais de vibração, conforme mostra o seguinte sistema:

$$
\begin{aligned}
& \xi_{1}=\frac{1}{2}\left(\lambda_{k} \omega_{1}+\frac{\lambda_{m}}{\omega_{1}}\right) \\
& \xi_{2}=\frac{1}{2}\left(\lambda_{k} \omega_{2}+\frac{\lambda_{m}}{\omega_{2}}\right)
\end{aligned}
$$


Resolvendo-se o sistema (4.137), obtém-se:

$$
\begin{gathered}
\lambda_{k}=\frac{2\left(\xi_{2} \omega_{2}-\xi_{1} \omega_{1}\right)}{\left(\omega_{2}^{2}-\omega_{1}^{2}\right)} \\
\lambda_{m}=\frac{2 \omega_{1} \omega_{2}\left(\xi_{1} \omega_{2}-\xi_{2} \omega_{1}\right)}{\left(\omega_{2}^{2}-\omega_{1}^{2}\right)}
\end{gathered}
$$

Usualmente, os valores das frequiências naturais são tomados da seguinte forma, Cook et al.(1989): para " $\omega_{1}$ " adota-se a menor frequiência natural de vibração da estrutura e para " $\omega_{2}$ " adota-se uma frequiencia relacionada com o carregamento externo de maior importância ou a freqüência subsequente à " $\omega_{1}$ ".

Com relação às frações do amortecimento crítico, as mesmas são dadas em função do tipo de material e do tipo de sistema estrutural empregado, lembrando-se que o amortecimento crítico é dado pela relação $\xi_{i}=1$. Portanto, para estruturas convencionais o valor de " $\xi_{i}$ " é sempre menor que a unidade (amortecimento subcrítico), sendo que para estruturas de aço adota-se $0,5 \%<\xi_{i}<5,0 \%$ e para estruturas de concreto adota-se 2,0응 $<\xi_{i}<15,0$ 응

\subsection{3 - Aspectos computacionais}

Conforme foi visto no item 4.5 deste trabalho, é desnecessário a consideração de coeficientes nãoIineares na obtenção da matriz de amortecimento. Dessa forma, monta-se a matriz de amortecimento no início da 
análise estrutural, através da utilização da equação (4.135), e emprega-se a mesma ao longo de todo o processo de integração numérica.

Para o cálculo de " $\omega_{1} "$ e " $\omega_{2} "$ utilizam-se os programas auxiliares "AUTOTREL" e "AUTOPORT", que calculam, respectivamente, as frequiências naturais para treliças planas e pórticos planos. Tais programas empregam o método de Jacobi na equação (4.140), CARNAHAN et al.(1969), que é obtida após a aplicação das propriedades da matriz inversa na equação (4.133), PANDIT et al. (1981).

$$
\left[L_{\sim}^{-1}\right]_{\sim}^{T} \underset{\sim}{M} L_{\sim}^{-1} \bar{X}=\bar{\sim} \underset{\sim}{X}
$$

Com a obtenção dos valores de " $\omega_{1}$ " e " $\omega_{2} "$, arbitramse valores para os coeficientes " $\xi_{i}$ " e calculam-se os parâmetros " $\lambda_{\mathrm{m}}$ " e " $\lambda_{\mathrm{k}}$ " com as equações (4.139) e (4.138), respectivamente. Dessa forma, a matriz de amortecimento " $C$ " fica determinada. 


\section{CAPÍTULO 5 - MODELOS FÍSICOS NÃO-LINEARES PARA O AÇO ESTRUTURAL}

\section{1 - Generalidades}

Na maioria dos projetos de estruturas treliçadas que apresentam grandes deformações, tais como edificios altos, torres de transmissão, pontes e outras, a consideração das não-linearidades física e geométrica é indispensável, uma vez que os efeitos produzidos por tal consideração provocam deslocamentos e esforços finais bastante amplificados.

Lembrando-se que a consideração da não-linearidade geométrica já foi tratada no capítulo anterior, passa-se ao estudo da não-linearidade física, que é caracterizada pela relação não-linear entre tensão e deformação, decorrente da modificação das propriedades físicas do material estrutural.

Assim, neste capitulo, far-se-á a consideração da não-linearidade física para análise de estruturas treliçadas planas, constituidas por barras de aço submetidas à esforços uniaxiais, cujo comportamento do material segue os preceitos da teoria da plasticidade.

\section{2 - Comportamento uniaxial do aço estrutural}

Para o estudo de problemas unidimensionais com plasticidade estrutural, adota-se um ensaio uniaxial 
simples, onde um corpo de prova, composto por uma barra de aço de comprimento " $L_{e}$ " e seção transversal " $A_{e}$ ", é submetido à um esforço de tração ou de compressão.

Neste caso, em função das diversas tensões aplicadas na barra, pode-se calcular as respectivas deformações e, assim, obter a relação tensão $x$ deformação procurada.

\subsection{1 - Carregamento unidirecional}

Supondo-se que a barra de aço descrita anteriormente seja submetida à um esforço de tração crescente, o comportamento típico do material pode ser resumido pela figura 5.1 .

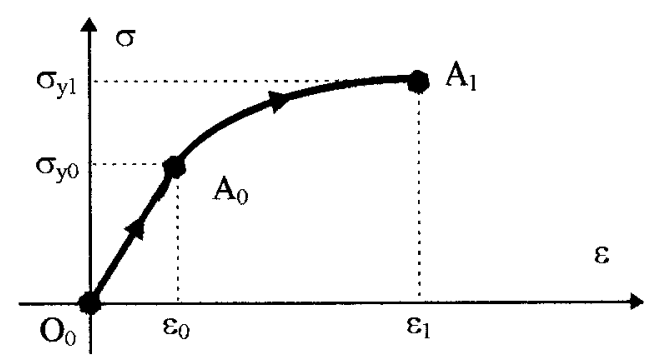

FIGURA 5.1 - Relação tensão x deformação elastoplástica. Carregamento.

A figura 5.1 mostra que até o nível da tensão de escoamento " $\sigma_{\mathrm{y} 0}$ ", correspondente ao trecho "O $\mathrm{O}_{0}-\mathrm{A}_{0}$ ", a relação tensão x deformação é linear, valendo, portanto, a lei de Hooke $(\sigma=\mathrm{E} \varepsilon)$ que caracteriza o regime elástico linear. Uma vez ultrapassada tal tensão, começa haver uma reorganização interna dos cristais que compõem o material, fazendo com que as propriedades físicas do mesmo sejam alteradas. Logo, o módulo de deformação longitudinal começa a modificar-se e com isso a 
inclinação da curva tensão $x$ deformação, dado pelo trecho " $\mathrm{A}_{0}-\mathrm{A}_{1}$ ", começa a diminuir progressivamente.

\section{2 .2 - Descarregamento e recarregamento}

Supondo-se que a mesma barra já descrita anteriormente seja, agora, descarregada, existem dois caminhos exequíveis que estão indicados na figura 5.2.

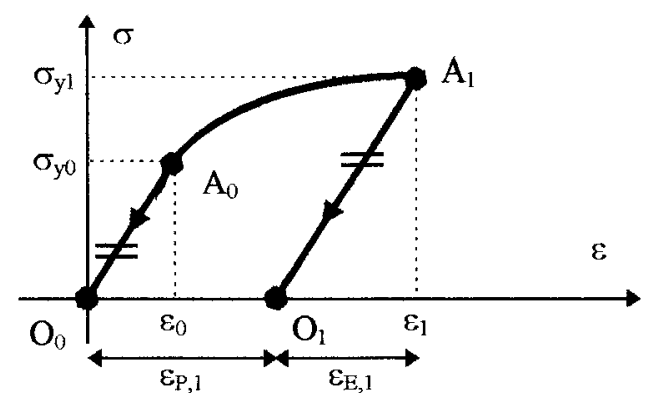

FIGURA 5.2 - Relação tensão x deformação elastoplástica. Descarregamento.

A primeira possibilidade está indicada no trecho "O $\mathrm{O}_{0}-\mathrm{A}_{0}$ " da figura 5.2, onde a tensão inicial aplicada não ultrapassou o valor de " $\sigma_{y 0}$ " e o descarregamento segue 0 caminho inverso do carregamento inicial. A outra possibilidade está indicada no trecho " $\mathrm{A}_{1}-\mathrm{O}_{1}$ ", onde a tensão aplicada já ultrapassou o valor de " $\sigma_{\text {yo }}$ " e o descarregamento se dá pela reta " $\mathrm{A}_{1}-\mathrm{O}_{1}$ ", que é paralela à reta "O $\mathrm{O}_{0}$ ". Neste caso, havendo um descarregamento completo, a barra ficará com uma deformação residual permanente, dada pela deformação plástica " $\boldsymbol{\varepsilon}_{\mathrm{p}, 1}$ ", recuperando a deformação elástica " $\varepsilon_{\mathrm{E}, 1}$ ".

Uma vez completado o descarregamento, pode-se carregar a barra novamente, conforme ilustra a figura 5.3 . 


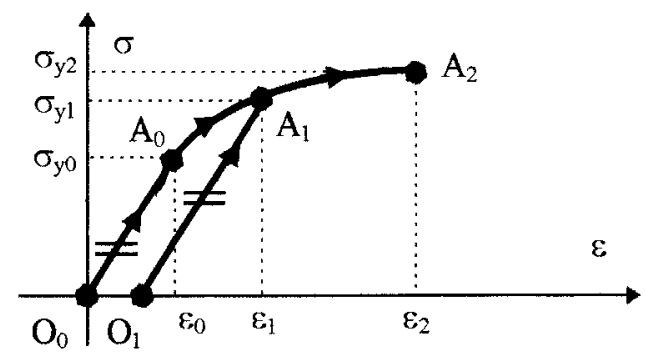

FIGURA 5.3 - Relação tensão x deformação elostoplástica. Recarregamento.

A figura 5.3 mostra que o recarregamento segue o caminho inverso do descarregamento, até que a curva original não-linear " $\mathrm{A}_{0}-\mathrm{A}_{2}$ " seja atingida. A partir desse ponto, a relação tensão $x$ deformação segue conforme descrito no item 5.2.1, como se o descarregamento e o recarregamento nunca tivessem ocorrido.

\section{2 .3 - Inversão de carregamento}

Retomando-se o caso do descarregamento dado pela figura 5.2, pode-se supor que após o descarregamento completo, dado pela reta " $\mathrm{O}_{1}-\mathrm{A}_{1}$ ", haja uma inversão do carregamento aplicado, de tal forma que a barra comece a ser comprimida. Neste caso, a relação tensão $x$ deformação é mostrada pela figura 5.4.

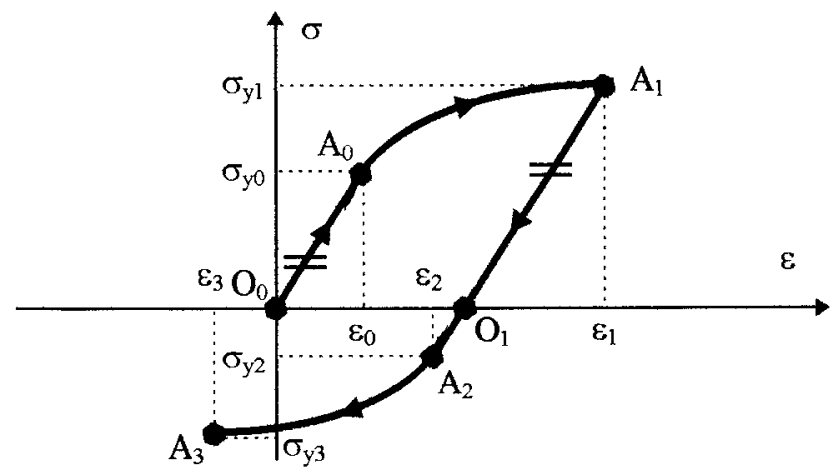

FIGURA 5.4 - Relação tensão x deformação elastoplástica. Efeito Bauschinger. 
A princípio, o comportamento do material é o mesmo tanto na tração como na compressão, de tal forma que a relação tensão $x$ deformação seja a mesma para os dois casos. Entretanto, pelo fato da barra ter sido plastificada anteriormente, a tensão de escoamento para - carregamento inverso é modificada, de modo que o módulo da nova tensão de escoamento " $\sigma_{\mathrm{y}^{2}}$ " seja menor que tensão de escoamento inicial " $\sigma_{\mathrm{y} 0}$ ". Este efeito foi estudado por J. Bauschinger e é chamado de efeito Bauschinger, TIMOSHENKO(1979). A partir desse ponto, o comportamento do material é mantido conforme descrição anterior.

\section{3 - Modelos elastoplásticos unidimensionais para elementos estruturais de aço}

Para a solução de um problema elastoplástico unidimensional, deve-se idealizar o comportamento do material através da utilização de modelos matemáticos que permitam a simulação da relação tensão x deformação real.

Entre os vários modelos disponiveis para este tipo de estudo destacam-se o modelo elastoplástico perfeito e - modelo elastoplástico com endurecimento linear, CHEN et al. (1988), que serão vistos na sequiência.

\subsection{1 - Modelo elastoplástico perfeito}

A figura 5.5 ilustra a relação tensão $x$ deformação do aço através do modelo elastoplástico perfeito. 


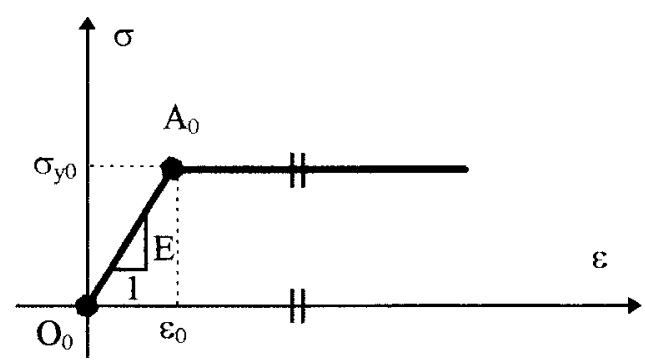

FIGURA 5.5 - Modelo elastoplástico perfeito.

Neste modelo, quando a tensão atuante atingir a tensão de escoamento " $\sigma_{\mathrm{y} 0}$ ", o elemento estrutural perde a capacidade de absorver um acréscimo de tensão e a deformação fica indefinida. Tal modelo pode ser resumido pelas seguintes equações:

$$
\begin{gathered}
\mathrm{p} / \sigma\left\langle\sigma_{y 0} \Rightarrow \varepsilon=\frac{\sigma}{E}\right. \\
\mathrm{p} / \sigma=\sigma_{y 0} \Rightarrow \varepsilon=\frac{\sigma}{E}+\lambda
\end{gathered}
$$

onde " $\lambda$ " é uma constante indefinida.

\subsection{2 - Modelo elastoplástico com endurecimento}

\section{linear}

A figura 5.6 ilustra a relação tensão $x$ deformação do aço através do modelo elastoplástico com endurecimento linear. 


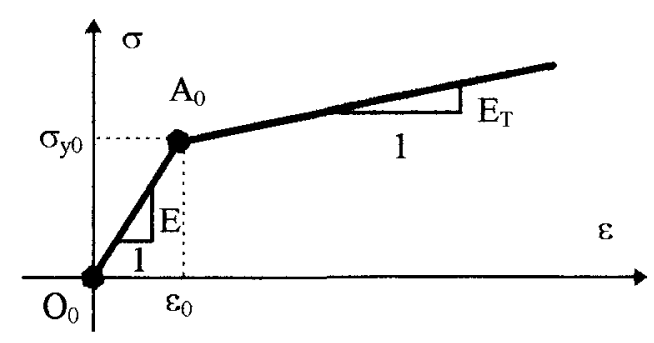

FIGURA 5.6 - Modelo elastoplástico com endurecimento linear.

Neste modelo, uma vez ultrapassada a tensão de escoamento " $\sigma_{\mathrm{y} 0}$ ", o módulo de deformação longitudinal " $E$ " é substituído pelo módulo tangente " $E_{\mathrm{T}}$ ", de tal forma que - elemento estrutural tenha capacidade de absorver um acréscimo de tensão às custas de deformações maiores. Evidentemente, o módulo tangente " $E_{\mathrm{T}}$ " é menor que o módulo de deformação longitudinal "E", uma vez que a inclinação da curva tensão $x$ deformação diminui com 0 acréscimo de tensão, conforme visto no item 5.2.1. Tal modelo pode ser resumido pelas seguintes equações:

$$
\begin{gathered}
\mathrm{p} / \sigma\left\langle\sigma_{y 0} \Rightarrow \varepsilon=\frac{\sigma}{E}\right. \\
\mathrm{p} / \sigma \geq \sigma_{y 0} \Rightarrow \varepsilon=\frac{\sigma}{E}+\frac{\sigma-\sigma_{y 0}}{E_{T}}
\end{gathered}
$$

Cabe ressaltar que este modelo é perfeitamente compatível com a relação tensão $x$ deformação do aço classe "A", sendo que para o aço classe "B" se faz necessário um ajuste no valor do módulo tangente. 


\section{4 - Modelos com endurecimento linear para} carregamentos cíclicos

Em problemas dinâmicos os elementos estruturais são submetidos, frequientemente, a esforços alternados, logo, é imprescindível a consideração de um modelo matemático que contemple a inversão de carregamento, conforme visto no item 5.2.3.

Entre os vários modelos destinados para esta finalidade destacam-se os modelos com endurecimento cinemático, isotrópico e independente, CHEN et al.(1991), conforme serão vistos na sequiência.

\subsection{1 - Modelo isotrópico}

A figura 5.7 ilustra o modelo com endurecimento linear isotrópico através do gráfico tensão x deformação do aço.

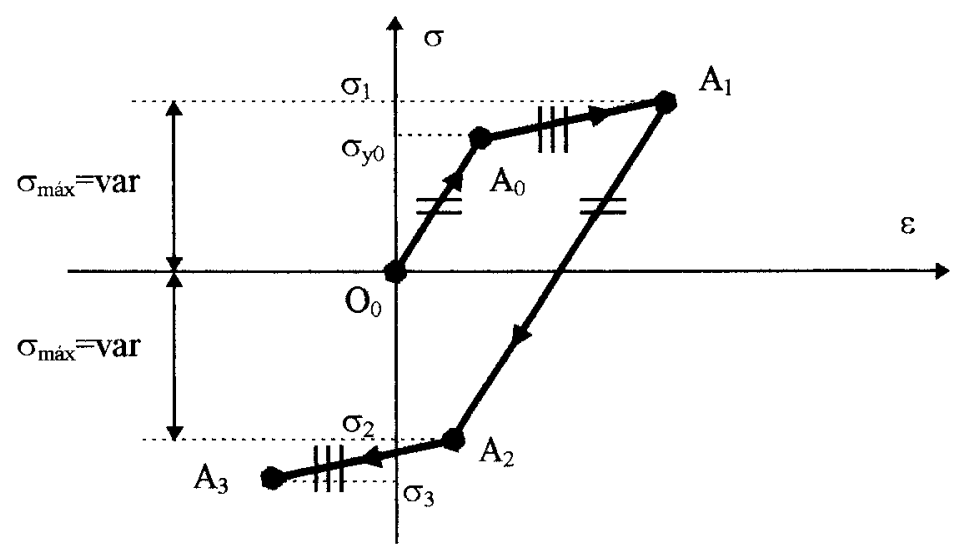

FIGURA 5.7 - Modelo com endurecimento linear isotrópico.

Neste modelo, a tensão de escoamento do material é dada pela máxima tensão calculada, devendo ser sempre maior ou igual a "$\sigma_{\mathrm{yo}}$ ". Esse valor permanecerá constante, tanto para a tração como para a compressão, até que um valor maior de tensão seja obtido. Tal mecanismo é 
mostrado pela figura 5.7, onde uma barra submetida à um esforço de tração tem como tensão atuante o valor " $\sigma_{1}$ ". Como " $\sigma_{1}$ " é maior que " $\sigma_{y 0}$ ", tal valor passa a ser o novo valor da tensão de escoamento. Efetuando-se o descarregamento $e$ inversão do mesmo, a tensão de escoamento na compressão é dada por $\sigma_{2}=-\sigma_{\text {máx }}=-\sigma_{1}$. Aumentando-se a compressão na barra, a mesma começa a escoar até atingir-se o ponto " $\mathrm{A}_{3}$ ", com tensão "$\sigma_{3}$ ". Como " $\left|\sigma_{3}\right|$ " é maior que "$\sigma_{1}$ ", este último valor passa a ser a nova tensão de escoamento do material, e assim sucessivamente. Dessa forma, a tensão de escoamento " $\sigma_{\text {esc }}$ " é dada pela seguinte equação:

$$
\left|\sigma_{e s c}\right|=\left|\sigma_{\max }\right|
$$

\subsection{2 - Modelo independente}

A figura 5.8 ilustra o modelo com endurecimento linear independente através do gráfico tensão $x$ deformação do aço.

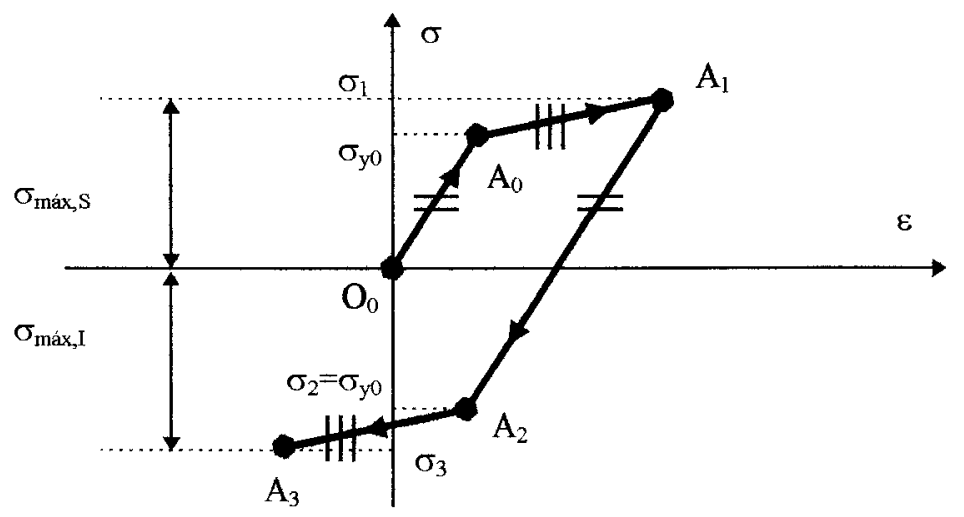

FIGURA 5.8 - Modelo com endurecimento linear independente. 
Neste modelo, a tensão de escoamento do material é dada pela máxima tensão calculada para o caso da tração e da compressão, de tal forma que o valor da tensão de escoamento na tração " $\sigma_{m a ́ x}, s$ " independa do valor da tensão de escoamento na compressão " $\sigma_{\text {máx,I" }}$ ". A figura 5.8 mostra tal mecanismo, onde após o descarregamento e inversão do carregamento a tensão de escoamento inicial na compressão é dada por $\sigma_{2}=-\sigma_{\mathrm{y} 0}$, passando posteriormente para $\sigma_{\mathrm{esc}, \mathrm{C}}=\sigma_{\mathrm{máx}, \mathrm{I}}$, enquanto que $\sigma_{\mathrm{esc}, \mathrm{T}}=\sigma_{\mathrm{mad} x, \mathrm{~s}}$ permanece inalterado. Analiticamente, a tensão de escoamento é dada por:

$$
\left|\sigma_{\text {esc } C, I}\right|=\left|\sigma_{\max I, S}\right|
$$

\section{4 .3 - Modelo cinemático}

A figura 5.9 ilustra o modelo com endurecimento linear cinemático através do gráfico tensão x deformação do aço.

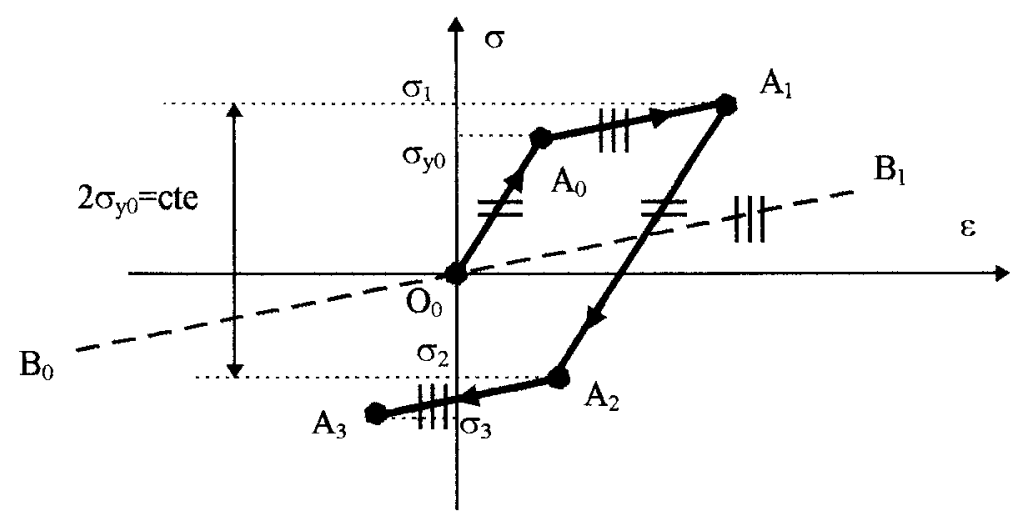

FIGURA 5.9 - Modelo com endurecimento linear cinemático. 
Neste modelo, a diferença entre a tensão de escoamento para carregamentos de tração e de compressão é mantida constante com valor igual ao dobro da tensão de escoamento " $\sigma_{\mathrm{y} 0}$ ". Tal mecanismo é mostrado pela figura 5.9, onde o valor da tensão de escoamento referente ao ponto "A $A_{2}$ " é dado por $\left|\sigma_{2}\right|=\left|2 \sigma_{\mathrm{y} 0}-\sigma_{1}\right|$. Dessa forma, a equação que rege tal modelo é dada por:

$$
\sigma_{e s c, T}+\left|\sigma_{e s c, C}\right|=2 \sigma_{y 0}
$$

onde " $\sigma_{\mathrm{esc}, \mathrm{T}}$ " e " $\sigma_{\mathrm{esc}, \mathrm{c}}$ " são as tensões de escoamento para a tração e para a compressão, respectivamente.

Cabe ressaltar que este modelo reproduz de forma simplificada o efeito Bauschinger descrito no item 5.2.3, uma vez que o centro elástico é movido ao longo da reta " $\mathrm{B}_{0}-\mathrm{B}_{1}$ ". Alternativamente, pode-se expressar tal modelo pela seguinte equação:

$$
|\sigma-\Psi|=\left|\sigma_{y 0}\right|
$$

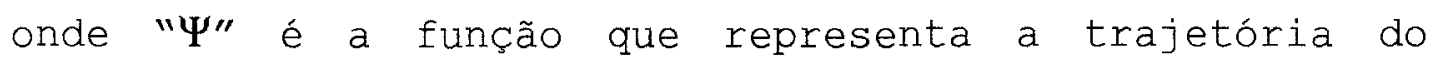
centro elástico, sendo $\Psi=0$ para $\sigma=0$.

\section{5 - Modelagem numérica}

Para introduzir a não-linearidade física na análise de estruturas treliçadas de aço sujeitas à ações dinâmicas, faz-se necessário a implementação numérica dos modelos com endurecimento linear para carregamentos cíclicos, conforme visto no item anterior. 
Tal implementação depende do desenvolvimento de equações matemáticas que simulem o comportamento estrutural do aço e da criação de um algoritmo computacional adequado que armazene toda a história anterior da relação tensão $x$ deformação dos elementos estruturais, conforme será visto a seguir.

\subsection{1 - Aspectos gerais}

Para o desenvolvimento de equações que descrevam o comportamento estrutural de um elemento de aço submetido à um processo incremental de carregamento, admite-se que tal elemento seja solicitado por um acréscimo de tensão " $\Delta \sigma^{r} "$, de tal forma que haja uma alteração no comportamento estrutural, definida pela passagem do regime de trabalho elástico para o regime de trabalho plástico. A figura 5.10 ilustra tal procedimento através do gráfico tensão $x$ deformação, onde a tensão atuante na iteração "r" ultrapassa a tensão de escoamento " $\sigma_{\mathrm{y}}{ }^{\mathrm{r}-1 "} \mathrm{da}$ iteração anterior "r-1".

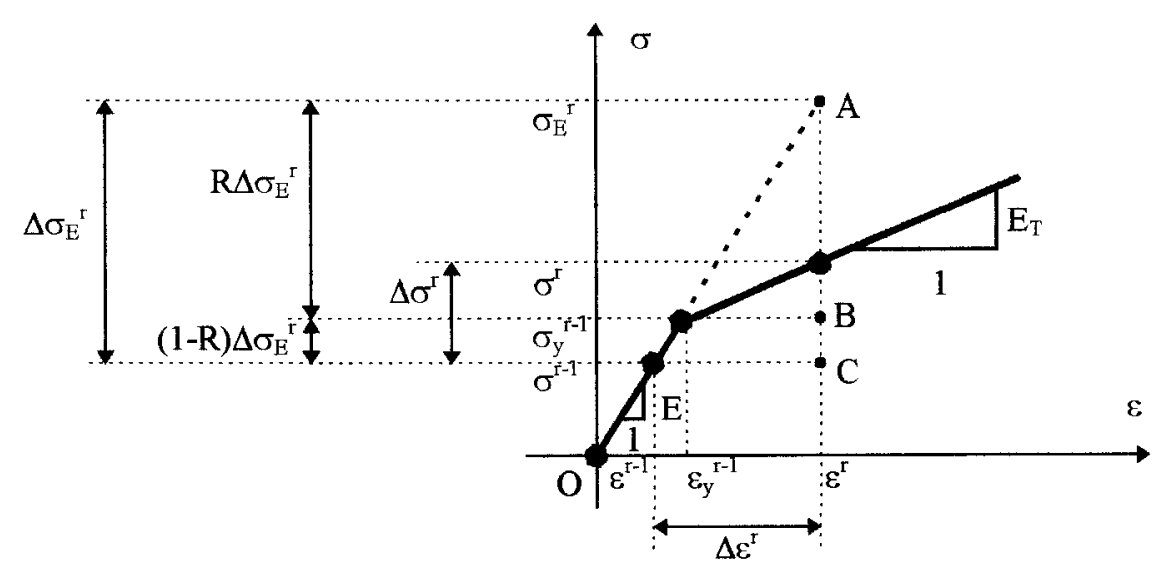

FIGURA 5.10 - Variação incremental da tensão e deformação para o caso unidimensional. 
Da figura 5.10 obtém-se diretamente as seguintes relações:

$$
\Delta \varepsilon^{r}=\varepsilon^{r}-\varepsilon^{r-1}
$$

$$
\Delta \sigma_{E}^{r}=E \Delta \varepsilon^{r}
$$

$$
\sigma_{E}{ }^{\mathrm{r}}=\sigma^{\mathrm{r}-1}+\Delta \sigma_{E}{ }^{\mathrm{r}}
$$

$$
\sigma^{r}=\sigma^{r-1}+\Delta \sigma^{r}
$$

onde

" $\Delta \varepsilon^{r "}$ é a variação da deformação ocorrida durante a iteração "r";

" $\varepsilon^{r "}$ é a deformação final da iteração "r";

" $\varepsilon^{r-1 "}$ é a deformação final da iteração "r-1";

" $\Delta \sigma_{\mathrm{E}}{ }^{\mathrm{N}}$ " é a variação da tensão elástica ocorrida durante a iteração "r";

" $\sigma_{\mathbb{E}}{ }^{r "}$ é a tensão elástica final da iteração " $r$ ";

" $\sigma^{r-1 "}$ é a tensão final da iteração "r-1";

" $\sigma^{r}$ " é a tensão final da iteração "r";

" $\Delta \sigma^{r} "$ é a variação da tensão ocorrida durante a iteração "r".

Calculando-se o valor de " $\Delta \sigma^{\mathrm{r}}$ ", tem-se:

$$
\Delta \sigma^{r}=\left(\sigma^{r}-\sigma_{y}{ }^{r-1}\right)+\left(\sigma_{y}{ }^{r-1}-\sigma^{r-1}\right)
$$

ou, simplesmente, 


$$
\Delta \sigma^{r}=\left(\sigma^{r}-\sigma_{y}{ }^{r-1}\right)+(1-R) \Delta \sigma_{E}{ }^{r}
$$

Aplicando-se a lei de Hooke na equação (5.14), obtém-se:

$$
\Delta \sigma^{\mathrm{r}}=\left(\varepsilon^{\mathrm{r}}-\varepsilon_{y}{ }^{\mathrm{r}-1}\right) E_{T}+(1-R) E \Delta \varepsilon^{\mathrm{r}}
$$

Por semelhança de triângulos, tem-se:

$$
\frac{\Delta \varepsilon^{\mathrm{r}}}{\Delta \sigma_{E}{ }^{\mathrm{r}}}=\frac{\varepsilon^{\mathrm{r}}-\varepsilon_{y}{ }^{\mathrm{r}-1}}{R \Delta \sigma_{E}{ }^{\mathrm{r}}}
$$

ou, simplesmente,

$$
\varepsilon^{\mathrm{r}}-\varepsilon_{y}^{\mathrm{r}-1}=R \Delta \varepsilon^{\mathrm{r}}
$$

Substituindo-se a equação (5.17) na equação (5.15), obtém-se:

$$
\Delta \sigma^{\mathrm{r}}=R E_{T} \Delta \varepsilon^{\mathrm{r}}+(1-R) E \Delta \varepsilon^{\mathrm{r}}
$$

Portanto, para a obtenção da tensão " $\sigma^{\mathrm{r}}$ " substituise a equação (5.18) na equação (5.12), resultando:

$$
\sigma^{\mathrm{r}}=\sigma^{\mathrm{r}-1}+\left(E-E R+E_{T} R\right) \Delta \varepsilon^{\mathrm{r}}
$$

Calculando-se, agora, a variação da deformação plástica " $\Delta \boldsymbol{\varepsilon}_{\mathrm{P}}^{\mathrm{r}}$ " ocorrida durante a iteração " $r$ ", tem-se: 


$$
\Delta_{\mathcal{E} P}{ }^{\mathrm{r}}=\Delta_{\mathcal{E}^{\mathrm{r}}}{ }^{\mathrm{s}} \Delta_{\mathcal{E}_{E}}{ }^{\mathrm{r}}
$$

Aplicando-se a lei de Hooke na equação (5.20), obtém-se:

$$
\Delta \varepsilon p^{r}=\Delta \varepsilon^{r}-\frac{\Delta \sigma^{r}}{E}
$$

Substituindo-se a equação (5.18) na equação (5.21) e rearrumando-se os termos, obtém-se:

$$
\Delta \varepsilon_{P}{ }^{\mathrm{r}}=R\left(\frac{E-E_{T}}{E}\right) \Delta \varepsilon^{\mathrm{r}}
$$

Resta, agora, definir o valor do fator de redução " $R$ ", que é dado pela relação entre a reta "A-B" e a reta "B-C" da figura 5.10, logo:

$$
R=\frac{\overline{A B}}{\overline{B C}}=\frac{\sigma_{E}{ }^{\mathrm{r}}-\sigma_{y}{ }^{\mathrm{r}-1}}{\Delta \sigma_{E}{ }^{\mathrm{r}}}
$$

$\mathrm{Na}$ seqüência, destacam-se os dois casos particulares que podem ocorrer em função dos valores da tensão final " $\sigma^{r-1 "}$ e do acréscimo de tensão " $\Delta \sigma^{\mathrm{r}}$ ".

o primeiro caso particular é mostrado pela figura 5.11 , onde a tensão " $\sigma^{\text {r" }}$ não ultrapassou a tensão de escoamento. 


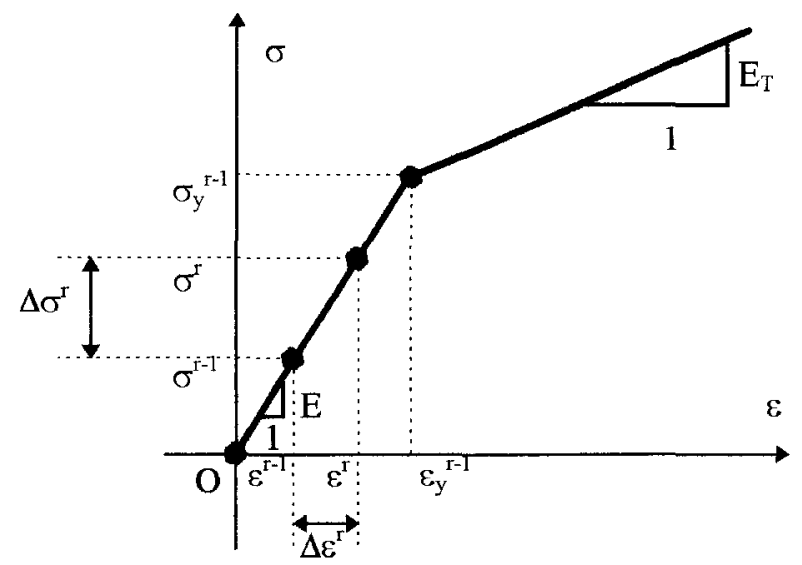

FIGURA 5.11 - Variação incremental da tensão no regime elástico.

Neste caso, a tensão " $\sigma^{r}$ " é dada por:

$$
\sigma^{\mathrm{r}}=\sigma^{\mathrm{r}-1}+E \Delta \varepsilon^{\mathrm{r}}
$$

sendo que a variação da deformação plástica " $\Delta \boldsymbol{\varepsilon}_{\mathrm{P}}{ }^{\mathrm{r}}$ " é nula. Cabe ressaltar que fazendo-se $R=0$ e substituindose nas equações (5.19) e (5.22), encontra-se o mesmo resultado já obtido.

O segundo caso particular é mostrado pela figura 5.12, onde a tensão " $\sigma^{r-1 " ~ j a ́ ~ u l t r a p a s s o u ~ a ~ t e n s a ̃ o ~ d e ~}$ escoamento.

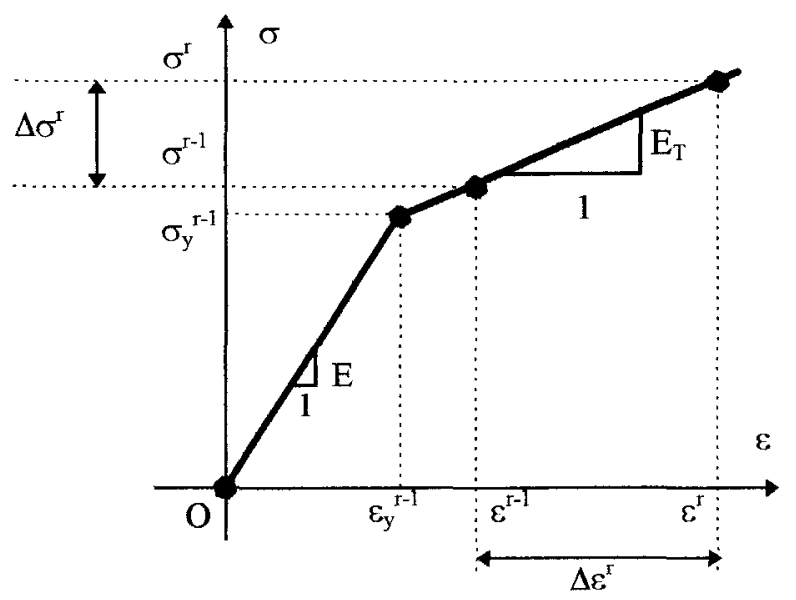

FIGURA 5.12 - Variação incremental da tensão no regime plástico. 
Neste caso, a tensão " $\sigma$ " é dada por:

$$
\sigma^{r}=\sigma^{r-1}+E_{T} \Delta \varepsilon^{r}
$$

Já a variação da deformação plástica " $\Delta \boldsymbol{\varepsilon}_{\mathrm{p}}{ }^{\mathrm{r}}$ é dada pela equação(5.21), logo, calculando-se o valor de " $\Delta \sigma^{\mathrm{r}}$ ", tem-se:

$$
\Delta \sigma^{\mathrm{r}}=E_{T} \Delta \varepsilon^{\mathrm{r}}
$$

Substituindo-se a equação (5.26) na equação (5.21) e rearrumando-se os termos, obtém-se:

$$
\Delta_{\varepsilon_{P}}{ }^{\mathrm{r}}=\left(\frac{E-E_{T}}{E}\right) \Delta \varepsilon^{\mathrm{r}}
$$

Analogamente ao primeiro caso, fazendo-se $\mathrm{R}=1$ e substituindo-se nas equações (5.19) e (5.22), encontramse as equações $(5.25)$ e (5.27), respectivamente.

\subsubsection{1 - Colocação do problema}

Admitindo-se que sejam conhecidos o valor da tensão e o valor da deformação ao final da iteração " $r-1$ ", pretende-se calcular o valor da tensão ao final da iteração "r" e, se houver, a respectiva variação da deformação plástica.

Calculando-se inicialmente o valor da deformação ao final da iteração "r", obtém-se a variação da deformação ocorrida durante a iteração "r" e o valor dos demais 
parâmetros através das equações já descritas anteriormente.

Assim, com o valor de " $\Delta \varepsilon^{r} "$, pode-se obter o valor de " $\sigma$ " e com isso calcular a força normal atuante no elemento em função da sua deformação.

Já o cálculo da variação da deformação plástica é necessário para que se possa corrigir o valor do módulo de deformação longitudinal no transcorrer do processo incremental, uma vez que para variação não nula utilizase o módulo tangente.

$\mathrm{Na}$ sequiência, descreve-se tal rotina de cálculo de forma mais detalhada, para que se tenha uma visão global do procedimento adotado.

\subsubsection{2 - Rotina de cálculo}

A rotina de cálculo desenvolvida é apresentada na figura 5.13 de maneira esquemática, onde é mostrada a sequiência de cálculos a serem executados através de desvios condicionais e incondicionais.

Para a utilização desta rotina deve-se, na inicialização do programa geral, zerar o valor de " $\varepsilon^{r-1 "}$ e de " $\sigma^{r-1 "} e$, na sequiência, atribuir à tensão de escoamento máxima " $\sigma_{s}{ }^{r-1 "}$ o valor de " $+\sigma_{\mathrm{yo}}$ " e à tensão de escoamento mínima " $\sigma_{I}{ }^{r-1 "}$ " valor de " $-\sigma_{\mathrm{Y} 0}$ ". A partir deste ponto, através da introdução do valor atualizado da deformação, calcula-se o valor de " $\sigma^{\mathrm{r} "}$ e de " $\Delta \boldsymbol{\varepsilon}_{\mathrm{p}}^{\mathrm{r}}$ " para o elemento em questão e, para finalizar, promove-se a atualização da deformação. Deve-se lembrar que todos os valores já mencionados são específicos para cada um dos elementos pertencentes ao sistema estrutural. 


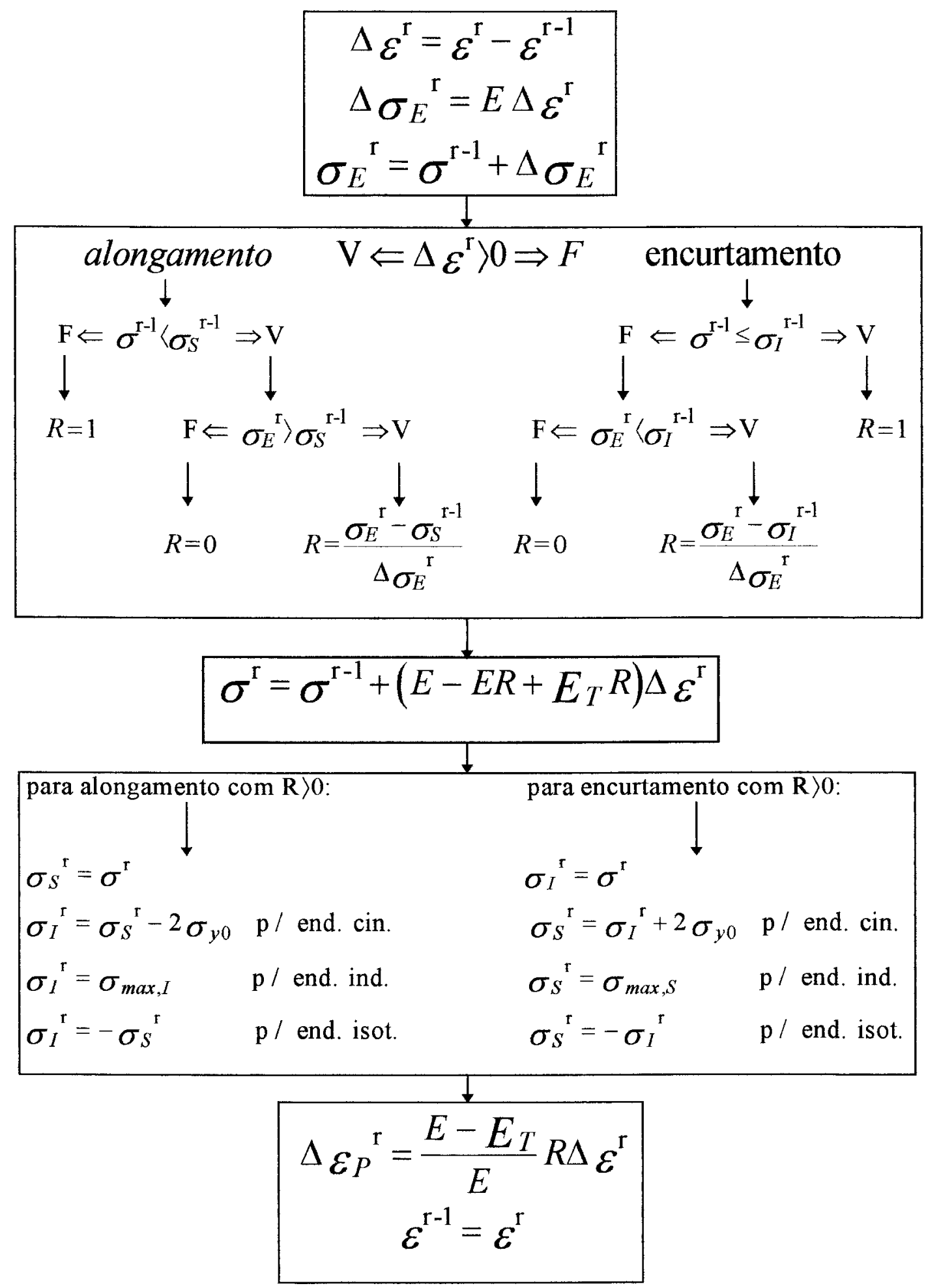

FIGURA 5.13 - Rotina de cálculo para não-linearidade física para treliças de aço. 
Com relação à rotina de cálculo descrita anteriormente, deve-se fazer a separação do cálculo para os casos de alongamento e encurtamento, tendo em vista a atualização das tensões de escoamento correspondentes à cada modelo de endurecimento e à utilização correta da equação que calcula o valor do fator de redução "R" .

Cabe ressaltar que a rotina apresentada na figura 5.13 contempla todos os modelos com endurecimento linear para carregamentos cíclicos, conforme descrição feita no item 5.4 deste trabalho.

\section{5 .2 - Aspectos computacionais}

A implementação computacional da não-linearidade física é feita através do cálculo específico das forças restauradoras, utilizando-se a rotina de cálculo descrita no item anterior. Para descrever tal implementação, apresenta-se, na seqüência, a documentação básica relativa ao código computacional da subrotina "FORÇAS RESTAURADORAS" descrita no item 3.5.2.H, através do respectivo diagrama de blocos e da descrição das funções internas existentes.

\subsubsection{1 - Esquema de cálculo}

- diagrama de blocos referente ao esquema de cálculo é mostrado na figura 5.14, onde cada bloco contém a descrição das funções internas que serão desenvolvidas na subrotina "FORÇAS RESTAURADORAS". 


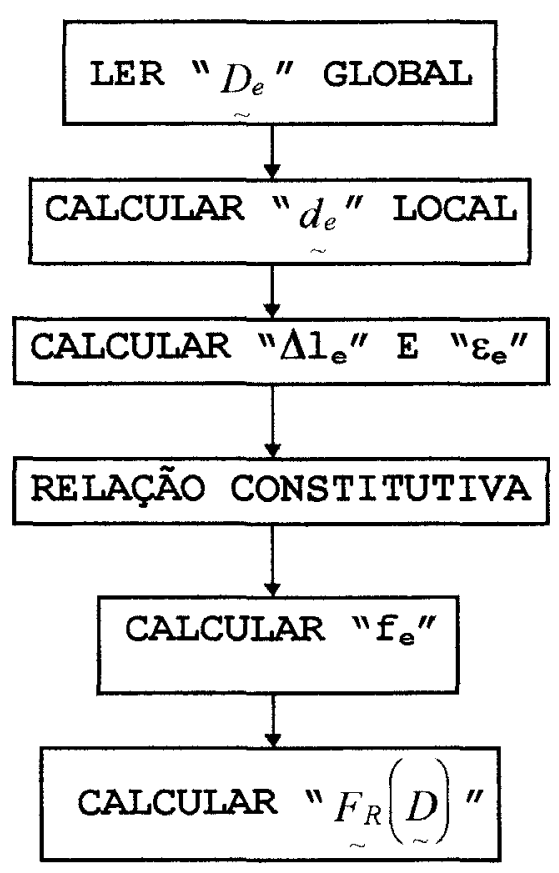

FIGURA 5.14 - Diagrama de blocos interno da subrotina "FORÇAS RESTAURADORAS".

Cabe ressaltar que tal esquema foi utilizado na elaboração do programa computacional "DINATREL" relativo à análise estrutural de treliças planas.

\subsubsection{2 - Descrição das funções internas}

A seguir, faz-se um detalhamento de cada função interna descrita no diagrama de blocos contido na figura 5.14 .

\section{A - Bloco "LER " $D_{e}$ " GLOBAL"}

Este bloco tem a função de capturar os deslocamentos globais " $D$ " que ocorrem na extremidade de cada elementos "e". 


\section{B - Bloco "CALCULAR " $d_{e}$ " LOCAL"}

Para o caso específico do elemento finito para treliça plana, não se faz necessário o cálculo direto de " $d_{e}$ ", pois este ficará embutido na obtenção de " $\Delta l_{e}$ ".

\section{C - Bloco "CALCULAR " $\Delta 1_{e}$ " $E$ " $\varepsilon_{e}$ ""}

Considerando-se a não-linearidade geométrica, temse: o valor de " $\Delta l_{e}$ " deve ser obtido observando-se a estrutura na sua "posição deslocada", ver figura 5.15, com o comprimento do elemento sendo mantido constante ao longo de cada incremento. Após o equilibrio, o comprimento do elemento e os co-senos diretores devem ser atualizados.

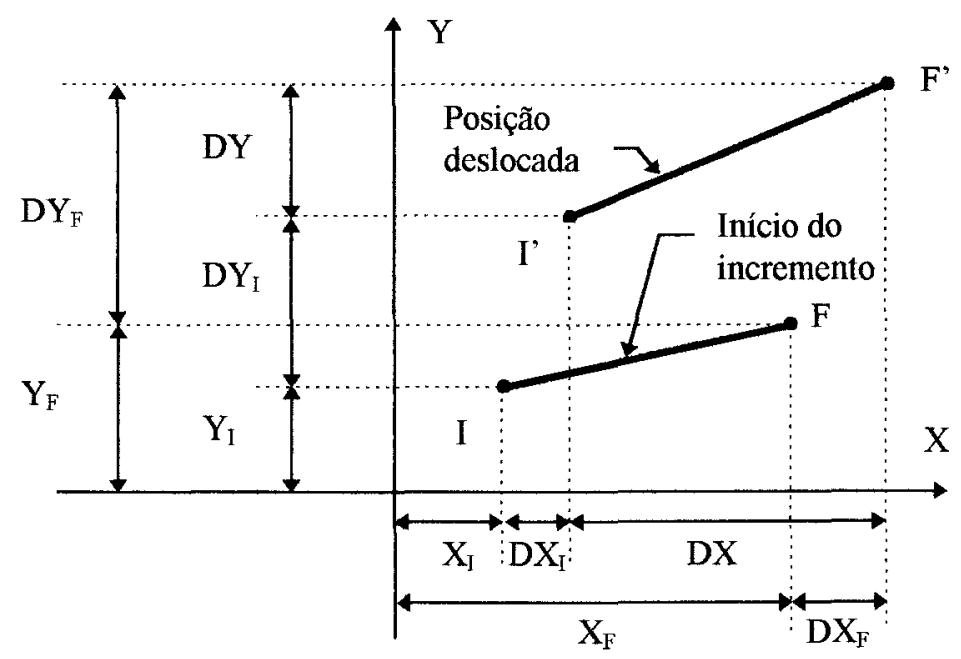

FIGURA 5.15 - Variação do comprimento para nãoIinearidade geométrica.

Neste caso, " $\Delta l_{e}$ " e " $\varepsilon_{e}$ " são calculados pelas seguintes equações: 


$$
\Delta l_{e}=\left(D X^{2}+D Y^{2}\right)^{1 / 2}-\overline{I F}
$$

onde

$$
\begin{aligned}
& D X=\left(X_{F}+D X_{F}\right)-\left(X_{I}+D X_{I}\right) \\
& D Y=\left(Y_{F}+D Y_{F}\right)-\left(Y_{I}+D Y_{I}\right)
\end{aligned}
$$

e

$$
\varepsilon_{e}=\frac{\Delta l_{e}}{I F}+\sum \varepsilon_{e, \text { anteriores }}
$$

Considerando-se, agora, a linearidade geométrica, tem-se: o valor de " $\Delta l_{e}$ " deve ser obtido observando-se a estrutura na sua "posição original", ver figura 5.16, através da projeção dos deslocamentos no elemento indeformado, sem atualização do comprimento e dos cosenos diretores do elemento.

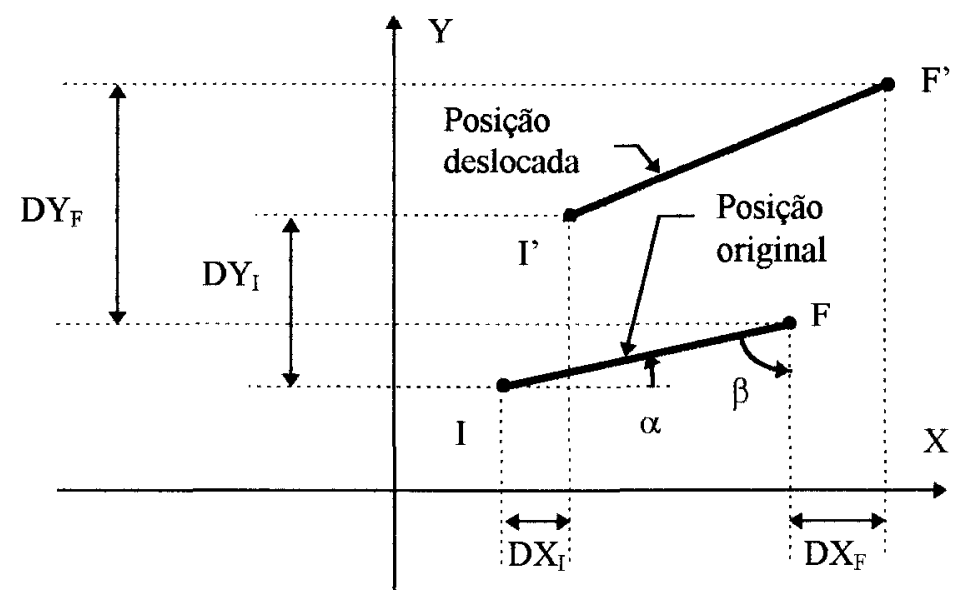

FIGURA 5.16 - Variação do comprimento para linearidade geométrica.

Neste caso, " $\Delta l_{e}$ " e " $\varepsilon_{\mathrm{e}}$ " são calculados pelas seguintes equações: 


$$
\Delta l_{e}=\left(D X_{F}-D X_{I}\right) \cos \alpha+\left(D Y_{F}-D Y_{I}\right) \cos \beta
$$

e

$$
\varepsilon_{e}=\frac{\Delta l_{e}}{\overline{I F}}
$$

\section{D - BlOCO "RELAÇÃO CONSTITUTIVA"}

Este bloco já foi amplamente discutido no item 5.5.1.2 deste trabalho, onde ao final da execucăo dos cálculos obtém-se os valores de "$\sigma_{e}$ " e " $\Delta \varepsilon_{\mathrm{p}, \mathrm{e}}$ ".

\section{$E$ - Bloco "CALCULAR " $f_{e} "$ "}

Este bloco tem a função de calcular a força restauradora de cada elemento através da seguinte equação:

$$
f_{e}=\sigma_{e} A_{e}
$$

onde " $A_{e}$ " é a área da seção transversal do elemento analisado.

$$
F \text { - Bloco "CALCULAR " } F_{R}(\underset{\sim}{D}) \text { "" }
$$

Neste bloco calcula-se a força restauradora de todo - sistema estrutural, através da somatória via equilíbrio nodal dos elementos que concorrem simultaneamente em cada nó de tal sistema. 


\section{CAPÍTULO 6 - MODELOS FÍSICOS NÃO-LINEARES PARA O CONCRETO ARMADO}

\section{1 - Generalidades}

Atualmente, com o avanço significativo da Engenharia Civil associada à computação, os calculistas de estruturas estão desenvolvendo projetos de edificios altos com elementos estruturais cada vez mais esbeltos. Como conseqüência imediata, a deslocabilidade lateral dessas estruturas, que pode ocorrer em função da ação do vento, começa a ser um fator decisivo na análise estrutural em virtude dos efeitos de segunda ordem global que possam ocorrer. Nesses casos, tais efeitos não podem ser desprezados, necessitando-se uma análise não-linear física e geométrica.

Assim, neste capítulo, far-se-á a consideração da não-linearidade física na análise de estruturas aporticadas planas, constituidas por elementos de concreto armado submetidos à flexão normal composta e força cortante, seguindo as orientações do manual do CEB (1985) e do ACI(1983). Cabe lembrar que a consideração da não-linearidade geométrica já foi tratada no capítulo 4 deste trabalho. 


\section{2 - Conceitos gerais sobre o concreto armado}

A característica principal do concreto armado é dada pela fissuração que pode ocorrer na região mais tracionada de uma peça qualquer, em função da baixa resistência do concreto quando o mesmo é solicitado à tração. Desse modo, utiliza-se uma armadura com a finalidade de suprir a resistência à tração do concreto e de limitar a abertura das fissuras, bem como a deformação excessiva da peça.

Para quantificar os parâmetros relativos à resistência, abertura das fissuras e deformação excessiva, utilizam-se os conceitos dos estados limites e dos Estádios de solicitação, conforme serão vistos na seqüência.

\section{2 .1 - Estados limites}

Quando qualquer elemento de um sistema estrutural, ou o conjunto, passa a não desempenhar as funções para as quais foi projetado, então conclui-se que a estrutura atingiu um estado limite. Entre os vários estados limites que podem ocorrer destacam-se os estados limites últimos e os estados limites de utilização.

Como o próprio nome sugere, os estados limites últimos ocorrem quando algum componente do sistema estrutural atinge a sua capacidade máxima resistente, fazendo com que a estrutura entre em colapso. Isso pode ocorrer quando se der a perda de equilíbrio, global ou parcial, admitida a estrutura como corpo rígido, se der a ruptura ou a deformação plástica excessiva dos materiais, se der a transformação da estrutura, no todo 
ou em parte, em um sistema hipostático, se der a perda de estabilidade por deformação ou por efeito dinâmico, etc. Estes estados limites formam a base de cálculo para - dimensionamento dos elementos resistentes em função do tipo de solicitação que possa ocorrer.

Já os estados limites de utilização ocorrem quando algum componente do sistema estrutural se torna inutilizável sem que a sua capacidade máxima resistente seja atingida, fazendo com que a estrutura deixe de ser funcional. Isso pode ocorrer em função da abertura excessiva das fissuras do concreto, possibilitanto a corrosão da armadura, em função da deformação excessiva ou da vibração com amplitude excessiva de algum elemento, etc. Dessa forma, esses estados limites devem ser verificados quando for feito o dimensionamento do sistema estrutural.

\subsection{2 - Estádios de solicitação}

Os estádios de solicitação são caracterizados pelas relações tensão $x$ deformação do concreto e da armadura que podem ocorrer quando um elemento estrutural é submetido à flexão.

Em função das diversas possibilidades que podem ocorrer, convencionou-se dividir os estádios de solicitação, FUSCO(1981), em: Estádio $I_{a}$ Estádio $I_{b}$, Estádio II e Estádio III.

A figura 6.1 apresenta os diagramas de tensão e de deformação referentes ao Estádio $I_{a}$, que é caracterizado por seção não fissurada com comportamento elástico linear para todo o concreto e para toda a armadura. 


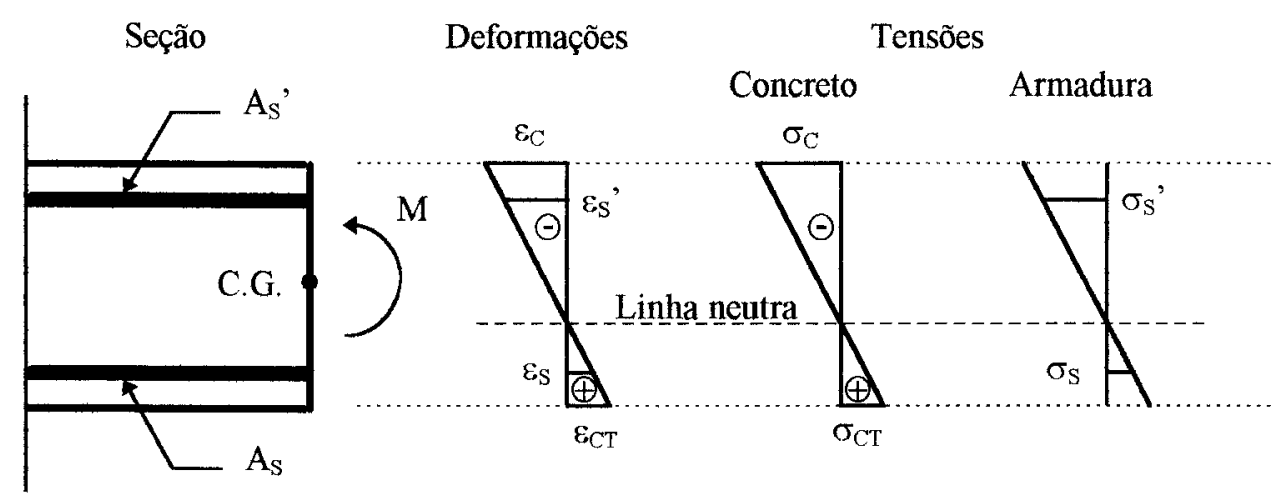

FIGURA 6.1 - Diagramas de tensão e de deformação para Estádio $I_{a}$.

Neste caso, as deformações de compressão " $\boldsymbol{\varepsilon}_{c}$ " e de tração " $\boldsymbol{\varepsilon}_{C T}$ " do concreto não ultrapassam os respectivos limites de proporcionalidade, de tal forma que as tensões permaneçam proporcionais às deformações. O mesmo ocorre com as deformações da armadura superior " $\varepsilon_{\mathrm{S}}$ " e inferior " $\varepsilon_{S}$ ".

Já a figura 6.2 apresenta os diagramas de tensão e de deformação referentes ao Estádio $I_{b}$, que é caracterizado por seção não fissurada com comportamento elástico linear para o concreto comprimido e para toda a armadura, e com comportamento não-linear para o concreto tracionado. Neste caso, a deformação do concreto tracionado ultrapassa o limite de proporcionalidade da tração, sendo que o ponto mais solicitado tem deformação igual à deformação de ruptura, fazendo com que o diagrama de tensão seja não-linear. Já para o concreto comprimido e para toda a armadura tem-se tensão proporcional à deformação. 


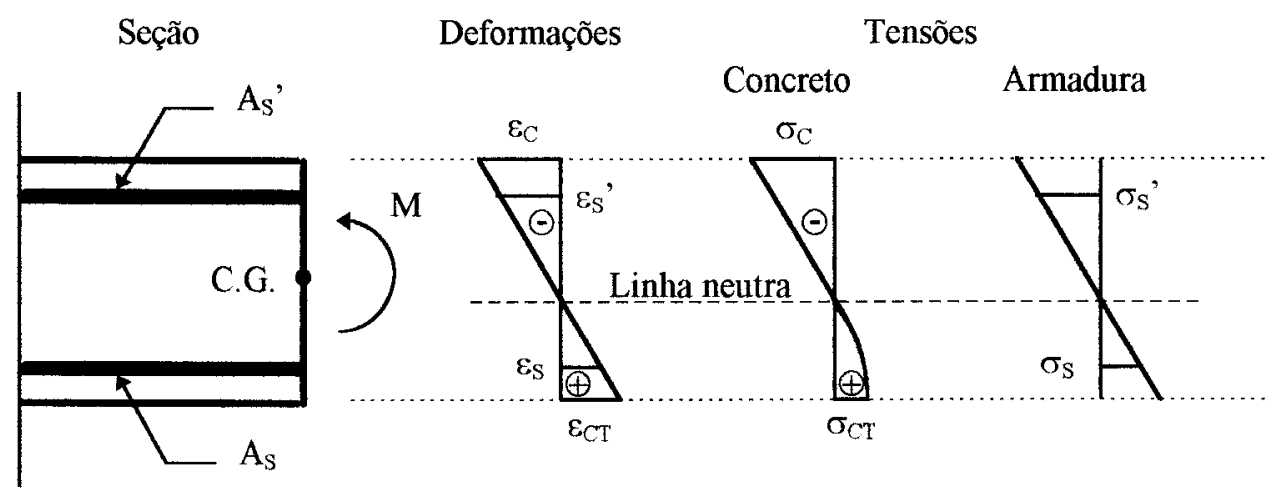

FIGURA 6.2 - Diagrama de tensão e de deformação para Estádio $I_{b}$.

- Estádio II, cujos diagramas de tensão e de deformação estão apresentados na figura 6.3, é caracterizado por seção fissurada com comportamento elástico linear para o concreto comprimido e para toda a armadura, desprezando-se a resistência à tração do concreto que ainda não fissurou. Neste caso, a deformação do concreto tracionado ultrapassa o limite de ruptura, fazendo com que haja a fissuração da região tracionada. Para o restante continua valendo a proporcionalidade entre tensão e deformação.

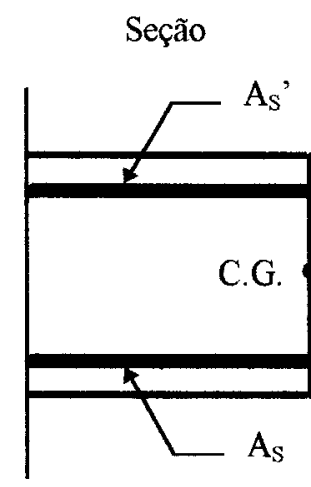

Deformações

Tensões

$A_{S}$

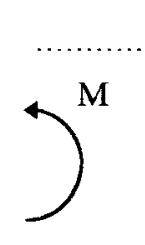

$A_{S}$
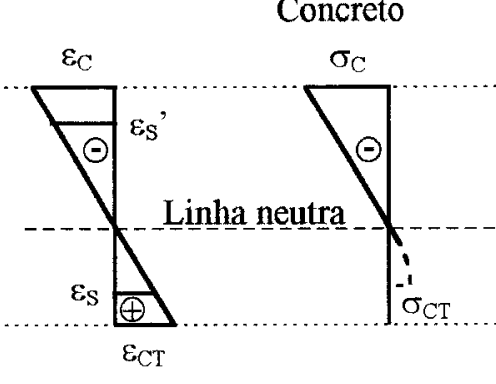

$\sigma_{\mathrm{S}}$

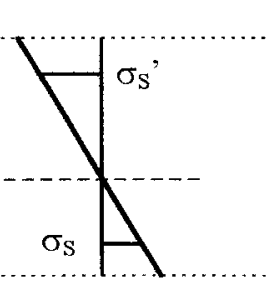

FIGURA 6.3 - Diagramas de tensão e de deformação para Estádio II. 
Para finalizar, a figura 6.4 apresenta os diagramas de tensão e de deformação referentes ao Estádio III, que é caracterizado por seção fissurada com plastificação do concreto comprimido e/ou da armadura, desprezando-se a resistência à tração do concreto que ainda não fissurou. Neste caso, a deformação do concreto comprimido supera o limite de proporcionalidade, atingindo o valor último da resistência para o ponto mais solicitado, fazendo com que o comportamento seja não-linear.

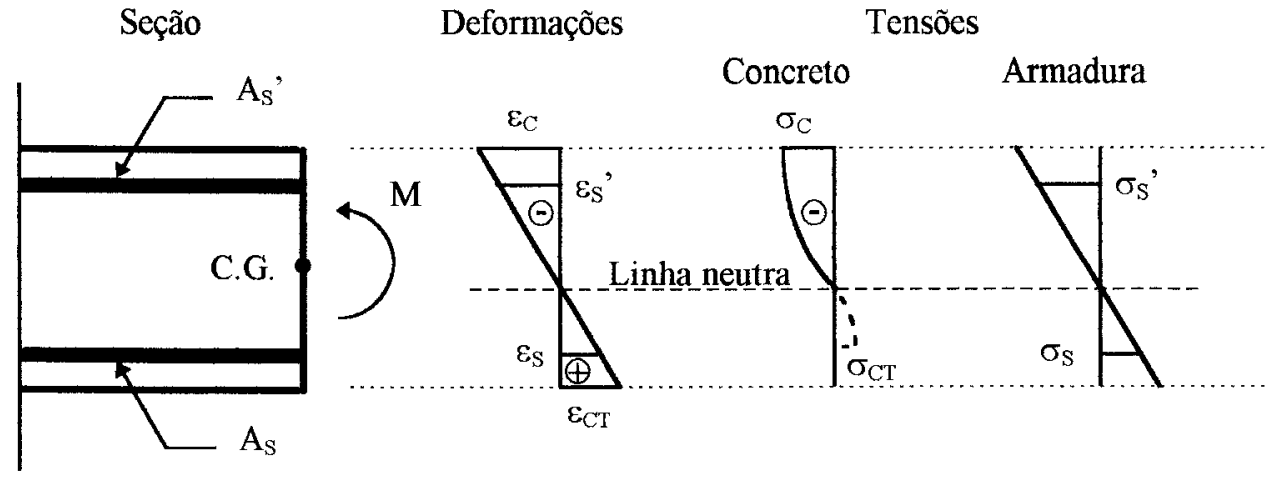

FIGURA 6.4 - Diagramas de tensão e de deformação para Estádio III.

Dessa forma, quando o cálculo das dimensões do elemento é feito admitindo-se o Estádio III como referência, considera-se que 0 elemento será dimensionado no estado limite último.

Por outro lado, para quantificar se a deformação é excessiva ou se a abertura das fissuras é compatível com as especificações de projeto, utilizam-se os conceitos pertinentes aos Estádios $I$ e II, configurando-se a verificação do elemento contra os estados limites de utilização.

Cabe ressaltar que nestes casos devem-se considerar coeficientes de ponderação que levam em conta a possibilidade de desvios das ações, a probabilidade de redução das solicitações, as aproximações nas hipóteses da cálculo e as inexatidões geométricas na construção. 


\title{
6.3 - Comportamento em serviço do concreto armado
}

\begin{abstract}
Quando um sistema estrutural está realmente trabalhando, os materiais utilizados não devem atingir a sua capacidade máxima resistente, configurando-se, assim, o comportamento em serviço da estrutura. Neste caso, para verificar tal comportamento, utilizam-se os conceitos dos Estádios I e II, conforme visto no item anterior.

Desse modo, deve-se elaborar um equacionamento referente a uma seção de concreto armado nos Estádios I e II, para que se possa avaliar a deslocabilidade real de uma estrutura aporticada composta por elementos de concreto armado, conforme será visto na sequiência deste trabalho.
\end{abstract}

\section{3 .1 - Disposições geométricas}

A seção transversal do elemento estrutural que será utilizada no estudo de pórticos planos é composta por uma seção retangular de concreto, com armadura disposta nas quatro faces, conforme mostra a figura 6.5.

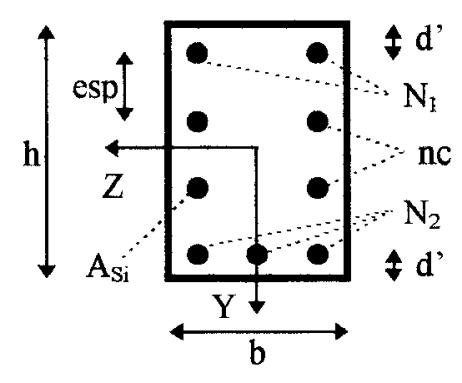

FIGURA 6.5 - Disposições geométricas de uma seção retangular de concreto armado.

A característica principal da seção transversal mostrada na figura 6.5 é dada pela simetria existente 
com relação ao eixo "Y", de tal forma que a flexão normal composta se dê em torno do eixo "Z". Já as disposições geométricas são dadas por:

" $A_{S i}$ " é a área da seção transversal de cada barra de aço, que por simetria deve ser constante, ou seja, $\AA_{S i}=A_{S}$; " $\mathrm{N}_{1}$ " é o número de barras da camada mais próxima à borda superior;

" $\mathrm{N}_{2}$ " é o número de barras da camada mais próxima à borda inferior;

"nc" é o número de camadas intermediárias entre $\mathrm{N}_{1}$ e $\mathrm{N}_{2}$; "d." é o cobrimento da armadura;

"b" é a largura da seção transversal;

"h" é a altura da seção transversal;

"esp" é o espaçamento entre camadas, calculado pela equação (6.1), RODRIGUES (1992) .

$$
\operatorname{esp}=\frac{h-2 d^{\prime}}{n c+1}
$$

\subsection{2 - Parâmetros auxiliares}

Uma vez definida a resistência característica do concreto à compressão " $f_{\mathrm{CK}}$ ", o valor do módulo de elasticidade secante para solicitações em serviço pode ser avaliado, CEB(1978), por:

$$
E_{C M}=950\left(10 f_{C K}+8\right)^{1 / 3}
$$

onde os valores de " $\mathrm{f}_{\mathrm{CK}}$ " e de " $\mathrm{E}_{\mathrm{CM}}$ " são dados em $\mathrm{kN} / \mathrm{cm}^{2}$. Já a resistência média do concreto à tração pode ser avaliada, CEB(1978), por: 


$$
f_{C T M}=0,139\left(f_{C K}\right)^{2 / 3}
$$

onde os valores de " $f_{\mathrm{CTM}}$ " e de " $\mathrm{f}_{\mathrm{CK}}$ " são dados em $\mathrm{kN} / \mathrm{cm}^{2}$.

Para o cálculo do momento de fissuração na flexão composta utiliza-se a equação (6.4), CEB(1978), dada por:

$$
M_{R}=\left(f_{C T M}-\frac{N}{A_{1}}\right) W_{1}
$$

onde

"N" é a força normal, sendo positiva para tração;

" $\mathrm{A}_{1}$ " é a área da seção homogeneizada no Estádio $I_{a}$;

" $W_{1}$ " é o módulo de resistência da seção homogeneizada no Estádio $I_{a}$, dada pela equação (6.5);

$$
W_{1}=\frac{I_{1}}{y}
$$

sendo

" $Y$ " a distância do centro geométrico no Estádio $I_{a}$ até a borda mais tracionada;

"I ${ }_{1}$ o momento de inércia da seção homogeneizada no Estádio $I_{a}$.

Com relação ao módulo de elasticidade longitudinal da armadura, deve-se obter o valor de tal módulo em função do tipo de aço utilizado como armadura principal, podendo-se adotar como exemplo o valor dado por:

$$
E_{s}=21000,0 \mathrm{kN} / \mathrm{cm}^{2}
$$


Finalmente, pode-șe definir 0 coeficiente de equivalência da armadura passiva pela equação (6.7):

$$
\alpha_{S}=\frac{E_{S}}{E_{C}}
$$

onde o valor de " $E_{C}$ " é calculado pela equação (6.2).

\subsection{3 - Equacionamento no Estádio $I_{a}$}

Para dar início ao equacionamento, se faz necessário efetuar a homogeneização da seção transversal, MACHADO(1989), mostrada na figura 6.5, utilizando-se a equação (6.8) dada por:

$$
A_{C S i}=\alpha_{S} A_{S i}
$$

onde "Acsi" é a área de concreto equivalente à área da armadura "Asi". Esta relação se deve à perfeita aderência entre a armadura e o concreto envolvente, fazendo com que ambos tenham a mesma deformação.

Desse modo, a área da seção homogeneizada " $\mathrm{A}_{1}$ " para - Estádio $I_{a}$ é dada por:

$$
A_{1}=b h+2\left(\alpha_{S}-1\right) A_{S} n c+\left(\alpha_{S}-1\right) A_{S} N_{1}+\left(\alpha_{S}-1\right) A_{S} N_{2}
$$

Já as equações de equilíbrio podem ser elaboradas utilizando-se a figura 6.6, através do equilíbrio entre os esforços internos e externos. 


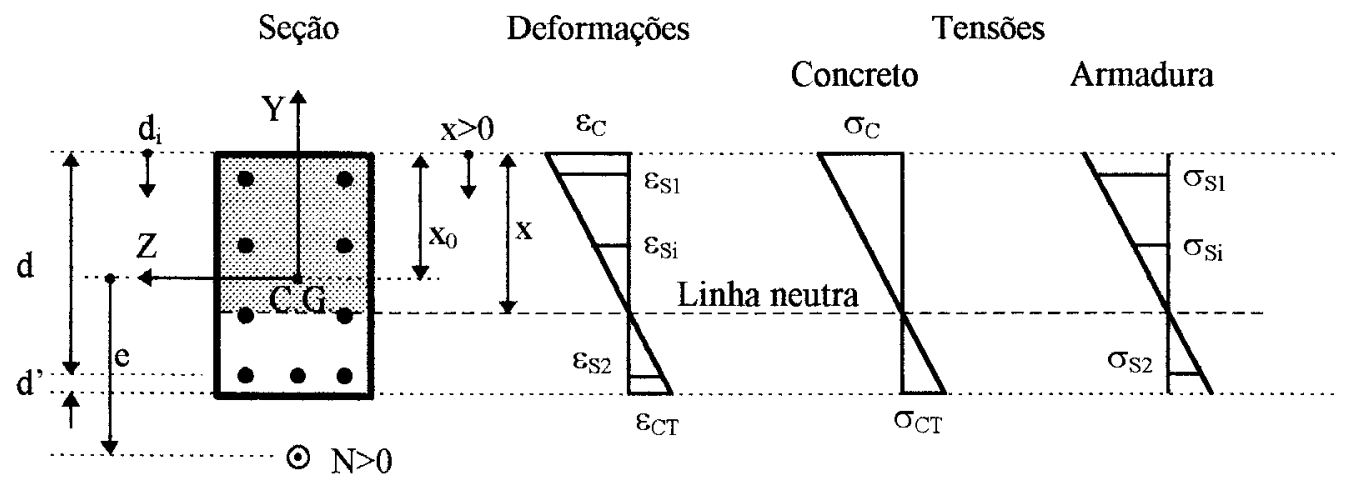

FIGURA 6.6 - Seção transversal submetida à flexão normal composta. Estádio $I_{a}$.

Logo, o equilíbrio para a força normal é dado por:

$$
\begin{aligned}
N= & \frac{\sigma_{C}}{x}\left\{\frac{b x^{2}}{2}-\frac{b(x-h)^{2}}{2}+2\left(\alpha_{S}-1\right) A_{S} \sum_{i=1}^{n c}\left(x-d_{i}\right)+\right. \\
& \left.\left(\alpha_{S}-1\right) A_{S} N_{1}\left(x-d^{\prime}\right)+\left(\alpha_{S}-1\right) A_{S} N_{2}(x-d)\right\}
\end{aligned}
$$

onde

"di" é a distância da borda superior até a camada "i" da armadura;

"x" é a distância da borda superior até a linha neutra; " $N$ " é a força normal atuante;

ou, simplesmente,

$$
N=\frac{\sigma_{C}}{x} S_{L . N}
$$

sendo 


$$
\begin{aligned}
S_{L . N .}= & \frac{b x^{2}}{2}-\frac{b(x-h)^{2}}{2}+2\left(\alpha_{S}-1\right) A_{S} \sum_{i=1}^{n c}\left(x-d_{i}\right)+ \\
& \left(\alpha_{S}-1\right) A_{S} N_{1}\left(x-d^{\prime}\right)+\left(\alpha_{S}-1\right) A_{S} N_{2}(x-d)
\end{aligned}
$$

que é o momento estático em relação à linha neutra para Estádio $I_{a}$.

Analogamente, o equilíbrio para o momento fletor é dado por:

$$
\begin{aligned}
N\left(e-x_{0}-x\right)= & \frac{\sigma_{C}}{x}\left\{\frac{b x^{3}}{3}-\frac{b(x-h)^{3}}{3}+2\left(\alpha_{S}-1\right) A_{S} \sum_{i=1}^{n c}\left(x-d_{i}\right)^{2}+\right. \\
& \left.\left(\alpha_{S}-1\right) A_{S} N_{1}\left(x-d^{\prime}\right)^{2}+\left(\alpha_{S}-1\right) A_{S} N_{2}(x-d)^{2}\right\}
\end{aligned}
$$

onde

"xo" é a distância da borda superior até o centro geométrico da seção;

" $e$ " é a excentricidade equivalente dada por:

$$
e=\frac{M}{N}
$$

" $M$ " é o momento fletor atuante;

ou, simplesmente,

$$
N\left(e-x_{0}-x\right)=\frac{\sigma_{C}}{x} I_{L . N}
$$


sendo

$$
\begin{aligned}
I_{L . N .}= & \frac{b x^{3}}{3}-\frac{b(x-h)^{3}}{3}+2\left(\alpha_{S}-1\right) A_{S} \sum_{i=1}^{n c}\left(x-d_{i}\right)^{2}+ \\
& \left(\alpha_{S}-1\right) A_{S} N_{1}\left(x-d^{\prime}\right)^{2}+\left(\alpha_{S}-1\right) A_{S} N_{2}(x-d)^{2}
\end{aligned}
$$

que é o momento de inércia em relação à linha neutra para Estádio $I_{a}$.

\subsection{4 - Equacionamento no Estádio II}

De forma análoga ao item anterior, a área da seção homogeneizada " $\mathrm{A}_{2}$ " para o Estádio II é dada por:

$$
\begin{aligned}
A_{2}= & A_{C C}+2\left(\alpha_{S}-1\right) A_{S} n c^{*}+2 \alpha_{S} A_{S}\left(n c-n c^{*}\right)+ \\
& \left(\alpha_{S}-1\right) A_{S} N_{1}+\alpha_{S} A_{S} N_{2}
\end{aligned}
$$

$(6.17)$

onde

"Acc" é a área bruta de concreto comprimido;

"nc*" é o número de camadas intermediárias entre $\mathrm{N}_{1}$ e $\mathrm{N}_{2}$ que se encontram na região comprimida.

Utilizando-se a figura 6.7, pode-se elaborar as equações de equilíbrio entre os esforços internos e externos, conforme as hipóteses pertinentes ao Estádio II. 


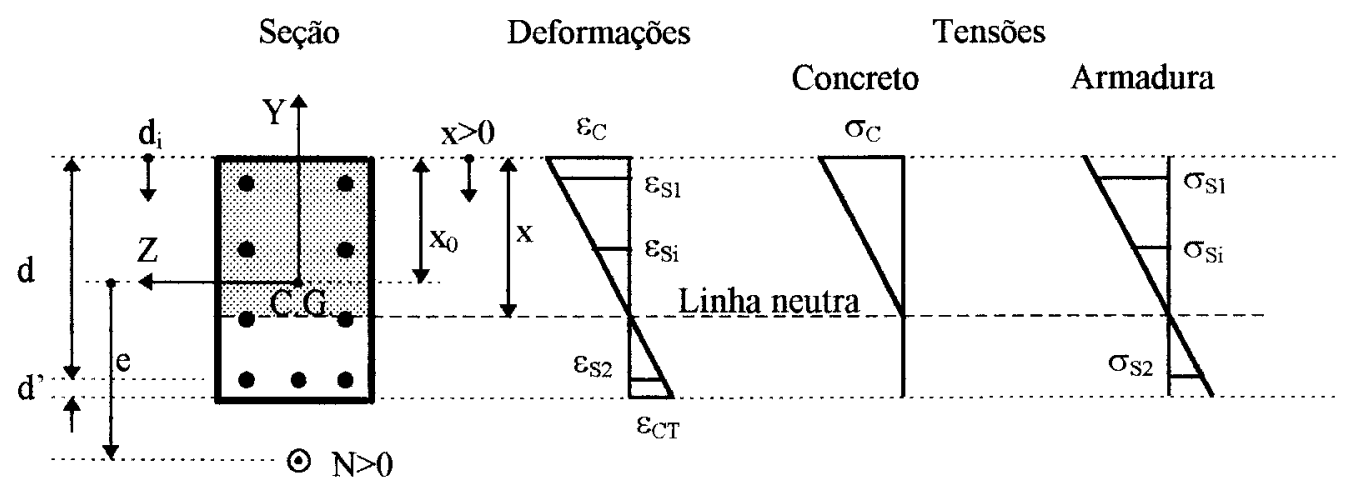

FIGURA 6.7 - Seção transversal submetida à flexão normal composta. Estádio II.

Para o equilíbrio da força normal, tem-se:

$$
\begin{aligned}
& N=\frac{\sigma_{C}}{x}\left\{\frac{b x^{2}}{2}-2 A_{S} \sum_{i=1}^{n c^{*}}\left(x-d_{i}\right)-A_{S} N_{1}\left(x-d^{\prime}\right)+\right. \\
& \left.2 \alpha_{S} A_{S} \sum_{i=1}^{n c}\left(x-d_{i}\right)+\alpha_{S} A_{S} N_{1}\left(x-d^{\prime}\right)+\alpha_{S} A_{S} N_{2}(x-d)\right\}
\end{aligned}
$$

sendo

$$
\begin{aligned}
& S_{L . N .}=\frac{b x^{2}}{2}-2 A_{S} \sum_{i=1}^{n c^{*}}\left(x-d_{i}\right)-A_{S} N_{1}\left(x-d^{\prime}\right)+ \\
& 2 \alpha_{S} A_{S} \sum_{i=1}^{n c}\left(x-d_{i}\right)+\alpha_{S} A_{S} N_{1}\left(x-d^{\prime}\right)+\alpha_{S} A_{S} N_{2}(x-d)
\end{aligned}
$$

que é o momento estático em relação à linha neutra para Estádio II.

Já o equilíbrio do momento fletor é dado por: 


$$
\begin{aligned}
N\left(e-x_{0}-x\right)= & \frac{\sigma_{C}}{x}\left\{\frac{b x^{3}}{3}-2 A_{S} \sum_{i=1}^{n c^{*}}\left(x-d_{i}\right)^{2}+2 \alpha_{S} A_{S} \sum_{i=1}^{n c}\left(x-d_{i}\right)^{2}+\right. \\
& \left.\left(\alpha_{S}-1\right) A_{S} N_{1}\left(x-d^{\prime}\right)^{2}+\alpha_{S} A_{S} N_{2}(x-d)^{2}\right\}
\end{aligned}
$$

sendo

$$
\begin{aligned}
I_{L . N .}= & \frac{b x^{3}}{3}-2 A_{S} \sum_{i=1}^{n c^{*}}\left(x-d_{i}\right)^{2}+2 \alpha_{S} A_{S} \sum_{i=1}^{n c}\left(x-d_{i}\right)^{2}+ \\
& \left(\alpha_{S}-1\right) A_{S} N_{1}\left(x-d^{\prime}\right)^{2}+\alpha_{S} A_{S} N_{2}(x-d)^{2}
\end{aligned}
$$

que é momento de inércia em relação à linha neutra para Estádio II.

Dessa forma, com as equações obtidas no presente item e no item anterior, pode-se apresentar os modelos físicos que serão utilizados neste trabalho, conforme será visto a seguir.

\section{4 - Modelos físicos não-lineares}

A finalidade especifica deste item refere-se à apresentação, de forma sucinta, dos modelos físicos nãolineares propostos pelo CEB(1985) e pelo ACI(1983), de tal forma que se possa efetuar a sua implementação na análise dinâmica de estruturas aporticadas planas de concreto armado. 


\subsection{1 - Modelo do CEB}

O modelo proposto pelo CEB(1985) consiste no cálculo de uma curvatura média dada pela equação (6.22), sendo:

$$
\frac{1}{r_{m}}=\left(1-\xi_{0}\right) \frac{1}{r_{1}}+\xi_{0}\left(\frac{1}{r_{2}}+\frac{1}{r_{2 N}}\right)
$$

onde

" $1 / r_{\mathrm{m}} "$ é a curvatura média para flexão combinada com força axial;

" $1 / r_{1} "$ é a curvatura total no Estádio $I_{a}$ para flexão simples;

" $1 / r_{2} "$ é a curvatura total no Estádio II para flexão simples;

" $1 / r_{2 \mathrm{~N}}$ " é a curvatura devida ao efeito do momento fletor causado pela força normal atuando no centro geométrico da seção total no Estádio $I_{a}$;

" $\xi_{0} "$ é o coeficiente de distribuição.

Neste caso, a curvatura total no Estádio $I_{a}$ é dada por:

$$
\frac{1}{r_{1}}=\frac{M}{E_{C M} I_{1}}
$$

onde

"M" é o momento fletor atuante;

" $E_{\mathrm{CM}}$ " é o módulo de elasticidade dado pela equação (6.2); " $I_{1}$ " é $O$ momento de inércia no Estádio $I_{a}$ dado pela equação (6.16) . 
Analogamente, a curvatura total no Estádio II é dada por:

$$
\frac{1}{r_{2}}=\frac{M}{E_{C M} I_{2}}
$$

onde

" $I_{2}$ " é 0 momento de inércia no Estádio II dado pela equação (6.21) .

Já a curvatura " $1 / r_{2 N}$ " é dada por:

$$
\frac{1}{r_{2 N}}=\frac{N\left(x_{1}-x_{2}\right)}{E_{C M} I_{2}}
$$

onde

" $\mathrm{x}_{1}$ " é a posição da linha neutra para Estádio $I_{a}$, dada pela equação (6.12) fazendo-se $\mathrm{S}_{\mathrm{L} . \mathrm{N} .}=0$;

" $x_{2}$ " é a posição da linha neutra para Estádio II, dada pela equação (6.19) fazendo-se $\mathrm{S}_{\mathrm{L} . \mathrm{N} .}=0$;

"N" é a força normal atuante.

Para o cálculo do coeficiente de distribuição utiliza-se a seguinte sistemática:

$p^{\prime} \sqrt{\beta_{1} \beta_{2}} M_{R} \geq M_{0} \Rightarrow\left\{\begin{array}{l}M \geq M_{R} \Rightarrow \xi_{0}=1-\left(\frac{\sqrt{\beta_{1} \beta_{2}} M_{R}-M_{0}}{M-M_{0}}\right)^{2} \\ M\left\langle M_{R} \Rightarrow \xi_{0}=0\right.\end{array}\right.$ 


$$
p / \sqrt{\beta_{1} \beta_{2}} M_{R}\left\langleM _ { 0 } \Rightarrow \left\{\begin{array}{l}
M \geq M_{R} \Rightarrow \xi_{0}=1 \\
M\left\langle M_{R} \Rightarrow \xi_{0}=0\right.
\end{array}\right.\right.
$$

onde

" $\boldsymbol{\beta}_{1}$ " é o coeficiente que quantifica a aderência da armadura, sendo $\beta_{1}=1,0$ para barras com alta aderência e $\beta_{1}=0,5$ para barras Iisas;

" $\beta_{2}$ " é o coeficiente que quantifica a influência da duração de aplicação do carregamento, sendo $\beta_{2}=1,0$ para primeiro carregamento e $\beta_{2}=0,5$ para carregamentos longos ou cíclicos;

" $M_{R}$ " é o momento de fissuração dado pela equação (6.4); " $\mathrm{M}_{0}$ " é o momento limite entre Estádio $\mathrm{I}_{a}$ e II dado por:

$$
M_{0}=-\frac{N\left(x_{1}-x_{2}\right)}{1-\left(\frac{I_{2}}{I_{1}}\right)}
$$

Dessa forma, uma vez calculada a curvatura média, dada pela equação (6.22), pode-se calcular o momento de inércia médio " $I_{M}$ " através da equação (6.28) dada por:

$$
I_{M}=\frac{1}{\left(\frac{1}{r_{m}}\right)} \frac{M}{E_{C M}}
$$

Conforme visto anteriormente, a curvatura média utilizada na equação (6.28) é calculada em função da curvatura no Estádio $I_{a}$ e no Estádio II através da 
utilização de um coeficiente de distribuição. Assim, quando o elemento começa a fissurar, o coeficiente se torna diferente de zero, fazendo com que a curvatura seja afetada pelo efeito da fissuração no concreto. Com isso, considera-se o efeito que a fissuração tem no cálculo do momento de inércia somente para os elementos que começaram a fissurar.

\section{4 .2 - Modelo do ACI}

O modelo proposto pelo ACI(1983) consiste no cálculo direto de um momento de inércia equivalente dado pela equação (6.29), sendo:

$$
I_{E}=\left(\frac{M_{R}}{M}\right)^{3} I_{B}+\left\{1-\left(\frac{M_{R}}{M}\right)^{3}\right\} I_{2}
$$

onde

"I ${ }_{B}$ " é o momento de inércia da seção bruta de concreto, desconsiderando-se a armadura;

" $I_{2}$ " é o momento de inércia no Estádio II dado pela equação (6.21);

" $M_{R}$ " é o momento de fissuração dado por:

$$
M_{R}=\frac{0,7 I_{B} \sqrt{f_{C K}}}{\mathrm{y}_{\mathrm{B}}}
$$

sendo " $\mathrm{y}_{\mathrm{B}}$ " a distância do centro geométrico da área bruta de concreto, desconsiderando-se a armadura, até a fibra mais tracionada e " $\mathrm{f}_{\mathrm{CK}}$ " dado em MPa. 
De forma análoga ao modelo proposto pelo CEB, o modelo do ACI também faz uma média entre o momento de inércia para seção não fissurada e seção fissurada, toda vez que o momento atuante for maior que o momento de fissuração. Dessa forma, considera-se a fissuração no cálculo do momento de inércia para cada elemento. Entretanto, cabe ressaltar que este modelo não contempla o efeito produzido pela força normal.

\section{5 - Modelagem numérica}

Analogamente ao item 5.5 deste trabalho, para introduzir a não-linearidade física na análise de estruturas aporticadas de concreto armado sujeitas à ações dinâmicas, faz-se necessário a implementação numérica dos modelos do $\mathrm{CEB}$ e do ACI, conforme visto no item anterior.

Tal implementação ficará restrita à criação de um algoritmo computacional compativel com os modelos já mencionados e à sua adequação ao programa "DINAPORT" para análise estrutural.

\section{5 .1 - Aspectos gerais}

Conforme dito anteriormente, $\circ$ equacionamento básico que será utilizado na elaboração do algoritmo computacional já foi apresentado no item 6.4 deste trabalho.

Sendo assim, pode-se abordar o problema de uma forma mais destacada e apresentar a rotina de cálculo especifica, conforme será visto na seqüência. 


\subsubsection{1 - Colocação do problema}

Admitindo-se que sejam conhecidos o valor da força normal e o valor do momento fletor que atuam em um elemento finito qualquer, bem como as suas características geométricas, pretende-se calcular o valor do momento de inércia específico "I" que será utilizado no cálculo das forças restauradoras, em função da fissuração do concreto que ocorre no mesmo.

Este cálculo deve contemplar o carregamento e o descarregamento que podem ocorrer durante uma análise dinâmica, inclusive prevendo a possibilidade de inversão de esforços.

$\mathrm{Na}$ sequiência, destaca-se a rotina que será utilizada no programa "DINAPORT".

\subsubsection{2 - Rotina de cálculo}

A rotina de cálculo elaborada é apresentada nas figuras 6.8 e 6.9 de maneira esquemática, onde é mostrada a sequiência de cálculos a ser executada através de desvios condicionais e incondicionais, respectivamente para o modelo do $\mathrm{CEB}$ e do ACI.

os diagramas de blocos apresentados em tais figuras contém as mesmas particularidades, onde inicialmente são efetuados os cálculos das caracteristicas geométricas e físicas de cada elemento finito. Na sequência, é realizado um teste para verificar se o elemento está fissurado (F) ou não (V). Após tal verificação, para qualquer um dos dois casos, é realizado outro teste para verificar se o elemento está sendo descarregado (F) ou se está sendo carregado (V). Quando o elemento está fissurado e está sendo carregado, calcula-se o momento de inércia médio ou equivalente. Já para o caso do 
elemento não estar fissurado e estar sendo carregado, adota-se o momento de inércia no Estádio I ou o momento de inércia da seção bruta de concreto.

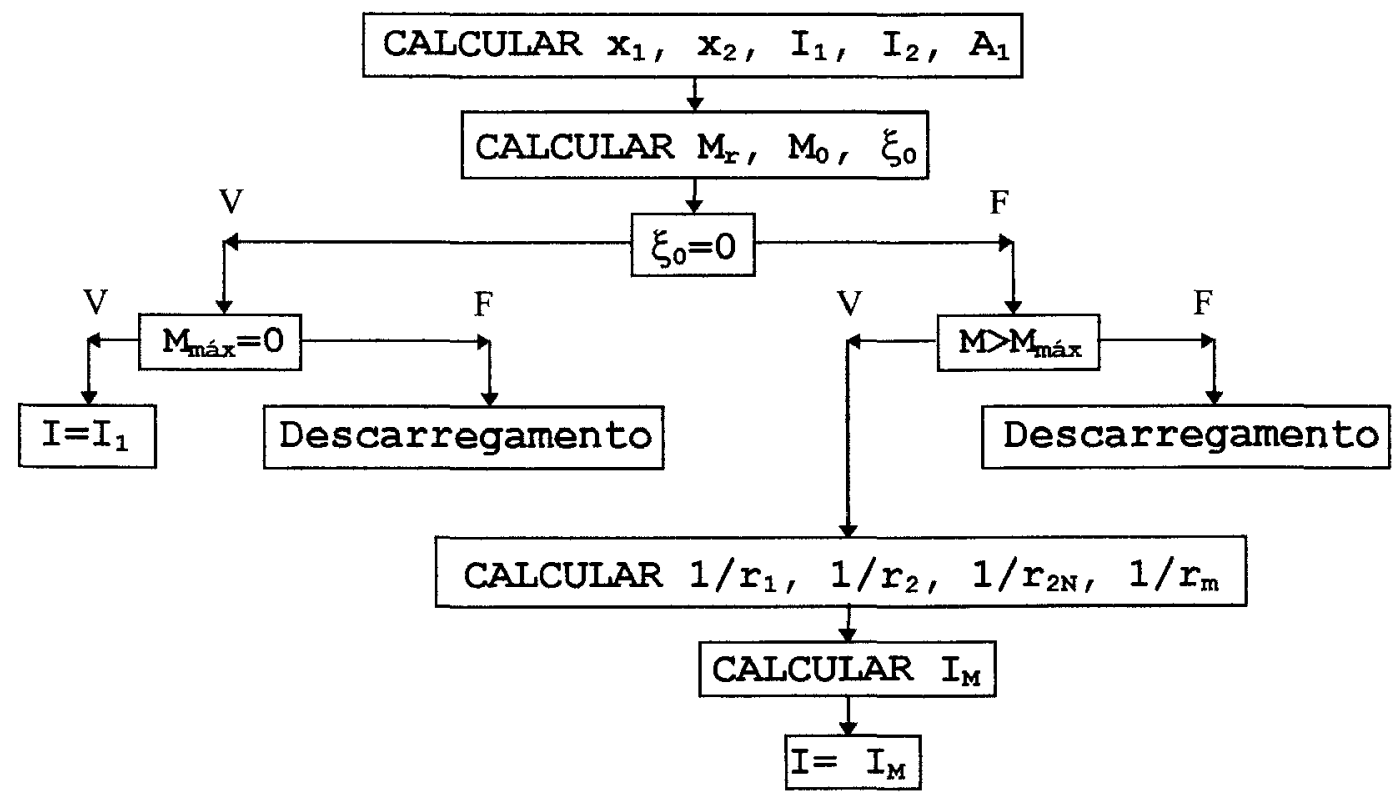

FIGURA 6.8 - Diagrama de blocos para o modelo físico do CEB.

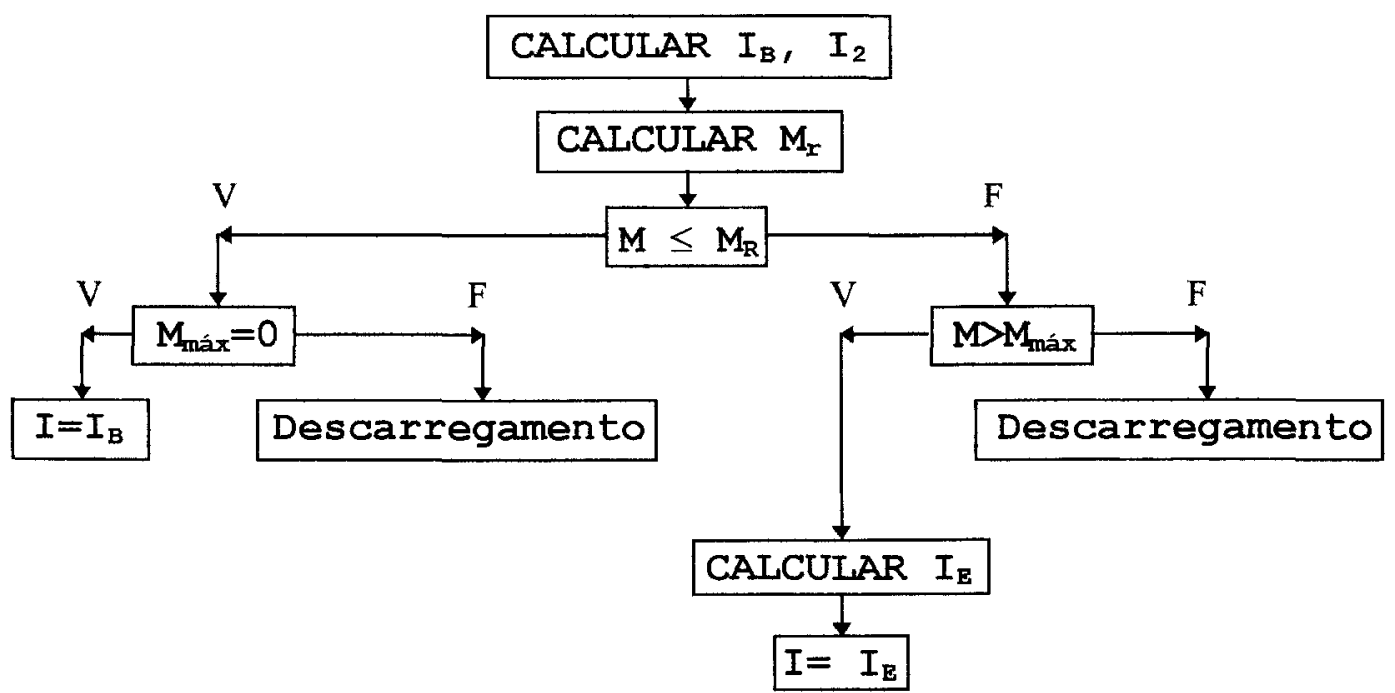

FIGURA 6.9 - Diagrama de blocos para o modelo físico do ACI. 


\subsubsection{3 - Descarregamento e inversão de} carregamento.

A figura 6.10 ilustra graficamente a evolução da curvatura em função do momento fletor atuante, onde o Estádio I é caracterizado pelo trecho "O-A", uma vez que - momento aplicado no elemento ainda não atingiu o momento de fissuração. Uma vez atingido tal momento, inicia-se uma ponderação entre as curvaturas do Estádio I e Estádio II, resultando uma curva dada pelo trecho "A-B", caracterizando, assim, o efeito não-linear.

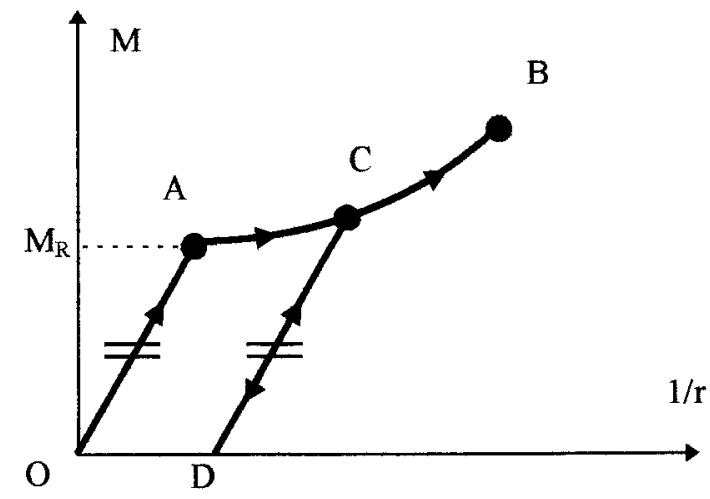

FIGURA 6.10 - Diagrama momento-curvatura.

Quando o momento fletor atuante já tiver ultrapassado o momento de fissuração, o descarregamento do elemento será feito conforme indicado pelo trecho "CD", considerando-se que tal trecho seja paralelo ao trecho "O-A", CORRÊA(1991) e ENSAIO(1995). Logo, o momento de inércia adotado no descarregamento será o momento de inércia do Estádio I ou da seção bruta de concreto, conforme modelo adotado.

Já a inversão de carregamento será feita de forma análoga ao modelo independente mostrado no item 5.4.2 deste trabalho. 


\section{5 .2 - Aspectos computacionais}

De forma análoga ao item 5.5.2 deste trabalho, utilizam-se as rotinas de cálculo descritas no item anterior para a implementação computacional da nãolinearidade física, através do cálculo específico das forças restauradoras. Na sequiência, apresenta-se a documentação básica relativa ao código computacional da subrotina "FORÇAS RESTAURADORAS" descrita no item 3.5.2.H, através do respectivo diagrama de blocos e da descrição das funções internas existentes.

\subsubsection{1 - Esquema de cálculo}

A figura 6.11 mostra o diagrama de blocos referente ao esquema de cálculo utilizado, onde cada bloco contém a descrição das funções internas que serão desenvolvidas na subrotina "FORÇAS RESTAURADORAS".

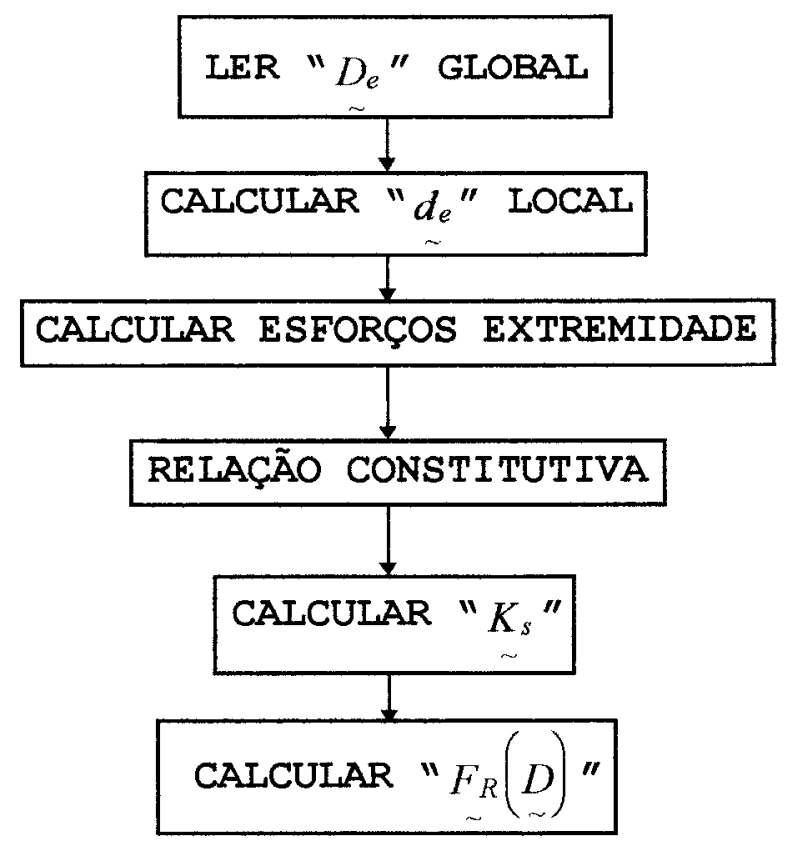

FIGURA 6.11 - Diagrama de blocos interno da subrotina "FORÇAS RESTAURADORAS". 
Cabe salientar que tal esquema foi utilizado na elaboração do programa computacional "DINAPORT", relativo à análise estrutural de pórticos planos.

\subsubsection{2 - Descrição das funções internas}

Na sequiência, faz-se um detalhamento de cada função interna descrita no diagrama de blocos contido na figura 6.11 .

\section{A - Bloco "LER " $D_{e}$ " GLOBAL"}

Este bloco tem a função de capturar os deslocamentos globais " $D$ " que ocorrem na extremidade de cada elemento "e".

\section{B - Bloco "CALCULAR " $d_{e}$ " LOCAL"}

O cálculo dos deslocamentos locais " $d$ " que ocorrem na extremidade de cada elemento "e" é feito utilizandose a seguinte equação:

$$
d_{e}=r D_{e}
$$

sendo " $r$ " a matriz que contém os co-senos diretores de cada elemento, dada pela relação (4.117). 


\section{C - BIOCO "CALCULAR ESFORÇOS DE EXTREMIDADE"}

O cálculo dos esforços de extremidade " $E E$ " de cada elemento " $e$ " é feito utilizando-se a equação dada por:

$$
E E_{e}=k_{S e} d_{e}+c \dot{d}_{e}+m \ddot{d}_{e}
$$

sendo " $k_{S}$ " a matriz secante do elemento "e", utilizandose o último momento de inércia calculado.

\section{D - BIOCO "RELAÇÃO CONSTITUTIVA"}

Este bloco já foi discutido no item 6.5 .1 .2 deste trabalho, onde ao final da execução dos cálculos, obtémse o valor corrigido do momento de inércia, em função dos valores dos esforços de extremidade calculados no item anterior.

\section{E - Bloco "CALCULAR " $K_{S}$ ""}

Com o valor dos momentos de inércia corrigidos para cada elemento, monta-se a matriz de rigidez secante global da estrutura.

$$
\text { F - Bloco "CALCULAR " } F_{R}(D) \text { " " }
$$

Neste bloco calcula-se a força restauradora de todo o sistema estrutural utilizando-se a seguinte equação: 


$$
\underset{\sim}{F_{R}}(\underset{\sim}{D})=\underset{\sim}{K_{S}} \underset{\sim}{D}
$$

sendo " $D$ " o vetor dos deslocamentos globais de toda a estrutura. 


\section{CAPÍTULO 7 - ANÁLISE NUMÉRICA}

\section{1 - Generalidades}

Este capítulo visa a análise do comportamento estático e dinâmico de estruturas planas treliçadas e aporticadas, considerando-se as não-linearidades física e geométrica. Para tal, resolvem-se vários exemplos elucidativos para cada tipo de estrutura, onde procurase efetuar uma análise quantitativa e qualitativa dos resultados obtidos.

Para a resolução de tais exemplos utilizam-se os programas computacionais "DINATREL" e "DINAPORT", que fazem análise estática e dinâmica, respectivamente para treliças e pórticos planos. Já para a obtenção das freqüências naturais e dos modos de vibração de tais estruturas, utilizam-se os programas "AUTOTREL" e "AUTOPORT", que seguem a mesma lógica descrita anteriormente.

Na apresentação de cada exemplo exibem-se somente as respostas dos problemas estudados, sendo que no apêndice encontram-se os arquivos de dados pertinentes a cada exemplo, com a finalidade de esclarecer eventuais dúvidas quanto ao tipo de análise que é realizada.

os exemplos foram divididos em dois grupos, em função do tipo do sistema estrutural analisado, conforme será visto a seguir. 


\section{2 - Estruturas treliçadas}

\section{2 .1 - Exemplo T1}

A estrutura treliçada deste exemplo é composta por um elemento finito biapoiado, solicitada por uma força constante " $F$ " com o tempo, conforme figura 7.1.

Progr: : DIMATheL

Projeto : 100

$$
\begin{aligned}
& \mathrm{F}=10,0 \mathrm{kN} \\
& \omega_{1}=4478,4793 \mathrm{rad} / \mathrm{s}
\end{aligned}
$$

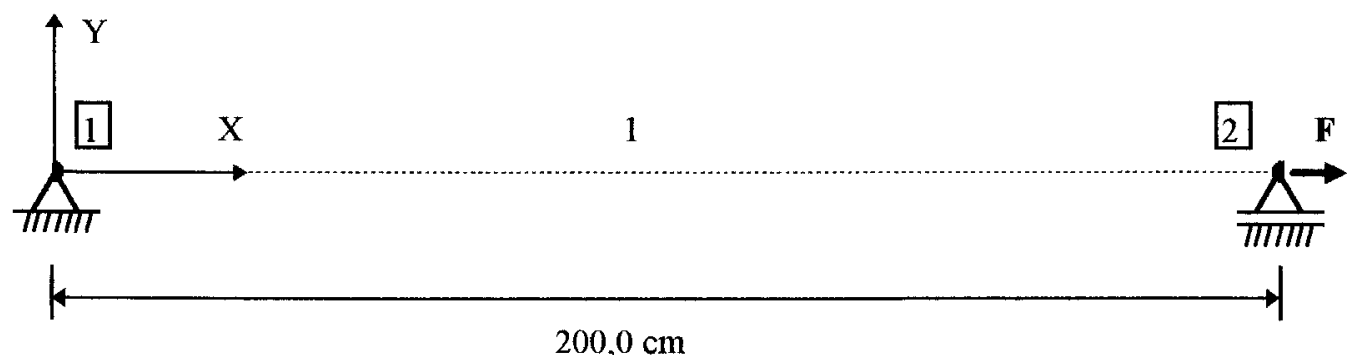

Inter. Tempo : 0

FIGURA 7.1 - Treliça constituída por apenas um elemento finito.

As características físicas e geométricas do elemento " 1 " são dadas por:

$$
\begin{gathered}
A=1,0 \mathrm{~cm}^{2} ; E=21000,0 \mathrm{kN} / \mathrm{cm}^{2} ; E_{\mathrm{T}}=0,0 \mathrm{kN} / \mathrm{cm}^{2} \\
\gamma=7,70.10^{-5} \mathrm{kN} / \mathrm{cm}^{3} ; \sigma_{\mathrm{ESC}}=15,0 \mathrm{kN} / \mathrm{cm}^{2}
\end{gathered}
$$

onde " $\gamma$ " é o peso específico do material. 
o primeiro passo importante para que se possa efetuar uma análise dinâmica de forma correta é dado pela escolha adequada do valor do intervalo de tempo " $\Delta t$ ", pois tal valor possibilitará a visualização do comportamento real da estrutura e evitará problemas de instabilidade numérica na resolução do sistema estudado, BATHE et al. (1973). Neste sentido, pode-se calcular o valor de " $\Delta t$ " pela relação (7.1), WARBURTON(1976), dada por:

\section{$\Delta t \leq 0,551 T$}

onde " $\mathrm{T}$ " é o período necessário para que o sistema desenvolva um ciclo completo de vibração, cujo valor é dado pela equação (7.2):

$$
T=\frac{2 \pi}{\omega_{1}}
$$

sendo " $\omega_{1}$ " calculado pela equação (4.134), com $i=1$, ou obtido pelo programa "AUTOTREL".

Inicialmente, para ilustrar a influência do valor do " $\Delta t$ " nos resultados, resolve-se o exemplo em questão considerando-se vários valores para " $\Delta t$ ", conforme ilustram as figuras 7.2, 7.3, 7.4, 7.5 e 7.6, sabendo-se que $\mathrm{T}=1,403 \cdot 10^{-3} \mathrm{~s}$. 


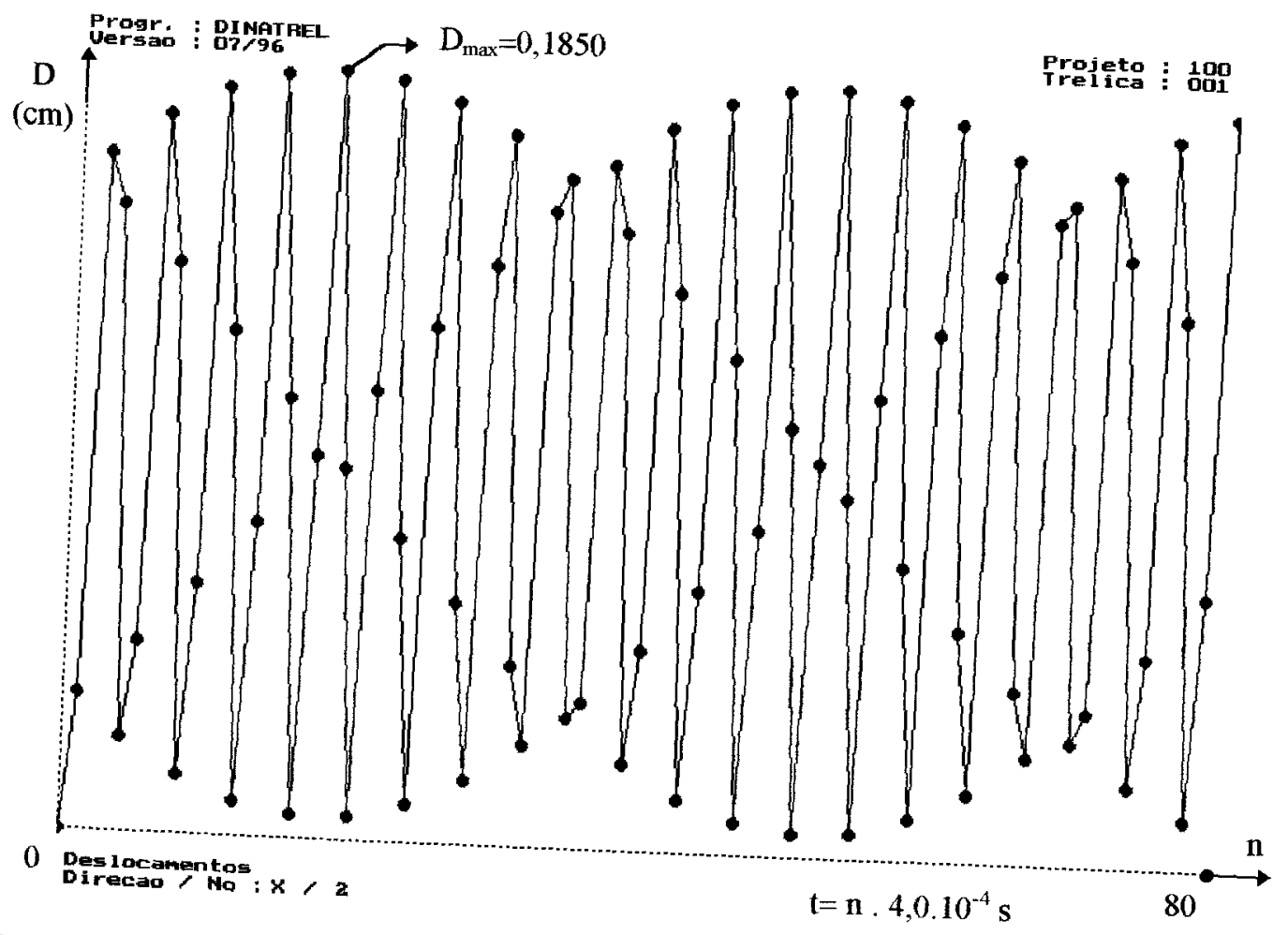

FIGURA 7.2 - Gráfico tempo x deslocamento considerandose $\Delta t=4,0.10^{-4} \mathrm{~s}$.

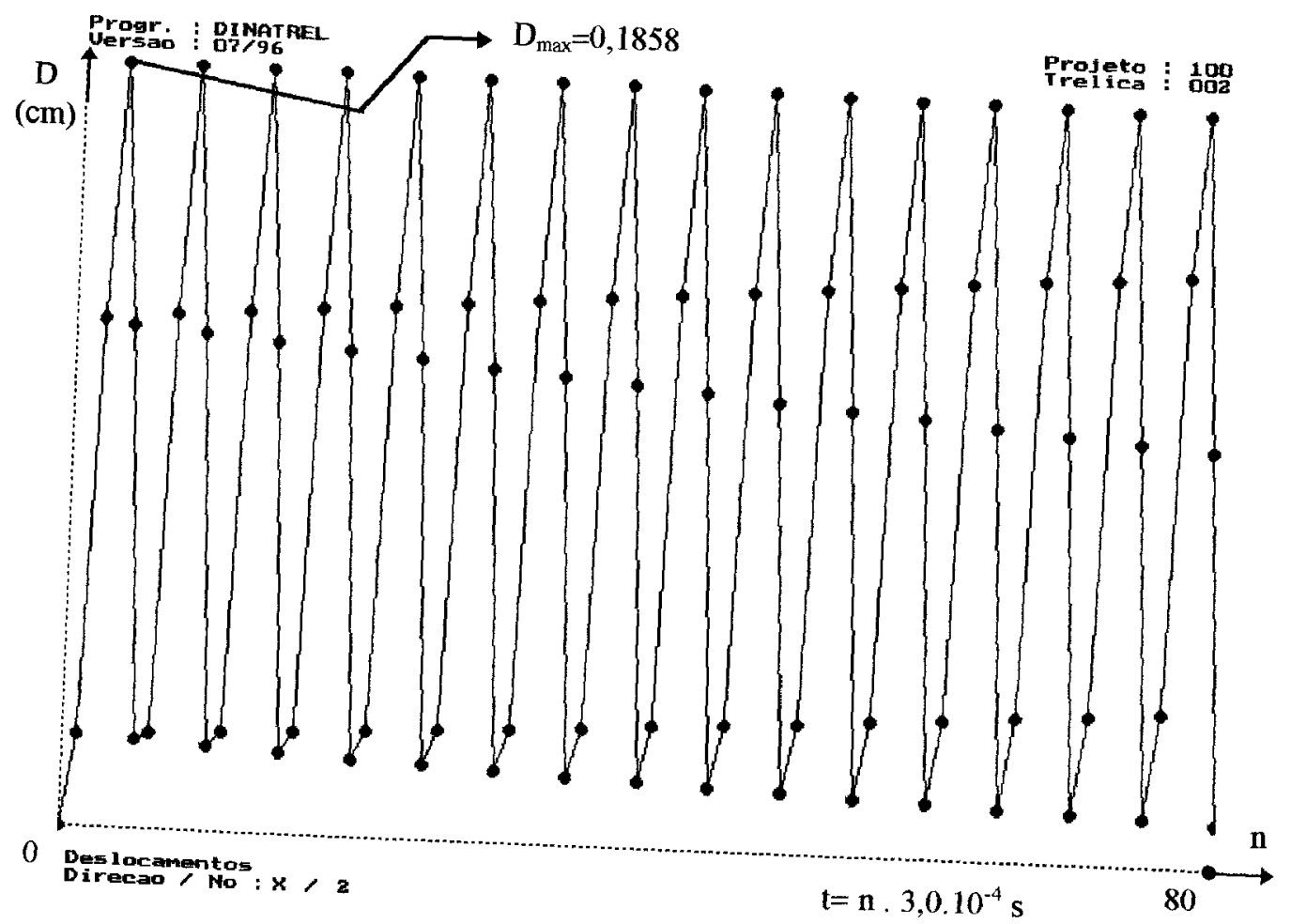

FIGURA 7.3 - Gráfico tempo $x$ deslocamento considerandose $\Delta t=3,0.10^{-4} \mathrm{~s}$. 


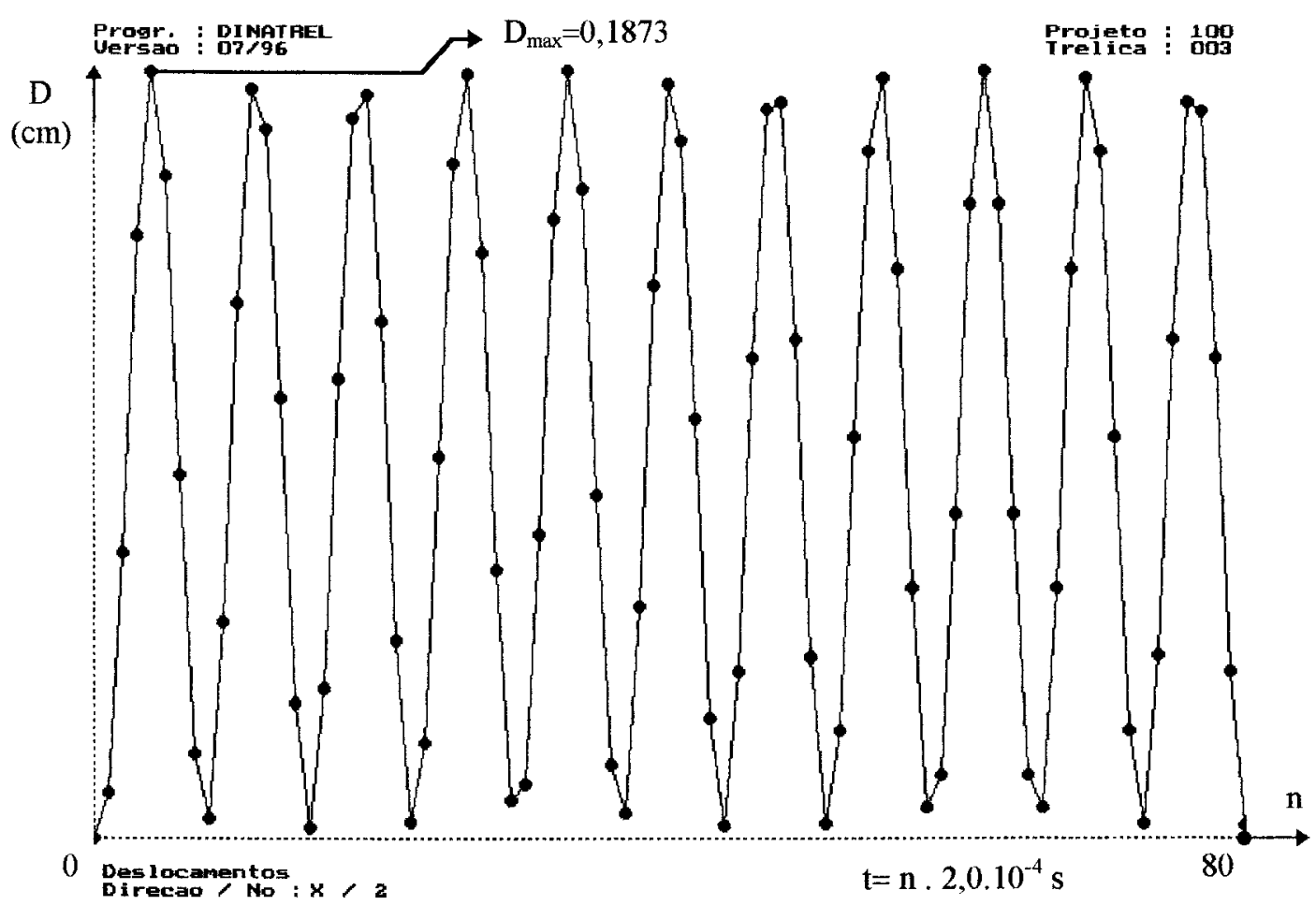

FIGURA 7.4 - Gráfico tempo x deslocamento considerandose $\Delta t=2,0.10^{-4} \mathrm{~s}$.

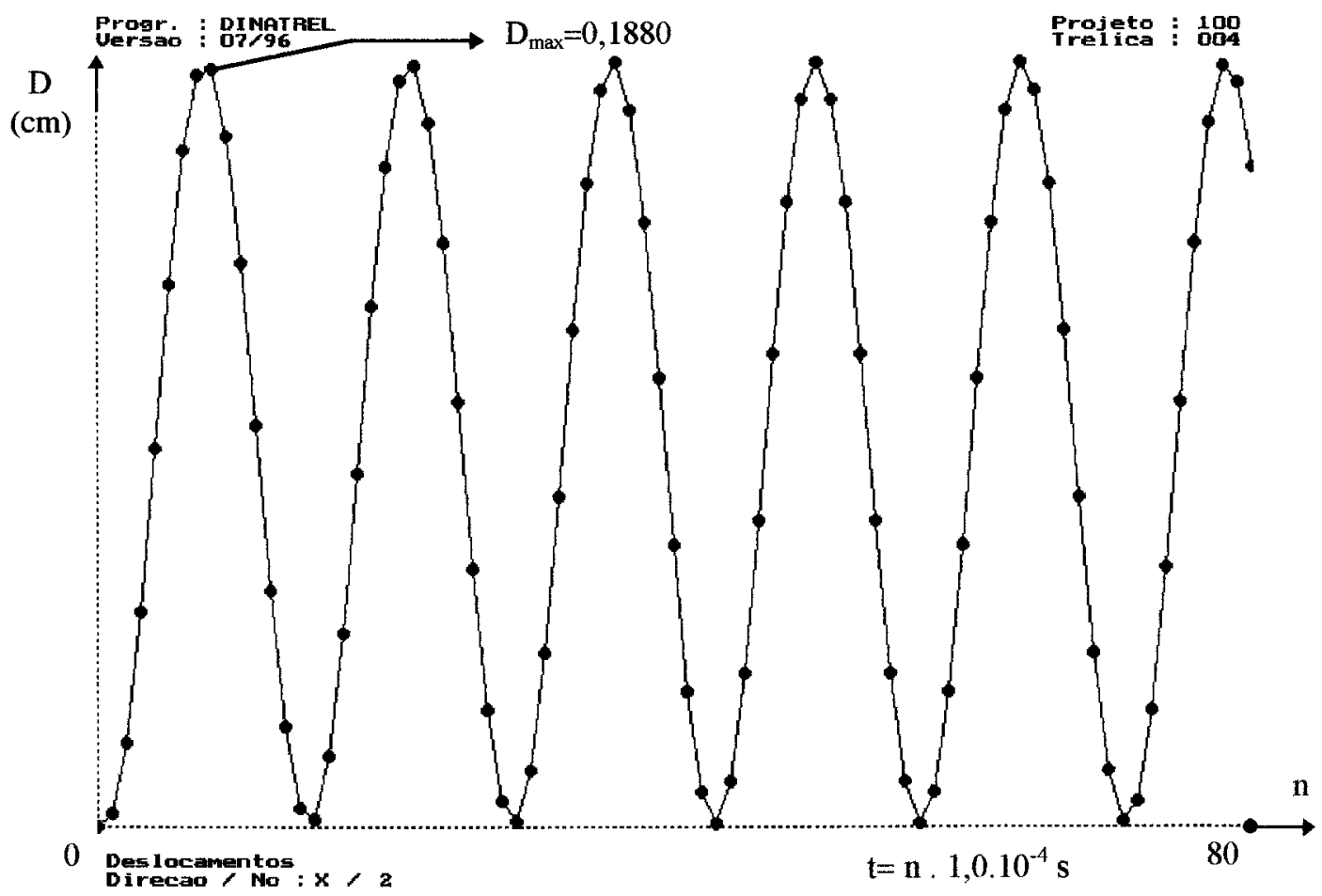

FIGURA 7.5 - Gráfico tempo x deslocamento considerandose $\Delta t=1,0.10^{-4} \mathrm{~s}$. 


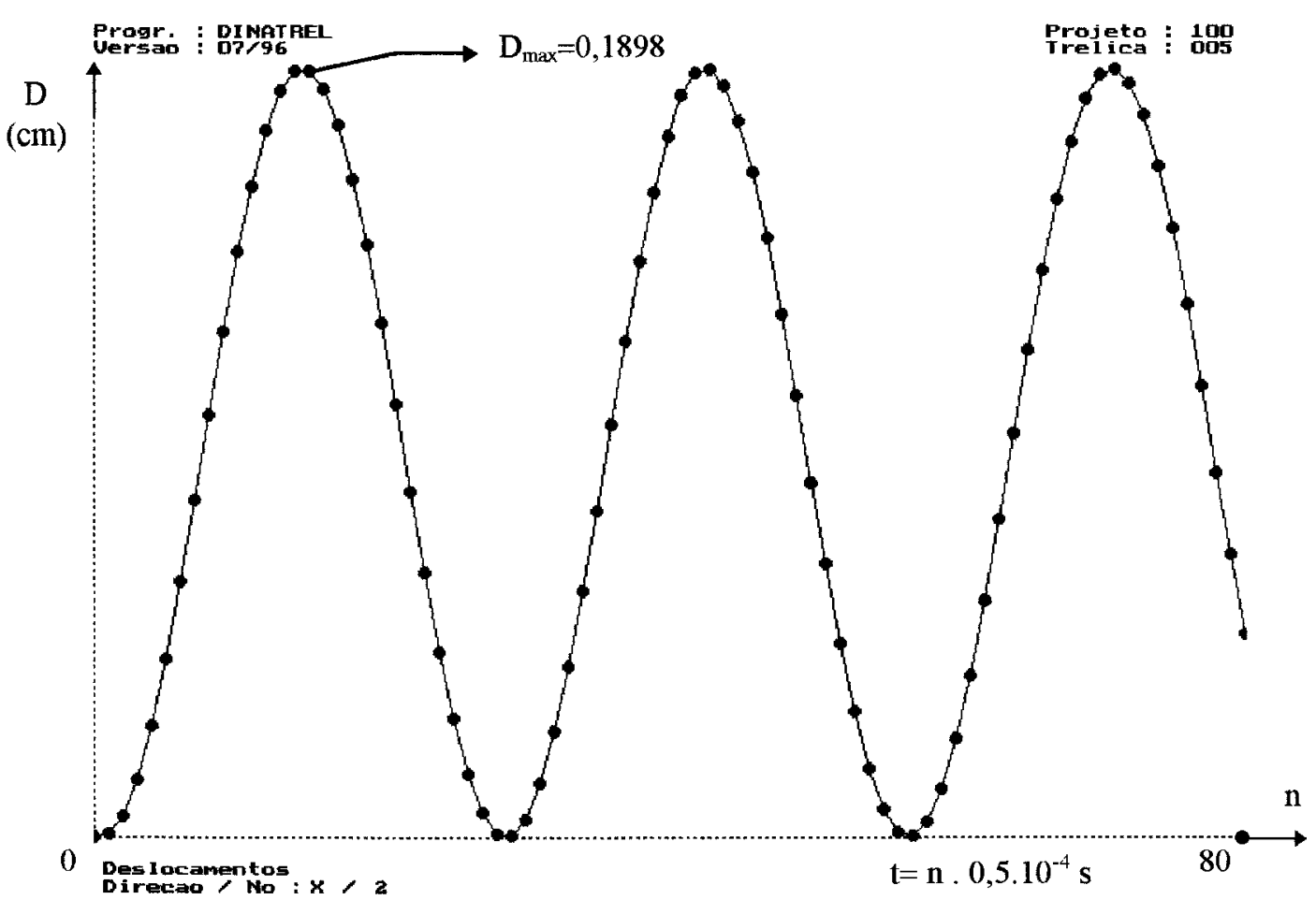

FIGURA 7.6 - Gráfico tempo x deslocamento considerandose $\Delta t=0,5 \cdot 10^{-4} \mathrm{~s}$.

Como pode-se perceber, com a diminuição do valor de " $\Delta t$ " descreve-se o comportamento completo da estrutura, visto que tal problema possui apenas um grau de liberdade e tem como resposta uma senóide, logo, para este caso o valor de " $\Delta t$ " ideal é dado por $\Delta t=\mathrm{T} / 30$. Pode-se, ainda, observar pela figura 7.6 que 0 deslocamento máximo obtido $(\mathrm{d}=0,1898 \mathrm{~cm})$ é aproximadamente igual ao dobro do deslocamento obtido via análise estática $(\Delta \mathrm{l}=0,0952 \mathrm{~cm})$, uma vez que o comportamento adotado é elástico linear e o carregamento é aplicado de forma constante com o tempo.

Uma vez definido 0 " $\Delta t$ " ideal, pode-se efetuar outro tipo de análise dinâmica, através da consideração da não-linearidade física do material, conforme ilustram as figuras 7.7 e 7.8 . 


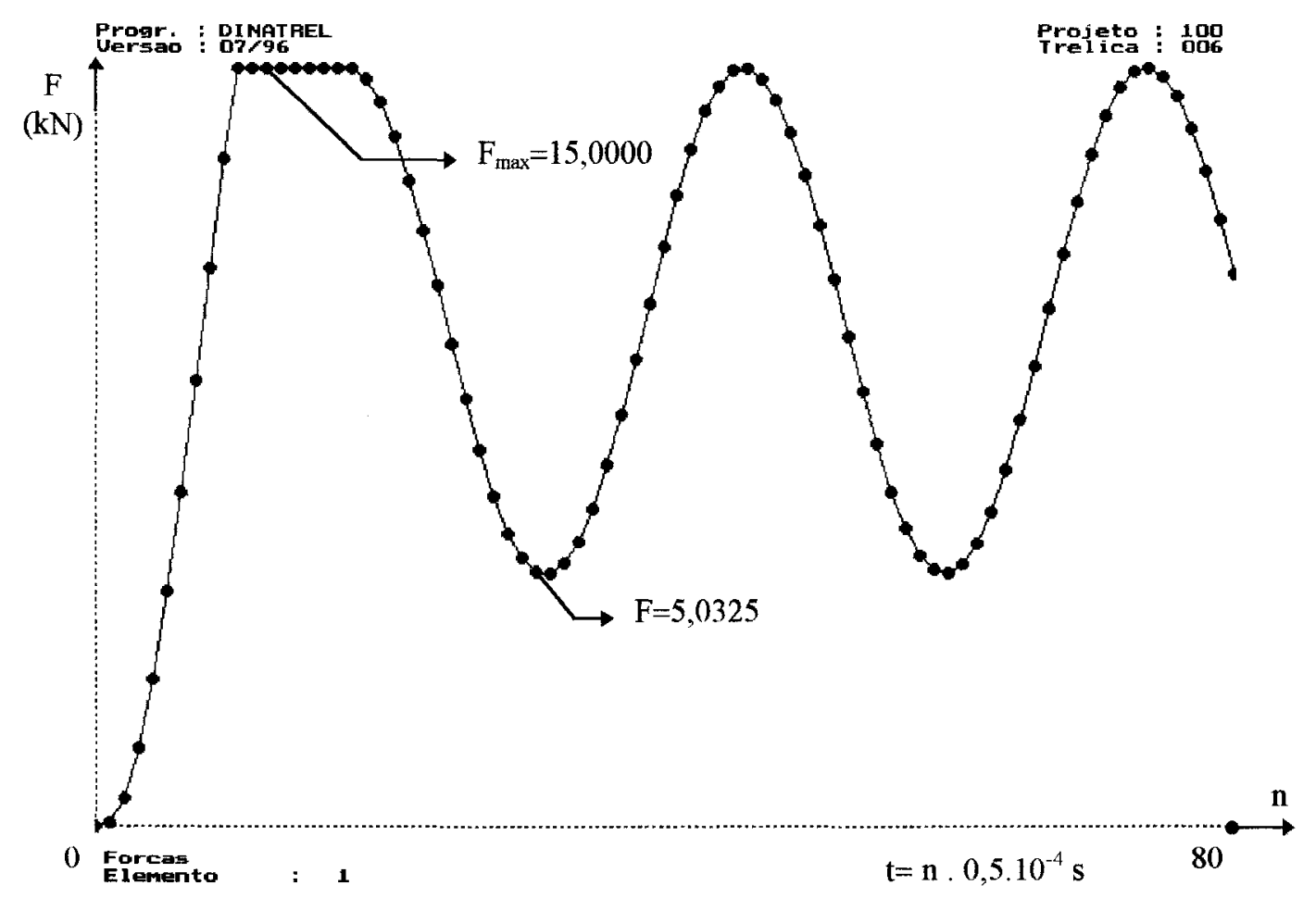

FIGURA 7.7 - Gráfico tempo x força considerando-se nãolinearidade física, com $\Delta t=0,5 \cdot 10^{-4} \mathrm{~s}$.

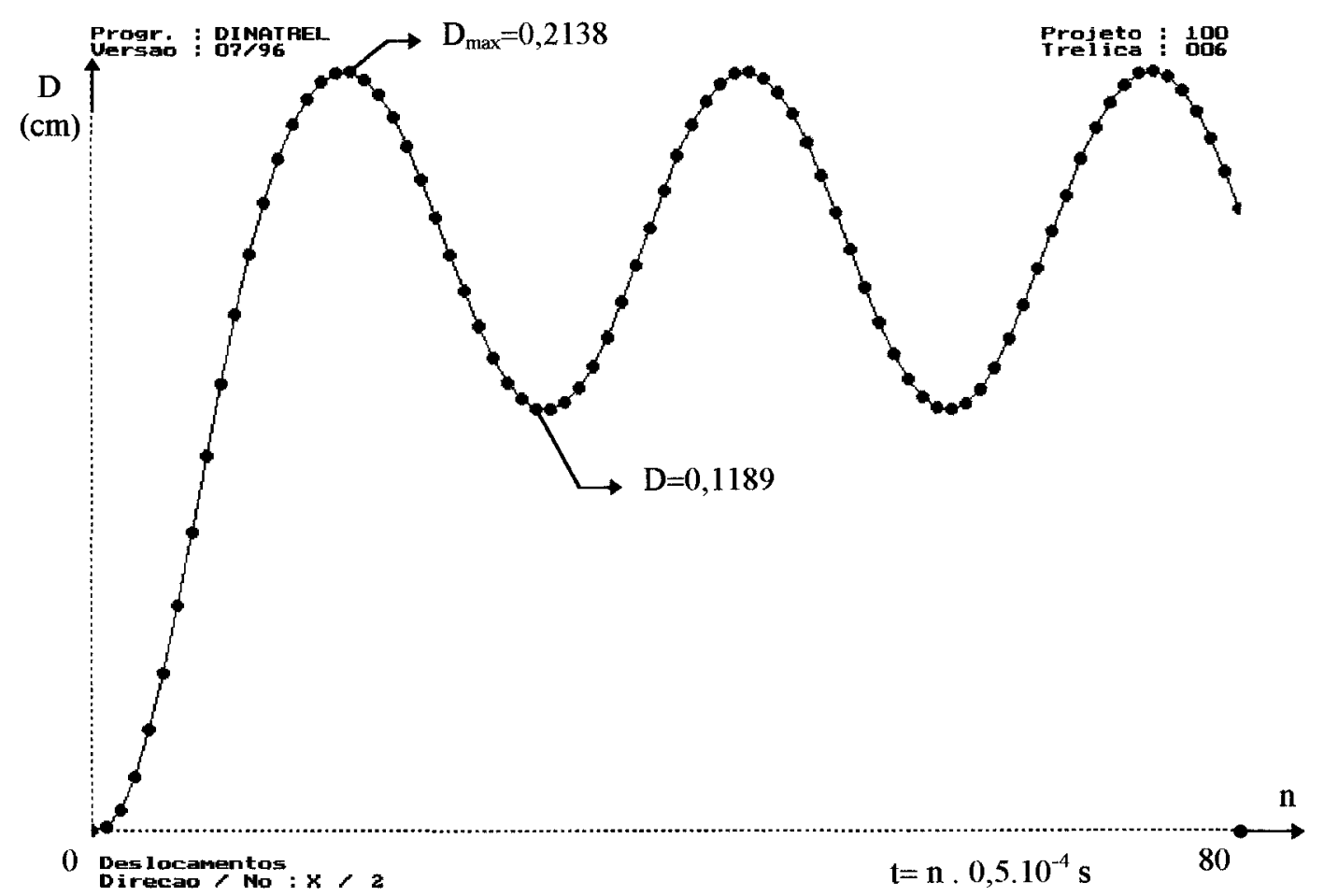

FIGURA 7.8 - Gráfico tempo x deslocamento considerandose não-linearidade física, com $\Delta t=0,5 \cdot 10^{-4} \mathrm{~s}$. 
A figura 7.7 mostra que o elemento começa a trabalhar no regime elástico até atingir a tensão de escoamento. Neste instante, o elemento passa a trabalhar no regime plástico perfeito, pois $E_{T}=0,0 \mathrm{kN} / \mathrm{cm}^{2}$, até o início do processo de descarregamento. A partir deste ponto, o elemento volta a trabalhar no regime elástico de forma permanente.

A figura 7.8 mostra uma alteração do comportamento do elemento após a plastificação, pois o elemento não consegue retornar à sua posição de equilíbrio inicial, uma vez que a deformação plástica acumulada durante 0 processo de plastificação é irreversivel. Como consequiência imediata tem-se uma diminuição da amplitude dos deslocamentos, embora o deslocamento máximo seja maior que o deslocamento obtido sem a consideração da não-linearidade física (vide figura 7.6). Cabe ressaltar que este resultado coincide com a resposta analítica obtida por CASTIGLIONI(1978), mostrando a eficácia do modelo não-linear físico elaborado.

Considerando-se, novamente, o comportamento elástico linear, faz-se uma divisão da treliça mostrada na figura $7.1 \mathrm{em}$ doze elementos finitos, conforme ilustra a figura 7.9. Já as figuras 7.10, 7.11, 7.12, $7.13,7.14$ e 7.15 mostram o comportamento dinâmico de tal estrutura. 
$\mathrm{F}=10,0 \mathrm{kN}$

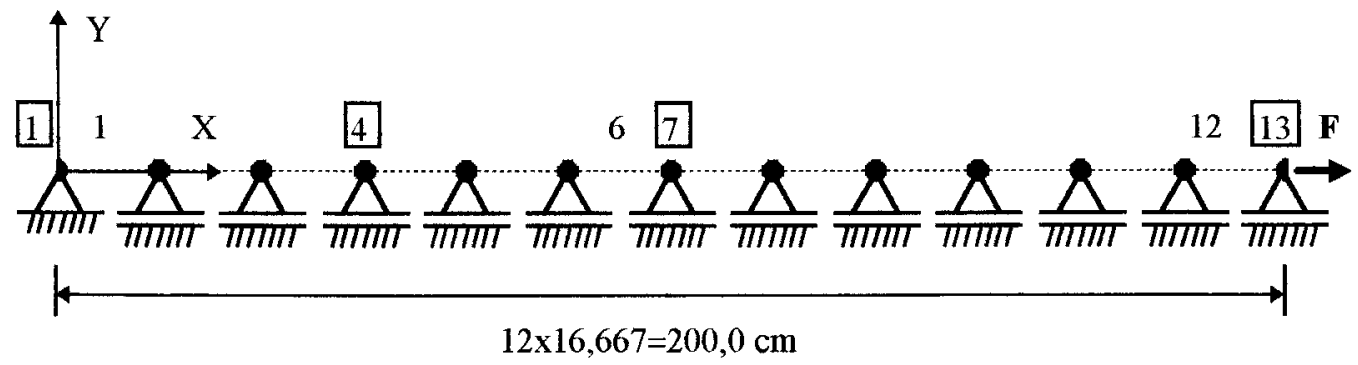

Inter. Tempo : 0

FIGURA 7.9 - Treliça constituída por vários elementos finitos alinhados.

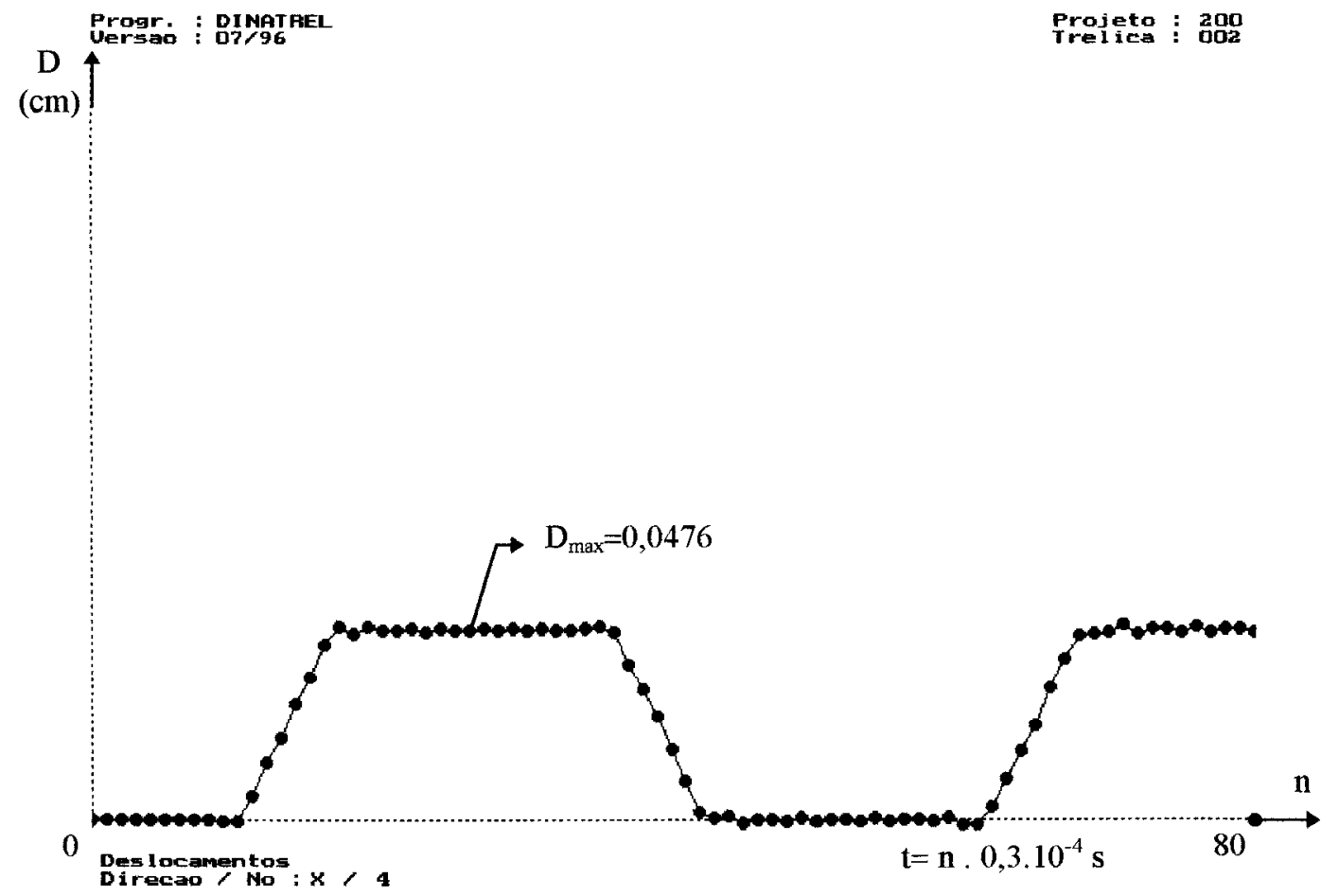

FIGURA 7.10 - Gráfico tempo x deslocamento do nó "4". 


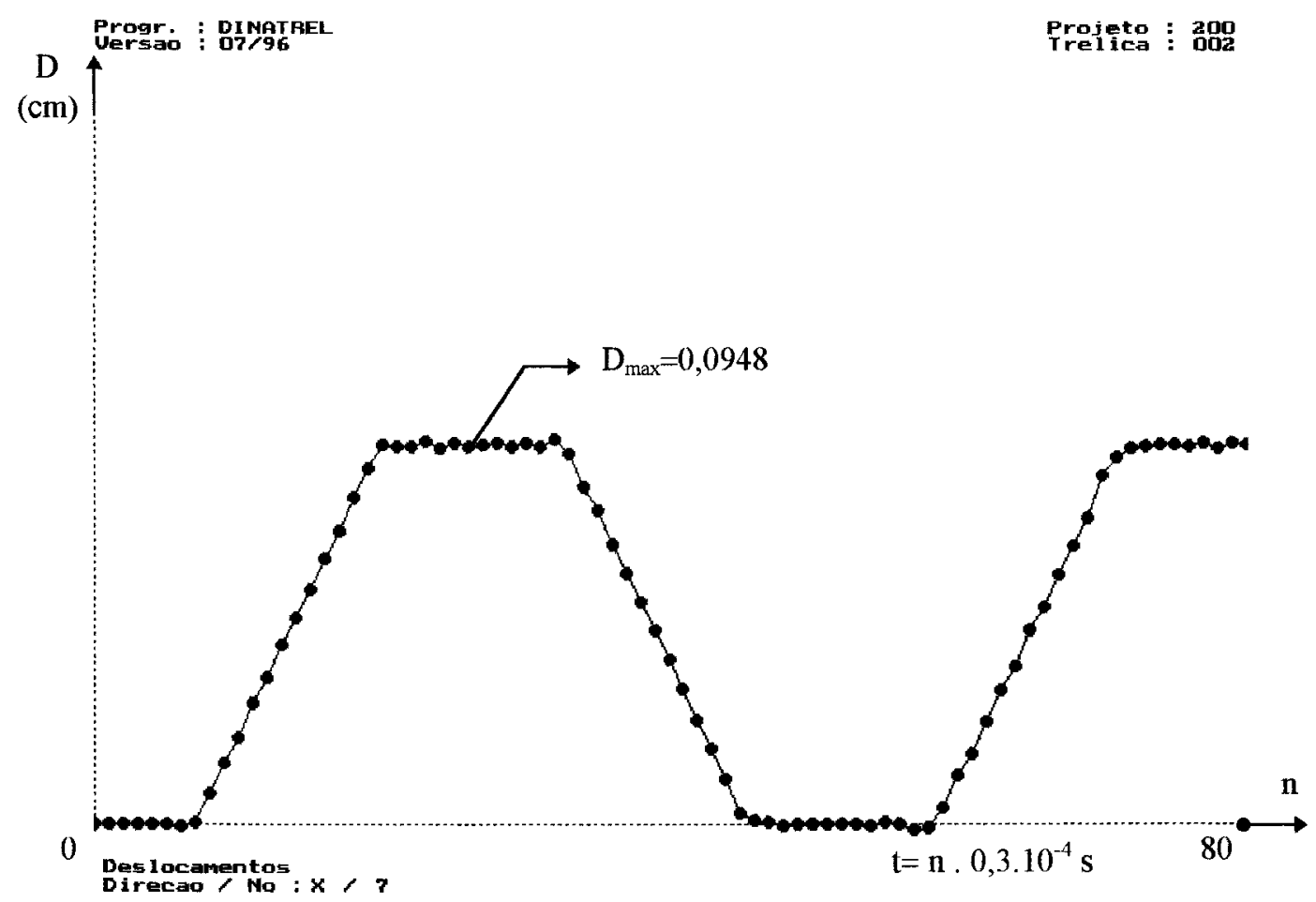

FIGURA 7.11 - Gráfico tempo x deslocamento do nó "7".

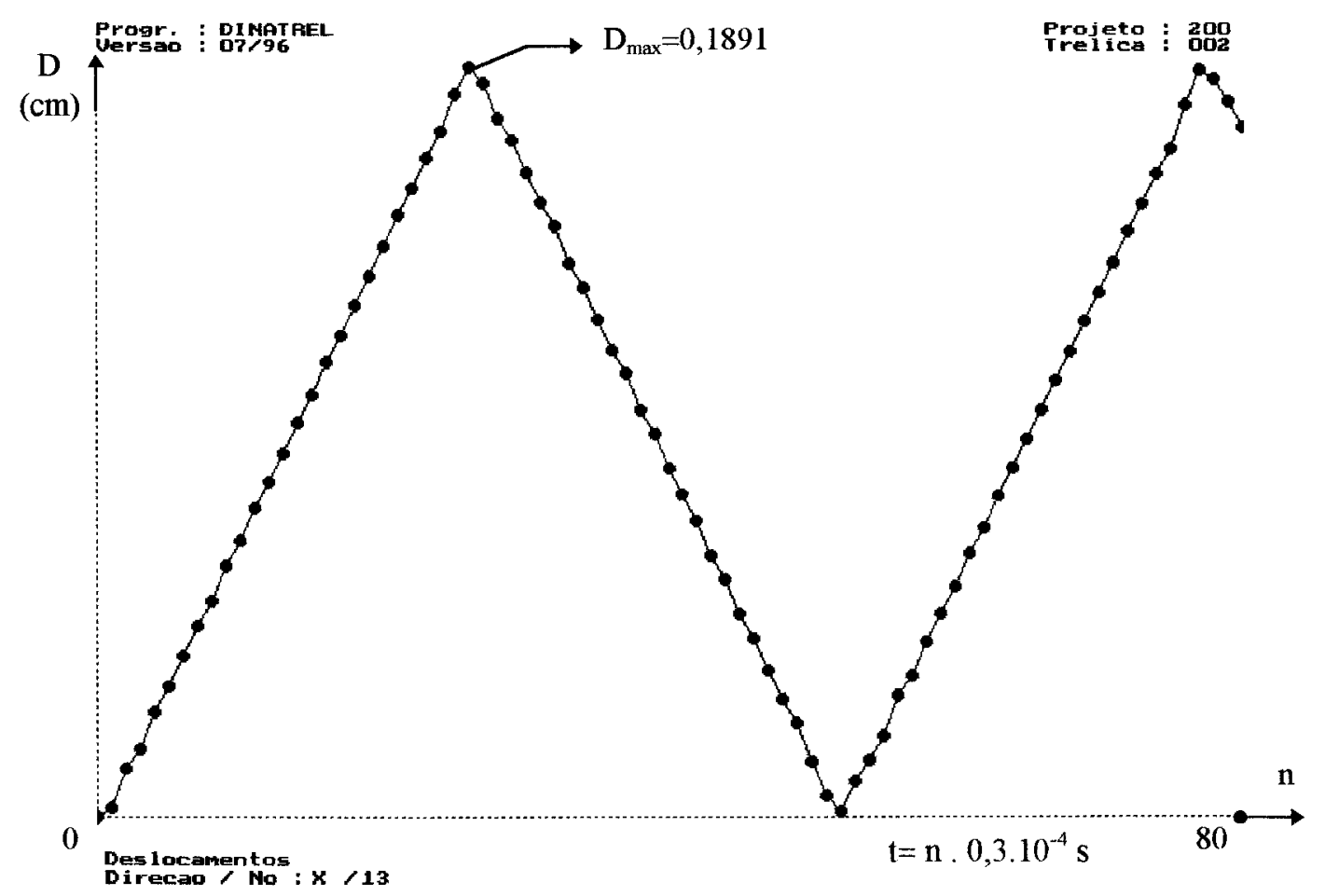

FIGURA 7.12 - Gráfico tempo x deslocamento do nó "13". 


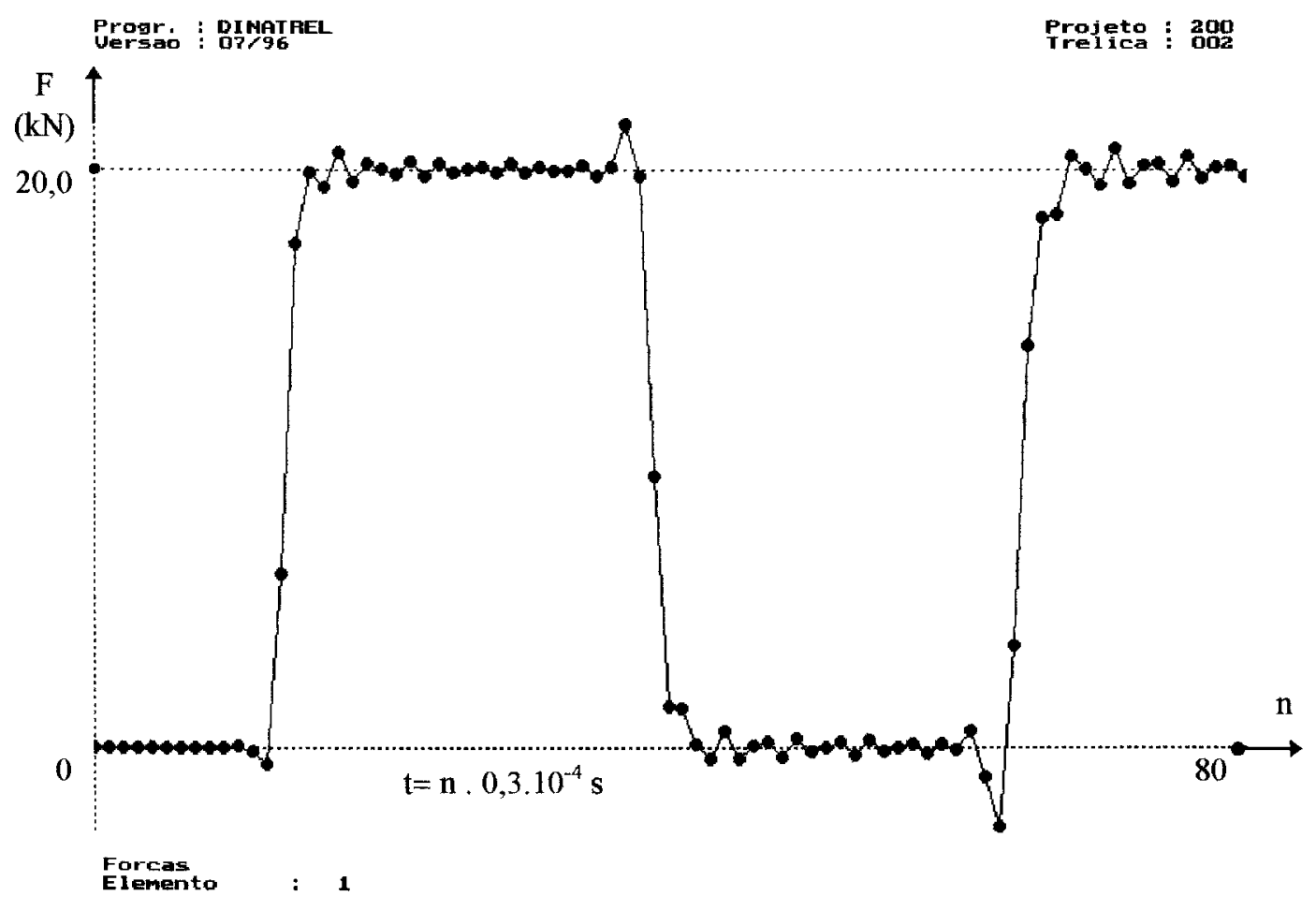

FIGURA 7.13 - Gráfico tempo x força do elemento "1".

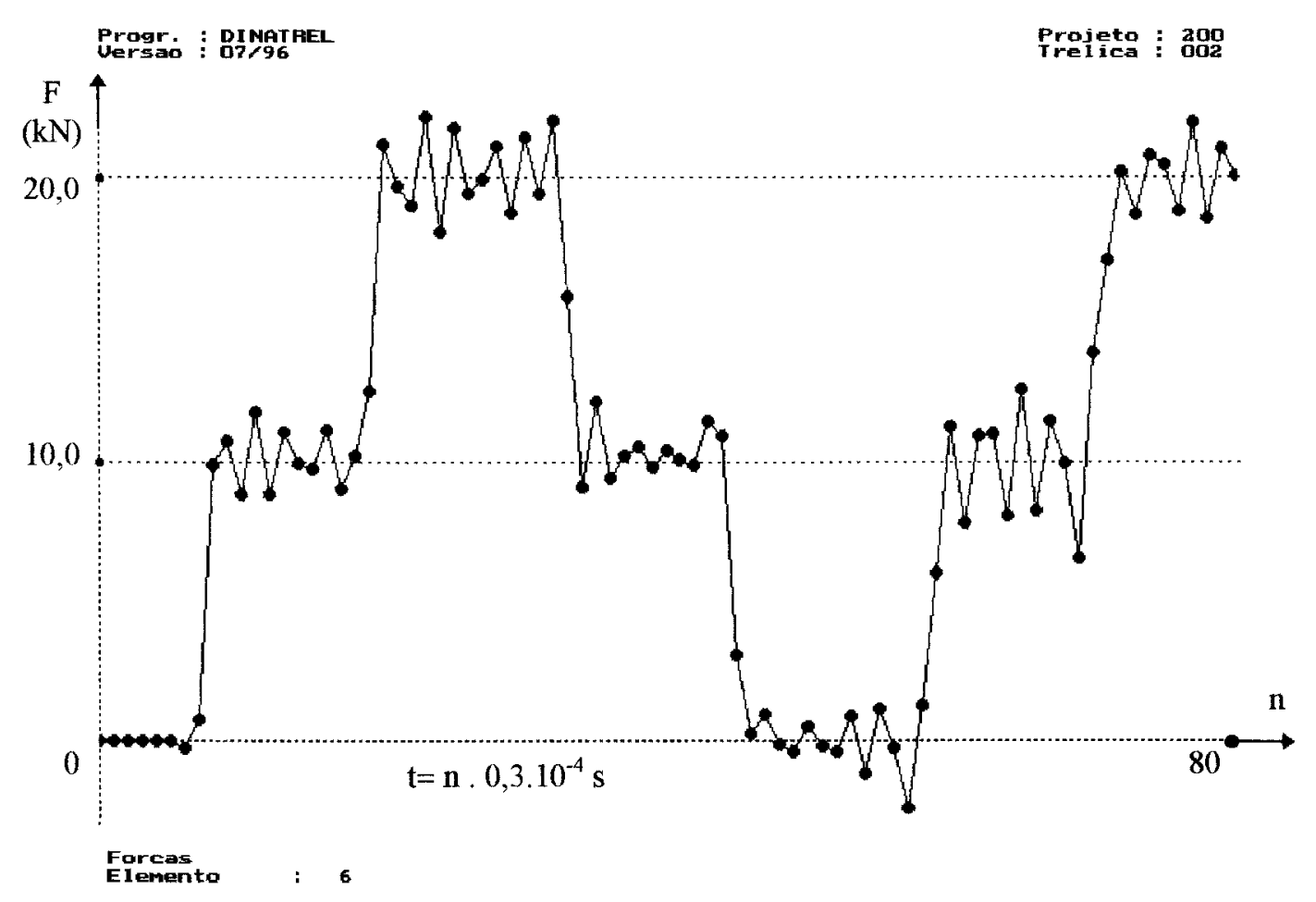

FIGURA 7.14 - Gráfico tempo x força do elemento "6". 


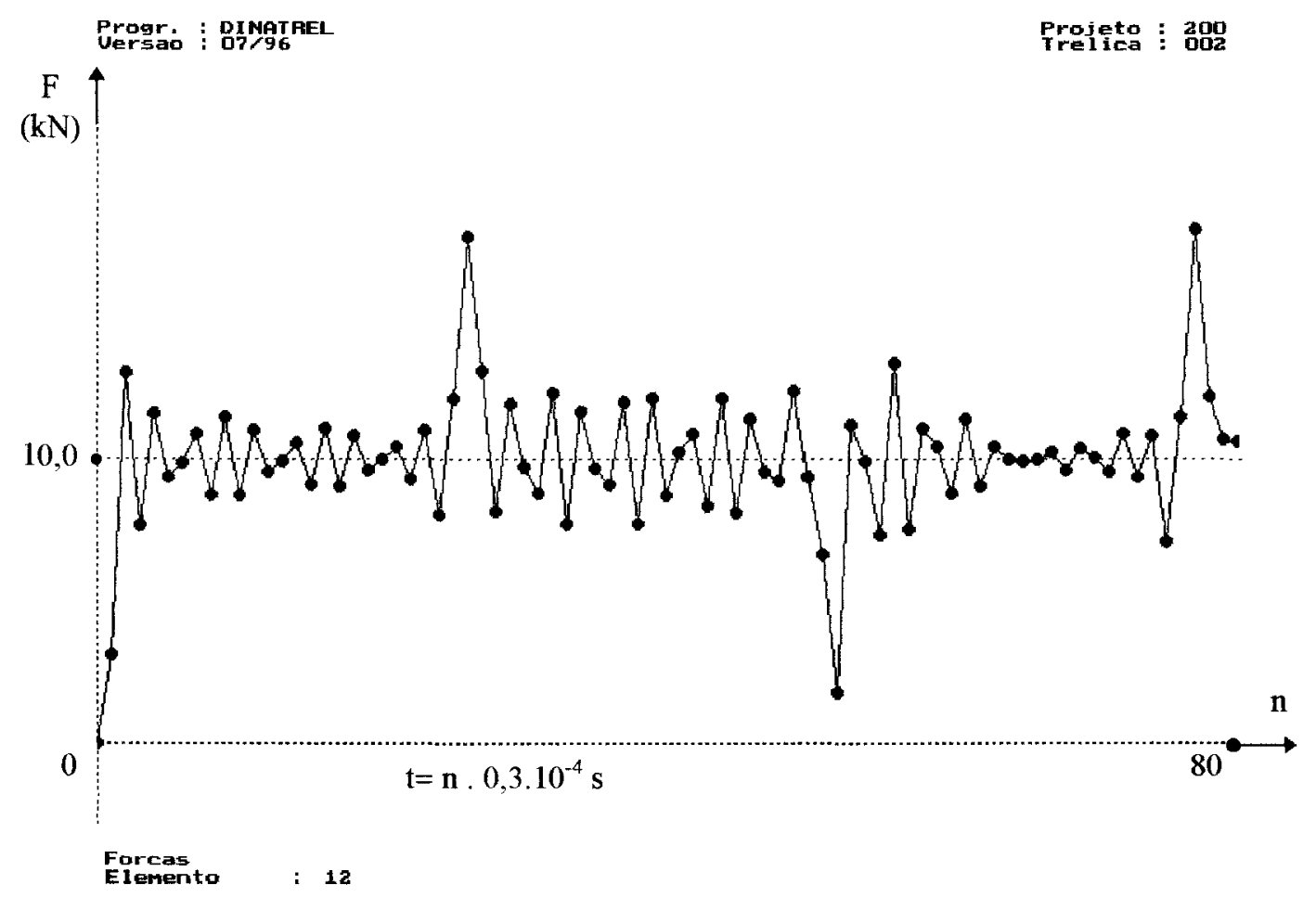

FIGURA 7.15 - Gráfico tempo x força do elemento "12".

Analisando-se os gráficos de tempo $x$ deslocamento, percebe-se que o deslocamento máximo do nó " 4 " é quatro vezes menor que o deslocamento máximo do nó "13", por estar situado a exatamente $1 / 4$ do vão. Raciocínio análogo pode ser feito comparando-se os deslocamentos máximos dos nós "7" e "13", onde um é a metade do outro em função da sua posição geométrica. Comparando-se, agora, os gráficos contidos nas figuras 7.6 e 7.12, nota-se que os valores dos deslocamentos máximos são praticamente coincidentes, embora o comportamento das curvas sejam diferentes em função da estrutura mostrada na figura 7.9 ter vários graus de liberdade. Com relação aos gráficos de tempo $x$ força, nota-se claramente o efeito da perturbação, provocada pelo carregamento, percorrendo toda a estrutura, uma vez que as forças aplicadas nos elementos se alteram bruscamente, oscilando em patamares definidos pelos valores $F=0,0 \mathrm{kN}$, $\mathrm{F}=10,0 \mathrm{kN}$ e $\mathrm{F}=20,0 \mathrm{kN}$. Convém observar que os valores 
dos deslocamentos apresentados também foram obtidos por MANSUR et al.(1984), através da utilização do Método dos Elementos de Contorno.

\section{2 .2 - Exemplo T2}

A estrutura treliçada deste exemplo é composta por dois elementos finitos, solicitada inicialmente por uma força "F" aplicada no nó de união entre os elementos, conforme ilustra a figura 7.16.

Progr: : DIMATREI

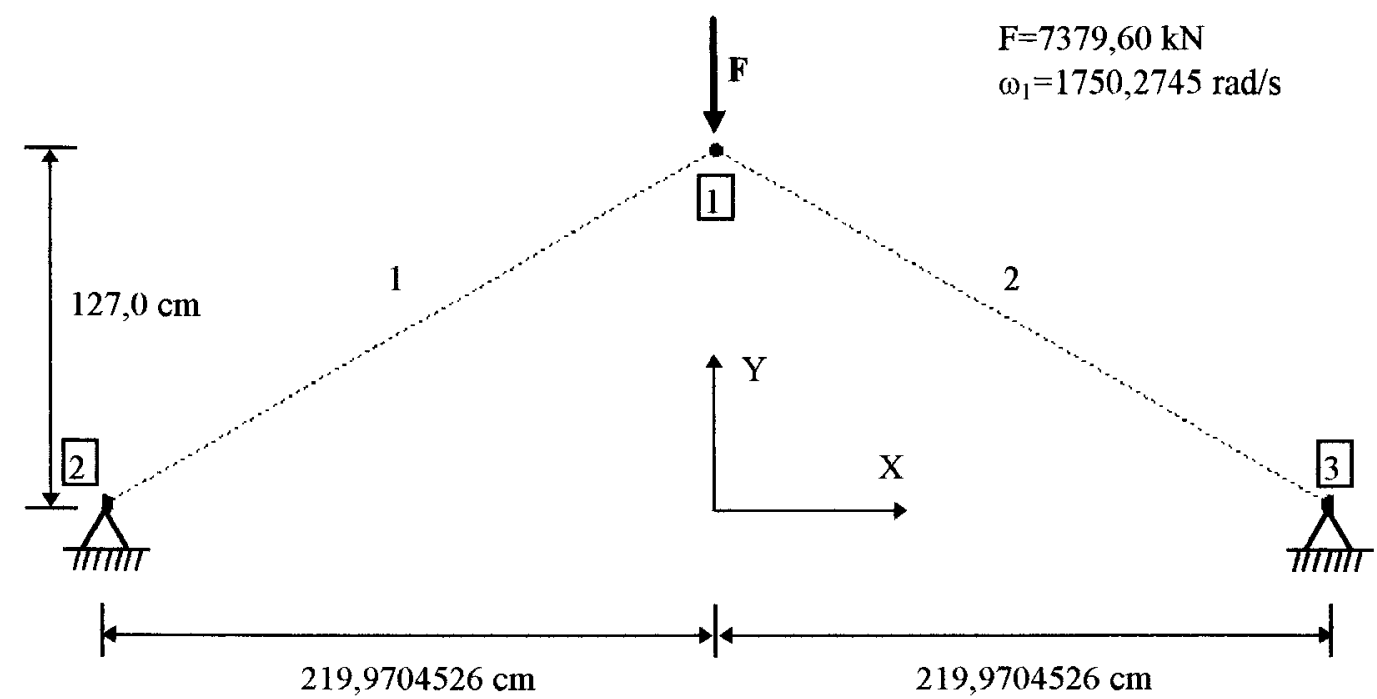

Inter. Tempo : 0
Projeto : ${ }_{\text {Treica }}^{400}$

$\mathrm{F}=7379,60 \mathrm{kN}$

$\omega_{1}=1750,2745 \mathrm{rad} / \mathrm{s}$

FIGURA 7.16 - Treliça constituida por dois elementos finitos.

As caracteristicas físicas e geométricas dos dois elementos são dadas por:

$$
\begin{gathered}
A=6,4516 \mathrm{~cm}^{2} ; E=20684,271 \mathrm{kN} / \mathrm{cm}^{2} ; E_{T}=5000,0 \mathrm{kN} / \mathrm{cm}^{2} \\
\gamma=7,70.10^{-5} \mathrm{kN} / \mathrm{cm}^{3} ; \sigma_{\mathrm{ESC}}=24,0 \mathrm{kN} / \mathrm{cm}^{2}
\end{gathered}
$$


Efetuando-se uma análise estática de tal forma que a força seja aplicada incrementalmente em 80 passos iguais, obtém-se a resposta da estrutura conforme ilustra a figura 7.17 .

- gráfico contido na figura 7.17 mostra o comportamento não-linear geométrico da estrutura treliçada, onde praticamente foi atingido o ponto limite de bifurcação do equilíbrio de tal sistema. Este resultado é exato e pode ser comprovado através da comparação com os resultados obtidos por ORAN et al. (1976), corroborando, assim, a eficácia do procedimento incremental adotado.

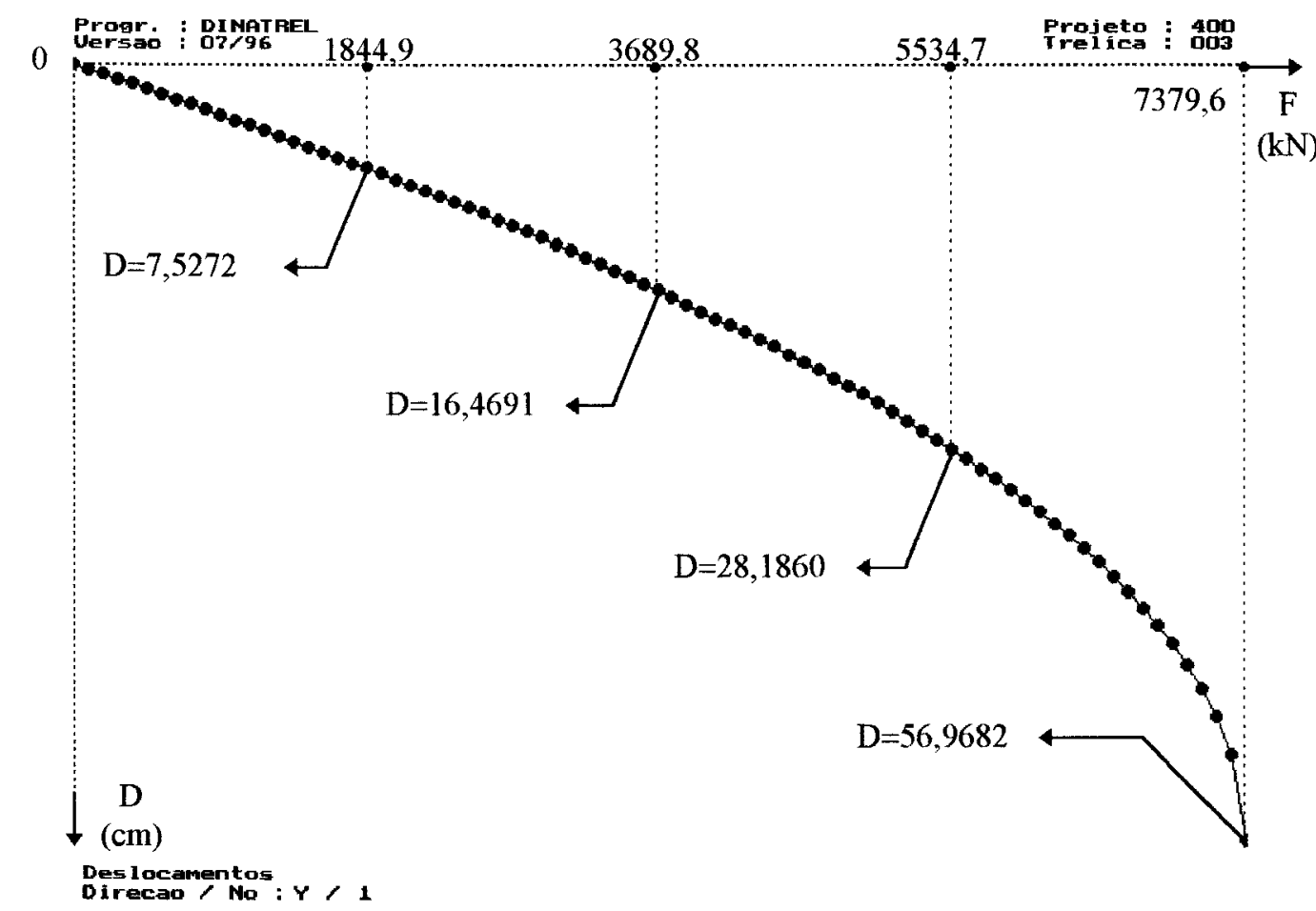

FIGURA 7.17 - Gráfico força x deslocamento do nó "1".

Invertendo-se, agora, a direção da força " $F$ " e alterando-se 0 valor do seu módulo para $F=300,0 \mathrm{kN}$ constante com o tempo, pode-se efetuar uma análise dinâmica com dupla não-linearidade, conforme mostram os resultados contidos nas figuras $7.18 \mathrm{e} 7.19$. 

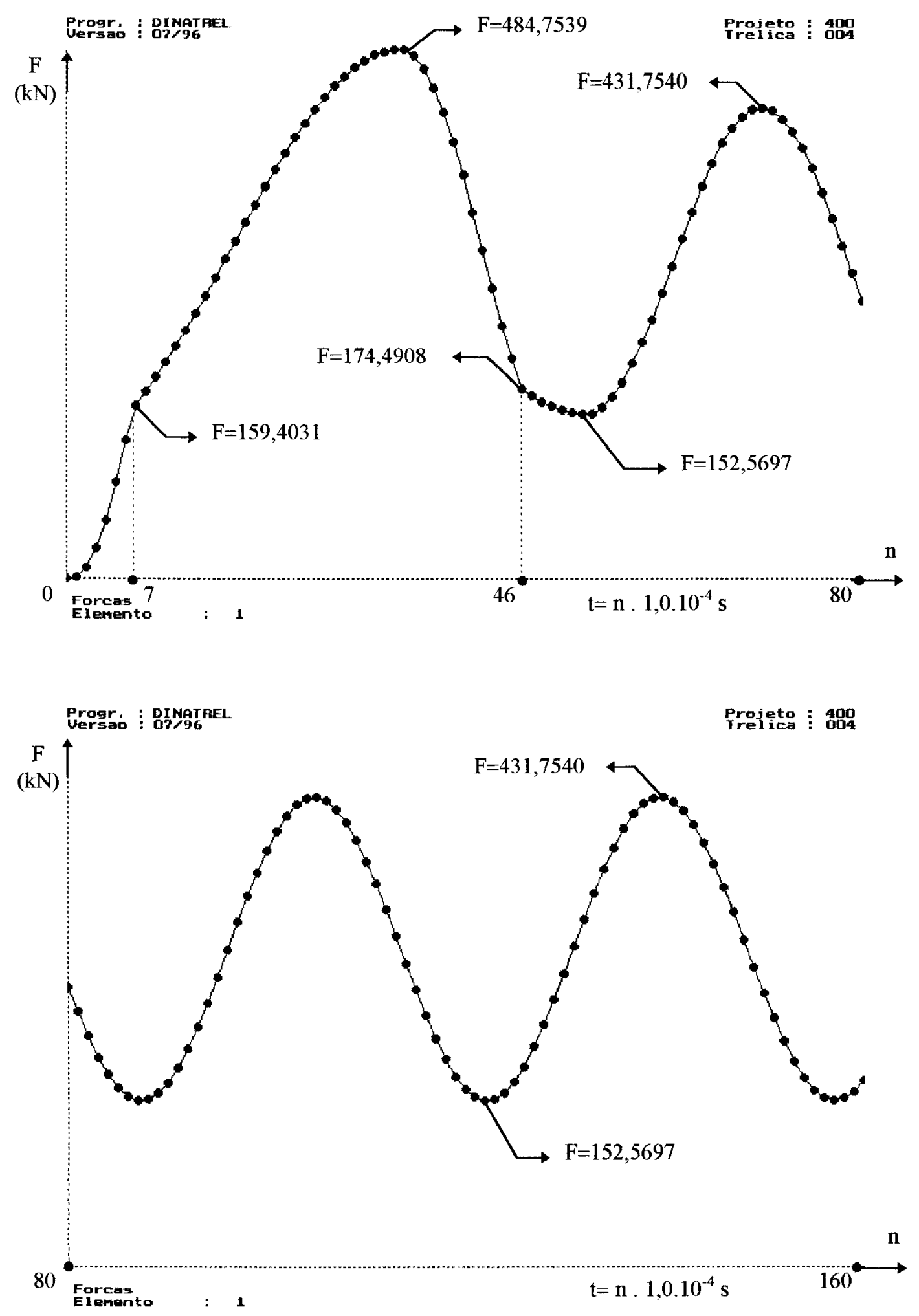

FIGURA 7.18 - Gráfico tempo x força do elemento "1". 


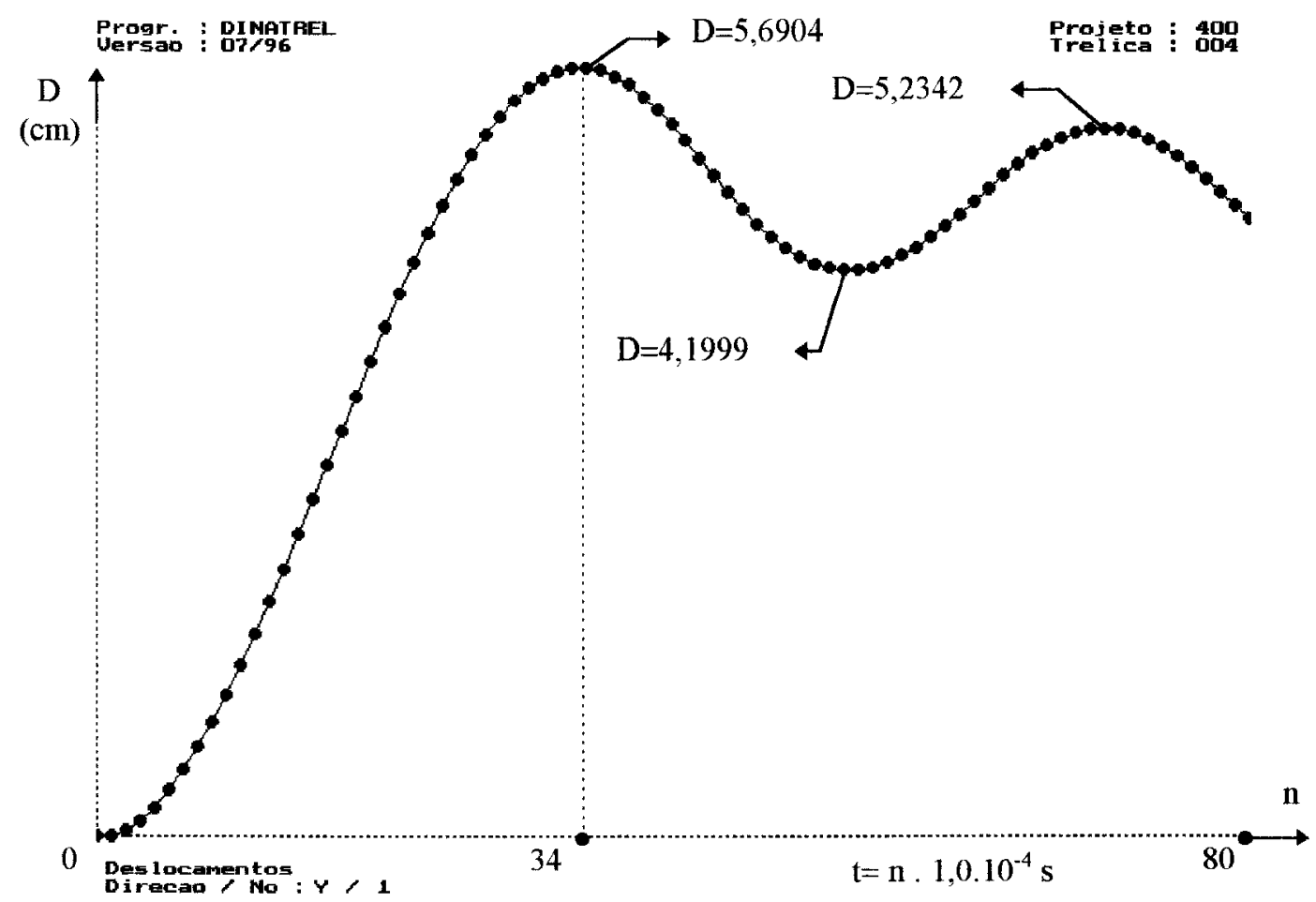

Pragr: : DINAgrat

Projeto : Ano

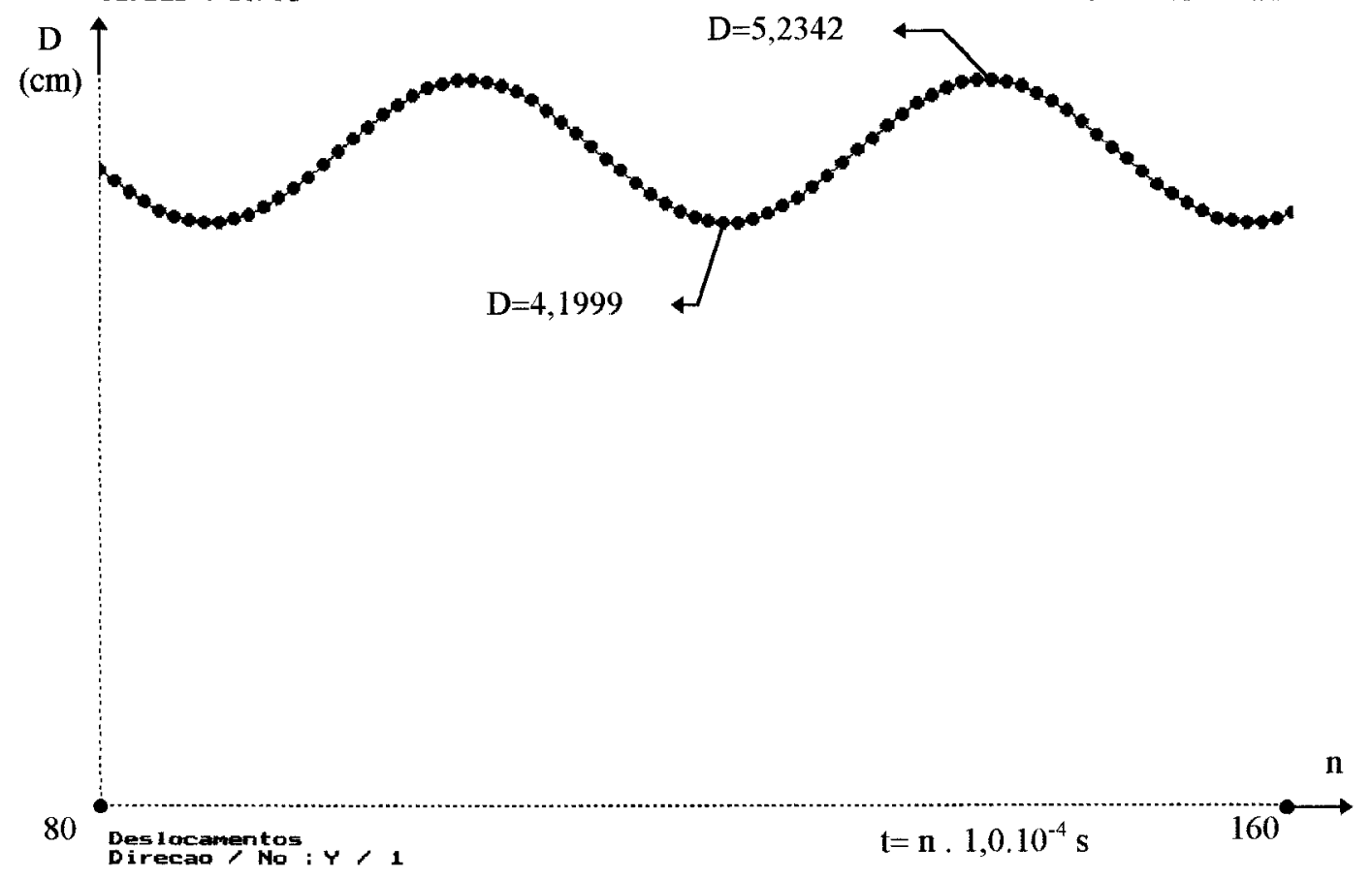

FIGURA 7.19 - Gráfico tempo x deslocamento do nó "1". 
Analisando-se o gráfico tempo x força da figura 7.18, percebe-se que ocorreu a plastificação do material nos intervalos de tempo $n=7$ e $n=46$, uma vez que houve uma alteração da curva durante o carregamento e o descarregamento inicial. Na fase de carregamento o material plastificou com uma variação de tensão igual ao valor da tensão de escoamento, sendo que na fase de descarregamento o material plastificou com uma variação de tensão igual ao dobro do valor da mesma tensão. Isto ocorreu em virtude da utilização do modelo físico cinemático, ilustrando o efeito de tal modelo na análise dinâmica estrutural. O gráfico tempo $x$ deslocamento da figura 7.19 também mostra tal efeito, uma vez que a estrutura não consegue retornar à sua posição inicial e, da mesma forma, não consegue atingir o deslocamento máximo que ocorreu no intervalo de tempo $n=34$. Uma vez cessadas as perdas por plastificação, o material volta a trabalhar no regime elástico de forma permanente.

\subsection{3 - Exemplo T3}

Este exemplo é composto por duas treliças de banzos paralelos com apoios situados em uma das extremidades, solicitadas por uma força constante "F" com o tempo, aplicada na extremidade oposta à dos apoios, conforme ilustram as figuras 7.20 e 7.21 .

As caracteristicas físicas e geométricas de todos os elementos são dadas por:

$$
A=25,0 \mathrm{~cm}^{2} \quad ; \quad E=21000,0 \mathrm{kN} / \mathrm{cm}^{2} \quad ; \quad \gamma=7,6518.10^{-5} \mathrm{kN} / \mathrm{cm}^{3}
$$

Efetuando-se uma análise dinâmica com nãolinearidade geométrica para as duas treliças, obtém-se 
as respostas para tais estruturas conforme ilustram as figuras 7.22 e 7.23 , respectivamente.

Progar. : DINATREL

Projeta: : 800

$\mathrm{F}=20000,0 \mathrm{kN}$

$\omega_{1}=445,1516 \mathrm{rad} / \mathrm{s}$

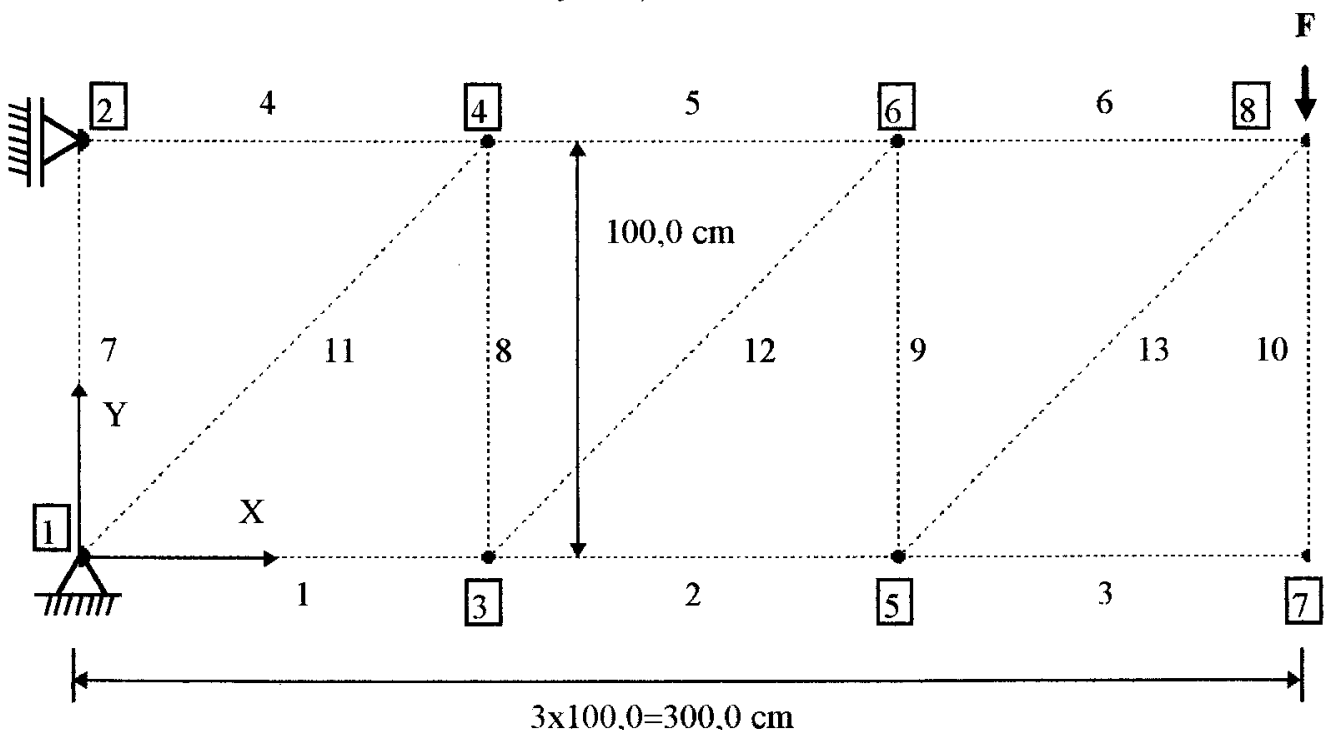

Inter. Tempo : 0

FIGURA 7.20 - Treliça em balanço. Arranjo "1".

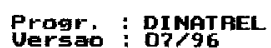

Projeto : 900

$\mathrm{F}=20000,0 \mathrm{kN}$

$\omega_{1}=391,2926 \mathrm{rad} / \mathrm{s}$

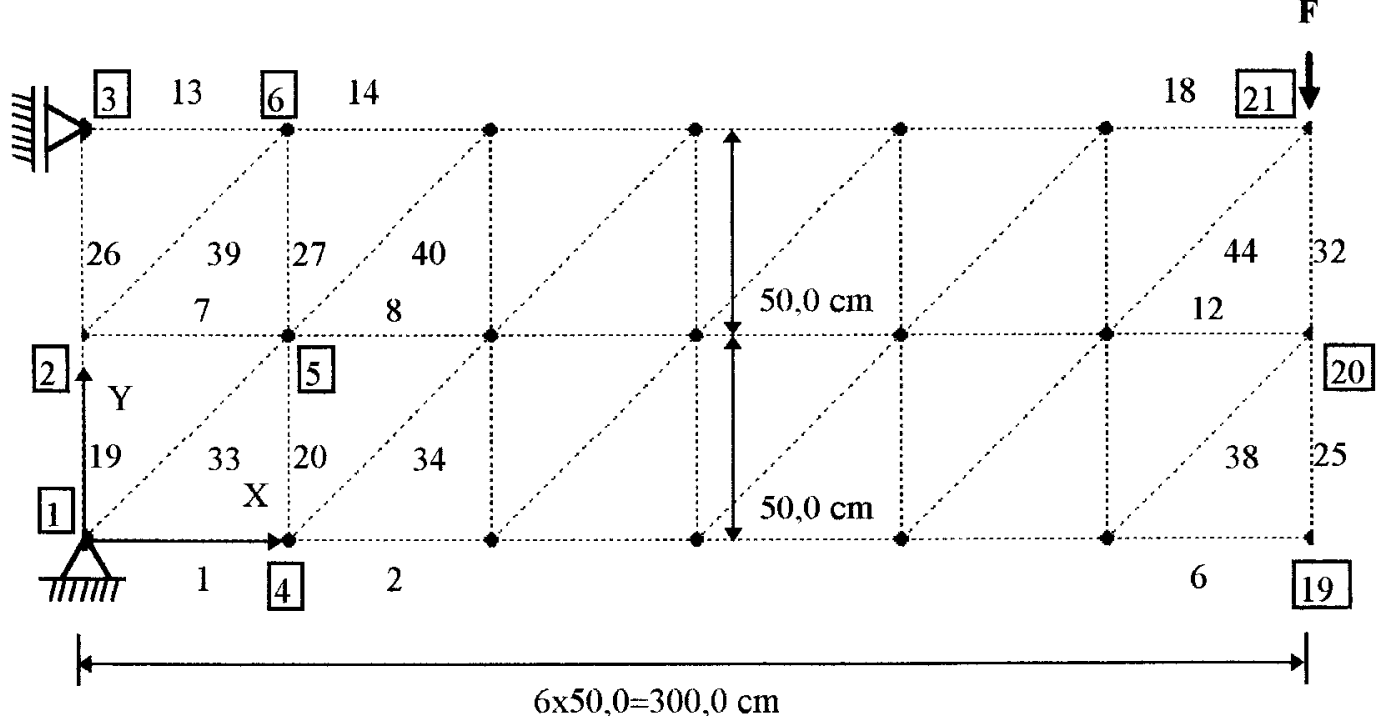

Inter. Tempo : 0

FIGURA 7.21 - Treliça em balanço. Arranjo "2". 

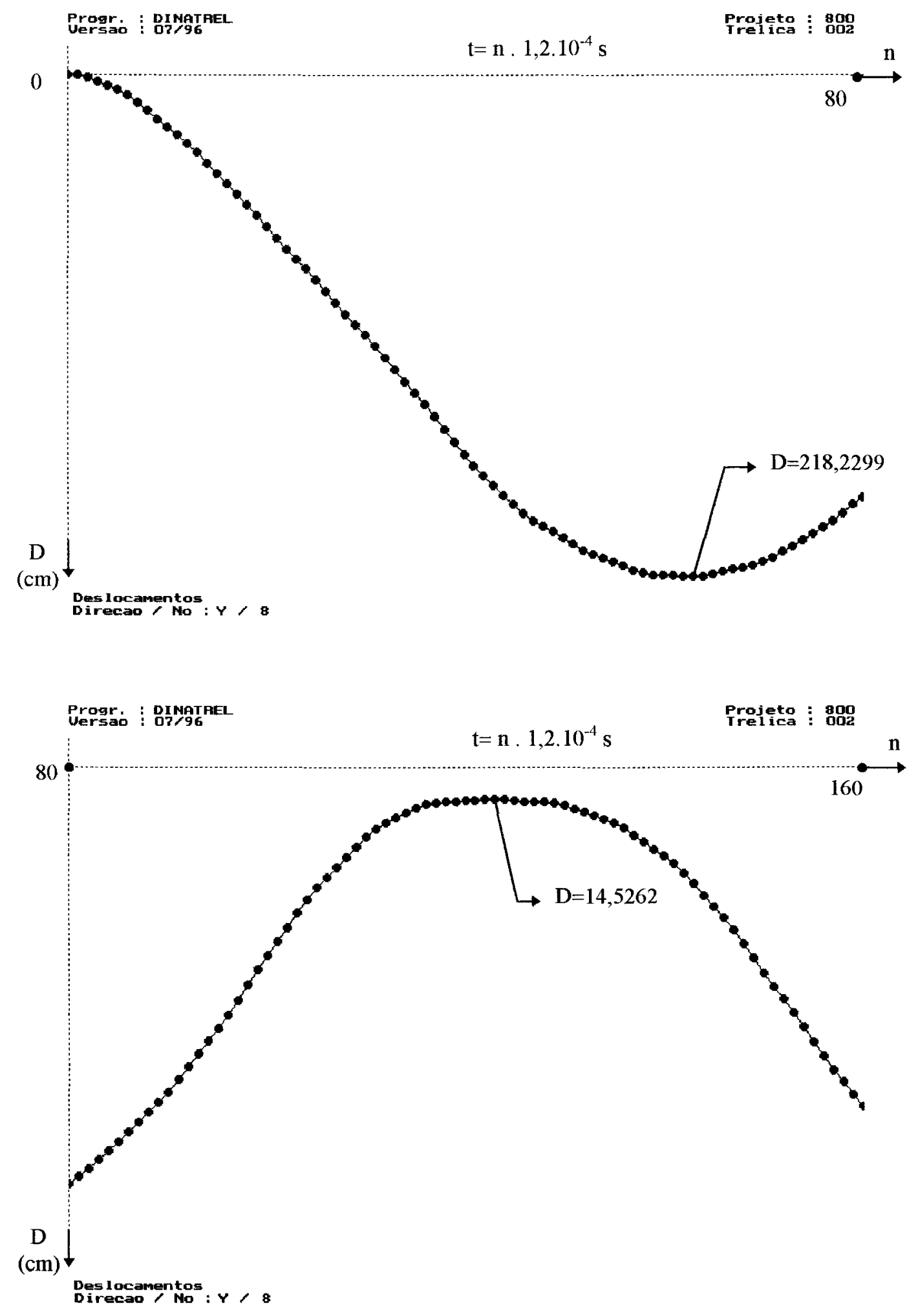

FIGURA 7.22 - Gráfico tempo x deslocamento do nó "8" para treliça com arranjo "I". 

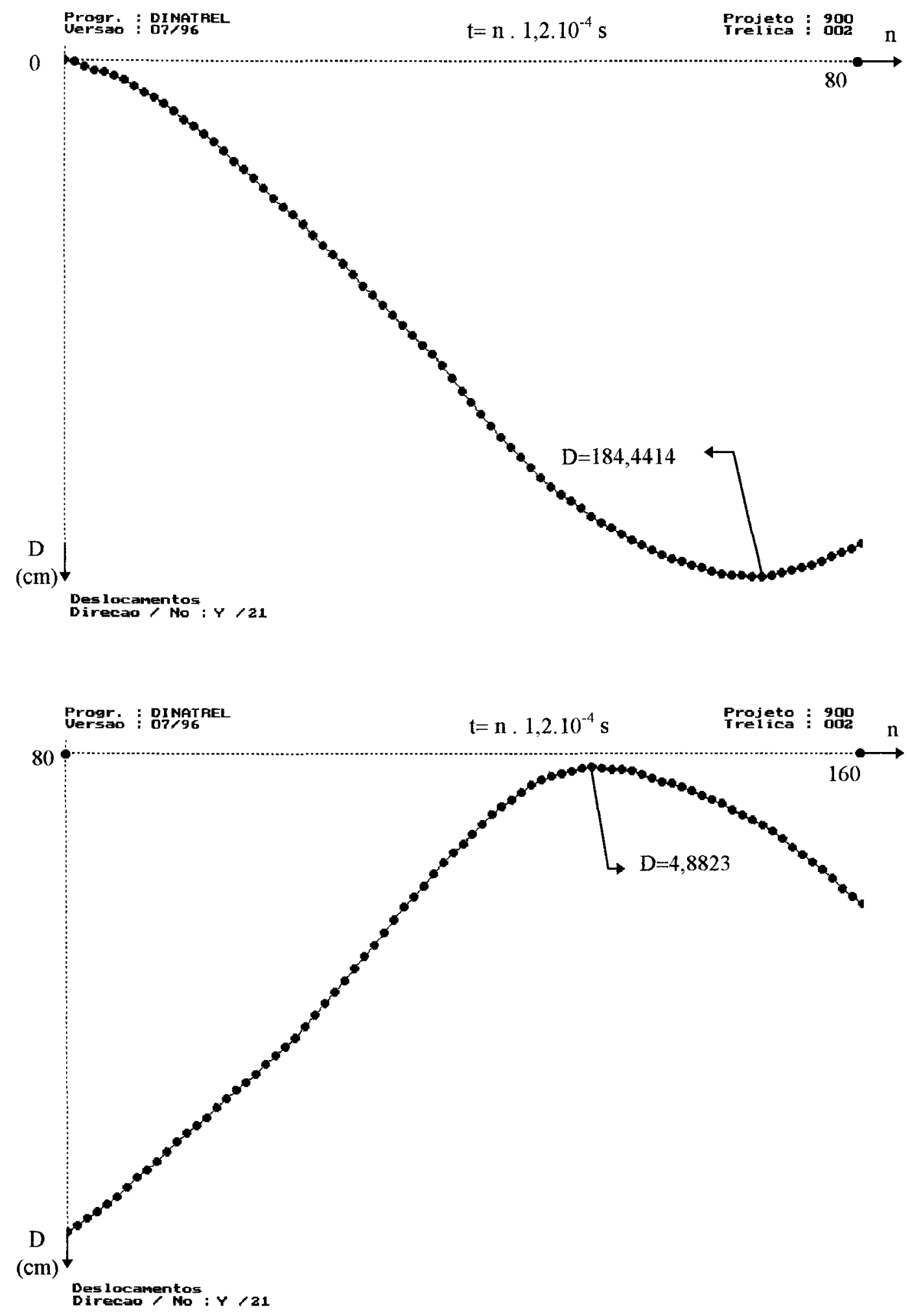

FIGURA 7.23 - Gráfico tempo x deslocamento do nó "21" para treliça com arranjo " 2 ". 
Os gráficos tempo $\mathrm{x}$ deslocamento apresentados pelas figuras 7.22 e 7.23 mostram o comportamento dinâmico de treliças com grande não-linearidade geométrica uma vez que a amplitude dos deslocamentos obtidos é bem maior que a dimensão vertical da estrutura. Comparando-se, agora, os resultados obtidos entre as duas malhas que foram utilizadas, percebe-se que a estrutura contida na figura 7.21 teve um deslocamento máximo menor, pois tal estrutura é mais rígida que a estrutura contida na figura 7.20. Cabe ressaltar que os dois resultados apresentados também foram obtidos por SLAATS et al. (1995).

\section{2 .4 - Exemplo T4}

Este exemplo é composto por uma treliça de banzos paralelos que reproduz a estrutura da viga principal de uma ponte metálica, cujos apoios estão situados nas extremidades do banzo inferior, conforme ilustra a figura 7.24 .

As características físicas e geométricas de todos os elementos são dadas por:

$$
\begin{gathered}
A=1,0 \mathrm{~cm}^{2} ; E=21000,0 \mathrm{kN} / \mathrm{cm}^{2} ; E_{T}=5000,0 \mathrm{kN} / \mathrm{cm}^{2} \\
\gamma=7,70.10^{-5} \mathrm{kN} / \mathrm{cm}^{3} ; \sigma_{E S C}=24,0 \mathrm{kN} / \mathrm{cm}^{2}
\end{gathered}
$$

- carregamento desta estrutura é composto por uma força " $F$ " com valor igual a $120,0 \mathrm{kN}$, produzida por um aparelho hipotético que se movimenta ao longo do tabuleiro que está situado no nível do banzo inferior da ponte. Como o tabuleiro é composto por vigas simples que se apoiam em transversinas situadas nos nós "1", "2", "3", "4" e "5", as forças aplicadas em cada um desses nós são dadas pelas respectivas reações de apoio de cada 
transversina, cujos valores serão alterados a cada incremento de tempo " $\Delta t$ ", conforme trem-tipo mostrado na figura 7.25 .

Progr. : DINATAEL

Projeto: $: \begin{gathered}600 \\ \text { Treica }\end{gathered}$

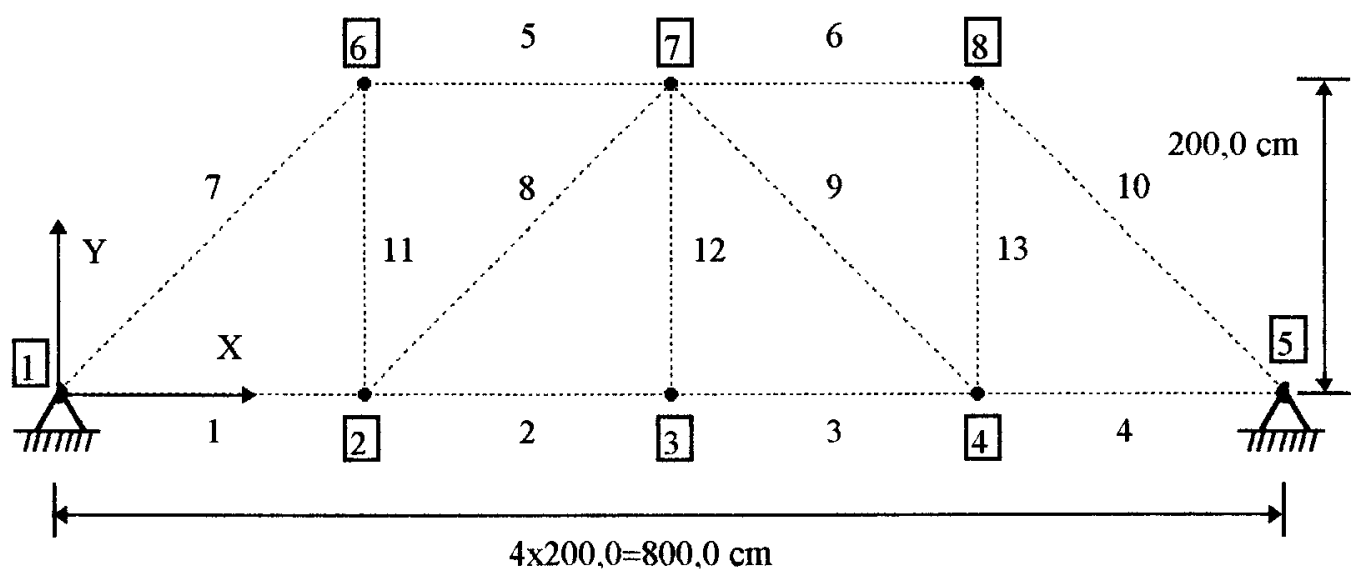

Inter. Tempo: 0

FIGURA 7.24 - Viga principal de uma ponte metálica treliçada.

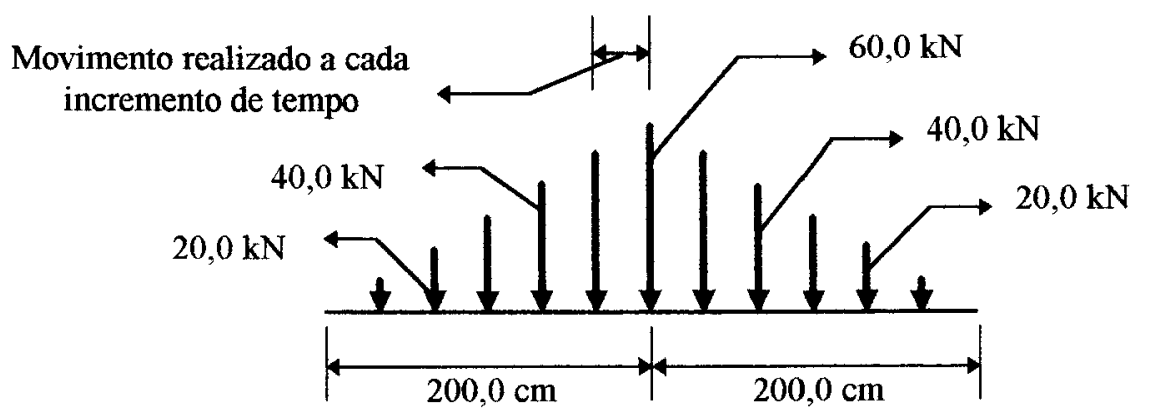

FIGURA 7.25 - Carregamento da viga principal da ponte treliçada.

Para a realização de uma análise dinâmica com amortecimento, deve-se, inicialmente, obter as frequências naturais e os modos de vibração da estrutura. Utilizando-se o programa já mencionado no início deste capítulo, apresentam-se os três primeiros 
modos de vibração com os respectivos valores das frequiencias naturais, conforme ilustram as figuras 7.26, 7.27 e 7.28 .

Progr, : AuTgTrael

$\omega_{1}=480,8398 \mathrm{rad} / \mathrm{s}$

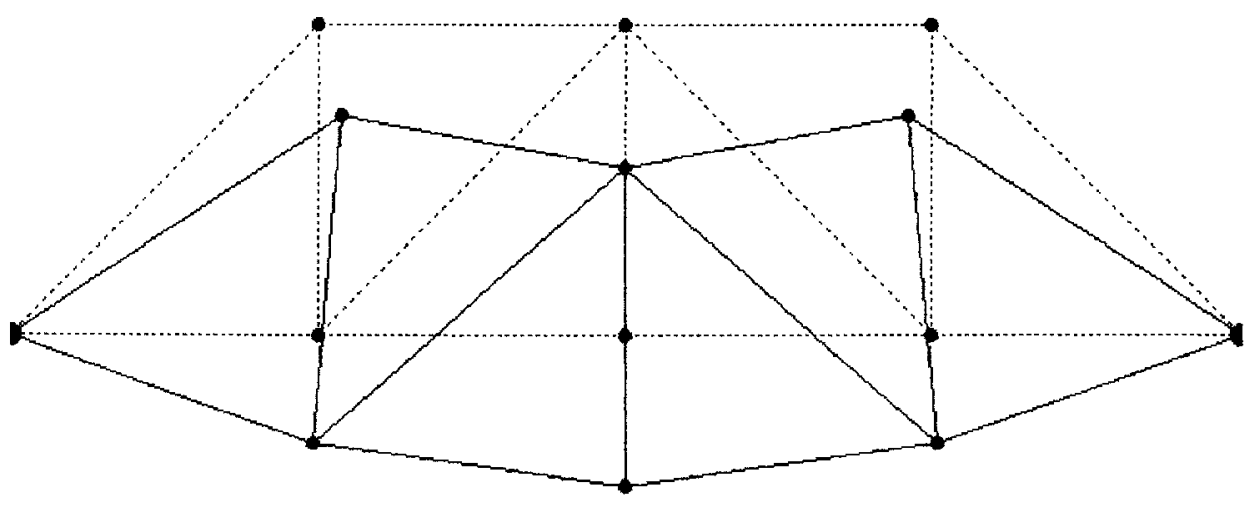

Modo Uibrac. : 1

FIGURA 7.26 - Primeiro modo de vibração da estrutura.

Progr. : Autgirel

Projeto : 600

$\omega_{2}=960,3259 \mathrm{rad} / \mathrm{s}$

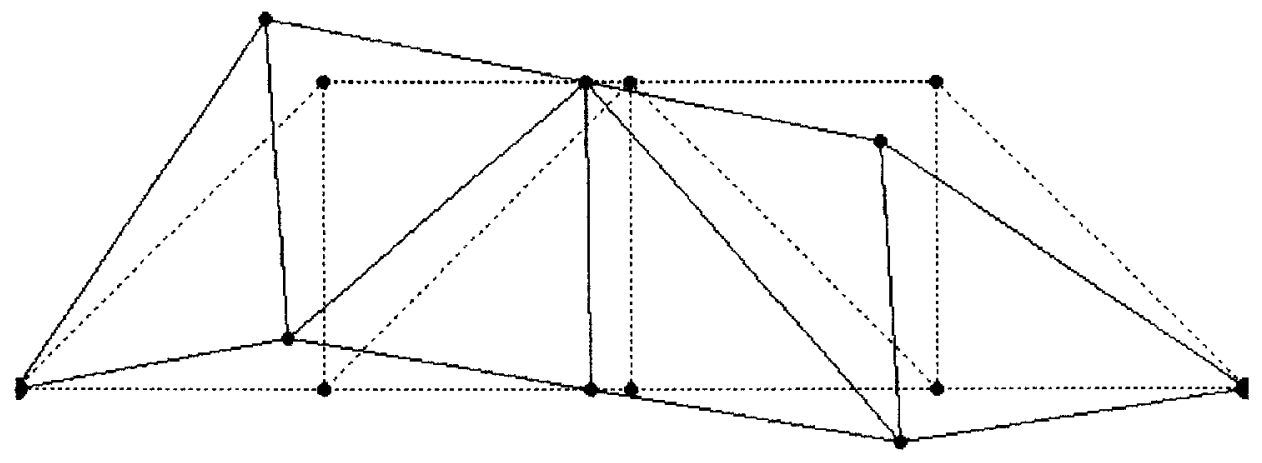

Modo Uibrac. : 2

FIGURA 7.27 - Segundo modo de vibração da estrutura. 


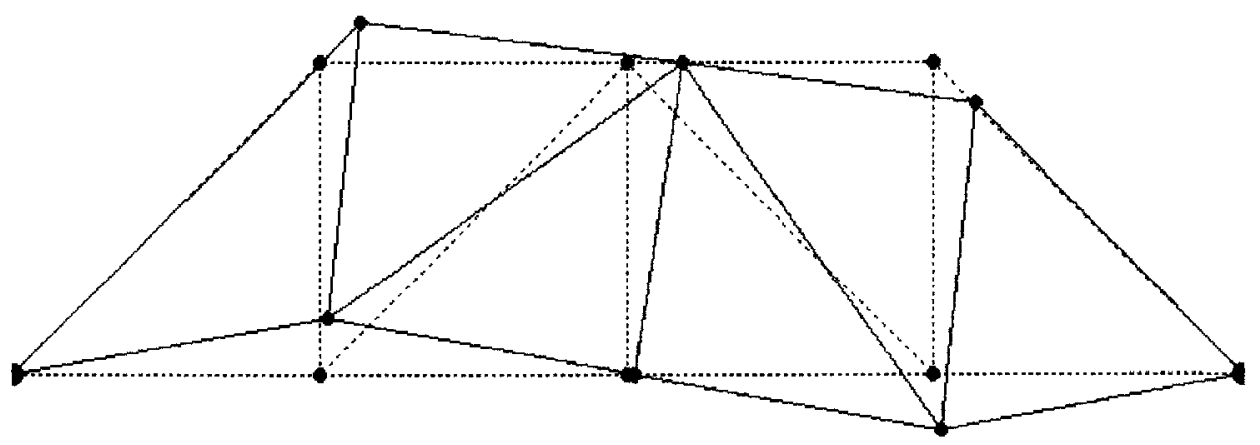

Moda Uibrac. :

FIGURA 7.28 - Terceiro modo de vibração da estrutura.

Com o valor das duas primeiras freqüências naturais pode-se obter as constantes de amortecimento através da utilização das equações (4.138) e (4.139). Calculando-se tais constantes para duas diferentes frações do amortecimento crítico, obtém-se:

$$
\begin{aligned}
p / \xi_{1}=\xi_{2}=1 \% \Rightarrow\left\{\begin{array}{l}
\lambda_{k}=1,39 \cdot 10^{-5} \mathrm{~s} \\
\lambda_{m}=6,408 \mathrm{~s}^{-1}
\end{array}\right. \\
p / \xi_{1}=\xi_{2}=10 \% \Rightarrow\left\{\begin{array}{l}
\lambda_{k}=1,39 \cdot 10^{-4} \mathrm{~s} \\
\lambda_{m}=64,08 \mathrm{~s}^{-1}
\end{array}\right.
\end{aligned}
$$


Estes valores permitem a realização de uma análise completa do comportamento estrutural da ponte, conforme resultados apresentados na tabela 7.1

TABELA 7.1 - Deslocamentos máximos obtidos no nó "3", na direção global "Y", em "cm".

\begin{tabular}{|c|c|c|c|c|}
\hline \multirow{2}{*}{$\begin{array}{l}\text { DESLOC.: } \\
\text { DIREÇÃO: }\end{array}$} & \multirow{2}{*}{$\begin{array}{l}\text { Nó } 3 \\
\text { Y GLOBAI }\end{array}$} & \multicolumn{3}{|c|}{$\xi_{i}$} \\
\hline & & $\xi_{1}=\xi_{2}=0 \%$ & $\xi_{1}=\xi_{2}=1 \%$ & $\xi_{1}=\xi_{2}=10 \%$ \\
\hline \multirow{4}{*}{$\begin{array}{l}\text { ANÁLISE } \\
\text { ESTÁTICA }\end{array}$} & $\bar{L}$ & $-2,9019[010]$ & - & - \\
\hline & $\mathrm{NLG}$ & $-2,9222 \quad[011]$ & - & - \\
\hline & $\mathrm{NLF}$ & $-6,6110 \quad[012]$ & - & - \\
\hline & DNL & $-6,7299 \quad[013]$ & $\overline{-}$ & - \\
\hline \multirow{4}{*}{$\begin{array}{l}\text { ANÁLISE } \\
\text { DINÂMICA }\end{array}$} & $\bar{L}$ & 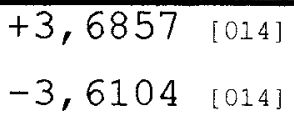 & $\begin{array}{ll}+2,9420 & {[018]} \\
-2,9763 & {[018]}\end{array}$ & $\begin{array}{ll}+1,7249 & {[022]} \\
-2,2122 & {[022]}\end{array}$ \\
\hline & NLG & 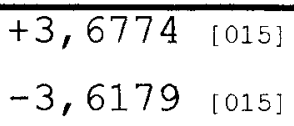 & $\begin{array}{ll}+2,9377 & {[019]} \\
-2,9943 & {[019]}\end{array}$ & $\begin{array}{ll}+1,7240 & {[023]} \\
-2,2315 & {[023]}\end{array}$ \\
\hline & $\mathrm{NLF}$ & 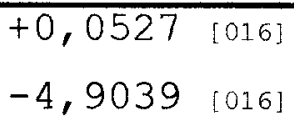 & $\begin{array}{ll}+0,0503 & {[020]} \\
-4,7529 & {[020]}\end{array}$ & $\begin{array}{l}+0,0333 \\
-3,47024] \\
-1024]\end{array}$ \\
\hline & $\overline{D N L}$ & $\begin{array}{ll}+0,0528 & {[017]} \\
-4,9354 & {[017]}\end{array}$ & $\begin{array}{l}+0,0503[021] \\
-4,7809\end{array}$ & $\begin{array}{ll}+0,0333 & {[025]} \\
-3,4862 & {[025]}\end{array}$ \\
\hline
\end{tabular}

Obs: L - comportamento linear;

NLG - comportamento não-linear geométrico;

NLF - comportamento não-linear físico;

DNL - comportamento duplamente não-linear;

$\left[n^{\circ}\right]$ - número da treliça do arquivo de dados.

Comparando-se os resultados obtidos via comportamento linear e não-linear geométrico, percebe-se que os deslocamentos máximos da análise dinâmica são superiores aos deslocamentos máximos da análise estática. Já quando se introduz o comportamento nãolinear físico ocorre fenômeno oposto ao mencionado 
anteriormente. Embora não se tenha um padrão definido, deve-se ressaltar que na análise dinâmica tem-se inversão de deslocamentos, com consequiente inversão de esforços nos elementos estruturais, logo, é indispensável este tipo de análise em problemas que tenham o carregamento variando com o tempo. Passando-se, agora, para a análise dos resultados como um todo, percebe-se que o efeito na não-linearidade geométrica é desprezivel e que o efeito da não-linearidade física é significativo, para o problema em questão. Como não se pode prever quando tais efeitos sejam relevantes, é necessário que se processe todas as alternativas de análise, para que se possa avaliar o comportamento da estrutura de forma correta.

A tabela 7.1 apresenta, também, os valores dos deslocamentos máximos do nó "3" quando se consideram as duas frações de amortecimento já descritas anteriormente. Como pode-se perceber, quanto maior forem os valores das frações do amortecimento crítico, menor serão os deslocamentos obtidos, comprovando-se a eficácia do modelo de amortecimento utilizado neste trabalho.

Para visualizar tal efeito, a figura 7.29 ilustra o comportamento da estrutura considerando-se dupla nãolinearidade e taxa de amortecimento igual a $\xi_{1}=\xi_{2}=10 \%$. Analisando-se tal gráfico, percebe-se que a taxa de amortecimento é bem elevada, pois a estrutura praticamente para de se movimentar em um período muito curto de tempo. Finalizando-se, deve-se ressaltar que o ponto de estabilização da estrutura se altera com o valor da taxa de amortecimento utilizada, pois com $\xi_{1}=\xi_{2}=1 \%$ obtém-se $d_{\text {ESTÁVEI }}=-1,47 \mathrm{~cm}$ e com $\xi_{1}=\xi_{2}=10 \%$ obtém-se $\mathrm{d}_{\mathrm{ESTAVEL}}=-1,37 \mathrm{~cm}$, encontrados via análise dinâmica com comportamento não-linear. 

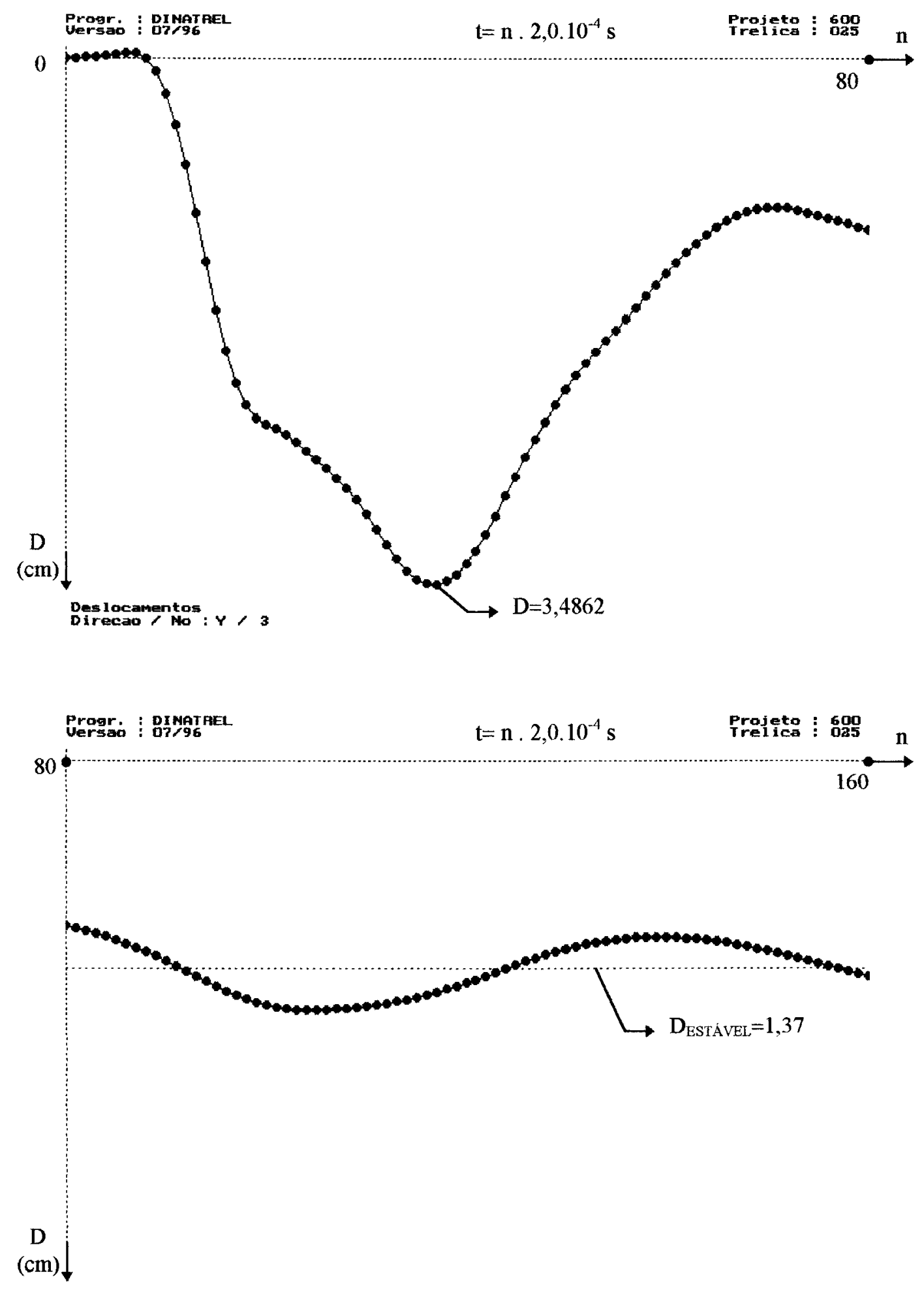

Des locamentos: $Y>3$

FIGURA 7.29 - Gráfico tempo x deslocamento do nó "3". 


\section{3 - Estruturas aporticadas}

\subsection{1 - Exemplo P1}

A estrutura aporticada deste exemplo é composta por apenas um elemento finito engastado em uma das extremidades, solicitado por uma força constante " $F$ " com - tempo, conforme ilustra a figura 7.30.

Progr: : DINaport

Projeto: 400

$$
\begin{aligned}
& F=10,0 \mathrm{kN} \\
& \omega_{1}=4479,4987 \mathrm{rad} / \mathrm{s}
\end{aligned}
$$

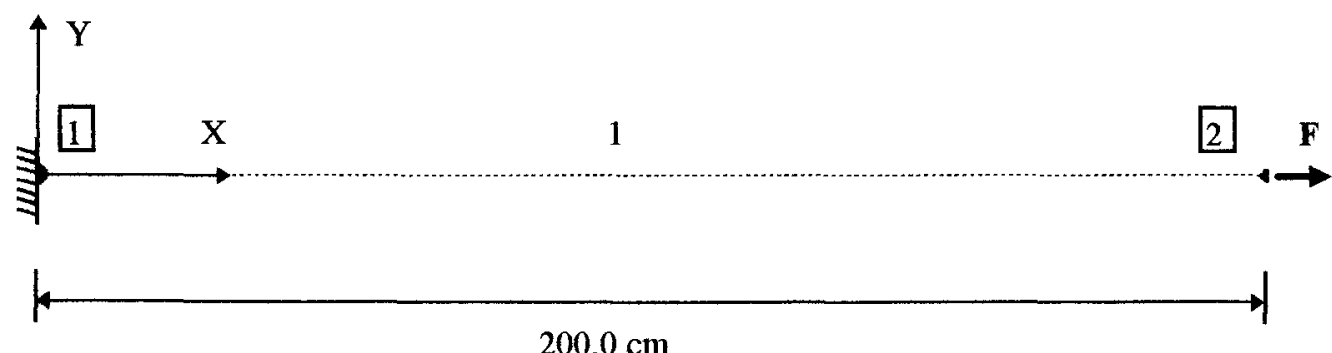

Inter. Tempo: 0

FIGURA 7.30 - Pórtico formado por um elemento finito.

As caracteristicas físicas e geométricas do elemento " 1 " são dadas por:

$$
\begin{gathered}
\mathrm{b}=1,0.10^{+5} \mathrm{~cm} ; \mathrm{h}=1,0.10^{-5} \mathrm{~cm} ; \mathrm{E}_{\mathrm{C}}=21000,0 \mathrm{kN} / \mathrm{cm}^{2} \\
\mathrm{f}_{\mathrm{CK}}=0,0 \mathrm{kN} / \mathrm{cm}^{2} ; \gamma=7,70.10^{-5} \mathrm{kN} / \mathrm{cm}^{3} ; \mathrm{E}_{\mathrm{S}}=\mathrm{E}_{\mathrm{C}}
\end{gathered}
$$

Neste exemplo pretende-se fazer uma comparação via análise dinâmica entre os elementos finitos para treliça 
e pórtico, respeitando-se as particularidades de cada elemento, através da utilização de dados compatíveis com os fornecidos no exemplo $\mathrm{T} 1$.

Neste sentido, resolve-se 0 exemplo em questão considerando-se $\Delta t=0,5 \cdot 10^{-4} \mathrm{~s}, \quad$ cujo resultado é apresentado na figura 7.31 .

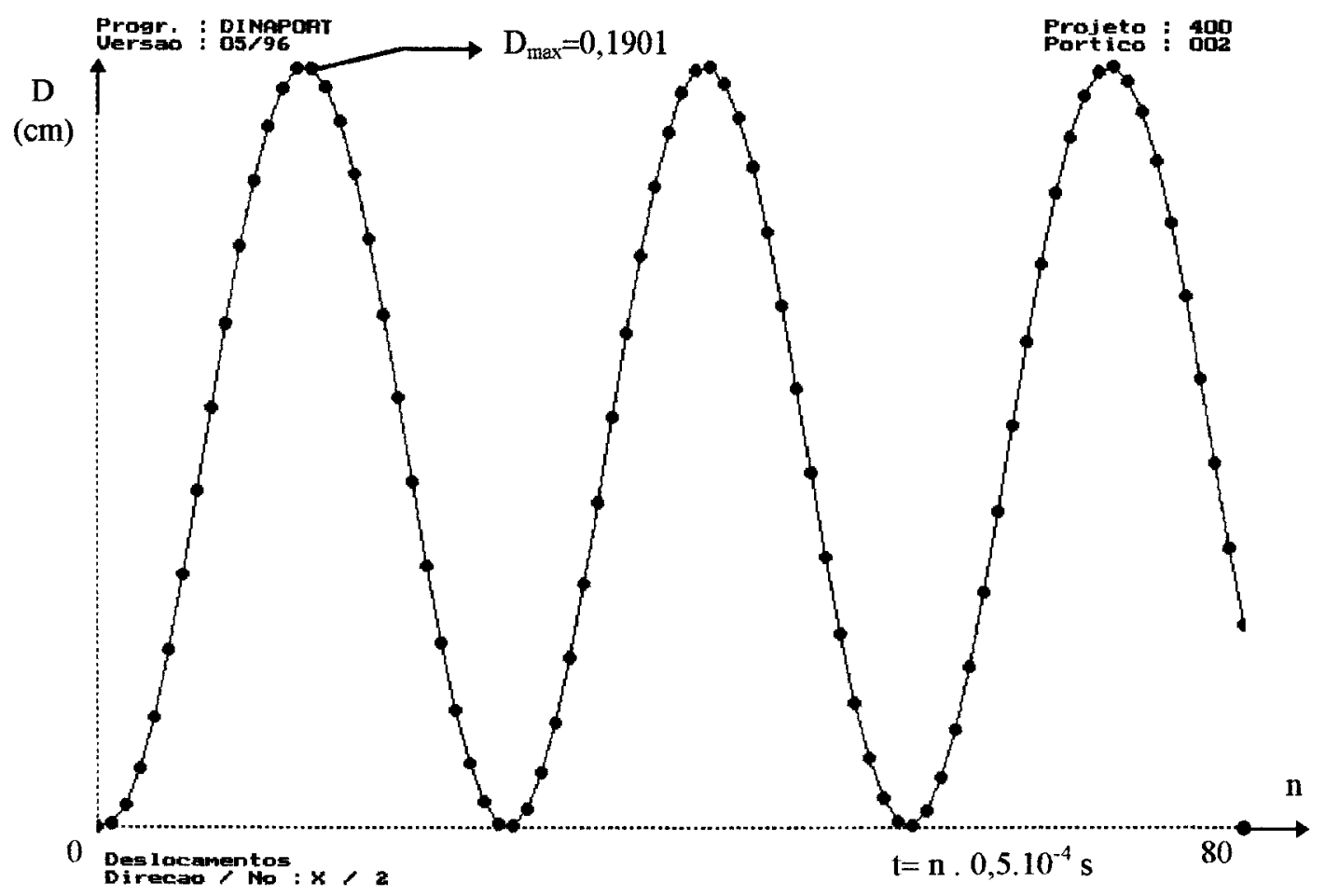

FIGURA 7.31 - Gráfico tempo $x$ deslocamento considerandose $\Delta t=0,5 \cdot 10^{-4} \mathrm{~s}$.

Comparando-se os gráficos contidos nas figuras 7.6 e 7.31 constata-se que ambos são iguais, com uma pequena diferença no valor do deslocamento máximo, sendo $\mathrm{d}_{\text {máx }}=0,1898 \mathrm{~cm}$ para treliça e $\mathrm{d}_{\text {máx }}=0,1901 \mathrm{~cm}$ para pórtico. Portanto ficam valendo as mesmas observações feitas na análise dos resultados do elemento para treliça.

Promovendo-se a divisão da estrutura em doze elementos conforme ilustra a figura 7.32, efetua-se a mesma análise dinâmica cujos resultados são mostrados nas figuras $7.33,7.34,7.35,7.36,7.37$ e 7.38 . 
$\mathrm{F}=10,0 \mathrm{kN}$

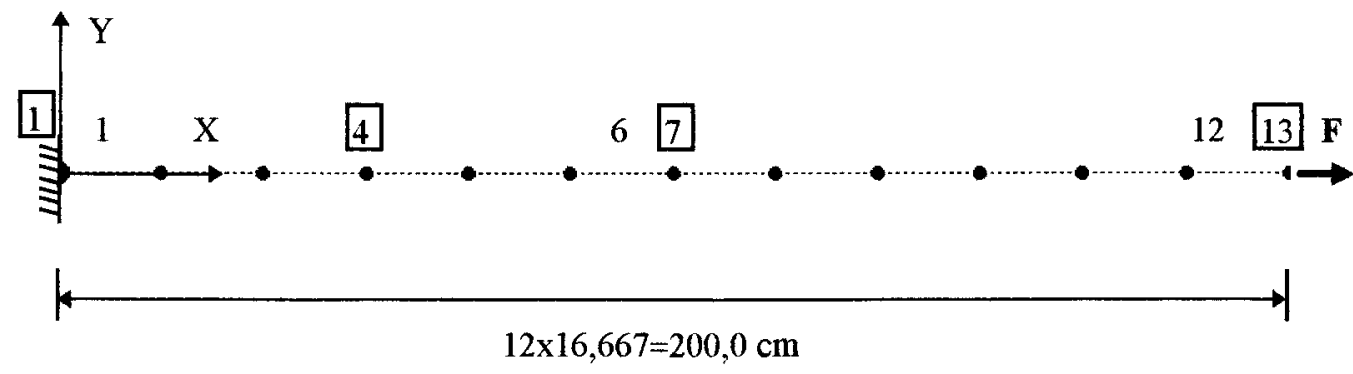

Inter. Tempo : 0

FIGURA 7.32 - Pórtico constituído por vários elementos finitos alinhados.

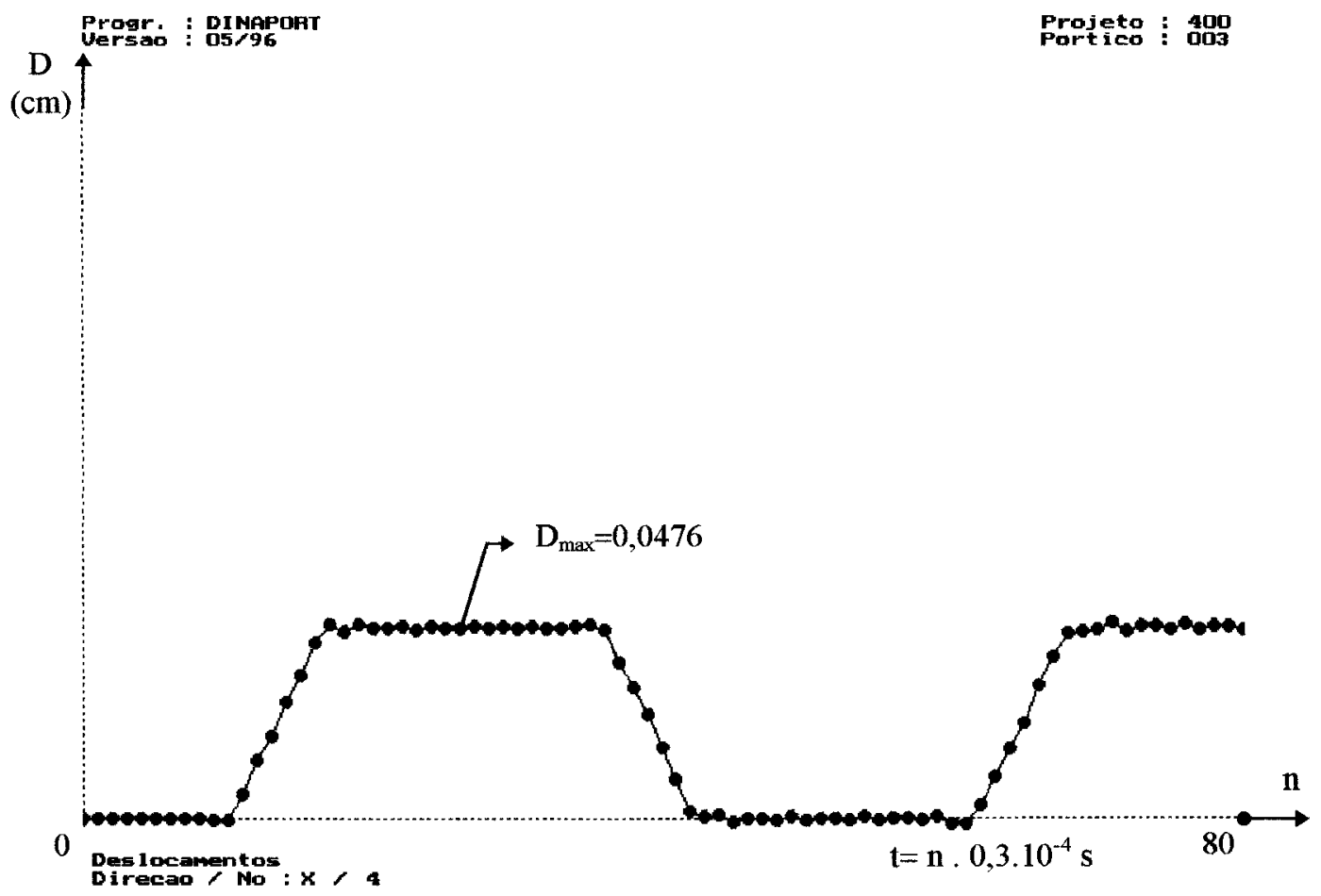

FIGURA 7.33 - Gráfico tempo x deslocamento do nó "4". 


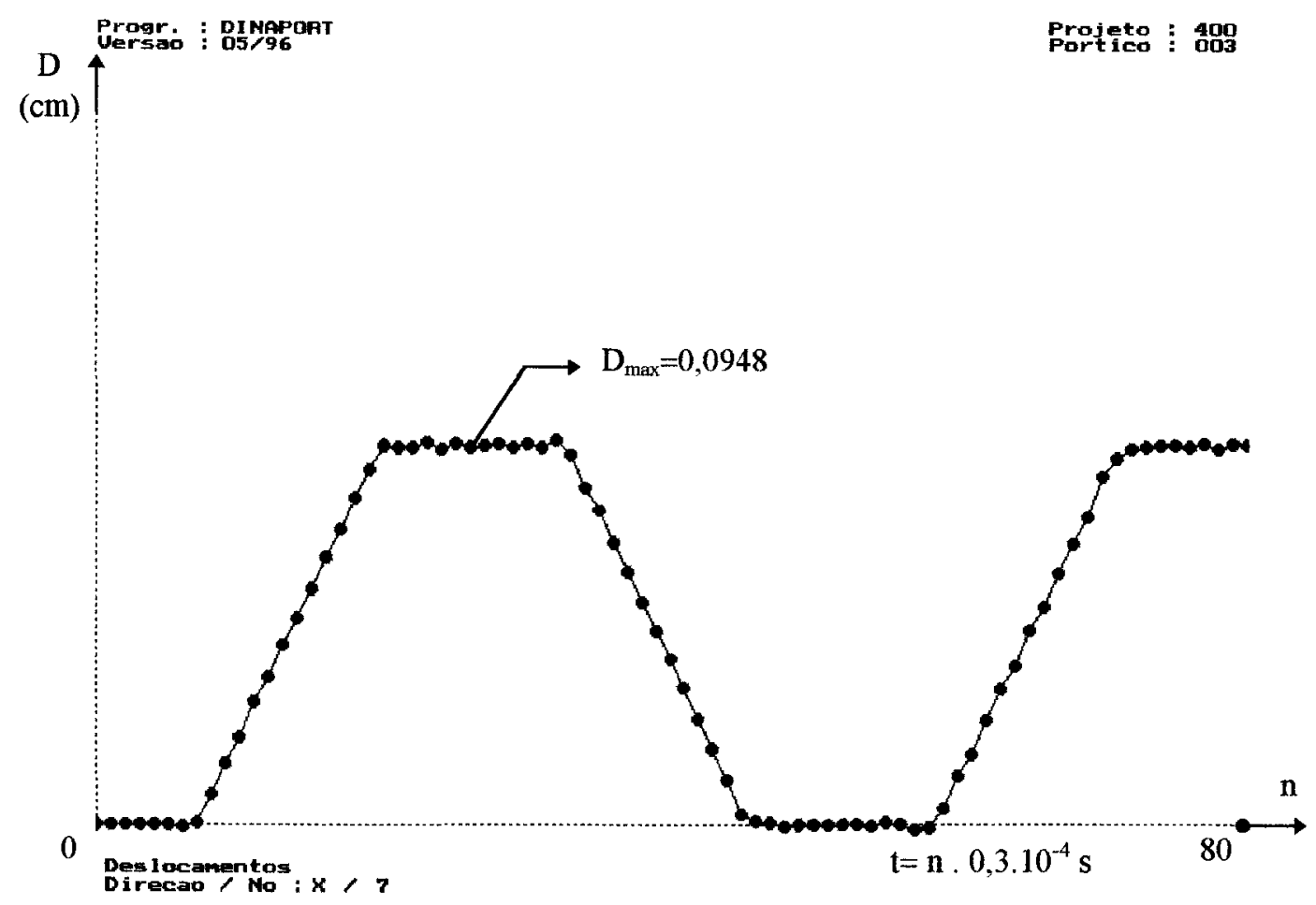

FIGURA 7.34 - Gráfico tempo x deslocamento do nó "7".

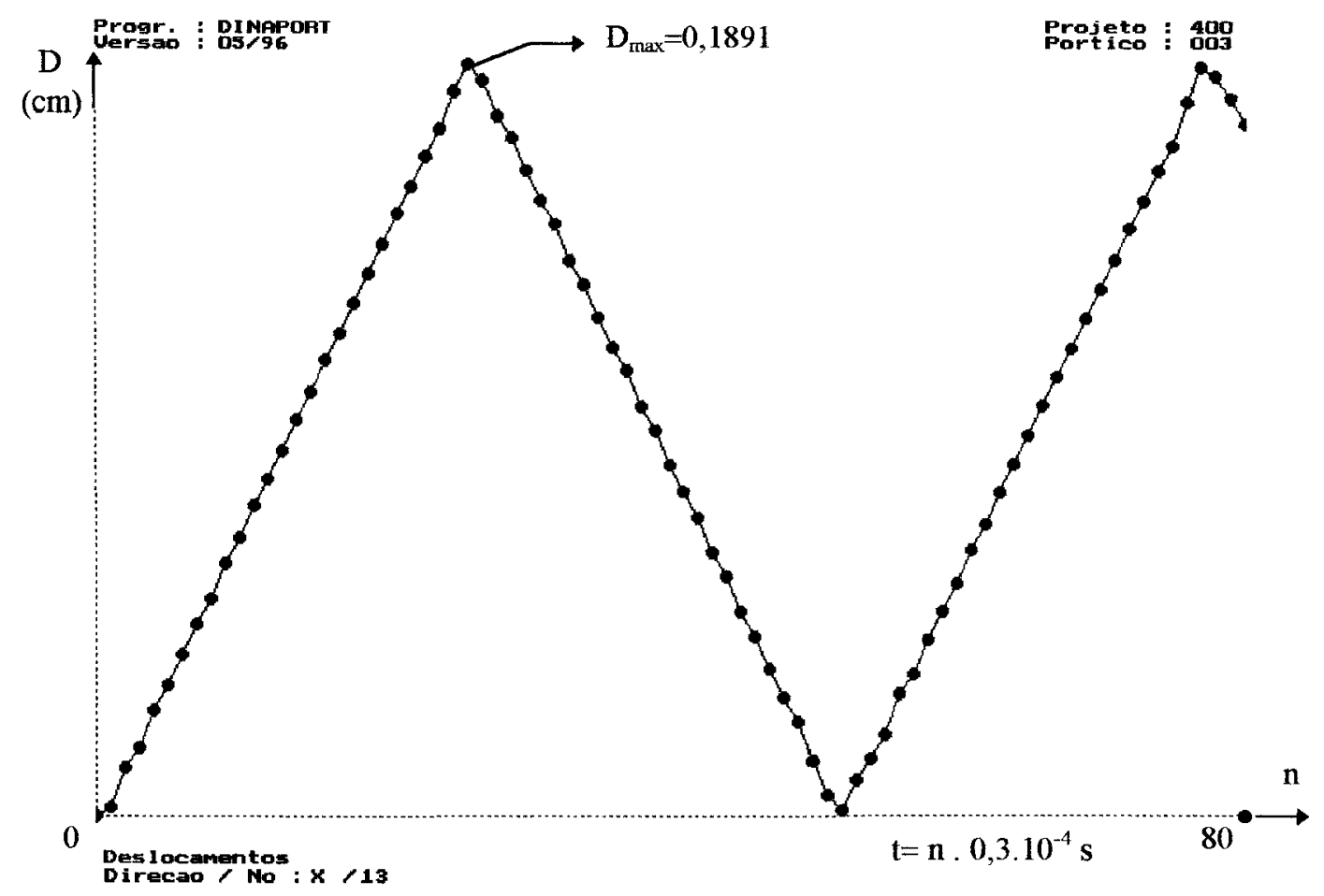

FIGURA 7.35 - Gráfico tempo x deslocamento do nó "13". 


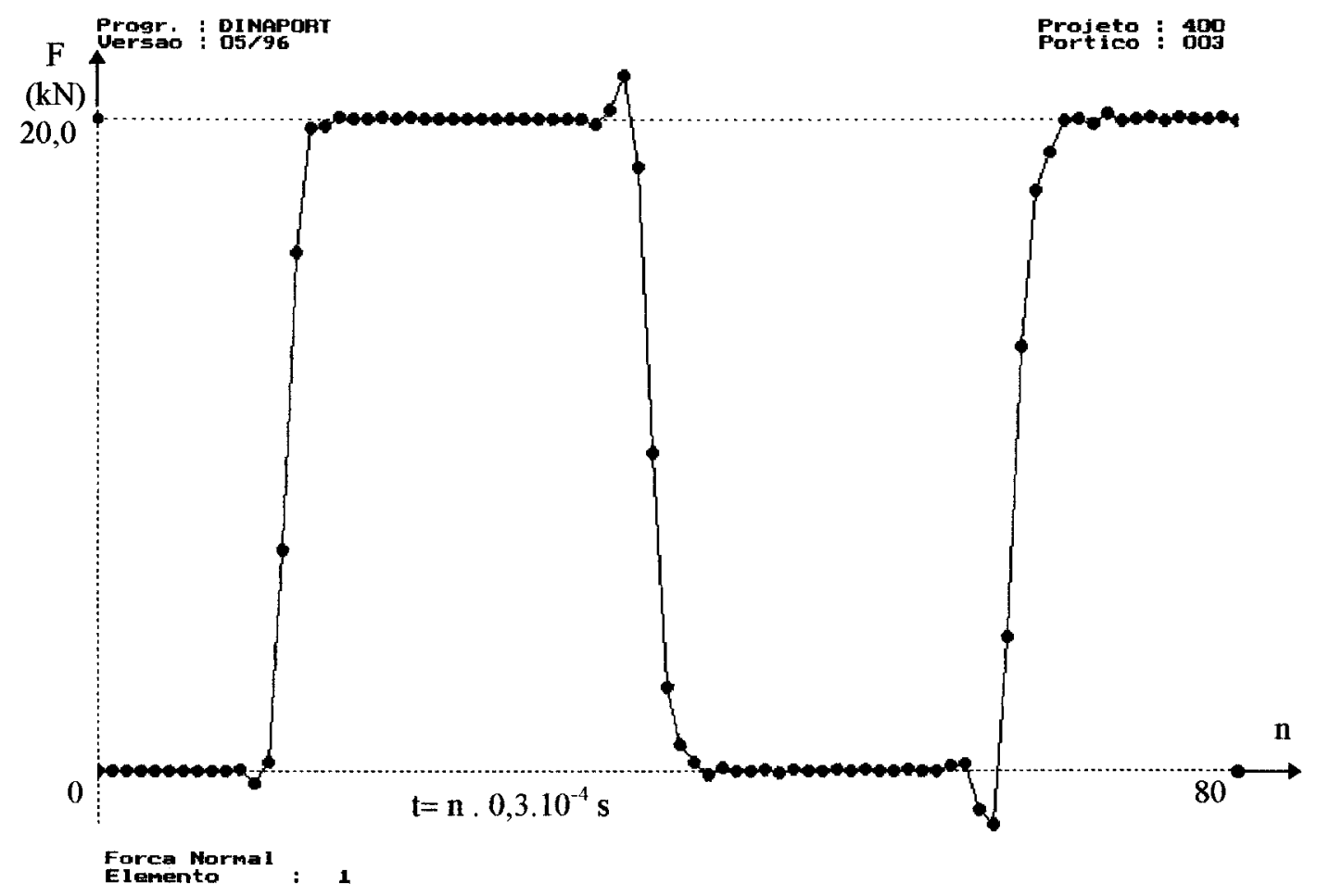

FIGURA 7.36 - Gráfico tempo x força do elemento "1".

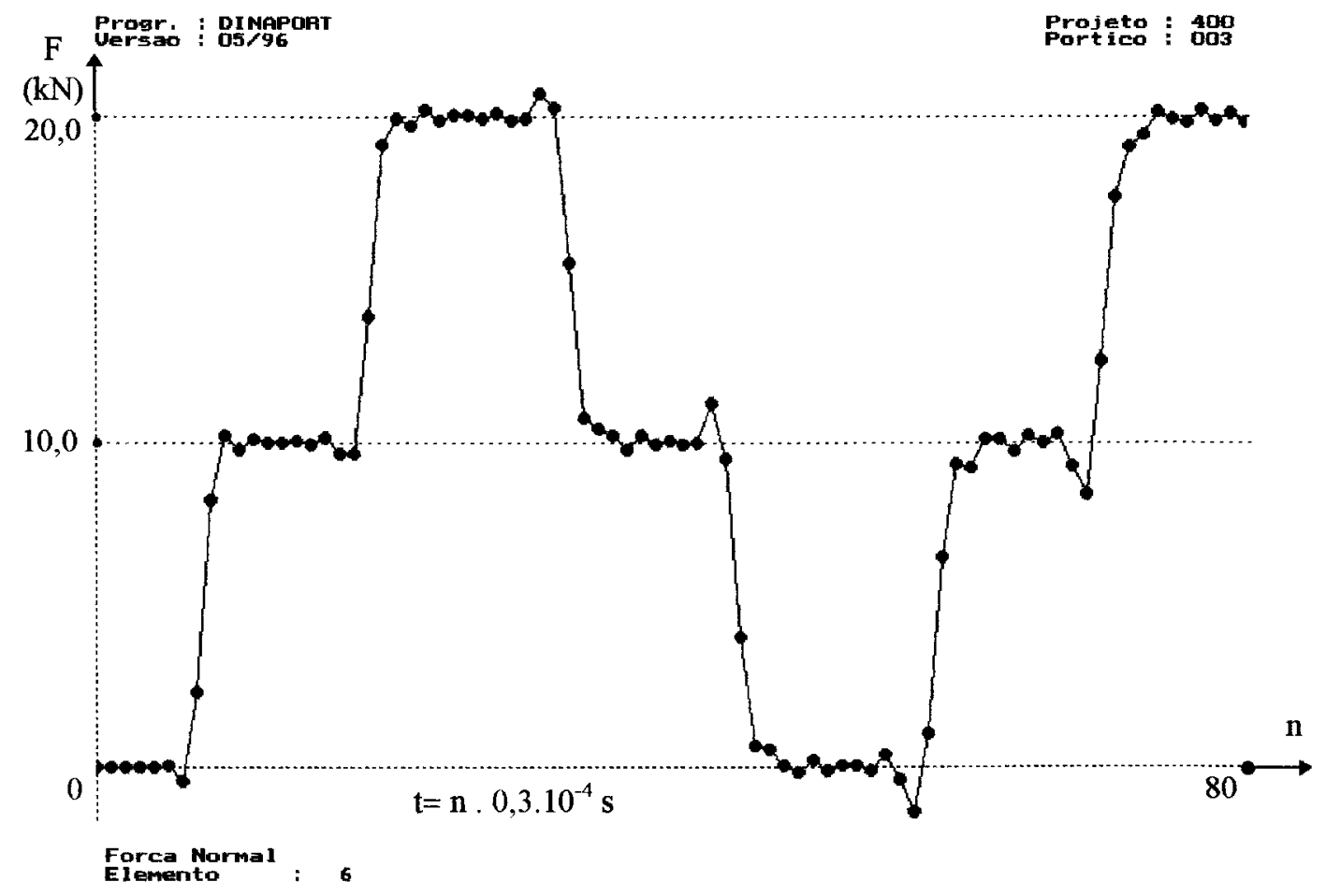

FIGURA 7.37 - Gráfico tempo x força do elemento "6". 


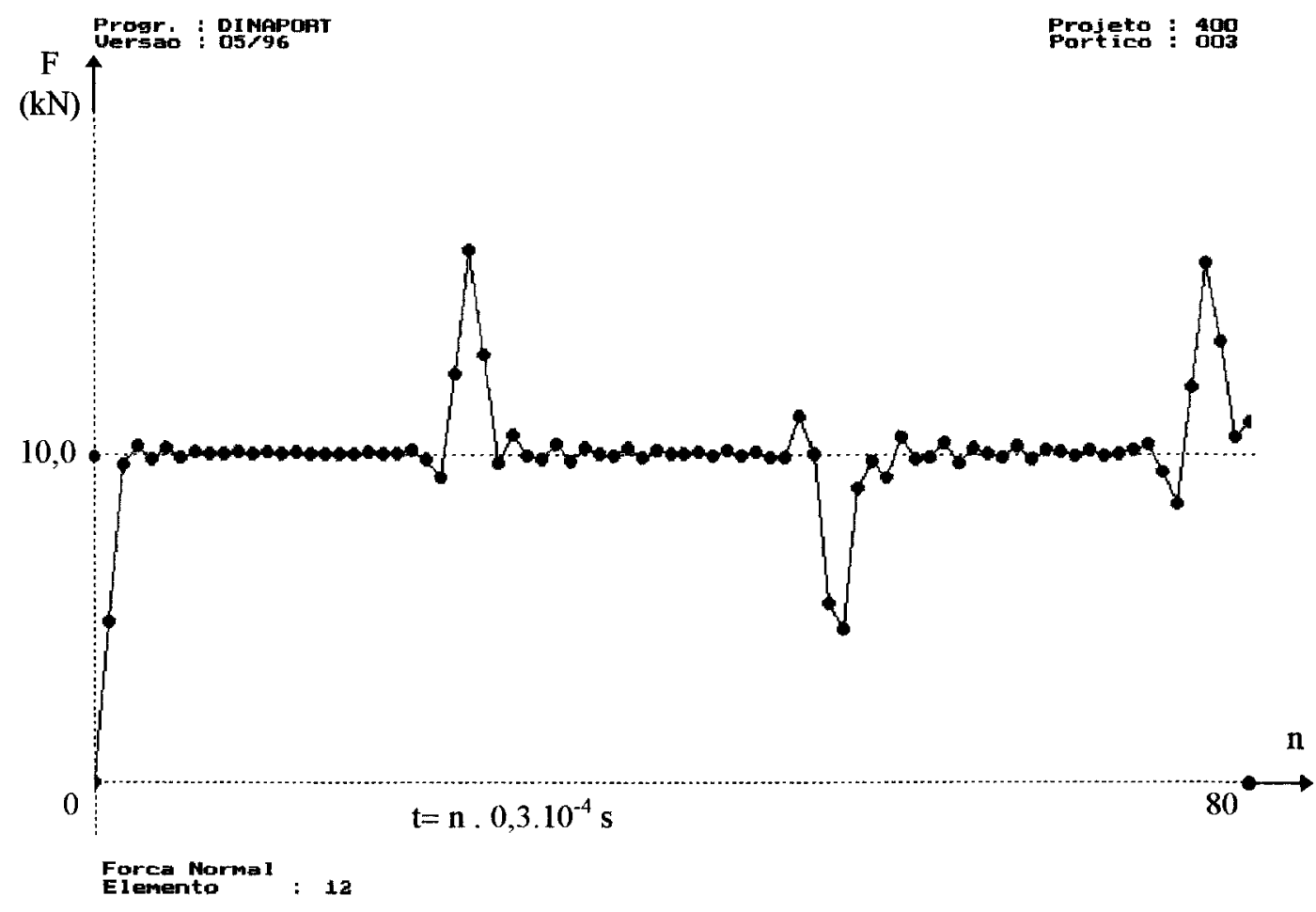

FIGURA 7.38 - Gráfico tempo x força do elemento "12".

Comparando-se os gráficos tempo $x$ deslocamento de ambos elementos, percebe-se que as respostas obtidas são as mesmas, inclusive em valores numéricos. Já com relação aos gráficos tempo x força normal nota-se que os resultados são mais homogêneos quando se utiliza o elemento para pórtico, sendo que tal fato esta relacionado com a forma de obtenção do equilíbrio que é utilizada em cada programa computacional. Convém salientar que o valor da força normal utilizado nos gráficos tempo x força para o elemento de pórtico é fornecido pela média entre os valores de extremidade do elemento, fato que não ocorre na análise do elemento de treliça. 


\section{3 .2 - Exemplo P2}

Este exemplo é composto por uma viga em balanço discretizada por dez elementos finitos, solicitada por uma força "F" aplicada na extremidade oposta a do apoio engastado, conforme ilustra a figura 7.39.

Progr. : PIMpropt

Projeto:

$\mathrm{F}=1,7792888 \cdot 10^{-3} \mathrm{kN}$

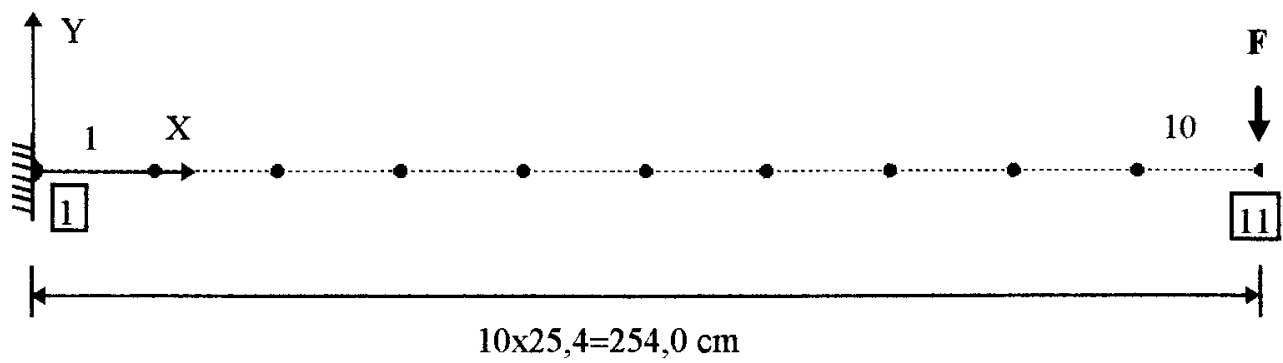

Inter. Tempo : 0

FIGURA 7.39 - Viga em balanço discretizada por elementos finitos.

As características físicas e geométricas de todos os elementos são dadas por:

$$
\begin{gathered}
\mathrm{b}=733,2348419 \mathrm{~cm} ; \mathrm{h}=0,8798818102 \mathrm{~cm} \\
\mathrm{E}_{\mathrm{S}}=0,0 \mathrm{kN} / \mathrm{cm}^{2} \quad ; \quad \mathrm{E}_{\mathrm{C}}=0,6894757 \mathrm{kN} / \mathrm{cm}^{2}
\end{gathered}
$$

Efetuando-se uma análise estática de tal forma que a força seja aplicada incrementalmente em 80 passos iguais, obtém-se a resposta da estrutura conforme ilustra a figura 7.40 . 


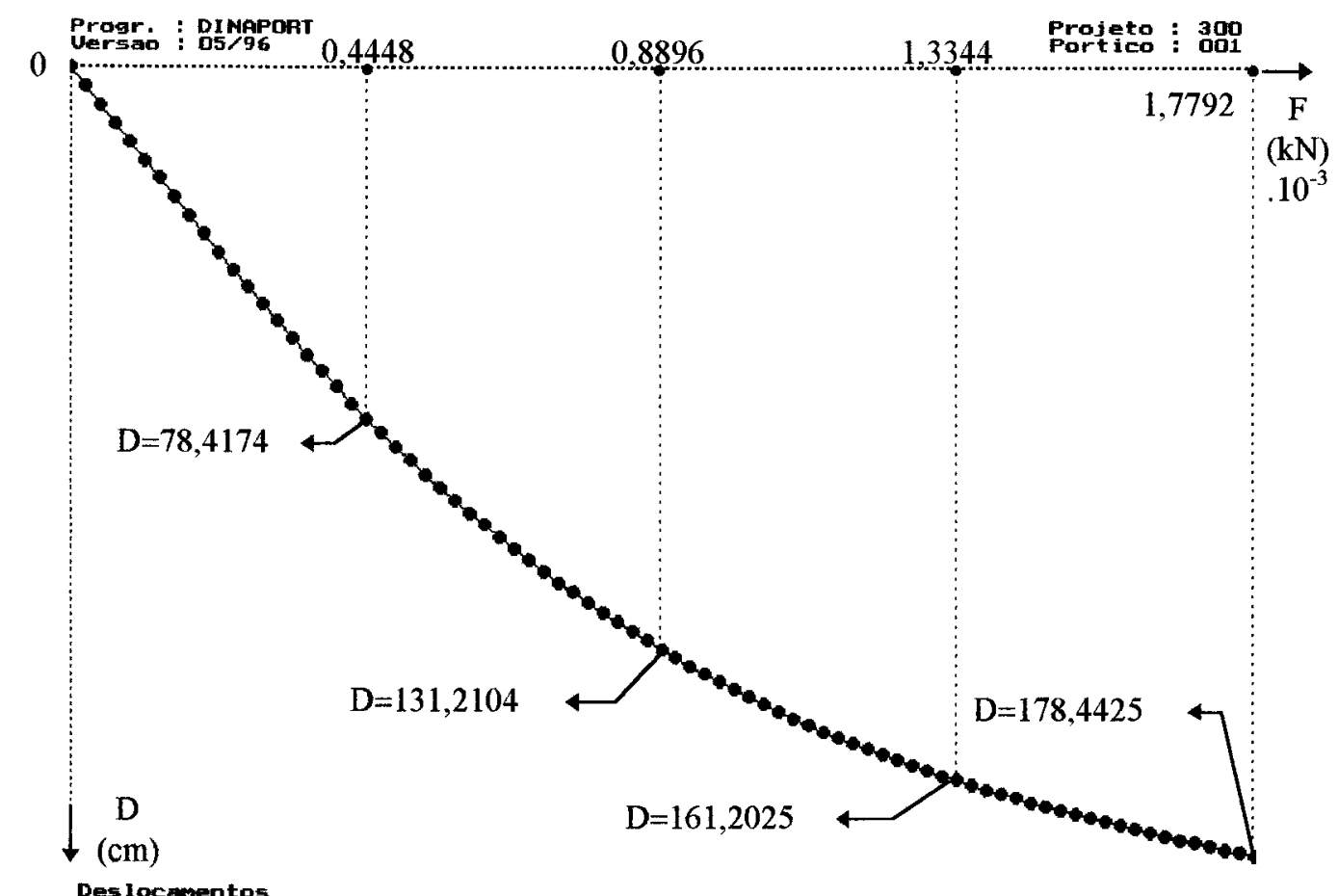

Des locamentos: $Y>11$

FIGURA 7.40 - Gráfico força x deslocamento do nó "11".

O gráfico contido na figura 7.40 mostra o comportamento da estrutura com grande não-linearidade geométrica, uma vez que o deslocamento máximo obtido no nó "11" é da mesma ordem de grandeza que o comprimento da viga, conforme ilustra a figura 7.41 .

Tal resposta coincide com os resultados obtidos por ORAN et al.(1976) via formulação incremental Euleriana, comprovando a eficácia do procedimento incremental adotado para o elemento finito de pórtico plano.

Um fato importante deve ser ressaltado quando se compara estes resultados com os obtidos via comportamento linear, pois quando se realiza este tipo de análise encontra-se um valor de deslocamento máximo $\left(d_{L}=338,6667 \mathrm{~cm}\right)$ muito maior que $\circ$ valor encontrado $\left(d_{N L}=178,4425 \mathrm{~cm}\right)$. 


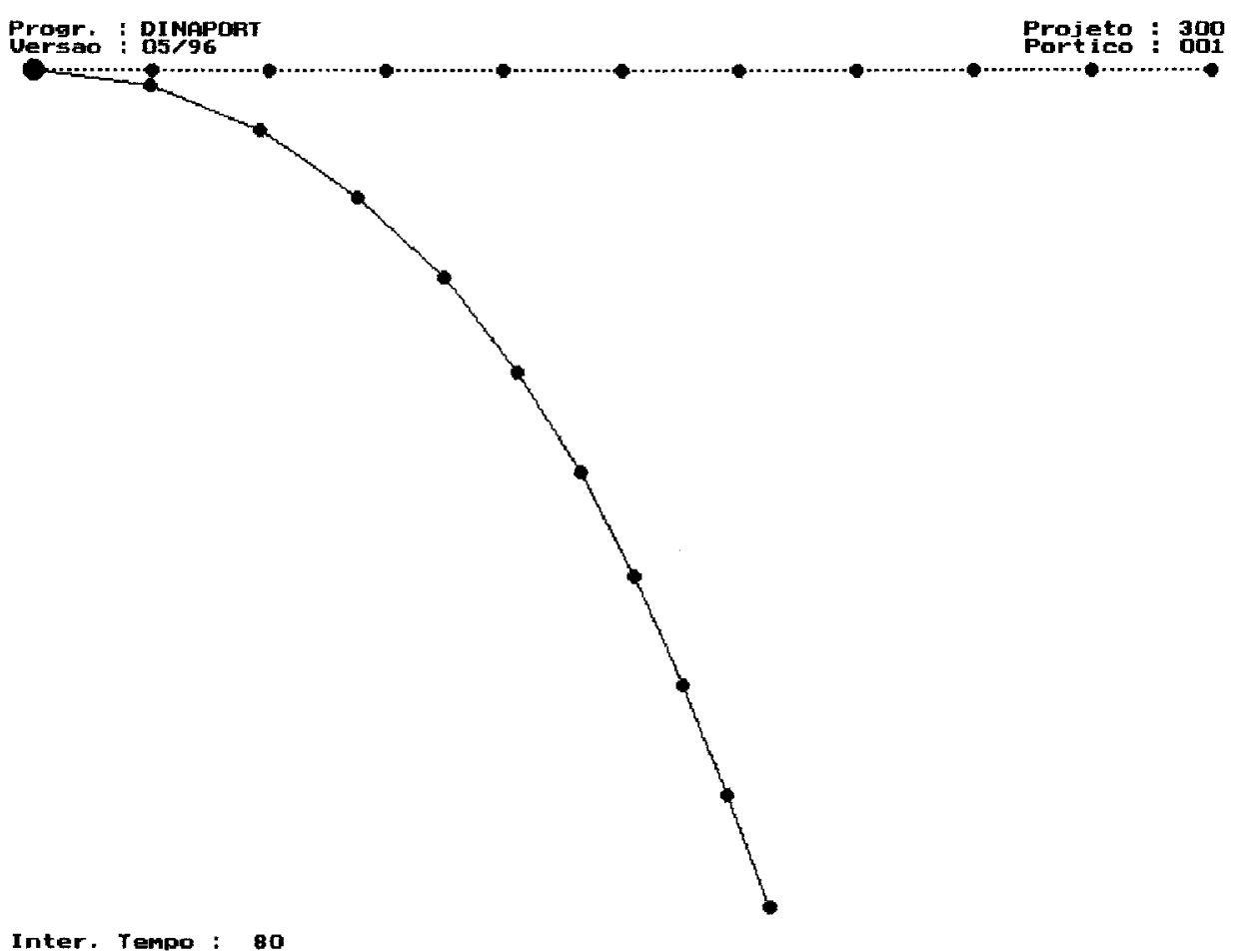

FIGURA 7.41 - Posição deslocada da viga após a aplicação de todo o carregamento.

\subsection{3 - Exemplo P3}

Este exemplo é composto por um pórtico simples biengastado discretizado por dezoito elementos finitos, solicitado por três forças, conforme ilustra a figura 7.42 .

As características físicas e geométricas de todos os elementos são dadas por:

$$
\begin{gathered}
\mathrm{b}=1,681345263 \mathrm{~cm} ; \mathrm{h}=45,16343767 \mathrm{~cm} \\
E_{S}=0,0 \mathrm{kN} / \mathrm{cm}^{2} ; \mathrm{E}_{\mathrm{C}}=20684,271 \mathrm{kN} / \mathrm{cm}^{2}
\end{gathered}
$$




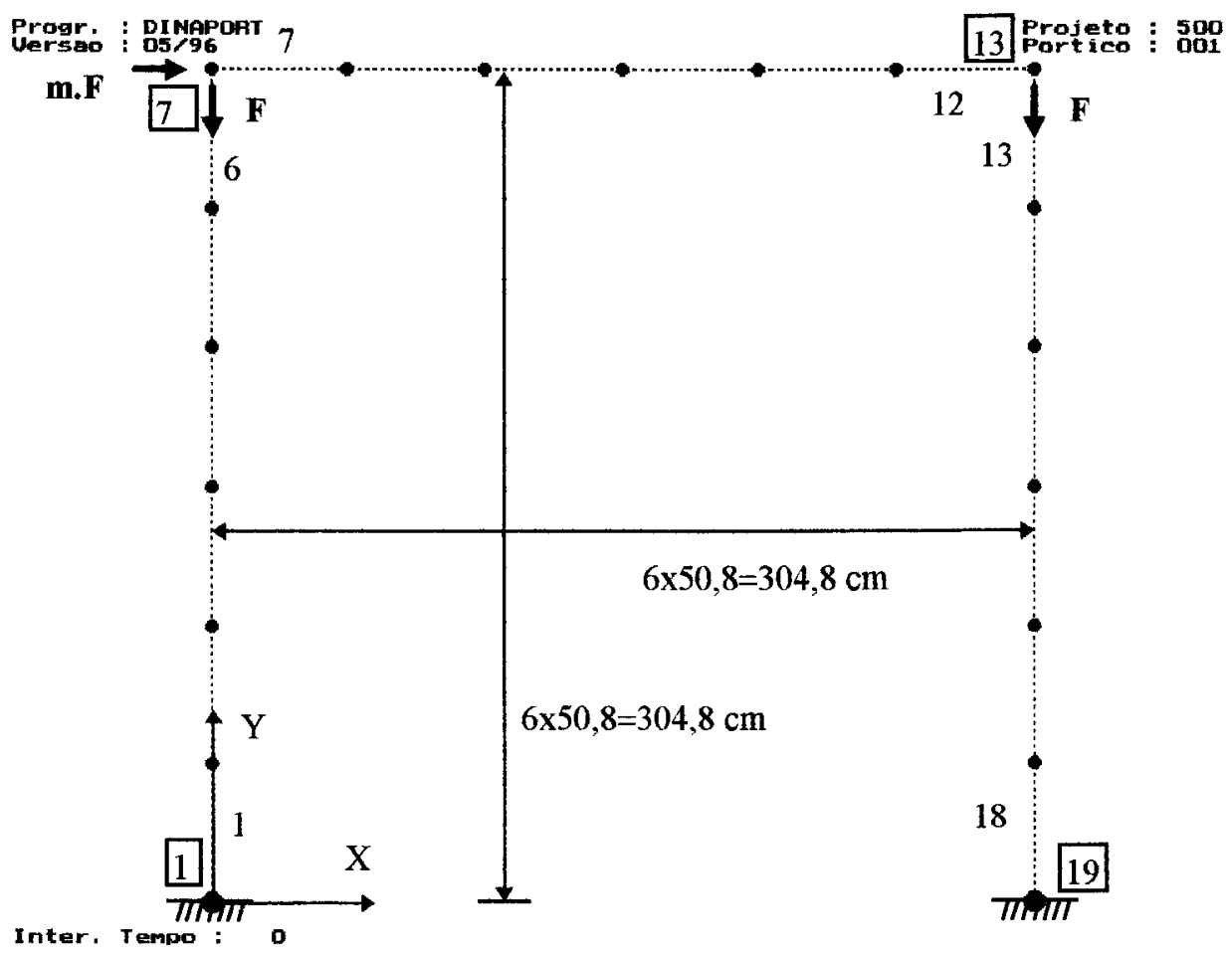

FIGURA 7.42 - Pórtico simples biengastado discretizado por elementos finitos.

Efetuando-se uma análise estática de tal forma que a força seja aplicada incrementalmente em 160 passos iguais, obtém-se a resposta da estrutura para dois diferentes valores do fator " $m$ " que multiplica uma das forças, conforme ilustram as figuras 7.43 e 7.44 .

Ambos os gráficos força $x$ deslocamento mostram 0 comportamento da estrutura com grande não-linearidade geométrica, tendo em vista a ordem de grandeza dos deslocamentos obtidos, conforme figura 7.45 que ilustra a posição de equilíbrio final da estrutura para m=1/2. 


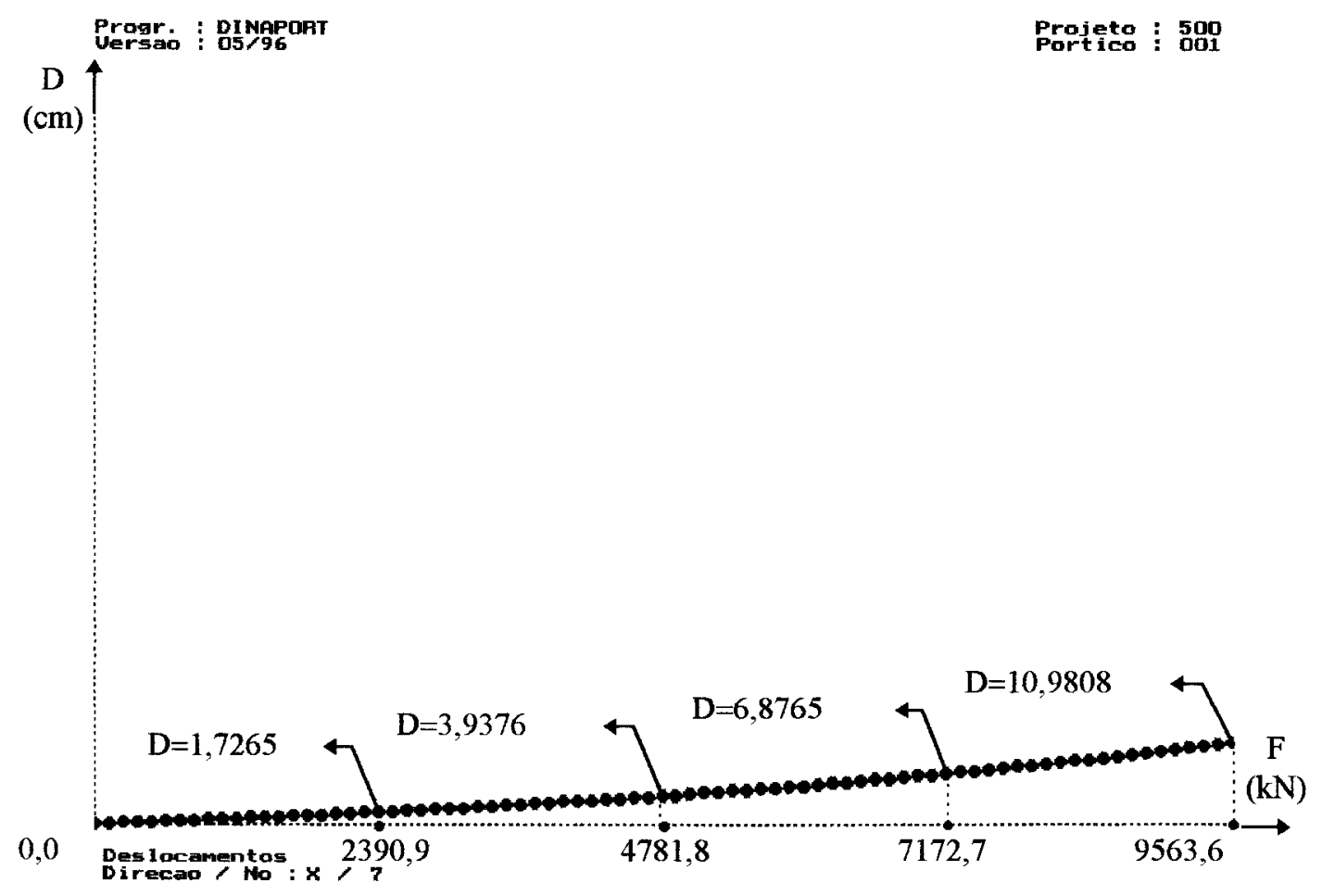

Progr: : Dringpart

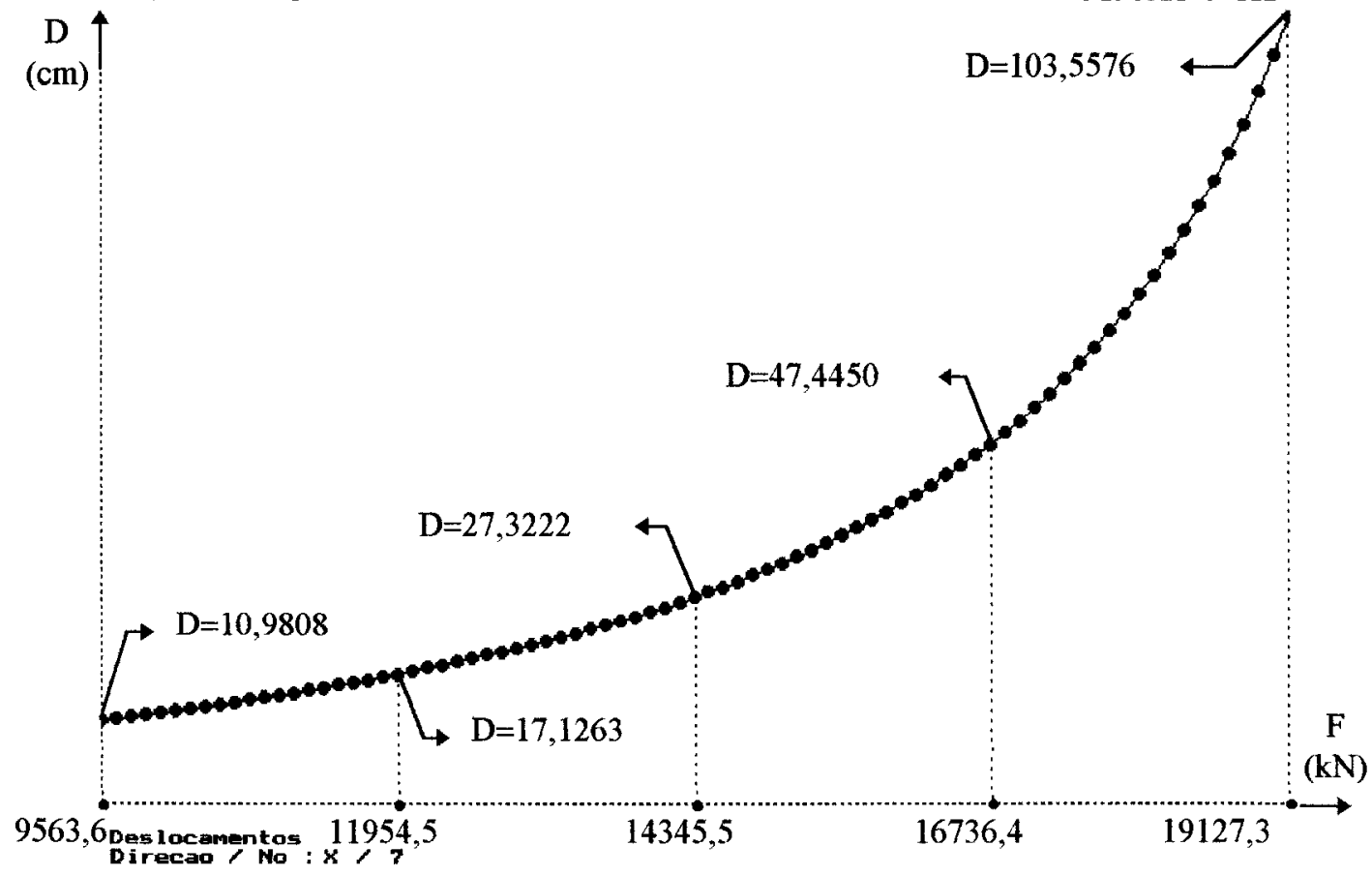

FIGURA 7.43 - Gráfico força $x$ deslocamento do nó "7" para $m=1 / 10$. 

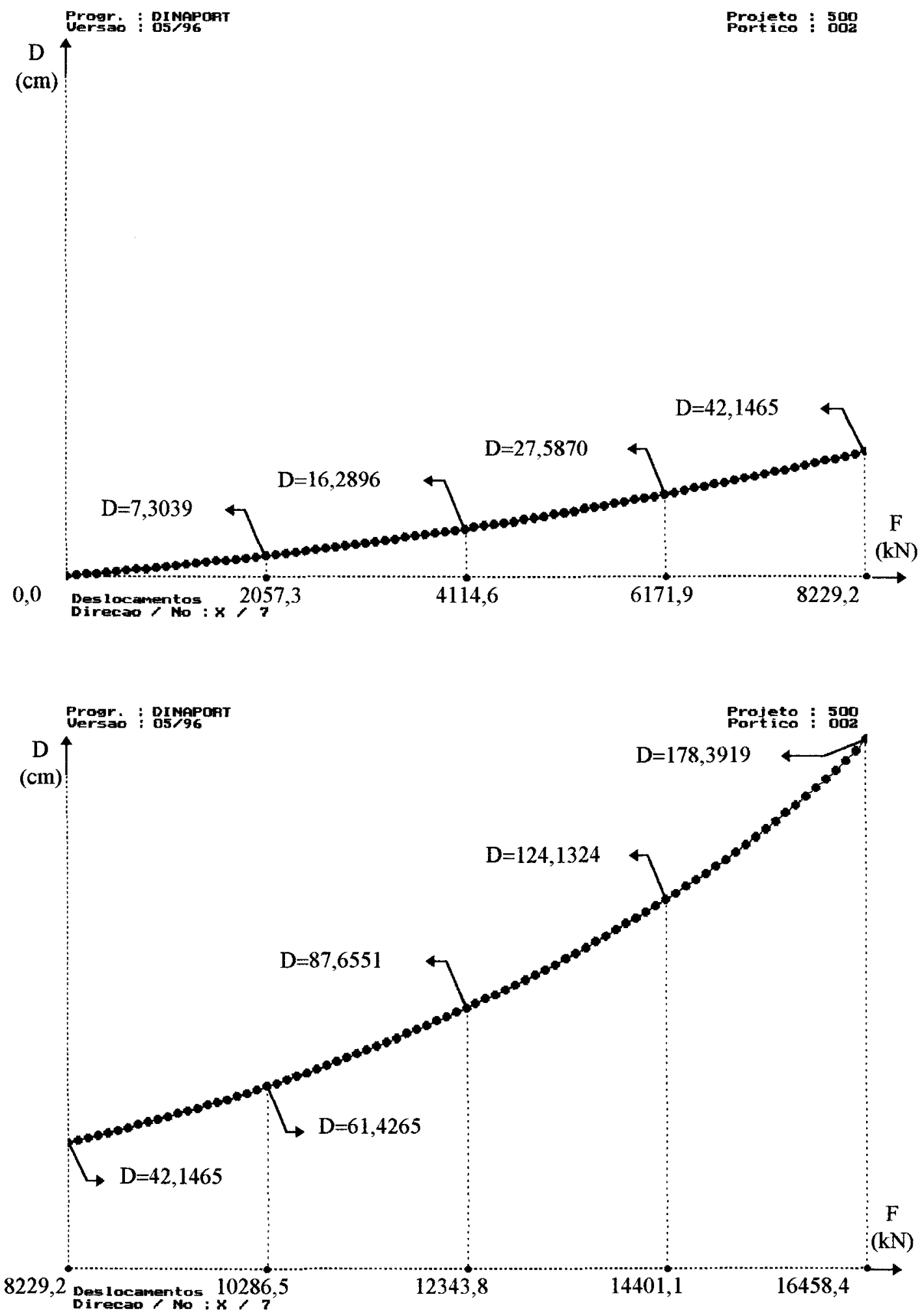

FIGURA 7.44 - Gráfico força $x$ deslocamento do nó "7" para $m=1 / 2$. 


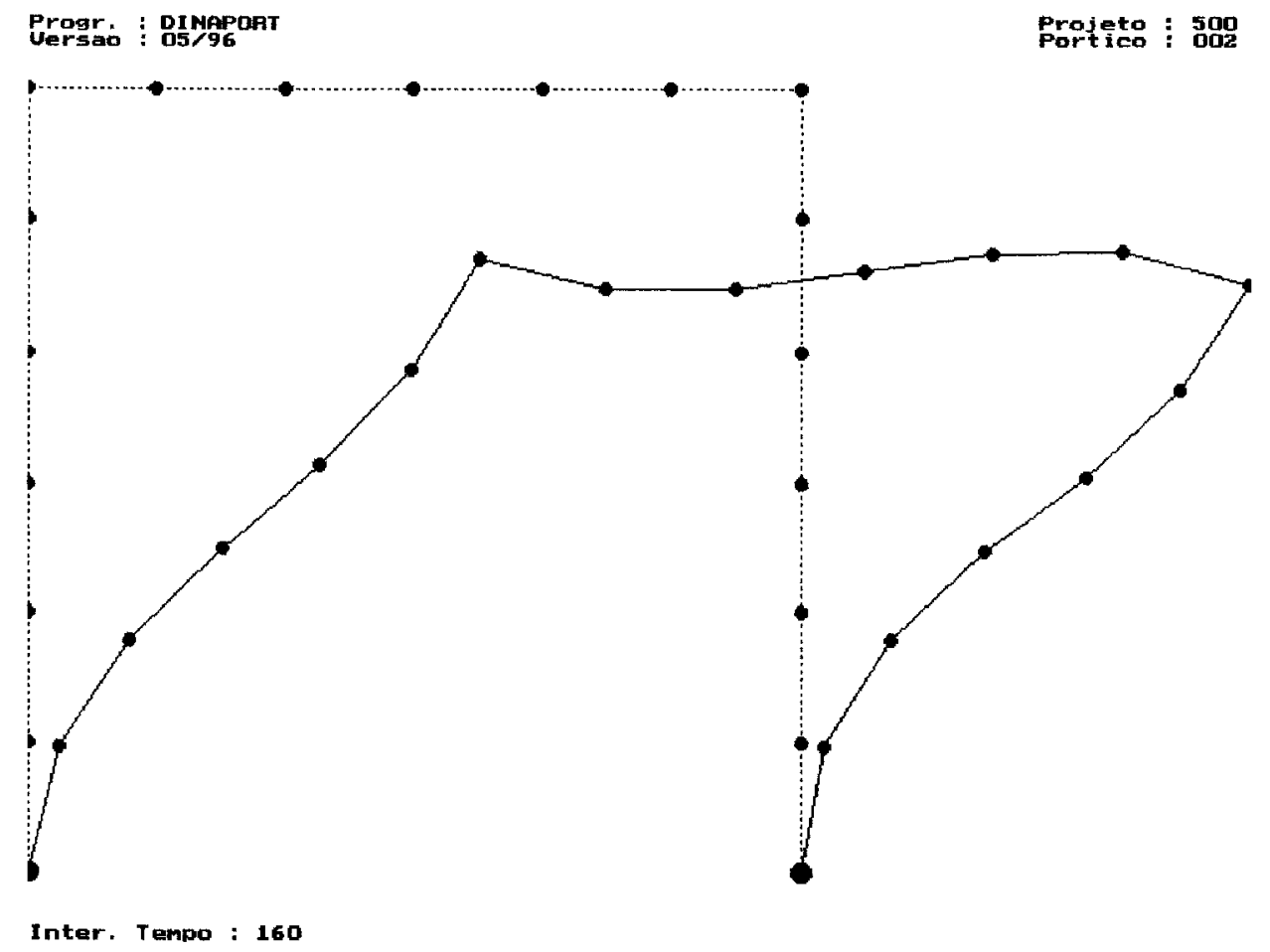

FIGURA 7.45 - Posição deslocada do pórtico considerandose $m=1 / 2$.

De forma análoga ao exemplo anterior, tais respostas também coincidem com os resultados obtidos por ORAN et al.(1976) via iteração Euleriana com $\delta=0$. Entretanto, quando é feita a comparação destes resultados com os obtidos via comportamento linear, ocorre o mesmo fato já descrito no exemplo P2 de forma oposta, pois os valores obtidos utilizando-se comportamento linear $\left(d_{L}=12,3035 \mathrm{~cm}\right.$ para $\mathrm{m}=1 / 10$ e $\mathrm{d}_{\mathrm{L}}=52,9337 \mathrm{~cm}$ para $\mathrm{m}=1 / 2$ ) são muito menores que os valores obtidos considerando-se não-linearidade geométrica $\left(d_{N L}=103,5576 \mathrm{~cm}\right.$ para $\mathrm{m}=1 / 10$ e $d_{N L}=178,3919 \mathrm{~cm}$ para $m=1 / 2$ ). Com isso, fica caracterizado a importância de se realizar uma análise mais refinada pois pode-se encontrar resultados a favor ou contra a segurança da estrutura. 


\section{3 .4 - Exemplo P4}

A estrutura aporticada deste exemplo é composta por uma viga biengastada discretizada por seis elementos finitos, solicitada por uma força constante " $F$ " com o tempo, aplicada no nó central, sendo que neste mesmo ponto tem-se um peso "P" fixo, conforme figura 7.46.

Progr. : DIMAPOAT

$\mathrm{F}=2,846862 \mathrm{kN}$

$\mathrm{P}=7,4102.10^{-4} \mathrm{kN}$

$\omega_{1}=609,0516 \mathrm{rad} / \mathrm{s}$

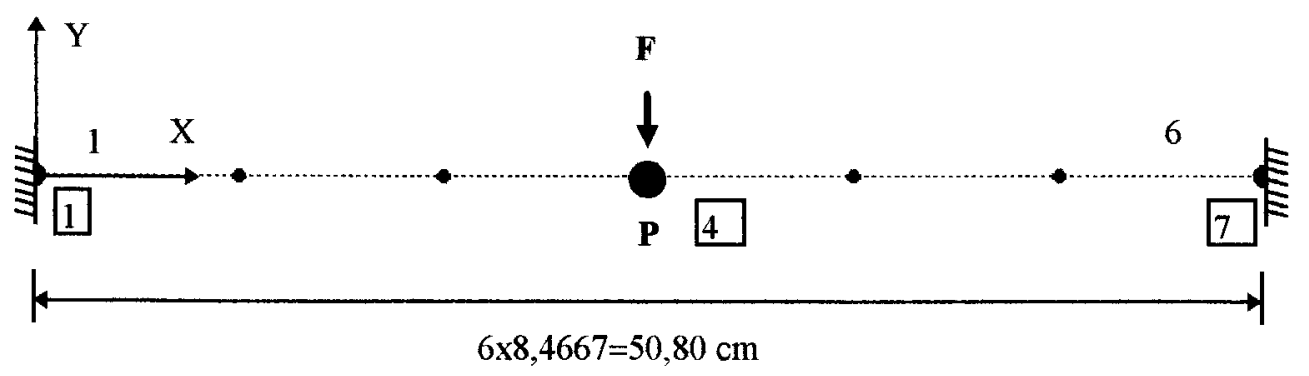

Inter. Tempo : 0

FIGURA 7.46 - Viga biengastada discretizada por elementos finitos.

As características físicas e geométricas de todos os elementos são dadas por:

$$
\begin{gathered}
\mathrm{b}=2,54 \mathrm{~cm} ; \mathrm{h}=0,508 \mathrm{~cm} \\
\gamma=1.10^{-15} \mathrm{kN} / \mathrm{cm}^{3} \quad ; \quad \mathrm{E}_{\mathrm{S}}=0,0 \mathrm{kN} / \mathrm{cm}^{2} ; \mathrm{E}_{\mathrm{C}}=6894,757 \mathrm{kN} / \mathrm{cm}^{2}
\end{gathered}
$$

Efetuando-se uma análise dinâmica com nãoIinearidade geométrica, obtém-se a resposta da estrutura conforme ilustra a figura 7.47 . 


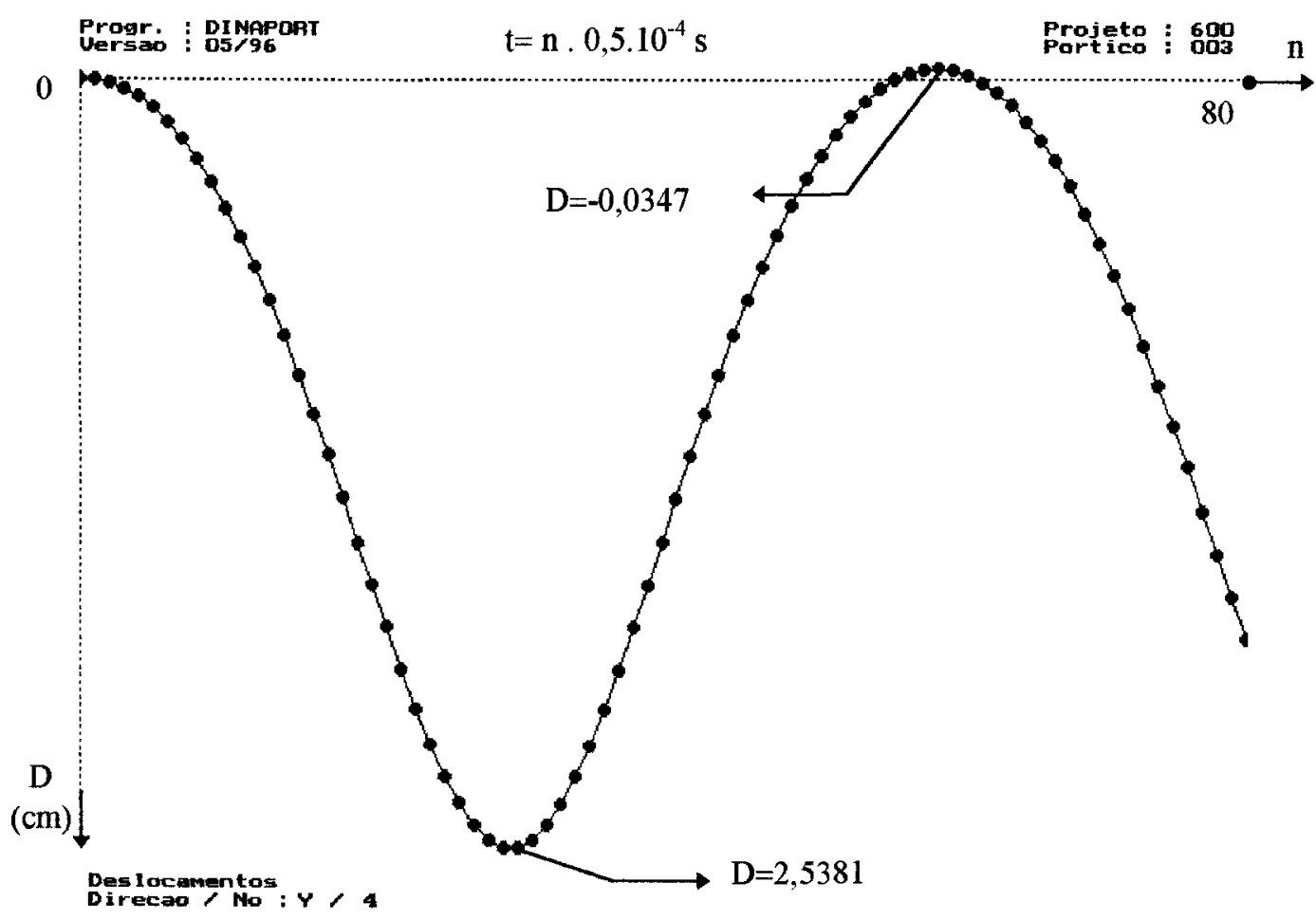

FIGURA 7.47 - Gráfico tempo x deslocamento do nó "4".

- gráfico tempo $x$ deslocamento contido na figura 7.47 mostra o comportamento de uma viga biengastada que possui um peso fixado no meio do vão, sendo que tal resultado é praticamente exato e pode ser comprovado através da confrontação com os resultados obtidos por ORAN et al.(1976). Efetuando-se o mesmo tipo de comparação feita ao final do exemplo P3, tem-se que o deslocamento obtido utilizando-se comportamento linear $\left(d_{L}=20,3183 \mathrm{~cm}\right)$ é bem maior que o valor obtido na análise que foi realizada $\left(\mathrm{d}_{\mathrm{NL}}=2,5381 \mathrm{~cm}\right)$, comprovando, mais uma vez, a necessidade de se efetuar uma análise mais realista.

\section{3 .5 - Exemplo P5}

A estrutura aporticada deste exemplo é composta por uma viga biapoiada discretizada por doze elementos 
finitos, solicitada por duas forças "F", conforme ilustra a figura 7.48 .

Progr. : DINapont

Projeto : 700

$\mathrm{F}=40,0 \mathrm{kN}$

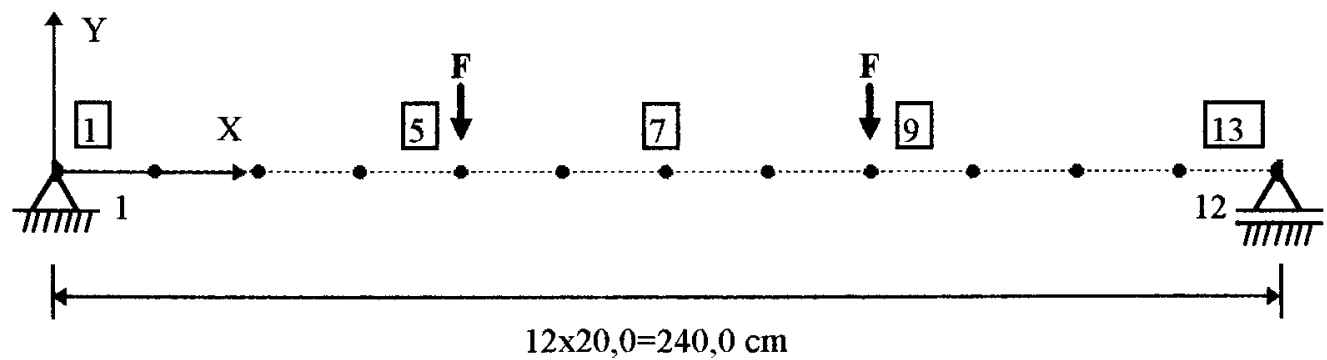

Inter. Tempo : 0

FIGURA 7.48 - Viga biapoiada discretizada por elementos finitos.

As características físicas e geométricas de todos os elementos são dadas por:

$$
\begin{gathered}
\mathrm{b}=12,0 \mathrm{~cm} ; \mathrm{h}=30,0 \mathrm{~cm} \\
\mathrm{f}_{\mathrm{CK}}=2,6 \mathrm{kN} / \mathrm{cm}^{2} ; \mathrm{f}_{\mathrm{CTK}}=0,268 \mathrm{kN} / \mathrm{cm}^{2} \\
\mathrm{E}_{\mathrm{S}}=19600,0 \mathrm{kN} / \mathrm{cm}^{2} ; \mathrm{E}_{\mathrm{C}}=2920,0 \mathrm{kN} / \mathrm{cm}^{2}
\end{gathered}
$$

Neste exemplo pretende-se fazer uma avaliação via análise estática do desempenho do modelo físico para o concreto armado que foi utilizado neste trabalho. Para isto, utilizam-se três diferentes arranjos para a disposição da armadura principal, CARVALHO(1994) e PROENÇA et al.(1994), conforme ilustram as figuras 7.49, 7.50 e 7.51 . 


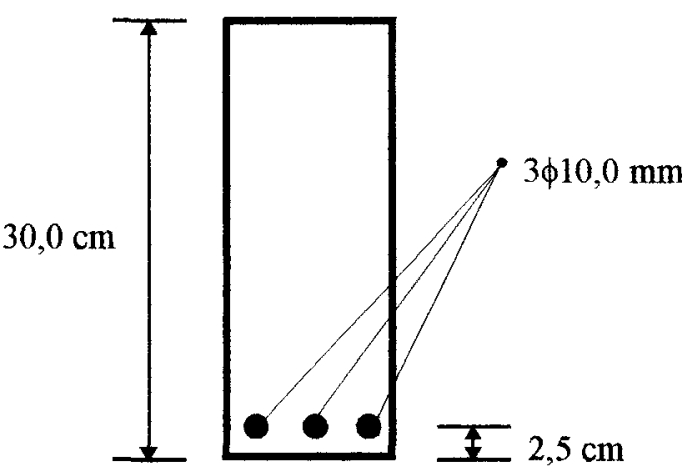

12,0 cm

FIGURA 7.49 - Seção transversal da viga. Arranjo "1".

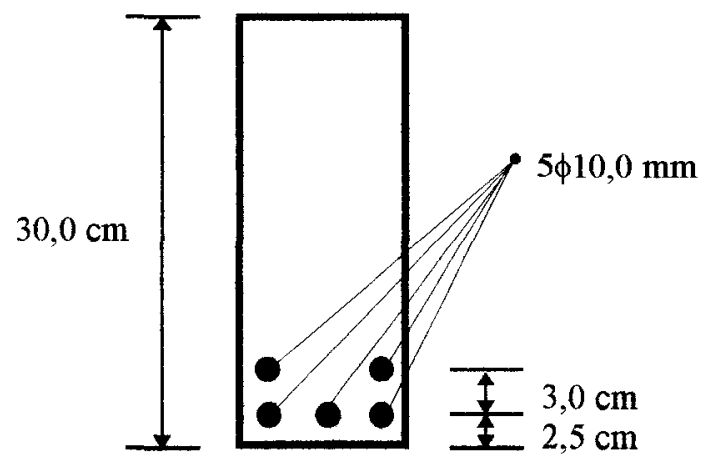

$$
\stackrel{12,0 \mathrm{~cm}}{\longrightarrow}
$$

FIGURA 7.50 - Seção transversal da viga. Arranjo "2".

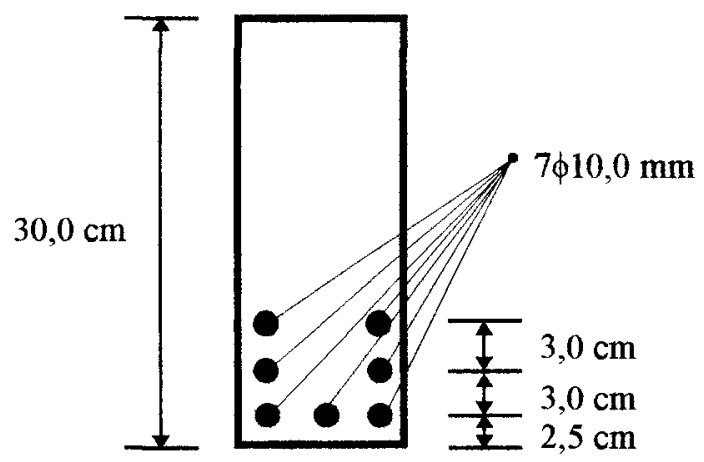

FIGURA 7.51 - Seção transversal da viga. Arranjo "3".

Resolvendo-se o exemplo de tal forma que as forças sejam aplicadas incrementalmente em 80 passos iguais, obtém-se a resposta da estrutura para os três tipos de arranjo da armadura, conforme ilustram as figuras 7.52, 7.53 e 7.54 . 


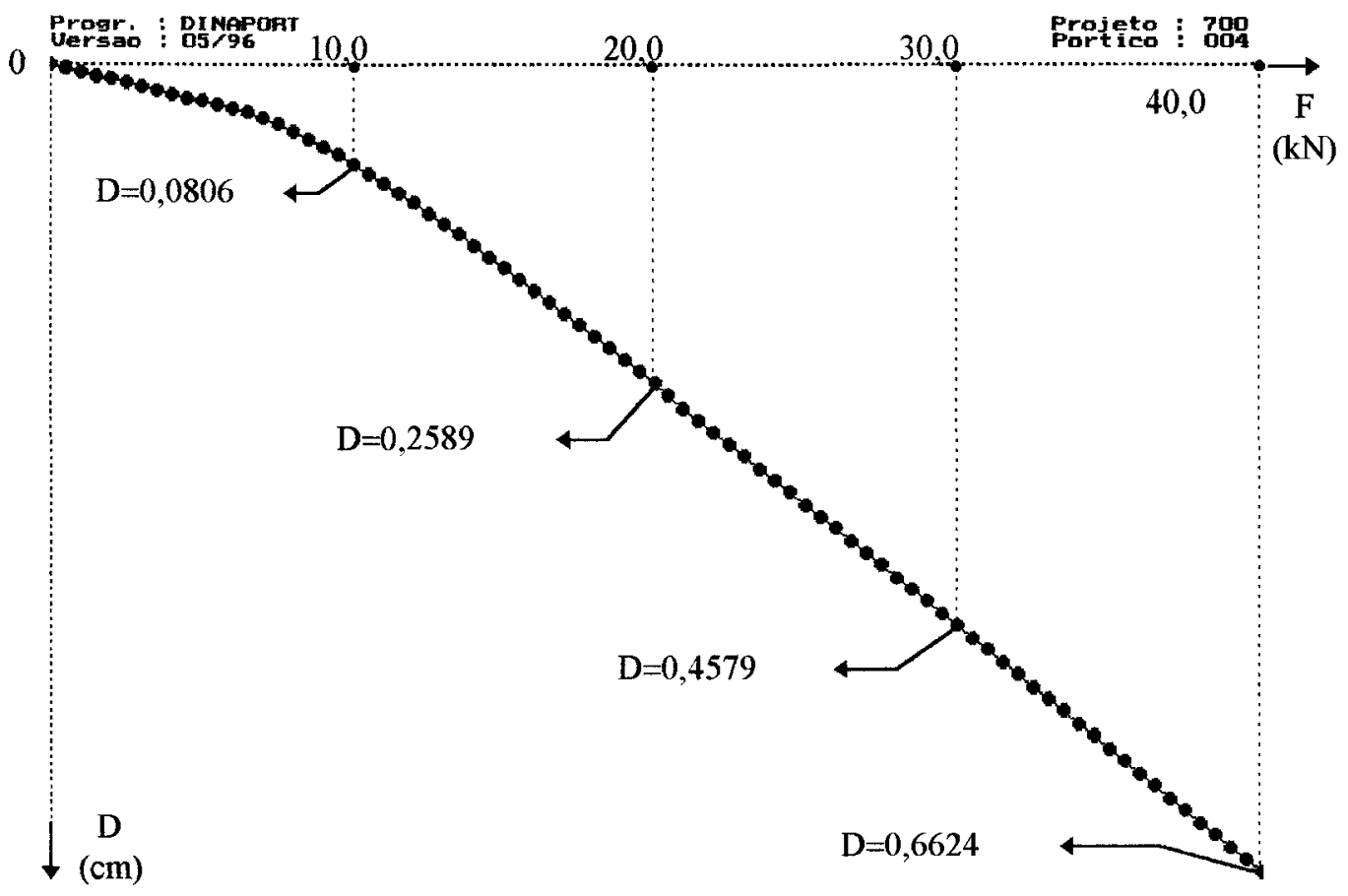

Deslocamentos: $Y$, ?

FIGURA 7.52 - Gráfico força $x$ deslocamento do nó "7" para arranjo " 1 ".

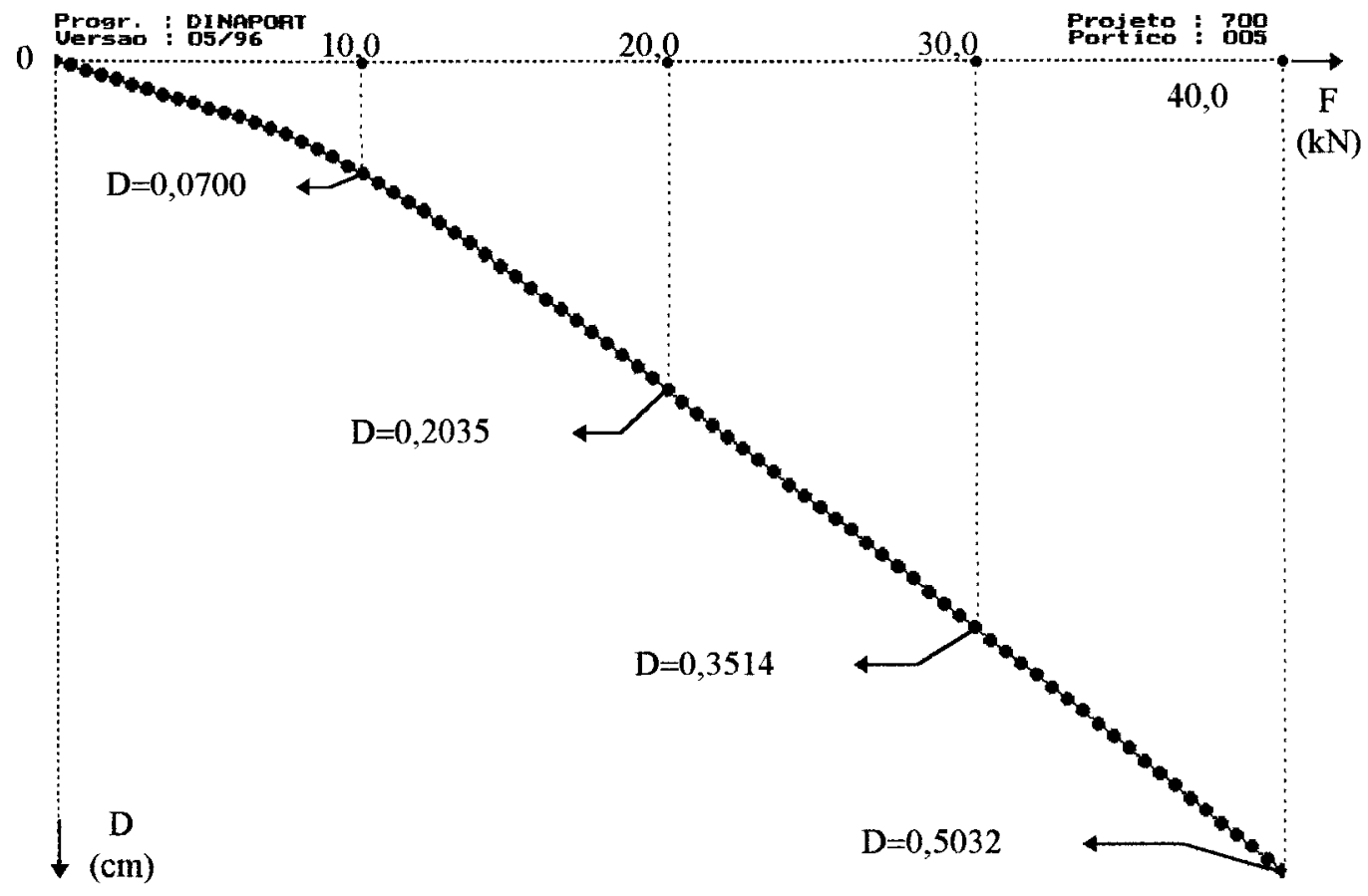

Des locamentos
Direcao $/$ No $: Y, 7$

FIGURA 7.53 - Gráfico força x deslocamento do nó "7" para arranjo " 2 ". 


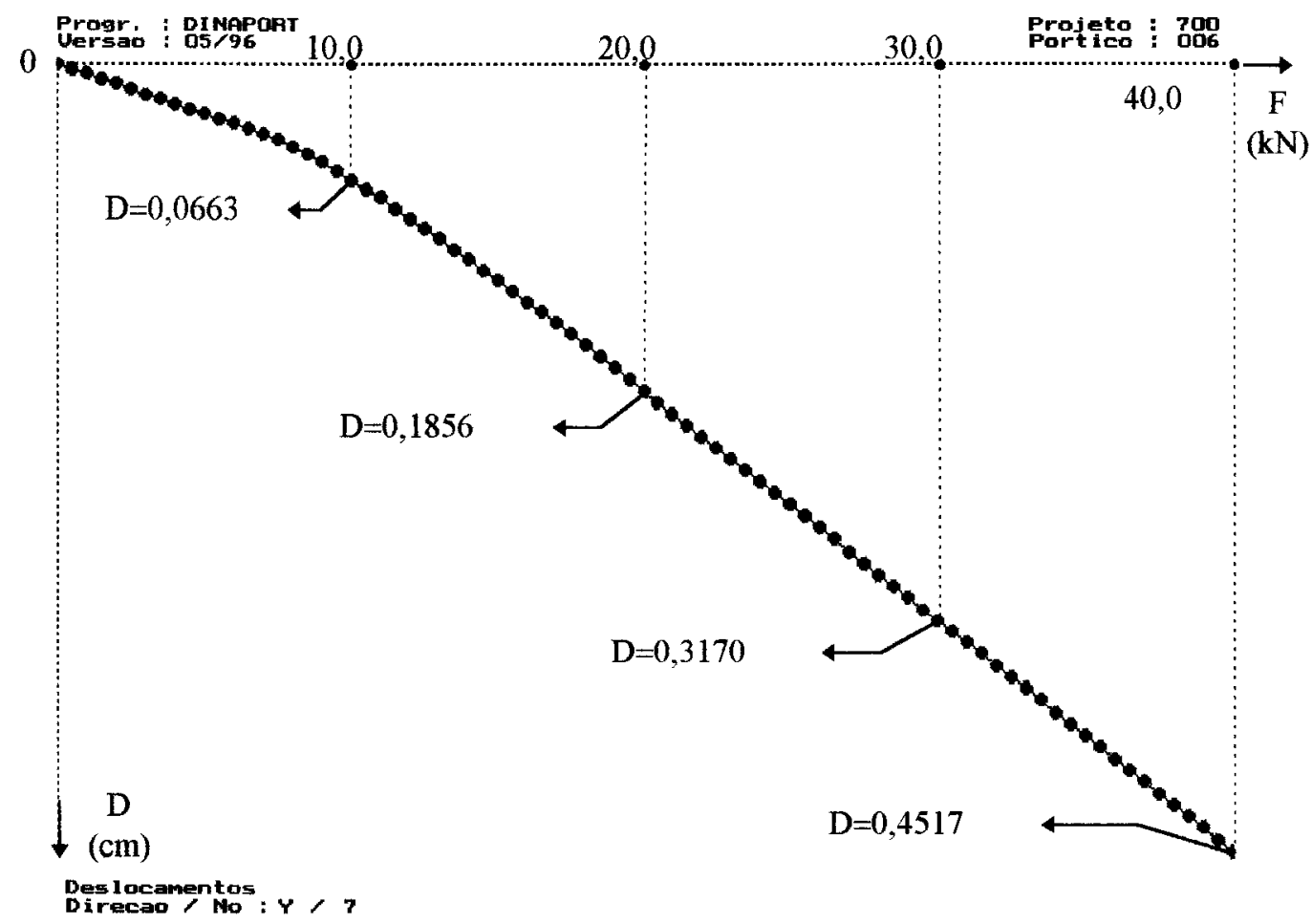

FIGURA 7.54 - Gráfico força $x$ deslocamento do nó "7" para arranjo "3".

Os gráficos força $x$ deslocamento mostram 0 comportamento não-linear físico do concreto armado pois quando é atingido o valor do momento de fissuração da seção transversal, começa a haver uma diminuição do valor do momento de inércia para os elementos mais solicitados, com consequiente aumento dos deslocamentos. Tais resultados são praticamente coincidentes com as respostas obtidas por PROENÇA et al. (1994), que utilizou os fundamentos da Mecânica do Dano Contínuo para a análise de tais vigas, mostrando a validade do procedimento numérico empregado neste trabalho.

Para demonstrar o funcionamento do modelo físico de forma completa, pode-se efetuar um descarregamento total da estrutura, com posterior recarregamento e aplicação da força complementar, conforme ilustram as figuras $7.55,7.56,7.57$ e 7.58, tomando-se como exemplo a viga com armadura principal disposta segundo o arranjo " 1 ". 
Progr.: DIMapdit

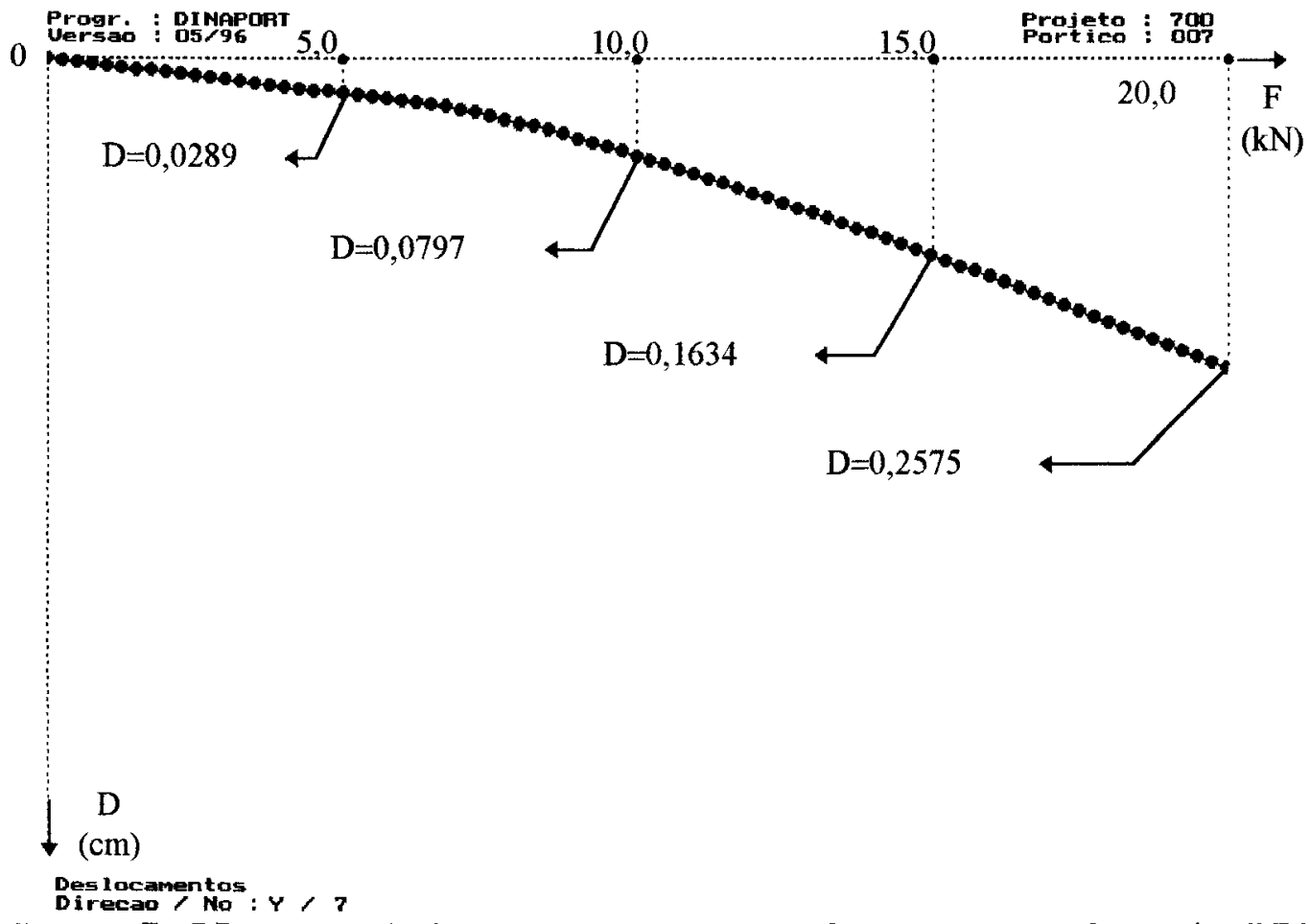

FIGURA 7.55 - Gráfico força $x$ deslocamento do nó "7" para " $F$ " variando de $0,0 \mathrm{kN}$ até $20,0 \mathrm{kN}$. Carregamento parcial.

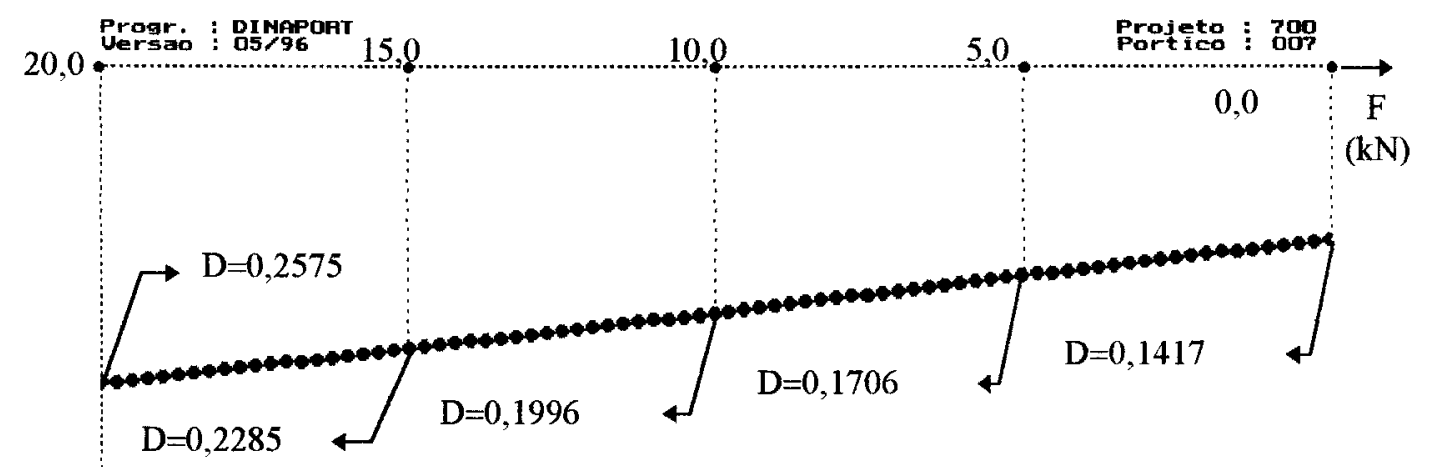

(cm)

Des lacamentos

FIGURA 7.56 - Gráfico força $x$ deslocamento do nó "7" para " $F$ " variando de $20,0 \mathrm{kN}$ até $0,0 \mathrm{kN}$. Descarregamento total. 


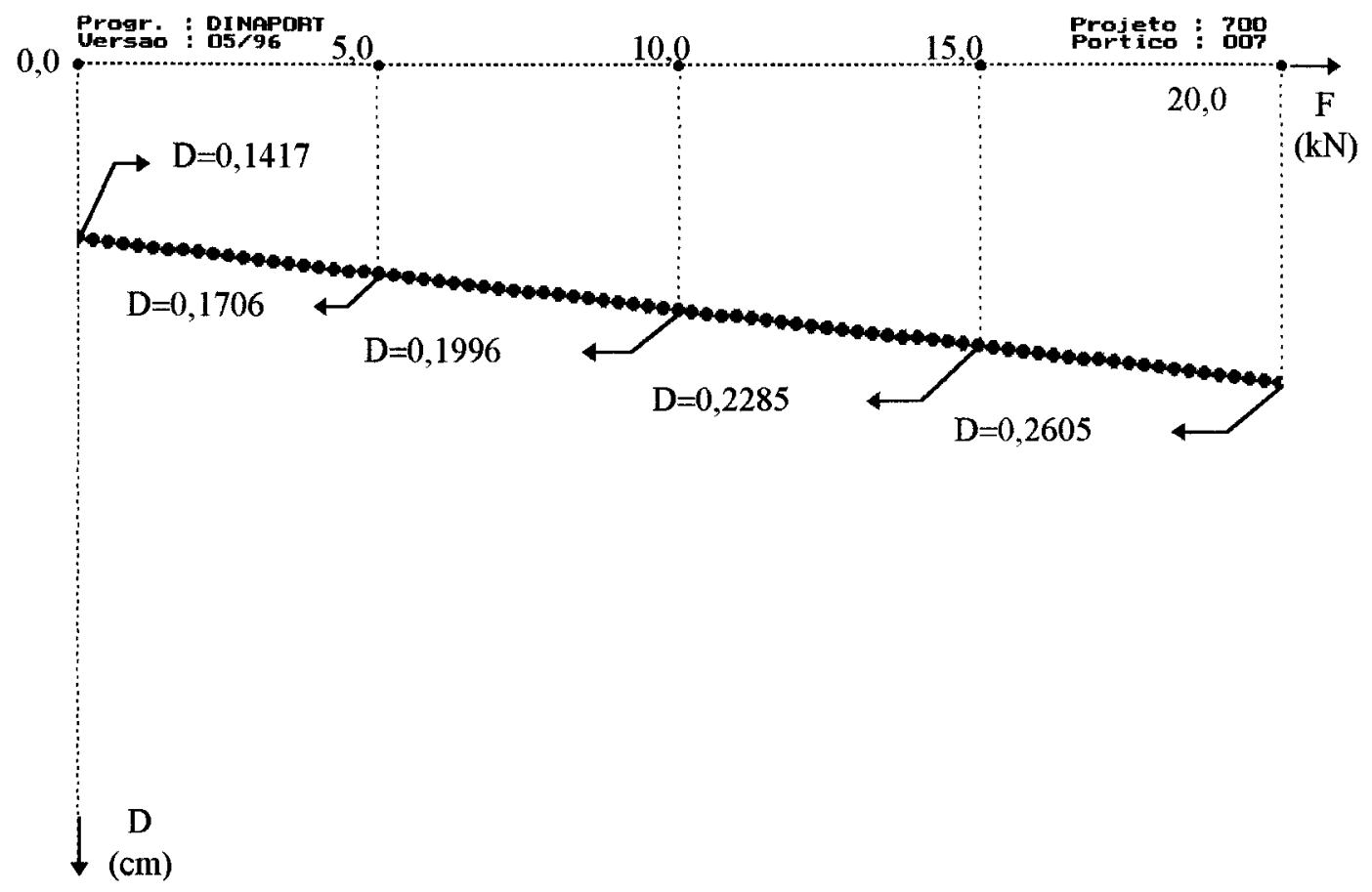

Des locamentos: $Y, 7$

FIGURA 7.57 - Gráfico força $x$ deslocamento do nó "7" para " $\mathrm{F}$ " variando de $0,0 \mathrm{kN}$ até $20,0 \mathrm{kN}$. Recarregamento total.

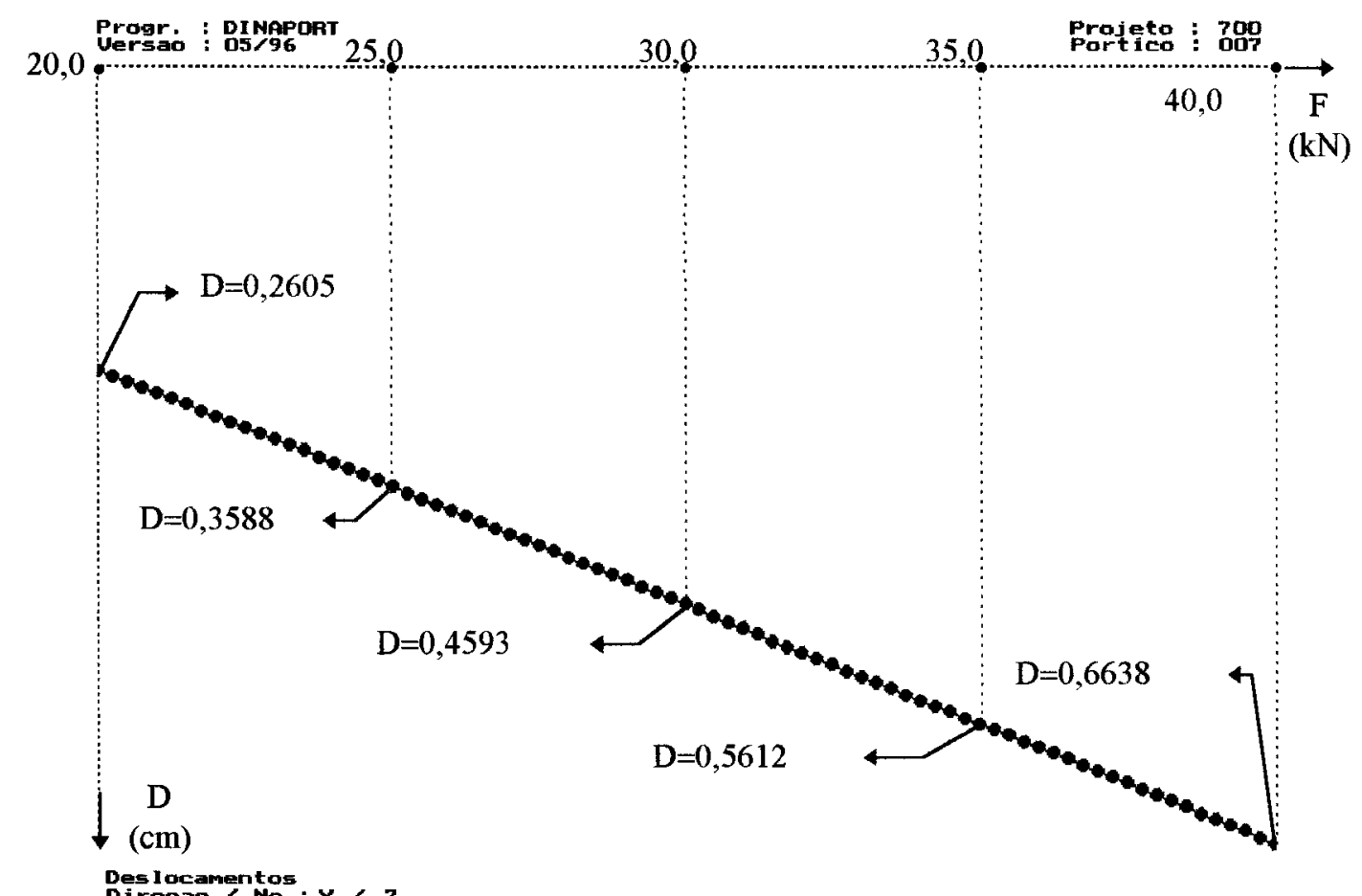

FIGURA 7.58 - Gráfico força $x$ deslocamento do nó "7" para "F" variando de $20,0 \mathrm{kN}$ até $40,0 \mathrm{kN}$. Carregamento complementar. 
Analisando-se tais respostas, percebe-se que os resultados finais encontrados são praticamente iguais aos resultados obtidos anteriormente, pois a união dos gráficos contidos nas figuras 7.55 e 7.58 resulta 0 mesmo gráfico contido na figura 7.52. Já a figura 7.56 mostra o comportamento da viga durante o descarregamento total, apresentando um deslocamento residual (d=0,1417 $\mathrm{Cm})$ para $F=0,0 \mathrm{kN}$ em função da fissuração que ocorreu em alguns elementos. De forma inversa, a figura 7.57 mostra - comportamento da viga durante o recarregamento, que segue o mesmo caminho descrito pela estrutura durante o descarregamento. Para finalizar, deve-se ressaltar que o valor do deslocamento residual obtido pode não ser preciso, pois o valor do momento de inércia adotado durante o processo de descarregamento é igual ao valor utilizado antes de ocorrer a fissuração no elemento, conforme definição feita no item 6.5.1.3 deste trabalho.

\section{3 .6 - Exemplo P6}

Este exemplo é composto por um pórtico biengastado de concreto armado, discretizado por doze elementos finitos, conforme ilustra a figura 7.59.

As caracteristicas físicas e geométricas de todos os elementos são dadas por:

$$
\begin{gathered}
\mathrm{b}=15,0 \mathrm{~cm} ; \mathrm{h}=30,0 \mathrm{~cm} \\
\mathrm{f}_{\mathrm{CK}}=2,6 \mathrm{kN} / \mathrm{cm}^{2} ; \mathrm{f}_{\mathrm{CTK}}=0,268 \mathrm{kN} / \mathrm{cm}^{2} \\
\mathrm{E}_{\mathrm{S}}=21000,0 \mathrm{kN} / \mathrm{cm}^{2} ; \mathrm{E}_{\mathrm{C}}=3050,0 \mathrm{kN} / \mathrm{cm}^{2} \\
\gamma=2,5.10^{-5} \mathrm{kN} / \mathrm{cm}^{3}
\end{gathered}
$$




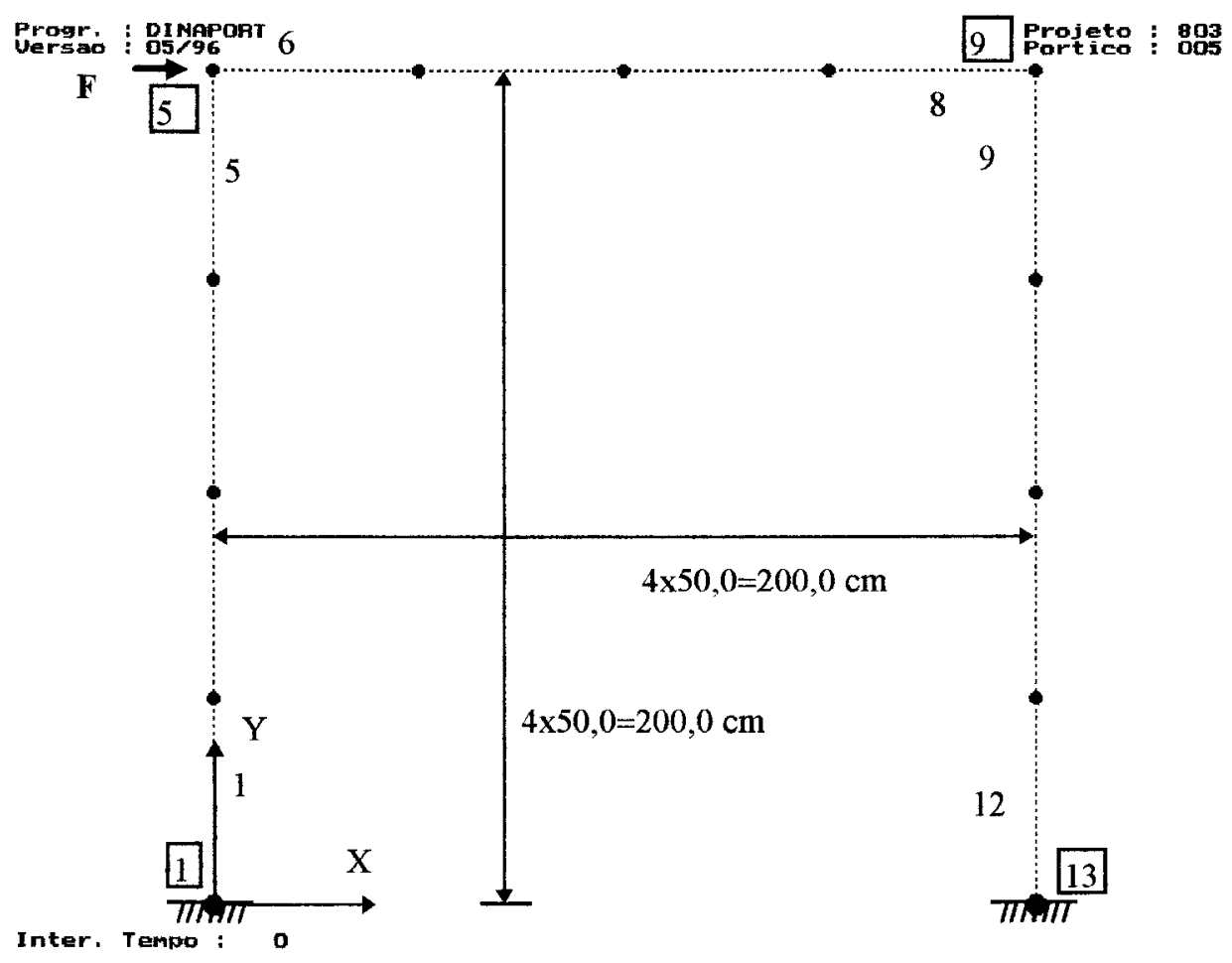

FIGURA 7.59 - Pórtico simples biengastado discretizado por elementos finitos.

A disposição da armadura principal para todos os elementos é mostrada na figura 7.60 .

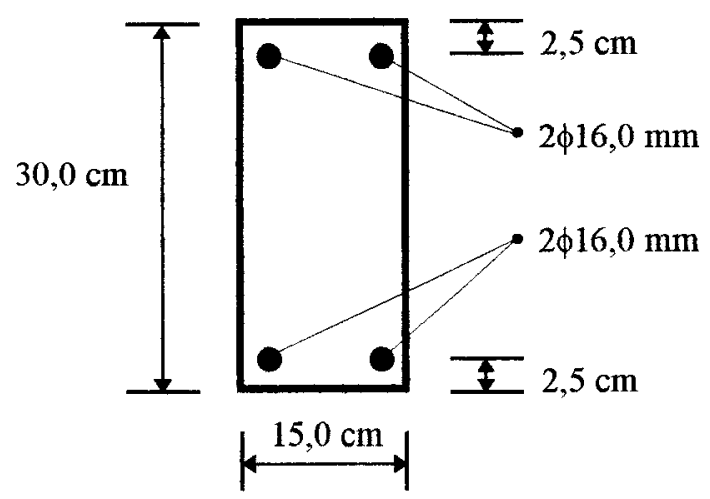

FIGURA 7.60 - Seção transversal de todos os elementos do pórtico.

O carregamento da estrutura é composto por uma única força concentrada " $F$ ", ver figura 7.59, cujo 
módulo varia com o tempo de acordo com o gráfico dado pela figura 7.61 .

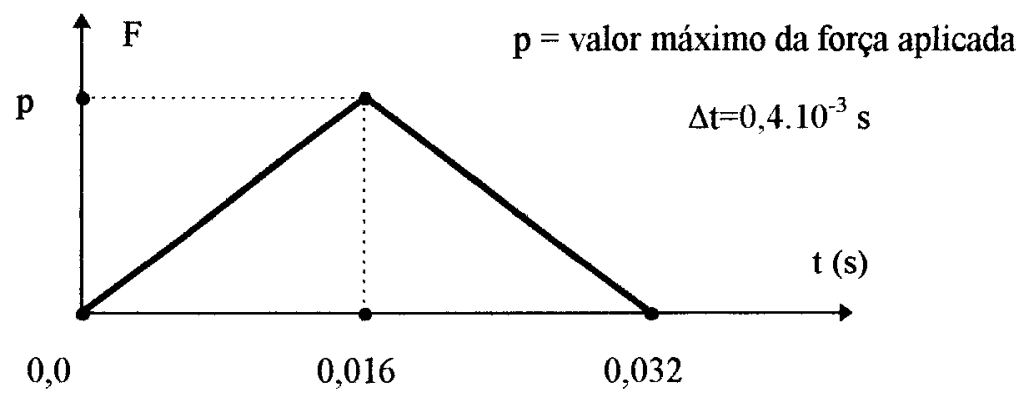

FIGURA 7.61 - Variação do módulo da força "F" com o tempo.

Utilizando-se o programa computacional "AUTOPORT" pode-se determinar as frequências naturais e os modos de vibração da estrutura, permitindo-se a realização de uma análise dinâmica com amortecimento. As figuras 7.62, 7.63 e 7.64 ilustram, na ordem correta, os três primeiros modos de vibração do pórtico em questão.

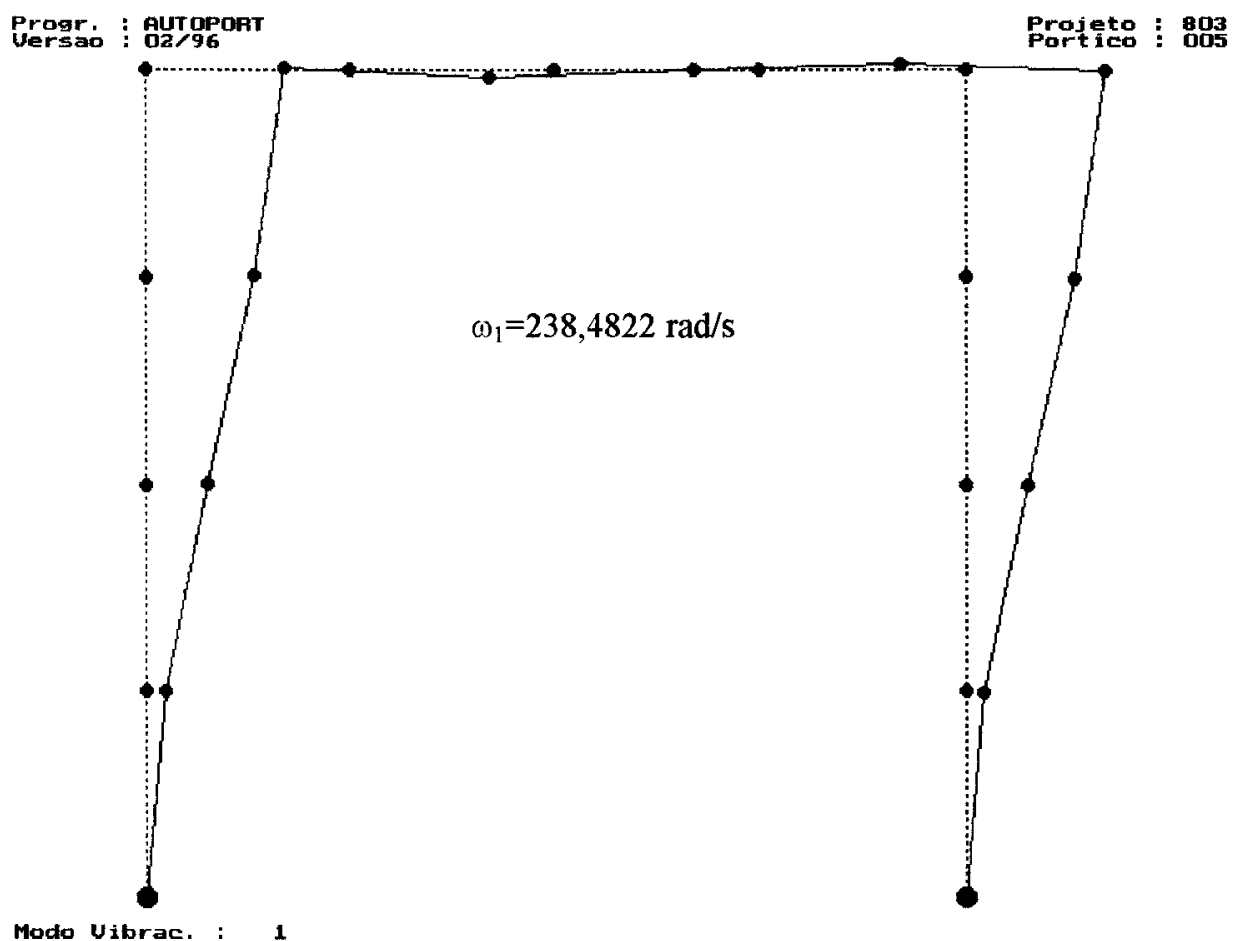

FIGURA 7.62 - Primeiro modo de vibração da estrutura. 
Progr: : putgeopr

Projeto: : 803

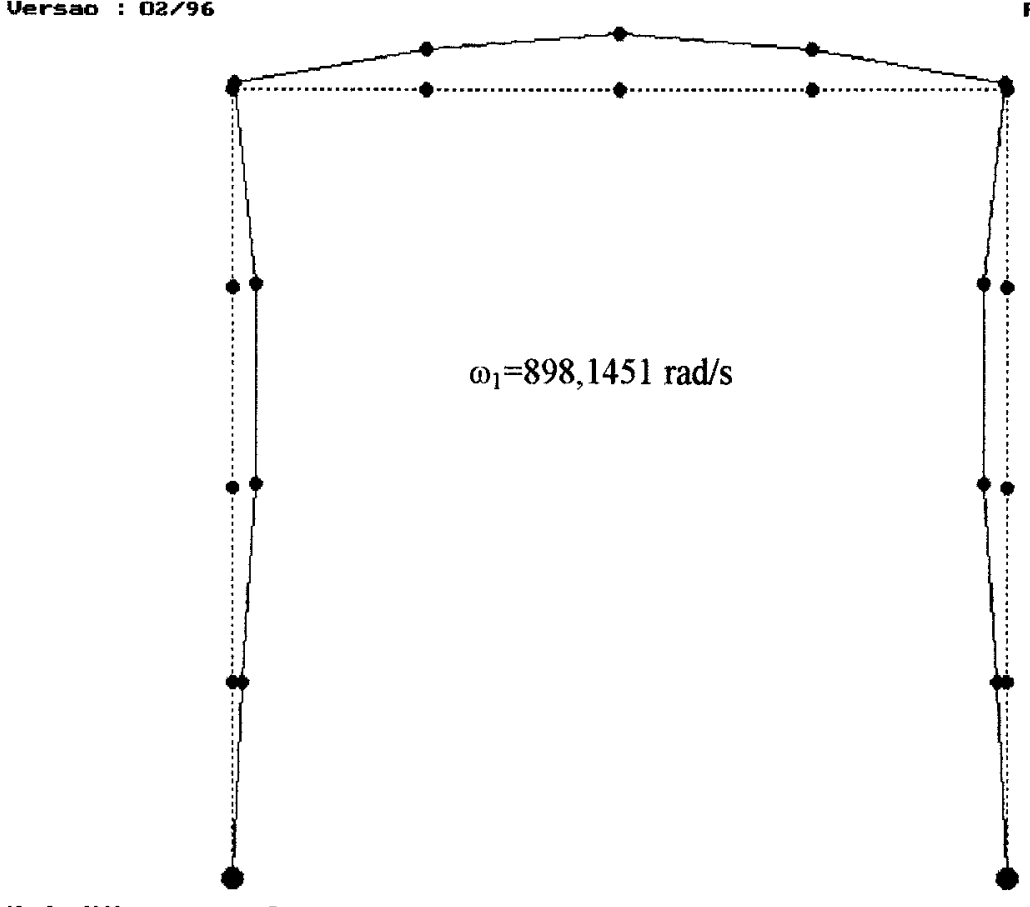

Modo Uibrac. : 2

FIGURA 7.63 - Segundo modo de vibração da estrutura.

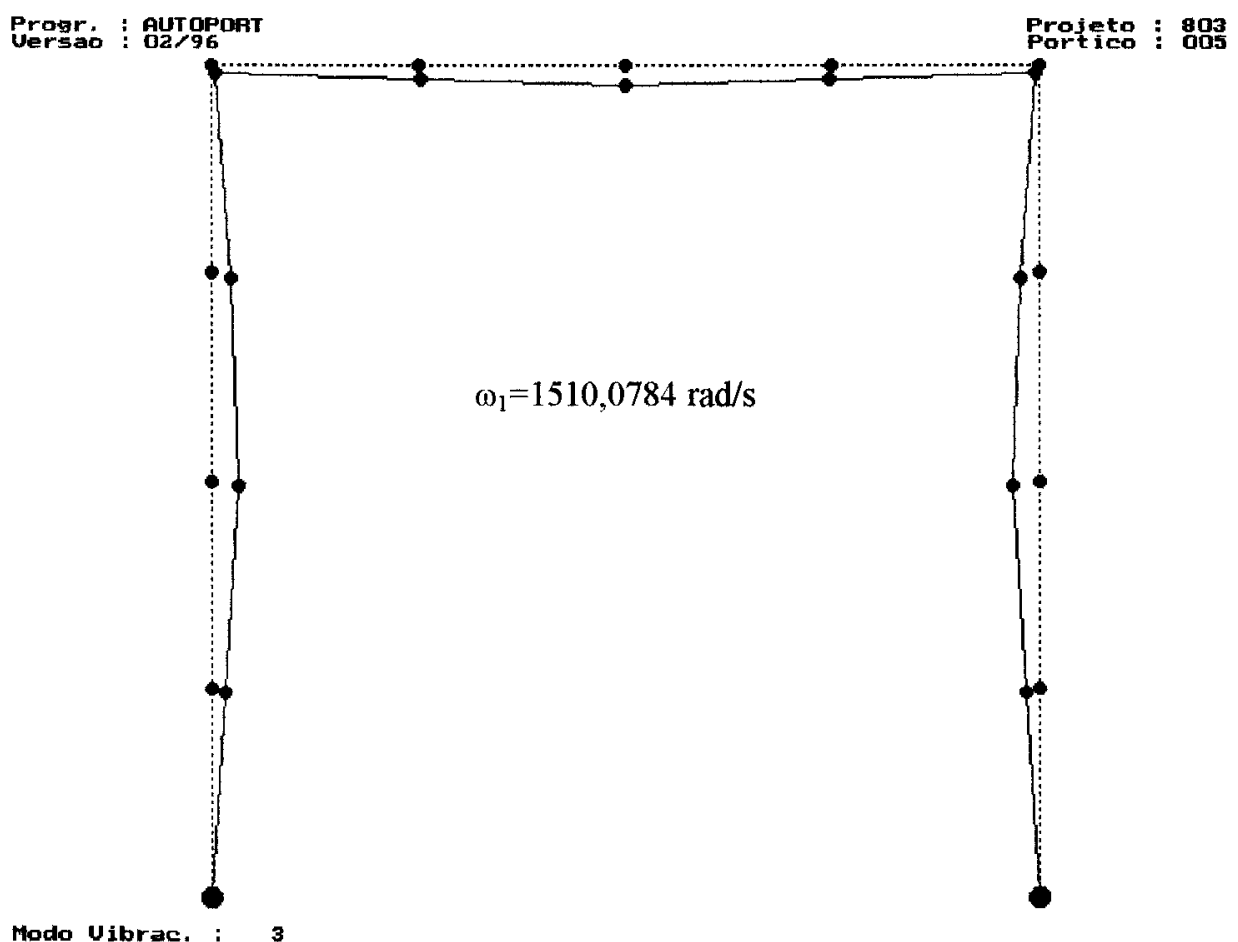

FIGURA 7.64 - Terceiro modo de vibração da estrutura. 
Com o valor das duas primeiras frequiencias naturais pode-se obter as constantes de amortecimento através da utilização das equações (4.138) e (4.139). Calculando-se tais constantes para uma fração do amortecimento crítico que provoque um rápido amortecimento, obtém-se:

$$
p / \xi_{1}=\xi_{2}=30 \% \Rightarrow\left\{\begin{array}{l}
\lambda_{k}=5,28 \cdot 10^{-4} s \\
\lambda_{m}=133,067 s^{-1}
\end{array}\right.
$$

Efetuando-se uma análise estática e dinâmica via comportamento linear e não-linear físico, com ou amortecimento, e considerando-se três valores distintos para a força aplicada, obtém-se os resultados apresentados nas tabelas $7.2,7.3$ e 7.4 .

TABELA 7.2 - Deslocamentos máximos obtidos no nó "5", na direção global " $x$ ", em "cm", para $t \geq 0,0 \mathrm{~s}$.

\begin{tabular}{|c|c|c|c|c|}
\hline \multirow{2}{*}{$\begin{array}{l}\text { DESLOC.: } \\
\text { DIREÇÃO: }\end{array}$} & \multirow{2}{*}{$\begin{array}{c}\text { NÓ } 5 \\
X \text { GLOBAL }\end{array}$} & \multicolumn{3}{|c|}{$\mathrm{p}(\mathrm{kN})$} \\
\hline & & $p=8,0$ & $\mathrm{p}=16,0$ & $p=24,0$ \\
\hline \multirow{2}{*}{$\begin{array}{l}\text { ANÁLISE } \\
\text { ESTÁTICA }\end{array}$} & $\mathrm{L}$ & $+0,0377 \quad 1001]$ & $+0,0754$ & $+0,1131$ \\
\hline & NLF & $+0,0310 \quad[002]$ & $+0,0656$ & $+0,1229$ \\
\hline \multirow{2}{*}{$\begin{array}{l}\text { ANÁLISE } \\
\text { DINÂMICA }\end{array}$} & $\mathrm{L}$ & $\left.\begin{array}{l}+0,0539 \\
-0,0347\end{array}\right]$ & $\begin{array}{l}+0,1078 \\
-0,0694\end{array}$ & $\begin{array}{l}+0,1617 \\
-0,1041\end{array}$ \\
\hline & $\mathrm{NLF}$ & $\begin{array}{l}+0,0425[006] \\
-0,0216[006]\end{array}$ & $\begin{array}{l}+0,0904 \\
-0,0339\end{array}$ & $\begin{array}{l}+0,1580 \\
-0,0369\end{array}$ \\
\hline \multirow{2}{*}{$\begin{array}{c}\text { ANÁIISE } \\
\text { DINÂMICA } \\
\text { COM } \\
\text { AMORTEC. }\end{array}$} & $\mathrm{L}$ & $\begin{array}{ll}+0,0397 & {[009]} \\
-0,0081 & {[009]}\end{array}$ & $\begin{array}{l}+0,0794 \\
-0,0162\end{array}$ & $\begin{array}{l}+0,1191 \\
-0,0243\end{array}$ \\
\hline & $\mathrm{NLF}$ & $\begin{array}{l}+0,0330[010] \\
-0,0060\end{array}$ & $\begin{array}{l}+0,0671 \\
-0,0089\end{array}$ & $\begin{array}{l}+0,1079 \\
-0,0033\end{array}$ \\
\hline
\end{tabular}

Obs: L - comportamento linear;

NLF - comportamento não-linear físico;

[n $\left.{ }^{\circ}\right]$ - número do pórtico do arquivo de dados. 
TABELA 7.3 - Deslocamentos máximos obtidos no nó "5", na direção global "X", em "cm", para $t \geq 0,032 \mathrm{~s}$.

\begin{tabular}{|c|c|c|c|c|}
\hline \multirow{2}{*}{$\begin{array}{l}\text { DESLOC.: } \\
\text { DIREÇÃO: }\end{array}$} & \multirow{2}{*}{$\begin{array}{l}\text { NÓ } 5 \\
x \text { GLOBAI }\end{array}$} & \multicolumn{3}{|c|}{$\mathrm{p}(\mathrm{kN})$} \\
\hline & & $p=8,0$ & $p=16,0$ & $\mathrm{p}=24,0$ \\
\hline \multirow{2}{*}{$\begin{array}{l}\text { ANÁLISE } \\
\text { DINÂMICA }\end{array}$} & $\mathrm{L}$ & $\begin{array}{c}+0,0346[005] \\
(+0,0000) \\
-0,0347\end{array}$ & $\begin{array}{c}+0,0693 \\
(+0,0000) \\
-0,0694\end{array}$ & $\begin{array}{l}+0,1040 \\
(+0,0000) \\
-0,1041\end{array}$ \\
\hline & NLF & $\begin{array}{c}+0,0216[006] \\
(+0,0000) \\
-0,0216[006]\end{array}$ & $\begin{array}{c}+0,0550 \\
(+0,0105) \\
-0,0339\end{array}$ & $\begin{array}{c}+0,1043 \\
(+0,0337) \\
-0,0369\end{array}$ \\
\hline
\end{tabular}

Obs: L - comportamento linear;

NLF - comportamento não-linear físico;

$\left(n^{\circ}\right)$ - valor médio do desiocamento;

[n $\mathrm{n}^{\circ}$ - número do pórtico do arquivo de dados.

TABELA 7.4 - Deslocamentos finais obtidos no nó "5", na direção global "x", em "cm", para $t=\infty \mathrm{s}$.

\begin{tabular}{|c|c|c|c|c|}
\hline \multirow{2}{*}{\multicolumn{2}{|c|}{$\begin{array}{lc}\text { DESLOC.: } & \text { NÓ } 5 \\
\text { DIREÇÃO: } & x \text { GLOBAI }\end{array}$}} & \multicolumn{3}{|c|}{$p(k N)$} \\
\hline & & $p=8,0$ & $p=16,0$ & $p=24,0$ \\
\hline $\begin{array}{l}\text { ANÁLISE } \\
\text { DINÂMICA }\end{array}$ & $\mathrm{L}$ & $+0,0000 \quad[009]$ & $+0,0000$ & $+0,0000$ \\
\hline AMORTEC. & NLF & $+0,0000 \quad[010]$ & $+0,0031$ & $+0,0155$ \\
\hline
\end{tabular}

Obs: L - comportamento linear;

NLF - comportamento não-linear físico;

$\left[n^{\circ}\right]$ - número do pórtico do arquivo de dados.

Analisando-se os resultados obtidos pelos três tipos de análise, conforme mostra a tabela 7.2, percebese um aumento no valor dos deslocamentos quando se realiza a análise dinâmica sem amortecimento e uma diminuição de tal valor quando se realiza a mesma 
análise com amortecimento, caracterizando o efeito do amortecimento utilizado neste trabalho. Já a comparação entre os resultados obtidos pelos dois tipos de comportamento fica um pouco sem efeito em função de se ter empregado valores diferentes para $\circ$ momento de inércia, pois para comportamento linear utiliza-se o momento de inércia da seção bruta e para comportamento não-linear físico utiliza-se o momento de inércia da seção homogeneizada.

$\mathrm{Na}$ continuidade da apresentação dos resultados, a tabela 7.3 mostra os deslocamentos máximos do nó "5" obtidos após a retirada total do carregamento externo. Analisando-se os dados contidos em tal tabela, percebese que os valores médios encontrados via comportamento linear são iguais a zero, indicando que a estrutura fica oscilando em torno da sua posição de equilíbrio inicial. Quando se considera a não-Iinearidade física, percebe-se que tal fato também ocorre para $\mathrm{p}=8,0 \mathrm{kN}$, pois neste caso nenhum elemento fissurou. Já o mesmo não acontece para $p=16,0 \mathrm{kN}$ e $\mathrm{p}=24,0 \mathrm{kN}$, pois devido à fissuração de alguns elementos a estrutura fica oscilando em torno de uma posição de equilíbrio deslocada, conforme ilustra a figura 7.65 .

- fato descrito anteriormente também pode ser constatado quando se introduz o amortecimento na resolução da estrutura, conforme resultados contidos na tabela 7.4, pois neste caso a estrutura apresenta um deslocamento final diferente de zero somente nos casos em que ocorre a fissuração de alguns elementos. A figura 7.66 ilustra o comportamento da estrutura quando se efetua este tipo de análise.

Para finalizar, deve-se ressaltar que o efeito do comportamento não-linear geométrico neste exemplo é desprezível em função da magnitude do carregamento aplicado. 


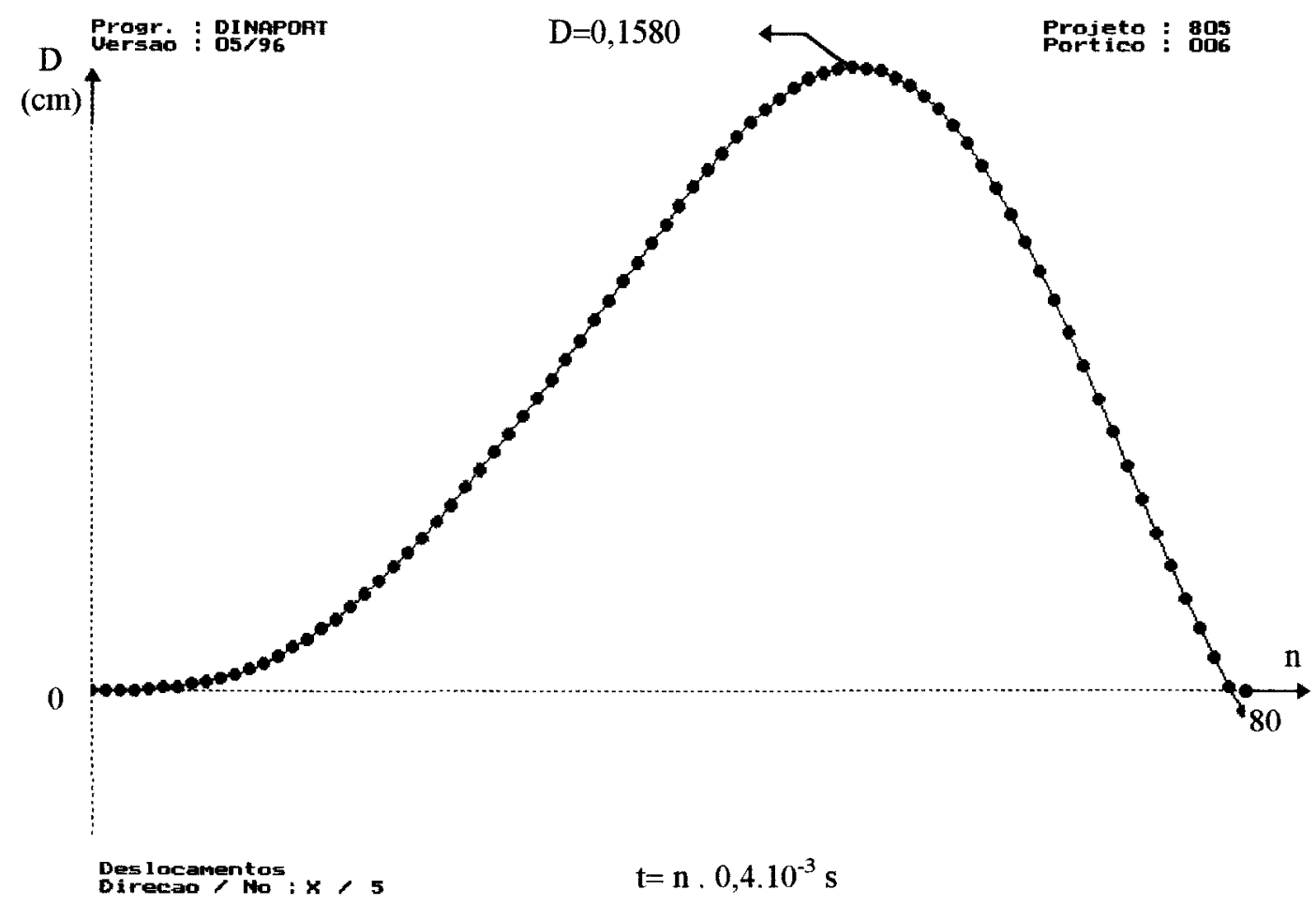

D Persao : Dingapoit

Projeto : 805

(cm)

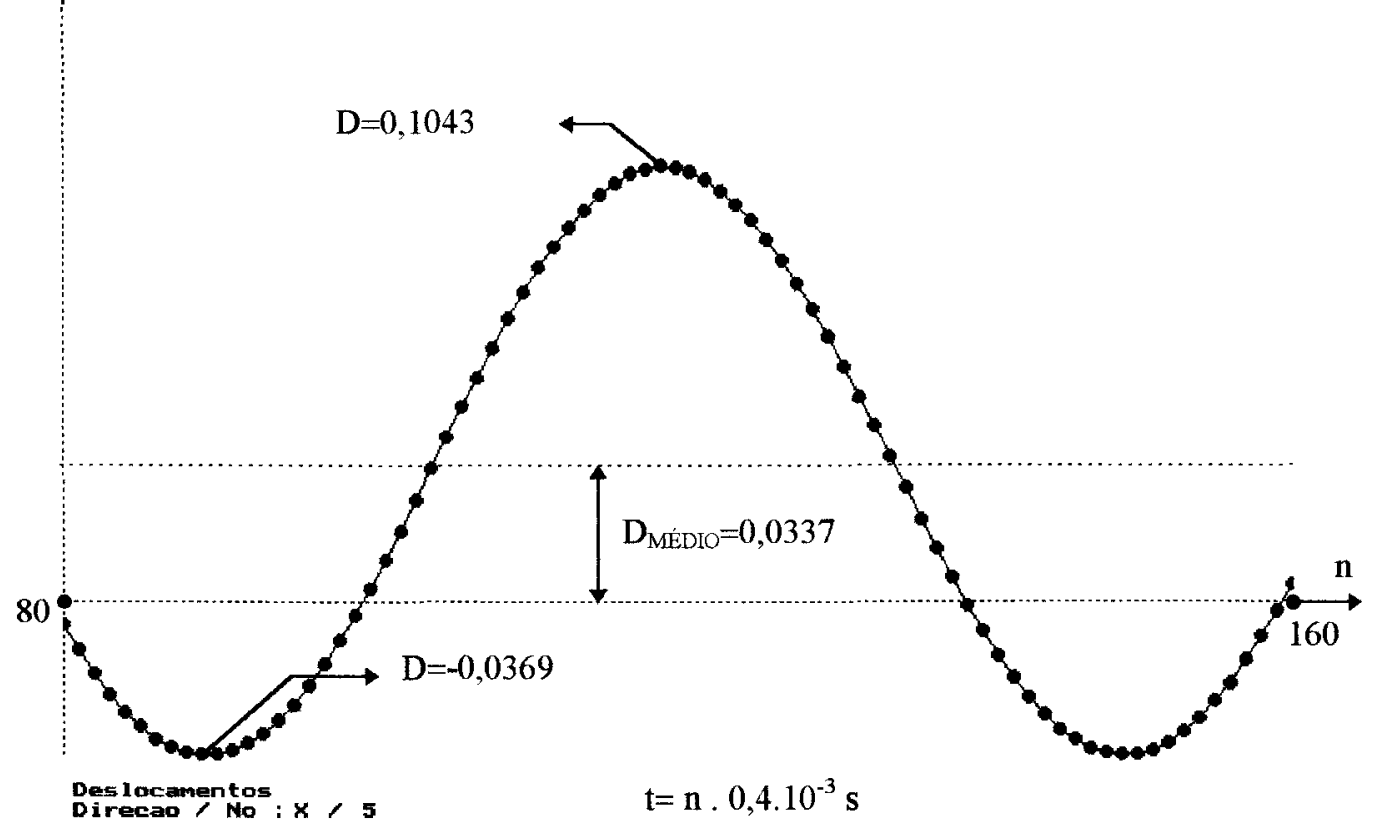

FIGURA 7.65 - Gráfico tempo x deslocamento do nó "5", para $\mathrm{p}=24,0 \mathrm{kN}$. 

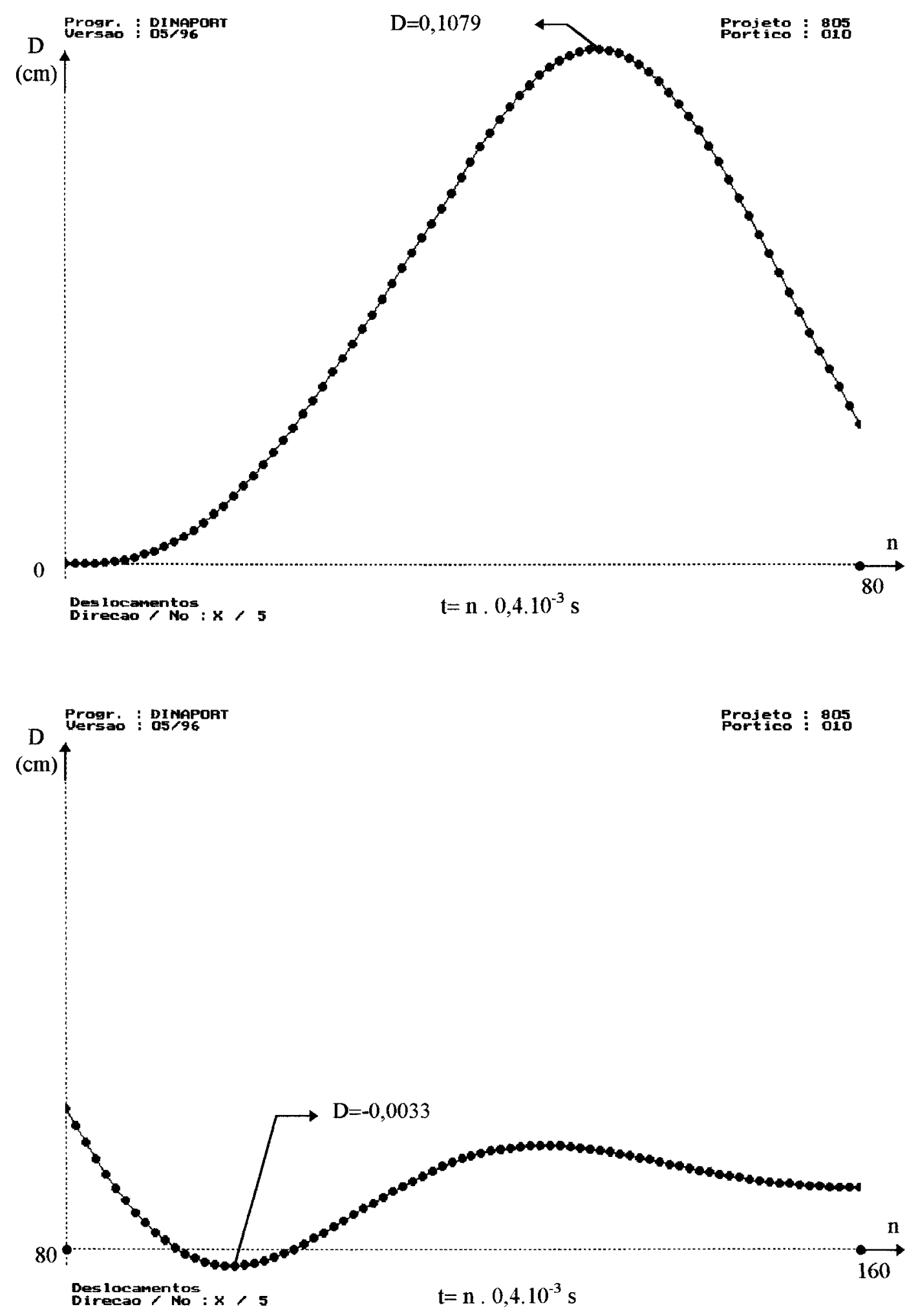

FIGURA 7.66A - Gráfico tempo x deslocamento do nó "5", considerando-se amortecimento, para $p=24,0 \mathrm{kN}$. 


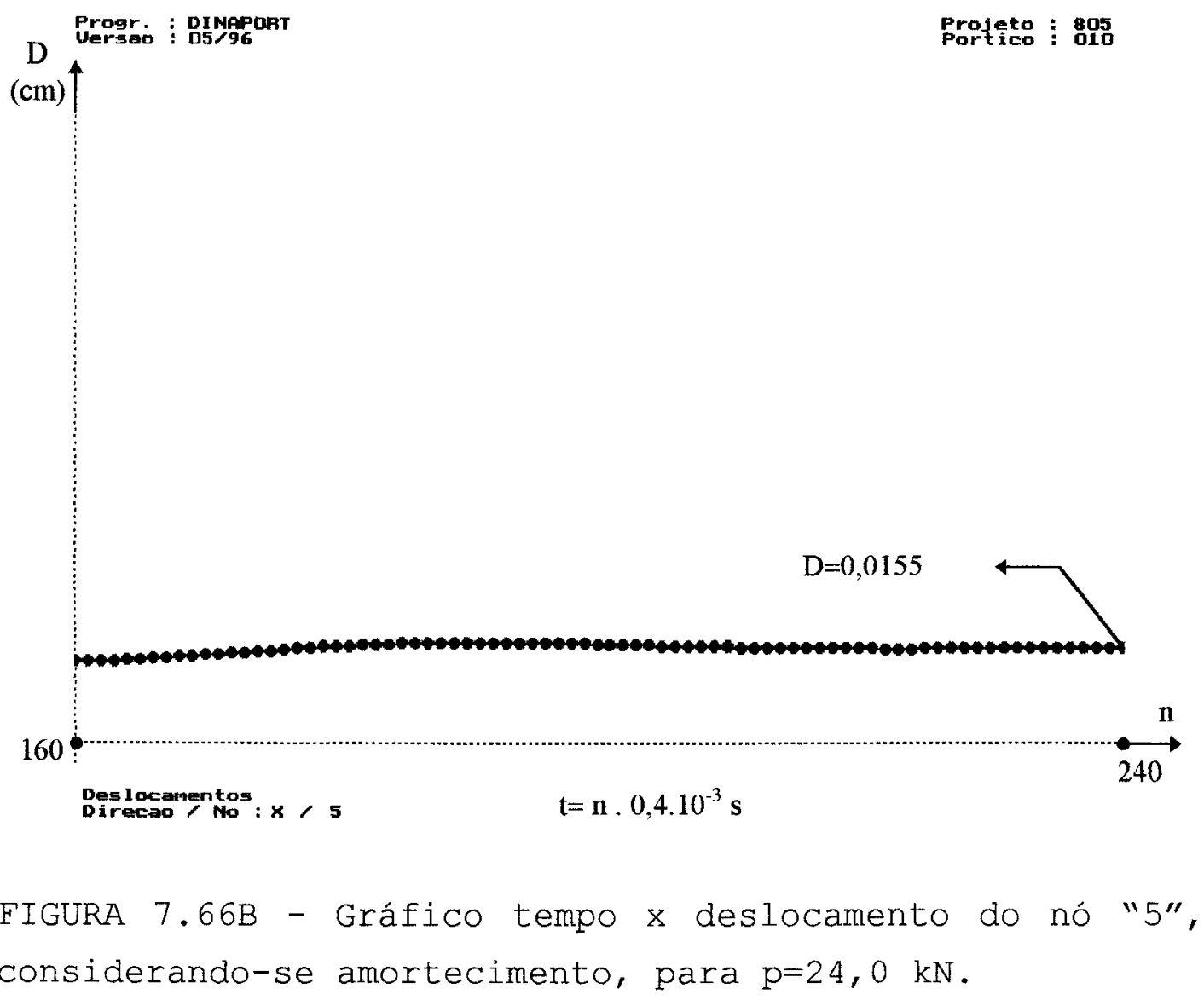




\section{CAPÍTULO 8 - CONSIDERAÇÕES FINAIS}

\section{1 - Conclusões}

No presente trabalho, procurou-se implementar as não-linearidades física e geométrica na análise dinâmica de estruturas reticuladas planas através da utilização de um procedimento incremental / iterativo. Uma vez estabelecida toda a teoria referente ao assunto em questão, desenvolvem-se programas computacionais que permitem a realização de vários tipos de análise numérica, possibilitando a visualização do comportamento estrutural de tais sistemas de uma forma mais realista.

Neste contexto, os problemas que foram resolvidos no capítulo 7 mostraram, por exemplo, que os deslocamentos obtidos via comportamento linear nem sempre são menores que os deslocamentos obtidos via comportamento não-linear e que as forças atuantes nos elementos estruturais podem mudar de sentido quando se realiza uma análise dinâmica. Dessa forma, se a análise estrutural for feita de forma inadvertida, os resultados obtidos podem conduzir o calculista de estruturas ao erro, pois o mesmo estará projetando outro tipo de estrutura e não aquela idealizada inicialmente.

Uma vez que for feita a opção por uma análise mais refinada, o calculista de estruturas deve estar habilitado a fornecer os dados da estrutura de forma coerente e deve saber interpretar os resultados obtidos de acordo com a teoria utilizada na análise escolhida. 
A primeira dificuldade encontrada no fornecimento de dados para a realização de uma análise dinâmica nãolinear é dada pela escolha conveniente do valor do intervalo de tempo " $\Delta t$ ", pois a seleção inadequada de tal valor poderá ocasionar problemas de instabilidade numérica. Neste sentido, o autor deste trabalho recomenda que uma primeira avaliação seja feita tomandose um valor para " $\Delta t$ " contido no seguinte intervalo $\mathrm{T} / 120 \leq \Delta t \leq \mathrm{T} / 30$.

A segunda dificuldade encontrada está relacionada com o valor do incremento de carregamento que deve ser aplicado no sistema estrutural, pois a escolha de um valor muito grande poderá provocar a violação de algumas premissas envolvidas na elaboração da teoria, podendo-se citar, como exemplo, as simplificações decorrentes da admissão de pequenas rotações para o elemento finito. Para isso, recomenda-se a utilização de pequenos incrementos de carregamento, que podem ser obtidos através de sucessivas tentativas.

outro fator importante está relacionado com o valor escolhido para a tolerância do erro de cálculo "ع", que é o fator responsável pela verificação do equilíbrio do sistema, pois um valor muito elevado provoca imprecisão na resposta e um valor muito pequeno não produz o equilíbrio almejado. Neste trabalho, o autor utilizou um valor para tal tolerância contido no seguinte intervalo $2.10^{-6} \leq \varepsilon \leq 2.10^{-3}$, sem prejuizo na obtenção dos resultados encontrados, ressaltando-se que tais valores são maiores que a precisão numérica das variáveis empregadas nos programas elaborados.

Uma vez sanada algumas dúvidas quanto ao fornecimento de dados da estrutura, é fundamental que o calculista se inteire da teoria envolvida na elaboração de programas computacionais usuais, para que o mesmo 
possa analisar de forma correta os resultados fornecidos por tais programas. Neste sentido, os exemplos contidos no capítulo 7 procuraram, na medida do possível, relacionar as respostas obtidas para alguns tipos de estruturas com os modelos físicos apresentados nos capitulos anteriores. Convém salientar, que tais exemplos serviram, também, para validar tais modelos e o procedimento numérico que foi adotado neste trabalho.

Após estas considerações, o autor espera ter alcançado os objetivos propostos no início deste trabalho e, de alguma forma, também espera ter contribuído para o aprimoramento da análise de estruturas usualmente empregadas na Engenharia Estrutural.

\section{2 - Propostas de desenvolvimento}

Sendo este trabalho o ponto de partida de um estudo mais extenso pode-se, de imediato, elaborar algumas propostas de desenvolvimento a nível de melhoria dos programas computacionais, de refinamento da teoria que foi elaborada e de incorporação de novos tipos de sistemas estruturais.

Com relação à melhoria dos programas computacionais pode-se otimizar a memória empregada durante o processamento de estruturas, introduzir a rotulação de extremidades para o elemento finito de pórtico e efetuar a fusão entre os programas para análise de treliças e pórticos.

Já com relação ao refinamento da teoria pode-se elaborar modelos físicos mais consistentes para o concreto armado através da consideração das relações tensão $x$ deformação dos materiais, incorporar os termos que contém produtos de parcelas de ordem superior no 
campo de deformações para o elemento de pórtico e promover ensaios para caracterizar o valor do momento de inércia que deve ser utilizado durante o descarregamento e o recarregamento de uma estrutura de concreto armado, em função do dano que ocorre nos materiais de tais estruturas.

A nível de incorporação de novos tipos de sistemas estruturais pode-se elaborar um programa para análise de treliças espaciais, de forma simples, e também elaborar um programa para análise de pórticos espaciais, sendo que para este caso se faz necessário a idealização de um modelo físico consistente que contemple o caso de flexão composta oblíqua para o concreto armado.

Por fim, pode-se formalizar como últimas propostas de desenvolvimento a introdução das parcelas nãolineares nas matrizes de massas e de amortecimento, BRASIL(1990), e o aprofundamento da pesquisa com relação aos efeitos provocados por ações dinâmicas, através da caracterização dos coeficientes de impacto e do refinamento dos coeficientes de ponderação usualmente empregados na análise de sistemas estruturais usuais. 


\section{REFERÊNCIAS BIBLIOGRÁFICAS}

AMERICAN CONCRETE INSTITUTE. (1983). ACI 318M/83 Building code requirements for reinforced concrete. Detroit.

ARGYRIS, J.H.; MLEJNEK, H.P.(1991). Dynamics of structures. Netherlands, Elsevier Science. v.5.

BATHE, K.J.(1996). Finite element procedures. New Jersey, Prentice-Hall. 1037p.

BATHE, K.J.; WILSON, E.L.(1973). Stability and accuracy analysis of direct integration methods. Earthquake Engineering and Structural Dynamics, v.1, p.283-291.

BIGGS, J.M.(1964). Introduction to structural dynamics. New York, McGraw-Hill. 341p.

BRASIL, R.M.L.R.F.(1990). Não-linearidade geométrica na dinâmica de estruturas aporticadas planas: um tratamento pelo método dos elementos finitos. São Paulo. Tese (Doutorado) - Escola Politécnica, Universidade de São Paulo.

BRASIL, R.M.L.R.F.; MAZZILLI, C.E.N. (1992). Nonlinear FE analysis in dynamics: simplifications aiming at small computers. In: YAJUN, Z. ed. (1992) International conference on education, practice and promotion of computational methods in engineering using small computers. Dalian, Dalian University of Technology Press, v.1, p.531-536. 
BRASIL, R.M.L.R.F.; MAZZILLI, C.E.N. (1993). A general FEM formulation of nonlinear dynamics applied to accessing the statical loading effect upon the dynamic response of planar frames. Appl. Mech. Rev., V.46, n.11, p.110-117.

CARNAHAN, B.; LUTHER, H.A.; WILKES, J.O. (1969). Applied numerical methods. New York, John Wiley \& Sons. 604p.

CARVALHO, R.C.(1994). Análise não-linear de pavimentos de edifícios de concreto através da analogia de grelha. São Carlos. Tese (Doutorado) - Escola de Engenharia de São Carlos, Universidade de São Paulo.

CASTIGLIONI, A.(1978). Introduzione alla dinamica delle strutture: appunti per le lezioni del corso di dinamica delle costruzioni. Milano, Masson Italia Editori. 373p.

CHEN, W.F.; HAN, D.J.(1988). Plasticity for structural engineers. New York, Springer-Verlag. 606p.

CHEN, W.F.; ZHANG, H.(1991). structural plasticity: theory, problems, and CAE software. New York, Springer-Verlag. 250p.

CILONI, A.D. (1993). Sobre o comportamento em serviço de estruturas planas de concreto armado. São Carlos. Tese (Doutorado) - Escola de Engenharia de São Carlos, Universidade de São Paulo.

CLOUGH, R. W.; PENZIEN, J.(1975). Dynamics of structures. New York, McGraw-Hill. 633p. 
COMITÉ EURO-INTERNATIONAL DU BÉTON. (1978). Model code for concrete structures. Bulletin $D^{\prime}$ Information, Lausanne. n.124/125.

COMITÉ EURO-INTERNATIONAL DU BÉTON.(1985). Manual on cracking and deformations. Bulletin $D^{\prime}$ Information, Lausanne. n.158-E.

COOK, R.D.; MALKUS, D.S.; PLESHA, M.E.(1989). Concepts and applications of finite element analysis. New York, John Wiley \& Sons. 630p.

CORREA, M.R.S.(1991). Aperfeiçoamento de modelos usualmente empregados no projeto de sistemas estruturais de edifícios. São Carlos. Tese (Doutorado)

- Escola de Engenharia de São Carlos, Universidade de São Paulo.

ENSAIO de estrutura de concreto: casa de válvulas da barragem de Santa Branca.(1995). São Carlos, USP. /Relatório Técnico/

FUSCO, P.B.(1981). Estruturas de concreto: solicitações normais. Rio de Janeiro, Guanabara Dois. 464p.

GERADIN, M., HOGGE, M., IDELSOHN, S.(1986). Implicit finite element methods. In: BELYTSCHKO, T.; HUGHES, T.J.R. ed. Computational methods for transient analysis. Amsterdam, North-Holland. p.417-471.

GOLUB, G.H.; LOAN, C.F.V.(1985) . Matrix: computations. Baltimore, The Johns Hopkins University Press. 476p. 
GRAD, J.; BREBNER, M.A.(1980). Eigenvalues and eigenvectors of a real general matrix [F2]. New York, ACM. V.2 (Algorithm, 343)

HALLAM, M.G.; HEAF, N.J.; WOOTTON, L.R. (1978). Dynamics of marine structures: methods of calculating the dynamic response of fixed structures subject to wave and current action. London, CIRIA Underwater Engineering Group. 313p.

HENRYCH, J.(1990). Finite models and methods of dynamics in structures. Czechoslovakia, Elsevier Science. 541p.

HUGHES, T.J.R.; LIU, W.K.(1978a). Implicit-explicit finite elements in transient analysis: implementation and numerical examples. Journal of Applied Mechanics, v.45, p.375-378.

HUGHES, T.J.R.; LIU, W.K.(1978b). Implicit-explicit finite elements in transient analysis: stability theory. Journal of Applied Mechanics, v.45, p.371-374.

HUGHES, T.J.R.; PISTER, K.S.; TAYLOR, R.L. (1979). Implicit-explicit finite elements in nonlinear transient analysis. Computer Methods in Applied Mechanics and Engineering, v.17/18, p.159-182.

HURTY, W.C.; RUBINSTEIN, M.F. (1967). Dynamics of structures. New Delhi, Prentice-Hall of India Private. $455 p$. 
MACHADO, C.P.(1989). Tensões, deformações e deslocamentos em estruturas de concreto armado e protendido. São Paulo. Dissertação (Mestrado) - Escola Politécnica, Universidade de São Paulo.

MANSUR, W.J.; BREBBIA, C.A.(1984). Further developments on the solution of the transient scalar wave equation. In: BREBBIA, C.A. ed. Topics in boundary element research. Berlin, Springer-Verlag. V.2: Time-dependent and vibration problems, p.87-123.

MATTHIES, H.; STRANG, G.(1979). The solution of nonlinear finite element equations. International Journal for Numerical Methods in Engineering, v.14, p. 1613-1626.

MAZZILLI, C.E.N.(1986). Comportamento não-linear de pórticos planos em regime elástico linear. In: CONGRESSO LATINO-AMERICANO SOBRE MÉTODOS COMPUTACIONAIS PARA ENGENHARIA, 7, São Carlos, 1986. Anais. São Carlos, EESC-USP. p.381-395.

MAZZILLI, C.E.N.; BRASIL, R.M.L.R.F.(1992). ANDROS: a finite element program for nonlinear dynamics. São Paulo, EPUSP. (Boletim Técnico BT/PEF/9213).

O'BRIEN, S.K.(1992). Turbo Pascal 6: completo e total. São Paulo, Makron Books, McGraw-Hill. 716p.

ORAN, C.; KASSIMALI, A.(1976). Large deformations of framed structures under static and dynamic loads. Computers \& Structures, v.6, p.539-547. 
OWEN, D.R.J.(1980). Implicit finite element methods for the dynamic transient analysis of solids with particular reference to non-linear situations. In: DONÉA, J. ed. Advanced structural dynamics. London, Applied Science. P.123-152.

OWEN, D.R.J.; GOMES, C.M.B.(1984). Some recent developments in solution techniques for nonlinear finite element problems. s.1., s.ed. p.137-153.

OWEN, D.R.J.; HINTON, E.(1980). Finite elements in plasticity: theory and practice. Swansea, Pineridge Press. 594p.

PANDIT, G.S.; GUPTA, S.P.(1981). Structural analysis: a matrix approach. New Delhi, Tata McGraw-Hill. 602p.

PROENÇA, S.P.B.; ÁLVARES, M.S.(1994). About numerical precision aspects on the use of a continuum damage model to concrete. In: CONGRESSO IBERO LATINOAMERICANO SOBRE MÉTODOS COMPUTACIONAIS PARA ENGENHARIA; SIMPÓSIO MINEIRO DE MECÂNICA COMPUTACIONAL, 15, Belo Horizonte, 1994. Anais. Belo Horizonte, Escola de Engenharia da Universidade Federal de Minas Gerais, p.1329-1338.

RODRIGUES, R.O.(1992). Automatização do projeto estrutural de pilares de concreto armado. São Carlos. Dissertação (Mestrado) - Escola de Engenharia de São Carlos, Universidade de São Paulo. 
RUBERT, J.B.(1993). Estudo do desempenho de algoritmos numéricos na solução de sistemas não-lineares de estruturas formadas por barras de treliça. São Carlos. Dissertação (Mestrado) - Escola de Engenharia de São Carlos, Universidade de São Paulo.

SAVASSI, W.(1996). Introdução ao método dos elementos finitos: em análise linear de estruturas. São Carlos, EESC-USP. 260p.

SILVA, R.M. (1996). Análise não-linear de pórticos planos de concreto armado: modelagem numérica e avaliação dos métodos aproximados. São Carlos. Tese (Doutorado) Escola de Engenharia de São Carlos, Universidade de São Paulo.

SLAATS, P.M.A.; JONGH, J.; SAUREN, A.A.H.J.(1995). Model reduction tools for nonlinear structural dynamics. Computers \& Structures, v.54, n.6, p.1155-1167.

SOLER, J.G.M.(1995). Análise não-linear de pórticos espaciais de concreto armado. São Paulo. Tese (Doutorado) - Escola Politécnica, Universidade de São Paulo.

SORIANO, H.L.(1981). Sistemas de equações algébricas lineares em problemas estruturais. Lisboa, Ministério da Habitação e Obras Públicas. /Seminário 280/

SOUZA, J.C.A.O.; ANTUNES, H.M.C.C.(1995). Introdução à análise matricial de estruturas. 2.ed. São Carlos, EESC-USP. $106 \mathrm{p}$. 
TIMOSHENKO, S.P.(1979). Resistência dos materiais. Rio de Janeiro, Livros Técnicos e Científicos. 2v.

VENANCIO FILHO, F.(1975). Análise matricial de estruturas: estática, estabilidade, dinâmica. Rio de Janeiro, Almeida Neves. 256p.

WARBURTON, G.B.(1976). The dynamical behaviour of structures. Oxford, Pergamon Press. 354p.

WEN, R.K.; ASCE, M.; RAHIMZADEH, J. (1983). Nonlinear elastic frame analysis by finite element. Journal of Structural Engineering, v.109, n.8, p.1952-1971, Aug.

WILSON, E.L.; FARHOOMAND, I.; BATHE, K.J. (1973). Nonlinear dynamic analysis of complex structures. Earthquake Engineering and Structural Dynamics, v.1, p. 241-252.

WONG, M.B.; TIN-LOI, F.(1990a). Analysis of frames involving geometrical and material nonlinearities. Computers \& Structures, v.34, n.4, p.641-646.

WONG, M.B.; TIN-LOI, F.(1990b). Geometrically nonlinear analysis of elastic framed structures. Computers \& structures, v.34, n.4, p.633-640. 


\section{OBRAS CONSULTADAS}

ALVES, B.K.; LUBLINER, J.(1992). A damage mechanics model for beams. Application to reinforced concrete bemas. In: CONGRESO INT. METODOS NUMERICOS EN INGENIERIA Y CIENCIAS APLICADAS, 1992, Barcelona. Anais. Barcelona. p.277-286.

ANDRÉ, J.C.(1992). Contribuição ao estudo das vibrações não-lineares em pórticos planos e vigas em regime elástico linear. São Paulo. Tese (Livre-Docência) Escola Politécnica, Universidade de São Paulo.

ASSOCIAÇÃO BRASILEIRA DE NORMAS TÉCNICAS. (1978). NBR6118- Procedimentos para projeto e execução de obras de concreto armado. Rio de Janeiro.

ASSOCIAÇÃO BRASILEIRA DE NORMAS TÉCNICAS.(1983). NBR7808- Símbolos gráficos para projetos de estruturas: simbologia. Rio de Janeiro.

ASSOCIAÇÃO BRASILEIRA DE NORMAS TÉCNICAS. (1984). NBR8681- Ações e segurança nas estruturas. Rio de Janeiro.

AUfAURE, M.; CHAUVEL, D.; L'HUBY, Y.(1986). Dynamic elasto-plastic analysis of reinforced concrete slabs and application to plastic design of some building structures. In: HINTON, E.; OWEN, R. ed. Computational modelling of reinforced concrete structures. Swansea, Pineridge Press. p.303-326. 
BERGAN, P.G.; HOLAND, I. (1979). Nonlinear finite element analysis of concrete structures. Computer Methods in Applied Mechanics and Engineering, n.17/18, p.443-467.

BERTOLINO JUNIOR, R.(1988). Contribuição ao estudo da estabilidade estrutural de arcos, em regime elastoplástico. São Paulo. Tese (Doutorado) - Escola Politécnica, Universidade de São Paulo.

BRANSON, D.E.; TROST, H.(1982a). Application of the Ieffective method in calculating deflections of partially prestressed members. ACI Journal, v.27, n.5, p. 62-77, sept/oct.

BRANSON, D.E.; TROST, H.(1982b). Unified procedures for predicting the deflection and centroidal axis location of partially cracked nonprestressed and prestressed concrete members. ACI Journal, v.79, n.2, p.119-130, Mar/Abr.

CEDOLIN, L; NILSON, A.H.(1978). A convergence study of iterative methods applied to finite element analysis of reinforced concrete. International Journal for Numerical Methods in Engineering, v.12, p.437-451.

CHANG, T.Y et al.(1987). Nonlinear finite element analysis of reinforced concrete panels. Journal of Structural Engineering, v.113, n.1, p.122-140, Jan.

CHEN, W.F.(1982). Plasticity in reinforced concrete. New York, McGraw-Hill. 474p. 
FRANCO, M.(1985). Problemas de estabilidade nos edifícios de concreto armado. In: COLÓQUIO SOBRE ESTABILIDADE GLOBAL DAS ESTRUTURAS DE CONCRETO ARMADO, São Paulo, 1985. Trabalhos Apresentados. São Paulo, Instituto Brasileiro do Concreto - IBRACON. /paginação irregular/

FRANCO, M.; VASCONCELOS, A.C.(1991). Practical assessment of second order effects in tall buildings. In: COLLOQUIUM ON THE CEB-FIP MC90, 1991, Rio de Janeiro. Trabalhos Apresentados. Rio de Janeiro, COPPE-UFRJ. p. 307-323.

GHASSEMIEH, M.; KUKRETI, A.R.(1990). An algorithm for the analysis of problems with combined material and geometric nonlinearities. Computers \& structures, v.35, n.5, p.579-591.

HU, H.T.; SCHNOBRICH, W.C.(1991). Nonlinear finite element analysis of reinforced concrete plates and shells under monotonic loading. Computers \& structures, v.38, n.5/6, p.637-651.

KASSIMALI, A.(1983). Large deformation analysis of elastic-plastic frames. Journal of structural Engineering, v.109, n.8, p.1869-1886, Aug.

LANGENDONCK, T.V.(1989). Vocabulário de teoria das estruturas. São Paulo, Associação Brasileira de Cimento Portland. 50p. 
LIMA, V.M.S., VENANCIO FILHO, F.(1984). A noção de rigidez tangente no estudo da não-linearidade geométrica de estruturas reticuladas. In: CONGRESSO LATINO-AMERICANO SOBRE MÉTODOS COMPUTACIONAIS EM ENGENHARIA, 5, 1984, Salvador. Anais. Salvador, s.ed. /paginação irregular/

LIMA, V.M.S.; VENANCIO FILHO, F.(1982). Considerações sobre a não-linearidade geométrica em estruturas reticuladas. Rio de Janeiro, III Escola de Matemática Aplicada - Laboratório de Computação Cientifica. 38p.

MARQUES, S.P.C.; CREUS, G.J.(1990). Análise não-linear física e geométrica de pórtico espaciais. In: CONGRESSO IBERO LATINO AMERICANO SOBRE MÉTODOS COMPUTACIONAIS PARA ENGENHARIA, 11, 1990, Rio de Janeiro. Anais. Rio de Janeiro, COPPE-UFRJ. p.13-24.

MAZZILLI, C.E.N.(1988). Non-linear finite element formulation dynamics. São Paulo, EPUSP. (Boletim Técnico $\mathrm{BT} / \mathrm{PEF} / 8820$ )

MCGREGOR, J.G.; HAGE, S.E. (1977). Stability analysis and design of concrete frames. Journal of the structural Division, v.103, n.ST10, p.1953-1971, oct.

MONTOYA, P.J.; MESEGUER, A.G.; CABRÉ, F.M. (1973). Hormigón armado. 7.ed. Barcelona, Editorial Gustavo Gili. 2v.

NEAL, B.G.(1970). The plastic methods of structural analysis. 2.ed. London, Chapman \& Hall. 358p. 
OTTER, D.E.; NAAMAN, A.E.(1989). Model for response of concrete to random compressive loads. Journal of Structural Engineering, v.115, n.11, p.2794-2809, Nov.

PAZ, M.(1991). Structural dynamics: theory and computation. New York, VNR. 626p.

PIMENTA, P.M.(1986). Aspectos da análise não linear de estruturas reticuladas. In: CONGRESSO LATINO-AMERICANO SOBRE MÉTODOS COMPUTACIONAIS PARA ENGENHARIA, 7, São Carlos, 1986. Anais. São Carlos, EESC-USP. p.449-464.

SAKAI, K.; KAKUTA, Y.(1980). Moment-curvature relationships of reinforced concrete members subjected to combined bending and axial force. ACI Journal, v.77, n.3, p.189-194, May/June.

SOLER, J.G.M.(1989). Análise não-linear de pórticos planos de concreto armado. São Paulo. Dissertação (Mestrado) - Escola Politécnica, Universidade de São Paulo.

SZILARD, R.(1985). Critical load and post-buckling analysis by FEM using energy balancing technique. Computers \& Structures, v.20, n.1-3, p.277-286.

SZILARD, R.(1986). An energy balancing strategy for solution of combined geometrical and material nonlinearity problems. Computers \& structures, v.23, n.2, p.147-162. 
TAGUTI, Y.(1987). Sobre a não-linearidade geométrica em treliças, pórticos e placas. São Paulo. Dissertação (Mestrado) - Escola Politécnica, Universidade de São Paulo.

UNIVERSIDADE DE SÃO PAULO.(1993). Escola de Engenharia de São Carlos. Diretrizes para elaboração de dissertações e teses na EESC-USP. São Carlos, SVBIBL. 37P.

VASCONCELOS, A.C.(1987). Como especificar a segurança quando há efeitos de $2^{a}$ ordem a considerar. In: COLLOQUIA, 1987, Porto Alegre. Anais. Porto Alegre, Escola de Engenharia da UFRGS - Departamento de Engenharia Civil. p.297-304.

YAGAWA, G.; HIRAYAMA, H.(1984). A finite element method for contact problems related to fracture mechanics. International Journal for Numerical Methods in Engineering, v.20, p.2175-2195. 


\section{APÊNDICE}

\section{A.1 - Generalidades}

Este apêndice contém os arquivos de dados dos exemplos que foram resolvidos no capitulo 7 deste trabalho, para que o leitor possa esclarecer eventuais dúvidas quanto ao tipo de análise que foi realizada. Para a compreensão de tais arquivos, apresentam-se no início de cada item as instruções básicas referentes à montagem dos mesmos e, na seqüência, apresentam-se os arquivos propriamente ditos.

\section{A.2 - Estruturas treliçadas}

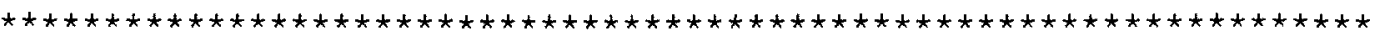

$\star \star \star \star *$ DINATREL : INSTRUÇÕES PARA MONTAGEM DO ARQUIVO DE DADOS

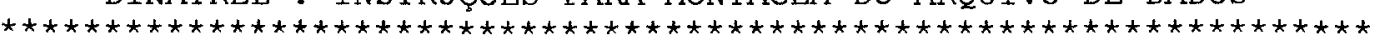

01- O nome do arquivo de dados deve ser do tipo aaaTRccc.TRE, onde "aaa" é o número do projeto e "CCc" é o número da treliça. Os arquivos criados pelo programa são os seguintes:

$>$ aaTRCCC.DAD = contém lista de dados lidos para relatório;

$>$ aaTRCcc.RES = contém resultados finais.

02- A primeira linha do arquivo deve conter o título da treliça.

03- As linhas de comentário devem ser iniciadas com a letra "C".

04- A disposição do arquivo deve ser mantida com o formato exposto, respeitando-se a quantidade de linhas de comentário.

05- Os valores das variáveis devem ser colocados abaixo das mesmas, devendo ser separados por espaços em branco, sendo que a unidade padrão e " $\mathrm{kN}$ " para força e " $\mathrm{cm}$ " para comprimento.

06- Significado das variáveis do primeiro bloco de dados:

$>$ PONTOS NODAIS............ NNODS (máx=MaxNNos)

$>$ NÚMERO DE ELEMENTOS........ NELEM (máx=MaxElem)

$>$ Nós VINCULADOS.......... NAPOS (máx=MaxNNos)

$>$ MATERIAIS DIFERENTES...... N NMATE (máx=NTM)

$>$ GERAÇÃO DE NÓS........... GERNO ( 1 ativada - 0 desativada)

$>$ GERAÇÃO DE ELEMENTOS....... GEREL (1 ativada - 0 desativada)

$>$ NÚM. NÓS C/ PESOS CONCENT..= NMASC (máx=MaxNNOS)

07- Significado das variáveis do segundo bloco de dados:

$>$ NÃO-IINEARIDADE FÍSICA..... = NLIFI ( 1 ativada - 0 desativada)

$>$ REGRA DE ENDURECIMENTO..... REGEN (0 p/NLIFI=0, $1 \mathrm{p} /$ endur. cinemático, $2 \mathrm{p} /$ endur. independente e $3 \mathrm{p} /$ endur. isotrópico)

$>$ NÃO-LINEARIDADE GEOMETRICA. = NLIGE (1 ativada - 0 desativada)

$>$ NÚMERO DE FASES DE CARREG..= NFACA (má $=$ NFC)

> NÚMERO DE ITERAÇÕES....... NITER (máx=32677)
} 
$>$ TOLERÂNCIA DO RESÍDUO....... TOLER (tolerância para verificação da convergência - minimizar o resíduo)

$>$ IMPRESSÃO RESULTADOS FINAIS = RESUL $(0 \mathrm{p} /$ desloc. e esforços, 1 somente $p /$ deslocamentos e 2 somente $p /$ esforços)

08- Significado das variáveis do terceiro bloco de dados:

> CÁLCULO DINÂMICO.......... DINAM ( 1 ativado - 0 desativado)

$>$ NÚMERO DE INTERVALOS TEMPO.= ITEMP (máx=Capac. Disco Rígido)

> VALOR INTERVALO TEMPO....... TEMPO (intervalo de tempo para a integração numérica)

$>$ PARÂMETROS DE NEWMARK....... NEWMA (Parâmetros de Newmark : NEWMA $=0 \mathrm{p} / \mathrm{DINAM}=0$ e NEWMA $=1$ p/ Beta $=1 / 6$ e Gama $=1 / 2$ ou NEWMA $=2$ $\mathrm{p} /$ Beta $=1 / 4$ e Gama=1/2 ou NEWMA=3 p/ Beta=1/12 e Gama=1/12 p/ DINAM=1)

$>$ AMORTECIMENTO VISCOSO...... AMORT ( 1 ativado - 0 desativado, sendo que para $A M O R T=1$ deve-se ter $D I N A M=1$ )

$>$ AMORTECIMENTO PROP. MASSAS.= LAMBM (proporção matriz massas)

$>$ AMORTECIMENTO PROP. RIGIDEZ= LAMBK (proporção matriz rigidez)

09- Significado das variáveis do quarto bloco de dados:

$>$ A numeração dos nós deve ser sequêencial, devendo começar pela unidade.

$>$ GERNO = 0 (geração de nós desativada) :

- fornecer os dados das três primeiras colunas;

- o número de linhas introduzidas deve ser igual a "NNODS".

$>$ GERNO = 1 (geração de nós ativada) :

- fornecer os dados de todas as colunas;

- a quantidade de nós criados por linha é igual a [(GERAR NNODS) +11 , sendo que a soma dos nós criados por todas as linhas deve ser igual a "NNODS";

- o incremento na numeração dos nós é dado por [INCREM.];

- as coordenadas finais dos nós gerados são dadas por [COORDEN. LIMITE] .

10- Significado das variáveis do quinto bloco de dados:

$>$ o número de nós vínculados a serem introduzidos deve ser igual a "NAPOS".

$>$ As restrições nodais são dadas por:

- "0" = nó liberado para se deslocar na direção em questão;

- "1" = nó impedido de se deslocar na direção em questão.

11- Significado das variáveis do sexto bloco de dados:

$$
>\quad \text { Tensão }
$$

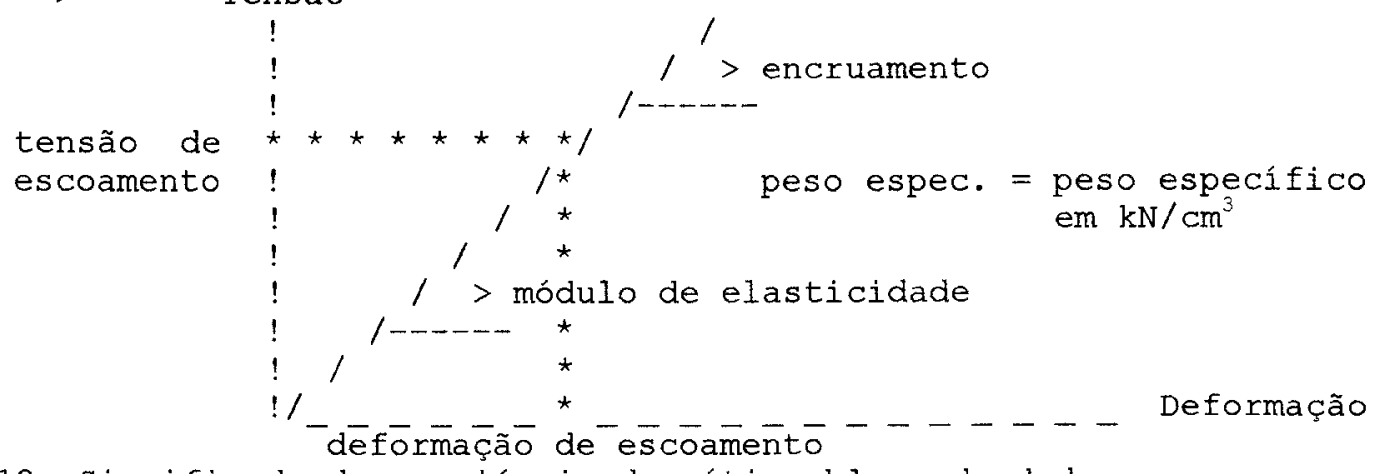

12- Significado das varíaveis do sétimo bloco de dados:

$>$ A numeração dos elementos deve ser seqüêncial, devendo começar pela unidade.

$>$ A numeração do NOI deve ser sempre menor que do NOF.

$>$ GEREL $=0$ (geração de elementos desativada) :

- fornecer os dados das cinco primeiras colunas;

- o número de linhas introduzidas deve ser igual a "NELEM".

$>$ GEREL $=1$ (geração de elementos ativada) :

- fornecer os dados de todas as colunas;

- a quantidade de elementos criados por linha é igual a [(GERAR 
NELEM) + 1], sendo que a soma dos elementos criados por todas as Iinhas deve ser igual a "NELEM";

- incremento na numeração dos elementos é dado por [INCREMENTAR ELEM.];

- o incremento na numeração dos nós dos elementos gerados é dado por [INCREMENTAR NOI NOE].

13- Significado das variáveis do oitavo bloco de dados:

> Para cada fase de carregamento repetir a sequência descrita a seguir.

$>$ NÓs CARREGADOS.......... N NCAR (máx=MaxNNos)

$>$ GERAÇÃO DE CARREGAMENTOS...= GERCA (1 ativada - 0 desativada)

$>$ TEMPO PARA MUDANÇA DE EASE.= TEMAC (tempo final para mudança de fase de carregamento, maior que zerol

$>$ CONST. DA FUNÇÃO MULTIPLIC. $=A, B, C, D, E, F, G, X, Y$ (função mult. é definida por $\mathrm{EPESO}=\mathrm{A}+\mathrm{B}^{\star} i^{\star}$ tempo $+\mathrm{C}^{\star}(i * \text { tempo })^{\wedge} 2+\mathrm{D}^{\star} \sin \left(\mathrm{E}^{\star} i \star \operatorname{tempo}+\right.$ $F^{\star} \cos \left(G^{\star} i^{\star}\right.$ tempo $)+X^{\star} \exp \left(Y^{\star} i * t e m p o\right)$, sendo " $I^{\star}$ " contador de intervalos de tempo. Esta função multiplica os carreg. nodais)

$>$ FORÇA X da esquerda para a direita positivo; FORÇA $Y$ de baixo para cima positivo.

$>$ GERCA $=0$ (geração de carregamentos desativada) :

- fornecer os dados das três primeiras colunas;

- número de linhas introduzidas deve ser igual a "NNCAR".

$>$ GERCA $=1$ (geração de carregamentos ativada) :

- fornecer os dados de todas as colunas;

- a quantidade de carregamentos criados por linha é igual a [(GERAR NNCAR) +1], sendo que a soma dos carregamentos criados por todas as linhas deve ser igual a "NNCAR";

- o incremento na numeração dos carregamentos é dado por [ INCREM. ] ;

14- Significado das variáveis do oitavo bloco de dados:

$>$ Este bloco é opcional, devendo ser introduzido se NMASC>0:

- fornecer os dados de todas as colunas;

- a quantidade de linhas introduzidas deve ser igual a "NMASC";

- PESO DIR. $\mathrm{X}=$ fornecer $\circ$ peso de qualquer objeto na direção $\mathrm{X}$ em "kN", que está localizada no nó em questão;

- PESO DIR. $Y=$ fornecer $\circ$ peso de qualquer objeto na direção $Y$ em "kN", que está localizada no nó em questão;

- este bloco só tem função quando DINAM=1.

OBSERVAÇÃO : A aceleração da gravidade é definida como: GRAVI $=981,0 \mathrm{~cm} / \mathrm{s}^{2}$

$\star \star \star *$ DINATREL / AUTOTREL : ARQUIVOS DE DADOS

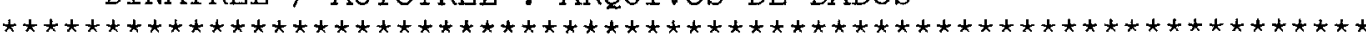

100TR001. TRE

$\begin{array}{cccc}\text { C } & & & \\ \text { C } & \text { NNODS } & \text { NELEM } & \text { NAPOS } \\ & 2 & 1 & 2 \\ \text { C } & \text { NLIFI } & \text { REGEN } & \text { NLIGE } \\ & 0 & 0 & 0 \\ \text { C } & \text { DINAM } & \text { ITEMP } & \text { TEMPO } \\ & 1 & 80 & 4 E-4\end{array}$

$\mathrm{C}$

C COORDEN. ORIGEM GERAR

C NO $\quad \mathrm{X} \quad \mathrm{Y}$ NNODS

$\begin{array}{cccc}\text { NMATE } & \text { GERNO } & \text { GEREL } & \text { NMASC } \\ 1 & 0 & 0 & 0 \\ \text { NFACA } & \text { NITER } & \text { TOLER } & \text { RESUL } \\ 1 & 200 & 2 \text { E- } 6 & 1 \\ \text { NEWMA } & \text { AMORT } & \text { LAMBM } & \text { LAMBK } \\ 1 & 0 & 0 & 0\end{array}$

$\begin{array}{lrr}1 & 0.00 & 0.00\end{array}$

$\mathrm{C}$

200.00

0.00

INCREM.

COORDEN .

LIMITE

$2 \quad 200.00 \quad 0.00$




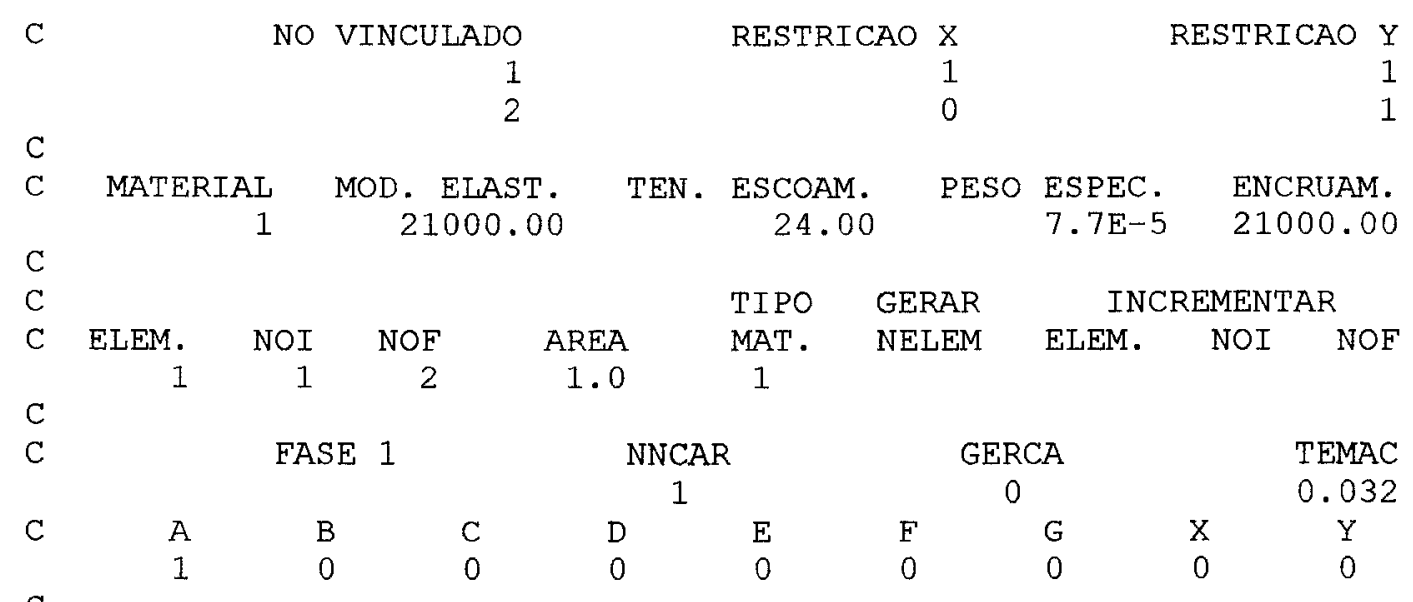

C NO CARREGADO FORCA X FORCA Y GERAR NNCAR INCREM. $2 \quad 10.00 \quad 0.00$

\section{TR002. TRE}

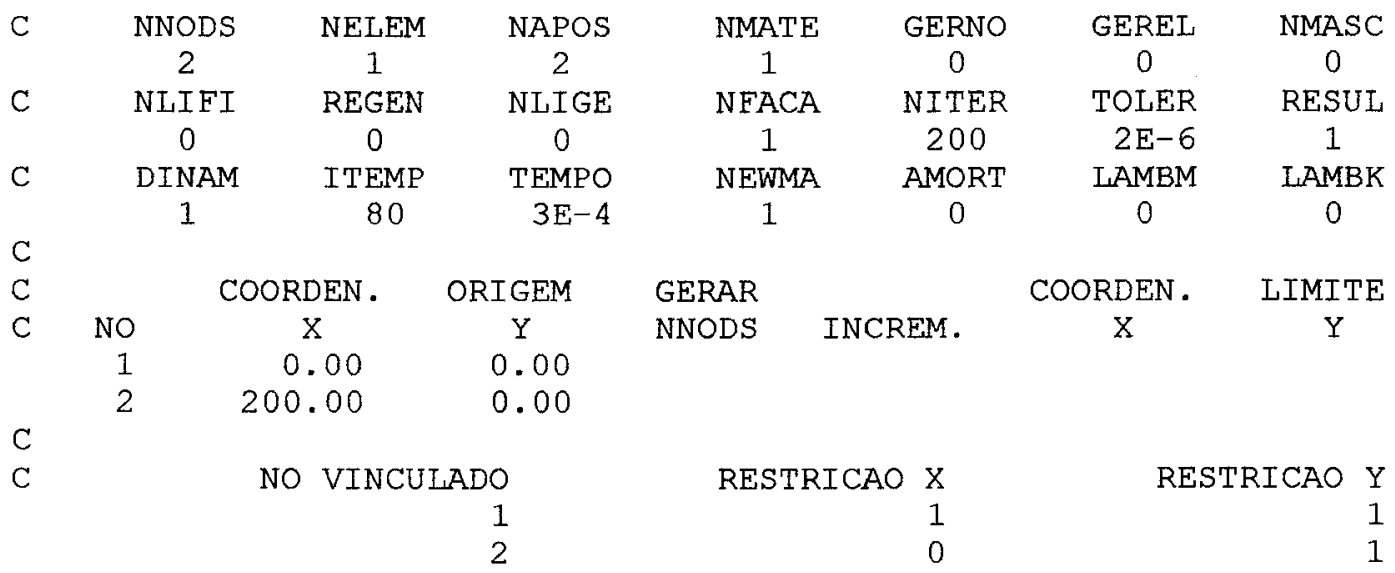

C MATERIAL MOD. ELAST. TEN. ESCOAM. PESO ESPEC. ENCRUAM.

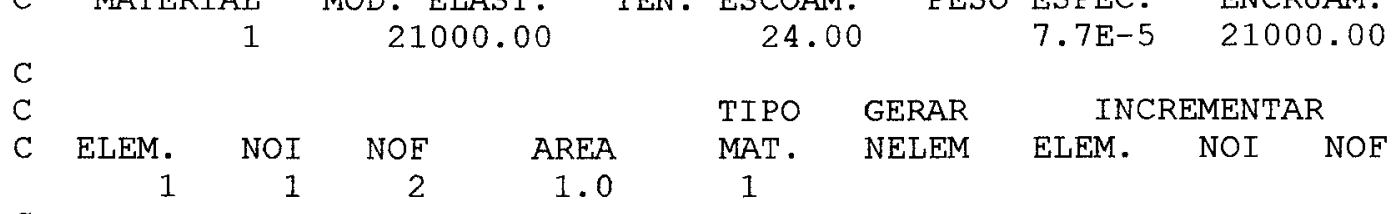

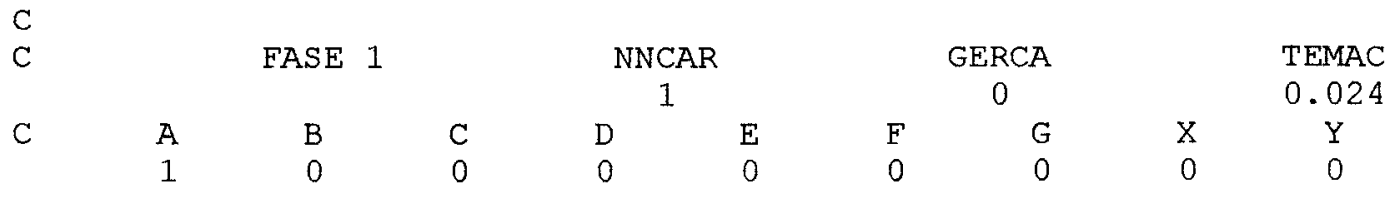

C NO CARREGADO FORCA X EORCA Y GERAR NNCAR INCREM.

$\begin{array}{rrrr}2 & 10.00 & 0.00 & \end{array}$

\section{TR003. TRE}

$\mathrm{C}$

$\begin{array}{cccccccc}\text { C } & \text { NNODS } & \text { NELEM } & \text { NAPOS } & \text { NMATE } & \text { GERNO } & \text { GEREL } & \text { NMASC } \\ & 2 & 1 & 2 & 1 & 0 & 0 & 0 \\ \text { C } & \text { NLIFI } & \text { REGEN } & \text { NLIGE } & \text { NFACA } & \text { NITER } & \text { TOLER } & \text { RESUL } \\ & 0 & 0 & 0 & 1 & 200 & 2 \mathrm{E}-6 & 1\end{array}$




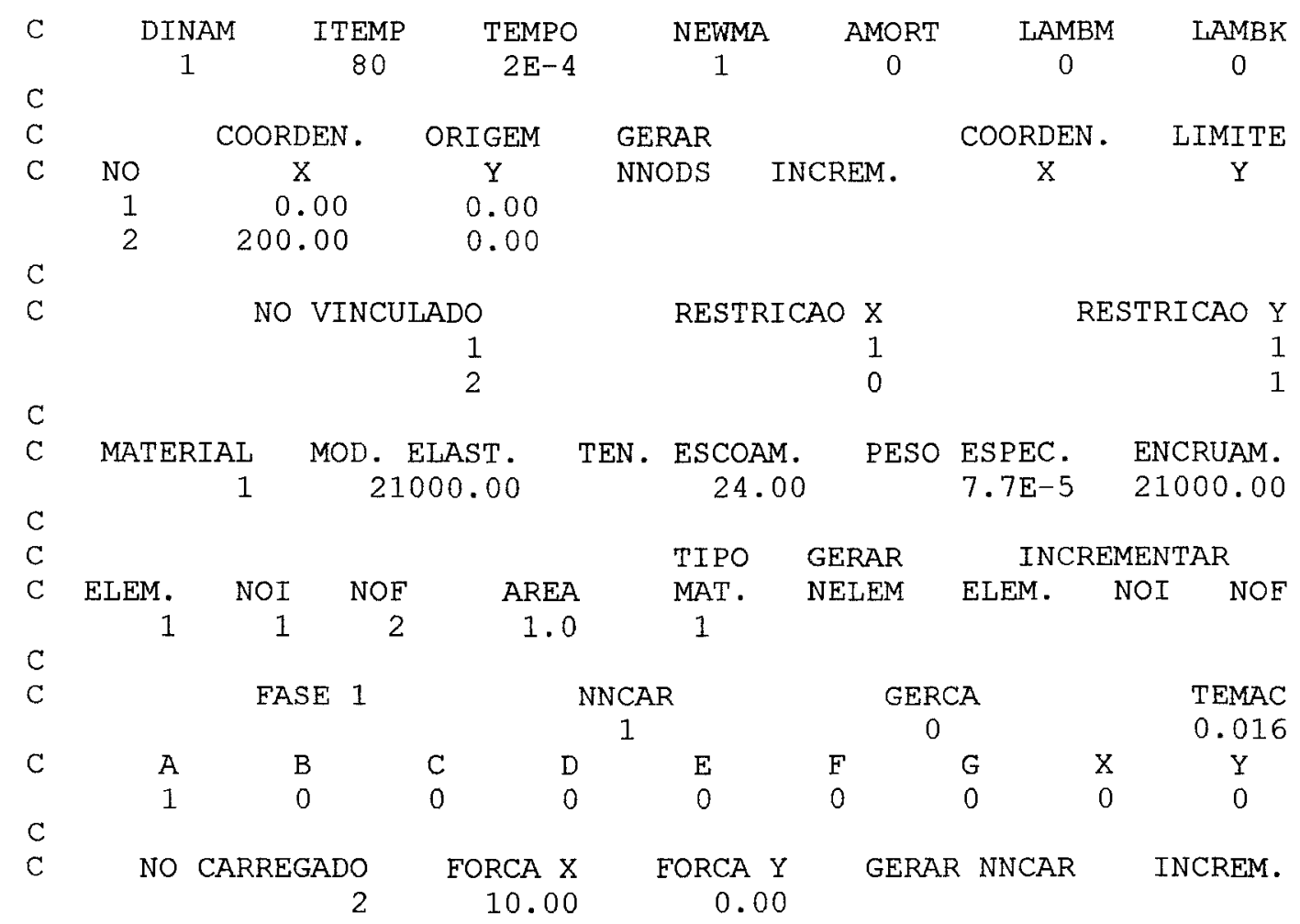

\section{TR004. TRE}

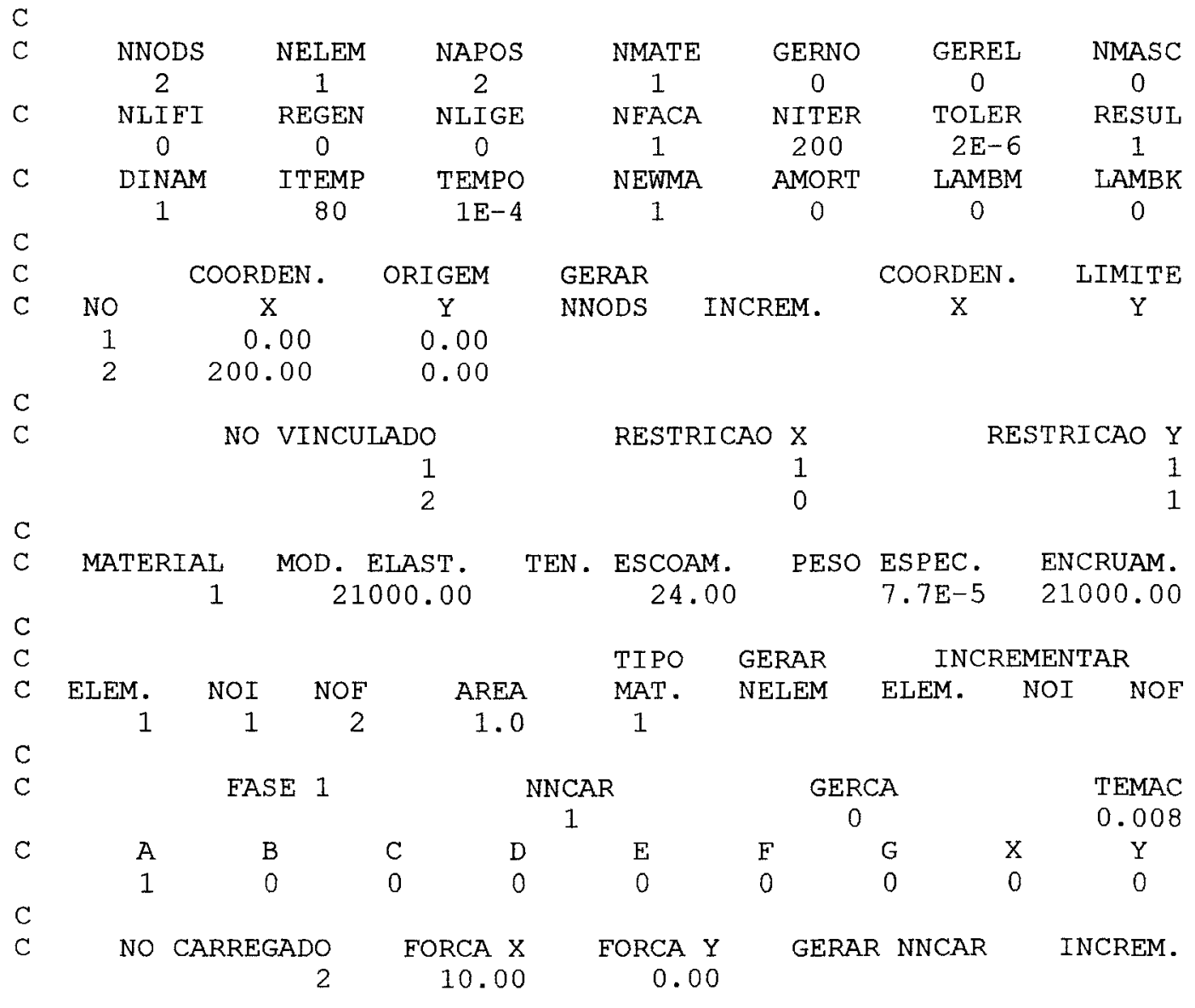




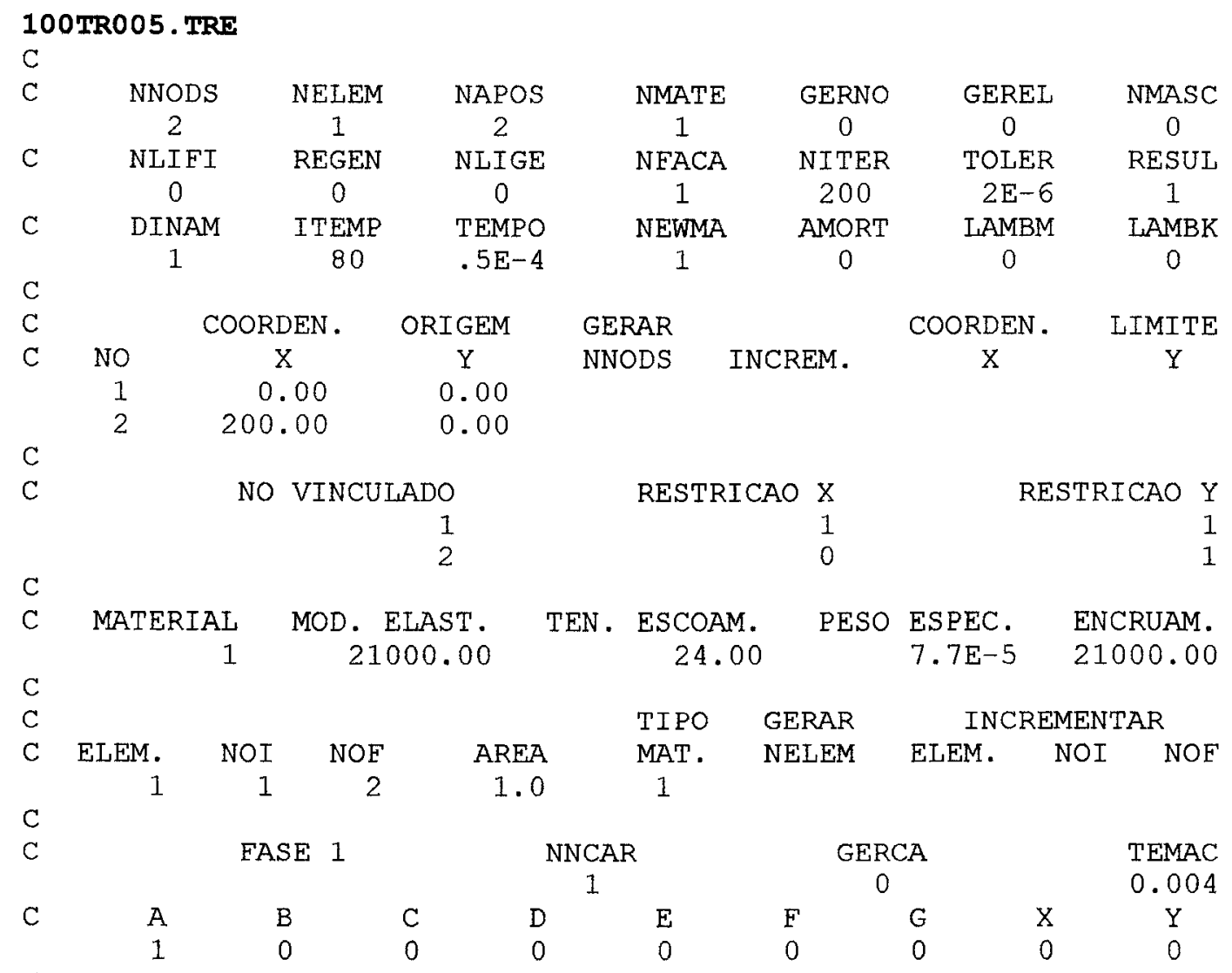

$\begin{array}{rrrrrr}\text { C NO CARREGADO } & \text { FORCA X } & \text { FORCA Y } & \text { GERAR NNCAR } & \text { INCREM. } \\ 2 & 10.00 & 0.00 & \end{array}$

\section{TR006. TRE}

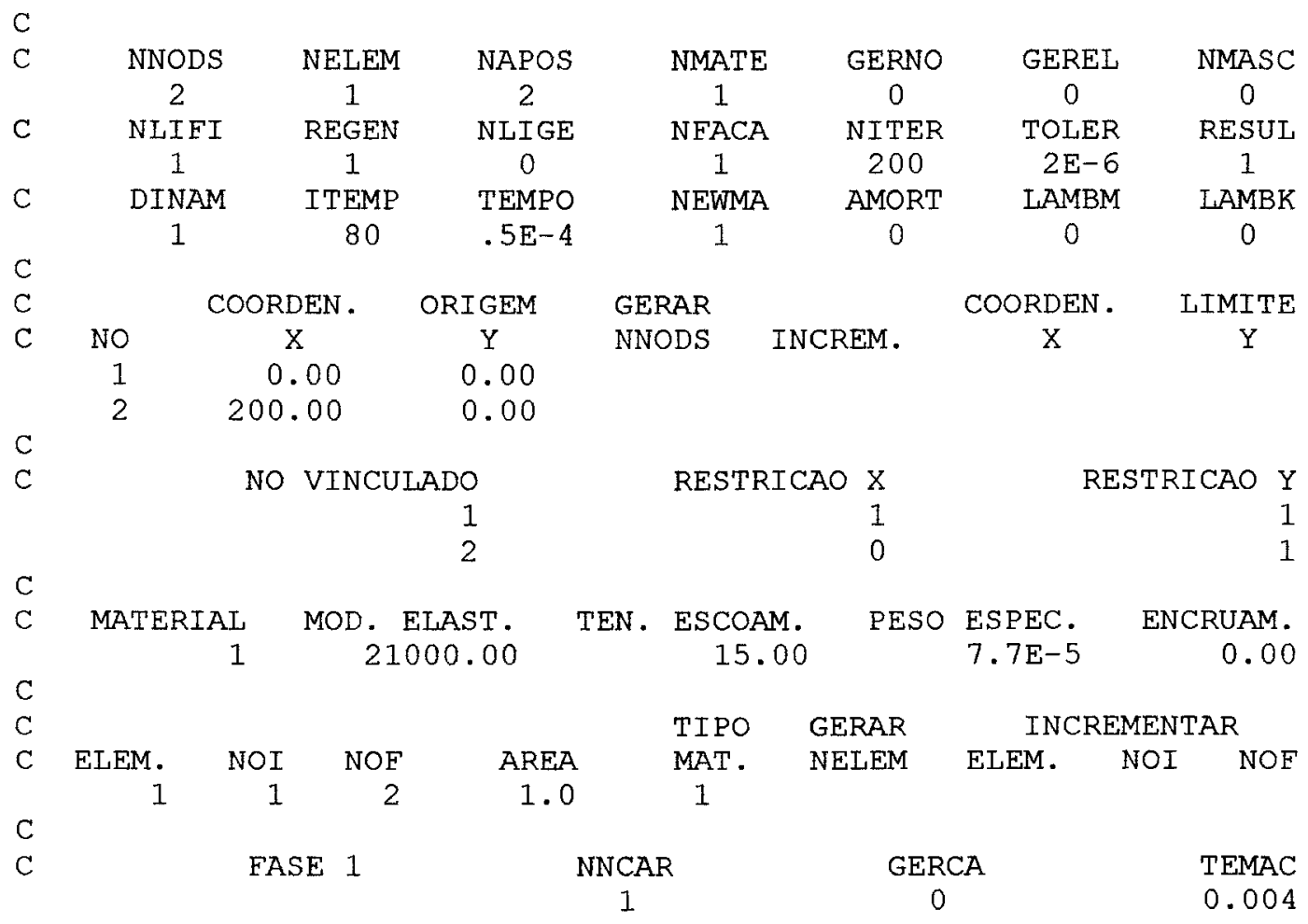




$\begin{array}{rrrrrrrrrr}C & \text { A } & \text { B } & \text { C } & \text { D } & \text { E } & \text { F } & \text { G } & \text { X } & Y \\ & 1 & 0 & 0 & 0 & 0 & 0 & 0 & 0 & 0 \\ \text { C } & & & & & & & & & \\ \text { C } & \text { NO CARREGADO } & \text { FORCA X } & \text { FORCA Y } & \text { GERAR NNCAR } & \text { INCREM. } \\ & & 2 & 10.00 & 0.00 & \end{array}$

\section{TR002. TRE}

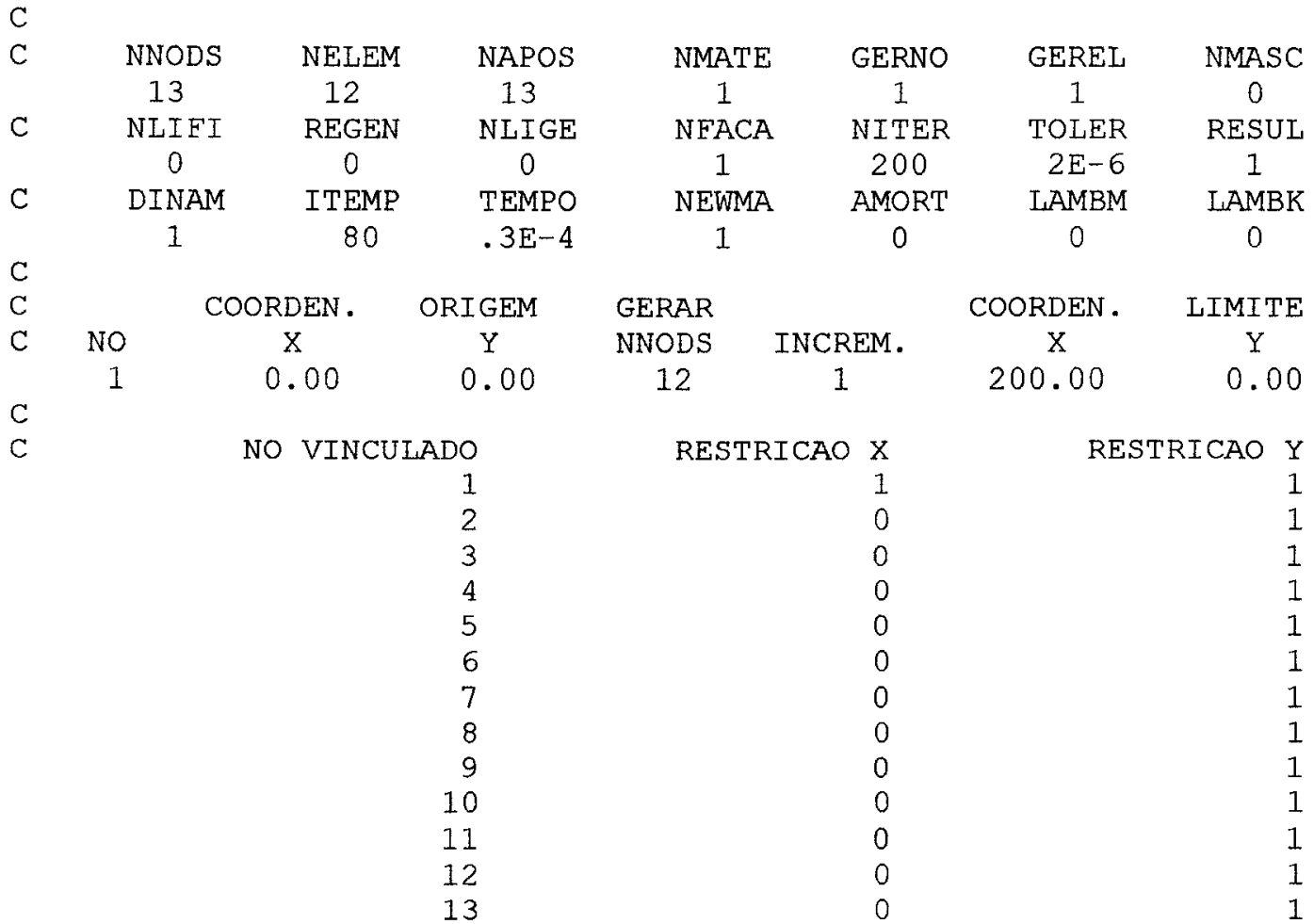

C MATERIAL MOD. ELAST. TEN. ESCOAM. PESO ESPEC. ENCRUAM. $\begin{array}{rrrrr}1 & 21000.00 & 24.00 & 7.7 \mathrm{E}-5 & 21000.00\end{array}$ \begin{tabular}{lllllll}
$\mathrm{C}$ & & & & & \multicolumn{2}{c}{ INCREMENTAR } \\
$\mathrm{C}$ & & & & TIPO & GERAR & \multicolumn{2}{c}{ INCR. NOI NOF } & AREA & MAT. & NELEM & ELEM. NOI NOF
\end{tabular}

\begin{tabular}{|c|c|c|c|c|c|c|c|c|}
\hline v & \multicolumn{2}{|c|}{ FASE 1} & \multicolumn{2}{|c|}{$\begin{array}{c}\text { NNCAR } \\
1\end{array}$} & \multicolumn{2}{|c|}{$\begin{array}{c}\text { GERCA } \\
0\end{array}$} & \multicolumn{2}{|c|}{$\begin{array}{r}\text { TEMAC } \\
0.0024\end{array}$} \\
\hline C & B & C & D & $E$ & $F$ & $\mathrm{G}$ & $x$ & $\mathrm{Y}$ \\
\hline 1 & 0 & 0 & 0 & 0 & 0 & 0 & 0 & 0 \\
\hline
\end{tabular}

C NO CARREGADO FORCA X FORCA $Y$ GERAR NNCAR INCREM.

$\begin{array}{rrrrrr}\text { C NO CARREGADO } & \text { FORCA X } & \text { FORCA Y } & \text { GERAR NNCAR } & \text { INCREM } \\ 13 & 10.00 & 0.00 & \end{array}$

\section{TR003. TRE}

\begin{tabular}{|c|c|c|c|c|c|c|c|}
\hline \multicolumn{8}{|l|}{ C } \\
\hline \multirow[t]{2}{*}{ C } & NNODS & NELEM & NAPOS & NMATE & GERNO & GEREL & NMASC \\
\hline & 3 & 2 & 2 & 1 & 0 & 0 & 0 \\
\hline \multirow[t]{2}{*}{ C } & NLIFI & REGEN & NLIGE & NFACA & NITER & TOLER & RESUL \\
\hline & 0 & 0 & 1 & 1 & 200 & $2 E-6$ & 1 \\
\hline \multirow[t]{2}{*}{ C } & DINAM & ITEMP & TEMPO & NEWMA & AMORT & LAMBM & LAMBK \\
\hline & 0 & 80 & 1 & 0 & 0 & 0 & 0 \\
\hline
\end{tabular}




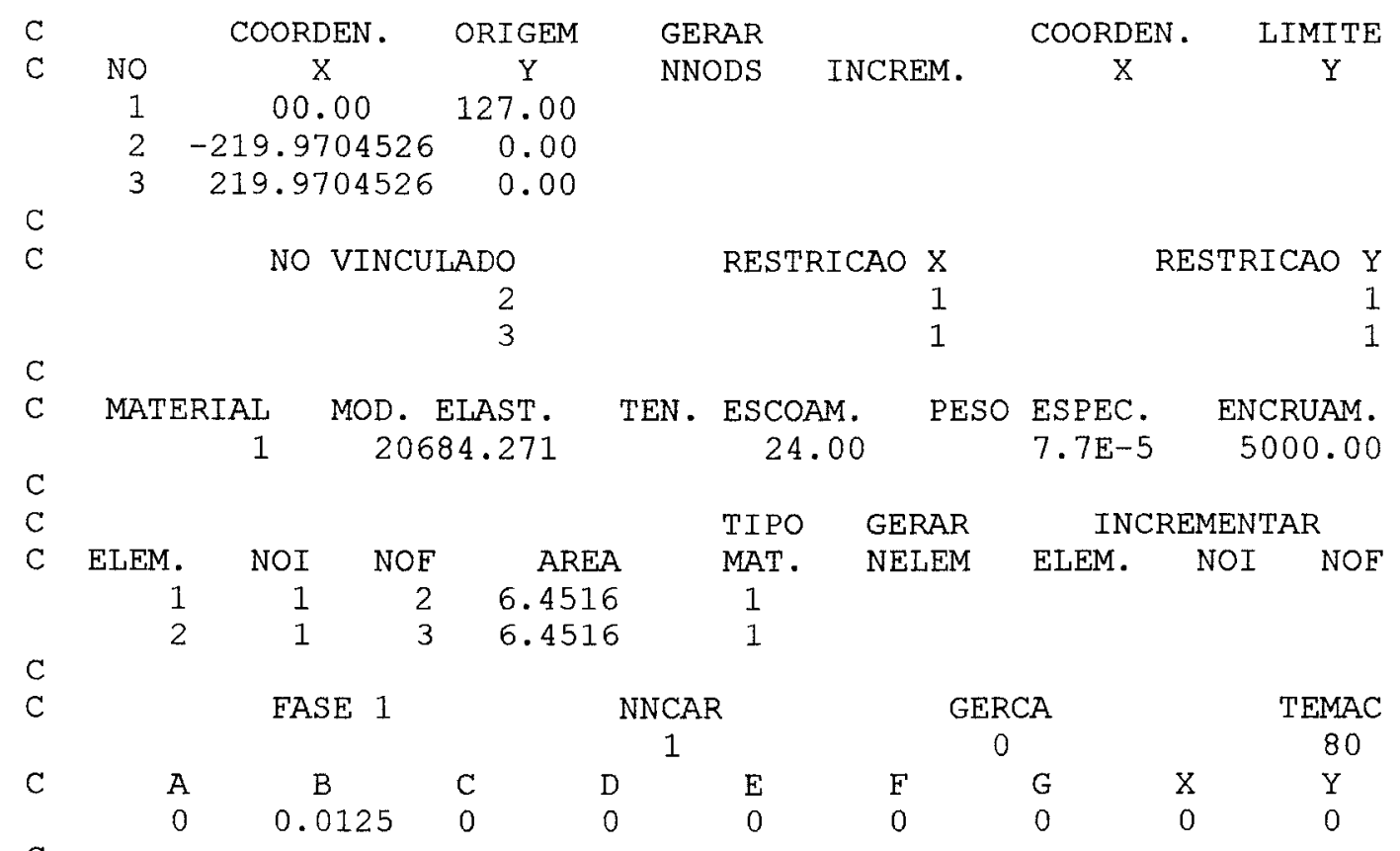

C NO CARREGADO FORCA X FORCA Y GERAR NNCAR INCREM.

\section{TR004 . TRE}

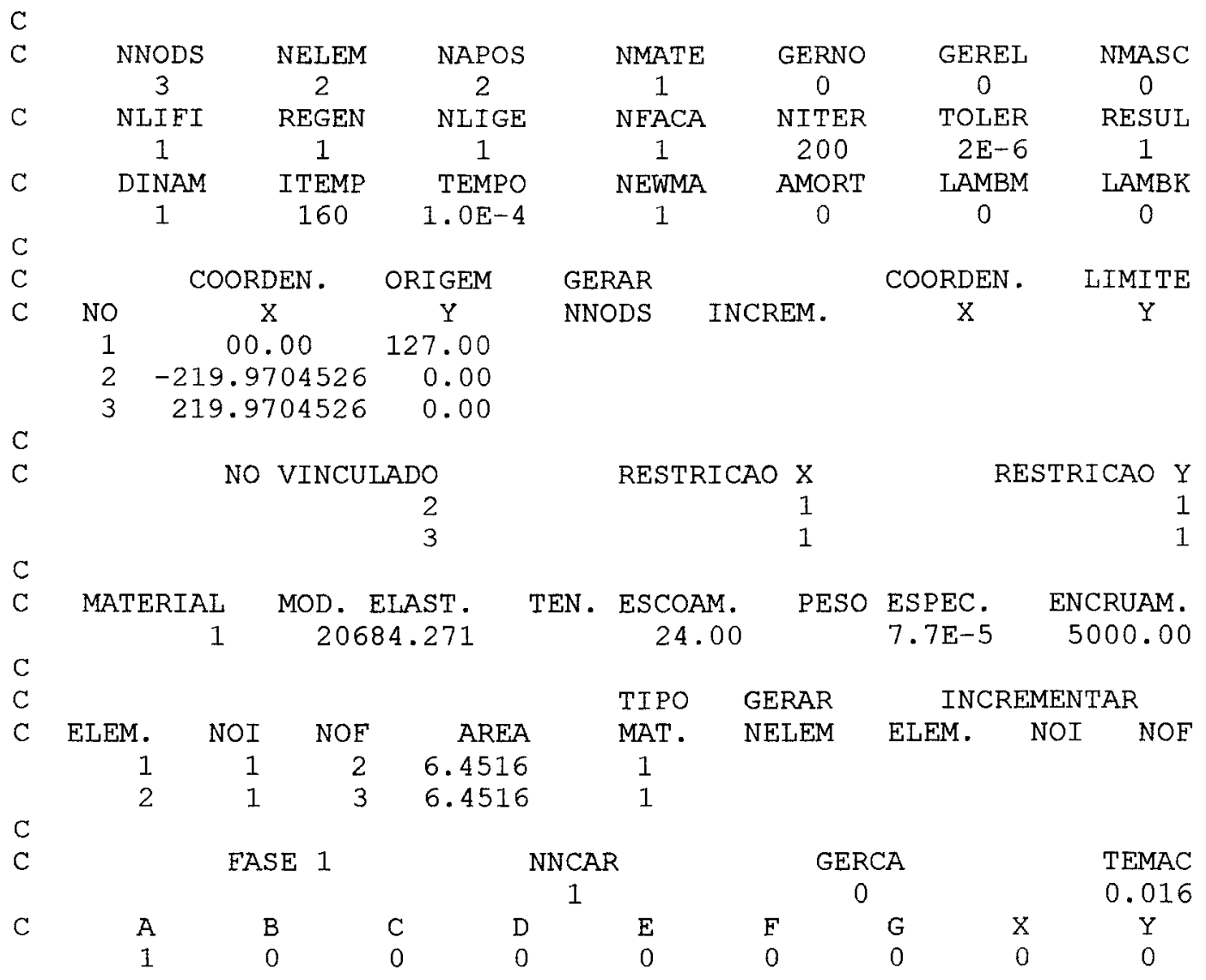

C NO CARREGADO FORCA X FORCA Y GERAR NNCAR INCREM.

$\begin{array}{rrrrrr}\text { C NO CARREGADO } & \text { FORCA X } & \text { FORCA Y } & \text { GERAR NNCAR } & \text { INCREM. } \\ 1 & 0 & 300.00 & & \end{array}$ 


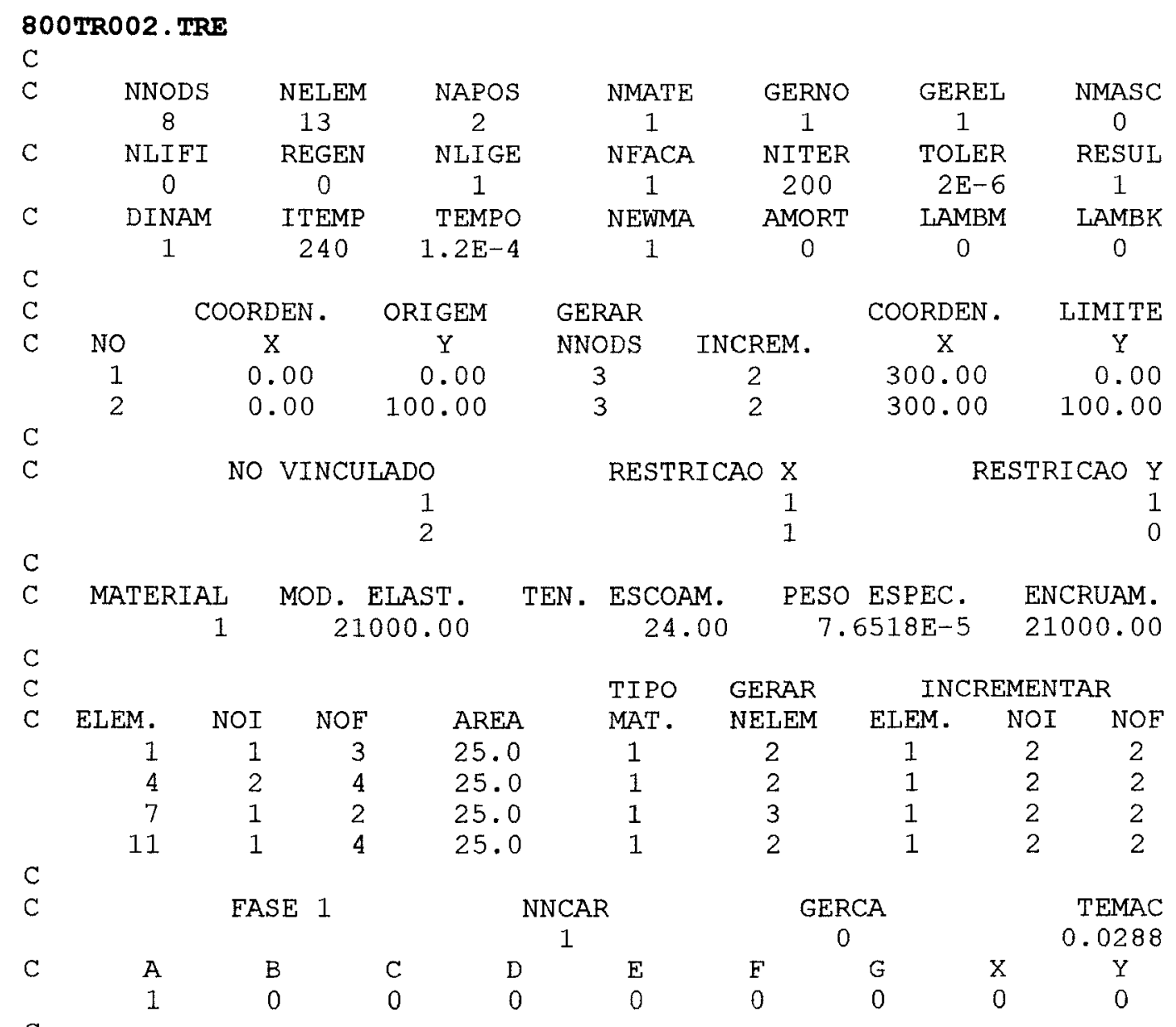

$\begin{array}{rrrrrr}\text { C } & \text { FO CARREGADO } & \text { FORCA X } & \text { FORCA Y } & \text { GERAR NNCAR } & \text { INCREM. } \\ & 8 & 0.00 & -20000.00 & \end{array}$

900TR002. TRE

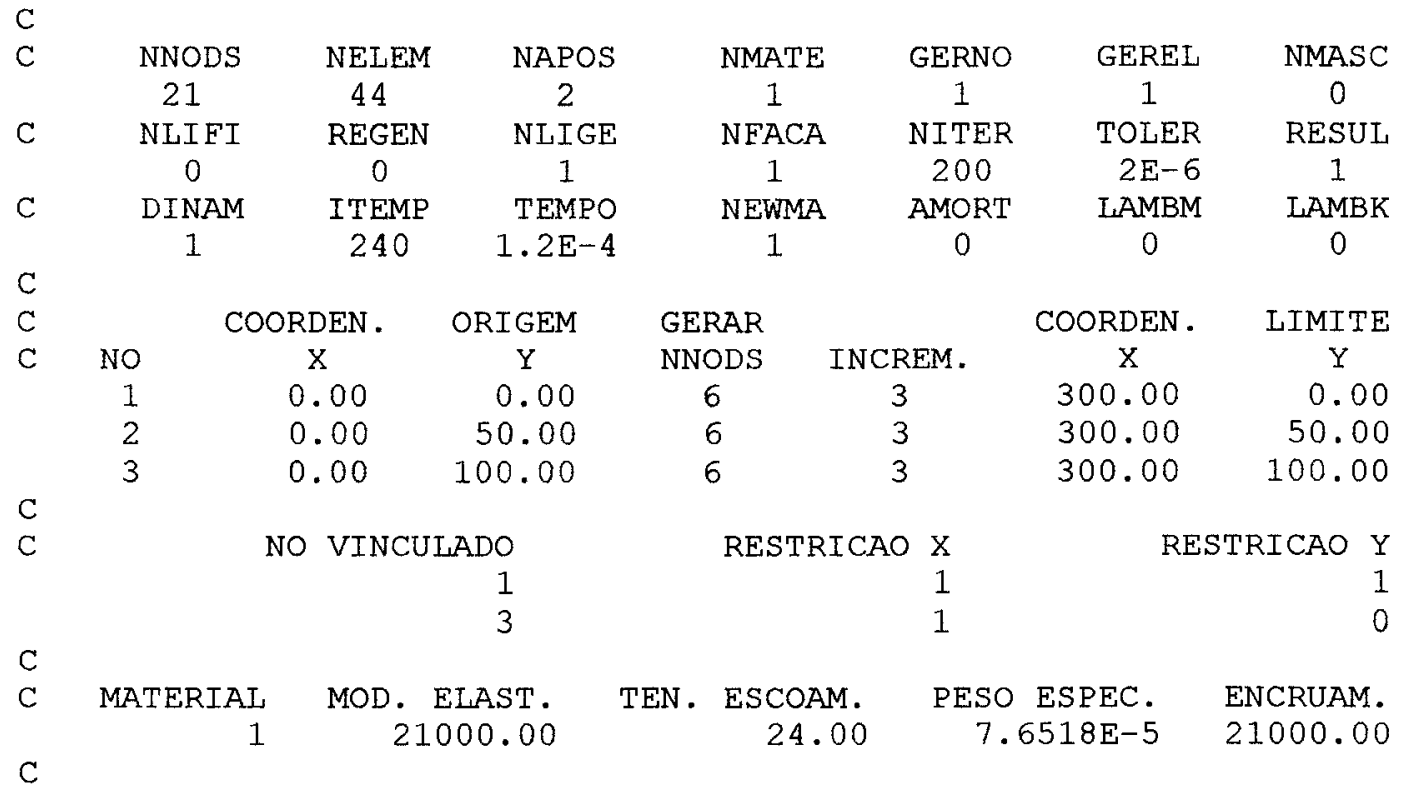




\begin{tabular}{|c|c|c|c|c|c|c|c|c|c|}
\hline \multirow{2}{*}{0} & \multirow[b]{2}{*}{ ELEM. } & \multirow[b]{2}{*}{ NOI } & \multirow[b]{2}{*}{ NOF } & \multirow[b]{2}{*}{ AREA } & \multirow{2}{*}{$\begin{array}{l}\text { TIPO } \\
\text { MAT. }\end{array}$} & \multirow{2}{*}{$\begin{array}{l}\text { GERAR } \\
\text { NELEM }\end{array}$} & \multicolumn{3}{|c|}{ INCREMENTAR } \\
\hline & & & & & & & ELEM. & NOI & NOF \\
\hline & 1 & 1 & 4 & 25.0 & 1 & 5 & 1 & 3 & 3 \\
\hline & 7 & 2 & 5 & 25.0 & 1 & 5 & 1 & 3 & 3 \\
\hline & 13 & 3 & 6 & 25.0 & 1 & 5 & 1 & 3 & 3 \\
\hline & 19 & 1 & 2 & 25.0 & 1 & 6 & 1 & 3 & 3 \\
\hline & 26 & 2 & 3 & 25.0 & 1 & 6 & 1 & 3 & 3 \\
\hline & 33 & 1 & 5 & 25.0 & 1 & 5 & 1 & 3 & 3 \\
\hline & 39 & 2 & 6 & 25.0 & 1 & 5 & 1 & 3 & 3 \\
\hline \multicolumn{10}{|c|}{ C } \\
\hline ( & \multicolumn{3}{|c|}{ FASE 1} & \multicolumn{2}{|c|}{$\begin{array}{c}\text { NNCAR } \\
1\end{array}$} & \multicolumn{2}{|c|}{$\begin{array}{c}\text { GERCA } \\
0\end{array}$} & \multicolumn{2}{|c|}{$\begin{array}{r}\text { TEMAC } \\
0.0288\end{array}$} \\
\hline C & A & B & $\mathrm{C}$ & $\mathrm{D}$ & $E$ & F & G & $\mathrm{x}$ & $Y$ \\
\hline & 1 & 0 & 0 & 0 & 0 & 0 & 0 & 0 & 0 \\
\hline
\end{tabular}

C NO CARREGADO FORCA X FORCA Y GERAR NNCAR INCREM. $21 \quad 0.00-20000.00$

\section{TR013. TRE}

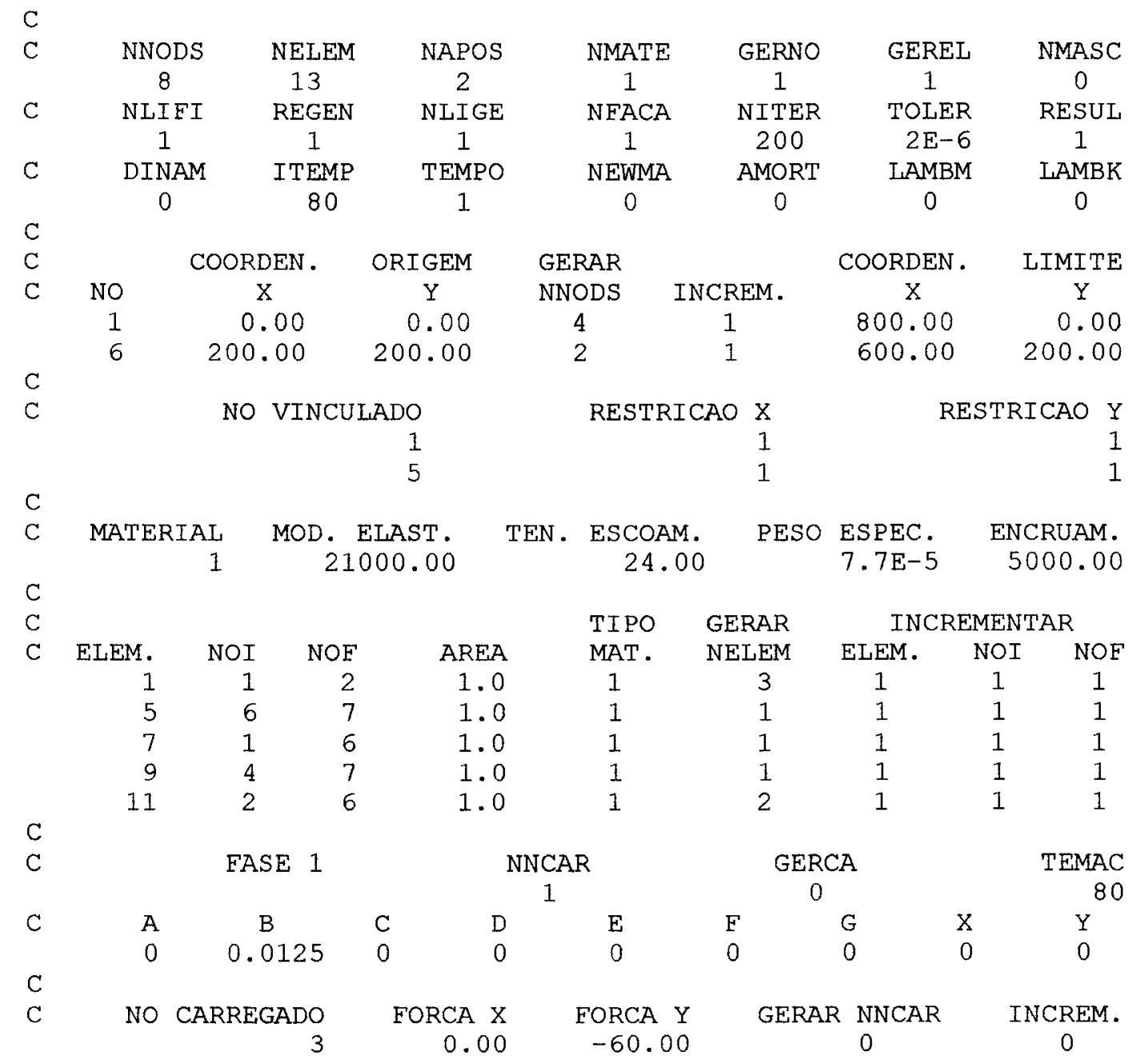

600TR017. TRE

C NNODS NELEM NAPOS NMATE GERNO GEREL NMASC

$\begin{array}{lllllll}8 & 13 & 2 & 1 & 1 & 1 & 0\end{array}$




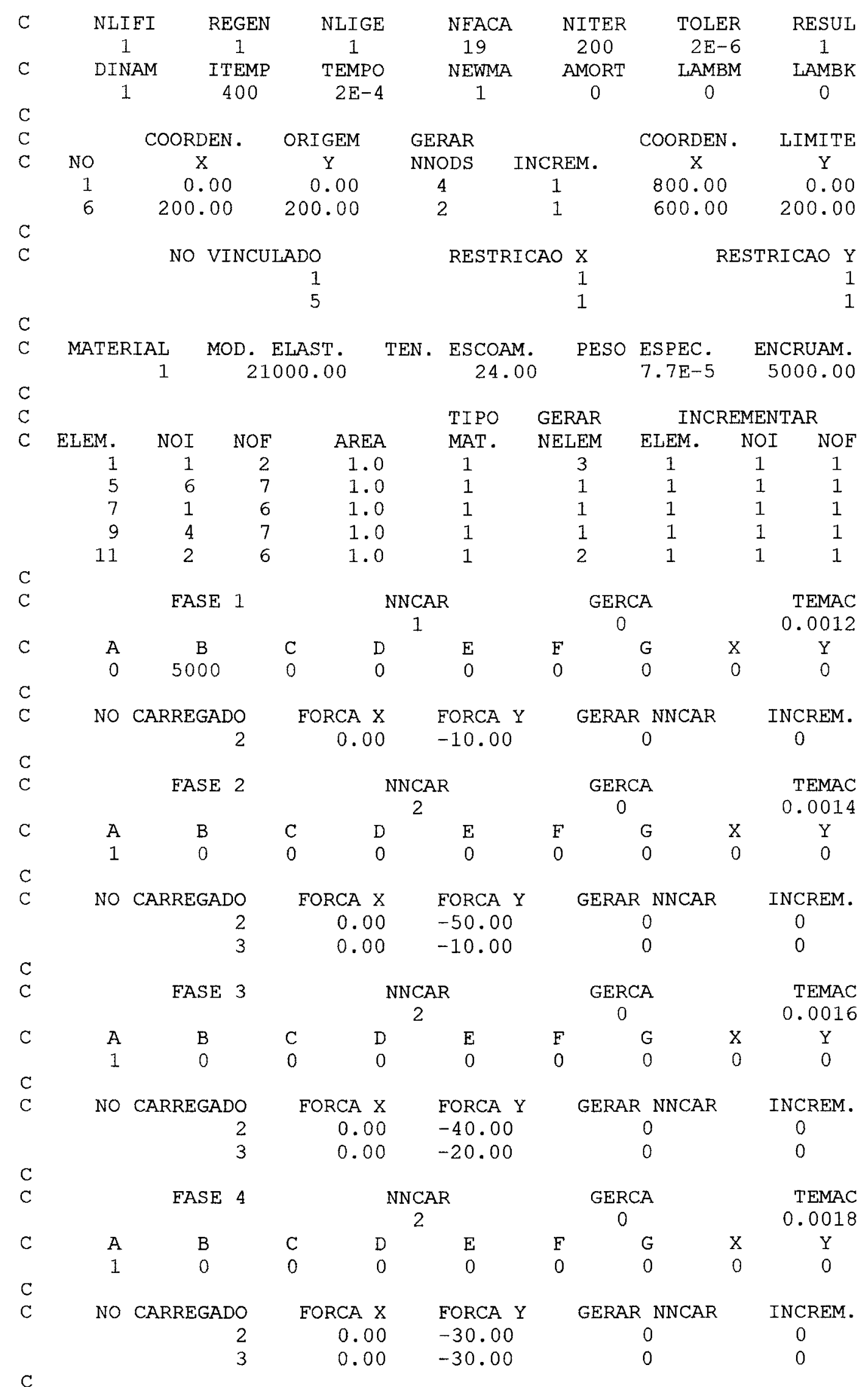




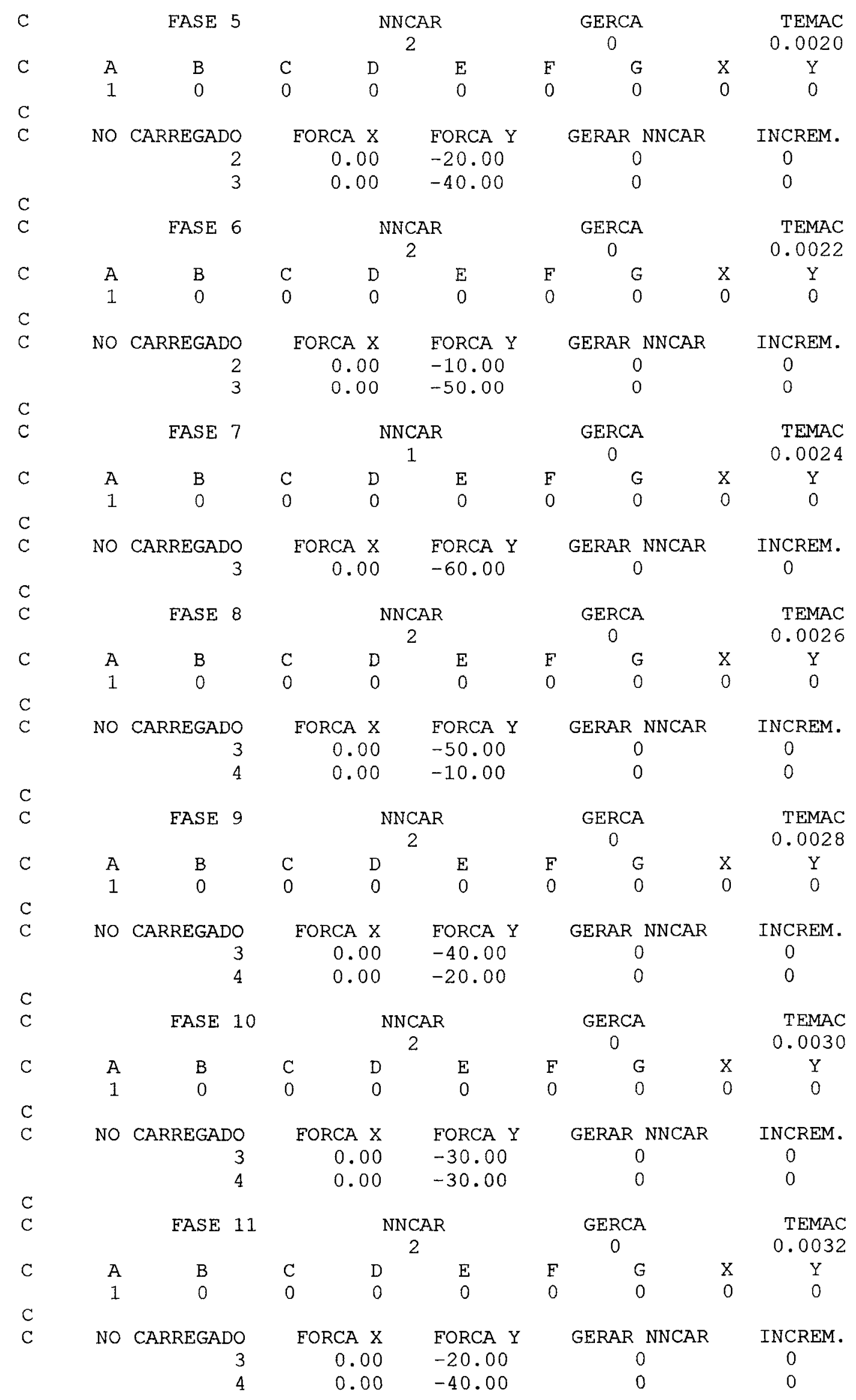




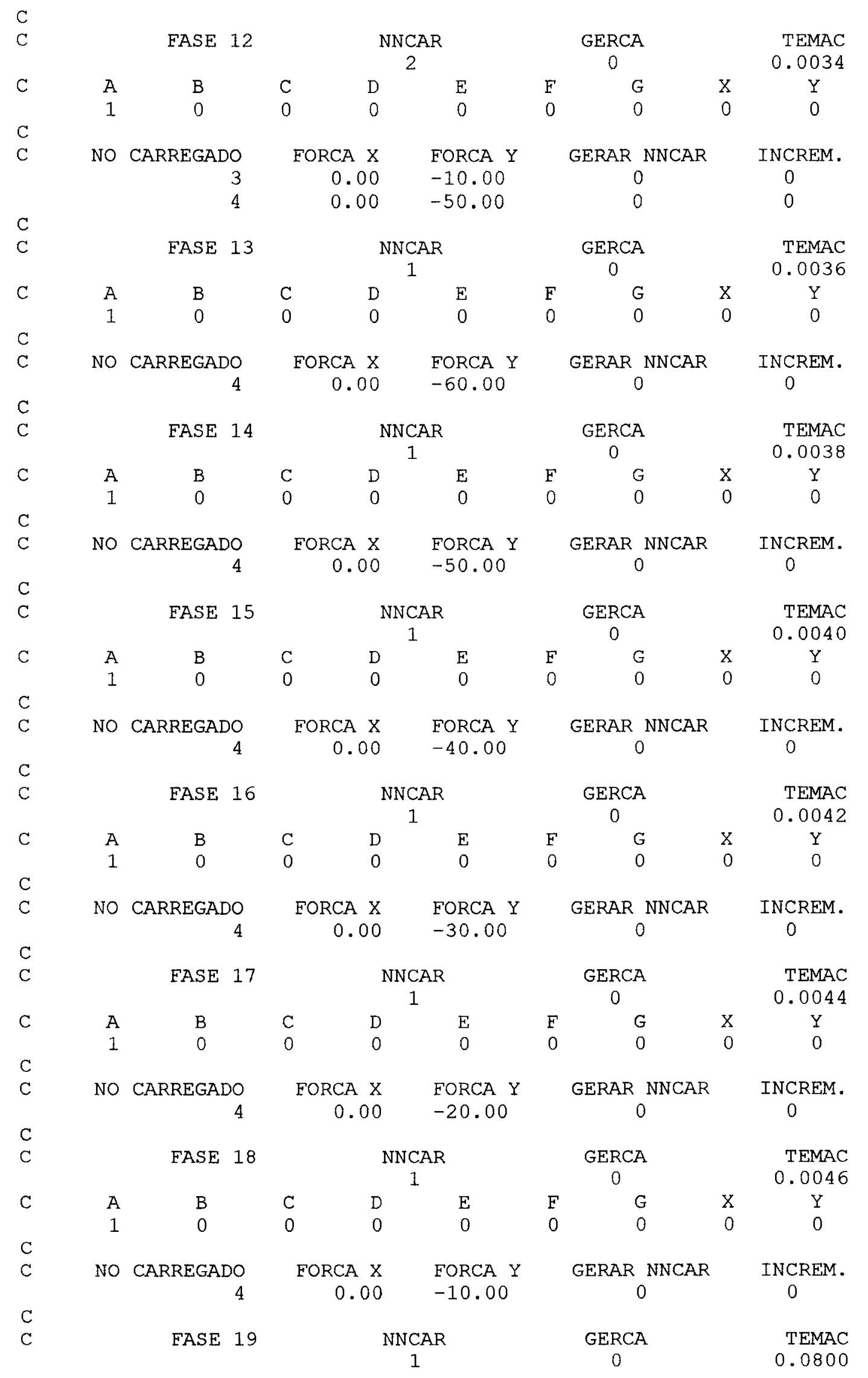




$\begin{array}{rrrrrrrrrr}C & \text { A } & \text { B } & \text { C } & \text { D } & \text { E } & \text { F } & \text { G } & \text { X } & Y \\ & 0 & 0 & 0 & 0 & 0 & 0 & 0 & 0 & 0 \\ \text { C } & & & & & & & & \\ \text { C } & \text { NO CARREGADO } & \text { FORCA X } & \text { FORCA Y } & \text { GERAR NNCAR } & \text { INCREM. } \\ & & 4 & 0.00 & 0.00 & 0 & 0\end{array}$

600TR021. TRE

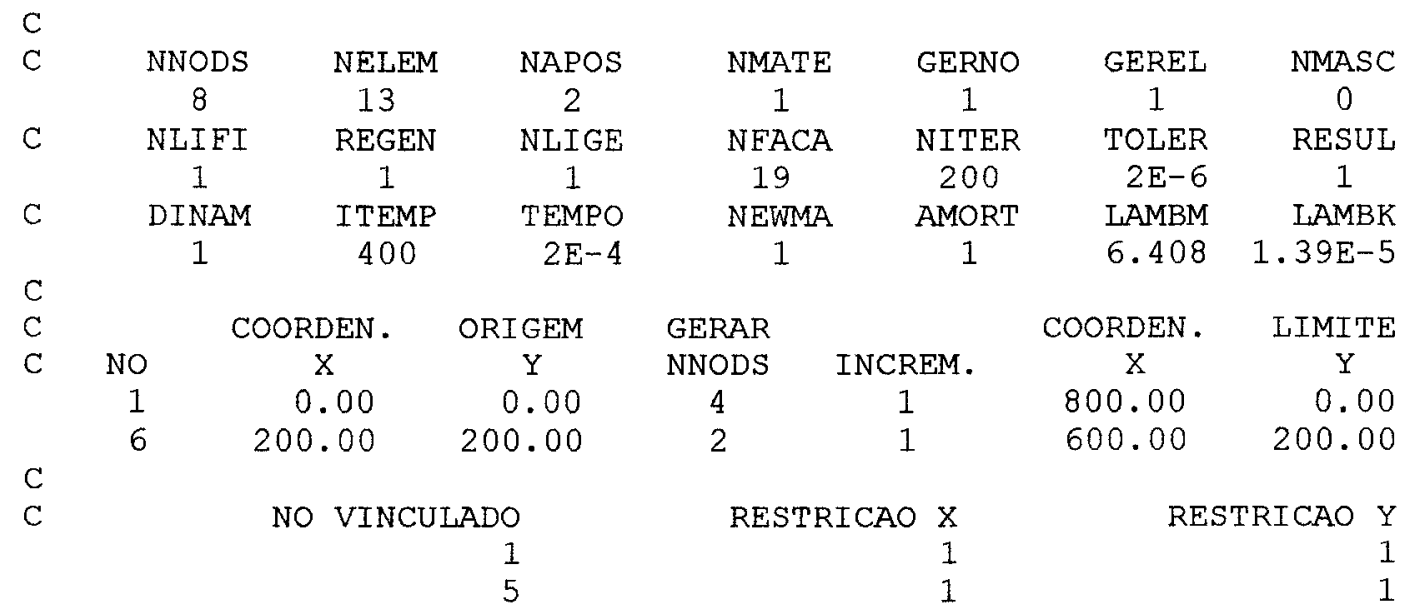

$\begin{array}{rrrrrr}\text { C } & & & & \\ \text { C MATERIAL } & \text { MOD. ELAST. } & \text { TEN. ESCOAM. } & \text { PESO ESPEC. } & \text { ENCRUAM. } \\ & 1 & 21000.00 & 24.00 & 7.7 E-5 & 5000.00\end{array}$

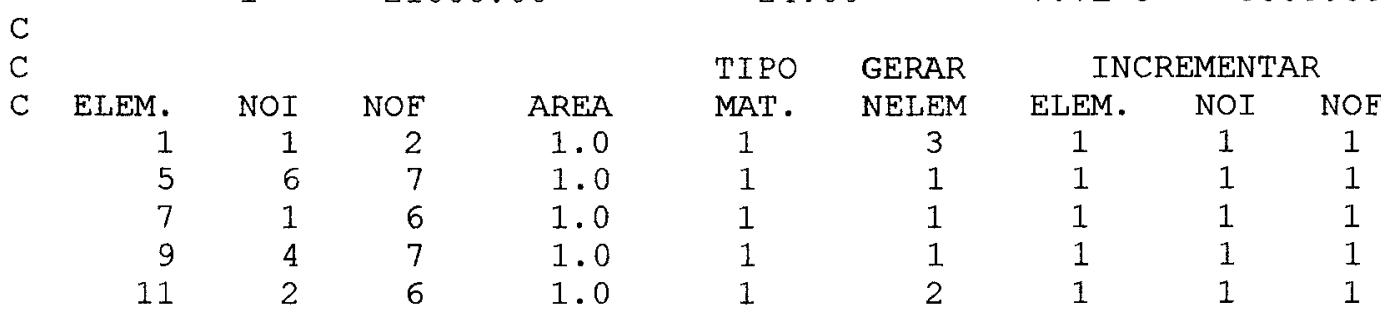

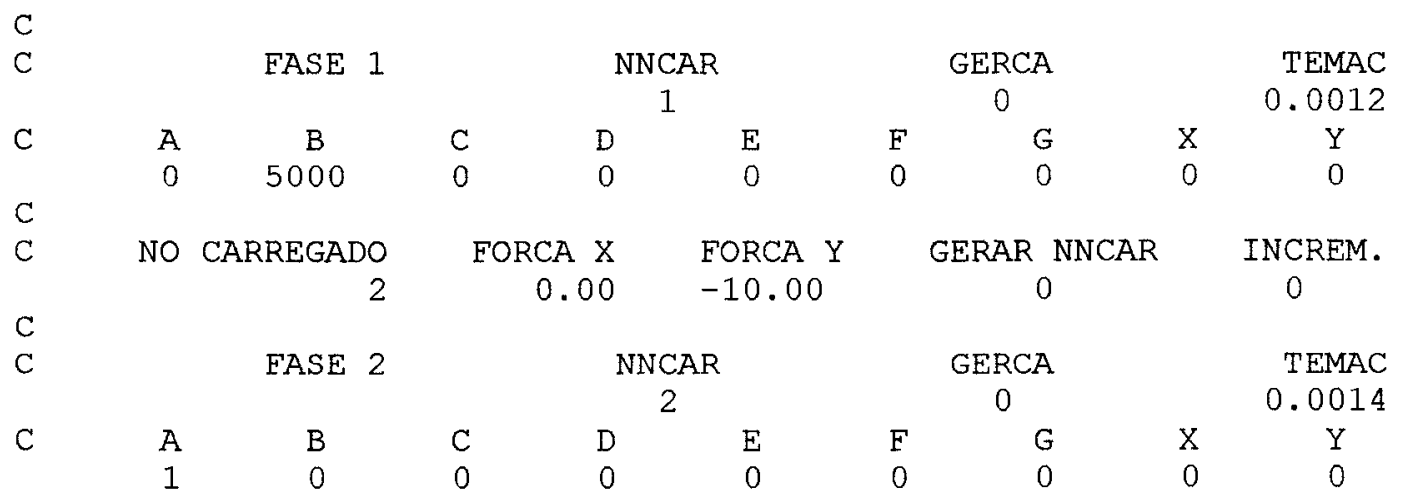

C NO CARREGADO FORCA X FORCA Y GERAR NNCAR INCREM.

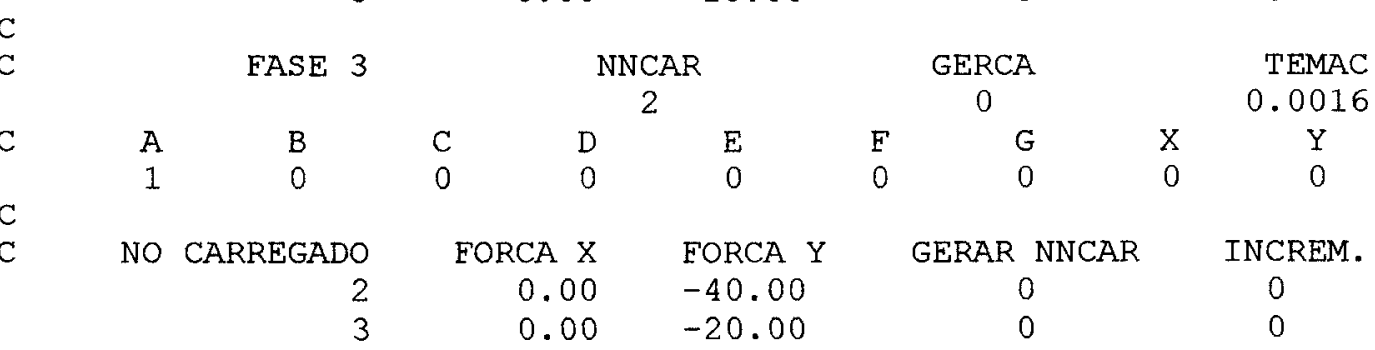




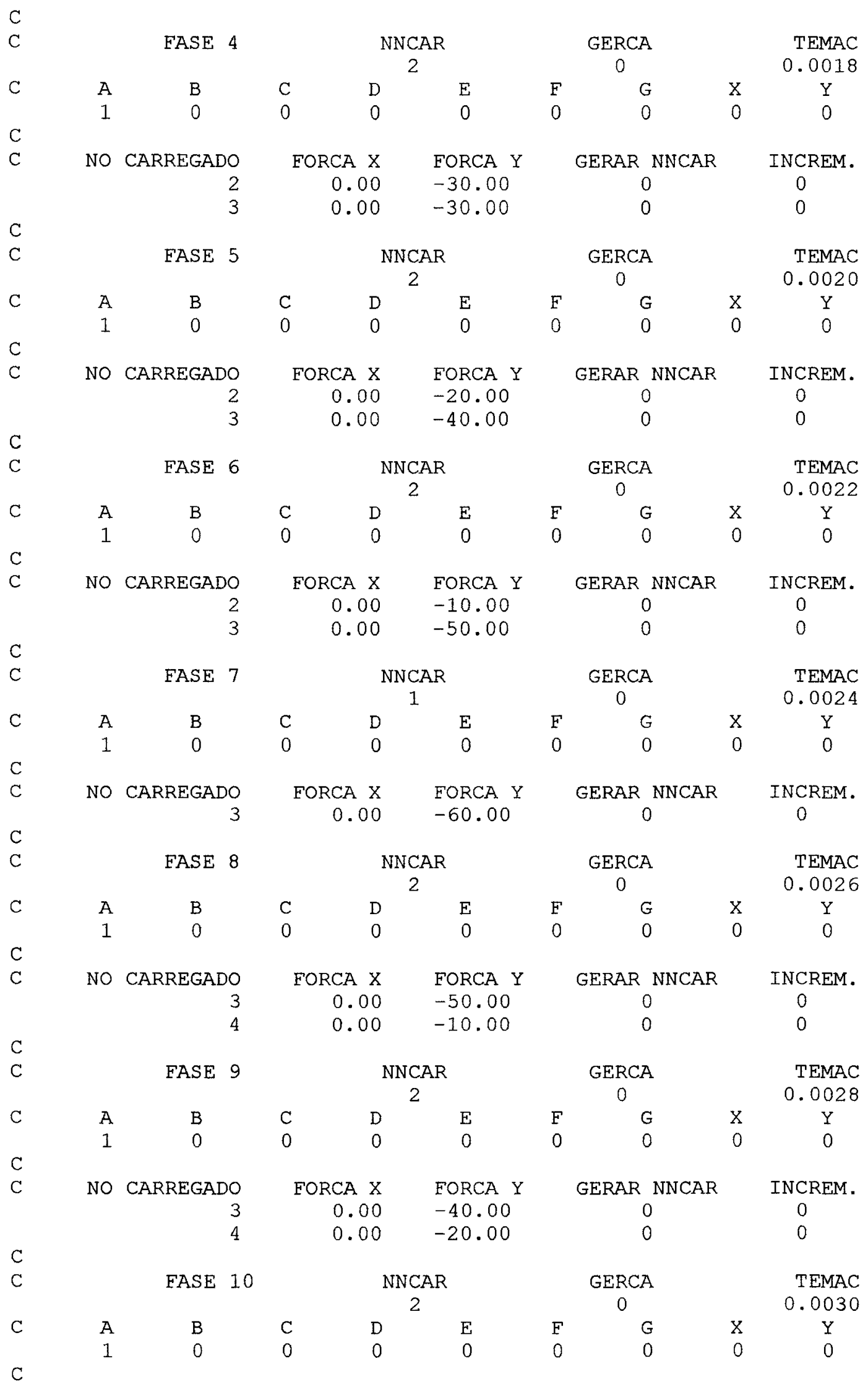




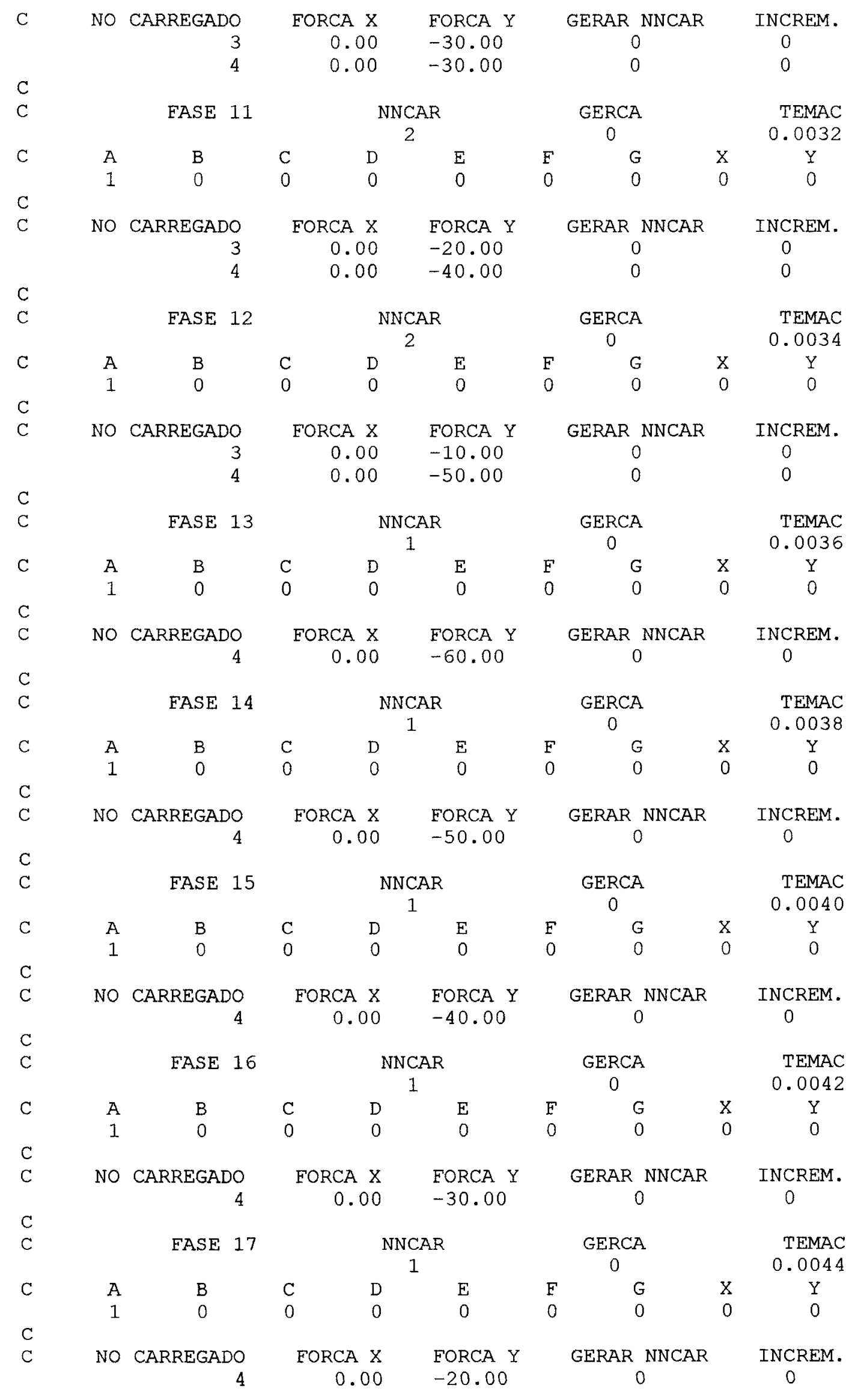




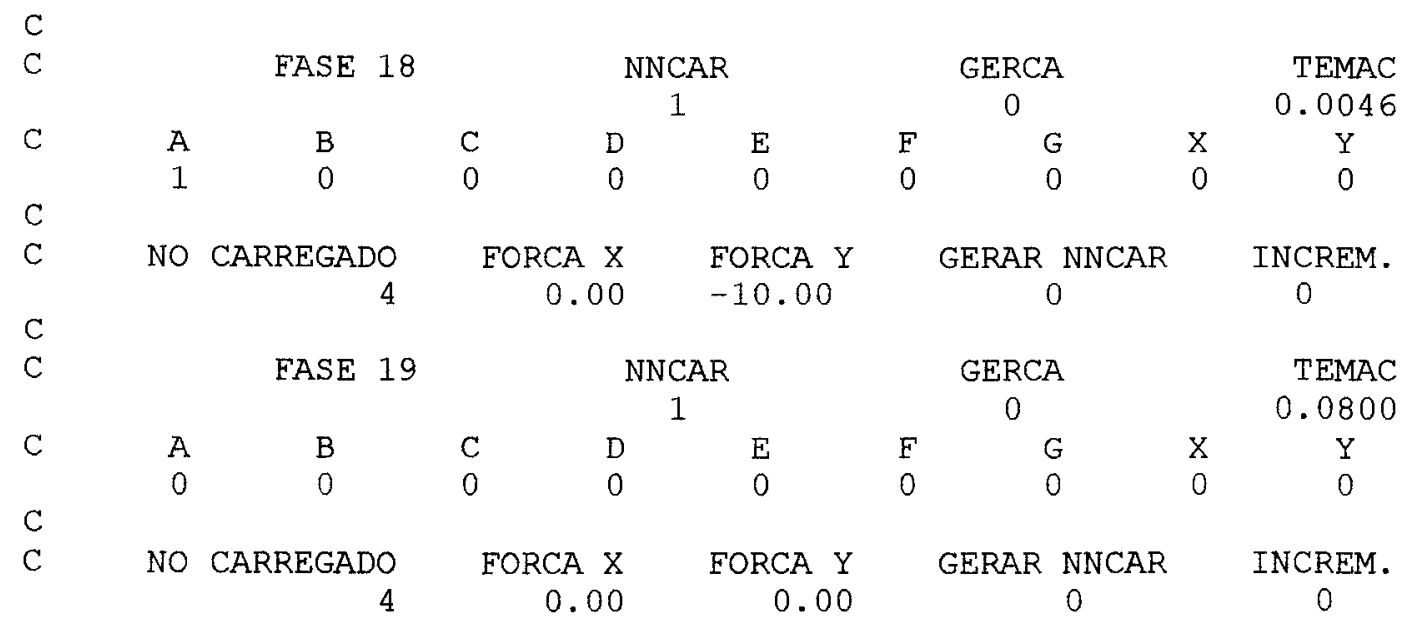

\section{TR025. TRE}

\begin{tabular}{|c|c|c|c|c|c|c|c|c|c|c|}
\hline \multicolumn{11}{|c|}{ 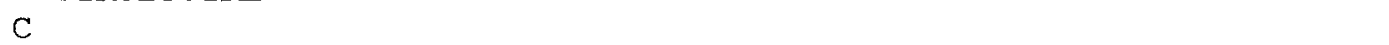 } \\
\hline C & \multicolumn{2}{|c|}{$\begin{array}{c}\text { NNODS } \\
8\end{array}$} & NELEM & \multicolumn{2}{|c|}{ NAPOS } & NMATE & GERNO & GEREL & & $\begin{array}{c}\text { NMASC } \\
0\end{array}$ \\
\hline & \multicolumn{2}{|c|}{ NLIFI } & $\begin{array}{c}13 \\
\text { REGEN }\end{array}$ & \multicolumn{2}{|c|}{$\begin{array}{c}2 \\
\text { NLIGE }\end{array}$} & & & \multicolumn{2}{|c|}{ TOLER } & \\
\hline & \multicolumn{2}{|c|}{1} & 1 & 1 & & 19 & 200 & $2 E-$ & -6 & $\begin{array}{c}\text { RESUI } \\
1\end{array}$ \\
\hline & \multirow{2}{*}{\multicolumn{2}{|c|}{$\begin{array}{c}\text { DINAM } \\
1\end{array}$}} & \multirow{2}{*}{$\begin{array}{c}\text { ITEMP } \\
400\end{array}$} & TEMPO & & NEWMA & AMORT & LAMB & & LAMBK \\
\hline & & & & $2 \mathrm{E}-$ & & 1 & 1 & 64.0 & & $1.39 E-4$ \\
\hline & & & & & & & & & & \\
\hline & & COORD & DEN. & ORIGEM & & QRAR & & COORDEN & & LIMITE \\
\hline & NO & x & & Y & & JODS & NCREM. & $x$ & & $Y$ \\
\hline & 1 & & .00 & 0.00 & & 4 & 1 & 800.00 & & 0.00 \\
\hline & 6 & 200. & .00 & 200.00 & & 2 & 1 & 600.00 & & 200.00 \\
\hline & & & & & & & & & & \\
\hline & & No & VINCU & LADO & & RESTRIC & CAO X & & REST & TRICAO Y \\
\hline & & & & 1 & & & 1 & & & \\
\hline & & & & 5 & & & 1 & & & \\
\hline & & & & & & & & & & \\
\hline & MATEF & $\begin{array}{r}\text { IIAL } \\
1\end{array}$ & $\begin{array}{r}\text { MOD. } \\
21\end{array}$ & $\begin{array}{l}\text { ELAST. } \\
000.00\end{array}$ & TEN. & $\begin{array}{r}\text { ESCOAM } \\
24.00\end{array}$ & PESO & $\begin{array}{l}\text { ESPEC. } \\
7.7 \mathrm{E}-5\end{array}$ & & $\begin{array}{r}\text { ENCRUAM. } \\
5000.00\end{array}$ \\
\hline & & & & & & & & & & \\
\hline & & & & & & TIPO & GERAR & INCF & REMF & IENTAR \\
\hline & ELEM. & NOI & NOF & ARE & & MAT. & NELEM & ELEM. & & NOI NOF \\
\hline & 1 & 1 & 2 & 1. & & 1 & 3 & 1 & & 1 \\
\hline & 5 & 6 & 7 & 1. & & 1 & 1 & 1 & & 1 \\
\hline & 7 & 1 & 6 & 1. & & 1 & 1 & 1 & & 1 \\
\hline & 9 & 4 & 7 & 1. & & 1 & 1 & 1 & & 1 \\
\hline & 11 & 2 & 6 & 1. & & 1 & 2 & 1 & & 1 \\
\hline & & & & & & & & & & \\
\hline & & FAS & $\mathrm{SE} 1$ & & $\mathrm{NNCAF}$ & & GER & $\mathrm{CA}$ & & TEMAC \\
\hline & & & & & 1 & & 0 & & & 0.0012 \\
\hline & A & B & & $\mathrm{C}$ & D & $\mathrm{E}$ & $\mathrm{E}$ & G & $\mathrm{x}$ & $\mathrm{Y}$ \\
\hline & 0 & 500 & & 0 & 0 & 0 & 0 & 0 & 0 & 0 \\
\hline & & & & & & & & & & \\
\hline & NO & CARREG & $\begin{array}{r}\text { GADO } \\
2\end{array}$ & $\begin{array}{r}\text { FORCA } \\
0.0\end{array}$ & & $\begin{array}{l}\text { FORCA Y } \\
-10.00\end{array}$ & GERA & $\begin{array}{c}\text { IR NNCAR } \\
0\end{array}$ & & $\begin{array}{c}\text { INCREM. } \\
0\end{array}$ \\
\hline & & & & & & & & & & \\
\hline & & EAS & SE 2 & & $\mathrm{NNCAI}$ & & GER & & & TEMAC \\
\hline & & & & & 2 & & 0 & & & 0.0014 \\
\hline & A & B & & C & D & $E$ & $\mathrm{~F}$ & G & $\mathrm{X}$ & $Y$ \\
\hline & 1 & 0 & & 0 & 0 & 0 & 0 & 0 & 0 & 0 \\
\hline
\end{tabular}




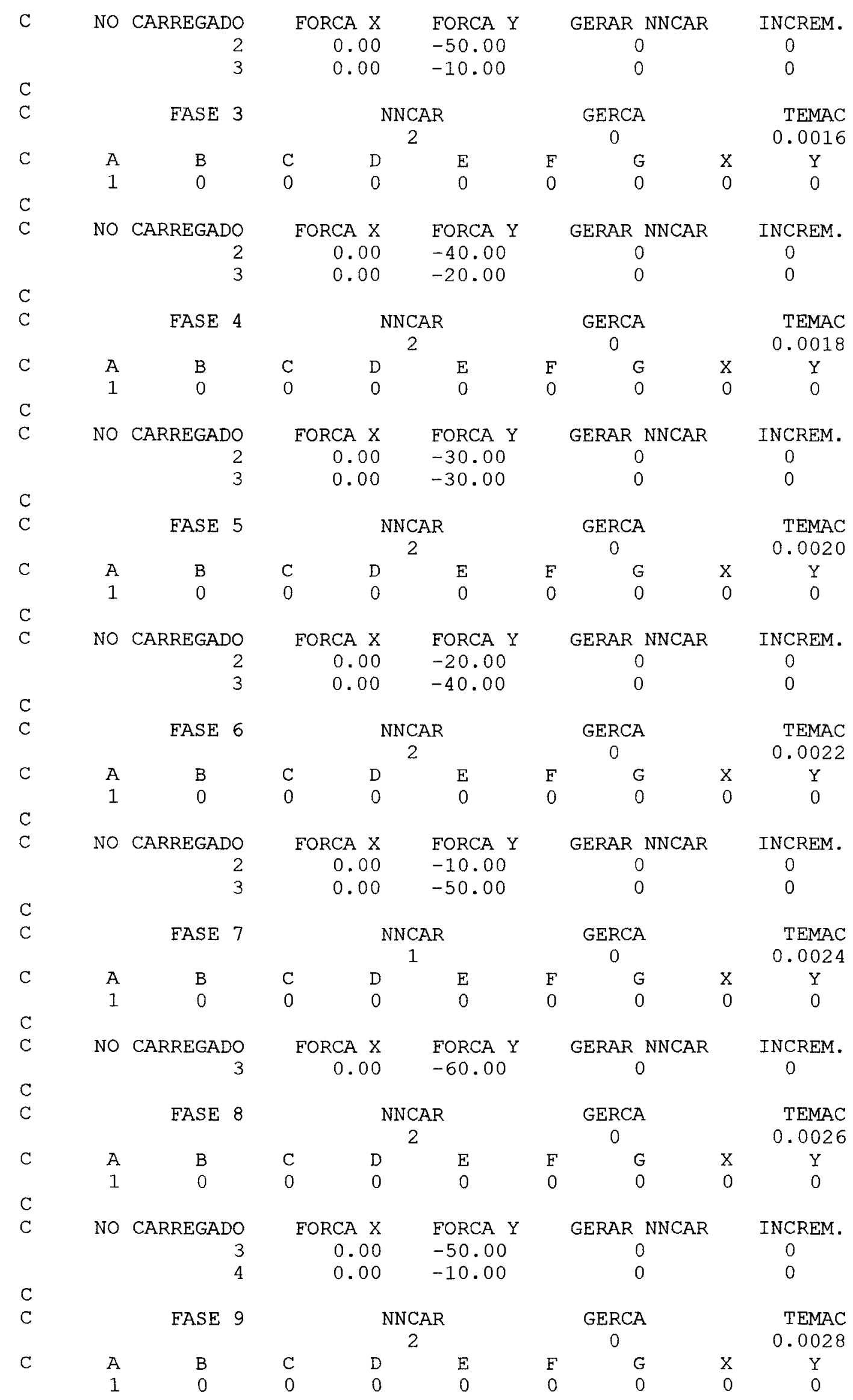




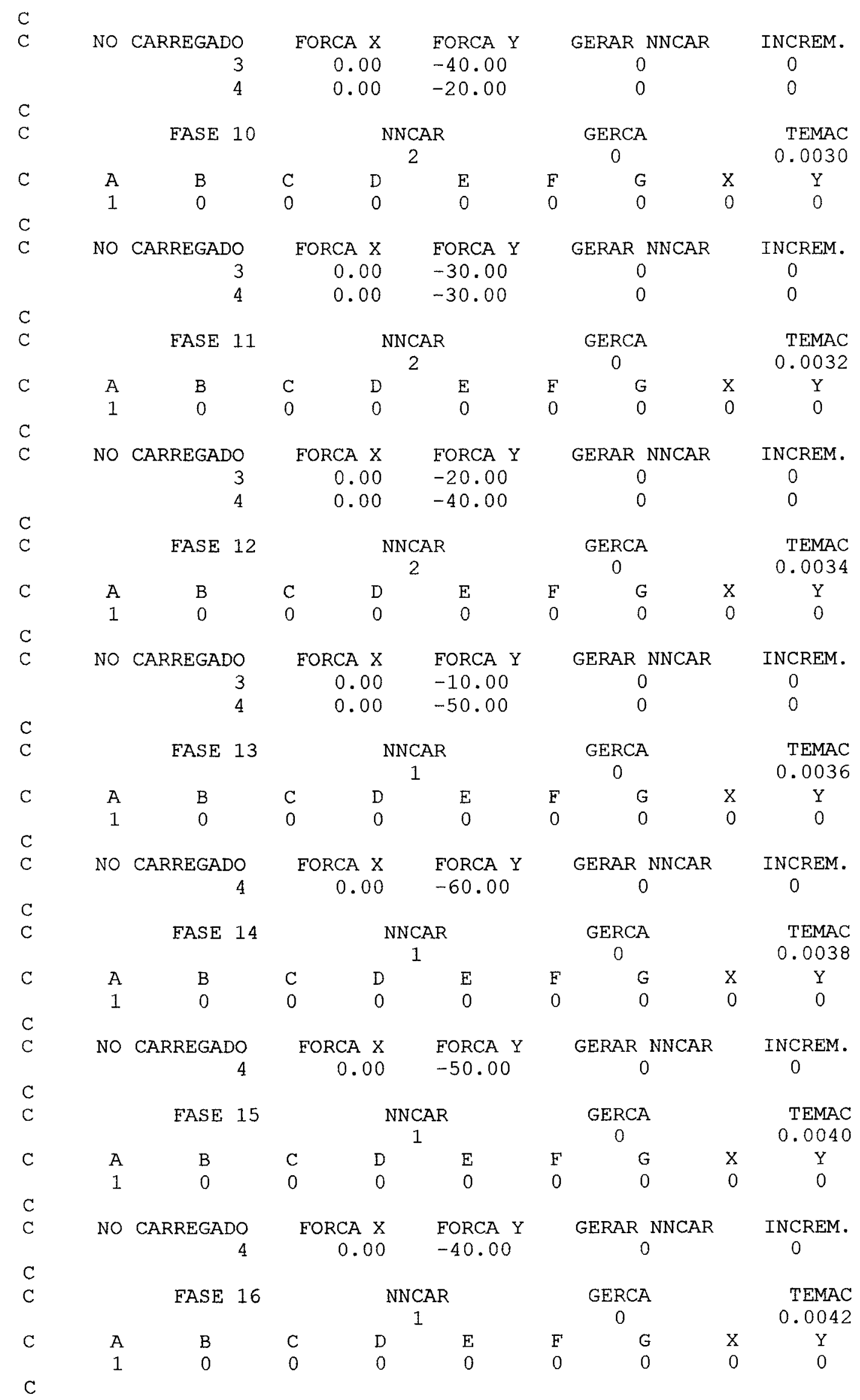




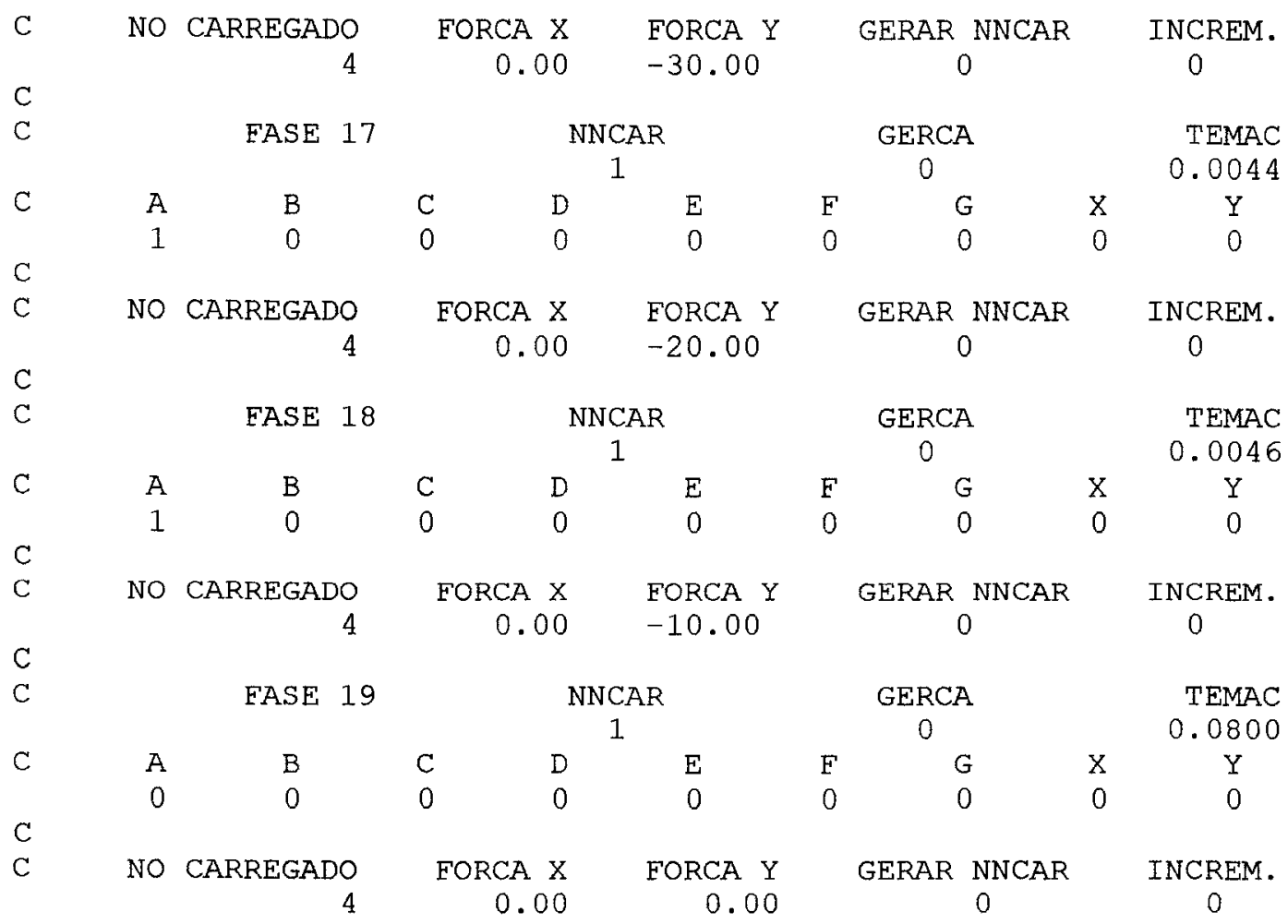

\section{A. 3 - Estruturas aporticadas}

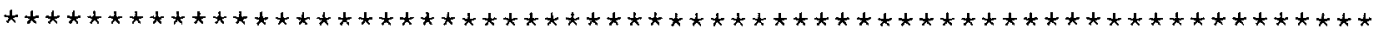

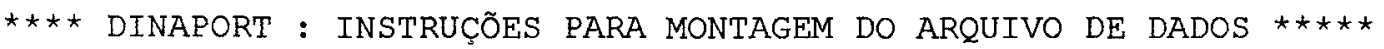

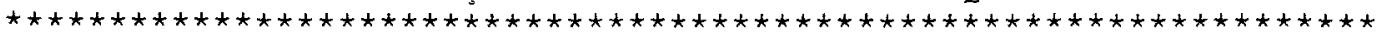

01- o nome do arquivo de dados deve ser do tipo aaaPoccc.Por, onde "aaa" é o número do projeto e "ccc" é o número do pórtico. Os arquivos criados pelo programa são os seguintes:

$>$ aaAPCCC. $\mathrm{DAD}=$ contém lista de dados lidos para relatório.

$>$ aaAPOCCC.RES = contém resultados finais.

02- A primeira linha do arquivo deve conter o título do pórtico.

03- As linhas de comentário devem ser iniciadas com a letra "C".

04- A disposição do arquivo deve ser mantida com o formato exposto, respeitando-se a quantidade de linhas de comentário.

05- Os valores das variáveis devem ser colocados abaixo das mesmas, devendo ser separados por espaços em branco, sendo que a unidade padrão e " $k N^{\prime}$ para força e " $\mathrm{cm}$ " para comprimento.

06- Significado das variáveis do primeiro bloco de dados:

$>$ PONTOS NODAIS........... NNODS (máx=MaxNNos)

$>$ NÚMERO DE ELEMENTOS........ NELEM (máx=MaxElem)

$>$ NÓS VINCULADOS.......... NAPOS (máx=MaxNNos)

$>$ MATERIAIS DIFERENTES...... NMATE (máx=NTM)

$>$ GERAÇÃO DE NÓS........... = GERNO (1 ativada - 0 desativada)

$>$ GERAÇÃO DE ELEMENTOS........ GEREL (1 ativada - 0 desativada)

$>$ NÚM. NÓS C/ PESOS CONCENT..= NMASC (máx=MaxNNos)

07- Significado das variáveis do segundo bloco de dados:

$>$ NÃO-LINEARIDADE FISICA.... = NLIFI ( 1 ativada - 0 desativada)
} 
$>$ MODELO FISSICO............. MOEIS 2 = Branson $\mathrm{p} / \mathrm{NLIFI}=1$ )

$>$ NÃO-LINEARIDADE GEOMÉTRICA. $=$ NLIGE

$>$ NÚMERO DE EASES DE CARREG. . = NEACA

$>$ NÚMERO DE ITERAÇÕES. . . . . . NITER

$>$ TOLERÂNCIA DO RESÍDUO...... = TOLER Ção da convergência - minimizar o resíduo

$>$ IMPRESSÃO RESULTADOS FINAIS= RESUL $(0 \mathrm{p} /$ desloc. e esforços, 1 somente $\mathrm{p} /$ deslocamentos e 2 somente $\mathrm{p} /$ esforços)

08 - Significado das variáveis do terceiro bloco de dados:

$>$ CÁLCULO DINÂMICO.......... DINAM ( 1 ativado - 0 desativado)

$>$ NÚMERO DE INTERVALOS TEMPO.= ITEMP (máx=Capac. Disco Rígido)

> VALOR INTERVALO TEMPO...... TEMPO (intervalo de tempo para a integração numérica)

$>$ PARAMETROS DE NEWMARK...... NEWMA (Parâmetros de Newmark : NEWMA $=0 \mathrm{p} / \mathrm{DINAM}=0$ e NEWMA $=1 \mathrm{p} / \mathrm{Beta}=1 / 6$ e Gama $=1 / 2$ ou $N E W M A=2$ $\mathrm{p} /$ Beta=1/4 e Gama=1/2 ou NEWMA=3 p/ Beta=1/12 e Gama=1/12 p/ DINAM $=1$ )

$>$ AMORTECIMENTO VISCOSO...... AMORT (1 ativado - 0 desativado, sendo que para $A M O R T=1$ deve-se ter DINAM=1)

$>$ AMORTECIMENTO PROP. MASSAS.= LAMBM (proporção matriz massas)

$>$ AMORTECIMENTO PROP. RIGIDEZ= LAMBK (proporção matriz rigidez)

09- Significado das variáveis do quarto bloco de dados:

$>$ A numeração dos nós deve ser sequièncial, devendo começar pela unidade.

$>$ GERNO = 0 (geração de nós desativada) :

- fornecer os dados das três primeiras colunas;

- o número de linhas introduzidas deve ser igual a "NNODS".

$>$ GERNO $=1$ (geração de nós ativada) :

- fornecer os dados de todas as colunas;

- a quantidade de nós criados por linha é igual a [(GERAR NNODS) $+1]$, sendo que a soma dos nós criados por todas as linhas deve ser igual a "NNODS";

- o incremento na numeração dos nós é dado por [INCREM.];

as coordenadas finais dos nós gerados são dadas por [COORDEN. IIMITE].

10- Significado das variáveis do quinto bloco de dados:

$>$ o número de nós vinculados a serem introduzidos deve ser igual a "NAPOS".

$>$ As restrições nodais são dadas por:

- "0" = nó liberado para se deslocar na direção em questão;

- "1" = nó impedido de se deslocar na direção em questão.

11- Significado das variáveis do sexto bloco de dados:

$>$ M. ELAS. CONCR. = módulo elasticidade do concreto;

$>$ PESO ESP. ...... peso específico em $\mathrm{kN} / \mathrm{cm}^{3}$;

$>$ Fck............ resistência do concreto à compressão;

$>$ Fctk.......... resistência do concreto à tração;

$>$ M. ELAS. AÇO.... = módulo elasticidade da armadura p/ NLIFI=1.

12- Significado das variáveis do sétimo bloco de dados:

$>$ A numeração dos elementos deve ser sequiêncial, devendo começar pela unidade.

$>$ A numeração do NOI deve ser sempre menor que do NOF.

$>$ LAR. = largura da seção transversal do elemento;

$>$ ALT. = altura da seção transversal do elemento;

$>\mathrm{TM}=$ tipo do material descrito no item 11;

$>$ GEREL $=0$ (geração de elementos desativada) :

- fornecer os dados das seis primeiras colunas;

- o número de linhas introduzidas deve ser igual a "NELEM".

$>$ GEREL $=1$ (geração de elementos ativada) :

- fornecer os dados das dez primeiras colunas;

- a quantidade de elementos criados por linha é igual a [EG+1], 
sendo que a soma dos elementos criados por todas as linhas deve ser igual a "NELEM";

- incremento na numeração dos elementos é dado por [INCREMEN NE];

- o incremento na numeração dos nós dos elementos gerados é dado por [INCREMEN NI NF].

$>\mathrm{NLIFI}=1$ (não-linearidade física ativada) :

- fornecer os dados da armadura do elemento;

- NBS = número de barras da camada superior que multiplica As;

- NBI = número de barras da camada inferior que multiplica AS;

- NC = número de camadas intermediárias, contendo duas barras com área individual AS;

- AS = valor da área da seção transversal de uma barra em " $\mathrm{cm}^{2}$ ";

- $d^{\prime}$ = valor do cobrimento da armadura superior e inferior.

- Exemplo:

LAR.

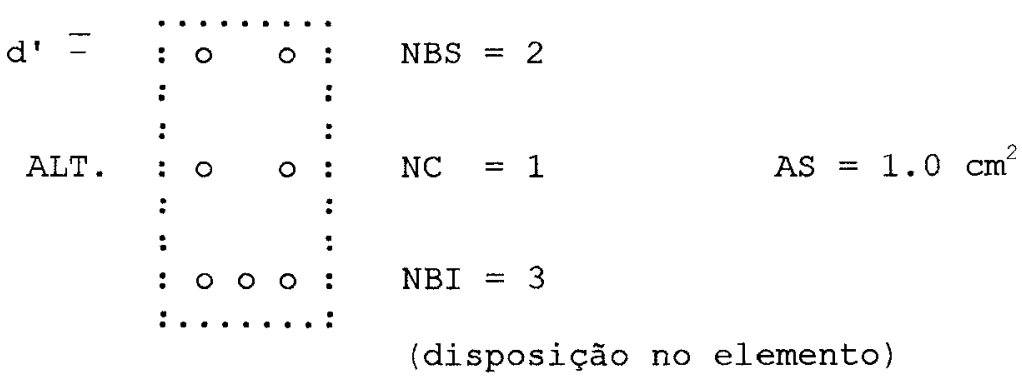

NOI

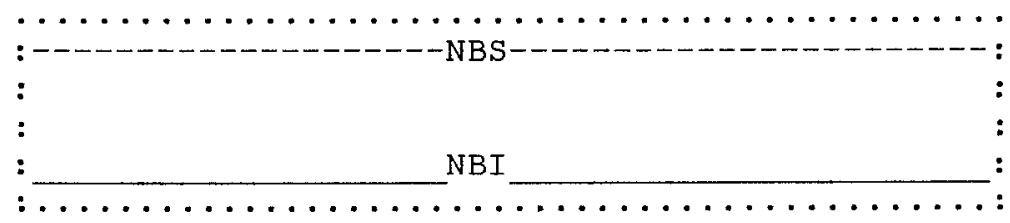

13- Significado das variáveis do oitavo bloco de dados:

$>$ Para cada fase de carregamento repetir a seqüência descrita a seguir.

$>$ NÓS CARREGADOS........... NNCAR (máx=MaxNNos)

$>$ GERAÇÃO DE CARREGAMENTOS... = GERCA ( 1 ativada - 0 desativada)

$>$ TEMPO PARA MUDANÇA DE FASE.= TEMAC (tempo final para mudança de fase de carregamento, maior que zerol

$>$ CONST. DA FUNÇÃO MULTIPLIC. $=A, B, C, D, E, F, G, X, Y$ (função mult. é definida por EPESO $=A+B * i *$ tempo $+C^{\star}(i * \text { tempo })^{\wedge} 2+D^{\star} \sin \left(E^{\star} i * t e m p o\right)+$ $F^{\star} \cos \left(G^{\star} i{ }^{*}\right.$ tempo $)+X^{\star} \exp \left(Y^{\star} i{ }^{\star}\right.$ tempo $)$, sendo " $i$ " $O$ contador de intervalos de tempo. Esta função multiplica os carreg. nodais)

$>$ FORÇA X da esquerda para a direita positivo;

FORÇA $Y$ de baixo para cima positivo;

VETOR MOMENTO $Z$ saindo do papel positivo.

$>$ GERCA $=0$ (geração de carregamentos desativada) :

- fornecer os dados das quatro primeiras colunas;

- o número de linhas introduzidas deve ser igual a "NNCAR".

$>$ GERCA $=1$ (geração de carregamentos ativada) :

- Eornecer os dados de todas as colunas;

- a quantidade de carregamentos criados por linha é igual a [(GERAR NNCAR) +1], sendo que a soma dos carregamentos criados por todas as linhas deve ser igual a "NNCAR";

- o incremento na numeração dos carregamentos é dado por [ INCREM. ] ;

14- Significado das variáveis do oitavo bloco de dados:

$>$ Este bloco é opcional, devendo ser introduzido se NMASC $>0$.

- fornecer os dados de todas as colunas;

- a quantidade de linhas introduzidas deve ser igual a "NMASC";

- PESO DIR. $X=$ fornecer o peso de qualquer objeto na direção $X$ 
em "kN", que está localizada no nó em questão;

- PESO DIR. Y = fornecer $\circ$ peso de qualquer objeto na direção $Y$ em "kN", que está localizada no nó em questão;

- este bloco só tem função quando DINAM=1.

OBSERVAÇÃO : A aceleração da gravidade é definida como:

GRAVI $=981,0 \mathrm{~cm} / \mathrm{s}^{2}$

400PO002. POR

$\mathrm{C}$

$\begin{array}{lrrrrrrr}\text { C } & \text { NNODS } & \text { NELEM } & \text { NAPOS } & \text { NMATE } & \text { GERNO } & \text { GEREL } & \text { NMASC } \\ & 2 & 1 & 1 & 1 & 0 & 0 & 0 \\ \text { C } & \text { NLIEI } & \text { REGEN } & \text { NLIGE } & \text { NFACA } & \text { NITER } & \text { TOLER } & \text { RESUL } \\ & 0 & 0 & 0 & 1 & 200 & 2 \text { E }-6 & 1 \\ \text { C } & \text { DINAM } & \text { ITEMP } & \text { TEMPO } & \text { NEWMA } & \text { AMORT } & \text { LAMBM } & \text { LAMBK } \\ & 1 & 80 & .5 E-4 & 1 & 0 & 0 & 0\end{array}$

C COORDEN. ORIGEM GERAR

$\begin{array}{rrrr}\text { C } & \text { NO } & X & Y \\ 1 & 0.00 & 0.00 \\ 2 & 200.00 & 0.00\end{array}$

NNODS

INCREM.

COORDEN .

LIMITE

.00

C

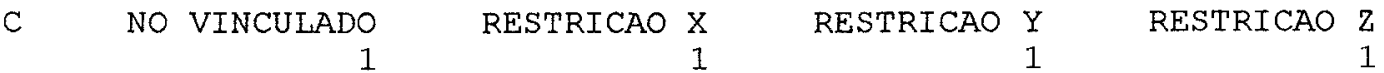

C

$\begin{array}{rrrrrr}\text { C MAT. } & \text { M. ELAS. CONCR. } & \text { PESO ESP. } & \text { FCk } & \text { FCtk } & \text { M. ELAS. ACO } \\ 1 & 21000.00 & 7.7 \mathrm{E}-5 & 0.0 & 0.00 & 21000.0\end{array}$

C

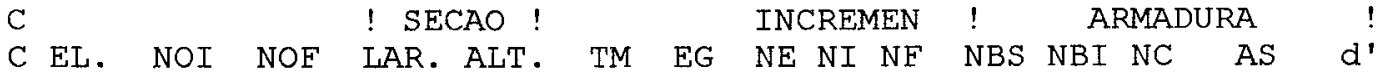

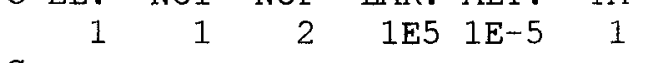

\begin{tabular}{|c|c|c|c|c|c|c|c|c|}
\hline \multirow[t]{2}{*}{ C } & \multirow{2}{*}{\multicolumn{2}{|c|}{ FASE 1}} & & & \multirow{2}{*}{\multicolumn{2}{|c|}{ GERCA }} & & \multirow{2}{*}{$\begin{array}{l}\text { TEMAC } \\
0.004\end{array}$} \\
\hline & & & & & & & & \\
\hline A & B & C & D & $\mathrm{E}$ & $F$ & G & $x$ & $\mathrm{Y}$ \\
\hline 1 & 0 & 0 & 0 & 0 & 0 & 0 & 0 & 0 \\
\hline
\end{tabular}

C NO FORCA $X$ FORCA $Y$ MOMENTO $Z$ GERAR NNCAR INCREM.

$$
2 \quad 10.00 \quad 0.00 \quad 0.00
$$

\section{PO003. POR}

$\mathrm{C}$

NNODS NELEM

C 13

12

NAPOS

NMATE

GERNO

GEREL NMASC

NLIGE

NEACA

1

$\begin{array}{rr}1 & 0\end{array}$

C DINAM

ITEMP TEMPO

$80 \quad .3 \mathrm{E}-4$

$\begin{array}{rr}1 & 200 \\ \text { NEWMA } & \text { AMORT }\end{array}$

$2 \mathrm{E}-6$

RESUL

1

1

LAMBM

LAMBK

C COORDEN. ORIGEM GERAR

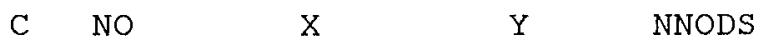

$1 \quad 0.00$

0.00

12

INCREM.

COORDEN .

LIMITE

C

C NO VINCULADO

RESTRICAO X

RESTRICAO Y

RESTRICAO Z 


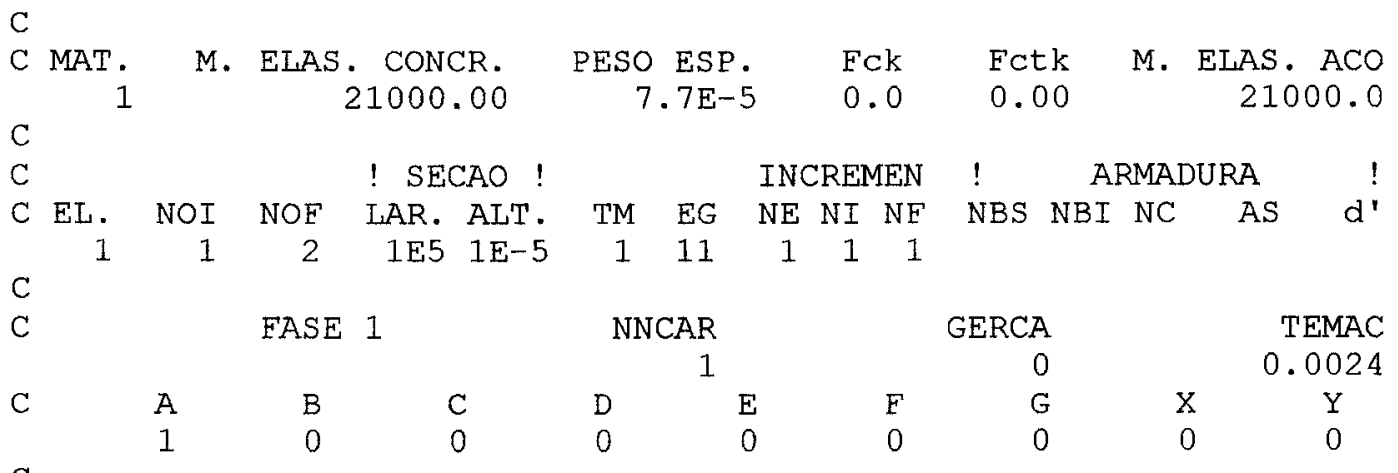

$\begin{array}{rrrrrr}\text { C } & & & & & \\ \text { NO } & \text { FORCA X } & \text { FORCA Y } & \text { MOMENTO Z } & \text { GERAR NNCAR } & \text { INCREM. } \\ & 13 & 10.00 & 0.00 & 0.00 & \end{array}$

\section{PO001. POR}

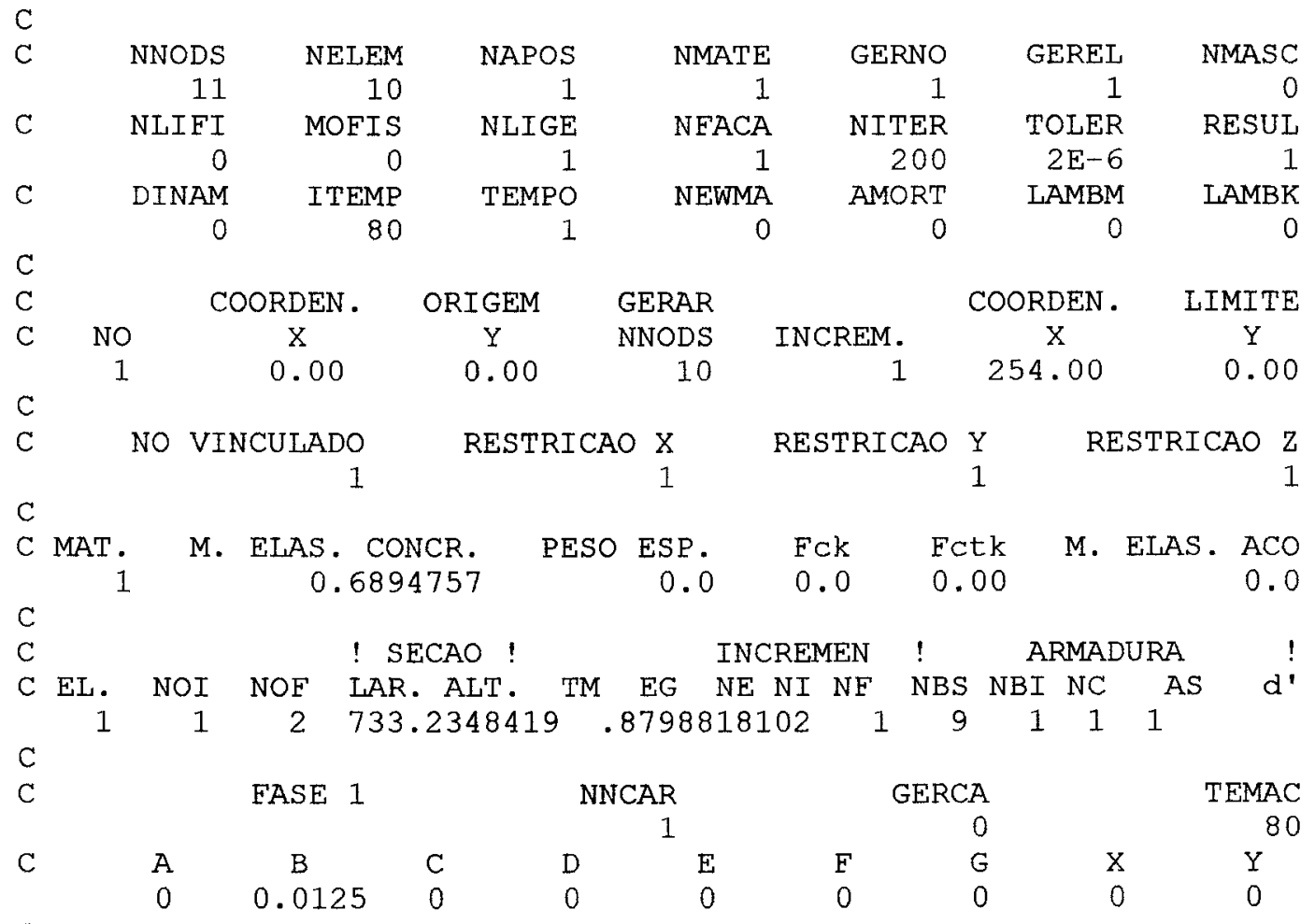

C NO FORCA $X$ FORCA $Y$ MOMENTO $Z$ GERAR NNCAR INCREM. $110.00-1.7792888 \mathrm{E}-3 \quad 0.00$

\section{PO001. POR}

$\mathrm{C}$

$\begin{array}{lrrrrrrr}\text { C } & \text { NNODS } & \text { NELEM } & \text { NAPOS } & \text { NMATE } & \text { GERNO } & \text { GEREL } & \text { NMASC } \\ & 19 & 18 & 2 & 1 & 1 & 1 & 0 \\ \text { C } & \text { NLIFI } & \text { MOEIS } & \text { NLIGE } & \text { NFACA } & \text { NITER } & \text { TOLER } & \text { RESUL } \\ & 0 & 0 & 1 & 1 & 200 & 2 \text { E- } & 1 \\ \text { C } & \text { DINAM } & \text { ITEMP } & \text { TEMPO } & \text { NEWMA } & \text { AMORT } & \text { LAMBM } & \text { LAMBK } \\ & 0 & 160 & 1 & 0 & 0 & 0 & 0 \\ \text { C } & & & & & & & \end{array}$




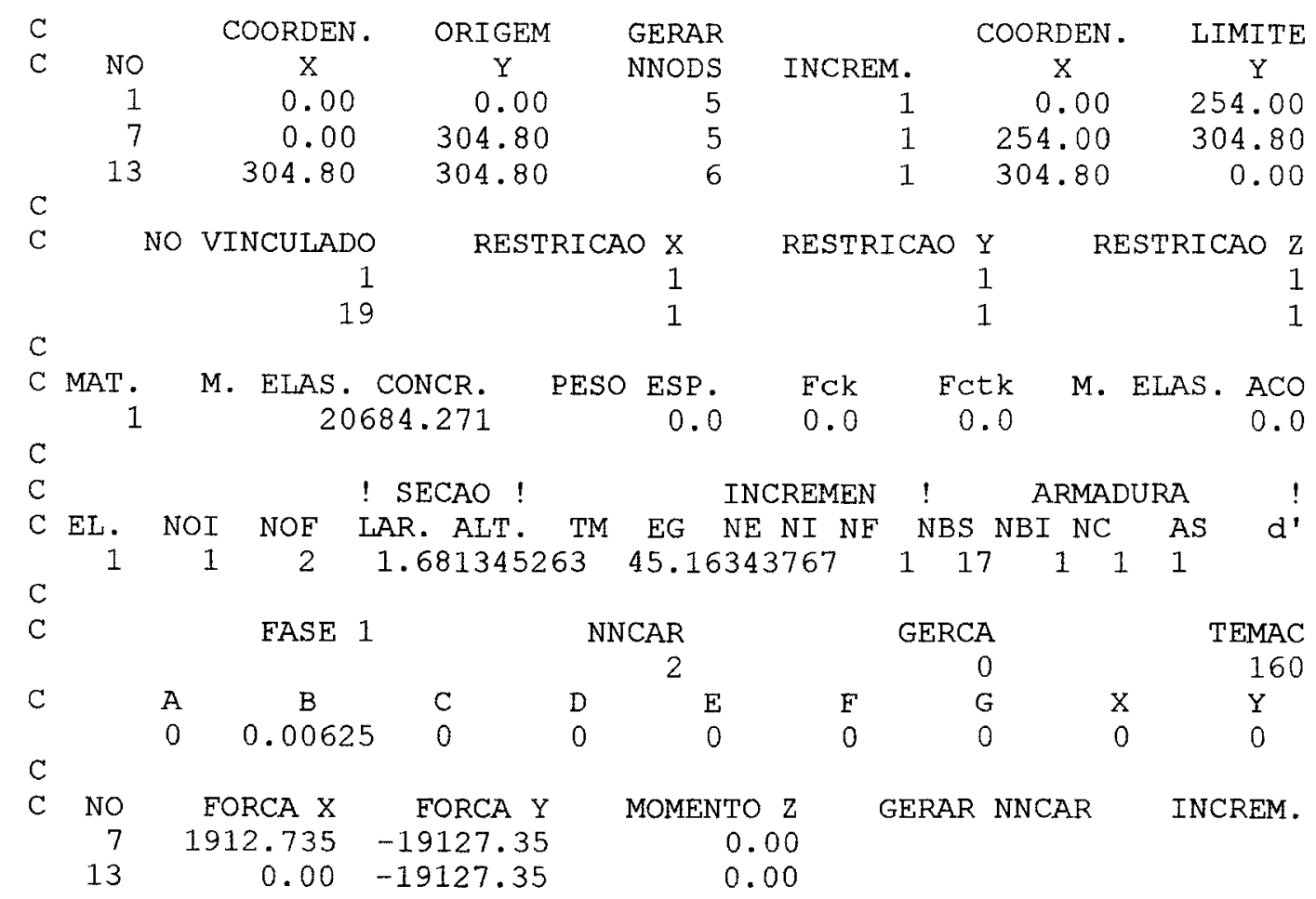

\section{PO002. POR}

C

$\begin{array}{lrrrrrrr}\text { C } & \text { NNODS } & \text { NELEM } & \text { NAPOS } & \text { NMATE } & \text { GERNO } & \text { GEREL } & \text { NMASC } \\ & 19 & 18 & 2 & 1 & 1 & 1 & 0 \\ \text { C } & \text { NLIFI } & \text { MOFIS } & \text { NLIGE } & \text { NFACA } & \text { NITER } & \text { TOLER } & \text { RESUL } \\ & 0 & 0 & 1 & 1 & 200 & 2 \mathrm{E}-3 & 1 \\ \mathrm{C} & \text { DINAM } & \text { ITEMP } & \text { TEMPO } & \text { NEWMA } & \text { AMORT } & \text { LAMBM } & \text { LAMBK } \\ & 0 & 160 & 1 & 0 & 0 & 0 & 0\end{array}$

\begin{tabular}{|c|c|c|c|c|c|c|}
\hline & COORDEN. & ORIGEM & GERAR & & COORDEN. & LIMITE \\
\hline NO & $\mathrm{x}$ & Y & NNODS & INCREM. & $x$ & $Y$ \\
\hline 1 & 0.00 & 0.00 & 5 & 1 & 0.00 & 254.00 \\
\hline 7 & 0.00 & 304.80 & 5 & 1 & 254.00 & 304.80 \\
\hline 13 & 304.80 & 304.80 & 6 & 1 & 304.80 & 0.00 \\
\hline
\end{tabular}

C NO VINCULADO RESTRICAO X RESTRICAO $Y$ RESTRICAO Z

$\begin{array}{rrrrr}1 & \text { RESTRICAO } & Y & \text { RESTRICAO Z } \\ 19 & 1 & 1 & 1 \\ & 1 & 1 & 1\end{array}$

C MAT. M. ELAS. CONCR. PESO ESP. FCk FCtk M. ELAS. ACO

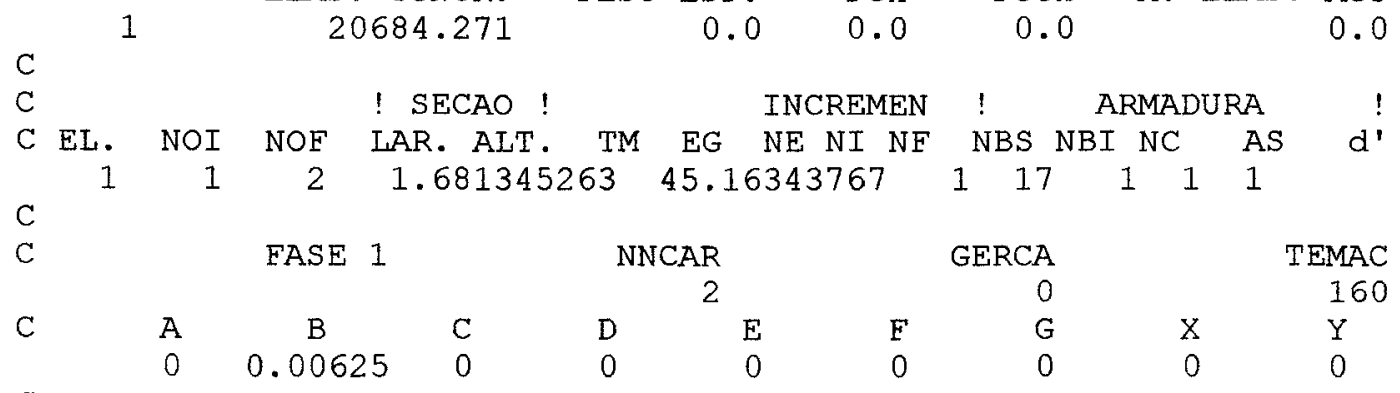

$\begin{array}{rrrrrr}\text { C } & \text { NO } & \text { FORCA X } & \text { FORCA Y } & \text { MOMENTO Z } & \text { GERAR NNCAR } \\ & 7 & 8229.21 & -16458.42 & 0.00 & \\ 13 & 0.00 & -16458.42 & 0.00 & \end{array}$ 


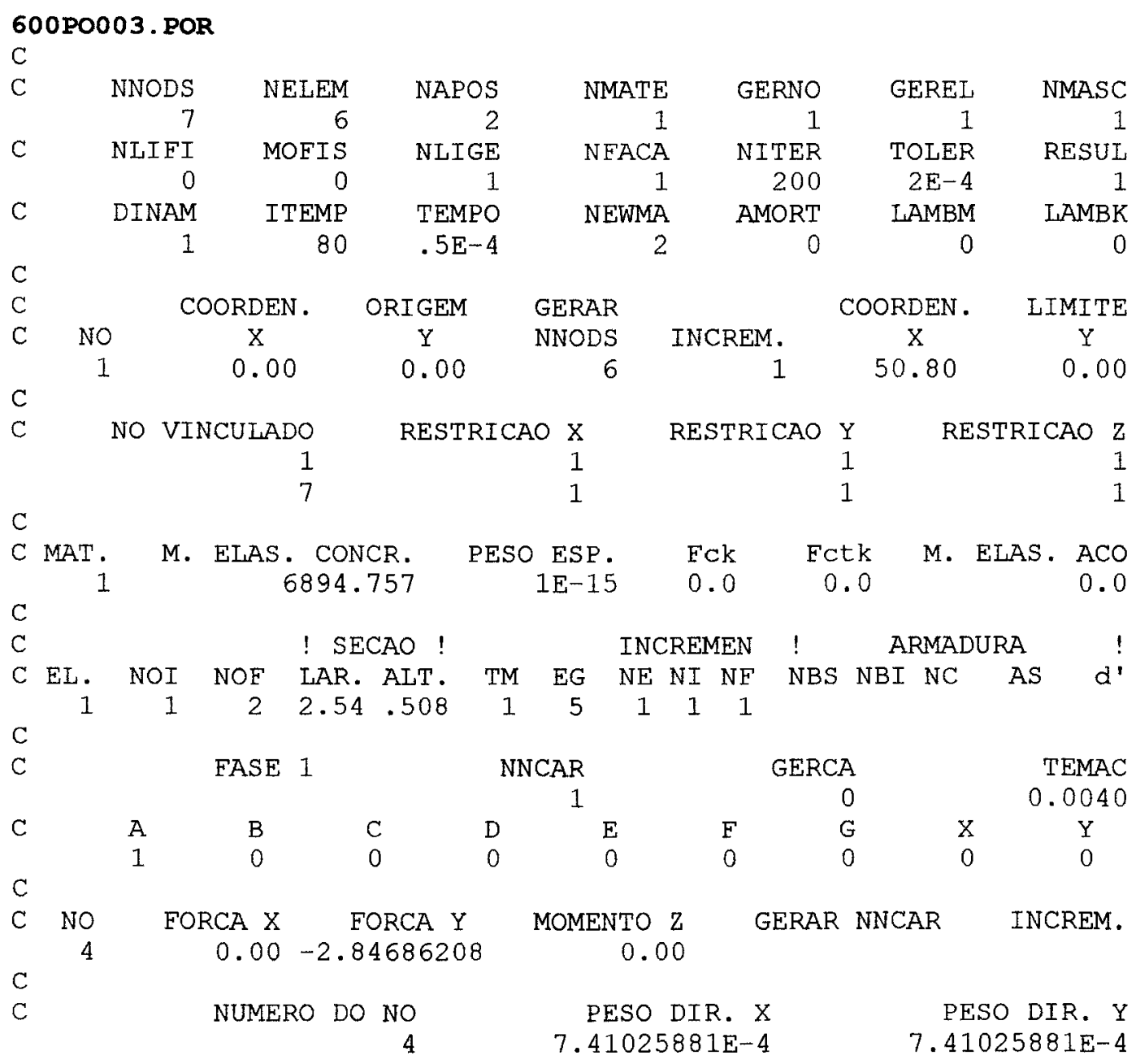

\section{PO004. POR}

$\mathrm{C}$

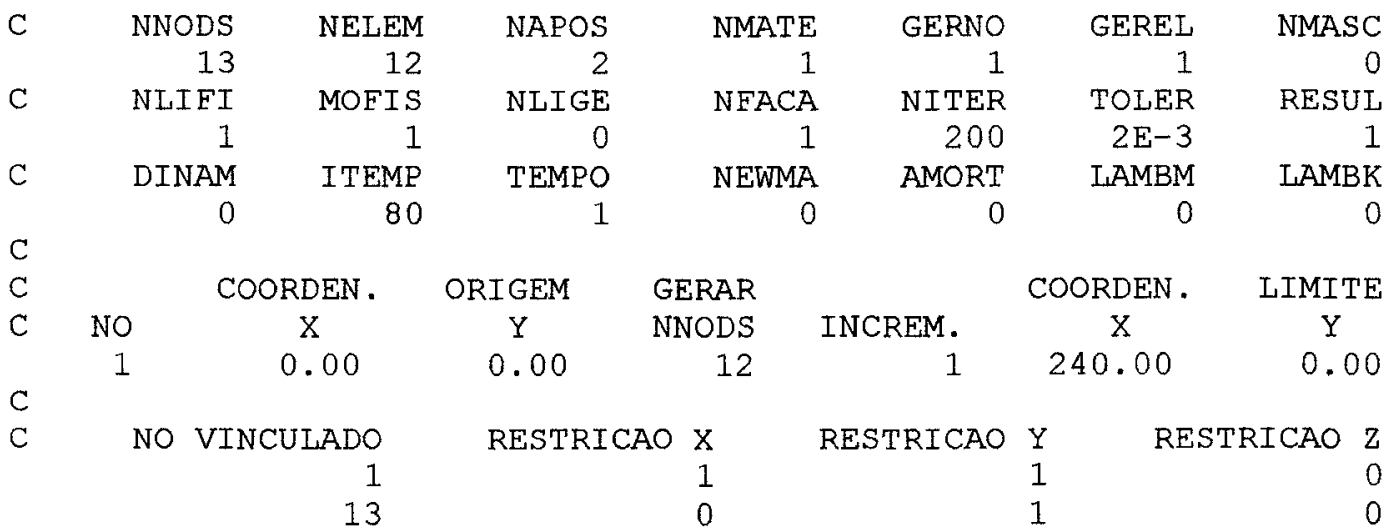
$C$
C MAT. M. ELAS. CONCR. PESO ESP. FCk FCtk M. ELAS. ACO $\begin{array}{llllll}1 & 2920.00 & 2.5 \mathrm{E}-5 & 2.6 & 0.268 & 19600.0\end{array}$

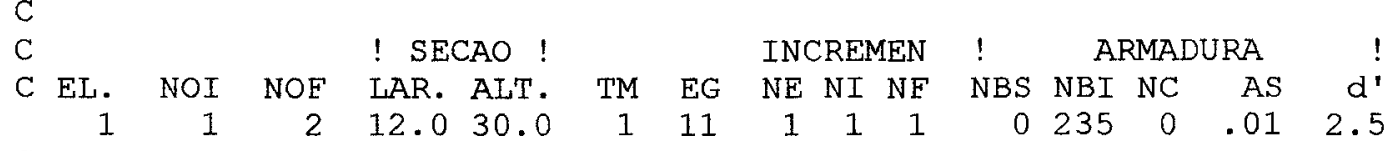 C 


\begin{tabular}{|c|c|c|c|c|c|c|c|}
\hline $\mathrm{C}$ & FASE 1 & & $\begin{array}{r}\text { NNCAR } \\
2\end{array}$ & GERC? & & & $\begin{array}{r}\text { TEMAC } \\
80\end{array}$ \\
\hline C & A & $\mathrm{C}$ & $\mathrm{E}$ & $\mathrm{F}$ & G & $\mathrm{X}$ & $Y$ \\
\hline & 0.0125 & 0 & 0 & 0 & 0 & 0 & 0 \\
\hline 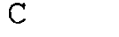 & & & & & & & \\
\hline $\begin{array}{r}\text { NO } \\
5 \\
9\end{array}$ & $\begin{array}{r}\text { FORCA X } \\
0.00 \\
0.00\end{array}$ & $\begin{array}{l}\text { FORCA Y } \\
-40.00 \\
-40.00\end{array}$ & $\begin{array}{r}\text { MOMENTO Z } \\
0.00 \\
0.00\end{array}$ & GERAR & NNCAR & & INCREM. \\
\hline
\end{tabular}

700PO005. POR

$\mathrm{C}$

$\begin{array}{lrrrrrrr}\text { C } & \text { NNODS } & \text { NELEM } & \text { NAPOS } & \text { NMATE } & \text { GERNO } & \text { GEREL } & \text { NMASC } \\ & 13 & 12 & 2 & 1 & 1 & 1 & 0 \\ \text { C } & \text { NLIFI } & \text { MOFIS } & \text { NLIGE } & \text { NEACA } & \text { NITER } & \text { TOLER } & \text { RESUL } \\ & 1 & 1 & 0 & 1 & 200 & 2 \mathrm{E}-3 & 1 \\ \text { C } & \text { DINAM } & \text { ITEMP } & \text { TEMPO } & \text { NEWMA } & \text { AMORT } & \text { LAMBM } & \text { LAMBK } \\ & 0 & 80 & 1 & 0 & 0 & 0 & 0\end{array}$

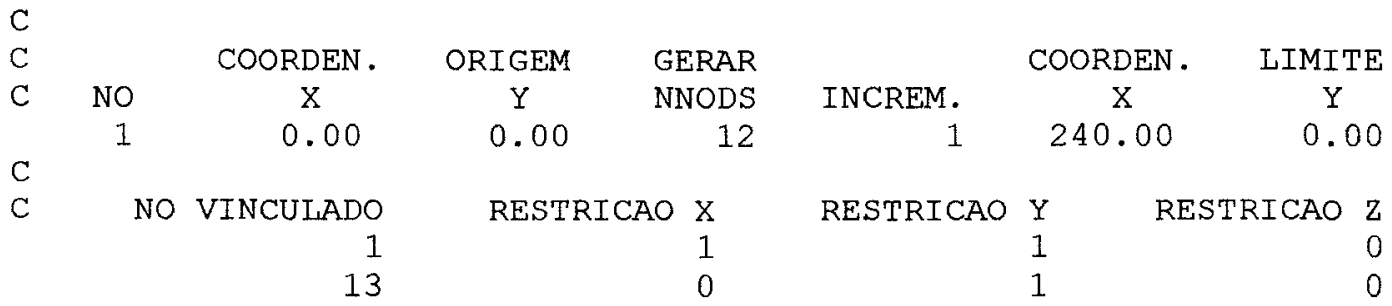

C MAT. M. ELAS. CONCR. PESO ESP. ECk ECtk M. ELAS. ACO

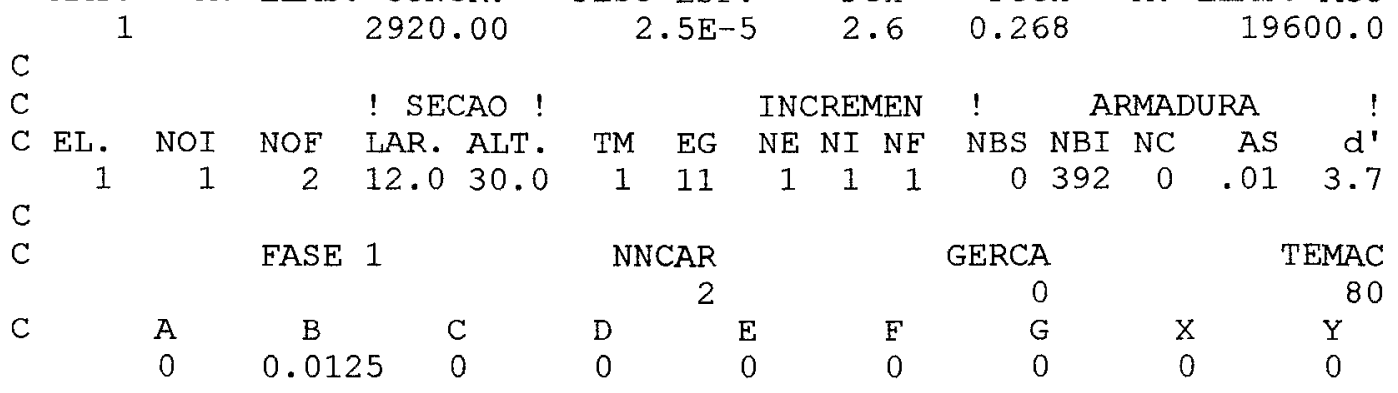

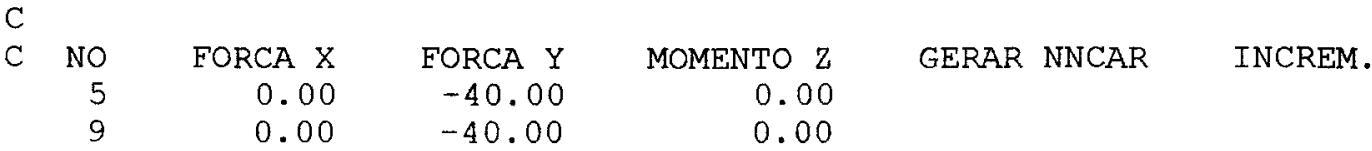

\section{PO006. POR}

C NNODS

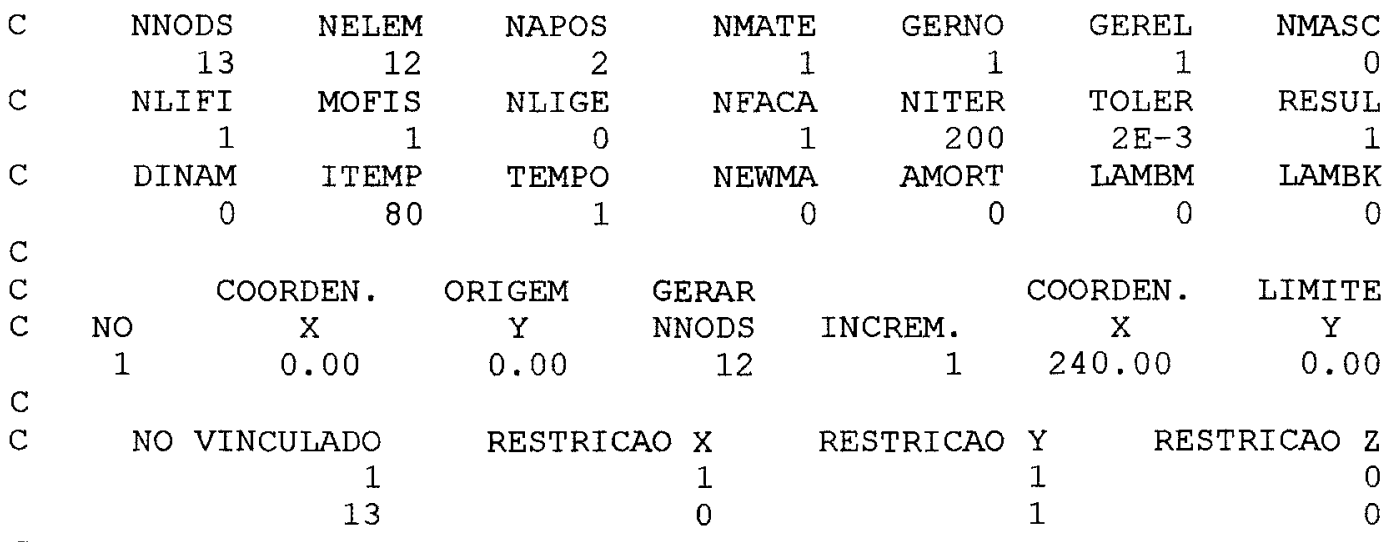

C 


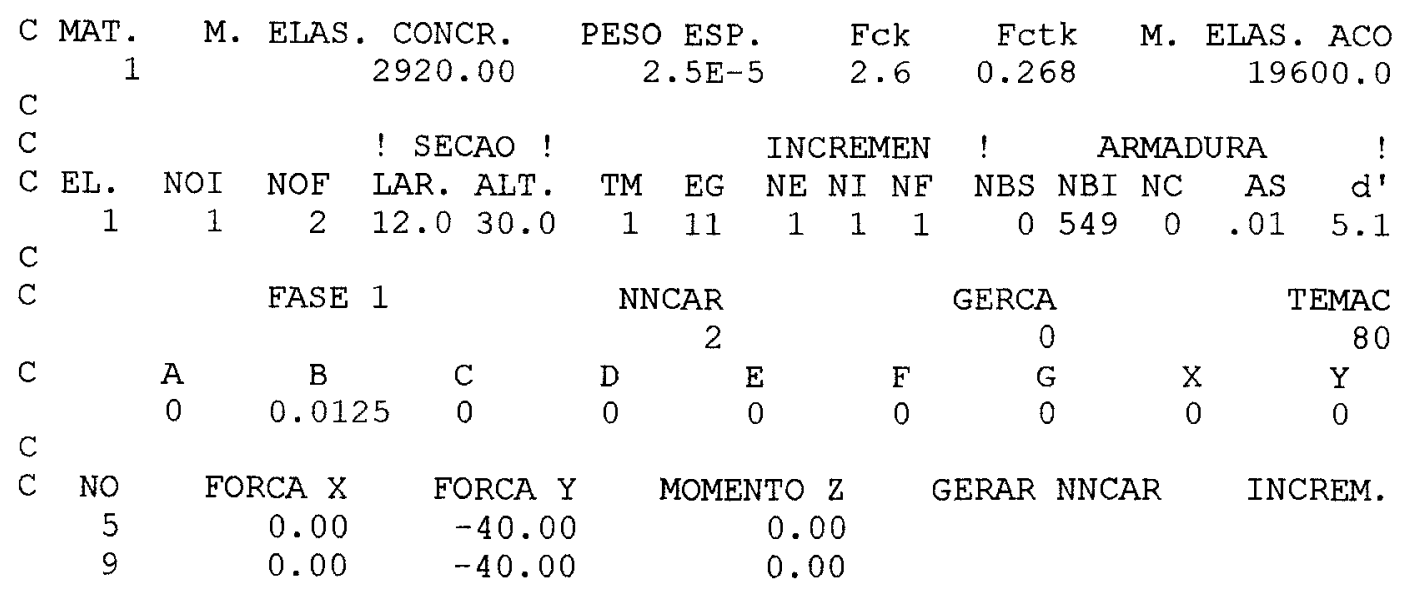

\section{P0007. POR}

C NNODS

13
C NLIFI

NELEM

NAPOS

NMATE

GERNO

GEREL NMASC

12
MOFIS

2

1
NFACA

1

TOLER

RESUL

DINAM

ITEMP 1

320

TEMPO

NEWMA

AMORT

IAMBK

C

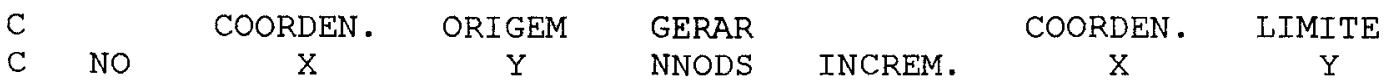

$\begin{array}{rrrrrrr}1 & 0.00 & 0.00 & 12 & 1 & 240.00 & 0.00\end{array}$

$\mathrm{C}$

NO VINCULADO

RESTRICAO $\mathrm{X}$

RESTRICAO Y

RESTRICAO Z

13

1
0

1
1

0

$\mathrm{C}$

C MAT. M. ELAS. CONCR. PESO ESP. FCk FCtk M. ELAS. ACO

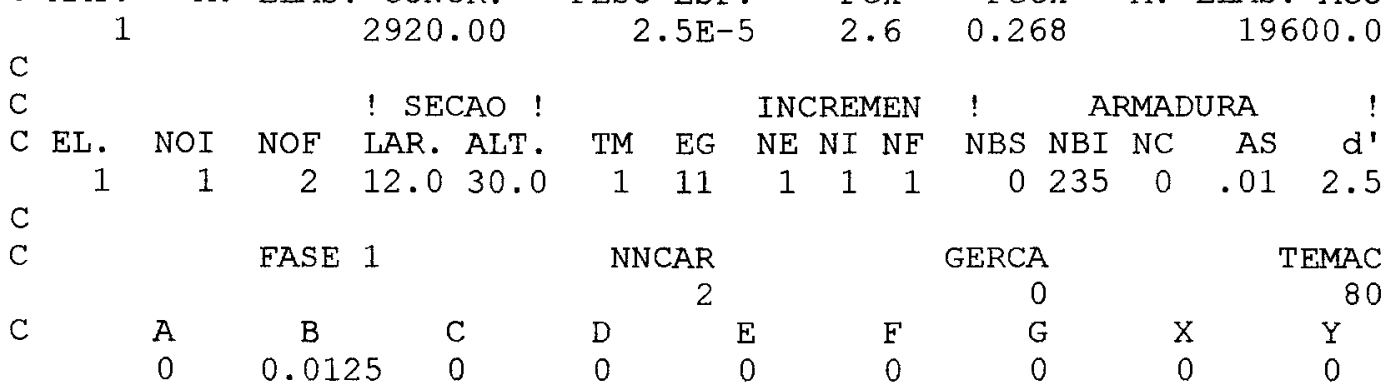

C

$\begin{array}{rrrrrr}\text { C NO } & \text { FORCA X } & \text { FORCA Y } & \text { MOMENTO Z } & \text { GERAR NNCAR } & \text { INCREM. } \\ 5 & 0.00 & -20.00 & 0.00 & & \\ 9 & 0.00 & -20.00 & 0.00 & \end{array}$

\begin{tabular}{|c|c|c|c|c|c|c|c|c|}
\hline C & \multicolumn{2}{|l|}{ FASE 2} & & & \multicolumn{2}{|c|}{ GERCA } & & TEMAC \\
\hline A & B & C & D & $\mathrm{E}$ & $\mathrm{F}$ & $\mathrm{G}$ & $\mathrm{X}$ & $Y$ \\
\hline 2 & -0.0125 & 0 & 0 & 0 & 0 & 0 & 0 & 0 \\
\hline
\end{tabular}

C NO FORCA X FORCA Y MOMENTO Z OOAR

$\begin{array}{rrrrrr}\text { C NO } & \text { FORCA X } & \text { FORCA Y } & \text { MOMENTO Z } & \text { GERAR NNCAR } & \text { INCREM. } \\ 5 & 0.00 & -20.00 & 0.00 & & \\ 9 & 0.00 & -20.00 & 0.00 & \end{array}$

$\begin{array}{llll}\mathrm{C} & \text { FASE } 3 & \text { GERCA } & \text { TEMAC }\end{array}$

$2 \quad 240$




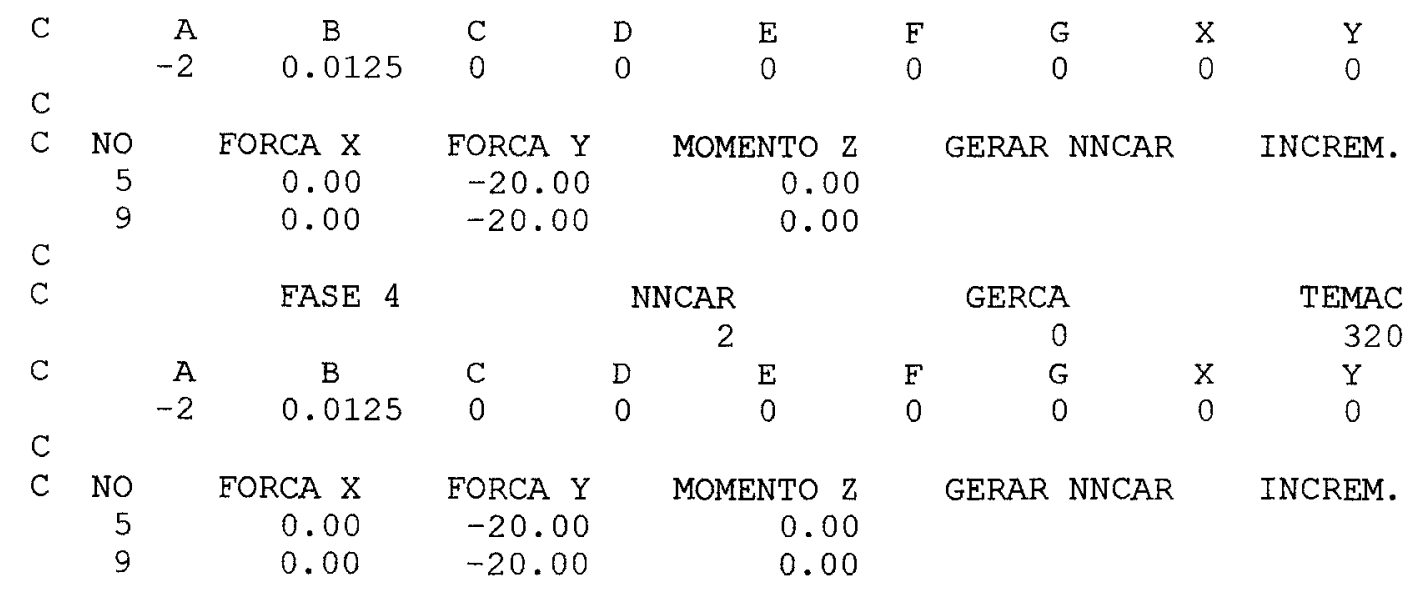

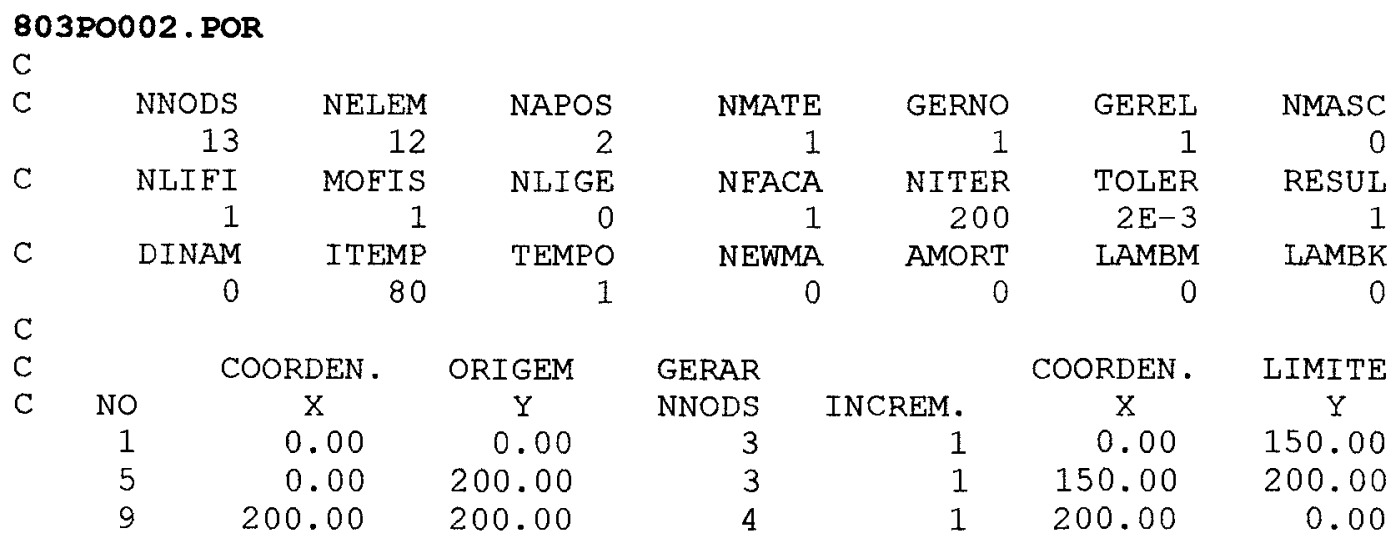

C NO VINCULADO RESTRICAO X RESTRICAO Y RESTRICAO Z

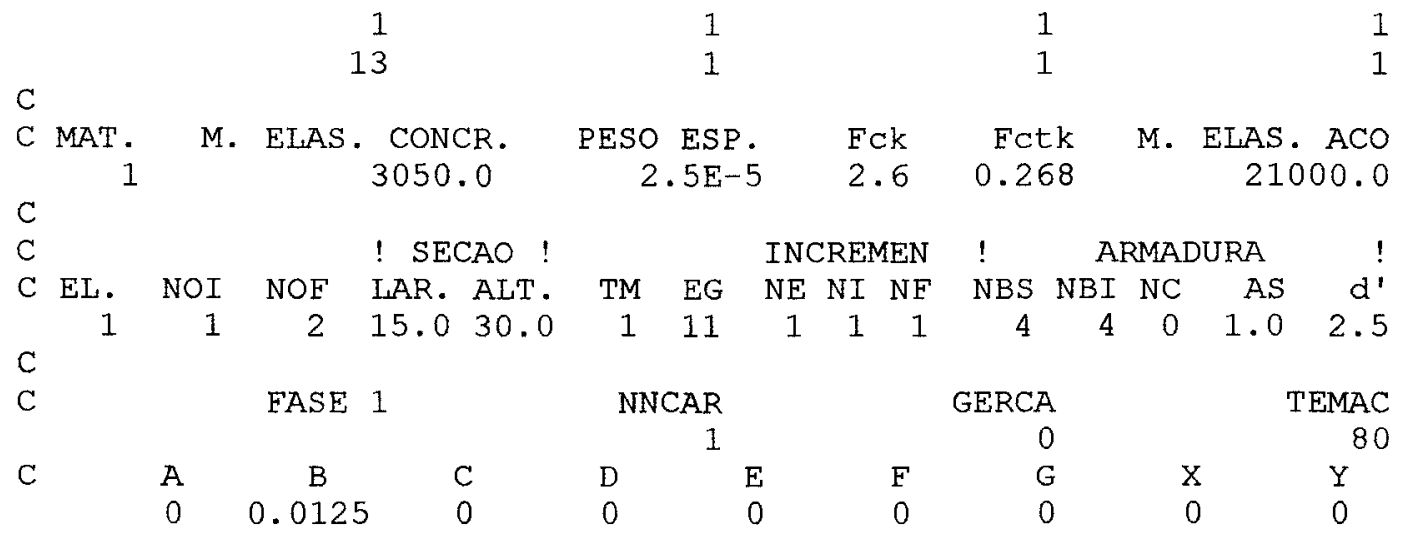

$\begin{array}{rrrrrr}C & \text { NO } & \text { FORCA X } & \text { FORCA Y } & \text { MOMENTO Z } & \text { GERAR NNCAR } \\ & 5 & 8.00 & 0.00 & 0.00 & \end{array}$

\section{P0006.POR}

C

$\begin{array}{lrrrrrrr}\text { C } & \text { NNODS } & \text { NELEM } & \text { NAPOS } & \text { NMATE } & \text { GERNO } & \text { GEREL } & \text { NMASC } \\ & 13 & 12 & 2 & 1 & 1 & 1 & 0 \\ \text { C } & \text { NLIFI } & \text { MOFIS } & \text { NLIGE } & \text { NFACA } & \text { NITER } & \text { TOLER } & \text { RESUL } \\ & 1 & 1 & 0 & 3 & 200 & 2 E-3 & 1 \\ \text { C } & \text { DINAM } & \text { ITEMP } & \text { TEMPO } & \text { NEWMA } & \text { AMORT } & \text { LAMBM } & \text { LAMBK } \\ & 1 & 240 & .4 E-3 & 2 & 0 & 0 & 0\end{array}$




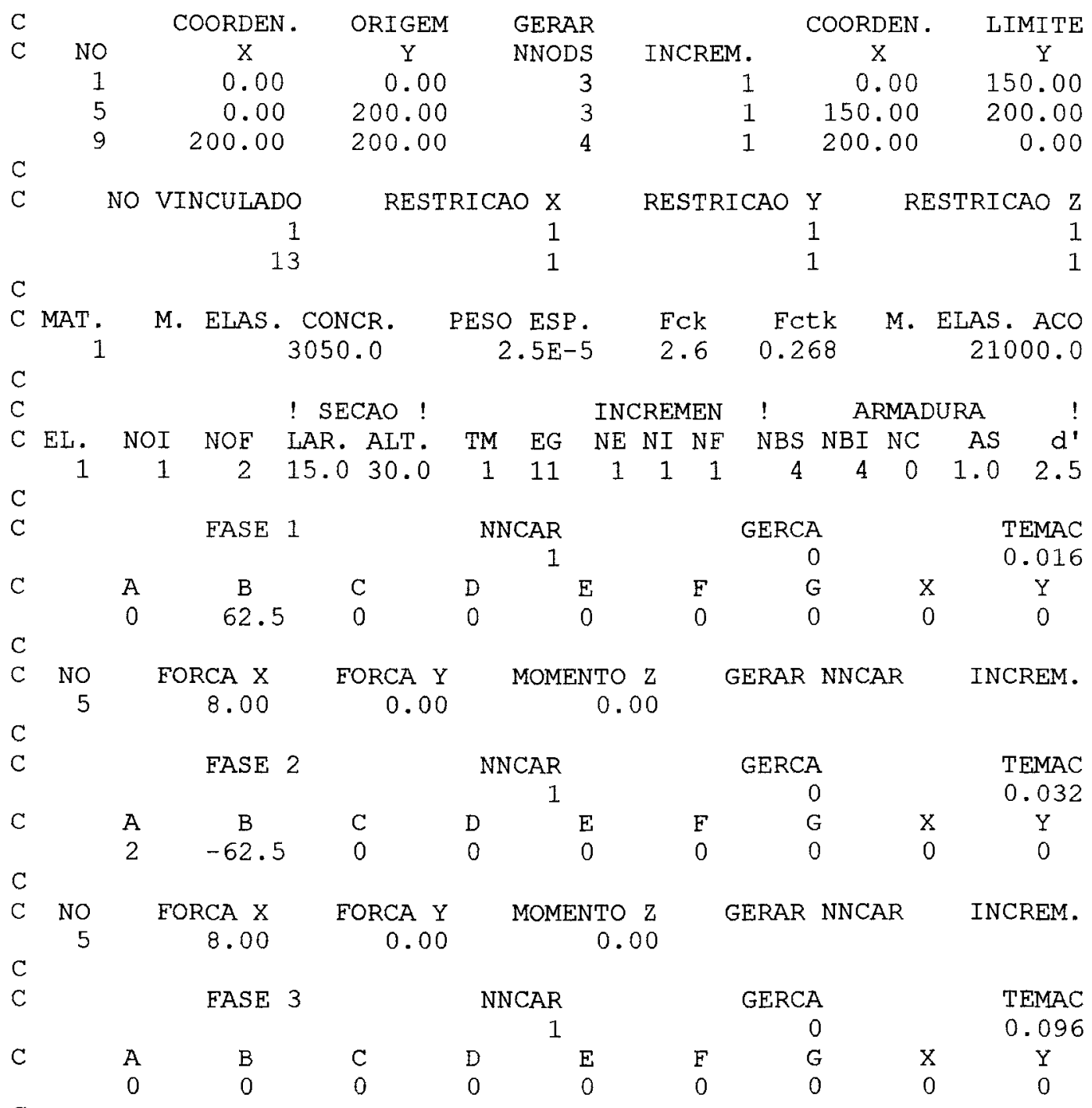

$\begin{array}{rrrrrr}\text { C NO } & \text { FORCA X } & \text { FORCA Y } & \text { MOMENTO Z } & \text { GERAR NNCAR } & \text { INCREM. } \\ & 5 & 0.00 & 0.00 & 0.00 & \end{array}$

\section{PO010. POR}

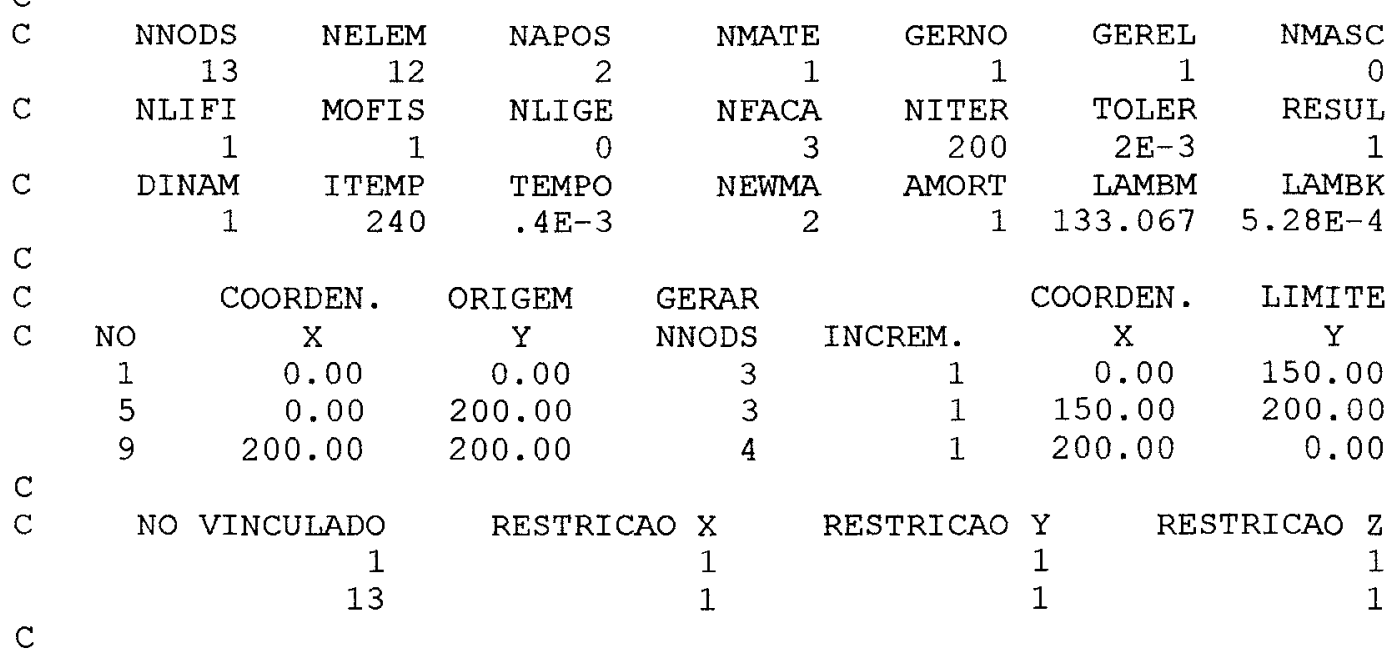




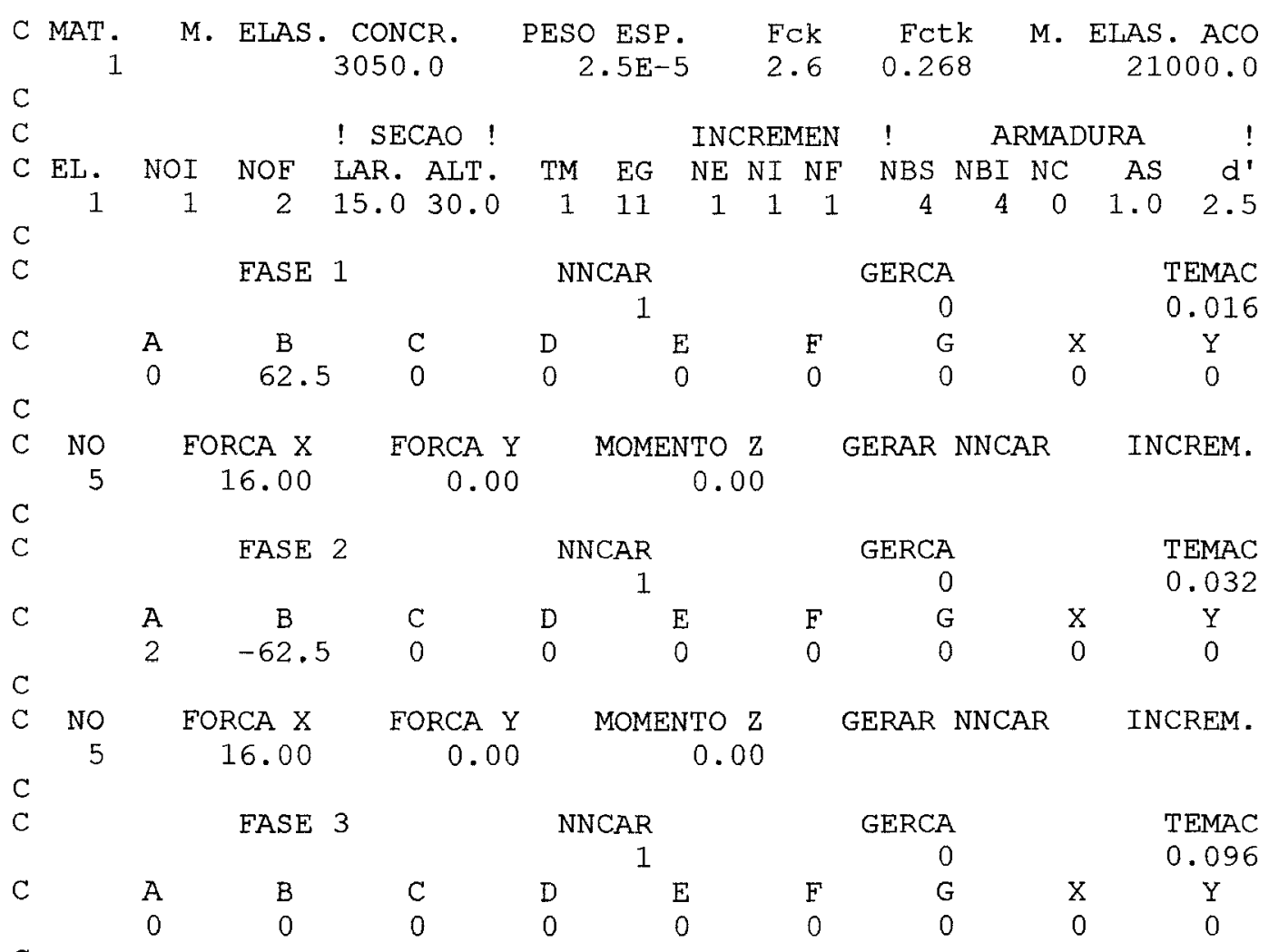

$\begin{array}{rrrrrr}\text { C } & & & & & \\ \text { C NO } & \text { FORCA X } & \text { FORCA Y } & \text { MOMENTO Z } & \text { GERAR NNCAR } & \text { INCREM. } \\ & 5 & 0.00 & 0.00 & 0.00 & \end{array}$

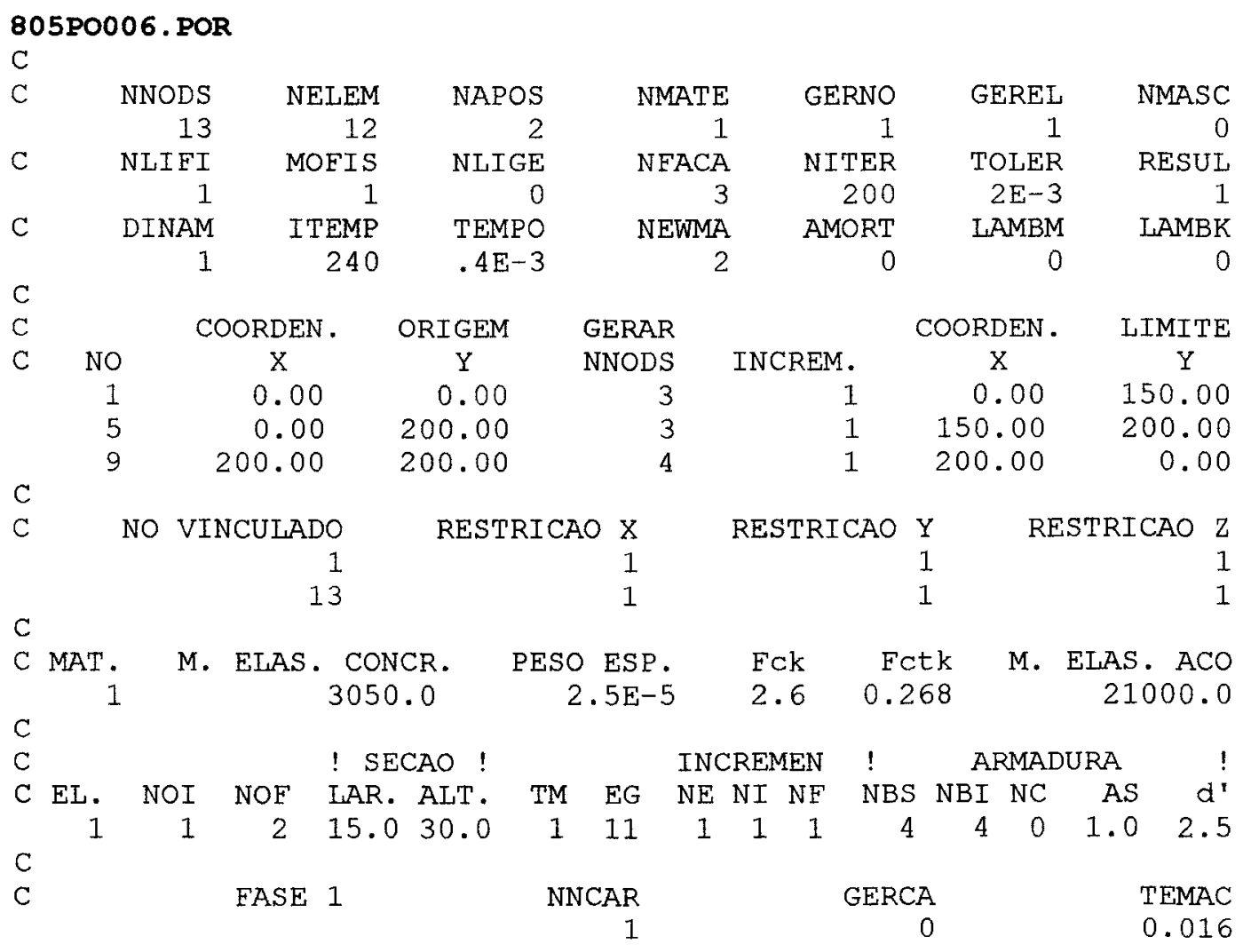




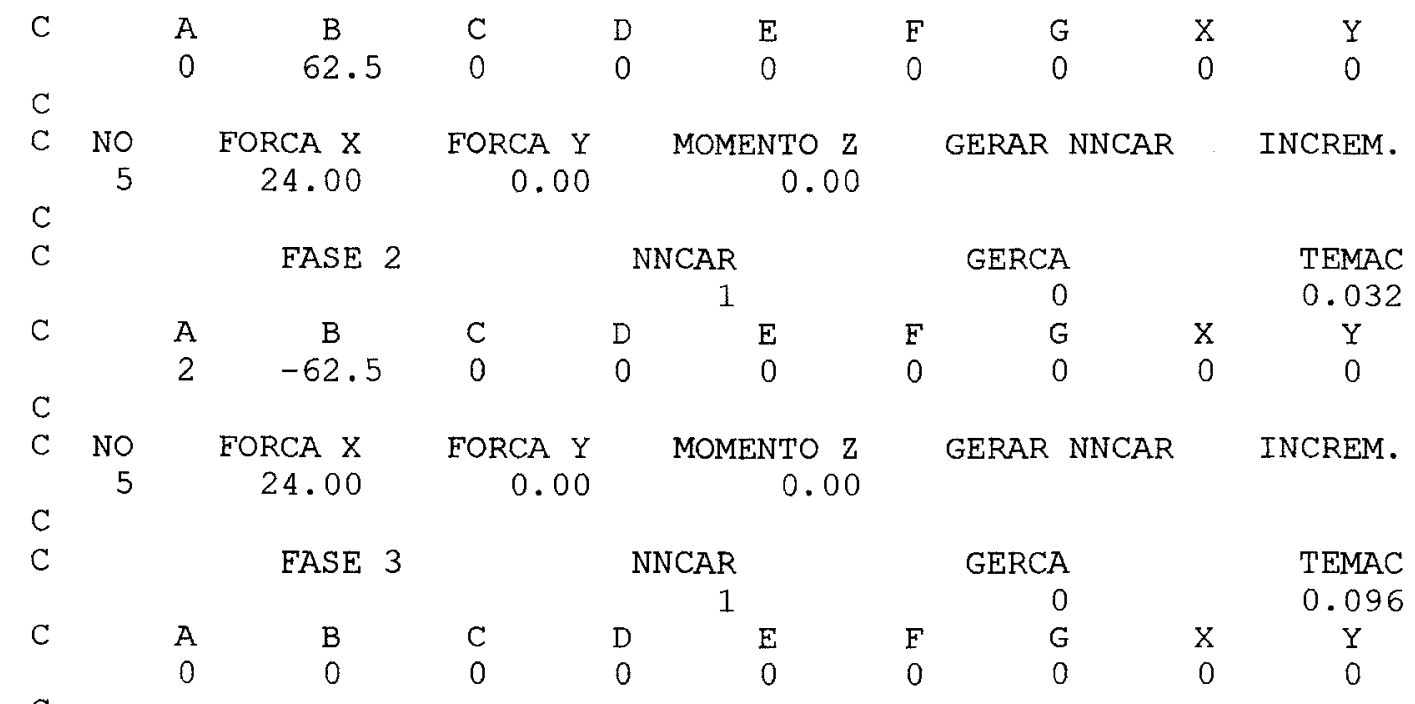

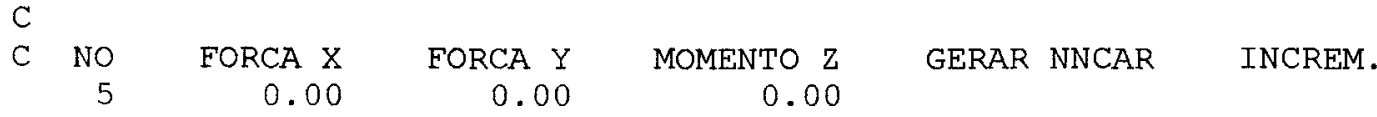

\section{P0010.POR}

$\mathrm{C}$

$\begin{array}{lrrrrrrr}\text { C } & \text { NNODS } & \text { NELEM } & \text { NAPOS } & \text { NMATE } & \text { GERNO } & \text { GEREL } & \text { NMASC } \\ & 13 & 12 & 2 & 1 & 1 & 1 & 0 \\ C & \text { NLIFI } & \text { MOFIS } & \text { NLIGE } & \text { NEACA } & \text { NITER } & \text { TOLER } & \text { RESUL } \\ & 1 & 1 & 0 & 3 & 200 & 2 \mathrm{E}-3 & 1 \\ \text { C } & \text { DINAM } & \text { ITEMP } & \text { TEMPO } & \text { NEWMA } & \text { AMORT } & \text { LAMBM } & \text { ILAMBK } \\ & 1 & 240 & .4 \mathrm{E}-3 & 2 & 1 & 133.067 & 5.28 E-4\end{array}$

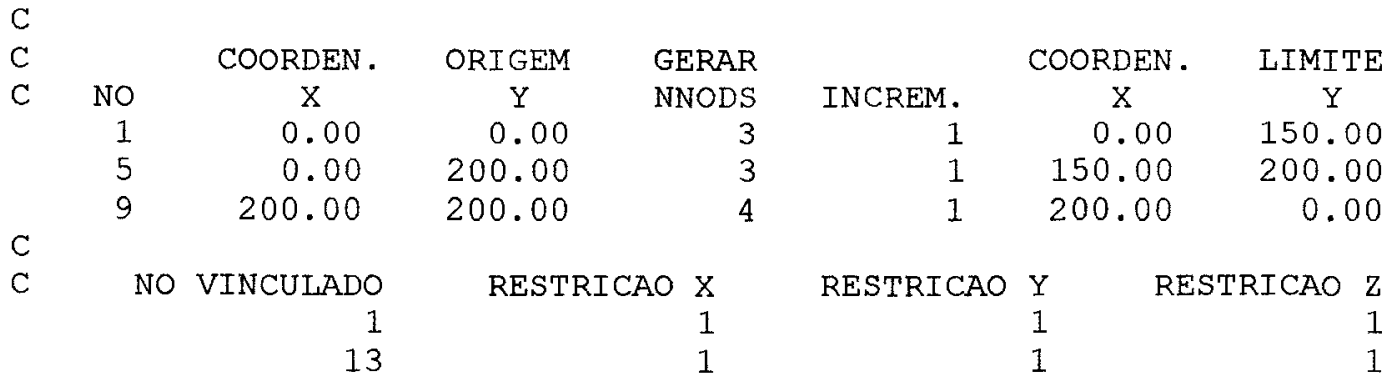

C MAT. M. ELAS. CONCR. PESO ESP. FCk FCtk M. ELAS. ACO

$\begin{array}{rrrrrr}1 & 3050.0 & 2.5 \mathrm{E}-5 & 2.6 & 0.268 & 21000.0\end{array}$

C ! SECAO ! INCREMEN ! ARMADURA !

C EL. NOI NOF LAR. ALT. TM EG NE NI NE NBS NBI NC AS d'

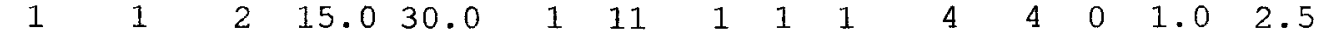

C FASE 1 NNCAR GERCA TEMAC

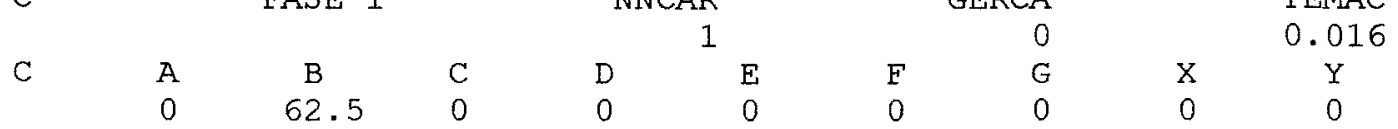

C NO FORCA $X$ FORCA Y MOMENTO $Z$ GERAR NNCAR INCREM.

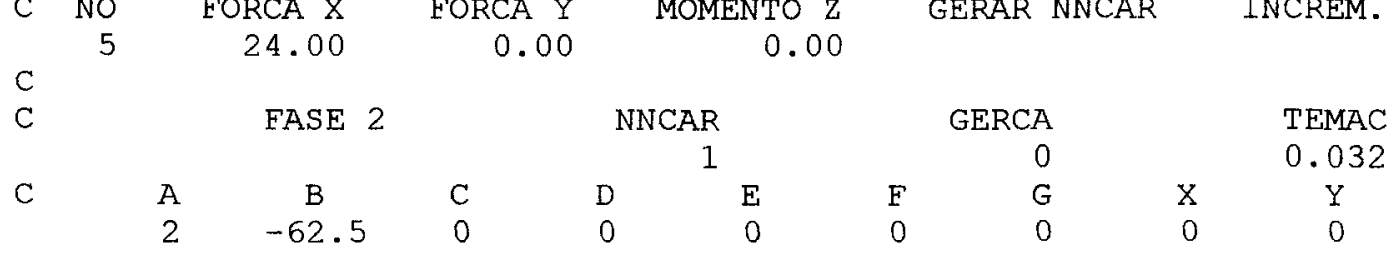




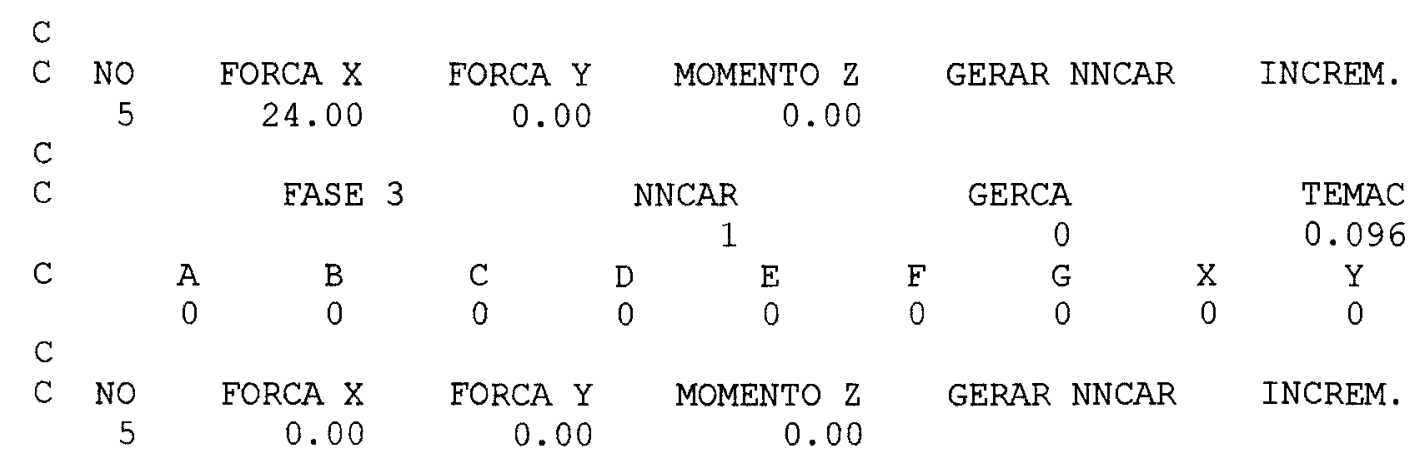

